\title{
Manufacturing Laser Glass by Continuous Melting
}

\author{
J.H. Campbell, S. Krenitsky, K. Takeuchi
}

July 1, 2001

Lawrence

Livermore

National

Laboratory

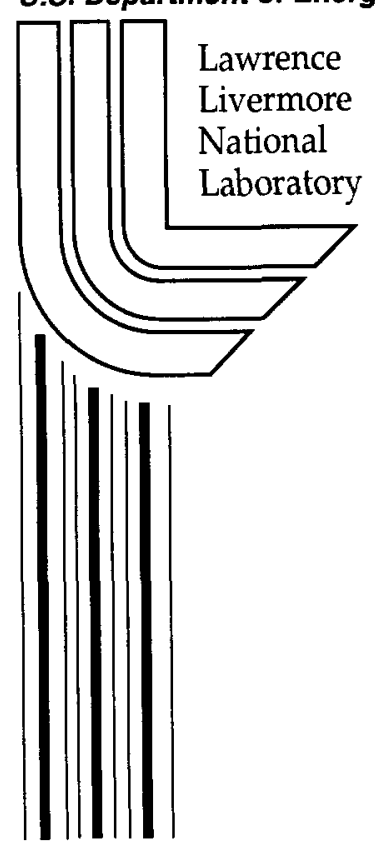




\section{DISCLAIMER}

This document was prepared as an account of work sponsored by an agency of the United States Government. Neither the United States Government nor the University of California nor any of their employees, makes any warranty, express or implied, or assumes any legal liability or responsibility for the accuracy, completeness, or usefulness of any information, apparatus, product, or process disclosed, or represents that its use would not infringe privately owned rights. Reference herein to any specific commercial product, process, or service by trade name, trademark, manufacturer, or otherwise, does not necessarily constitute or imply its endorsement, recommendation, or favoring by the United States Government or the University of California. The views and opinions of authors expressed herein do not necessarily state or reflect those of the United States Government or the University of California, and shall not be used for advertising or product endorsement purposes.

This work was performed under the auspices of the U.S. Department of Energy by the University of California, Lawrence Livermore National Laboratory under Contract No. W-7405-Eng-48.

This report has been reproduced directly from the best available copy.

Available electronically at http://www.doe.gov/bridge

Available for a processing fee to U.S. Department of Energy and its contractors in paper from

U.S. Department of Energy

Office of Scientific and Technical Information

P.O. Box 62

Oak Ridge, TN 37831-0062

Telephone: (865) 576-8401

Facsimile: (865) 576-5728

E-mail: reports@adonis.osti.gov

Available for the sale to the public from

U.S. Department of Commerce

National Technical Information Service

5285 Port Royal Road

Springfield, VA 22161

Telephone: (800) 553-6847

Facsimile: (703) 605-6900

E-mail: orders@ntis.fedworld.gov

Online ordering: http://www.ntis.gov/ordering.htm

\section{OR}

Lawrence Livermore National Laboratory

Technical Information Department's Digital Library

http://www.llnl.gov/tid/Library.html 


\title{
2001 R\&D 100 Awards Entry Form
}

\section{Manufacturing Laser Glass by Continuous Melting ${ }^{1}$}

\author{
Lawrence Livermore National Laboratory \\ Hoya Corporation, USA \\ Schott Glass Technologies, Inc.
}

\begin{abstract}
A novel, continuous melting process is being used to manufacture meter-sized plates of laser glass at a rate 20-times faster, 5-times cheaper, and with 2-3 times better optical quality than with previous one-ata-time, "discontinuous" technology processes. This new technology for manufacturing laser glass, which is arguably the most difficult continuously-melted optical material ever produced, comes as a result of a $\$ 60$ million, six-year joint R\&D program between government and industry. The glasses manufactured by the new continuous melting process are Nd-doped phosphate-based glasses and are marketed under the product names LG-770 (Schott Glass Technologies) and LHG-8 (Hoya Corporation USA). With this advance in glass manufacturing technology, it is now possible to construct high-energy, high-peak-power lasers for use in fusion energy development, national defense, and basic physics research that would have been impractical to build using the old melting technology. The development of continuously melted laser glass required technological advances that have lead to improvements in the manufacture of other optical glass products as well. For example, advances in forming, annealing, and conditioning steps of the laser glass continuous melting process are now being used in manufacture of other large-size optical glasses.
\end{abstract}

\section{Cover:}

(Top-left) Front cover from Laser Focus World magazine (July 2000) showing laser glass produced by continuous melting technology; (bottom-right) a finished laser glass plate ready for installation in the laser.

This work was performed under the auspices of the U.S. Department of Energy by the University of California, Lawrence Livermore National Laboratory under Contract No. W-7405-Eng-48. 
1. Submitting organization:

Address:

City:

State:

ZIP:

Country:

Submitter's Name:

Phone:

Fax:

E-mail:
Lawrence Livermore National Laboratory (LLNL)

7000 East Avenue, P.O. Box 808

Livermore

California

94551

USA

Jack Campbell

(925) 422-6497

(925) 423-0792

campbell12@llnl.gov

AFFIRMATION: I affirm that all information submitted as part of, or supplemental to, this entry is a fair and accurate representation of this product.

Submitter's signature:

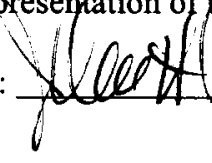

2. Joint entry with:

Address:

City:

State:

ZIP:

Country:

Submitter's Name:

Phone:

Fax:

E-mail:

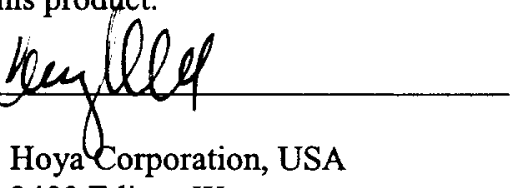

3400 Edison Way

Fremont

California

94538-6190

USA

Gerald Bottero

(510) 252-8370

(510) 490-3900

gerry@mail.hoyausa.com

2. Joint entry with:

Schott Glass Technologies, Inc.

Address:

400 York Avenue

City:

State:

Duryea

ZIP:

Pennsylvania

Country:

18642

Submitter's Name:

USA

Phone:

Steve Krenitsky

(570) 457-7485

Fax:

(570) 414-0322

E-mail:

skrenitsky@schottglasstech.com

3. Product: Continuous laser glass melting process

4. Entry description:

Glass production process carried out in a highly automated, custom designed melting system capable of processing several tons/day of raw material into a continuously moving ribbon of laser glass-the largest strip melt ever achieved of any optical glass.

5. When product first marketed or available for order:

April 2000 


\section{R\&D 100 Awards Entry Form}

6. Inventor or principal developer:

Additional developers listed on separate sheets in appendix [X]

Developer:

Position:

Organization:

Address:

City:

State:

ZIP:

Country:

Submitter's Name:

Phone:

Fax:

E-mail:

Developer:

Position:

Organization:

Address:

City:

State:

ZIP:

Country:

Submitter's Name:

Phone:

Fax:

E-mail:

Developer:

Position:

Organization:

Address:

City:

State:

ZIP:

Country:

Submitter's Name:

Phone:

Fax:

E-mail:
Jack Campbell

Physical Chemist, Laser Glass Group Leader

Lawrence Livermore National Laboratory (LLNL)

7000 East Avenue, P.O. Box 808

Livermore

California

94551

USA

Jack Campbell

(925) 422-6497

(925) 423-0792

campbell12@llnl.gov

Steve Krenitsky

Vice President of Manufacturing

Schott Glass Technologies

400 York Avenue

Duryea

Pennsylvania

18642

USA

Steve Krenitsky

(570) 457-7485

(570) 451-0800

skrenitsky@schottglasstech.com

Kunio Takeuchi

Program Leader, Laser Glass Business

Hoya Corporation, USA

3400 Edison Way

Fremont

California

94538-6190

USA

Kunio Takeuchi

(510) 252-8370

(510) 490-3900

JStorms@hoyaoptics.com

7. Product price: Price depends on quantity ordered and size of part; price for LLNL order is about $\$ 1000 /$ liter $(\$ 15,000$ per glass plate).

8. Patents or patents pending on this product? Yes [ ] No [X] 


\section{Product description}

\section{R\&D 100 Awards Entry Form}

What does it do? The continuous laser glass melting process, shown schematically in Fig. 1, converts high-purity, powdered raw materials into one continuously moving strip of high optical-quality laser glass. Plates of laser glass $(\sim 1 \mathrm{~m} \times 0.5 \mathrm{~m}$ for our specific application) are then cut from the end of this strip as it exits the production system. The laser glass product is marketed under the names LHG-8 (Hoya) and LG-770 (Schott).

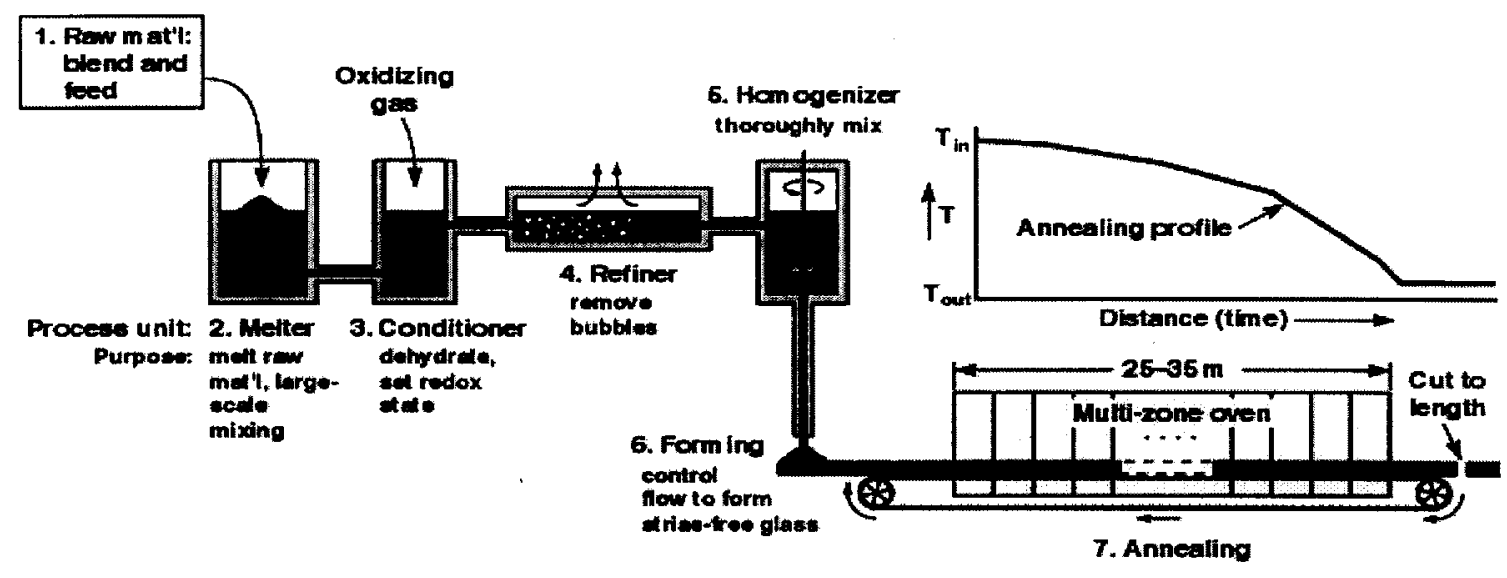

Figure 1. Schematic representation of the continuous laser glass melting systems now being used to manufacture laser glass.

How does it do it? A detailed description of the process is given in the supporting documents (Appendix E-1). In brief, the laser glass melting process requires seven separate operations carried out in separate vessels; to make the process continuous, the vessels are interconnected. The first process unit is designed to mix and dry the high purity raw materials with minimal contamination. The laser glass specifications require that the raw materials contain only trace amounts ( $\leq 10 \mathrm{ppm})$ of most common transition metal ions and less than $0.1 \mathrm{wt} \%$ of either physically or chemically absorbed water.

The second unit is the melter system, which dissolves the powdered raw materials into a pool of molten glass and mixes these ingredients using convection currents inside the melter. The melter consists of custom designed high-purity refractory materials and employs a proprietary electrical heating system.

All units beyond the melter are lined with high-purity platinum metal, as are the interconnecting pipes. Platinum is required to achieve the part-per-million optical homogeneity necessary for laser applications. However, the platinum can contaminate the glass with microscopic metallic inclusions. When a high-power laser beam hits an inclusion it causes it to explode, generating fractures within the glass. To overcome this, we developed a unique conditioner unit (the third unit in the process) that uses oxygen and chlorine to remove platinum inclusions as well as any residual water. This is perhaps the most complex unit in the whole system.

The glass from the conditioner next moves to a refiner section where bubbles are removed using a combination of high temperature and proprietary additives. From here the glass enters the homogenizing 
unit and is thoroughly mixed to achieve the one-part-per-million chemical uniformity required to meet optical homogeneity specifications. Finally, the glass flows through a platinum tube to a mold where it is formed into one continuously moving strip about 5 to $8-\mathrm{cm}$ thick, $0.5-\mathrm{m}$ wide, and $30-\mathrm{m}$ long. The glass strip finally passes through a custom-designed annealing oven over one hundred feet long where it is gradually cooled from more than $600^{\circ} \mathrm{C}$ to room temperature. Annealing the laser glass strip is difficult because of its size and the unusually high thermal expansion and low inherent strength of the glass. In fact, laser glass is a factor of five more sensitive to fracture by thermal shock than most other optical glasses.

What theories, if any, are involved? The laser glass continuous melting process involves a number of theories, some of which were developed as part of the associated R\&D program. Specifically, we developed and published a theory for laser glass dehydroxylation (i.e. - $\mathrm{OH}$ removal) based on extensive laboratory experiments and model calculations. This theory is included in our numerical process model used to design the melting system and set baseline process conditions.

We also used the theory for platinum inclusion dissolution developed in the late 80 's to set the conditioner and melt redox conditions to give platinum-inclusion-free glass. Finally we used finite element mass and heat transport models, based on contemporary theories of fluid dynamics and heat transport, to define the critical glass forming and thermal annealing process. 


\section{R\&D 100 Awards Entry Form}

\section{A. Product competitor methods}

Neodymium-doped phosphate laser glass can be manufactured either by a discontinuous, one-at-atime melting process or by our novel continuous melting process. Schott Glass Technologies and Hoya Corporation are the only two companies in the world with the technology to make meter-square sized plates of phosphate laser glass by either a continuous or a discontinuous process. Therefore the "competitor" in this case is really the old, discontinuous technology for producing laser glass. The discontinuous melting process involves first melting raw materials in a refractory vessel, then manually transferring to a second platinum-lined vessel, and then finally manually casting the glass into a mold. The whole process must then be repeated to make the next glass piece. Discontinuous processing methods have been used for producing laser glass for over 25 years. However, this process has a small throughput of two to three pieces per week. In addition, product quality can vary from one melt to the next simply because of small run-to-run variations in processing conditions. Most importantly, the product cost is high $(>\$ 5000 /$ liter). Continuous glass melting, on the other hand, not only has the advantage of a much greater production rate of 70 to 300 pieces per week, but also little, if any, measurable variation in glass properties from one glass plate to the next. Also, the cost is dramatically less $(\leq \$ 1000 /$ liter $)$.

\section{B. Competitive matrix}

Table 1 gives a comparison of our continuous melting process with the nearest competing process of discontinuous melting.

Table 1: Competitive matrix of discontinuous versus continuous melting of phosphate laser glass.

\begin{tabular}{|c|c|c|c|}
\hline & Discontinuous melting & $\begin{array}{c}\text { Continuous } \\
\text { melting }\end{array}$ & $\begin{array}{c}\text { Better, worse, or } \\
\text { Same }\end{array}$ \\
\hline Glass cost (per liter) & $>\$ 5000^{*}$ & $\leq \$ 1000^{*}$ & $>5 \times$ Better \\
\hline Production rate (pieces/week) & $2-3$ & $70-300$ & $>20 \times$ Better \\
\hline Yield & $* *$ & $* *$ & $>2 \times$ Better \\
\hline \multicolumn{4}{|l|}{ Optical homogeneity (waves at $633 \mathrm{~nm}$ ): } \\
\hline Power & $\leq 0.30$ waves & $\leq 0.15$ waves & $2 \times$ Better \\
\hline Astigmatism & $\leq 0.35$ waves & $\leq 0.11$ waves & $3 \times$ Better \\
\hline Higher order & $\leq 0.15$ waves & $\leq 0.07$ waves & $2 \times$ Better \\
\hline RMS gradient & $\leq 0.01$ waves $/ \mathrm{cm}$ & $\leq 0.0040$ waves $/ \mathrm{cm}$ & $2.5 \times$ Better \\
\hline $\begin{array}{l}\text { Nd-doping uniformity } \\
\text { Optical transmission } \\
\text { (at } 1053 \mathrm{~nm} \text {; 1-cm thick) }\end{array}$ & $\begin{array}{c} \pm 5 \% \\
\geq 99.95 \%\end{array}$ & $\begin{array}{l} \pm 2.5 \% \\
\geq 99.95 \%\end{array}$ & $\begin{array}{l}2 \times \text { Better } \\
\text { Same }\end{array}$ \\
\hline OH content & $<100 \mathrm{ppm}$ & $<100 \mathrm{ppm}$ & Same \\
\hline Impurity concentration & $<20 \mathrm{ppm} \mathrm{Fe}$ & $<20 \mathrm{ppm} \mathrm{Fe}$ & Same \\
\hline
\end{tabular}

*Numbers based on sales to Lawrence Livermore from 1983 to 1995 (discontinuous) and 2000 (continuous); exact quotes depend on the customers' specific quantity, size, and specification.

**Exact numbers are proprietary.

\section{C. Improvements upon competitive product or technologies}

The competitive discontinuous melting process fails to provide the production rate, cost, or optical quality needed to meet the demands required for today's high-energy laser systems. The implementation of continuous melting process has led to significant improvements in all three of these areas, as outlined in 
Table 1 above. The technical improvements are a result of a six-year, $\$ 60$ million joint R\&D effort between LLNL, Hoya, and Schott. The specific technological developments and associated technical references are listed below:

1) Pt-inclusion removal: Microscopic Pt particles $(\leq 10 \mu \mathrm{m})$ in the laser glass can absorb laser light and cause fracture in the glass (laser induced damage). Research on their formation and dissolution has led to a redox-controlled process for minimizing the number and size of inclusions in the glass (see Appendix E-1, E-6, E-7, and E-8).

2) $\mathrm{OH}$ removal: Hydroxyl $(\mathrm{OH})$ groups in the glass quench the fluorescence of the $\mathrm{Nd}$ and reduce the laser output energy. Our research on the chemical mechanism of $\mathrm{OH}$ removal (dehydroxylation) using reactive gas bubbling and the incorporation of this information in numerical process models has led to a $10 \times$ reduction of $\mathrm{OH}$ content of continuously melted glass (see Appendix E-1 and E-3).

3) Fracture prevention: Phosphate laser glasses are prone to fracture due to their low fracture toughness and high thermal expansion. Finite elemental heat transport and stress analysis combined with the identification of various stress sources and research in crack growth have led to improvements in the annealing process that eliminate fracturing (see Appendix E-9, E-10 and E-11).

4) Impurity minimization: Metal ion impurities (such as $\mathrm{Fe}^{2+}$ and $\mathrm{Cu}^{2+}$ ) $\gtrsim 10$ parts-per-million level can increase the optical absorption of the glass above acceptable limits. New analytical techniques to quantify impurity levels combined with research on the absorption characteristics of these impurities (see Appendix E-12) has led to much improved specifications and QC procedures for both the laser glass and the raw materials.

5) Homogeneity: Laser glass requires a refractive index uniformity (i.e. optical homogeneity) of about one-part-per-million requiring advanced forming technologies. The details of this technology are proprietary.

6) Quality assurance: A number of unique quality-assurance tools have been developed to inspect large optical glass plates at a high rate. These tools include large-aperture (24-inch) phasemeasuring interferometers and large-aperture laser damage testers (see Appendix E-13). 


\section{R\&D 100 Awards Entry Form}

\section{A. Principal applications}

The continuous melting process is now being used to manufacture two commercial phosphate laser glasses marketed under the product names LG-770 (Schott) and LHG-8 (Hoya). These are primarily being sold for use in high-energy glass laser systems; two such systems are currently under construction in the U.S. and France. Each laser system is about the size of a municipal football stadium and will require approximately 3000 to 4000 square-meter-sized pieces of continuously melted laser glass; if stacked endto-end the glass pieces would stretch nearly $8 \mathrm{~km}$ ( 5 miles). Continuous glass melting is the only method that can be used to produce the large quantity and high quality of laser glass necessary for these systems; without this melting technology it would be clearly impractical, and probably impossible, to build these lasers. The laser glass is the heart of these systems in that it is the optical medium in which the laser energy is first stored and then later extracted as high-power optical pulses.

The U.S. system, called the National Ignition Facility (NIF) will cost about $\$ 2$ billion dollars and is approximately $50 \%$ complete. Its primary purpose is to demonstrate nuclear fusion ignition. The results from that achievement play an important role in maintaining the US nuclear defense capabilities and in providing the first step in the road to an inexhaustible supply of clean energy.

\section{B. Other applications}

A number of new technologies have been developed to make the continuous laser glass melting process a success. These technologies, both individually and as a whole, have opened the door for manufacturing other large optical glass components by continuous melting. For example, Schott Glass Technologies is now continuously melting a borosilicate optical glass (BK-7) using several of the technologies developed from producing laser glass. BK-7 is one of the most common optical glasses in use today and is commonly found in cameras, binoculars, and other optical instruments. Certain aspects of the forming, annealing, and conditioning steps of the laser glass process are now being incorporated into the manufacturing process of other optical glasses. For example this includes glasses for digital cameras, hard

disk drive (HDD) substrates, liquid crystal display (LCD), projector lenses, and telecommunications devices. 


\section{C. Potential applications}

Understandably, there is considerable reluctance to discuss the potential future applications of this technology. This is simply because our two co-developers (Hoya and Schott) are intense competitors in the optical glass marketplace and they consider such plans proprietary. The three testimonial letters that are a part of this application, however, independently attest to the significance of this technology on future optical glass production and products. Also, the Otto Schott award, an international award given every two years by the Ernst-Abbe Foundation for advances in glass science (see Appendix B-2) recognizes our research on continuous melting as a major advancement in glass science and technology.

There are two potential applications which we can discuss. Glasses for photonic applications, such as Schott's waveguide-based glasses, can be produced in a continuous melting operation when the demand requires this increase in production capacity. In addition, the technological advances in dehydrating, forming, inclusion control, annealing and melter design that have resulted from the laser glass work are being planned for use with other product lines. For example, a number of the doped glasses that are used for precision optical filter applications are phosphate-based material. The advancements from our laser glass development can be used directly to improve the quality of these glasses and broaden their market. 


\section{R\&D 100 Awards Entry Form}

\section{Summary}

The construction of high-energy, high-peak-power lasers such as NIF is critical to define the conditions for nuclear fusion ignition and gain necessary for future fusion energy development and maintenance of a safe and reliable US nuclear defense strategy. Without the development of continuous glass melting it would be impractical, if not impossible, to build such laser systems. The importance of the glass melting technology explains the driving force behind the $\$ 60 \mathrm{M}$, six-year R\&D investment to make this a reality.

The difficulty of developing this new technology was compounded by the fact that high-opticalquality phosphate glasses, the compositional matrix used in the best laser glasses, have never before been continuously melted. Moreover, the size and quality of the optical laser glass strip exceeds that produced for any other optical glass of this quality whether it be silicate, phosphate, or other matrix. Achieving this breakthrough required a number of scientific and technological advances that were only possible with the unique partnership of industry and a government research lab. As a result of this joint venture, laser glass can now be produced more than 20 times faster, five times cheaper, and with optical quality two to three times better than glass produced by conventional techniques. Other properties that dramatically affect laser performance, such as microscopic inclusions, hydroxyl contamination, transition metal impurities, and doping uniformity, meet or exceed what could be achieved with the old technology.

The development of continuously melted laser glass has led to improvements in the manufacture of other optical glass products as well. For example, advances in forming, annealing, and conditioning steps of the laser glass continuous melting process are now being used in manufacture of other large-size optical glasses for applications such as digital cameras, HDD substrates, LCD-projector lenses, and in telecommunications devices. Continuous forming of large strips of the most common optical glass, BK-7, is now possible with the technology developed to make laser glass. Also, glasses for photonic applications, such as Schott's waveguide-based glasses, will be produced in a continuous melting operation when the demand requires this increase in production capacity. 


\section{ORGANIZATION DATA}

\section{Chief Executive Officer}

\begin{tabular}{|c|c|c|c|}
\hline Name: & Bruce Tarter & Position: Director & \\
\hline Organization: & \multicolumn{3}{|c|}{ Lawrence Livermore National Laboratory } \\
\hline Address: & 7000 East Avenue, & P.O. Box 808, L-001 & \\
\hline City: & Livermore & State: CA ZIP: 94551 & Country: USA \\
\hline Phone: & (925) 422-4169 & & \\
\hline E-mail: & tarter1@llnl.gov & & \\
\hline Name: & Bruce Jennings & Position: President & \\
\hline Organization: & \multicolumn{3}{|c|}{ Schott Glass Technologies } \\
\hline Address: & 400 York Avenue & & \\
\hline City: & Duryea & State: PA ZIP: 18642 & \multirow[t]{3}{*}{ Country: USA } \\
\hline Phone: & (510) $252-8370$ & Fax: (570) 414-0322 & \\
\hline E-mail: & \multicolumn{2}{|c|}{ bjennings@schottglasstech.com } & \\
\hline Name: & Gerald Bottero & Position: President & \\
\hline Organization: & \multicolumn{3}{|c|}{ Hoya Corporation, USA } \\
\hline Address: & \multicolumn{3}{|c|}{3400 Edison Way } \\
\hline City: & Fremont & State: CA ZIP: $94538-6190$ & Country: USA \\
\hline Phone: & (510) 252-8370 & Fax: $(510) 490-3900$ & \\
\hline E-mail: & \multicolumn{3}{|c|}{ gerry@mail.hoyausa.com } \\
\hline
\end{tabular}

14. Contact person for exhibits, banquet and publicity

$\begin{array}{llll}\text { Name: } & \text { Darlene Horne } & \text { Position: Partnering Services Administrator } \\ \text { Organization: } & \text { Lawrence Livermore National Laboratory } & \\ \text { Address: } & 7000 \text { East Avenue, } & \text { P.O. Box 808, L-795 } & \\ \text { City: } & \text { Livermore } & \text { State: CA ZIP: 94551 } & \text { Country: USA } \\ \text { Phone: } & (925) \text { 423-1929 } & & \\ \text { E-mail: } & \text { horne1@ (1llnl.gov } & & \end{array}$

15. Reader inquiries contact

\begin{tabular}{|c|c|c|c|}
\hline Name: & Julie Storms & \multicolumn{2}{|c|}{ Position: Director of Contracts and Program } \\
\hline Organization: & \multicolumn{3}{|c|}{ Hoya Corporation, USA Communications } \\
\hline Address: & \multicolumn{3}{|c|}{3400 Edison Way } \\
\hline City: & Fremont & State: CA ZIP: $94538-6190$ & Country: USA \\
\hline Phone: & (510) $252-8370$ & \multicolumn{2}{|l|}{ Fax: $(510) 490-3900$} \\
\hline E-mail: & \multicolumn{3}{|c|}{ JStorms@hoyaoptics.com } \\
\hline Name: & Steve Krenitsky & \multicolumn{2}{|c|}{ Position: Vice President of Manufacturing } \\
\hline $\begin{array}{l}\text { Organization: } \\
\text { Address: }\end{array}$ & \multicolumn{3}{|c|}{$\begin{array}{l}\text { Schott Glass Technologies, Inc. } \\
400 \text { York Avenue }\end{array}$} \\
\hline City: & Duryea & State: PA ZIP: 18642 & Country: USA \\
\hline Phone: & (570) $457-7485$ & Fax: $(570) 451-0800$ & \\
\hline E-mail: & skrenitsky@scho & tech.com & \\
\hline
\end{tabular}


Appendices: Supporting Documentation

A) List of co-developers

B) Awards

B-1) NIF program awards

B-2) Otto-Schott Award

C) Brochures on Laser Glass at Schott and Hoya

D) Testimonials

E) Journal publications and conference proceedings

E-1) Continuous Melting of Phosphate Laser Glass

E-2) Nd-doped Phosphate Glasses for High-energy/High-peak-power Lasers

E-3) Dehydroxylation of Phosphate Laser Glass

E-4) Development of Continuous Glass Melting for Production of Nd-doped Phosphate Glasses for the NIF and LMJ Laser Systems

E-5) 25 Years of Laser Glass Development Leading to a 1.8 MJ, 500 TW Laser for Fusion Ignition

E-6) Continuous Melting of Phosphate Laser Glass by Hoya Corporation

E-7) Effect of melting conditions on platinum inclusions content in phosphate laser glass

E-8) Effects of process gas environment on platinum-inclusion density and diffusion rate in phosphate laser glass

E-9) Modeling platinum-inclusion dissolution in phosphate laser glasses

E-10) Surface Tensile Layer Generation during Thermal Annealing of Phosphate Glass

E-11) Sub-critical Crack Growth in a Phosphate Laser Glass

E-12) Effects of OH Content, Water Vapor Pressure, and Temperature on Sub-critical Crack Growth in Phosphate Glass

E-13) Optical Loss and $\mathrm{Nd}^{3+}$ Non-radiative Relaxation by $\mathrm{Cu}, \mathrm{Fe}$, and Several Rare Earth Impurities in Phosphate Laser Glasses

E-14) Platinum Particle Detection in Phosphate Laser Glasses

F) Press coverage: Trade journal articles, newspaper articles, press releases

G) Video Supplement

The video, "Manufacturing Laser Glass by Continuous Melting" gives an overview and illustrates size, scale and complexity of the continuous melting process. 


\section{Appendix A}

\section{List of Co-Developers}


A1) Co-developers (Lawrence Livermore National Laboratory)

Developer:

Position:

Organization:

Address:

City:

State:

Zip:

Country:

Phone:

Fax:

E-mail:

Developer:

Position:

Organization:

Address:

City:

State:

Zip:

Country:

Phone:

Fax:

E-mail:

Developer:

Position:

Organization:

Address:

City:

State:

Zip:

Country:

Phone:

Fax:

E-mail:
Tayyab I Suratwala

Materials Scientist, Laser Glass Research

Lawrence Livermore National Laboratory (LLNL)

7000 East Avenue, P.O. Box 808, L-487

Livermore

California

94551

USA

(925) 422-1884

(925) 423-0792

suratwala1@llnl.gov

Charles B. Thorsness

Chemical Engineer, Laser Glass Research

Lawrence Livermore National Laboratory (LLNL)

7000 East Avenue, P.O. Box 808, L-487

Livermore

California

94551

USA

(925) $422-8124$

(925) 423-0792

thorsness1@1lnl.gov

Paul Ehrmann

Chemist, Laser Glass Research

Lawrence Livermore National Laboratory (LLNL)

7000 East Avenue, P.O. Box 808, L-487

Livermore

California

94551

USA

(925) 423-2949

(925) 423-0792

ehrmann1@llnl.gov 


$\begin{array}{ll}\text { Developer: } & \text { William A. (Rusty) Steele } \\ \text { Position: } & \text { Chemist, Laser Glass Research } \\ \text { Organization: } & \text { Lawrence Livermore National Laboratory (LLNL) } \\ \text { Address: } & \text { 7000 East Avenue, P.O. Box 808, L-487 } \\ \text { City: } & \text { Livermore } \\ \text { State: } & \text { California } \\ \text { Zip: } & 94551 \\ \text { Country: } & \text { USA } \\ \text { Phone: } & (925) 422-9943 \\ \text { Fax: } & (925) 423-0792 \\ \text { E-mail: } & \\ & \\ \text { Developer: } & \text { Michael O. Riley } \\ \text { Position: } & \text { Chemist, Laser Glass Project Manager } \\ \text { Organization: } & \text { Lawrence Livermore National Laboratory (LLNL) } \\ \text { Address: } & 7000 \text { East Avenue, P.O. Box 808, L-487 } \\ \text { City: } & \text { Livermore } \\ \text { State: } & \text { California } \\ \text { Zip: } & 94551 \\ \text { Country: } & \text { USA } \\ \text { Phone: } & \text { (925) 422-3045 } \\ \text { Fax: } & (925) 423-0792 \\ \text { E-mail: } & \text { riley3@1lnl.gov } \\ & \end{array}$


(Schott Glass Technologies, Inc.)

Developer:

Position:

Organization:

Address:

City:

State:

Zip:

Country:

Phone:

Fax:

E-mail:

Developer:

Position:

Organization:

Address:

City:

State:

Zip:

Country:

Phone:

Fax:

E-mail:

Developer:

Position:

Organization:

Address:

City:

State:

Zip:

Country:

Phone:

Fax:

E-mail:
Alfred Thorne

Manager of Engineering Services

Schott Glass Technologies, Inc.

400 York Avenue

Duryea

Pennsylvania

18642

USA

(570) 457-7485

(570) 414-0322

athorne@schottglasstech.com

Joseph S. Hayden

Manager/R\&D Materials Group

Schott Glass Technologies, Inc.

400 York Avenue

Duryea .

Pennsylvania

18642

USA

(570) 457-7485

(570) 414-0322

jhayden@schottglasstech.com

Hardy Pankratz

Assistant Manager Hot Melting and Forming

Schott Glass Technologies, Inc.

400 York Avenue

Duryea

Pennsylvania

18642

USA

(570) 457-7485

(570) 414-0322

hpankratz@schottglasstech.com 


$\begin{array}{ll}\text { Developer: } & \text { Dave Sapak } \\ \text { Position: } & \text { Laser Glass Process Engineer } \\ \text { Organization: } & \text { Schott Glass Technologies, Inc. } \\ \text { Address: } & 400 \text { York Avenue } \\ \text { City: } & \text { Duryea } \\ \text { State: } & \text { Pennsylvania } \\ \text { Zip: } & 18642 \\ \text { Country: } & \text { USA } \\ \text { Phone: } & (570) 457-7485 \\ \text { Fax: } & (570) 414-0322 \\ \text { E-mail: } & \text { dsapak@schottglasstech.com } \\ & \\ \text { Developer: } & \text { Ed Vozenilek } \\ \text { Position: } & \text { Scientist } \\ \text { Organization: } & \text { Schott Glass Technologies, Inc. } \\ \text { Address: } & 400 \text { York Avenue } \\ \text { City: } & \text { Duryea } \\ \text { State: } & \text { Pennsylvania } \\ \text { Zip: } & 18642 \\ \text { Country: } & \text { USA } \\ \text { Phone: } & \text { (570) 457-7485 } \\ \text { Fax: } & \text { (570) 414-0322 } \\ \text { E-mail: } & \text { evozenilek@schottglasstech.com } \\ \text { Developer: } & \text { Joe Cimino } \\ \text { Position: } & \text { Laser Glass Manufacturing Engineer } \\ \text { Organization: } & \text { Schott Glass Technologies, Inc. } \\ \text { Address: } & 400 \text { York Avenue } \\ \text { City: } & \text { Duryea } \\ \text { State: } & \text { Pennsylvania } \\ \text { Zip: } & 18642 \\ \text { Country: } & \text { USA } \\ \text { Phone: } & (570) 457-7485 \\ \text { Fax: } & (570) 414-0322 \\ \text { E-mail: } & \text { jcimino@schottglasstech.com } \\ & \end{array}$




$\begin{array}{ll}\text { Developer: } & \text { Michael Timms } \\ \text { Position: } & \text { Laser Glass Manufacturing Engineer } \\ \text { Organization: } & \text { Schott Glass Technologies, Inc. } \\ \text { Address: } & 400 \text { York Avenue } \\ \text { City: } & \text { Duryea } \\ \text { State: } & \text { Pennsylvania } \\ \text { Zip: } & 18642 \\ \text { Country: } & \text { USA } \\ \text { Phone: } & (570) 457-7485 \\ \text { Fax: } & (570) 414-0322 \\ \text { E-mail: } & \text { mtimms@schottglasstech.com }\end{array}$




\section{(Hoya Corporation USA)}

Developer:

Position:

Organization:

Address:

City:

State:

Zip:

Country:

Phone:

Fax:

E-mail:

Developer:

Position:

Organization:

Address:

City:

State:

Zip:

Country:

Phone:

Fax:

E-mail:

Developer:

Position:

Organization

Address:

City:

State:

Zip:

Country:

Phone:

Fax:

E-mail:
Mrs. Julie Storms

Director of Contracts and Program Communications, Laser Glass Business Hoya Corporation, USA

3400 Edison Way

Fremont

California

94538-6190

USA

(510) $252-8370$

(510) 490-3900

JStorms@hoyaoptics.com

Mr. Koji Suzuki

Laser Glass Melting Engineer, Laser Glass Business

Hoya Corporation, USA

3400 Edison Way

Fremont

California

94538-6190

USA

(510) $252-8370$

(510) 490-3900

ksuzuki@hoyaoptics.com

Mr. Ryo Konta

Laser Glass Production Engineer, Laser Glass Business

Hoya Corporation, USA

3400 Edison Way

Fremont

California

94538-6190

USA

(510) $252-8370$

(510) 490-3900

rkonta@hoyaoptics.com 


$\begin{array}{ll}\text { Developer: } & \text { Mr. Kohei Yamamoto } \\ \text { Position: } & \text { Laser Glass Development Engineer, Laser Glass Business } \\ \text { Organization: } & \text { Hoya Corporation, USA } \\ \text { Address: } & 3400 \text { Edison Way } \\ \text { City: } & \text { Fremont } \\ \text { State: } & \text { California } \\ \text { Zip: } & 94538-6190 \\ \text { Country: } & \text { USA } \\ \text { Phone: } & (510) 252-8370 \\ \text { Fax: } & (510) 490-3900 \\ \text { E-mail: } & \text { kyamamoto@hoyaoptics.com }\end{array}$




\title{
Appendix B
}

\author{
B-1: NIF Program Award
}

\section{B-2: Otto-Schott Award}


N" эPOGRANS AWARD

Laser Glass

Pilot Production Team
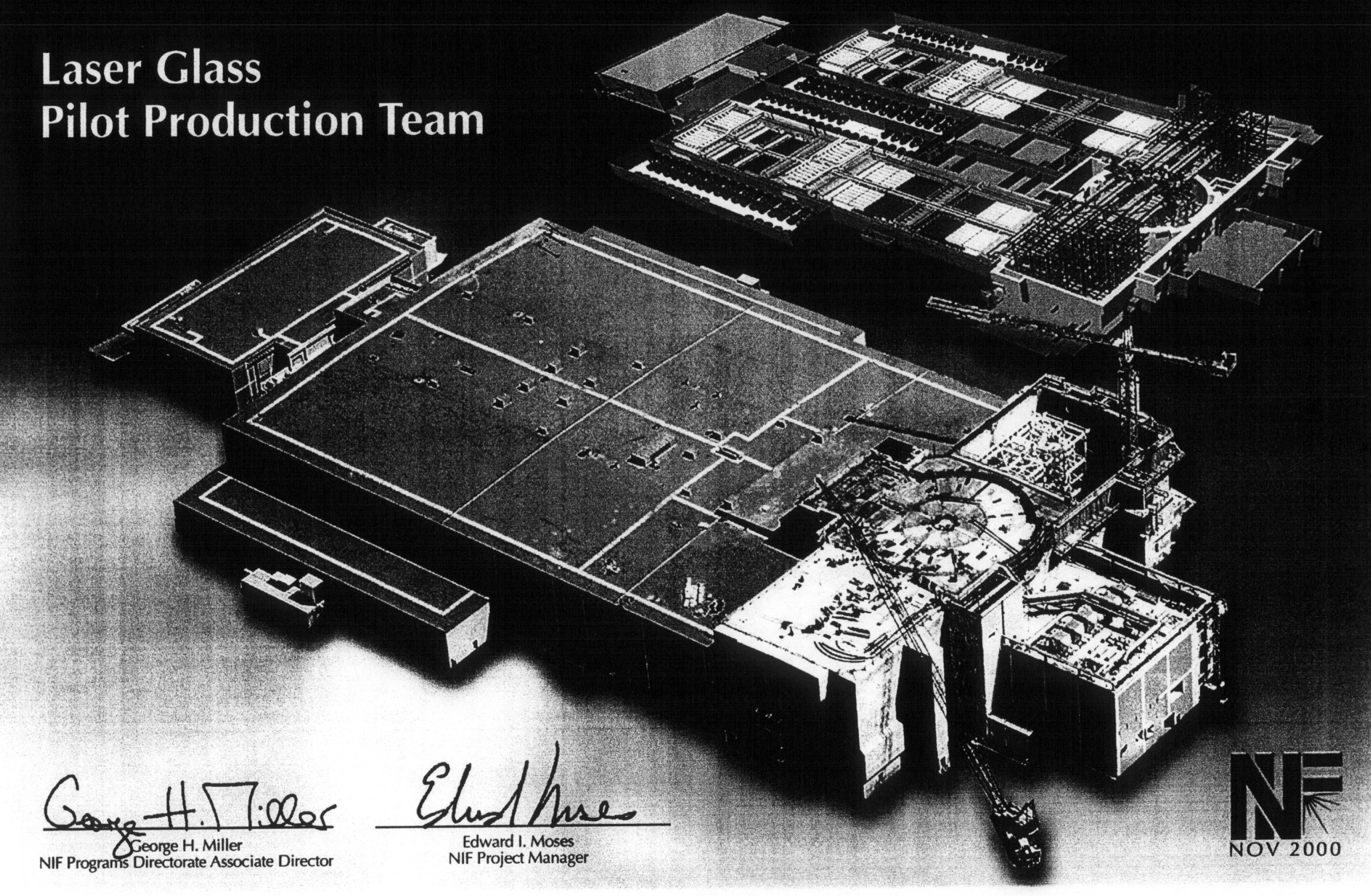
ERNST-ABBE-FONDS

Member of

STIFTERVERBAND

FÜR DIE DEUTSCHE WISSENSCHAFT

presents in honour of outstanding achievements in basic research, technology and application within the field of glass and glass ceramics the

\section{Otto Schott Research Award}

\section{9}

to

\section{or. John H. Campbell wermoresese}

for his leadership directed to the development, characterization, manufacturing and application of optical materials for high-power lasers, particularly the continuous melting of high-quality, multicomponent phosphate laser glasses.

For the curatorium
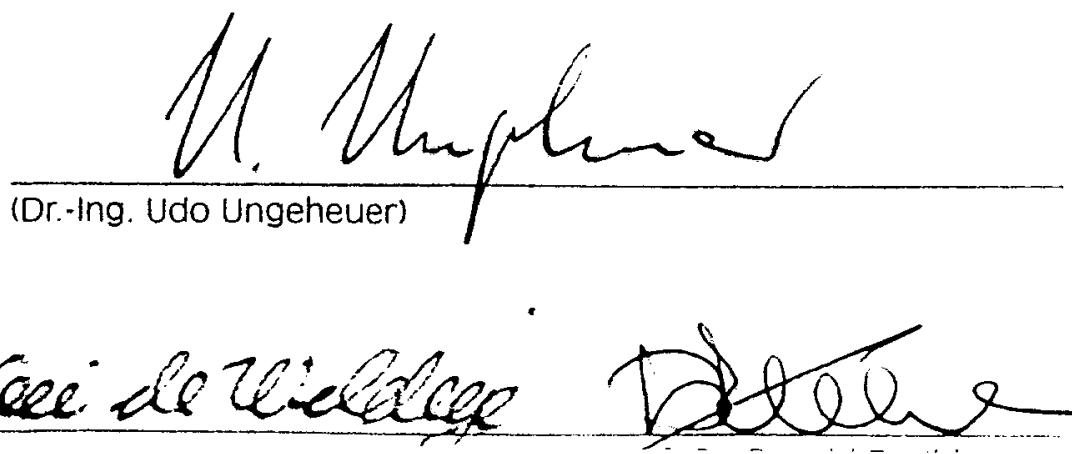


\section{Appendix C}

\section{Laser Glass Product Brochures}




\section{Manufacturing Laser Glass}

\section{by \\ Continuous Melting}

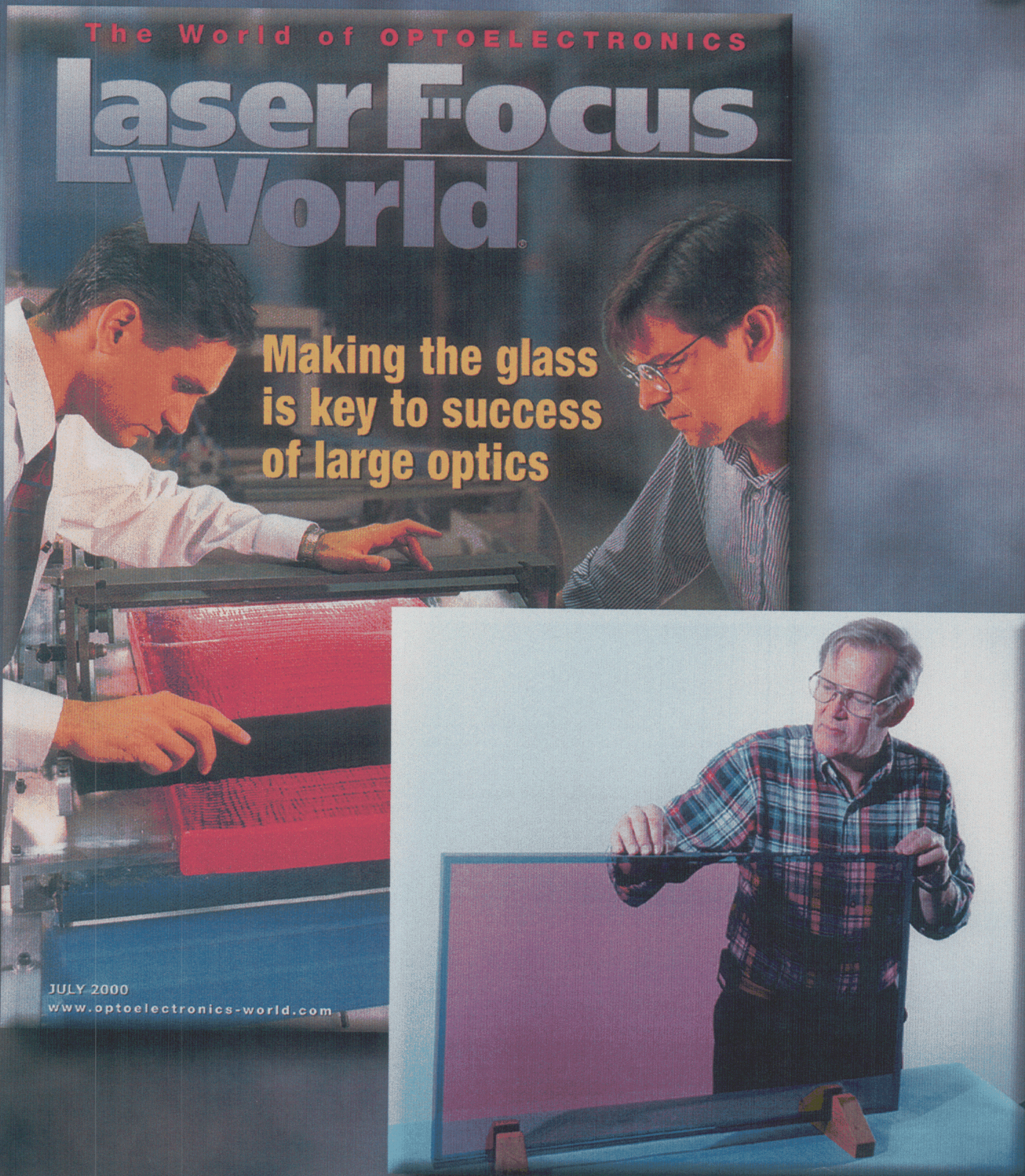




\section{LG-770 Phosphate Laser Glass}

For High Energy Applications

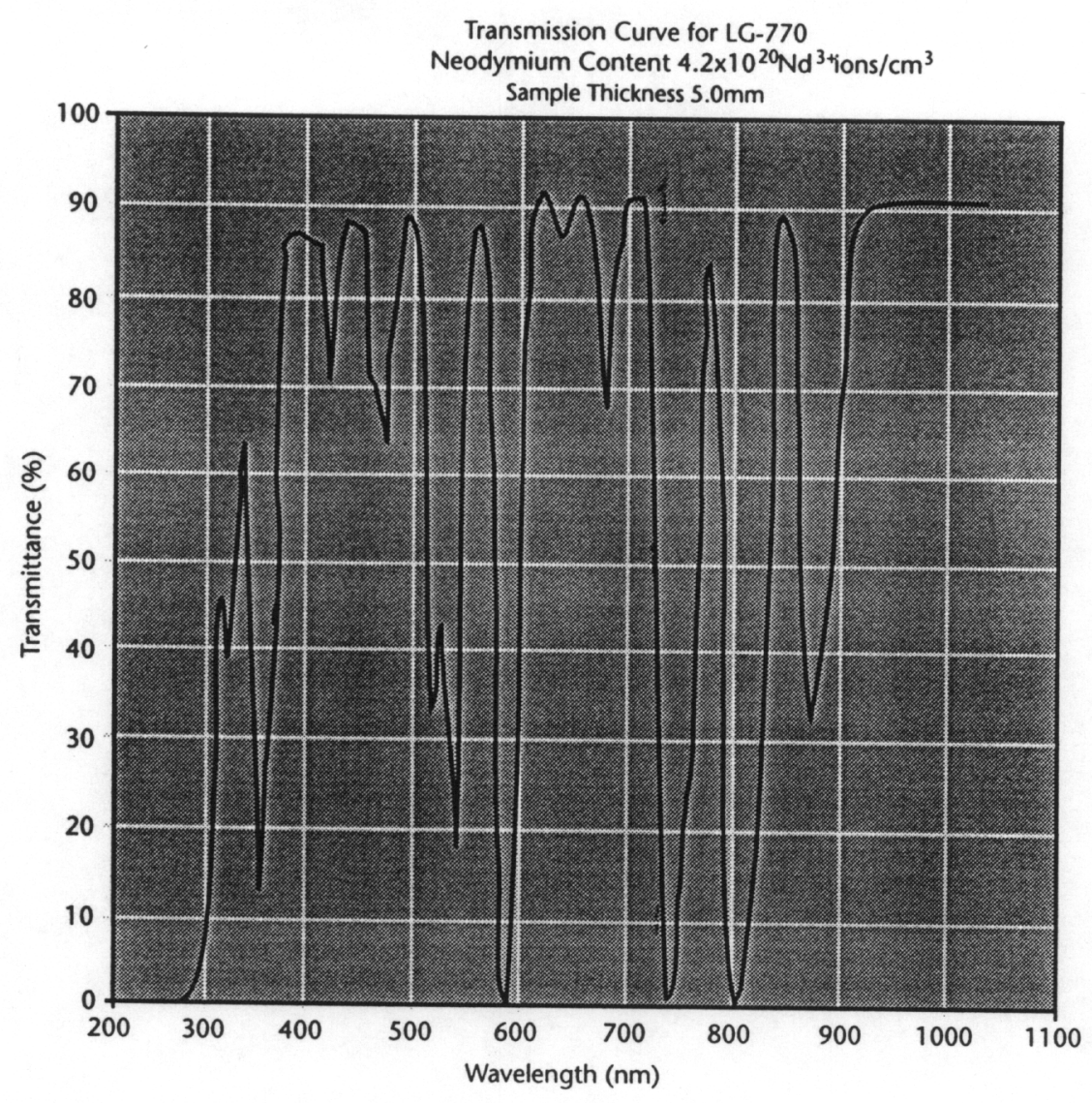

\begin{tabular}{|c|c|}
\hline \multicolumn{2}{|c|}{ Chemical Properties } \\
\hline $\begin{array}{c}\text { Weight Loss in } 50^{\circ} \mathrm{C} \text { Water } \\
\left.\text { [mg } /\left(\mathrm{cm}^{2} \bullet \text { day }\right)\right]\end{array}$ & 0.040 \\
\hline $\begin{array}{c}\text { Acid Resistance SR } \\
\text { pH=0.3 at } 25^{\circ} \mathrm{C}\end{array}$ & 3.0 \\
\hline $\begin{array}{c}\text { Alkali Resistance AR } \\
\text { pH }=12 \text { at } 50^{\circ} \mathrm{C}\end{array}$ & 4.0 \\
\hline $\begin{array}{c}\text { Staining Resistance FR } \\
\text { pH=4.6 } 100 \mathrm{~h} \text { at } 25^{\circ} \mathrm{C}\end{array}$ & 0 \\
\hline $\begin{array}{c}\text { Climatic Resistance CR } \\
\text { Water Vapor at } 40-50^{\circ} \mathrm{C} \text { for } 30 \mathrm{~h}\end{array}$ & 3 \\
\hline
\end{tabular}

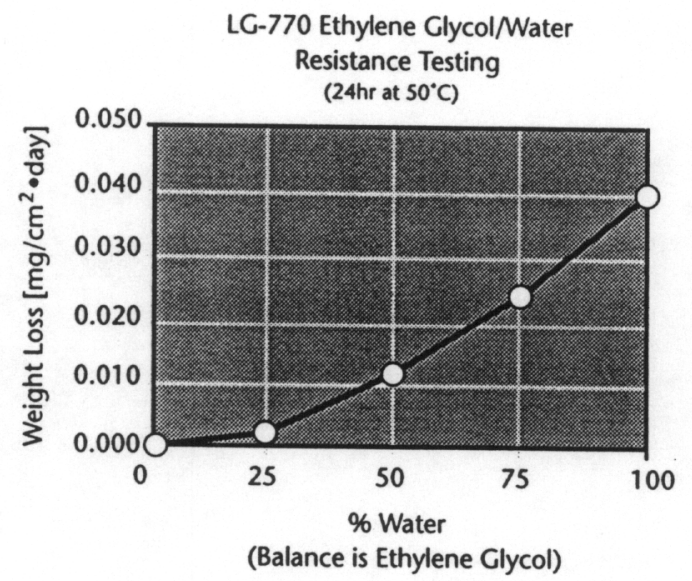

Schott Glass Technologies Inc.

400 York Avenue

Duryea, PA 18642

TEL: $(570)$ 457-7485

FAX: $(570) 457-7330$

e-mail: sgt@sg23øL.attmail.com

http://www.schottglasstech.com

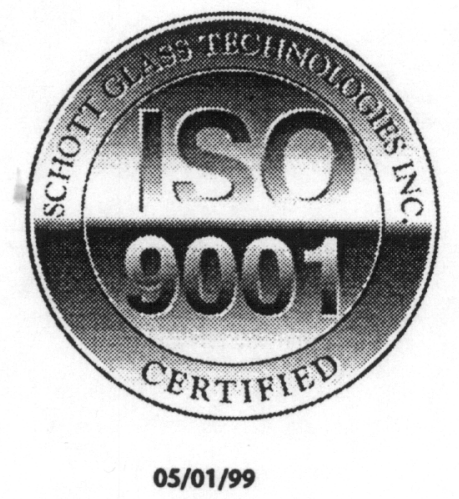




\section{LG-770 Phosphate Laser Glass}

\section{For High Energy Applications}

\begin{tabular}{|c|c|}
\hline \multicolumn{2}{|c|}{ Neodymium Laser Properties } \\
\hline $\begin{array}{c}\text { Emission Peak, } \lambda \\
{[\mathrm{nm}]}\end{array}$ & 1052.7 \\
\hline $\begin{array}{c}\text { Emission Width, } \Delta \lambda_{\mathrm{em}} \\
{[\mathrm{nm}]}\end{array}$ & 25.4 \\
\hline $\begin{array}{c}\text { Radiative Lifetime } \boldsymbol{T}_{\text {Rad }} \\
{[\mu \mathrm{sec}]}\end{array}$ & 350 \\
\hline $\begin{array}{c}\text { Emission Cross Section } \sigma_{\mathrm{em}} \\
{\left[10^{-20} \mathrm{~cm}^{2}\right]}\end{array}$ & 3.9 \\
\hline $\begin{array}{c}\text { *Quenching Constant-Zero Concentration Lifetime, } \mathrm{T}_{\mathrm{o}} \\
{[\mu \mathrm{sec}]}\end{array}$ & 372 \\
\hline $\begin{array}{c}\text { *Quenching Constant-Q Factor, Q } \\
{\left[10^{20} \mathrm{~cm}^{-3}\right]}\end{array}$ & 8.8 \\
\hline
\end{tabular}

*Lifetime as a function of neodymium content is approximated by: $T=T_{0} /\left(1+(N d / Q)^{2}\right)$, $\mathrm{Nd}=\mathrm{Nd}$ concentration in $10^{20}$ ions $/ \mathrm{cm}^{3}$

\begin{tabular}{|c|c|c|c|c|}
\hline \multicolumn{5}{|c|}{ Optical Properties } \\
\hline \multicolumn{4}{|c|}{$n_{d}$} & 1.5086 \\
\hline \multicolumn{4}{|c|}{$v_{d}$} & 68.40 \\
\hline \multicolumn{4}{|c|}{$n_{633 n m}$} & 1.5070 \\
\hline \multicolumn{4}{|c|}{$\mathrm{n}_{1054 \mathrm{~nm}}$} & 1.4996 \\
\hline \multicolumn{4}{|c|}{$\begin{array}{l}\text { Nonlinear Refractive Index at } 1054 \mathrm{~nm}, \mathrm{n}_{2} \\
{\left[10^{-13} \mathrm{esu}\right]}\end{array}$} & 1.02 \\
\hline \multicolumn{4}{|c|}{$\begin{array}{c}\text { Stress-Optic Coefficient, } \mathrm{K} \\
\left(588 \mathrm{~nm}, 22^{\circ} \mathrm{C}\right)\left[10^{-6} \mathrm{~mm}^{2} / \mathrm{N}\right]\end{array}$} & 2.10 \\
\hline \multicolumn{4}{|c|}{$\begin{array}{l}\text { Stress-Optic Coefficient, }-\mathrm{K}_{\text {par }} \\
\left(632.8 \mathrm{~nm}, 25^{\circ} \mathrm{C}\right)\left[10^{-6} \mathrm{~mm}^{2} / \mathrm{N}\right]\end{array}$} & 2.20 \\
\hline \multicolumn{4}{|c|}{$\begin{array}{l}\text { Stress-Optic Coefficient, }-K_{\text {per }} \\
\left(632.8 \mathrm{~nm}, 25^{\circ} \mathrm{C}\right)\left[10^{-6} \mathrm{~mm}^{2} / \mathrm{N}\right]\end{array}$} & 3.90 \\
\hline \multicolumn{4}{|c|}{$\begin{array}{l}\text { Temperature Coefficient of Refractive Index, } \mathrm{dn} / \mathrm{dT} \text { ret } \\
\qquad\left(1060 \mathrm{~nm}, 20-40^{\circ} \mathrm{C}\right)\left[10^{-6} /{ }^{\circ} \mathrm{C}\right]\end{array}$} & -4.7 \\
\hline \multicolumn{4}{|c|}{$\begin{array}{l}\text { Temperature Coefficient of Optical Pathlength, } \\
\qquad W=\alpha_{20-40^{\circ} \mathrm{C}}(\mathrm{n}-1)+\mathrm{dn} / \mathrm{dT}\left[10^{-6} /{ }^{\circ} \mathrm{C}\right]\end{array}$} & 1.1 \\
\hline \multicolumn{5}{|c|}{ Sellmeier Coefficients } \\
\hline B1 & 1.03692728 & $\mathrm{C} 1$ & \multicolumn{2}{|c|}{0.00577291} \\
\hline B2 & 0.21105327 & $\mathrm{C} 2$ & \multicolumn{2}{|c|}{0.01976189} \\
\hline B3 & 0.77362466 & C3 & \multicolumn{2}{|c|}{101.422203} \\
\hline \multicolumn{5}{|c|}{ Attenuation Coefficient $\left[\mathrm{cm}^{-1}\right]$} \\
\hline $400 \mathrm{~nm}$ & $\leq 0.20$ & $3000 \mathrm{~nm}$ & & $\leq 0.80$ \\
\hline $1054 \mathrm{~nm}$ & $\leq 0.0015$ & $3333 \mathrm{~nm}$ & & $\leq 2.00$ \\
\hline
\end{tabular}

LG-770 is an aluminum-phosphate based glass with a high cross section for stimulated emission, extremely low nonlinear refractive index, and good athermal characteristics. This glass was initially developed for the US DOE National Ignition Facility and French CEA Project Laser Megajoule. The development and the advantages of this glass are discussed in "Laser and thermo-physical properties of Nd-doped phosphate glasses" Proc SPIE, Vol 1761, 162-173 (1992).

LG-770 Fluorescence Lifetime

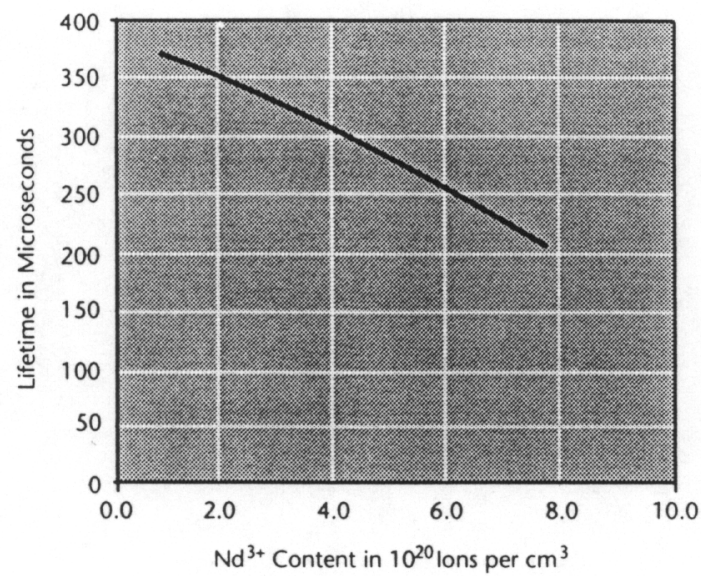

Physical Properties

\begin{tabular}{|c|c|}
\hline $\begin{array}{l}\text { Density, p } \\
{\left[\mathrm{g} / \mathrm{cm}^{3}\right]}\end{array}$ & 2.585 \\
\hline $\begin{array}{l}\text { Thermal Conductivity }\left(25^{\circ} \mathrm{C}\right), \mathrm{K} \\
\qquad[\mathrm{W} / \mathrm{m} \cdot \mathrm{K}]\end{array}$ & 0.57 \\
\hline $\begin{array}{l}\text { Thermal Conductivity }\left(90^{\circ} \mathrm{C}\right), \mathrm{K} \\
\qquad[\mathrm{W} / \mathrm{m} \bullet \mathrm{K}]\end{array}$ & 0.63 \\
\hline $\begin{array}{l}\text { Young's Modulus, E } \\
\text { [GPa] }\end{array}$ & 47.29 \\
\hline Poisson's Ratio, v & 0.253 \\
\hline $\begin{array}{l}\text { Fracture Toughness, } \mathrm{K}_{1 \mathrm{c}} \\
\text { [MPa・m } \\
\end{array}$ & 0.48 \\
\hline Knoop Hardness, $\mathrm{HK}_{0.1 / 20}$ & 330 \\
\hline $\begin{array}{l}\text { Heat Capacity }\left(25^{\circ} \mathrm{C}\right), \mathrm{C}_{\mathrm{p}} \\
{\left[\mathrm{J} / \mathrm{g}^{\circ} \mathrm{C}\right]}\end{array}$ & 0.77 \\
\hline $\begin{array}{l}\text { Thermal Diffusivity }\left(25^{\circ} \mathrm{C}\right), 0 \\
{\left[10^{-7} \mathrm{~m}^{2} / \mathrm{sec}\right]}\end{array}$ & 2.86 \\
\hline $\begin{array}{l}\text { Thermal Expansion, } \alpha_{20-300^{\circ} \mathrm{C}} \\
\qquad\left[10^{-7} /{ }^{\circ} \mathrm{C}\right]\end{array}$ & 133.6 \\
\hline $\begin{array}{l}\text { Thermal Expansion, } \alpha_{20-40^{\circ} \mathrm{C}} \\
\qquad\left[10^{-7} /{ }^{\circ} \mathrm{C}\right]\end{array}$ & 116.1 \\
\hline $\begin{array}{c}\text { Transformation Temperature, } T_{g} \\
{\left[{ }^{\circ} \mathrm{C}\right]}\end{array}$ & 461 \\
\hline
\end{tabular}


Athermal Laser Glass

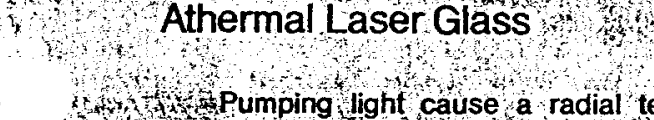
. 3 , highly repeated shots cause temperature change in laser $\rightarrow, 160$ olass rod which result the change in optical length. As a result, WW spatial oscillation pattern and oscillation performance are

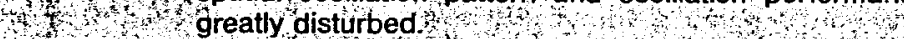

. In order to avoid the thermal effect, athermal phosphate

aser glass $\mathrm{LHG}-8$ has been developed, which has nearly th th

ro temperature coefficient of optical path length $\mathrm{LHG}-8$ i

as the temperature coefficient of optical path length

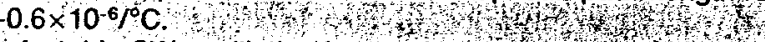

A stable CW oscillation in glass laser was actileved for the

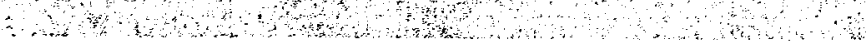

\section{Lasing Properties}

$\mathrm{Nd}_{2} \mathrm{O}_{3}$ (Standard doping)

$\mathrm{Nd}^{3}+$ concentration

Cross section for stimulated emission

Fluorescence lifetime

Specific gain

Fluorescence half-line width at $290^{\circ} \mathrm{K}$

Center lasing wavelength

Attenuation coeff. at $1054 \mathrm{~nm}$

\section{first time using of LHG-8.}

\section{Optical properties}

Non-linear refractive index coeff.

Refractive index at $1054 \mathrm{~nm}$

Refractive index at $632.8 \mathrm{~nm}$

Refractive index at $587.6 \mathrm{~nm}$

Refractive index at $486.1 \mathrm{~nm}$

Refractive index at $656.3 \mathrm{~nm}$

Abbe value

Brewster's angle

Temp. coeff. of refractive index $\left(20 \sim 40^{\circ} \mathrm{C}\right)$

coeff. of linear thermal expansion $\left(20 \sim 40^{\circ} \mathrm{C}\right)$

Temp. coeff. of optical path length $\left(20 \sim 40^{\circ} \mathrm{C}\right)$

\begin{tabular}{c|c|l} 
& wt. $\%$ & 3.0 \\
& $10^{20}$ ions $/ \mathrm{cm}^{3}$ & 3.1 \\
$\delta p$ & $10^{-20} \mathrm{~cm}^{2}$ & 4.2 \\
$\tau$ & $\mu \mathrm{sec}$ & 315 \\
$\gamma$ & $\mathrm{cm}-1 / \mathrm{J} / \mathrm{cm}^{3}$ & 0.223 \\
$\Delta \lambda$ & $\dot{A}$ & 218 \\
$\lambda p$ & $\mathrm{~nm}$ & 1054 \\
& $\mathrm{~cm}-1$ & 0.0015 \\
\hline
\end{tabular}

\section{Themal properties}

Transformation temp.

Sag temp.

Coeff. of linear thermal expansion $\left(100 \sim 300^{\circ} \mathrm{C}\right)$

Thermal conductivity $\left(25^{\circ} \mathrm{C}\right)$

Specific heat $\left(25^{\circ} \mathrm{C}\right)$

\begin{tabular}{|c|c|c|}
\hline $\mathrm{n}_{2}$ & $10^{-13}$ e.s.u. & 1.13 \\
\hline$n(1054)$ & & 1.52005 \\
\hline n (632.8) & & 1.52793 \\
\hline กฮ & & 1.52962 \\
\hline$\Pi=$ & & 1.53515 \\
\hline$\Pi_{c}$ & & 1.52718 \\
\hline$\nu_{c}$ & & 66.5 \\
\hline & & $56^{\circ} 40^{\prime}$ \\
\hline $\mathrm{dn} / \mathrm{dT}$ & $10^{-6 / \circ} \mathrm{C}$ & -5.3 \\
\hline & $10^{-6 /{ }^{\circ} \mathrm{C}}$ & 11.2 \\
\hline $\mathrm{ds} / \mathrm{dT}$ & $10^{-6 /{ }^{\circ} \mathrm{C}}$ & +0.6 \\
\hline
\end{tabular}

\section{Chemical properties}

Water durability $\left(\mathrm{H}_{2} \mathrm{O}, 100^{\circ} \mathrm{C}, 1 \mathrm{Hr}\right)$

Acid durability $\left(\mathrm{HNO}_{3}, \mathrm{PH} 2.2,100^{\circ} \mathrm{C} 1 \mathrm{Hr}\right)$

\begin{tabular}{c|c|c}
\hline $\mathrm{T}_{9}$ & ${ }^{\circ} \mathrm{C}$ & 485 \\
$\mathrm{~T}_{5}$ & ${ }^{\circ} \mathrm{C}$ & 520 \\
$\alpha$ & $10^{-7} /{ }^{\circ} \mathrm{C}$ & 127 \\
$\chi$ & $\mathrm{Kcal} / \mathrm{m} \cdot \mathrm{h} \cdot{ }^{\circ} \mathrm{C}$ & 0.50 \\
$\mathrm{C}_{0}$ & $\mathrm{cal} / \mathrm{g} \cdot{ }^{\circ} \mathrm{C}$ & 0.18 \\
\hline
\end{tabular}

Other properties

Density
Young's modulus
Modulus of rigidity
Poisson's ratio
Knoop hardness $(100 \mathrm{gf}, 15 \mathrm{sec})$
Abration factor
Stress optical coeff.

Density

Young's modulus

Modulus of rigidity

Abration factor

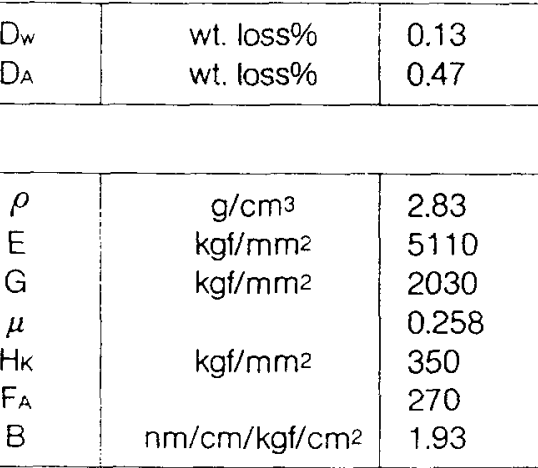


Appendix D

\section{Testimonials}




\section{Alfred University}

The New York State

College of Ceramics at Alfred University

A Statutory College of the State University of New York
Office of the Dean

2 Pine Streel

Alfred, NY 14802-1296

$607 \cdot 871 \cdot 2411$

FAX871. 2344

pyooking.alfred.edu

February 6, 2001

To whom it may concem:

RECOMMENDATION FOR 2001 RESEARCH AND DEVELOPMENT 100 AWARD

It is strongly recommended that the application entitled "Continuous Melting of Laser Glass" be selected for the 2001 Research and Development 100 Award. This recommendation is based on:

1. The break-through achievement of continuous fabrication of extraordinary, high-quality laser glass critical to meeting the goals of the National Ignition Facility;

2. the remarkable technological advances that were made to achieve this fabrication and especially the integration of melting, conditioning, forming, and annealing; and

3. the potential application of these advances to heretofore unavailable large-scale manufacturing of a wide variety of valuable optical glasses ranging from the industry standard, Schott $\mathrm{BK}^{7}$, in more esoteric types having high coefficients of thermal expansion and low fracture toughness.

The technological milestones achieved in developing this continuous process included the reduction of dissolved water $(\mathrm{OH})$ content to less than $100 \mathrm{ppm}$, a marked increase in optical homogeneity, the near elimination of undesirable micro inclusions of platinum, and the fine annealing of highquality optical glass of uncommon width, thickness, and length. It is confidently anticipated that these advances will be of great help in supporting the opto-electronic industry of the U.S. 
Recommendation letter for 2001 R\&D 100 Award

Page 2

February 6, 2001

The achievement of these goals has also produced within Schott Glass Technologies an increased awareness of the importance and value of ; communication, cooperation, and sharing of technical insights and expertise among all units involved: manufacturing, research and development, quality assurance, purchasing, sales, finance, and human resources. Thus the remarkable progress achieved to date has served to strengthen not only Schott Glass Technologies, but the entire optical materials industry as well.

The success of this project can only be regarded as a win-win situation for all involved: the National Ignition Facility, the optical materials industry, Schott Glass Technologies, and the scientists/engineers/technicians who participated in this once in a lifetime engineering effort of great national importance. For these reasons, conferment of this award can only reflect credit upon Lawrence Livermore National Laboratory for having funded and guided this effort, and those charged with making decisions on the 2001 R\&D 100 Awards.

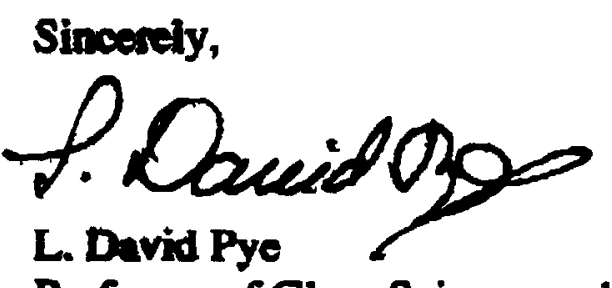

Professor of Glass Science and Past Dean of the NYS College of Ceramics Member of the International Academy of Ceramics

Past Trustee, Glass and Optical Materials Division, American Ceramic Society Immediate Past President, The International Commission on Glass 


\title{
School of Optics/CREOL ${ }^{\oplus}$
}

\section{TO WHOM IT MAY CONCERN}

From

\author{
Martin Richardson \\ Professor of Optics, Physics and Electrical \& Computer Engineering, \\ School of Optics \& CREOL, Univ. of Central Florida, 4000 Central Florida Blvd, Orlando FL 32816-2700 \\ Tel 4078236819 Fax 4078233570 Email: mcr@creol.ucf.edu
}

Date

February 5, 2001

Subject

Recommendation for Research \& Development 100 Award (R\&D 100)

I am grateful for the opportunity to support the application being made for an R\&D 100 Award by LLNL, Schott Glass Technologies and Hoya Corp, for the development of the continuous melting of phosphate laser glass. This is an extremely important achievement, having national and international significance extending well beyond the boundaries of laser science and fusion technology.

I feel qualified to comment on this from a balanced viewpoint, since, although for a long time I played an important role in this field, I now no longer work directly in the ICF program. Nonetheless as an academician I have several reasons for maintaining a keen and critical eye on recent developments. Firstly, I have established a research laboratory here at the School of Optics that focuses on advanced applications of ultra-high-power solid state lasers, a program that of necessity considers the limits of existing laser materials and methods. Secondly, I recently served as a technical expert on an assessment committee established by the US Congress, the Lockwood-Greene committee that made a thorough review of the NIF facility. Lastly, I have through the years come to know well, many of the principal scientists at both Schott Glass Technologies Inc., and the Hoya Research Laboratories, as well, of course, as those at LLNL.

The NIF facility, and its counterpart in France, the MegaJoule Project, is considered a cornerstone of our national defense program. It is the centerpiece of the stockpile stewardship program that allows us to maintain pre-eminence in nuclear weapons technology while subscribing to a comprehensive nuclear test ban policy. Building this facility, a facility over an order of magnitude more difficult and complex than any other laser fusion facility, forced major innovative developments in many areas of laser technology. The sheer size of the laser, the sheer magnitude of the number of individual components, is well beyond anything else that has ever been built. The biggest challenge by far is the fabrication of the vast number of extremely large, finely-fabricated optical components within extremely tight tolerances on precision, material quality, cost and delivery. This forced the development of new crystal growth techniques, new coating technologies, and innovative electro-optical engineering. However, perhaps the biggest challenge was associated with the laser medium itself, the ultra-pure, Nd-doped phosphate glass that both generates and sustains the power within the laser system. The sheer size and number of laser glass elements required was well beyond the capabilities of existing technologies. Had these technologies been used, the laser system would probably have taken well over two decades to build and the price would have been astronomical. The conventional method of making laser glass blanks was a show-stopper to the project itself. It took the combined efforts of an international team, between scientists at LLNL, Schott Glass Technologies and Hoya Corp, to develop a whole new way of making and processing precision optical glass. This process, the Continuous Melt Process, reduced the production cost of laser glass by a factor of five, and perhaps more important, resulted in a twenty-fold decrease in the production time. Not only that, but the optical homogeneity was also improved several-fold, an important requirement, given the power levels that this laser will have to sustain. Without this development, the NIF and MegaJoule projects could not have proceeded.

For these reasons I strongly recommend you recognize this achievement with a 2001 R\&D 100 Award to the LLNL, Schott, Hoya team for this tremendous accomplishment.

Yours truly,

dLCRoindse

Martin Richardson

CREOL Building • P. O. BOx $162700 \bullet 4000$ Central Florida Blvd. • Orlando, FL 32816-2700

(407) 823-6800 • FAX (407) 823-6880

An Equal Opportunity and Affirmative Action Institution 
February 7, 2001

R\&D100 Cornmittee

Lawrence Livermore National Laboratory

7000 East Ave.

Livermore, CA $94550-9234$

Dear R\&D100 Committee,

The purpose of this note is to strongly endorse the work of LLNL, Hoya Corporminin and Schott Corporation in "Manufacturing Laser Glass by Continuous Melting" for an R\&D 100 Award. This revolutionary development in the low cost, high production of laser glass with extremely demanding tolerances exceeds all of the criteria for this award. As described in the accompanying documentation, this effort involved high risk R\&D that had to be successful, not only in the laboratory, but on the factory floor. It involved unprecedented cooperation amongst a world leading laser and optical sciences laboratory and the two leading (and competing) companies in large laser glass production to significantly advance the state of the art.

This effort which utilizes advanced glass chemistry and manufacturing techniques, and state of the art thermal management and quality control has been "reduced to practice." The continuous melting process has now produced nearly $40 \%$ of the laser glass slabs required for the multi-megajoule National Ignition Facility now under construction at LLNL. The resulting laser glass not only exceeds the size and specifications of all other previous lasers of this type but at a cost per unit volume and production schedule that has been reduced by an order of magnitude!

The continuous low cost production of highly quality large aperture optical glass should have impact well beyond megajoule class solid state lasers for fusion, national security and scientific research that are now under construction in the US and France. This propess will benefit every product that requires such optical components including flat pane $1-\frac{1}{r}$.ays, high quality windows (including those with specialized adsorbing characteristics) and the mass production of devices for the optical telecom industry.

In summary, "Manufacturing Laser Glass by Continuous Manufacturing" represents and demonstrates the best of the National laboratories and industry. Together they have taken a daunting, high-risk challenge to significantly advance the field and they have succeeded. This success has enabled a major federal project and will impact the entire field in the manufacture of low cost, high quality optics. In my 24 years as a participant in the high-energy:laser community, I have rarely seen such a deserving submission.

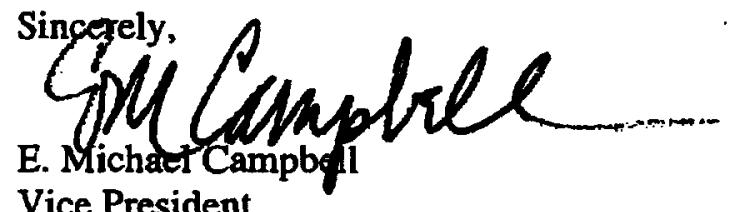

Lasers and Inertial Fusion 


\section{Appendix E}

\section{Journal publications, conference proceedings, technical reports}




\title{
Continuous melting of phosphate laser glasses
}

\author{
J.H. Campbell a,* , T.I. Suratwala ${ }^{a}$, C.B. Thorsness ${ }^{a}$, J.S. Hayden ${ }^{b}$, A.J. Thorne ${ }^{b}$, \\ J.M. Cimino $^{b}$, A.J. Marker III ${ }^{b}$, K. Takeuchi ${ }^{c}$, M. Smolley ${ }^{c}$, G.F. Ficini-Dorn ${ }^{\text {d }}$ \\ a Lawrence Livermore National Laboratory, P.O. Box 808. Livermore, CA 94550, USA \\ ' Schott Glass Technologies, 400 York Ave., Duryea, PA 18642, USA \\ ' Hoya Corporation, USA, 3400 Edison Way, Fremont, CA 94538-6190, USA \\ 'Centre d'Etudes de Limeil-Valenton, EME/ECO, 94795 Villeneuve St. Georges cedex, France
}

\begin{abstract}
Continuous melting of phosphate laser glass is being used for the first time to prepare meter-scale amplifier optics for megajoule lasers; a description of the melting process is given. Two key factors in the successful melting of laser glasses are the elimination of damage-causing $\mathrm{Pt}$-inclusions and dehydroxylation of the glass to concentrations less than $\sim 100$ ppmw $\mathrm{OH}$. Oxidizing conditions using $100 \% \mathrm{O}_{2}$ or $\mathrm{O}_{2}+\mathrm{Cl}_{2}$ mixtures (at one atmosphere) can be used to dissolve $\mathrm{Pt}$ inclusions and the effects of different gases on the dissolution of Pt-inclusions show the trend $\mathrm{O}_{2}+\mathrm{Cl}_{2}>\mathrm{O}_{2} \gg \mathrm{N}_{2}$. The removal of hydroxyl groups is achieved by reactive $\left(\mathrm{O}_{2}+\mathrm{Cl}_{2}\right)$ or non-reactive $\left(\mathrm{O}_{2}\right)$ gas bubbling; model calculations are used to simulate this process. (c) 2000 Published by Elsevier Science B.V. All rights reserved.
\end{abstract}

\section{Introduction}

Continuous laser glass melting is being used for the first time to supply glass for large laser systems designed for fusion energy research $[1,2]$. One of these laser systems is under construction in the US [1] and a second is planned for construction in France [2]. The US facility is called the National Ignition Facility (NIF); the name is derived from its purpose: to achieve controlled thermonuclear (fusion) ignition. The French laser system is called the Laser MegaJoule (LMJ).

The NIF laser will be capable of delivering nearly $1.8 \mathrm{MJ}$ of energy in about a $3.5 \mathrm{~ns}$ pulse, giving a peak power of approximately

\footnotetext{
Corresponding author. Tel.: +1-925 422 6497; fax: +1-925 4230792.

E-mail address: cambell12@llnl.gov (J.H. Campbell).
}

$5.0 \times 10^{14} \mathrm{~W}$. To achieve this output, NIF uses 192 individual laser beamlines each of which contains 16 Nd-doped laser glass plates (Fig. 1). More than 3000 glass plates will be installed on the NIF. Similarly, the planned French laser will require nearly $\mathbf{4 5 0 0}$ glass plates. Thus, almost 8000 laser glass plates will be needed for the two laser systems: this represents a volume in excess of $125 \mathrm{~m}^{3}$ (330 metric tons) of finished optical quality glass. Note that the quantity of raw glass that must be melted is larger than 330 metric tons to account for various process losses.

In contrast to the $1.8 \mathrm{MJ}$ NIF and LMJ laser systems, the largest $\mathrm{Nd}$-glass lasers currently in operation are the $70 \mathrm{~kJ}$ Nova (LLNL) [3] and the $40 \mathrm{~kJ}$ Omega [4] (University of Rochester) laser systems. These two systems use only about 2.2 and $1.1 \mathrm{~m}^{3}$ of laser glass, respectively. In addition, the largest size Nd-glass amplifier disks installed on these two lasers are the $7 \ell$ ( $46 \mathrm{~cm}$ aperture) elliptical 


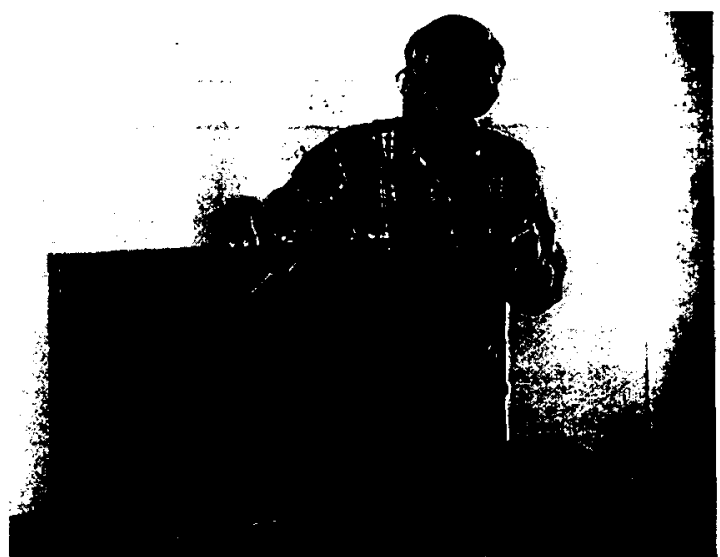

Fig. 1. One of the 3072 laser glass optics that will be used on the $1.8 \mathrm{MJ}$ NIF laser. Each optic is about $81 \times 46 \times 4 \mathrm{~cm}^{3}$ and is comprised of a rectangular plate of either LHG-8 or LG-770 Nd-doped phosphate laser glass. The edges of the plate are edge-clad with $1.2 \mathrm{~cm}$ thick strips of an index-matching $\mathrm{Cu}$-doped phosphate glass. Each optic can store about $3.5 \mathrm{~kJ}$ of energy.

disks on Nova and the $2 \ell(21 \mathrm{~cm}$ aperture $)$ disks on Omega. Therefore, the combined NIF and LMJ lasers require approximately 75 times the laser glass production capacity used for Nova and Omega with glass-part sizes more than 2 times larger.

Both the NIF and LMJ laser systems employ a compact laser amplifier design called the 'multisegment amplifier' (MSA) [5-8]. These amplifiers consist of stacked $4 \times 1$ arrays of laser glass plates inside a flashlamp-pumped cavity. By using square apertures (i.e., square beams), it is possible to tightly pack the individual laser glass amplifiers into a compact matrix and greatly reduce the size and cost of the system $[1,8]$. This design requires that the laser glass be manufactured in rectangular plates (Fig. 1) [9]. Note that although the laser aperture is square, the laser glass plates are rectangular because they are mounted at Brewster's angle to the propagation direction of the beam. Mounting the glass at Brewster's angle minimizes the Fresnel reflection losses at the slab surfaces [10]. In addition, mounting at an angle increases the coupling efficiency of the flashlamp-pump light with the slabs $[5,10]$.

In this paper, we first summarize the composition and properties of the two laser glasses to be used in the megajoule lasers and then describe the advanced continuous optical glass melting systems that have been developed to produce these laser glasses. The remaining sections of the paper describe technical advances in understanding two of the key processing steps that affect the laser glass performance: (1) elimination of metallic Pt-inclusions that might induce laser damage and (2) reduction in concentration of hydroxyl groups that shortens the $\mathrm{Nd}^{3+}$ fluorescence lifetime.

Continuous laser glass melting systems, based on the technology described here, have been constructed and are currently producing glass at both Schott Glass Technologies and Hoya Corporation, USA.

\section{Laser glass composition and properties}

The laser glasses used in the large laser amplifiers are Nd-doped metaphosphate glasses [11]. The two specific glasses that meet the gain, energy storage, extraction efficiency and damage resistance requirements of NIF and LMJ [11-13] are LHG-8 (Hoya Corporation) [11,14-17] and LG770 (Schott Glass Technologies) [11,12,14,17,18]. The composition and key properties of LHG-8 and LG-770 are summarized in Table 1 and the $\mathrm{Nd}^{3+}$ absorption and emission spectra of the two glasses are given in Fig. 2. Campbell and Suratwala [11] have reviewed recent advances in $\mathrm{Nd}$ phosphate laser glasses used for high-energy and high-peak-power applications; consequently, we will not discuss laser glass properties further here except as they directly relate to continuous melting.

The glass composition data (Table 1) are given on an oxide equivalent basis. Both glasses have near-metaphosphate compositions $(O / P \sim 3)$ and have very similar performance properties allowing them to be used interchangeably on the laser system. The major compositional difference in the two glasses is the group II modifier: LHG-8 contains $\mathrm{BaO}$ whereas LG-770 contains MgO. Both glasses use the same $\mathrm{Nd}$-doping-level (4.2x $10^{20}$ ions $/ \mathrm{cm}^{3}$ ).

The compositions given in Table 1 are listed as ranges and are intended to reflect the maximum 
Table 1

Composition and properties of Nd-doped phosphate laser glasses LHG-8 and LG-770 [14,16,17]

\begin{tabular}{|c|c|c|}
\hline Composition " or property & LHG-8 & LG-770 \\
\hline $\mathrm{P}_{2} \mathrm{O}_{5}$ & $55-60$ & $58-62$ \\
\hline $\mathrm{Al}_{2} \mathrm{O}_{3}$ & $8-12$ & $6-10$ \\
\hline $\mathrm{K}_{2} \mathrm{O}$ & $13-17$ & $20-25$ \\
\hline $\mathrm{BaO}$ & $10-15$ & - \\
\hline $\mathrm{MgO}$ & - & $5-10$ \\
\hline $\mathrm{Nd}_{2} \mathrm{O}_{3}{ }^{\mathrm{b}}$ & $0-2$ & $0-2$ \\
\hline Other & $<2$ & $<2$ \\
\hline$O / P( \pm 0.1)$ & 3 & 3 \\
\hline \multicolumn{3}{|l|}{ Optical } \\
\hline \multicolumn{3}{|l|}{ Refractive index ${ }^{\mathfrak{C}}$} \\
\hline$n_{\mathrm{d}}(587.3 \mathrm{~nm})$ & 1.5296 & 1.5067 \\
\hline$n_{\mathrm{l}}(1053 \mathrm{~nm})$ & 1.5201 & 1.4991 \\
\hline \multicolumn{3}{|l|}{ Non-linear refractive index } \\
\hline$n_{2}\left(10^{-13} \mathrm{esu}\right)$ & 1.12 & 1.01 \\
\hline$\gamma\left(10^{-20} \mathrm{~m}^{2} / \mathrm{W}\right)$ & 3.08 & 2.78 \\
\hline Abbe number $( \pm 0.05)$ & 66.5 & 68.4 \\
\hline \multicolumn{3}{|l|}{ Laser } \\
\hline Emission cross-section $\left(10^{-20} \mathrm{~cm}^{2}\right)( \pm 0.2)$ & 3.6 & 3.9 \\
\hline Radiative lifetime (zero-Nd) $(\mu s)( \pm 3)$ & 365 & 372 \\
\hline Judd-Ofelt radiative lifetime $(\mu s)( \pm 10 \%)$ & 351 & 349 \\
\hline Emission band width $(\mathrm{nm})( \pm 0.1)$ & 26.5 & 25.4 \\
\hline \multicolumn{3}{|l|}{ Thermal } \\
\hline Thermal conductivity, $90^{\circ} \mathrm{C}(\mathrm{W} / \mathrm{mK})( \pm 0.03)$ & 0.58 & 0.57 \\
\hline Thermal diffusivity $\left(10^{-7} \mathrm{~m}^{2} / \mathrm{s}\right)$ & 2.7 & 2.9 \\
\hline Specific heat, $C p(J / g K)( \pm 0.02)$ & 0.75 & 0.77 \\
\hline Coeff. thermal expansion, $20-300^{\circ} \mathrm{C}\left(10^{-7} / \mathrm{K}\right)( \pm 3)$ & 127 & 134 \\
\hline Glass transition temperature ${ }^{\mathrm{c}}, T_{\mathrm{g}}\left({ }^{\circ} \mathrm{C}\right)( \pm 5)$ & 485 & 460 \\
\hline \multicolumn{3}{|l|}{ Mechanical } \\
\hline Density $\left(g / \mathrm{cm}^{3}\right)^{\mathrm{c}}( \pm 0.01)$ & 2.83 & 2.59 \\
\hline Poisson's ratio $( \pm 0.01)$ & 0.26 & 0.25 \\
\hline Fracture toughness $(\mathrm{MPa} \mathrm{m} / 2)( \pm 0.02)$ & 0.51 & 0.43 \\
\hline Hardness $(\mathrm{GPa})( \pm 0.10)$ & 3.43 & 3.58 \\
\hline Young's modulus (GPa) $( \pm 1.0)$ & 50.1 & 47.3 \\
\hline
\end{tabular}

${ }^{\mathrm{a}}$ Range in composition values reflect variations due to $\mathrm{Nd}$-doping concentration, melt volatility, and batching variations.

${ }^{b} \mathrm{Nd}$-doping levels typically $<2 \mathrm{~mol} \% \mathrm{Nd}_{2} \mathrm{O}_{3}\left(<5 \times 10^{20} \mathrm{Nd}\right.$ ions $\left./ \mathrm{cm}^{3}\right)$; the NIF and LMJ use a doping of $4.2( \pm 0.1) \times 10^{20}$ ions $/ \mathrm{cm}^{3}$.

c Values may vary slightly with Nd-doping level.

variability in composition that can occur due to volatile losses, different $\mathrm{Nd}$-doping levels and batching variations. In addition, this protects certain proprietary aspects of the exact composition. However, once the continuous melting conditions are established the composition variation is insignificant as indicated by the very small index fluctuations in the product glass over any $24 \mathrm{~h}$ period $(\leqslant \pm 0.0001)$ and confirmed by chemical analysis of the product glass.

Note that small ranges in phosphate laser glass composition, such as those shown in Table 1 , have little effect on the key laser properties. LHG-8 and LG-770 have nearly identical properties (see Table 1 and Fig. 2) yet their range of compositions and modifiers differs. Campbell and Suratwala [11] 

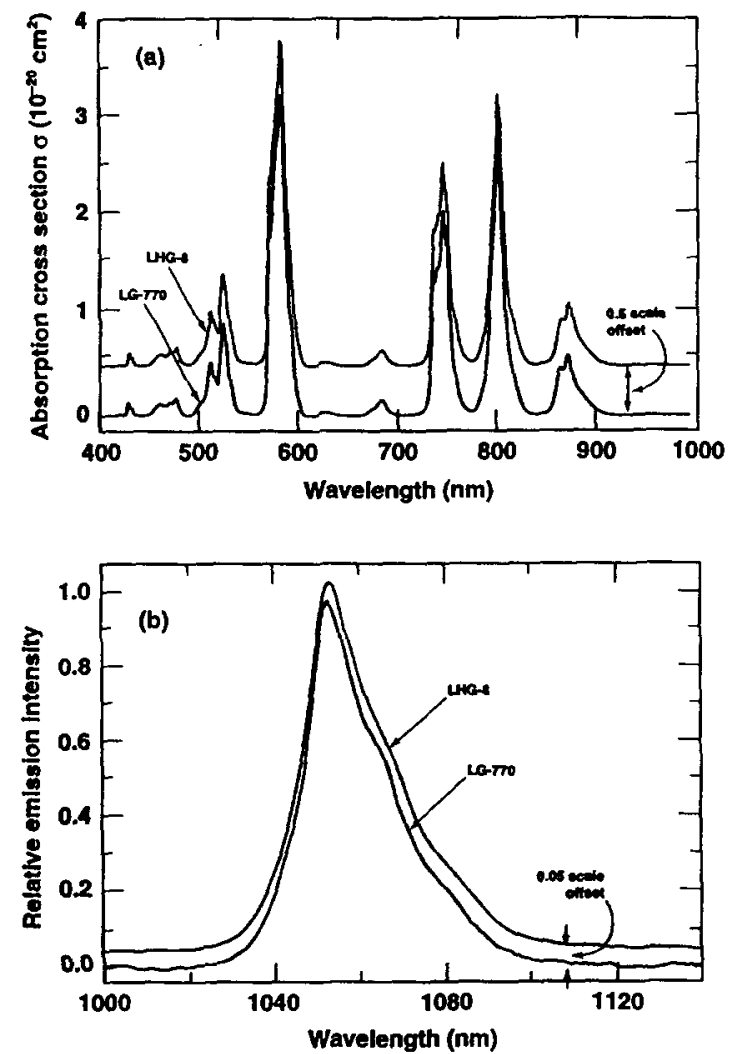

Fig. 2. Absorption (a) and emission (b) spectra for $\mathrm{Nd}^{3+}$ in the two phosphate laser glasses LHG-8 and LG-770.

have reported a similar insensitivity of most properties to minor changes in composition for laser glass having the approximate composition $60 \mathrm{P}_{2} \mathrm{O}_{5}-10 \mathrm{Al}_{2} \mathrm{O}_{3}-30\left(\mathrm{M}_{2} \mathrm{O} / \mathrm{MO}\right)$. As regards this particular manuscript, the range of compositions shown does not affect the results and conclusions given here for continuous glass melting.

\section{Discontinuous melting}

To put in perspective the scale of the continuous laser glass melting process, it is instructive to briefly describe the older discontinuous process $[19,20]$. In the past, the glasses made for the large ICF laser systems (e.g., Nova [LLNL], Phebus [CEA], Beamlet [LLNL], Gekko [Osaka], and Omega [University of Rochester]) [12] were manufactured using a one-at-a-time, discontinuous melting system. The first step of the discontinuous process is a pre-melting step designed to melt and mix (on a large-scale length) the raw materials (Fig. 3). A gas is often bubbled through the premelt to remove unwanted volatile products, particularly water and, if necessary adjust the melt redox state. The pre-melt is carried out in a relatively inert refractory crucible such as $\mathrm{SiO}_{2}$. The walls of the refractory vessel dissolve over time eventually requiring the vessel to be replaced. The glass from the pre-melter generally contains bubbles, striae, and, occasionally, some small particles of unmelted starting material.

The product glass from the pre-melt stage is next processed in a physically separate unit called the 'remelter'. The remelter is a platinum-lined refractory vessel that also has provisions for stirring and gas bubbling. The main purpose of the remelter is to dissolve any platinum-inclusions, remove bubbles and finally, improve the homogeneity of the glass to provide the striae-free, optical quality glass necessary for laser applications. The remelting process occurs in several stages [19]. During the first stage, the redox state of the glass is adjusted to increase platinum particle dissolution [21]. This step is followed by a refining process conducted at temperatures greater than $1050^{\circ} \mathrm{C}$ at which the viscosity of the glass is $<10$ poise, allowing bubbles to rise to the surface. The third

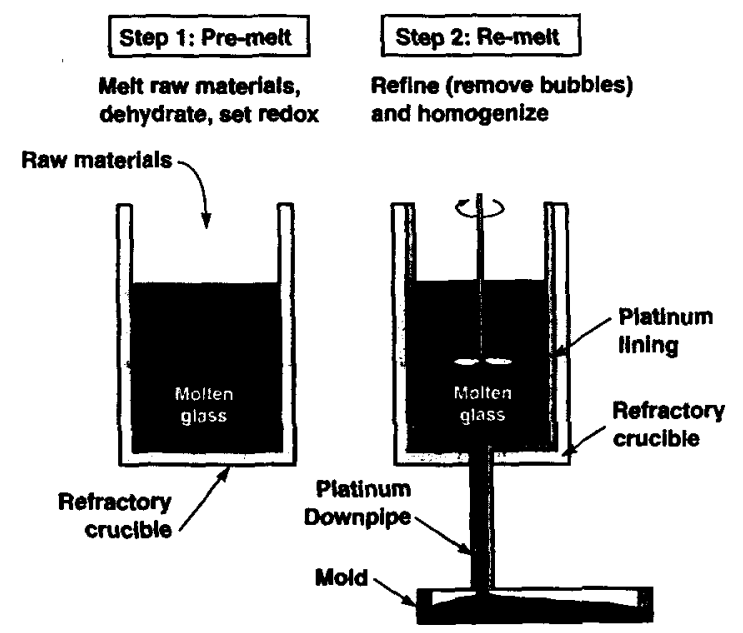

Fig. 3. Schematic representation of the discontinuous, 2-step melting process formerly used to produce laser glass. 
stage is a stirring process that is generally conducted at temperatures lower than either the melting or the refining stages. The continuous stirring thoroughly distributes all components within the glass melt, eliminating striae and increasing the uniformity of the refractive index over the entire casting. Finally, the melt is cooled to a temperature such that the viscosity of the glass is proper for casting into a mold of the appropriate size and shape. After casting, the glass undergoes an initial, relatively rapid annealing step, is inspected for inclusions and striae, and then is again annealed at a slower rate (several weeks) to reduce any residual thermal stresses.

Discontinuous processing methods have been used with good results for producing small quantities of laser glass. However, the discontinuous process has a small through-put and a single melting system can, at best, only produce a few glass plates per week $(<5)[19,20]$. In addition, the quality of the product glass can vary from one melt to the next simply because of small, but random, run-to-run variations in processing conditions. Continuous glass melting, on the other hand, has the advantage that not only can a much greater production rate be achieved but, in addition, once steady-state is achieved, there is little if any measurable variation in glass properties from one glass plate to the next.

\section{Continuous glass melting}

Continuous optical glass melting systems are generally divided into several interconnected zones $[20,22]$. Each zone consists of one or more vessels designed to carry out a particular part of the process. In the specific case of the laser glass continuous melters, there are six main interconnected processing zones (Fig. 4): (1) raw material mixing and feeding, (2) melting, (3) conditioning, (4) refining, (5) homogenization and (6) continuous strip forming. Each of these is described briefly below.

\subsection{Laser glass raw material, mixing and feeding}

The glass transmission losses at the laser wavelength $(1054 \mathrm{~nm})$ must be very low $(\$ 0.0015$ $\mathrm{cm}^{-1}$ ). Therefore the purity requirements for the raw materials are very demanding. In particular, only trace amounts (few ppm) of most transition metal ions are permitted [23-26]. Although $\mathrm{Cu}$ has the highest measured absorption loss at $1054 \mathrm{~nm}$, $\mathrm{Fe}$ is perhaps the most troublesome impurity to control because most processing equipment uses iron-based metals. Therefore, the purity requirements affect the choice of the raw material processing equipment and procedures. As an example, Table 2 gives the purity requirements for the $\mathrm{Nd}$

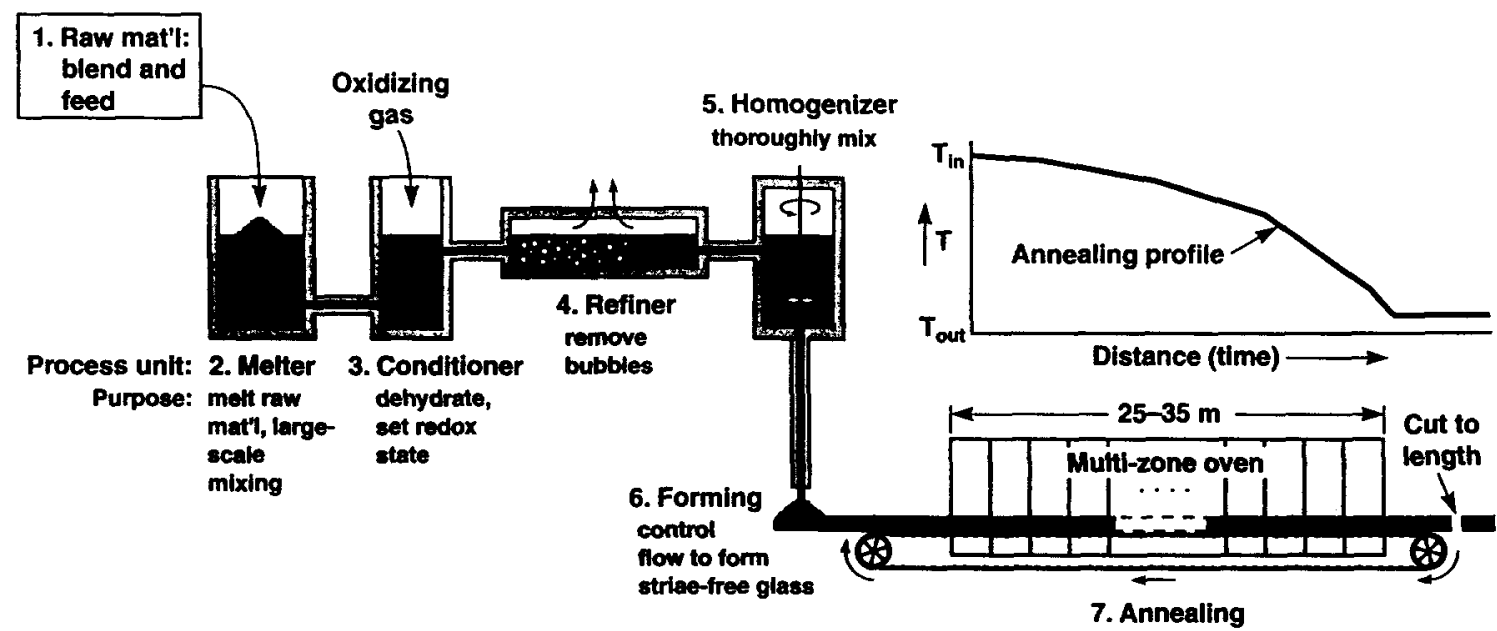

Fig. 4. Schematic representation of the continuous laser glass melting systems now being used to manufacture phosphate laser glass. 
Table 2

Metal ion purity for $\mathrm{Nd}$ salt (on oxide basis) used in laser glass melting

\begin{tabular}{lcl}
\hline Element (as oxide) & \multicolumn{2}{l}{ Purity level (ppmw) } \\
\cline { 2 - 3 } & $\begin{array}{l}\text { Specified } \\
\text { (maximum) }\end{array}$ & $\begin{array}{l}\text { Measured } \\
\text { (typical) }\end{array}$ \\
\hline Transition metals & 1 & 0.25 \\
$\mathrm{CuO}$ & 2 & 1.3 \\
$\mathrm{Fe} \mathrm{O}_{3}$ & 1 & 0.05 \\
$\mathrm{CoO}$ & 1 & 0.44 \\
$\mathrm{NiO}$ & 1 & 0.03 \\
$\mathrm{~V}_{2} \mathrm{O}_{5}$ & 1 & 0.42 \\
$\mathrm{Cr}_{2} \mathrm{O}_{3}$ & & \\
$\mathrm{Rare}$ earths & & \\
$\mathrm{Pr}_{6} \mathrm{O}_{11}$ & 100 & 18 \\
$\mathrm{La}_{2} \mathrm{O}_{3}$ & 100 & 27 \\
$\mathrm{Sm}_{2} \mathrm{O}_{3}$ & 30 & 0.9 \\
$\mathrm{CeO}_{2}$ & 30 & 1.4 \\
$\mathrm{Dy}_{2} \mathrm{O}_{3}$ & 10 & $<0.5$ \\
$\left(\mathrm{Other}_{2}\right.$ rare earths) & 10 & $<10$ \\
\hline
\end{tabular}

salt used in the melting process; the transition metal impurity levels are typical of the requirements for most of the raw materials. Unique to the $\mathrm{Nd}$, however, is the low concentration of other rare earths $(<100 \mathrm{ppmw})$ that is required. Rare earth ions are usually separated by a solvent extraction process [27]. This process can make the manufacture of a high-purity Nd salt quite difficult because the similar reaction chemistry among rare earths often makes the extraction process inefficient particularly for certain pairs of rare earth ions.

Compounding the difficulty of raw material purity is the need to achieve these levels for many tons of material. Recall from above that more than 300 tons of finished glass must be manufactured. Of course, much more than this must be melted to cover the yield and fabrication losses inherent in the process. The Nd raw material requirements alone consume most of the world-wide manufacturing capacity for high-purity $\mathrm{Nd}$ salt.

In addition to transition and rare earth elements, the raw materials should contain little physically or chemically absorbed water $(<0.1$ wt $\%)$ as this introduces hydroxyl groups in the glass that can increase the $\mathrm{Nd}$ non-radiative decay rate [11]. This requirement can be quite trouble- some because of the inherent hygroscopic nature of some of the laser glass raw materials and the fact they are supplied as finely ground powders. The raw materials should be mixed in a dry atmosphere and then delivered continuously to the melter with precautions to avoid water uptake.

\subsection{Melting}

The batch powder that enters the melter dissolves in the molten glass and undergoes largescale mixing driven by convection currents within the melter. Off-gas handling equipment collects any gas emissions from the melter (or other vessels) and treats the effluent to meet environmental regulations.

Compared to silicate glasses, phosphate laser glasses generally melt in the range of $1000-1200^{\circ} \mathrm{C}$. Heat is supplied to the melter by electrical means because gas-fired heat sources increase the concentration of hydroxyl groups in the glass.

The lifetime of the whole melting system is governed by the dissolution rate of the refractory walls of the melter unit. Phosphate glasses tend to be relatively corrosive to most refractories; therefore the choice of a proper refractory becomes a critical decision in the design of the melter system. This choice is made by comparing results from

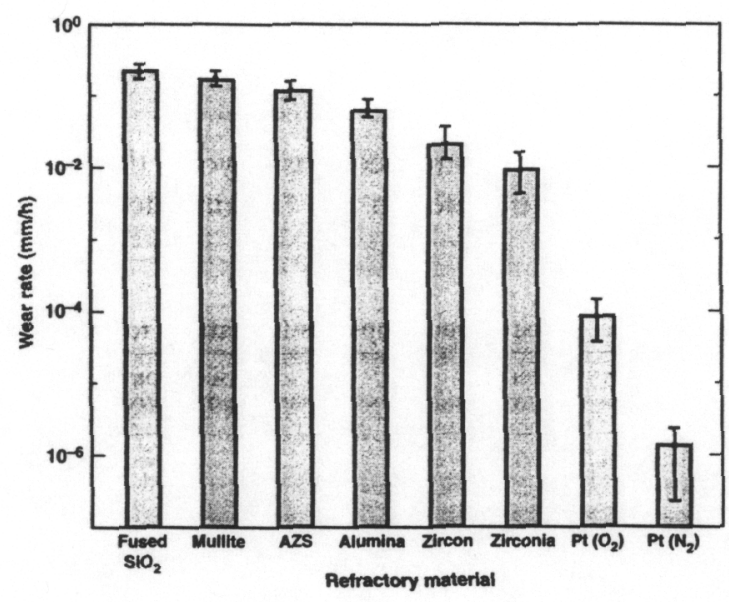

Fig. 5. Comparison of dissolution rates of various refractories with those for pure platinum $(99.95 \%)$ in a metaphosphate laser glass melt (LG-750, see Table 3). Unless noted, all data are for melts in ambient air at $1300^{\circ} \mathrm{C}$. 
lab-scale measurements of the dissolution rate of candidate refractories exposed to the molten glass composition over the range of temperatures of interest. Fig. 5 compares the dissolution rate of a range of typical refractories when exposed to a metaphosphate laser glass at $1300^{\circ} \mathrm{C}$. Also shown, for comparison, is the corrosion rate of Pt metal under both oxidizing and reducing conditions; this will be discussed further in the next section. The dissolution rate of the refractory is usually not uniform over the whole area exposed to the melt but tends to be greatest at the three-phase region where the melt surface contacts the refractory [28]. The melter refractory material must be high purity so as not to significantly add impurities into the melt. This includes not only dissolved impurities such as transition metals or $-\mathrm{OH}$ groups $[11,24,26]$, but also particulate material or, as commonly labeled, 'stones' [21]. Table 3 summarizes the observed dissolution properties for the same set of refractories whose wear rate is shown in Fig. 5.

One advantage in melting phosphate glasses is that the dissolved refractory wall material can generally be easily identified in the glass matrix. Therefore, by periodically analyzing the product glass for dissolved refractory material, one can continuously monitor the melter wear rate and, using a simple mass balance, estimate the life remaining in the melter.

\subsection{Glass conditioning}

All glass-processing sections beyond the melter (from the conditioner to the forming down-pipe, see Fig. 4) use platinum-lined vessels. In addition, all interconnecting pipes, stirrers, etc., are also Pt. The Pt purity is $>99.95 \%$ and is refined and processed into the needed shapes at a precious metal fabricator. Platinum is used in the melter systems because of its low wear rate (Fig. 5) and because the small quantity of ionic platinum that is introduced into the melt ( $\leqslant 100-200 \mathrm{ppm}$ ) has a negligible effect on the laser glass properties.

Apart from cost, the one major technical disadvantage in using platinum is the possible introduction of Pt-metal inclusions into the glass. For many years Pt-inclusions limited the output fluence of glass lasers because the interaction of the laser light with the inclusions generates fracture sites within the glass [21,29-31]. Processing conditions have since been developed that largely eliminated $\mathrm{Pt}$-inclusions in phosphate glasses by controlling the redox state of the melt $[32,33]$. In fact, one of the major purposes of the conditioning unit is to adjust the redox state of the glass melt to increase Pt-inclusion dissolution. The redox state of the melt is controlled by addition of an oxidizing gas. Because of the size and continuous flow of the glass through this system, it is generally most efficient to bubble the oxidizing gas through the glass melt. Studies of platinum dissolution rates under oxidizing conditions show that $\mathrm{O}_{2}[32,33]$, $\mathrm{Cl}_{2}$ [33], Cl-containing gases (e.g., $\mathrm{CCl}_{4}$ [33], $\mathrm{POCl}_{3}[34]$ ) or $\mathrm{O}_{2}$ in combination with these gases can dissolve Pt-inclusions.

Bubbling gas through the glass melt has the added advantage of increasing the removal of $-\mathrm{OH}$ groups [35-38]. In the case of a non-reactive bubbling gas (e.g., $\mathrm{O}_{2}$ ) the removal is achieved by

Table 3

Comparison of dissolution properties for various refractories exposed to a metaphosphate laser glass ${ }^{\mathrm{a}}$ at $1300^{\circ} \mathrm{C}$ [21]

\begin{tabular}{lcll}
\hline Refractory material & $\begin{array}{l}\text { Absorption at } 1060 \mathrm{~nm} \\
\left(10^{-3} \mathrm{~cm}^{-1}\right)( \pm 1)\end{array}$ & Wear rate $(\mathrm{mm} / \mathbf{h})$ & Refractory inclusions \\
\hline Fused silica & 3 & $0.28 \pm 0.03$ & Few \\
Mullite & 6 & $0.20 \pm 0.03$ & Few \\
AZS (chrome) & 15 & $0.11 \pm 0.02$ & Several \\
AZS (fused) & 7 & $0.07 \pm 0.02$ & Several \\
Sintered alumina & 5 & $0.06 \pm 0.02$ & None \\
Zircon (medium density) & 4 & $0.02 \pm 0.01$ & Several \\
Zircon (dense) & 7 & $0.02 \pm 0.01$ & Few \\
Zirconia (fused) & 27 & $0.01 \pm 0.005$ & Many \\
\hline
\end{tabular}

${ }^{2} \mathrm{LG}-750$ (mol\%): (55-60) $\mathrm{P}_{2} \mathrm{O}_{5}-(8-12) \mathrm{Al}_{2} \mathrm{O}_{3}-(13-17) \mathrm{K}_{2} \mathrm{O}-(10-15) \mathrm{BaO}-(0-2) \mathrm{Nd}_{2} \mathrm{O}_{3}$. 
equilibrium between the $-\mathrm{OH}$ in the glass and $\mathrm{H}_{2} \mathrm{O}$ in the bubble as described by the reaction.

$2\left(\begin{array}{c}\mathrm{O} \\ -\stackrel{\|}{\mathrm{P}} \\ 1 \\ \mathrm{O}_{-}\end{array}\right) \leftrightarrow \mathrm{OH}_{2} \mathrm{O}+\begin{array}{cc}\mathrm{O} & \mathrm{O} \\ \stackrel{\mathrm{P}}{\mathrm{P}} & -\mathrm{O}-\stackrel{\|}{\mathrm{P}}- \\ \mathrm{O}- & \mathrm{O}-\end{array}-$

$>$ where the $\mathrm{OH}$ equilibrium constant is proportional to the $\left(P_{\mathrm{H}_{2} \mathrm{O}}\right)^{1 / 2}[39,40]$. The data in Fig. 6 are measured hydroxyl contents in LG-770 and LHG-8 glasses as a function of the water vapor partial pressure equilibrated with the glass. Equilibrium was achieved by bubbling an inert gas $\left(\mathrm{O}_{2}\right)$ containing water vapor at a fixed vapor pressure through the glass melt at the temperatures shown in Fig. 6. The hydroxyl content is given in terms of the $-\mathrm{OH}$ absorption coefficient at 3000 $\mathrm{cm}^{-1}[40,41]$. The slope of the data yields equilibrium constants of 0.41 and $0.51 \mathrm{~cm}^{-1} / \mathrm{Pa}^{1 / 2}$ for LG-770 and LHG-8, respectively.

Reactive gases, such as the chlorine-containing gases mentioned above, are more effective than $\mathrm{O}_{2}$ because they react with the $\mathrm{H}_{2} \mathrm{O}$ generated at the bubble interface via Eq. (1) and form $\mathrm{HCl}$. For example, in the case of $\mathrm{Cl}_{2}$, the governing reaction with $\mathrm{H}_{2} \mathrm{O}$ is [42]

$2 \mathrm{H}_{2} \mathrm{O}+2 \mathrm{Cl}_{2} \stackrel{K_{d}}{\leftrightarrow} 4 \mathrm{HCl}+\mathrm{O}_{2}$.

The equilibrium constant, $K_{\mathrm{d}}$, for this reaction, known as the reverse Deacon reaction [42], favors the products (i.e., $K_{d} \gg 1$ ). Therefore the consumption of $\mathrm{H}_{2} \mathrm{O}$ (i.e., $\mathrm{OH}$ ) is much greater than can be achieved with a non-reactive gas. More specifically, when an inert gas such as $\mathrm{O}_{2}$ is used to 'dry' the glass then the factor limiting $\mathrm{OH}$ removal is the build-up of $\mathrm{H}_{2} \mathrm{O}$ within the bubble. As soon as the $\mathrm{H}_{2} \mathrm{O}$ level reaches equilibrium then a net mass transport of $\mathrm{OH}$ across the bubble interface stops. Furthermore, the smaller the $\mathrm{OH}$ content of the glass the quicker the bubble saturates and the less effective the drying process. On the other hand, a reactive gas such as $\mathrm{Cl}_{2}$ consumes $\mathrm{H}_{2} \mathrm{O}$ at the bubble interface greatly increasing the drying capacity of the bubble. Of course, the equilibrium constant for Eq. (2) still governs the amount of $\mathrm{H}_{2} \mathrm{O}$ consumed.

Further details of platinum particle dissolution and dehydroxylation are discussed in later sections
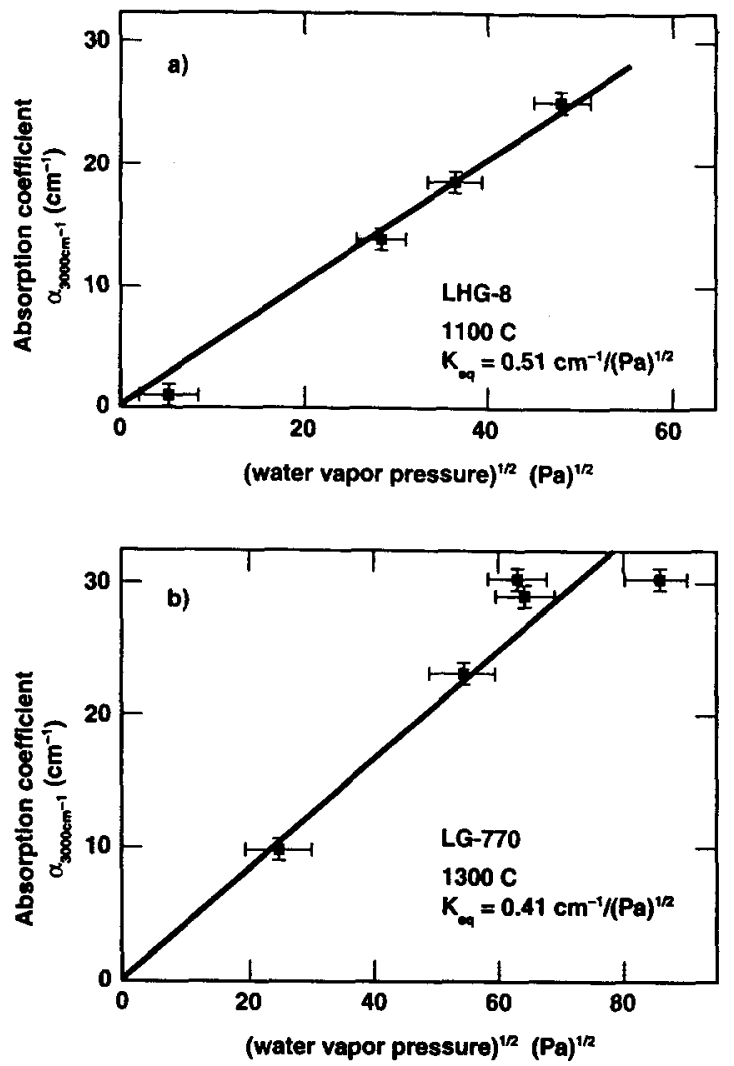

Fig. 6. Equilibrium hydroxyl content in (a) LHG-8 and (b) LG770 metaphosphate laser glasses versus $\sqrt{P_{\mathrm{H}_{2} \mathrm{O}}}$ at melt temperatures of $1100^{\circ} \mathrm{C}$ and $1300^{\circ} \mathrm{C}$, respectively. The $\mathrm{OH}$ content is expressed in terms of the measured absorption coefficient at $3000 \mathrm{~cm}^{-1}$.

because of their critical importance to the production of phosphate laser glasses.

\subsection{Refining, homogenization, and forming}

The molten glass from the conditioning unit then flows to the refiner section where the temperature is elevated to reduce the glass viscosity and thereby increase the bubble rise velocity to promote bubble removal. This glass process, known as refining, is described in the literature (see, for example [22]).

The bubbles reach terminal velocity $\left(v_{t}\right)$ which is governed by a balance of forces due to buoyancy and viscous drag, and at steady state is described by the Stokes equation [43] 
$v_{\mathrm{t}}=g\left(\rho_{\mathrm{g}}-\rho_{\mathrm{b}}\right) d_{\mathrm{b}}^{2} / 18 \eta$

where $\eta$ is the glass viscosity (poise), $d_{\mathrm{b}}$ the bubble diameter $(\mathrm{cm}), g$ the acceleration due to gravity $\left(980 \mathrm{~cm} / \mathrm{s}^{2}\right)$, and $\rho_{\mathrm{b}}$ and $\rho_{\mathrm{g}}$ is the density $\left(\mathrm{g} / \mathrm{cm}^{3}\right)$ of the gas in the bubble and the liquid, respectively. Phosphate glasses tend to have much lower viscosities at a given temperature than silicates (Fig. 7) with the result that bubble rise velocities are comparatively larger. Bubbles, in most cases, are not a problem in continuous melting of phosphate laser glasses.

The glass from the refiner next enters the homogenization section where Pt stirrers thoroughly mix the glass to achieve the part-per-million index homogeneity required for laser applications. Just as in the discontinuous process, the temperature of the homogenizing section is reduced to adjust the glass viscosity to give the desired flow properties needed to form a wide $(\sim 50 \mathrm{~cm})$, thick $(\sim 5 \mathrm{~cm})$, homogeneous strip of glass.

The combined width, thickness, and length of the glass strip produced during the forming operation is greater than any optical glass produced prior to continuous laser glass melting development. The technology used to 'form' (i.e., cast) the glass into a homogeneous continuous strip is proprietary and will not be discussed further here.

\subsection{Coarse annealing}

Once successfully formed, the cast strip moves via a conveyer belt through a long $(25-35 \mathrm{~m})$ coarse annealing oven where the temperature is ramped down at a rate to avoid generating unacceptable thermal stresses in the glass. The coarse annealing step is typically much more of a challenge for phosphate laser glasses than other optical glasses because phosphate glasses have high coefficients of thermal expansions and low fracture toughnesses (Table 1). For example, compared to common commercial silicate optical glasses (e.g., BK-7 [44] or BSC-7 [45]), the thermal expansion coefficient of phosphate laser glasses is nearly twice as large and the fracture toughness only one-half as large. Therefore, the thermal shock resistance

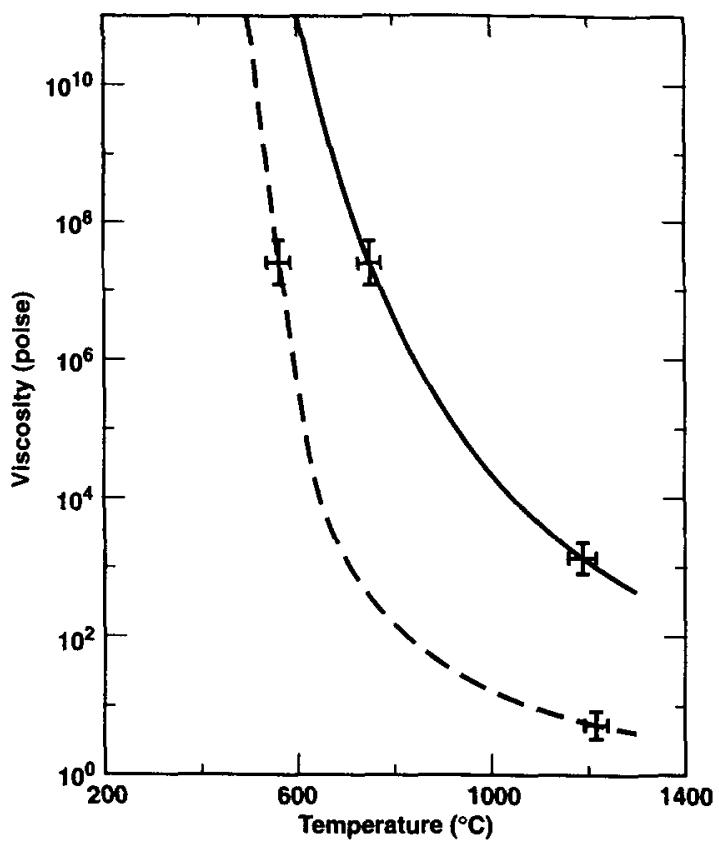

Fig. 7. Viscosity versus temperature for a typical silicate (solid line) and phosphate (dashed line) glass.

[11] of the phosphate laser glass is only about onefourth that of BK-7, and the probability of fracture during coarse annealing and other post-processing steps becomes proportionally greater.

At the end of the coarse annealing oven, the continuous as-cast strip is cut into pieces that are then individually processed to give the desired laser glass plate.

\subsection{Glass processing after melting}

There are four laser glass processing steps after melting: (1) final annealing, (2) optical metrology, (3) fabrication into prefinished blanks, and (4) cladding and final finishing. The first three steps are carried out at the glass manufacturers (Schott and Hoya) and the last step at an optical glass finishing company. The order in which various inspection, annealing, and fabrication steps are carried out may vary and depends on how each company has chosen to optimize their process.

The specified optical homogeneity and residual stress-induced birefringence of the laser glass re- 
quire that it be annealed a second time at a much slower rate. During this second annealing step, called 'fine annealing', the glass plate is reheated to a temperature near the glass transition temperature $\left(\sim 450-500^{\circ} \mathrm{C}\right.$, see Table 1$)$ and then slowly cooled over a period of several weeks ( $\geqslant 25$ days). Under these conditions the thermal gradients across the plate are small enough that residual stresses, as measured by the stress induced birefringence, are less than $5 \mathrm{~nm} / \mathrm{cm}$ across the optic.

The laser glass must meet a given set of optical and laser performance criteria that are measured on each plate. Perhaps the four most important properties are: (i) index homogeneity, (ii) absorption loss at the laser wavelength, (iii) residual $-\mathrm{OH}$ content (specified by a maximum allowed absorbance at $3000 \mathrm{~cm}^{-1}$ ) and (iv) platinum-inclusion content. The latter two are discussed in more detail in Sections 5 and 6, and the absorption loss is measured using standard spectroscopic transmission methods and thus is not discussed here. Instead we briefly discuss the index homogeneity measurements.

In the absence of residual stress, the homogeneity of the glass, as measured by variations in the refractive index $(\Delta n)$ is $< \pm 2 \times 10^{-6}$. The refractive index homogeneity of the glass is specified in terms of an allowable aberration in transmitted optical wavefront. This is measured directly on a $61 \mathrm{~cm}$ aperture, phase interferometer (Veeco Metrology). The interferometer measures the spatial variation in the phase of the transmitted wavefront that, in turn, is related to the refractive index homogeneity by

$\Delta \phi(x, y)=\frac{2 \pi \ell \Delta n(x, y)}{\lambda}$

where $\Delta \phi(x, y)$ and $\Delta n(x, y)$ are the spatial variation in phase (radians) and refractive index, respectively, when measured at wavelength, $\lambda(\mathrm{m})$, using a glass of thickness, $\ell(\mathrm{m})$. The magnitude of the allowed phase variation due to the glass inhomogeneity is usually expressed in terms of either the common set of optical aberrations (sphere, coma, astigmatism) or the set of orthogonal Zernike polynomials [46]. Note that in addition to specifications on the absolute magni- tude of the phase error, there is also a limit on the magnitude of the phase gradient (i.e., $\delta \phi / \delta x$, $\delta \phi / \delta y$ ). Measurement of glass index homogeneity is carried out in a fashion that eliminates phase error contributions from the front and back surfaces.

\subsection{Cladding and finishing}

Each laser glass plate is eventually edge-clad with an index-matched glass containing a dopant ion $\left(\mathrm{Cu}^{2+}\right)$ at a concentration sufficient to produce an absorption coefficient of $0.28 \mathrm{~cm}^{-1}$ at $1054 \mathrm{~nm}$ [47]. The purpose of the cladding glass is to absorb emission from the spontaneous fluorescent decay of excited-state $\mathrm{Nd}^{3+}$. These spontaneously emitted photons are amplified as they travel along the length of the glass plate either near the surface or by total internal reflectance. If these rays are not suppressed by a non-reflecting (i.e., index matched) edge-cladding then they can lead to parasitic laser oscillations which effectively de-excite the entire glass plate $[47,48]$.

The cladding glass is produced using standard continuous strip melting operations in a separate melting system to avoid cross-contamination of the $\mathrm{Cu}^{2+}$ dopant into the laser glass. Nearly 20 metric tons (14000 pieces) of cladding glass are needed to clad the roughly 3500 glass plates needed for the NIF laser system.

The cladding is bonded to the edges of the laser slab using a custom-formulated, index-matched, amine-cured epoxy [47]. The adhesive strength of the phosphate glass-to-epoxy bond is increased by use of a silane coupling agent [49]. Care is taken to avoid particulate (dust) contamination in the epoxy or on the bonded glass surfaces to eliminate sites for optical damage. Details of the cladding process are described elsewhere [47]; the process has been further developed so that glass plates can be automatically cleaned and clad using a combination of continuous and semi-continuous processing steps.

The cladding operations are the first step in final finishing. Once the cladding has been applied, the slab surfaces are ground and polished to achieve the overall transmitted wavefront quality needed for the laser. 


\section{Dissolution of damage-causing Pt-inclusions}

The operating fluence and irradiance of the megajoule scale lasers will be larger than any current laser system. Peak fluences in the laser glass will approach $18-20 \mathrm{~J} / \mathrm{cm}^{2}$ with a peak irradiance of about $5.0 \mathrm{GW} / \mathrm{cm}^{2}[8]$. To avoid optical damage the laser glass must be free of defects, specifically microscopic inclusions (either metallic or ceramic) left from the melting process. The most common inclusion source is metallic Pt-inclusions from the Pt-lined vessels used in the melting system [21]. Prior to about 1988, Pt-inclusion damage represented the major source of damage in laser glass used for peak-power application. However new processing methods have been developed that reduce the Pt-inclusion concentration by more than 1000 fold to $<0.1$ per liter $[32,33]$.

The process for eliminating Pt-inclusions relies on the intrinsic property of many phosphate glasses to dissolve $\mathrm{Pt}$ metal under oxidizing conditions. Rindone and Rhoads [50] and Ryder and Rindone [51] were the first to report increased platinum dissolution in phosphate glasses with the addition of $\mathrm{O}_{2}$ and $\mathrm{Cl}_{2}$. Izumitani et al. [34] have reported the use of gaseous $\mathrm{POCl}_{3}$ as an oxidizing additive, and Campbell and co-workers $[21,32,33]$ studied the effects of $\mathrm{O}_{2}, \mathrm{Cl}_{2}, \mathrm{CCl}_{4}$ and $\mathrm{N}_{2} / \mathrm{O}_{2}$ mixtures. The rate of $\mathrm{Pt}$ dissolution follows the approximate trend [21,33]:

$$
\begin{aligned}
& \mathrm{Cl}_{2}+\mathrm{O}_{2} \gtrsim \mathrm{CCl}_{4}+\mathrm{O}_{2} \gtrsim \mathrm{O}_{2} \approx \mathrm{Cl}_{2} \\
& >\mathrm{N}_{2}+\mathrm{O}_{2}+\mathrm{Cl}_{2}>\mathrm{N}_{2}+\mathrm{O}_{2} \gg \mathrm{N}_{2} .
\end{aligned}
$$

The measured rate of platinum dissolution at $1100^{\circ} \mathrm{C}$ as a function of both $\mathrm{O}_{2}$ partial pressure and different gas additives, based on data from Campbell et al. [21], is shown in Fig. 8.

The proposed reactions [32,33] governing $\mathrm{Pt}$ dissolution in either $\mathrm{O}_{2}$ or $\mathrm{Cl}_{2}$ containing additives are

$\mathrm{Pt}^{\circ}+\frac{n}{4} \mathrm{O}_{2} \rightarrow \mathrm{Pt}^{n+}+\frac{n}{2} \mathrm{O}^{2-}$,
$\mathrm{Pt}^{\circ}+\frac{n}{2} \mathrm{Cl}_{2} \rightarrow \mathrm{Pt}^{n+}+n \mathrm{Cl}^{-}$.

In the absence of $\mathrm{O}_{2}\left(\right.$ or $\mathrm{Cl}_{2}$ ) as gas additives, the oxidation is controlled by the equilibrium oxygen fugacity of the glass melt.
Ionic platinum gives the glass a slight yellow color due to its optical absorption below $450 \mathrm{~nm}$. Correlation of ionic platinum content with the absorption at $400 \mathrm{~nm}$ has been reported [21]

$\left[\mathrm{Pt}^{\mathrm{n}+}\right]=k \alpha_{400}-1.6$

where $\left[\mathrm{Pt}^{n+}\right]$ is the ionic platinum content in the glass (ppmw), $\alpha_{400}$ the absorption coefficient $\left(\mathrm{cm}^{-1}\right)$ at $400 \mathrm{~nm}$, and $\mathrm{k}$ is an empirically derived constant with a value of $855 \mathrm{ppmw} \mathrm{Pt} / \mathrm{cm}^{-1}$ for LHG-8, LG-750, and LG-770 laser glasses [21]. Therefore values for the optical absorption of the product glass at $400 \mathrm{~nm}$ provide a measure of the degree of platinum dissolution during continuous melting.

The first published Pt solubility study was by Ryder and Rindone [51] on lead-alkali silicates, phosphates, and borates who report that the solubility follows the trend: phosphates $\gg$ borates $>$ silicates. The work by Ryder and Rindone [51] combined with the more recent work by Izumatani et al. [34] show the effects of glass composition on platinum solubility follow the trend: phosphate $>$ silica-phosphate $\gg$ fluoro phosphate $\approx$ borates $>$ silicate $[34,51]$. Izumatani et al. [34] results are based on solubility measurements using LHG-5 and LHG-8 (phosphates), HAP-3 (silicophosphate), LHG-10 (fluorophosphate) and LSG-91H (silicate). In another study, Hayden et al. [52] examined the effects of the $\mathrm{Al}_{2} \mathrm{O}_{3}$ concentration in phosphate glasses on $\mathrm{Pt}$ solubility. They chose three commercial phosphate laser glasses (LG-770, LG-760 and APG-1) each having different $\mathrm{Al}_{2} \mathrm{O}_{3}$ content. The effects of alumina were studied because it is a common modifier added to improve thermal-mechanical properties and chemical durability [11]. These researchers [52] report that the $\mathrm{Pt}$ solubility decreases as the $\mathrm{Al}_{2} \mathrm{O}_{3}$ content increases. The effects of $\mathrm{Al}_{2} \mathrm{O}_{3}$ on $\mathrm{Pt}$ solubility tend to parallel those reported by Izumitani et al for $\mathrm{SiO}_{2}$ in phosphate glasses [34]. The compositions of LHG-8 and LG-770 (Table 1) have been selected in part because of their Pt solubility properties under oxidizing conditions.

A model for Pt-inclusion dissolution has been reported [53]. When the temperature is sufficiently high, mass transport (molecular diffusion), rather 

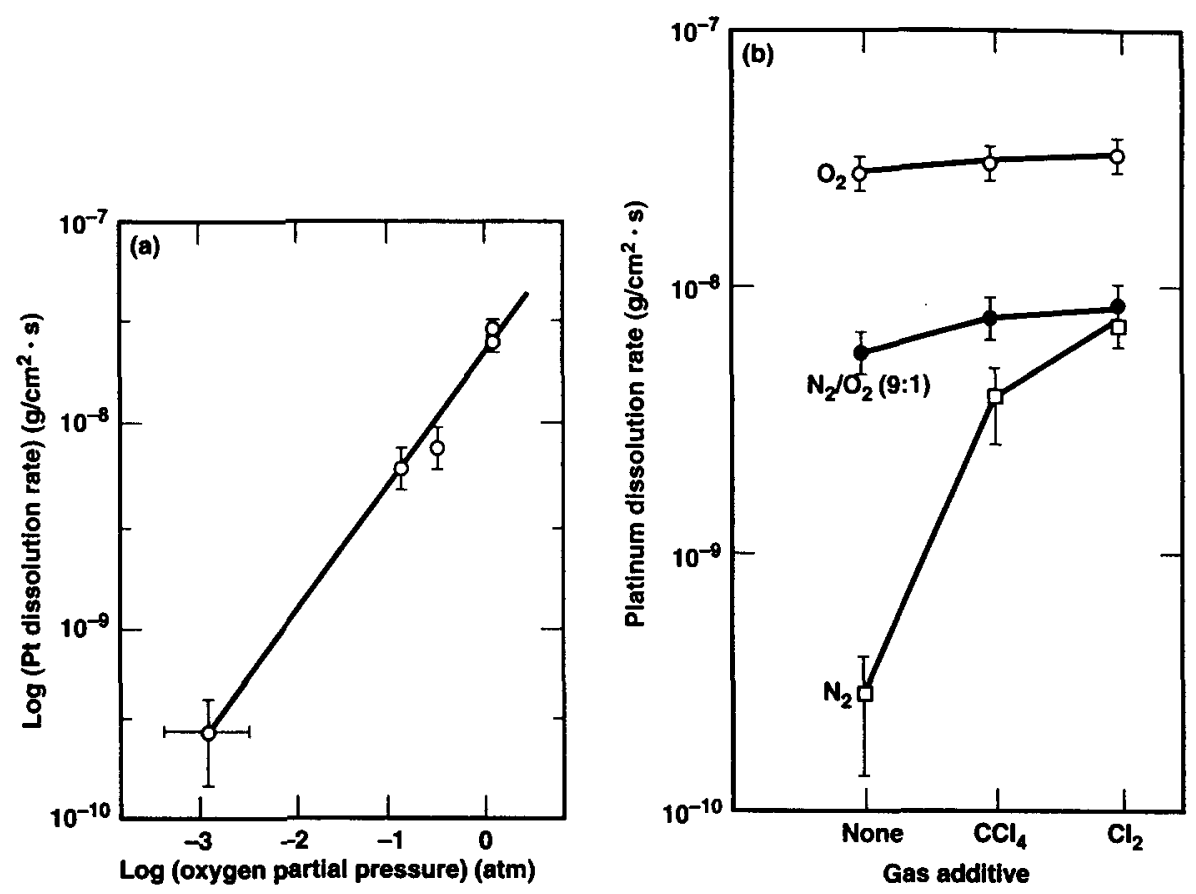

Fig. 8. Platinum dissolution rate in the metaphosphate laser glass, LHG-8 at $1200^{\circ} \mathrm{C}$ as a function of (a) $\mathrm{O}_{2}$ partial pressure, and (b) type of chlorinated gas additive in various $\mathrm{O}_{2}+\mathrm{N}_{2}$ gas mixtures.

than reaction kinetics, dominates the dissolution process. The time to dissolve a Pt-inclusion can be approximated by the simple expression

$t_{\mathrm{d}}=\rho_{\mathrm{i}} r_{0}^{2} /\left[2 D\left(C_{\mathrm{s}}-C_{0}\right) M\right]$,

where $t_{\mathrm{d}}$ is the dissolution time $(s), \rho_{\mathrm{i}}$ the inclusion material density $\left(19 \mathrm{~g} / \mathrm{cm}^{2}\right.$ for $\left.P t\right), r_{0}$ the initial inclusion radius $(\mathrm{cm}), M$ the gram-atomic weight of $\mathrm{Pt}$, and $D$ is the Pt-ion diffusion constant $\left(\mathrm{cm}^{2} / \mathrm{s}\right) . C_{\mathrm{s}}$ and $C_{0}$ refer to the Pt-ion concentration $\left(\mathrm{g} / \mathrm{cm}^{3}\right)$ at saturation and measured in the melt, respectively; $C_{\mathrm{s}}$ is about $1100 \mathrm{ppmw}^{\mathrm{Pt}^{n+}}$ at $1100^{\circ} \mathrm{C}$ in LHG-8 [53] and $C_{0}$ is determined from Eq. (8). The diffusion constant for $\mathrm{Pt}^{n+}$ in LHG-8 laser glass has been estimated to be about $10^{-7}$ $\mathrm{cm}^{2} / \mathrm{s}$ at $1100^{\circ} \mathrm{C}$ [53].

The dissolution of platinum-inclusions is more difficult in continuous than discontinuous melting because of the variable melt residence time. In the discontinuous process the entire glass melt sees the same process time whereas in a continuous melter the glass experiences a distribution of residence times. The residence time distributions depend entirely on the properties of the fluid and the geometry and degree of mixing within the melter. Therefore, to insure complete Pt-inclusion dissolution in a continuous melter requires vigorous addition of oxidizing gas.

In most cases a small number of inclusions can be tolerated if the size of the inclusion is small $(<5 \mu \mathrm{m})$ and the laser-induced damage (i.e., fractures) they produce does not exceed $300 \mu \mathrm{m}$. Inspection methods have been developed and put into production to scan each piece of laser glass with the output from a pulsed laser and measure the size of any damage site generated at fluences between 7 and $14 \mathrm{~J} / \mathrm{cm}^{2}$ (laser pulse length $\sim 8 \mathrm{~ns}$ ) [54]. These fluences are similar to those the glass sees in operation on the megajoule laser [8].

\section{OH removal from phosphate laser glasses}

As discussed in Section 4.3, phosphate glasses react with water vapor forming chain terminating 
hydroxyl groups at equilibrium concentrations that vary as $\sqrt{\mathrm{P}_{\mathrm{H}_{2} \mathrm{O}}}$ (see Fig. 6). These hydroxyl groups increase the rate of non-radiative decay of $\mathrm{Nd}^{3+}$ from the upper ${ }^{4} \mathrm{~F}_{3 / 2}$ laser level [11] and thus adversely affect laser performance.

The gases added to promote Pt-inclusion dissolution can also increase the removal of residual hydroxyl groups in the glass. The reduction of $-\mathrm{OH}$ in the glass by addition of either inert or reactive gases has been the subject of numerous studies (see, for example [35-38,55-57]). In particular, the addition of chlorine or chlorine-containing compounds is a well-documented method for $\mathrm{OH}$ removal in silicate and phosphate glasses $[36,38,40,55,56]$.

We have developed a computer model that describes the removal of $\mathrm{OH}$ groups from phosphate laser glass using either an inert (e.g., $\mathrm{O}_{2}, \mathrm{~N}_{2}$ ) or reactive (e.g., $\mathrm{Cl}_{2}$ ) gas employing reaction equilibrium and mass transfer constraints (Fig. 9). The model is based on a time-dependent, one-dimensional bubble column formulation [58] and is designed to calculate glass dehydration for either discontinuous or continuous melting operations involving one or more interconnected processing tanks and one or more dehydrating bubble columns.

\subsection{Equilibrium chemistry and mass transport governing dehydration}

The model treats the dehydration process by a combination of mass transport and chemical equilibrium. This process was discussed in Section 4.3. The transport step involves the diffusion of a water carrying component $(-\mathrm{OH})$ from the interior of the glass liquid to a liquid/vapor interface. This interface may occur at the exposed top surface of a melt or at a bubble surface for the case in which bubbling through the melt is employed. At the interface, the model uses Eq. (1) as the governing reaction with the $-\mathrm{OH}$ in the liquid in equilibrium with water in the vapor phase according to the equilibrium relation

$$
K_{w}=C_{\mathrm{gH}_{2} \mathrm{O}} /\left(C_{\mathrm{mOH}}\right)^{2} \text {, }
$$

where $K_{w}$ is the equilibrium constant $\left(1 /\left(\mathrm{mol} / \mathrm{m}^{3}\right)\right)$, $C_{\mathrm{gH}_{2} \mathrm{O}}$ the water vapor concentration in the gas

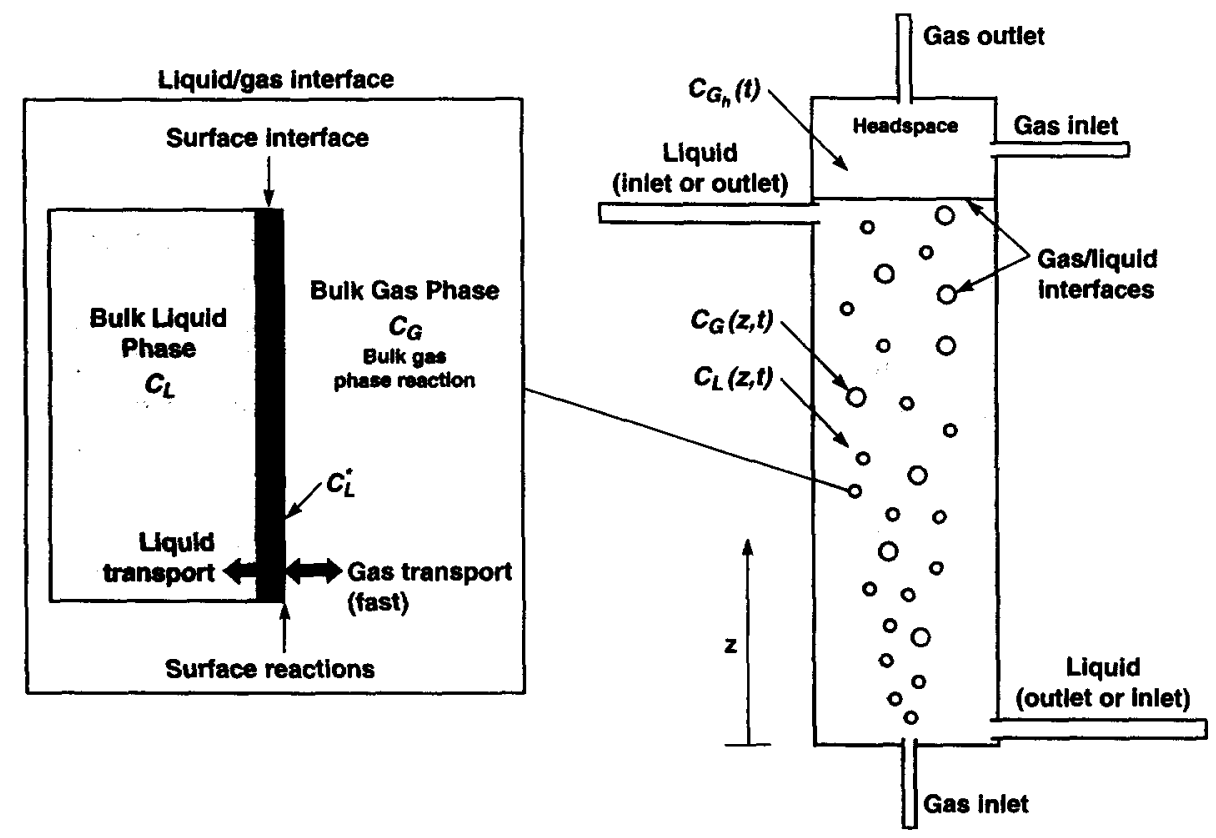

Fig. 9. Physical representation of the numerical model for $\mathrm{OH}$ removal using gas bubbling through a phosphate glass melt. The model treats bubbling using both inert and reactive gases. 
phase $\left(\mathrm{mol} / \mathrm{m}^{3}\right)$ and $C_{\mathrm{mOH}}$ the $\mathrm{OH}$ concentration in the melt $\left(\mathrm{mol} / \mathrm{m}^{3}\right)$.

In the presence of chlorine we add the additional vapor phase equilibrium given by Eq. (2). As written, Eq. (2) is known as the reverse Deacon reaction [42], and chlorine acts to dehydrate the vapor phase (e.g., bubble). It is assumed that the bubble contents are held near equilibrium for the reverse Deacon reaction that has an equilibrium constant given by

$K_{\mathrm{d}}=\frac{[\mathrm{HCl}]^{4}\left[\mathrm{O}_{2}\right]}{\left[\mathrm{H}_{2} \mathrm{O}\right]^{2}\left[\mathrm{Cl}_{2}\right]^{2}}$

where the square brackets denote species concentrations $\left(\mathrm{mol} / \mathrm{m}^{3}\right)$ and $K_{d}$ is the equilibrium constant that has a value of 5523 and $9871 \mathrm{~mol} / \mathrm{m}^{3}$ at $1150^{\circ} \mathrm{C}$ and $1250^{\circ} \mathrm{C}$, respectively [42]. These relatively large $K_{d}$ values lead to low values of water vapor in equilibrium mixtures. As a consequence, in systems containing chlorine in the bubbling gas, the concentration gradient that controls the rate of mass transfer across the liquid/gas interface remains high. In contrast, in systems where only oxygen is present the bubbles tend to reach water vapor saturation because of the equilibrium imposed by Eq. (1). In this case, the concentration gradient for transport of $\mathrm{OH}$ is smaller and the dehydration rate is correspondingly slower.

Mass transport across the bubble interface is computed by using an effective transport parameter, $(k A)$, which is the product of the mass transfer coefficient, $k$, and the interfacial area, $A$. Deckwer [59] has proposed a correlation for mass transfer that can be employed over a range of bubble flow conditions; we have used this correlation in model simulations of bubble column dehydration in both discontinuous and continuous melting.

The dehydration model has been used to predict dehydration levels for both discontinuous and continuous melting processes; in Fig. 10 the computed relative $\mathrm{OH}$ levels are compared to measured levels in the product glass from both melting processes. The continuous melting data represent operating regimes for which the bubbling flow rate and $\mathrm{Cl}_{2}$ content differed by more than 10 times and thus is a good test of the model. The ability to
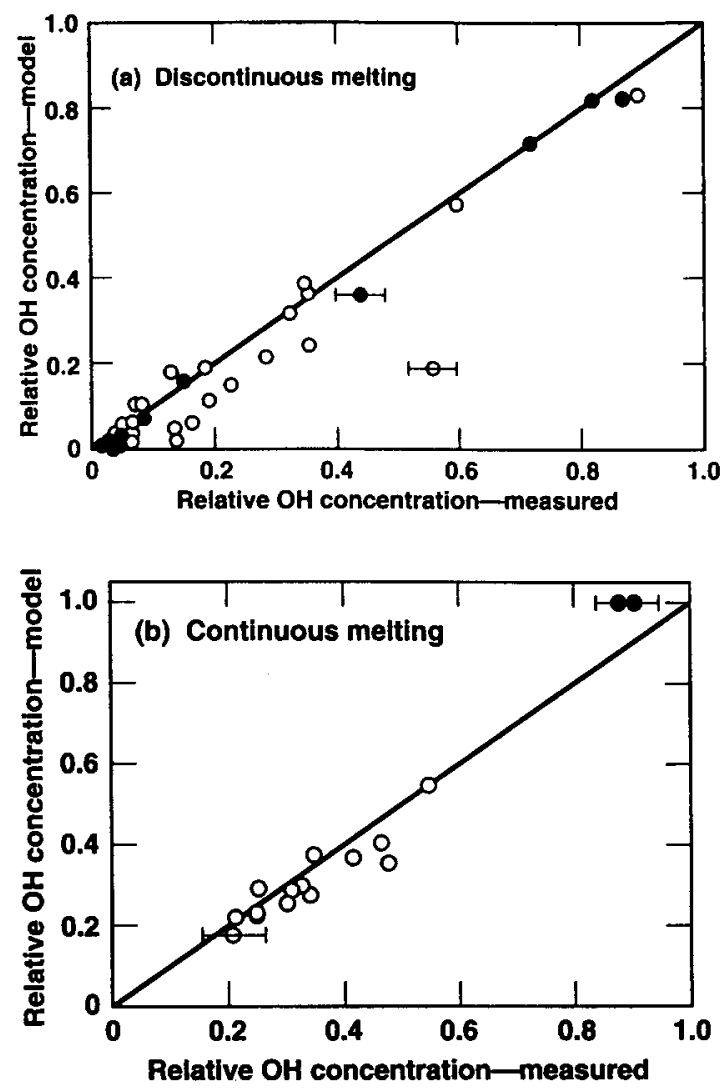

Fig. 10. Comparison of measured versus predicted $\mathrm{OH}$ concentrations in glass produced by (a) small-scale $(<1 \ell)$ discontinuous melts and (b) production-scale continuous melting operations The solid circles are $100 \%$ oxygen bubbling only, while open circles represent bubbling with oxygen and variable amounts of chlorine $(<50 \%)$.

predict the dehydration in both discontinuous and continuous melts confirms that the basic model assumptions capture the primary physics and chemistry involved in dehydration of phosphate glass by gas bubbling.

\section{Summary and conclusion}

Continuous melting has been used for the first time to prepare meter-scale plates of Nd-doped phosphate laser glass. Two laser glasses have been successfully manufactured using this process: LHG-8 and LG-770. 
To meet the laser performance criteria, the glass must have high-optical quality $\left(\Delta n \leqslant 2 \times 10^{-6}\right)$, be free of Pt-inclusions, and have only trace amounts of hydroxyl group contamination. The latter two specifications require special processing features in the continuous melter system, in particular the addition of oxidizing and chlorine-containing gases into the glass melt.

Platinum inclusions are removed by dissolution in the melt under oxidizing conditions; the time to dissolve Pt-inclusions increases as the square of the inclusion diameter. The rate of $\mathrm{Pt}$ dissolution is highest with the use of a $\mathrm{Cl}_{2}$ and $\mathrm{O}_{2}$ mixture.

The measured equilibrium $\mathrm{OH}$ content in the glass depends on the square root of the surrounding water vapor pressure as expected from simple reaction equilibrium. The equilibrium constant has an approximate value of $0.41 \mathrm{~cm}^{-1} / \sqrt{\mathrm{Pa}}$ at $1300^{\circ} \mathrm{C}$ in LG-770 and $0.51 \mathrm{~cm}^{-1} / \sqrt{\mathrm{Pa}}$ at $1100^{\circ} \mathrm{C}$ for LHG-8.

A computational model is used to simulate dehydroxylation of the laser glass using either reactive gas (e.g., $\mathrm{Cl}_{2}$ ) or inert gas (e.g., $\mathrm{O}_{2}$ ) bubbling. The model accurately predicts $\mathrm{OH}$ removal during both discontinuous and continuous melting operations of both LHG-8 and LG-770.

\section{Acknowledgements}

This work is supported in the US by the Department of Energy under contract W-7405-ENG48 and in France by the Commissariat à l'Energie Atomique (CEA). The authors gratefully acknowledge the efforts by R. Steele, S. Pucilinski, and $\mathrm{K}$. Suzuki on the small-scale test melts. The authors also deeply appreciate the assistance of $\mathrm{A}$. Clasen in the preparation of this manuscript.

\section{References}

[1] J.R. Murray, SPIE 3492 Supplement, 1998, p. 1.

[2] M. Andre, M. Novaro, D. Schirmann, Chocs Revue Scientifique et Technique de la Direction de Applications Militaires 13 (1995) 73.

[3] J.T. Hunt, D.R. Speck, Opt. Eng. 28 (1989) 461.

[4] T.R. Boehly, D.L. Brown, R.S. Craxton, R.L. Keck, J.P. Knauer, J.H. Kelly, T.J. Kessler, S.A. Kumpan, S.J.
Loucks, S.A. Letzring, F.J. Marshall, R.L. McCrory, S.F.B. Morse, W. Seka, J.M. Soures, C.P. Verdon, Opt. Commun. 133 (1997) 495.

[5] A.C. Erlandson, M.D. Rotter, D.N. Frank, R.W. McCracken, Design and Performance of the Beamlet Amplifiers, ICF Quarterly Report, Lawrence Livermore National Laboratory Report UCRL-LR-105821-95-1, 1994, p. 18.

[6] A. Erlandson, J. Horvath, K. Jancaitis, J. Lawson, K. Manes, C. Marshall, E. Moor, S. Payne, L. Pedrotti, S. Rodriguez, M. Rotter, S. Sutton, L. Zapata, S. Seznec, J. Beullier, O. Carbourdin, E. Grebot, J. Guenet, M. Guenet, X. Maille, Fusion Technol. 34 (1998) 1105.

[7] G. Le Touzé, O. Cabourdin, J.F. Mengué, M. Guénet, E. Grebot, S. Seznec, K. Jancaitis, C.D. Marshall, L. Zapata, A. Erlandson, SPIE 3492 (1998) 630.

[8] B.M. VanWonterghem, J.R. Murray, J.H. Campbell, D.R Speck, C.E. Barker, I.C. Smith, D.F. Browning, W.C. Behrendt, Appl. Opt. 36 (1997) 4932.

[9] J.H. Campbell, L.J. Atherton, J.J. DeYoreo, M.R. Kozlowski, R.T. Maney, R.C. Montesanti, L.M. Sheehan, C.E. Barker, Large-Aperture, High-Damage-Threshold Optics for Beamlet, ICF Quarterly Report, Lawrence Livermore National Laboratory Report UCRL-LR-105821-95-1, 1994, p. 52.

[10] J.L. Emmett, W.F. Krupke, J.B. Trenholme, The Future Development of High-Power Solid State Laser Systems, Lawrence Livermore National Laboratory Report UCRL53344,1982, p. 1.

[11] J. Campbell, T. Suratwala, these Proceedings, p. 318.

[12] J.H. Campbell, SPIE CR64 (1996) 3.

[13] J.H. Campbell, 25 Years of Laser Glass Development Leading to a $1.8 \mathrm{MJ}, 500 \mathrm{TW}$ Laser for Fusion Ignition, Lawrence Livermore National Laboratory Report, UCRLJC-129507, 1998, p. 1.

[14] J. Campbell, T. Suratwala, C. Thorsness, J. Hayden, A. Thorne, A. Marker, K. Takeuchi, M. Smolley, G. FiciniDorn, presented at 15 th University Conference on Glass Science, Rolla, MO, June 1999.

[15] Laser Glass Product Catalog, Hoya Corporation USA, Fremont, CA, 1994, p. 1.

[16] S.E. Stokowski, R.A. Saroyan, M.J. Weber, Laser Glass Nd-Doped Glass Spectroscopic and Physical Properties, Lawrence Livermore National Laboratory Report M-095, Rev. 2, vols. 1, 2, 1981.

[17] J. Atherton, Optics Technology for the National Ignition Facility, Lawrence Livermore National Laboratory Report UCRL-LR-105821-99-2, 1999, p. 111.

[18] Laser Glass Product Catalog, Schott Glass Technologies, Duryea, PA, 1999, p. 1.

[19] A.J. Marker, SPIE 531 (1985) 2.

[20] T.S. Izumitani, Optical Glass, Am. Inst. Phys. Transl. Ser., New York, 1986, ch. 3.

[21] J.H. Campbell, E.P. Wallerstein, J.S. Hayden, D.L. Sapak, D.E. Warrington, A.J. Marker, H. Toratani, H. Meissner, S. Nakajima, T. Izumitani, Elimination of Platinum Inclusions in Phosphate Laser Classes, Lawrence Livermore National Laboratory Report UCRL-53932, 1989, p. 1. 
[22] H. Bach, N. Neuroth, The Properties of Optical Glass, Springer, Berlin, 1995.

[23] H. Toratani, PhD thesis, Kyoto University, Kyoto, 1989, p. 1.

[24] S.E. Stokowski, D. Krashkevich, Mater. Res. Soc. Symp. 61 (1986) 273

[25] D. Sapak, J. Ward, J. Marion, SPIE 970 (1988) 107.

[26] P. Ehrmann, J.H. Campbell, T.I. Suratwala, J.S. Hayden, D. Krashkevich, K. Takeuchi, these Proceedings, p. 251.

[27] F.A. Cotton, G. Wilkinson, Advanced Inorganic Chemistry, 5th Ed., Wiley, New York, 1988, p. 962.

[28] A.R. Cooper, in: T.D. McGee (Ed.), Proceedings of the Educational Symposium on Refractories in Slagging Environments, Amer. Ceram. Soc., 1981, p. 1063.

[29] Fundamentals of Damage in Laser Glass, National Materials Advisory Board, Division of Engineering, National Research Council NMAB-271, 1970, p. 1.

[30] R.W. Hopper, D.R. Uhlmann, J. Appl. Phys. 41 (1970) 4023.

[31] R. Gonzales, D. Milam, Laser Induced Damage in Optical Materials: National Bureau of Standards (special publication), 745, 1988, p. 128.

[32] J.H. Campbell, E.P. Wallerstein, J.S. Hayden, D.L. Sapak, D.E. Warrington, A.J. Marker, Glastech. Ber. Glass Sci. Technol. 68 (1995) 11.

[33] J.H. Campbell, E.P. Wallerstein, H. Toratani, H.E. Meissner, S. Nakajima, T.S. Izumitani, Glastech. Ber. Glass Sci. Technol. 28 (1995) 59.

[34] T. Izumitani, M. Matsukawa, H. Miyade, Laser Induced Damage in Optical Materials, National Institute of Standards and Technology (special publication), 756, 1988, p. 29.

[35] R. Adams, Phys. Chem. Glasses 2 (1961) 50.

[36] J. Chun, Z. Junzhou, Z. Dunshui, Chin. J. Lasers A 23 (1996) 182.

[37] F. Gomez, P. Vast, P. Llewellyn, F. Rouquerol, J. NonCryst. Solids 222 (1997) 415.

[38] T. Elmer, Glastech. Ber. Glass Sci. Technol. 61 (1988) 24.

[39] E. Boulos, N. Kreidl, J. Canadian Ceram. Soc. 41 (1972) 83.

[40] J. Shelby, Handbook of Gas Diffusion in Solids and Melts, ASM International, Materials Park, OH, 1996, p. 217.

[41] H. Ebendorff-Heidepriem, D. Ehrt, Glastech. Ber. Glass Sci. Technol. 68 (1995) 139.
[42] C.W. Arnold, K.A. Kobe, Chem. Eng. Prog. 48 (1952) 266.

[43] R.B. Bird, W.E. Stewart, E.N. Lightfoot, Transport Phenomena, Wiley, New York, 1960.

[44] Schott Optical Glass Catalog, Schott Glass Technologies, Duryea, PA, 1992.

[45] Hoya Optical Glass Technical Data, Hoya Corporation USA, Fremont, CA, 1990.

[46] D. Malacara, S.L. DeVore, in: D. Malacara (Ed.), Optical Shop Testing, Wiley, 1992, p. 455.

[47] J.H. Campbell, G. Edwards, F. Frick, D.S. Gemmell, K.S. Jancaitis, E.S. Jessop, M.K. Fong, R.E. Lyons, J.E. Murray, H.G. Patton, J.H. Pitts, H.T. Powell, M.O. Riley, E.P. Wallerstein, C.R. Wolfe, B.W. Woods, Laser Induced Damage in Optical Materials: National Institute of Standards and Technology (special publication), 752, 1988, p. 19.

[48] D.C. Brown, High-Peak-Power Nd: Glass Laser Systems, Springer, New York, 1981, p. 276.

[49] E.P. Plueddemann, Silane Coupling Agents, Plenum, New York, 1991.

[50] G.E. Rindone, J.L. Rhoads, J. Am. Ceram. Soc. 39 (1956) 173.

[51] R.J. Ryder, J.L. Rindone, J. Am. Ceram. Soc. 41 (1958) 415.

[52] Y.T. Hayden, J.H. Campbell, S.A. Payne, G.D. Wilke, Ceramic Translations: Solid-State Optical Materials, in: A.J. Bruce, B.V. Hiremath (Eds.), Amer. Ceram. Soc., Westerville $\mathrm{OH}, 28,1992$, p. 283.

[53] J.H. Campbell, Glastech. Ber. Glass Sci. Technol. 68 (1995) 96.

[54] J.H. Campbell, S. Schwartz, J.F. Kimmons, Analysis of Composition and Structure of Glass and Glass Ceramics, Schott Series on Glass and Glass Ceramics, vol. 7, Springer, 1999 (Chapter 5.5) in press.

[55] T. Elmer, J. Am. Ceram. Soc. 64 (1980) 150.

[56] Z. Dunshui, X. Wenjuan, J. Yasi, Chin. J. Lasers 12 (1985) 173.

[57] C.J. Brinker, G.W. Scherer, The Physics and Chemistry of Sol-Gel Processing, Academic Press, San Diego, 1990.

[58] C.Y. Wen, L.T. Fan, Model for Flow Systems and Chemical Reactors, Marcel Dekker, New York, 1975, p. 175.

[59] W.D. Deckwer, A. Schumpe, Chem. Eng. Sci. 48 (5) (1993) 889. 
Reprinted from

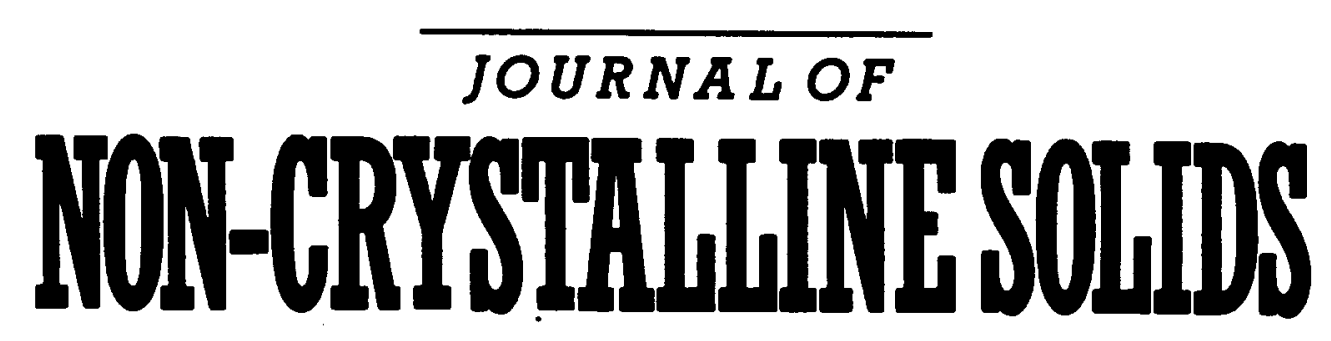

Journal of Non-Crystalline Solids 263\&264 (2000) 318-341

Section 3. Applications

Nd-doped phosphate glasses for high-energy/high-peak-power lasers

J.H. Campbell *, T.I. Suratwala

Lawrence Livermore National Laboratory, P.O. Box 808, Livermore, CA 94550, USA

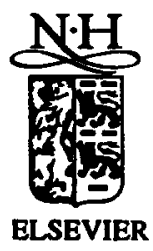


rials,

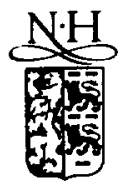

ELSEVIER

\author{
J.H. Campbell *, T.I. Suratwala \\ Lawrence Livermore National Laboratory, P.O. Box 808, Livermore, CA 94550, USA
}

\begin{abstract}
The composition and properties of neodymium-doped (Nd-doped) phosphate glasses used for simultaneous highenergy $\left(10^{3}-10^{6} \mathrm{~J}\right)$ and high-peak-power $\left(10^{12}-10^{15} \mathrm{~W}\right)$ laser applications such as fusion energy research, are reviewed. The most common base glasses are meta-phosphates $(\mathrm{O} / \mathrm{P} \sim 3)$ with the approximate composition: $60 \mathrm{P}_{2} \mathrm{O}_{5}-10 \mathrm{Al}_{2} \mathrm{O}_{3}-$ $30 \mathrm{M}_{2} \mathrm{O} / \mathrm{MO} ; \mathrm{K} / \mathrm{Ba}$ or $\mathrm{K} / \mathrm{Mg}$ are typical modifiers. The spectroscopy of $\mathrm{Nd}^{3+}$ in these glasses is well understood and laser properties can be accurately determined from measured spectroscopic properties. The major mechanisms for $\mathrm{Nd}^{3+}$ non-radiative relaxation are reviewed and empirical expressions are presented that predict these effects in phosphate glasses. Optical and thermal-mechanical properties have been measured on a number of laser glasses and can be correlated with composition. Sub-critical crack growth rates in stress regions I, II and III have been reported for the first time in phosphate laser glasses. The mechanism for Pt inclusion formation and dissolution has been studied leading to damage resistant (Pt-inclusion-free) laser glasses. (c) 2000 Elsevier Science B.V. All rights reserved.
\end{abstract}

\section{Introduction}

This review covers recent advances in phosphate laser glasses used for simultaneous highenergy and high-peak-power laser applications such as the multi-kilojoule, multi-terrawatt lasers used for fusion energy research [1-6]. Two new laser systems with output energies of nearly $2 \mathrm{MJ}$ and peak-powers in excess of $500 \mathrm{TW}$ are currently under construction [1,2]; both lasers will use neodymium-doped (Nd-doped) phosphate glasses $[7,8]$. This paper deals only with Nd-doped phosphate glasses as they represent the most common and largest volume of laser glass produced today [8].

\footnotetext{
Corresponding author. Tel.: +1-925 422 6497; fax: +1-925 4230972.

E-mail address: campbell12@llnl.gov (J.H. Campbell).
}

Unfortunately, space prohibits us from reviewing the many developments of phosphate laser glasses using other rare-earth dopants or those used for fiber optics and wave-guided structures; the reader is referred to recent reviews and articles by others in this field (see for example [9-18]). Similarly, in the past there have been several excellent reviews of earlier work on both phosphate and nonphosphate laser glasses (silicates, borates, fluorides, fluorophosphates, aluminates, germanates, chalcogenides and sulfates) $[16,19-29]$ and as a consequence that material is not covered here.

The manuscript is organized in sections dealing with key properties of laser glasses; the main exception is the brief review in Section 2 of the compositional space that has been studied during the development of $\mathrm{Nd}$ :phosphate laser glasses. Where possible the results are presented in a format that should be useful to both glass researchers and laser engineers for estimating key performance

0022-3093/00/\$ - see front matter 2000 Elsevier Science B.V. All rights reserved.

PII: S $0022-3093(99) 00645-6$ 
properties of laser glasses. In addition we attempt to show why the laser glasses in wide use on multikilojoule/multi-terrawatt lasers have evolved to a specific set of metaphosphate compositions.

\section{Phosphate laser glass composition development}

Fig. 1 is a ternary composition diagram for the $\mathrm{P}_{2} \mathrm{O}_{5}-\left(\mathrm{Al}_{2} \mathrm{O}_{3}, \mathrm{RE}_{2} \mathrm{O}_{3}\right)-\left(\mathrm{MO}, \mathrm{M}_{2} \mathrm{O}\right)$ system showing the range of laser glasses that have been studied as well as the specific compositions of several commercial laser glasses produced today. Note that most of the commercial glasses lie near the line representing the metaphosphate join and have the approximate molar composition $60 \mathrm{P}_{2} \mathrm{O}_{5}-10 \mathrm{Al}_{2} \mathrm{O}_{3}-$ $30 \mathrm{M}_{2} \mathrm{O} / \mathrm{MO}$. Nd is added to this base composition at concentrations of about $0.2 \mathrm{~mol} \%\left(\sim 5 \times 10^{19}\right.$ ions $/ \mathrm{cm}^{3}$ ) for laser rods and up to $2 \mathrm{~mol} \%$ $\left(\sim 5 \times 10^{20}\right.$ ions $\left./ \mathrm{cm}^{3}\right)$ for disks and plates $[8,30,31]$.
The compositions of the three most widely used commercial metaphosphate laser glasses, LG-750, LHG-8 and LG-770, have recently been reported for the first time [7]: LHG-8: $(56-60) \mathrm{P}_{2} \mathrm{O}_{5}-(8-$ 12) $\mathrm{Al}_{2} \mathrm{O}_{3}-(13-17) \mathrm{K}_{2} \mathrm{O}-(10-15) \mathrm{BaO}-(0-2) \mathrm{Nd}_{2} \mathrm{O}_{3}$, LG-750: $\quad(55-60) \mathrm{P}_{2} \mathrm{O}_{5}-(8-12) \mathrm{Al}_{2} \mathrm{O}_{3}-(13-17) \mathrm{K}_{2} \mathrm{O}-$ $(10-15) \mathrm{BaO}-(0-2) \mathrm{Nd}_{2} \mathrm{O}_{3}$ and LG-770: (5862) $\mathrm{P}_{2} \mathrm{O}_{5}-(6-10) \mathrm{Al}_{2} \mathrm{O}_{3}-(20-25) \mathrm{K}_{2} \mathrm{O}-(5-10) \mathrm{MgO}-$ $(0-2) \mathrm{Nd}_{2} \mathrm{O}_{3}$. The compositions are reported as ranges to account for variability due to doping and melting methods and protect certain proprietary aspects of the compositions [7]. Nevertheless, as discussed later in this manuscript, the laser, optical and physical properties of these three glasses are quite similar $( \pm 10 \%)$ suggesting that over these minor ranges in composition (and modifiers) the laser glass properties are largely unchanged. The reasons these specific modifiers and compositions make good laser glasses is discussed in several of the later sections.

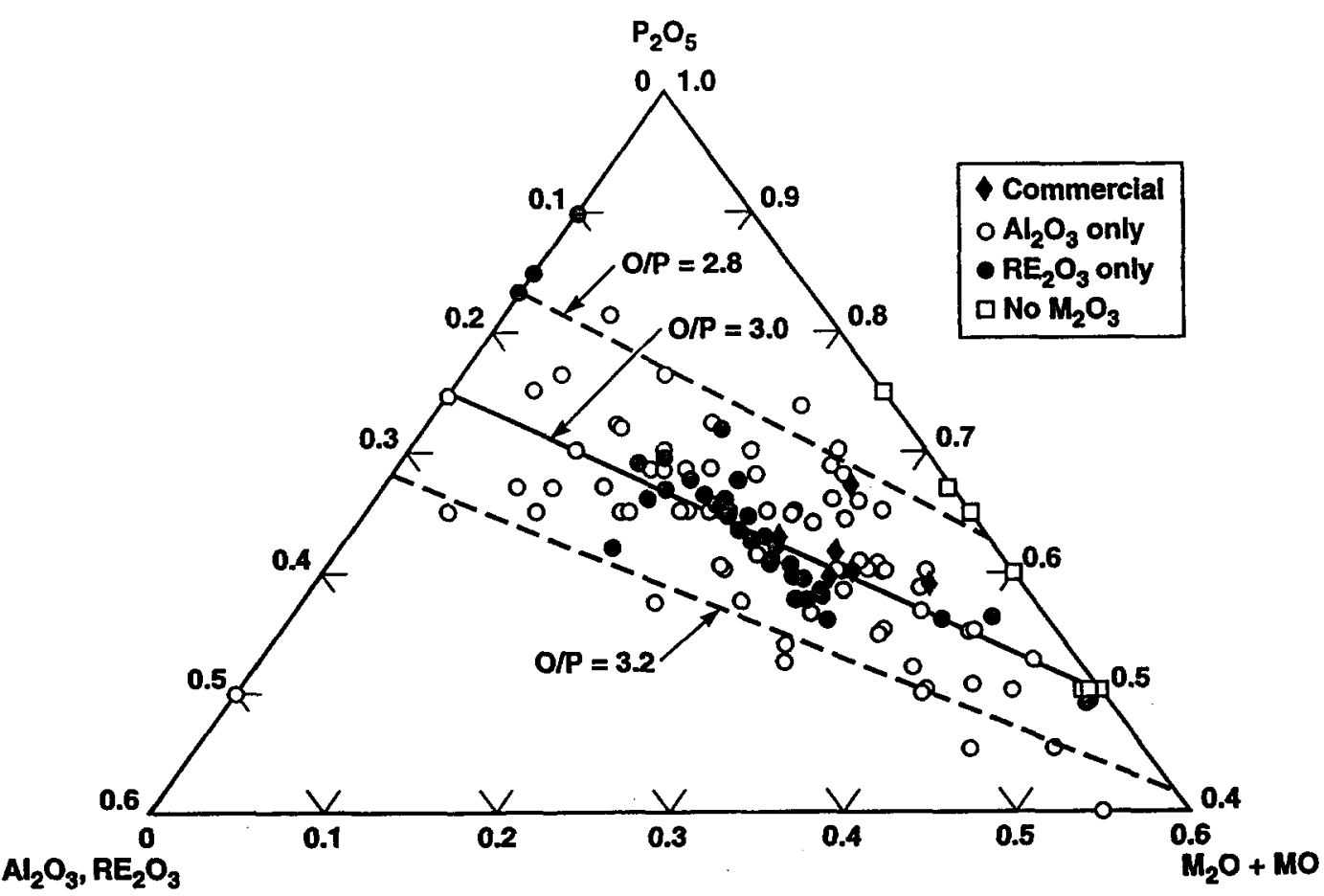

Fig. 1. $\mathrm{P}_{2} \mathrm{O}_{5}-\mathrm{Al}_{2} \mathrm{O}_{3}, \mathrm{RE}_{2} \mathrm{O}_{3}-\mathrm{MO} / \mathrm{M}_{2} \mathrm{O}$ composition diagram showing both research and commercial laser glass compositions. The sources for the research samples are given in Table 1; the compositions for the commercial glasses are from chemical analyses by the authors. 
Table 1

Systematic composition studies of Nd phosphate laser glasses

\begin{tabular}{llll}
\hline Composition space & Fixed components & Varied components & Source \\
\hline $\mathrm{P}_{2} \mathrm{O}_{5}-\mathrm{Al}_{2} \mathrm{O}_{3}-\mathrm{M}_{x} \mathrm{O}$ & - & $\mathrm{P}, \mathrm{Al}, \mathrm{Li}, \mathrm{Na}, \mathrm{K}, \mathrm{Mg}, \mathrm{Ca}, \mathrm{Sr}, \mathrm{Ba}, \mathrm{Zn}, \mathrm{Pb}$ & {$[32]$} \\
$\mathrm{P}_{2} \mathrm{O}_{5}-\mathrm{Al}_{2} \mathrm{O}_{3}-\mathrm{M}_{x} \mathrm{O}$ & $\mathrm{Al}$ & $\mathrm{P}, \mathrm{Na}, \mathrm{Li}, \mathrm{K}, \mathrm{Cs}, \mathrm{Mg}, \mathrm{Ca}, \mathrm{Ba}$ & {$[34,35]$} \\
$\mathrm{P}_{2} \mathrm{O}_{5}-\mathrm{Al}_{2} \mathrm{O}_{3}-\mathrm{M}_{2} \mathrm{O}-\mathrm{MO}$ & $\mathrm{Al}$ & $\mathrm{P}, \mathrm{Na}, \mathrm{Li}, \mathrm{K}, \mathrm{Ba}$ & {$[36]$} \\
$\mathrm{P}_{2} \mathrm{O}_{5}-\mathrm{Al}_{2} \mathrm{O}_{3}-\mathrm{M}_{2} \mathrm{O}-\mathrm{MO}$ & - & $\mathrm{P}, \mathrm{Al}, \mathrm{Li}, \mathrm{Na}, \mathrm{Ba}, \mathrm{Ca}$ & {$[37]$} \\
$\mathrm{P}_{2} \mathrm{O}_{5}-\mathrm{B}_{2} \mathrm{O}_{3}-\mathrm{M}_{2} \mathrm{O}-\mathrm{MO}$ & - & $\mathrm{P}, \mathrm{B}, \mathrm{K}, \mathrm{Na}, \mathrm{Li}, \mathrm{Ba}, \mathrm{Sr}, \mathrm{La}$ & {$[38]$} \\
$\mathrm{P}_{2} \mathrm{O}_{5}-\mathrm{Al}_{2} \mathrm{O}_{3}-\mathrm{SiO}_{2}$ & - & $\mathrm{P}, \mathrm{Al}, \mathrm{Si}$ & {$[32]$} \\
$\mathrm{P}_{2} \mathrm{O}_{5}-\mathrm{Nd}_{2} \mathrm{O}_{3}-\mathrm{SiO}_{2}$ & $\mathrm{P}, \mathrm{Nd}, \mathrm{Si}$ & {$[32]$} \\
$\mathrm{P}_{2} \mathrm{O}_{5}-\mathrm{SiO}_{2}-\mathrm{Li}_{2} \mathrm{O}-\mathrm{Al}_{2} \mathrm{O}_{3}$ & - & $\mathrm{P}, \mathrm{Si}, \mathrm{Li}, \mathrm{Al}$ & {$[32]$} \\
$\mathrm{P}_{2} \mathrm{O}_{5}-\mathrm{Al}_{2} \mathrm{O}_{3}-\mathrm{M}_{2} \mathrm{O}-\mathrm{MO}$ & $\mathrm{P}, \mathrm{Al}$ & $\mathrm{Li}, \mathrm{K}, \mathrm{Na}, \mathrm{Mg}, \mathrm{Ca}, \mathrm{Ba}$ & {$[39]$} \\
$\mathrm{P}_{2} \mathrm{O}_{5}-\mathrm{Al}_{2} \mathrm{O}_{3}-\mathrm{Na}_{2} \mathrm{O}-\mathrm{MO}$ & $\mathrm{P}, \mathrm{Al}$ & $\mathrm{Na}, \mathrm{Mg}, \mathrm{Ca}, \mathrm{Ba}$ & {$[40]$} \\
$\mathrm{P}_{2} \mathrm{O}_{5}-\mathrm{Al}_{2} \mathrm{O}_{3}-\mathrm{Ln}_{2} \mathrm{O}_{5}-\mathrm{M} \mathrm{M}_{2} \mathrm{O}$ & - & $\mathrm{Li}, \mathrm{K}, \mathrm{Nd}, \mathrm{La}, \mathrm{P}, \mathrm{Al}$ & {$[41]$} \\
$\mathrm{P}_{2} \mathrm{O}_{5}-\mathrm{Al}_{2} \mathrm{O}_{3}-\mathrm{Na}_{2} \mathrm{O}-\mathrm{MO}$ & $\mathrm{P}, \mathrm{Na}$ & $\mathrm{Al}, \mathrm{Mg}, \mathrm{Ca}, \mathrm{Ba}$ & {$[42]$} \\
$\mathrm{P}_{2} \mathrm{O}_{5}-\mathrm{Al}_{2} \mathrm{O}_{3}-\mathrm{MO}_{2} \mathrm{M} \mathrm{M}_{2} \mathrm{O}$ & - & $\mathrm{Be}, \mathrm{Mg}, \mathrm{Ca}, \mathrm{Sr}, \mathrm{Ba}, \mathrm{Li}, \mathrm{Na}, \mathrm{K}, \mathrm{Rb}$ & {$[43]$} \\
$\mathrm{P}_{2} \mathrm{O}_{5}-\mathrm{Al}_{2} \mathrm{O}_{3}-\mathrm{M}_{2} \mathrm{O}$ & $\mathrm{Li}, \mathrm{Na}, \mathrm{K}, \mathrm{Rb}, \mathrm{Cs}$ & {$[44]$} \\
$\mathrm{P}_{2} \mathrm{O}_{5}-\mathrm{Al}_{2} \mathrm{O}_{3}-\mathrm{SiO}_{2}-\mathrm{K}_{2} \mathrm{O}$ & $\mathrm{P}$ & $\mathrm{Si}, \mathrm{Al}$ & {$[44]$} \\
$\mathrm{P}_{2} \mathrm{O}_{5}-\mathrm{Al}_{2} \mathrm{O}_{3}-\mathrm{M}_{2} \mathrm{O}-\mathrm{MO}$ & $\mathrm{P}, \mathrm{K}$ & $\mathrm{Al}, \mathrm{Be}, \mathrm{Mg}, \mathrm{Ca}, \mathrm{Sr}, \mathrm{Ba}, \mathrm{Cd}, \mathrm{Li}, \mathrm{Na}, \mathrm{K}, \mathrm{Rb}$ & {$[20,23]$} \\
$\mathrm{P}_{2} \mathrm{O}_{5}-\mathrm{SrO}_{-} \mathrm{K}_{2} \mathrm{O}$ & - & $\mathrm{P}, \mathrm{K}$ & {$[45]$} \\
$\mathrm{P}_{2} \mathrm{O}_{5}-\mathrm{K}_{2} \mathrm{O}_{-} \mathrm{B}_{2} \mathrm{O}_{3}-\mathrm{MO}$ & $\mathrm{Sr}, \mathrm{Ba}, \mathrm{B}, \mathrm{P}$ & {$[45]$} \\
$\mathrm{P}_{2} \mathrm{O}_{5}-\mathrm{K}_{2} \mathrm{O}_{-}-\mathrm{Ln}_{2} \mathrm{O}_{3}-\mathrm{Y}_{2} \mathrm{O}_{3}$ & $\mathrm{Sr}$ & $\mathrm{P}$ & {$[45]$} \\
\hline
\end{tabular}

A number of systematic composition studies of phosphate laser glasses have been carried out. Unfortunately, these cannot all be represented in the single ternary diagram shown in Fig. 1. Instead we summarize many of these in Table 1 . One of the most important systematic composition investigations is that reported by Toratani [32]. He examined not only laser properties but other key glass properties for the composition series $\mathrm{P}_{2} \mathrm{O}_{5}-\mathrm{Al}_{2} \mathrm{O}_{3}-$ $\left(\mathrm{M}_{2} \mathrm{O}, \mathrm{MO}\right)$ with $\mathrm{M}=\mathrm{Li}, \mathrm{Na}, \mathrm{K}, \mathrm{Mg}, \mathrm{Ca}, \mathrm{Sr}, \mathrm{Ba}$, $\mathrm{Zn}$ and $\mathrm{Pb}$. In addition, his compositions span the ultraphosphate to polyphosphate composition region. Also included in his work is an exploration of the $\mathrm{P}_{2} \mathrm{O}_{5}-\mathrm{SiO}_{2}-\mathrm{Al}_{2} \mathrm{O}_{3}, \mathrm{P}_{2} \mathrm{O}_{5}-\mathrm{SiO}_{2}-\mathrm{Nd}_{2} \mathrm{O}_{3}$ and $\mathrm{P}_{2} \mathrm{O}_{5}-\mathrm{SiO}_{2}-\mathrm{Al}_{2} \mathrm{O}_{3}-\mathrm{Li}_{2} \mathrm{O}$ glass forming systems. The latter system yielded a lithium silicophosphate glass with acceptable laser properties and much improved thermal shock resistance that was a forerunner of commercial glasses for high-averagepower (HAP) applications [33].

Many composition studies [20,23,32,43-45], correlate variations in glass properties with modifier additions using the cation electric fieldstrength parameter [46]. Hayden et al. [39] extended this to include a compositionally averaged field strength that summed the contributions of the individual modifiers into one 'effective' field strength. They [39] were able to successfully cor- relate laser, optical, thermal and mechanical properties with the effective field strength parameter for a range of modifiers.

Although there is generally a variation in the $\mathrm{M}^{+}$or $\mathrm{M}^{2+}$ modifiers used in laser glasses, the $\mathrm{M}^{3+}$ modifier is nearly always $\mathrm{Al}^{3+}$. Thus the role of $\mathrm{Al}^{3+}$ in metaphosphate laser glasses has been a subject of much interest. This interest is because $\mathrm{Al}^{3+}$ not only affects thermal-mechanical properties but also laser properties $[20,32,47]$. The most authoritative study of effects of $\mathrm{Al}^{3+}$ in phosphate glass structures is the work of Brow et al. [48-50]. They showed that physical property changes observed with addition of $\mathrm{Al}_{2} \mathrm{O}_{3}$ are predominantly due to cross-linking of the long metaphosphate chains by $\mathrm{Al}^{3+}$ in octahedrally coordinated sites $\left(\mathrm{Al}(\mathrm{OP})_{6}\right)[49,50]$. This cross-linking is in contrast to the earlier-held view that the Al formed a threedimensional network via the weaker tetrahedral $\mathrm{AlPO}_{4}$ units. Also, $\mathrm{Al}^{3+}$ in the octahedral symmetry is the only form observed for $\leqslant 12.5 \mathrm{~mol} \%$ $\mathrm{Al}_{2} \mathrm{O}_{3}$ additive; at larger concentrations 4- and 5fold coordinated $\mathrm{Al}$ are detected [50]. It is interesting that the optimum $\mathrm{Al}_{2} \mathrm{O}_{3}$ composition used in most commercial laser glasses is in the same $\leqslant 12.5 \mathrm{~mol} \%$ range (see Fig. 1).

Raman [32,51-54] and NMR [55-60] spectroscopy continue to be used to investigate phosphate glass str compos (specific ous assi bands $\mathbf{s}$ routine one of $\mathrm{t}$ laser $\mathrm{gl}$ [62] rep systema compos marily $t$ cay rat energeti. glass. I given $t c$ show va glass $\mathrm{cc}$ structur. ${ }^{27} \mathrm{Al},{ }^{29} \mathrm{~S}$ reported metaph Brow ha

3. Laser measure

The 1 determis In this : spectros to laser

The e and glas gation $\mathrm{f}$ Powell [ account rare-ear matrices referenc

The configur the glas configur with the the well $[63,64]$ ( 
glass structures and many of these studies span the compositional region of interest for laser glasses (specifically, metaphosphate glasses). Unambiguous assignments have been made for many Raman bands such that these bands can now be used as a routine tool for structural investigations $[54,61]$. In one of the few Raman spectroscopy studies of just laser glasses, Toratani [32] and Izumatani et al. [62] reported spectra for each of the glasses in a systematic study of the $\mathrm{P}_{2} \mathrm{O}_{5}-\mathrm{Al}_{2} \mathrm{O}_{3}-\mathrm{MO}\left(\mathrm{M}_{2} \mathrm{O}\right)$ composition space. Toratani used the data primarily to relate measured $\mathrm{Nd}^{3+}$ multi-phonon decay rates (from the ${ }^{4} \mathrm{~F}_{3 / 2}$ level) to the most energetic phonon modes observed in a specific glass. Little structural interpretation has been given to his data although the Raman spectra show variations in band structure with changes in glass composition. Similarly, a number of glass structure studies using ${ }^{31} \mathrm{P}$ in combination with ${ }^{27} \mathrm{Al},{ }^{29} \mathrm{Si},{ }^{11} \mathrm{~B},{ }^{7} \mathrm{Li}$ and ${ }^{23} \mathrm{Na}$ MAS NMR have been reported for phosphate glasses in general and metaphosphates in particular. Kirkpatrick and Brow have recently reviewed this work [60].

1 in the the $\mathbf{M}^{3+}$ role of been a because Jropere most osphate [48-50]. jes ob.inantly osphate ad sites ontrast a threesahedral Il symj mol\% - and 5 $s$ interin used re same

rectroslosphate

The laser properties of $\mathrm{Nd}$ in a glass host are determined by the $\mathrm{Nd}^{3+}$ spectroscopic properties. In this section, we review recent research on $\mathrm{Nd}$ spectroscopy in phosphate glasses and its relation to laser performance.

The electronic spectra of rare earths in crystalline and glass matrices has been the subject of investigation for more than $\mathbf{4 0}$ years. The excellent text by Powell [63] is perhaps the most recent authoritative account of the spectroscopy of transition metal and rare-earth lasant ions in crystalline and amorphous matrices; the reader is referred to this text and the references cited therein for further details.

The neutral $\mathrm{Nd}$ atom has the outer electronic configuration $4 \mathrm{f}^{4} 6 \mathrm{~s}^{2}$ which, when incorporated in the glass gives $\mathrm{Nd}^{3+}$ with the ground electronic configuration $4 f^{3}$. The energy levels associated with the $\mathrm{Nd}^{3+} 4 \mathrm{f}^{3}$ configuration are determined by the well-known, multi-electron atom Hamiltonian

$$
\begin{aligned}
H= & H_{\mathrm{H}-\text { like }}+H_{\mathrm{coul}}+H_{\mathrm{SO}}+H_{\mathrm{CF}} \\
= & \left(\frac{-h^{2}}{2 m} \sum_{i}^{n} \nabla_{i}^{2}-Z_{\mathrm{efr}} \sum_{i}^{n} \frac{e^{2}}{r_{i}}\right)+\sum_{i<j}^{n} \frac{e^{2}}{r_{i j}}+\lambda L \\
& \cdot S+\sum_{i} e V_{C_{i}}(r, \theta, \phi) .
\end{aligned}
$$

The terms inside the parentheses are sums of the individual (discrete) hydrogen-like kinetic and potential energy contributions summed over all $n$ electrons of charge, $e$ and mass, $m$. The electrons lie at distances, $r_{i}$, from the shielded nucleus that has an effective nuclear charge, $e Z_{\text {eff. }}$. The next term, $H_{\text {coul }}$, accounts for the pair-wise electron coulombic repulsions where the restriction on $i$ prevents double counting and $r_{i j}$ is the pair-wise interelectronic separation. The third term, $H_{\mathrm{SO}}$, describes the electron-spin and orbital-angular momentum interactions, where $\lambda$ is the multielectron spin-orbit coupling constant. Finally, the last term, $H_{\mathrm{CF}}$, describes the electron perturbations, $V_{C_{i}}$, caused by the surrounding crystal field, where $V_{C_{i}}$ is dependent on all three spatial coordinates $(r, \theta, \phi)$. In general for $\mathrm{Nd}^{3+}$ in glass the magnitude of the various interactions described by the Hamiltonian in Eq. (1) are [63]

$\left|H_{\mathrm{H}-\text { like }}\right| \gg H_{\text {coul }} \gtrsim H_{\text {So }}>H_{\mathrm{CF}}$. [63,64] (Fig. 2):
The crystal field interaction $\left(H_{\mathrm{CF}}\right)$ is quite small because the rare earth $4 \mathrm{f}$ orbitals well shielded by the overlying $5 s^{2}$ and $5 p^{6}$ shells and therefore the states arising from the $4 \mathrm{f}^{n}$ configurations are only mildly affected by their surroundings $[63,65]$. The magnitude of the crystal field splitting for rare earths in glasses and crystals is of order $100 \mathrm{~cm}^{-1}$ (Fig. 2) and thus approximates $k T$ at ambient temperatures $\left(200 \mathrm{~cm}^{-1}\right)$. In addition, in most glasses, including phosphates, the $\mathrm{Nd}$ ions reside in sites of low symmetry $\left(C_{1}\right)$ with each site having a slightly different crystal field interaction [63]. Therefore the Stark splittings associated with the crystal field perturbations cannot be individually resolved. This lack of resolution is represented in Fig. 2 by using broad, shaded bands to represent the site-to-site variation in the crystal field Stark splitting. 
The single-electron spin-orbit coupling constant is large for $\mathrm{Nd}$, being a value of $884.6 \mathrm{~cm}^{-1}$ [64]. This large coupling constant is important for the laser performance of $\mathrm{Nd}^{3+}$ in that the $\mathrm{J}$-state immediately above the ground state remains virtually unpopulated at ambient temperatures. The energy gap between the ${ }^{4} \mathrm{~F}_{3 / 2}$ state and the terminal ${ }^{4} I$ states, combined with the thermal isolation of the terminal laser levels from the ground state (see Fig. 2), gives Nd-doped materials their fourlevel lasing properties [66].

Fusion laser systems use the broadband output from a flashlamp to pump the large-aperture, Nddoped glass laser amplifiers [67,68]. The typical spectral overlap of the output from a xenon flashlamp with the $\mathrm{Nd}^{3+}$ absorption (i.e. 'pump') bands is shown in Fig. 2 [30]. Beach et al. [69] have recently developed a unique diode-pumped glass rod amplifier for use in the smaller preamplifier systems of a fusion laser system. This amplifier uses a diode-bar array operating at $808 \mathrm{~nm}$ (12400 $\mathrm{cm}^{-1}$ ) and a unique lens duct to transport the diode output to the glass rod; the diode pumps the ${ }^{4} I_{9 / 2}$ to ${ }^{4} F_{5 / 2},{ }^{2} H_{9 / 2}$ transition (see Fig. 2). This diode pumped glass amplifier has been demonstrated using rods, $5 \mathrm{~mm}$ dia. $\times 50 \mathrm{~mm}$ long, of phosphate glass-doped with $4 \times 10^{19} \mathrm{Nd}$ ions $/ \mathrm{cm}^{3}$ [70].

The states above the ${ }^{4} F_{3 / 2}$ level are split by energies of order $1000 \mathrm{~cm}^{-1}$ (Fig. 2). These energies are similar to the phonon energies of the glass matrix $\left(\sim 1100-1200 \mathrm{~cm}^{-1}\right.$ for phosphates $\left.[32,71]\right)$ and therefore electrons excited to these levels relax by non-radiative multi-phonon processes. As a result, the electrons excited to these upper bands cascade down to the ${ }^{4} F_{3 / 2}$ state where they become 'bottle-necked'. This bottle-neck is a result of the large energy gap $\left(\sim 5500 \mathrm{~cm}^{-1}\right)$ between the ${ }^{4} \mathrm{~F}_{3 / 2}$ state and the lower-lying ${ }^{4} \mathrm{I}$ manifold (Fig. 2). The phonon coupling for this magnitude energy gap is poor and therefore radiative relaxation dominates [71]. Radiative transitions can occur to all the lower lying ${ }^{4} I_{J}$ levels but the transition of greatest interest is the one to the ${ }^{4} I_{11 / 2}$ level; this laser transition produces output radiation near $1053 \mathrm{~nm}$ in most phosphate glasses $[23,30,66]$.

The electrons terminating in the ${ }^{4} I_{11 / 2}$ state undergo non-radiative, multi-phonon decay to the ground state. This decay process must be fast compared to the pulse length of the laser for $\mathrm{Nd}^{3+}$ to operate as a four-level system. Bibeau et al. [7274] have recently determined the decay rates from the ${ }^{4} I_{11 / 2}$ to the ${ }^{4} I_{9 / 2}$ ground state in several Nddoped laser glasses using different measurement techniques. They report lifetimes between 250 and $450 \mathrm{ps}$ for three commercial phosphate laser glasses (LG-750, APG-1 and APG-2). These decay times are such that they can affect laser performance for pulse-lengths less than $1 \mathrm{~ns}$; Bibeau et al. [74] present a model that can be used to predict these performance effects. The megakilojoule lasers used for fusion energy research will operate at nominal pulse-lengths between 1 and $20 \mathrm{~ns}$ [1] and thus the performance should not be affected by the $\mathrm{Nd}^{3+}$ terminal level lifetime.

Payne and Bibeau [75] have extended this work to include measurements of the non-radiative decay rate from the ${ }^{4} G_{7 / 2}$ to $\left({ }^{4} G_{5 / 2},{ }^{2} G_{7 / 2}\right)$ state. These measurements were carried out on the same set of glasses (and some crystals) as used in the previous study [72]. The reason for studying this particular transition is that the energy gap is similar to that between the ${ }^{4} I_{11 / 2}$ to ${ }^{4} I_{9 / 2}$ levels. In addition, the decay rate is more amenable to direct measurement. The measured rate of decay from the ${ }^{4} \mathrm{G}_{7 / 2}$ state correlates to within about $15 \%$ with that measured for the ${ }^{4} I_{11 / 2}$ state.

Payne and Bibeau [75] analyze their data using the Förster [76] and Dexter [77] theory for dipoledipole energy transfer, treating the $\mathrm{Nd}$ ions as donors and the phonons as energy acceptors. From this theory they independently derive a form of the well-known energy gap law in which they separate the information regarding the host and rare earth $\left(\mathrm{Nd}^{3+}\right)$ into the exponential and preexponential factors, respectively.

To predict the performance of a laser amplifier containing a given $\mathrm{Nd}$-doped glass medium requires knowledge of the $\mathrm{Nd}^{3+}$ laser properties for the particular glass (e.g., emission cross-section, radiative lifetime, etc.). In a classic paper, Krupke [78] showed how these laser properties can be accurately estimated for a given glass from measured $\mathrm{Nd}^{3+}$ absorption and emission spectra. Krupke's method, based on the Judd-Ofelt $(\mathrm{J}-\mathrm{O})$ treatment $[79,80]$ of spectral intensities for trivalent rare earth ions, provided glass chemists with a means of 


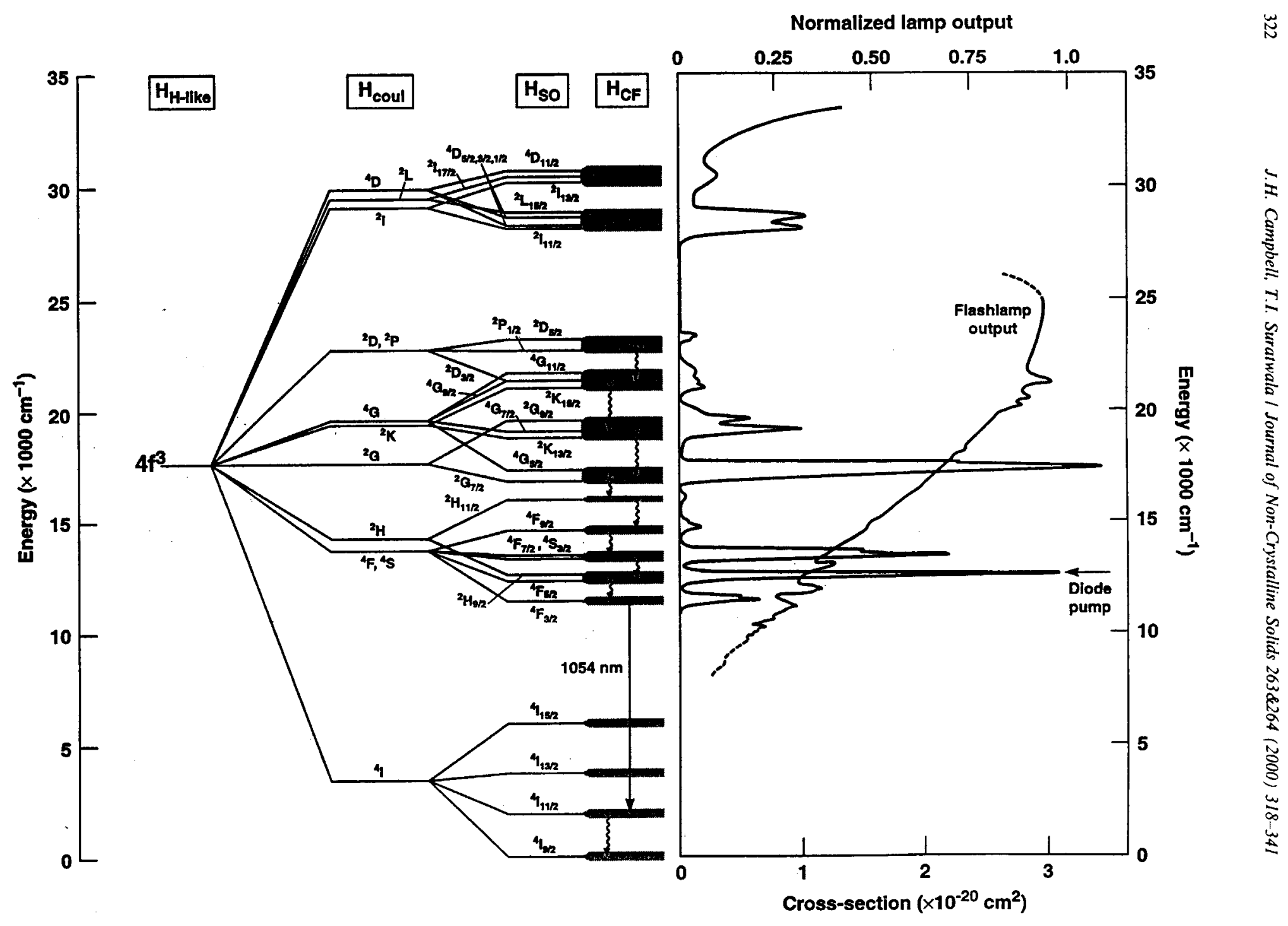

Fig. 2. Energy levels for $\mathrm{Nd}^{3+}$ evolving from the $4 \mathrm{f}^{3}$ configuration showing the coulombic $\left(H_{\text {coul }}\right)$, spin-orbit coupling $\left(H_{\mathrm{SO}}\right)$ and crystal field $\left(H_{\mathrm{CF}}\right)$ interactions. Also shown is the measured Nd-absorption cross-section in a typical metaphosphate glass host [7] and the relative output intensity for a xenon flashlamp and laser diode pump source. The laser transition of interest $\left(1053 \mathrm{~nm}\right.$ ) is from the metastable ${ }^{4} \mathrm{~F}_{3 / 2}$ state to the ${ }^{4} \mathrm{I}_{11 / 2}$ terminal level. The wavy lines denote rapid non-radiative (multi-phonon) transitions. The energies shown are relative to the ${ }^{4} I_{9 / 2}$ ground state.

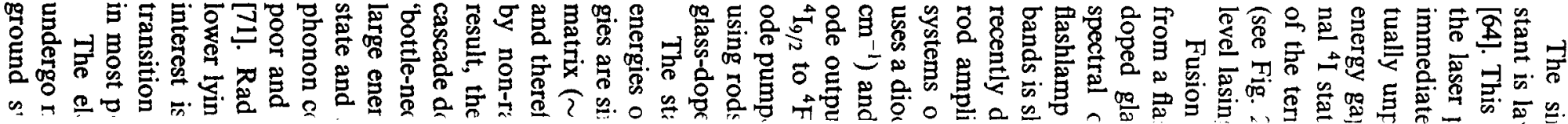


assessing key laser properties using straightforward spectroscopic measurements on glass samples from small-scale test melts. As a result, a large number of glass composition studies followed (e.g. $[23,25,27,28,32,39,81])$ and continue today $[35,45,82-84]$. The number of phosphate glass compositions studied in this fashion probably exceeds a thousand; in our laboratory alone we have evaluated several hundred individual phosphate glasses.

In the $\mathrm{J}-\mathrm{O}$ treatment, the line strength, $S$, of a transition between the initial $(J)$ and terminal $\left(J^{\prime}\right)$ states is given by

$S\left(a J: b J^{\prime}\right)=\sum_{t=2,4,6} \Omega_{t}\left|\left\langle a J\left|U^{(t)}\right| b J^{\prime}\right\rangle\right|^{2}$,

where $a$ and $b$ denote $S, L$ and other quantum numbers that completely specify the state. The individual matrix elements $\mid\left\langle a J\left|U^{(t)}\right| b J^{\prime}\right\rangle$ between the various $J$-states of the $\mathrm{Nd} 4 \mathrm{f}^{3}$ configuration have been calculated and are tabulated in readily available sources $[23,63,78]$. The $\mathrm{J}-\mathrm{O}$ intensity coefficients $\left(\Omega_{2}, \Omega_{4}\right.$ and $\left.\Omega_{6}\right)$ are phenomenological parameters determined by a least-squares fit to the integrated absorption band strengths measured in the 400-950 nm (25000-10500 $\left.\mathrm{cm}^{-1}\right)$ region [23]. The bands that are usually included in this calculation are shown in Fig. 2.

Once the $\mathrm{J}-\mathrm{O}$ parameters are determined, it is straightforward to calculate the all-important emission cross-section at the peak wavelength from the relationship

$\sigma\left(\lambda_{\mathrm{p}}\right)=\frac{8 \pi^{3} e^{2}}{27 h c(2 J+1)}\left(\frac{\lambda_{\mathrm{p}}}{\Delta \lambda_{\mathrm{eff}}}\right) \frac{\left(n^{2}+2\right)^{2}}{n} S\left(a J: b J^{\prime}\right)$,

where $n$ is the refractive index at $\lambda_{p}$, the peak fluorescence wave wavelength, $\Delta \lambda_{\text {eff }}$ the effective bandwidth and the other constants have their usual meaning. The effective linewidth is determined from the measured fluorescence intensity $\left(I_{\mathrm{f}}(\lambda)\right)$ for the associated fluorescence transition

$\Delta \lambda_{\text {eff }}=\int_{\text {band }} \frac{I_{f}(\lambda) \mathrm{d} \lambda}{I_{f}\left(\lambda_{\mathrm{p}}\right)}$.

The cross-section determined by the $\mathrm{J}-\mathrm{O}$ treatment is accurate to within $\pm 10 \%$ provided the Nd-dop- ing density has been accurately measured $(\leqslant \pm 1 \%)$.

The $\mathrm{J}-\mathrm{O}$ method can also be used to calculate the radiative decay rate, $k_{\mathrm{r}}$ and the branching ratio, $\beta_{y^{\prime}}$. The radiative decay rate is the sum of the individual radiative decay rates from the ${ }^{4} \mathrm{~F}_{3 / 2}$ state to the ${ }^{4} I$ terminal $J^{\prime}$ states (see Fig. 2) and the branching ratio is the fraction of radiative transitions that terminate at a particular $\mathrm{J}^{\prime}$ state. The branching ratio depends on the ratio of the $\mathrm{J}-\mathrm{O}$ intensity parameters, $\Omega_{4} / \Omega_{6}[23,63,85]$. In general, $\Omega_{4} / \Omega_{6}$ is near-unity for most commonly used phosphate laser glass compositions $[20,23,32]$ and therefore the branching ratios for the various $\mathrm{Nd}^{3+}$ fluorescence transitions are nearly the same. To be more specific, in meta-phosphate laser glass compositions approximately $50 \%$ of transitions terminate at the ${ }^{4} I_{11 / 2}$ state, $40 \%$ at the ${ }^{4} I_{9 / 2}$ state and $10 \%$ at ${ }^{4} \mathrm{I}_{13 / 2}$; typically less than $0.5 \%$ radiate to the ${ }^{4} I_{15 / 2}$ state $[20,23,86]$.

The emission cross-section (at the peak-emission wavelength), $\sigma_{\mathrm{em}}$, is related to the other key spectroscopic properties through the expression

$\sigma_{\mathrm{em}}=\beta k_{\mathrm{r}} \lambda_{\mathrm{p}}^{4} /\left(8 \pi c n^{2} \Delta \lambda_{\mathrm{eff}}\right)$

where $\beta$ is the branching ratio, $k_{\mathrm{r}}$, the radiative decay rate and the other terms have been defined previously. Tabulations of cross-sections, branching ratios and radiative decay rates have been published for a number of Nd-doped phosphate glass compositions as well as many other nonphosphate glass compositions (see, for example Ref. [23]).

Caird et al. [87] have determined the radiative lifetime and cross-section by direct measurement of the quantum yield. The quantum yield $(\varepsilon)$ is the ratio of the measured fluorescence lifetime ( $\left.\tau_{\text {meas }}\right)$ to the radiative lifetime $\left(\tau_{r}\right)$

$\varepsilon=\tau_{\text {meas }} / \tau_{\mathrm{r}}$

and represents the fraction of ions in the metastable state that can potentially produce emitted photons. Payne et al. [47] have also used this method to measure quantum efficiency for other phosphate laser glasses. The results show that the radiative lifetime determined by the $\mathrm{J}-\mathrm{O}$ treatment and from the quantum yield method agree to within : have $\mathrm{m}$. Krupke the $\mathrm{J}-\mathrm{C}$

Base. studies . been $c c$ generali compos gy lase Toratar $\mathrm{P}_{2} \mathrm{O}_{5} \mathrm{pi}$ give the

It is : in multi cross-se row em show th $\mathrm{Al}_{2} \mathrm{O}_{3} \mathrm{c}$ adverse the lase: in the $\mathrm{n}$ compos commer tions (si Toratan Note glass to general
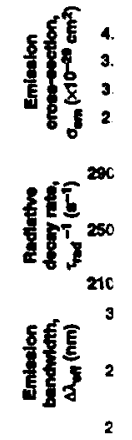

Fig. 3. Ra cross-secti reported $b$ 
easured

salculate

hing ra1 of the ne ${ }^{4} F_{3 / 2}$ 1 and the : transite. The the $\mathrm{J}-\mathrm{O}$ general, ly used $i, 32]$ and us $\mathrm{Nd}^{3+}$ 2. To be ass comas termiate and te to the

ak-emisher key ession

radiative defined branchive been zosphate er nonexample

adiative urement $(\varepsilon)$ is the ie ( $\left.\tau_{\text {meas }}\right)$

1e metaemitted sed this or other that the reatment -agree to within about $\pm 10 \%$ for the phosphate glasses they have measured. This number is in agreement with Krupke's original assessment of the accuracy for the $\mathrm{J}-\mathrm{O}$ method for glasses [78].

Based on the combination of composition studies and laser property measurements that have been carried out to date, it is now possible to generalize about which metaphosphate glass compositions make the best glasses for high-energy laser applications. Results from the work by Toratani [32] on the system $\mathrm{MO}-\mathrm{M}_{2} \mathrm{O}-\mathrm{Al}_{2} \mathrm{O}_{3}-$ $\mathrm{P}_{2} \mathrm{O}_{5}$ perhaps best illustrate which compositions give the best laser performance (Fig. 3)

It is generally desirable that the laser glass used in multi-kilojoule laser system has a large emission cross-section, long fluorescence lifetime and narrow emission bandwidth $[8,20,30,66,88]$. The data show that $\mathrm{K}_{2} \mathrm{O}$ is perhaps the best modifier and the $\mathrm{Al}_{2} \mathrm{O}_{3}$ content should be minimized because of its adverse effect on the cross-section. Furthermore, the laser properties also tend toward an optimum in the meta-phosphate to slightly ultra-phosphate composition region $\left(60-65 \mathrm{~mol} \% \mathrm{P}_{2} \mathrm{O}_{5}\right)$. Indeed, commercial laser glasses generally have compositions (see Section 2) close to that inferred from Toratani's data (Fig. 3).

Note that some $\mathrm{Al}_{2} \mathrm{O}_{3}$ must be added to the glass to improve its physical properties but in general the tendency is to decrease $\mathrm{Al}_{2} \mathrm{O}_{3}$ to as

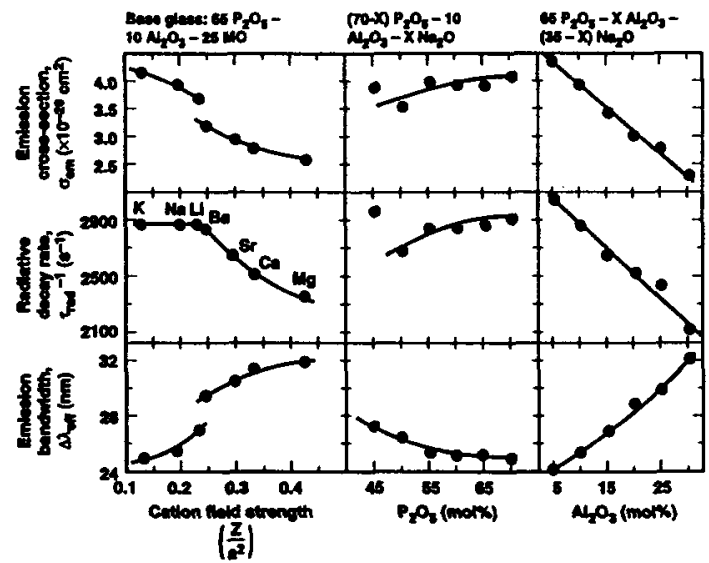

Fig. 3. Radiative decay rate, emission bandwidth and emission cross-section vs. compositional parameters derived from data reported by Toratani [32] for the ternary glass systems shown. small as possible. Similarly, using $\mathrm{K}_{2} \mathrm{O}$ as the only modifier is not practical, so each manufacturer has added a group II modifier: $\mathrm{BaO}$ in the case of LHG-8 and MgO for LG-770. MgO was chosen because it gives a smaller non-linear index [39] which improves the laser glass performance at larger intensities (see Section 6.1). Similarly, $\mathrm{BaO}$ is used because it improves physical properties (over $\mathrm{K}_{2} \mathrm{O}$ alone) with little degradation of laser properties $[32,39]$. The output energies and peakpowers obtained using either LHG-8 or LG-770 are essentially identical [8] and both glasses have been successfully melted on a large-scale [7]. Other commercial phosphate glasses are near-metaphosphates (see Fig. 1) and are in the same composition region.

\section{Non-radiative energy losses}

Non-radiative energy losses from the ${ }^{4} \mathrm{~F}_{3 / 2}$ state can reduce the stored energy and thereby affect the laser gain and overall system performance $[20,63,66]$. Non-radiative losses in phosphate laser glasses have been studied to such an extent that it is now possible to estimate the magnitude of most loss processes.

The rate of energy transfer, $k_{\text {total }}$, from the ${ }^{4} \mathrm{~F}_{3 / 2}$ level is given by

$k_{\mathrm{total}}=k_{\mathrm{r}}+k_{\mathrm{nr}}$

where $k_{\mathrm{r}}$ is the radiative relaxation rate and $k_{\mathrm{nr}}$ the non-radiative rate. Experimentally the rate of energy transfer $\left(k_{\text {total }}\right)$ is determined by measuring the fluorescence decay of the sample after it has been excited using a short-pulse pump source [23,47]. The measured decay rate can generally be fit using an exponential decay with characteristic time constant, $\tau_{\text {meas }}$; thus in Eq. (9) $k_{\text {total }}=\tau_{\text {meas }}^{-1}$ and

$k_{\mathrm{nr}}=\left(\frac{1}{\tau_{\text {meas }}}-\frac{1}{\tau_{\mathrm{r}}}\right)$,

where the radiative decay rate, $k_{\mathrm{r}}$, is given by $\tau_{\mathrm{r}}^{-1}$ and is independently determined using the $\mathrm{J}-\mathrm{O}$ treatment (see Eq. (7)).

The non-radiative decay rate is a sum of contributions from all non-radiative processes [63] 
$k_{\mathrm{nr}}=k_{\mathrm{mp}}+k_{\mathrm{aug}}+k_{\mathrm{Nd}}+k_{\mathrm{OH}}+\sum_{i=1}^{n} k_{\mathrm{TM} i}+\sum_{j=1}^{m} k_{\mathrm{RE} j}$.

The first three terms refer to loss by multi-phonon relaxation $\left(k_{\mathrm{mp}}\right)$, Nd self-quenching $\left(k_{\mathrm{Nd}}\right)$ and Auger up-conversion $\left(k_{\mathrm{aug}}\right)$. All three of these terms are intrinsic losses that depend on the glass structure and composition (Nd-doping level). The last three terms represent non-radiative losses due to impurities that enter during glass processing, specifically: hydroxyl groups $\left(k_{\mathrm{OH}}\right)$, transition metal ions $\left(k_{\mathrm{TM}}\right)$ and rare earth ions $\left(k_{\mathrm{RE}}\right)$ (e.g. $[20,45,47,89,90])$. Since there is the possibility of several transition metal or rare-earth impurities then the losses are given as a sum of the individual ion contributions [90]. Fig. 4 schematically illustrates each of the non-radiative loss processes.

Intrinsic processes

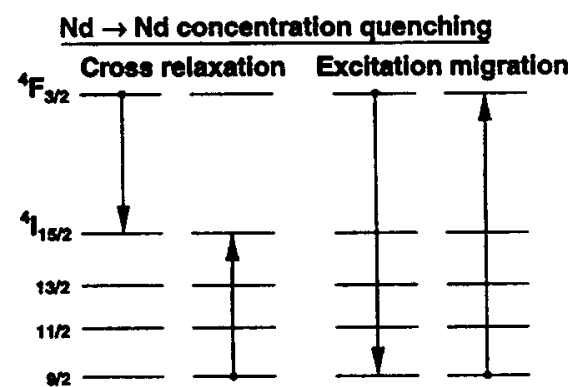

Experimentally it is relatively straightforward to determine the contributions due to the last four terms in Eq. (11). This measurement is done by first preparing a 'reference' glass and then doping it with different concentrations of either $\mathrm{Nd}, \mathrm{OH}$ or impurities (e.g. $[89,90])$. The increased decay rate due to the additive is then

$k_{\mathrm{additive}}=\tau_{\mathrm{w}}^{-1}-\tau_{\mathrm{w} / \mathrm{o}}^{-1}$

where $\tau_{w}$ and $\tau_{w / o}$ are the measured fluorescence decay times with and without the additive, respectively.

\subsection{Multi-phonon relaxation $\left(k_{\mathrm{mp}}\right)$}

The rate of multi-phonon relaxation between two states can be described using an energy-gap law $[20,71,72,75,91]$

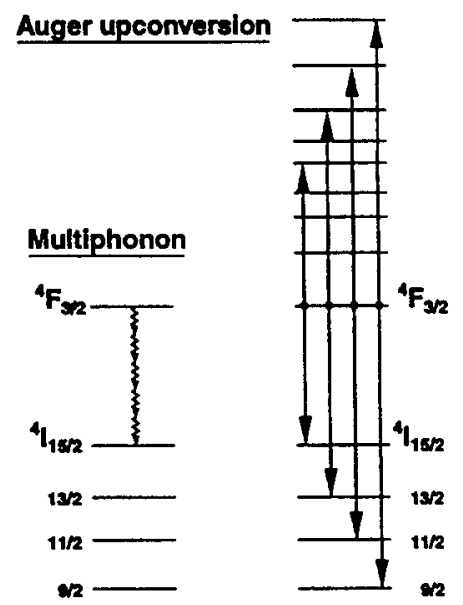

$k_{\mathrm{mp}}=A$

where $\Delta$ states (C constan $4 \times 10^{12}$ $67 \mathrm{P}_{2} \mathrm{O}_{5}$ measure were se cently I phonon and rep gap law

Direr non der because From e: [71] and $\mathrm{cm}^{-1}\left({ }^{4}\right]$ Hz. Me commer 760) ar measure $220 \pm 1$. studies Eq. (13) and 4.3 are in a Layne $\mathrm{E}$

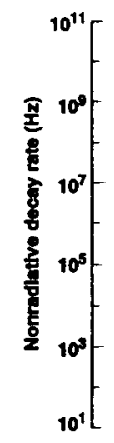

Fig. 5. $\mathrm{P}$ glasses $v$ : Bibeau e1

Fig. 4. Non-radiative $\mathrm{Nd}^{3+}$ relaxation processes in phosphate laser glasses. 
tforward last four done by doping it ', $\mathrm{OH}$ or cay rate

orescence additive,

between nergy-gap
$k_{\mathrm{mp}}=A \exp (-\alpha \Delta E)$

where $\Delta E$ is the energy difference between the two states $\left(\mathrm{cm}^{-1}\right)$ and $A$ and $\alpha$ are empirically derived constants. Layne et al. [71] report $A$ and $\alpha$ of $4 \times 10^{12} \mathrm{~Hz}$ and $4.61 \times 10^{-3} \mathrm{~cm}$, respectively, for a $67 \mathrm{P}_{2} \mathrm{O}_{5}-15 \mathrm{Na}_{2} \mathrm{O}-18 \mathrm{BaO}$ phosphate glass. The measurements were made for excited states that were separated by about $2500-3900 \mathrm{~cm}^{-1}$. Recently Bibeau et al. [75] have measured multiphonon decay rates from the ${ }^{4} G_{7 / 2}$ and ${ }^{4} I_{11 / 2}$ states and report that these data also follow an energy gap law.

Direct measurement of the rate of multi-phonon decay from the ${ }^{4} \mathrm{~F}_{3 / 2}-\mathrm{I}_{15 / 2}$ state is difficult because the rate is less than a few hundred $\mathrm{Hz}$. From extrapolation of the data from Layne et al. [71] and Bibeau et al. [75] to an energy gap of 5500 $\mathrm{cm}^{-1}\left({ }^{4} \mathrm{~F}_{3 / 2}{ }^{4}{ }^{4} \mathrm{I}_{15 / 2}\right)$ we get a rate of only about 150 Hz. Measurements by Caird et al. [87] on two commercial phosphate glasses (LG-750 and LG760) are consistent with this observation; the measured multi-phonon relaxation rate is about $220 \pm 120 \mathrm{~Hz}$. The data from the above-mentioned studies are shown in Fig. 5; a least-squares fit of Eq. (13) to the data gives $A$ and $\alpha$ of $2.4 \times 10^{12} \mathrm{~Hz}$ and $4.35 \times 10^{-3} \mathrm{~cm}$, respectively. These numbers are in agreement with those originally reported by Layne et al. [71].

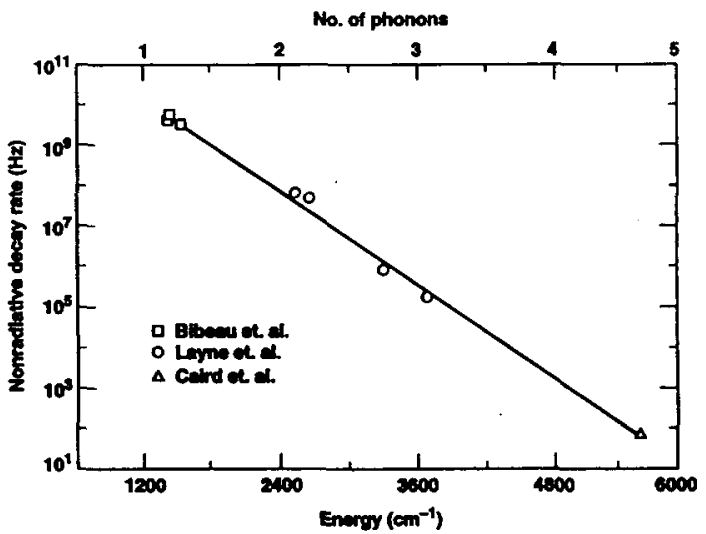

Fig. 5. Rate of $\mathrm{Nd}^{3+}$ multi-phonon relaxation in phosphate glasses vs. energy gap between $J$-states, based on data from Bibeau et al. [73], Layne et al. [71] and Caird et al. [87].

\subsection{Nd-concentration quenching $\left(k_{\mathrm{Nd}}\right)$}

The study of $\mathrm{Nd}$ self-quenching in laser glasses has received perhaps the most attention of all the non-radiative decay processes. One reason for such scrutiny is that most multi-kilojoule lasers use glass disks or slabs with $\mathrm{Nd}$ doping densities which maximize the pumping efficiency (pump light absorption) and the stored energy density [30]. Concentration quenching refers to the energy exchange between a pair of $\mathrm{Nd}$ ions and is the result of two relaxation mechanisms (Fig. 4) [63]. One is cross-relaxation in which two neighboring ions exchange energy and the second is migration of the excitation energy from one ion to the next (the so-called 'hopping' mechanism). In theory the rate of relaxation due to concentration quenching varies as $r^{-6}$, where $r$ is the inter-ion distance; note that the $r^{-6}$ dependence is physically equivalent to the square of the $\mathrm{Nd}^{3+}$ concentration. In reality the effect of the $\mathrm{Nd}$ concentration on relaxation rate is dependent on the glass composition and varies from near-linear in ultra-phosphates to quadratic in near-metaphosphates and from quadratic to cubic in silicates $[20,41,45,47,86,87,92,93]$.

The empirical relationship commonly used to describe concentration quenching in metaphosphate laser glasses is [47]

$k_{\mathrm{Nd}}=k_{0}(N / Q)^{2}$,

where $k_{0}$ is the zero concentration decay rate, $k_{\mathrm{Nd}}$ the increased decay rate due to the presence of $\mathrm{Nd}$ (see Eq. (11)), $N$ the $\mathrm{Nd}^{3+}$ ion concentration $\left(\mathrm{cm}^{-3}\right)$ and $Q\left(\mathrm{~cm}^{-3}\right)$ is an empirically determined quantity for a given glass. $Q$ is physically equivalent to the $\mathrm{Nd}$ concentration needed to reduce the lifetime to one-half its zero concentration limit (i.e., twice the zero-concentration decay rate). The parameter, $Q$, has been reported to vary linearly with the emission bandwidth for a number of phosphate laser glasses (Fig. 6) [47]. This trend is physically reasonable on the basis of the Förster/ Dexter theory [76,77] for dipolar energy transfer because the rate of concentration quenching is related to the extent of spectral overlap between the two adjacent $\mathrm{Nd}$ ions. Therefore greater 


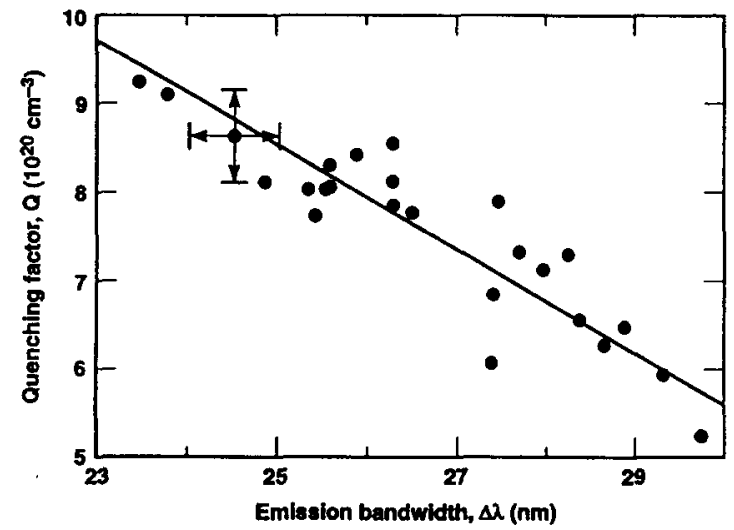

Fig. 6. Measured Nd concentration quenching factor $(Q)$ vs. the measured emission bandwidth for a series of multi-component metaphosphate laser glasses, based on data from [47].

concentration quenching rates are expected for glasses with greater emission bandwidths.

Fig. 7 shows the concentration quenching rate measured for samples of two commercially available meta-phosphate laser glasses commonly used in high-energy applications: LHG-8 and LG-770 [8]. Both have a linear dependence of decay rate with the square of the Nd-doping concentration as predicted by Eq. (14); measurement errors are within the size of the data symbols.

Caird et al. [87] have reported Nd concentration quenching effects in LG-750 and LG-760. They have measured the quantum efficiency over a concentration range from about 0.2 to $13 \times 10^{20} \mathrm{Nd}^{3+} / \mathrm{cm}^{3}$ and analyzed the non-radiative decay using the Förster [76] model for crossrelaxation, but modified for energy migration using Burshtein's [95] 'hopping' model. The results show that both mechanisms are needed to model the change in quantum efficiency with $\mathrm{Nd}$ concentration; however, cross-relaxation appears to be the dominant relaxation mechanism in these glasses.

Lunter et al. [81] report the affects of Group I modifier ions on the rate of concentration quenching in an ultraphosphate laser glass and show that the quenching increases from $\mathrm{Cs}$ to $\mathrm{Li}$. They also show that the quenching rate increases linearly rather than quadratically with Nd-concentration in agreement with the work of Sto-

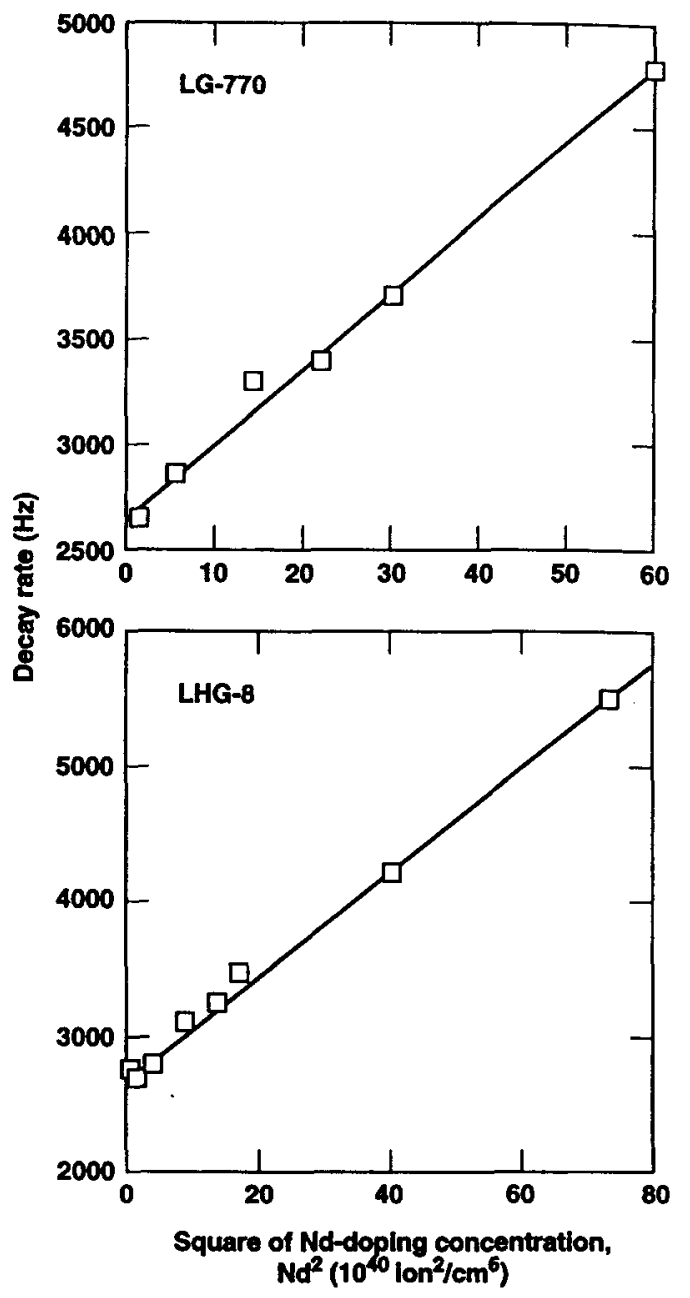

Fig. 7. Nd concentration quenching in LHG-8 and LG-770 metaphosphate laser glasses based on data reported in $[8,94]$; the measurement errors are within the symbol size.

kowski on ultraphosphates [20]. The relaxation rate can be represented by the expression

$\left(k_{\text {meas }}-k_{0}\right)=A[\mathrm{Nd}]$,

where $k_{\text {meas }}$ is the measured transition rate, $k_{0}$ the rate in the absence of concentration quenching and $A$ is a constant for any given cation. Fig. 8 shows that the quantity $A$, determined from the slope of the decay rate data reported by Lunter et al. [81], increases with the cation field strength $\left(Z / a^{2}\right)$.

Jiang et al. [96] report measurements of $\mathrm{Nd}^{3+}$ concentration quenching in the two glasses

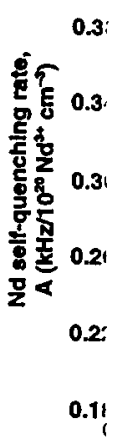

Fig. 8. C, electric fie et al. [81].

$18 \mathrm{~K}_{2} \mathrm{O}$ $10 \mathrm{Ln}_{2} \mathrm{O}$ : modifier trend a Lunter 6 amount glasses $r$

The e modifier ported is $\mathrm{Nd}^{3+}$-do two $\mathrm{me}$ $52.5 \mathrm{P}_{2} \mathrm{O}$ ( $\mathrm{R}=\mathrm{Mg}$ $\mathrm{Ba}<\mathrm{Ca}$ trend ag. I oxides creases :

Eben concentr meta-ph $28 \mathrm{BaO}-1$ 1 and 11 linearly 1 predicter Eq. (14): metapho cussed : also con fiers, suc 

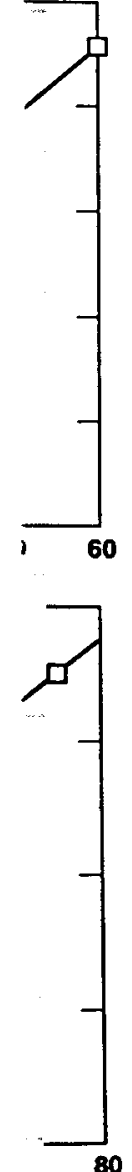

un,

d LG-770

1 in $[8,94]$;

laxation

n

ite, $k_{0}$ the hing and

8 shows e slope of at al. [81], $\left.7 a^{2}\right)$. - of $\mathrm{Nd}^{3+}$ , glasses

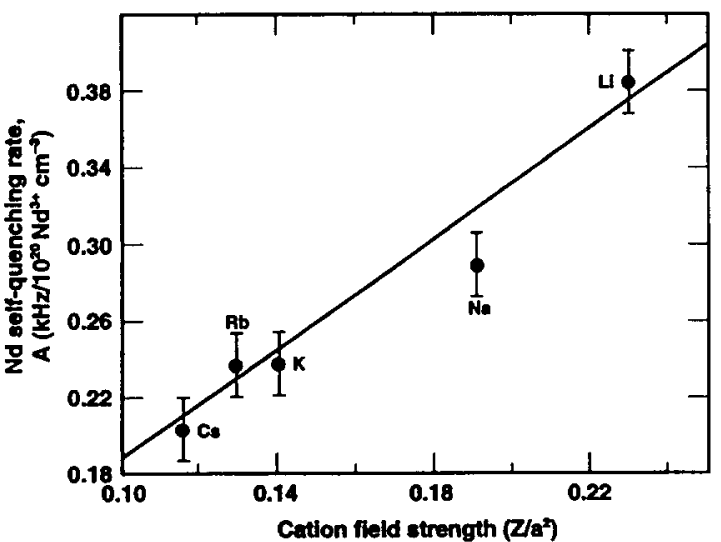

Fig. 8. Correlation of Nd self-quenching rate with modifier electric field strength; generated from data reported by Lunter et al. [81].

$18 \mathrm{~K}_{2} \mathrm{O}-10 \mathrm{Al}_{2} \mathrm{O}_{3}-6 \mathrm{Ln}_{2} \mathrm{O}_{3}-66 \mathrm{P}_{2} \mathrm{O}_{5}$ and $26 \mathrm{Li}_{2} \mathrm{O}$ $10 \mathrm{Ln}_{2} \mathrm{O}_{3}-64 \mathrm{P}_{2} \mathrm{O}_{5}$. The glass containing the $\mathrm{Li}$ modifier had a much greater quenching rate. This trend agrees qualitatively with the results from Lunter et al. [81], although the effect of the small amount of $\mathrm{Al}_{2} \mathrm{O}_{3}$ used in one of the Jiang et al. glasses raises some uncertainty.

The effect of a systematic change in the group II modifiers on $\mathrm{Nd}$ concentration quenching is reported in the work by Byun et al. [97]. They use a $\mathrm{Nd}^{3+}$-doping range of $0.2-10 \times 10^{20}$ ions $/ \mathrm{cm}^{3}$ in two meta-phosphate glasses: $45 \mathrm{RO}-2.5 \mathrm{Al}_{2} \mathrm{O}_{3}-$ $52.5 \mathrm{P}_{2} \mathrm{O}_{5}$ and $35 \mathrm{RO}-10 \mathrm{Na}_{2} \mathrm{O}-2.5 \mathrm{Al}_{2} \mathrm{O}_{3}-52.5 \mathrm{P}_{2} \mathrm{O}_{5}$ $(\mathrm{R}=\mathrm{Mg}, \mathrm{Ca}$ or $\mathrm{Ba})$. The data show a trend $\mathrm{Ba}<\mathrm{Ca}<\mathrm{Mg}$ in increased Nd self-quenching. This trend agrees with the trend observed for the group I oxides (Fig. 8) in that the quenching rate increases with modifier field strength.

Ebendorff-Heidepriem et al. [45] report $\mathrm{Nd}$ concentration quenching measurements in the two meta-phosphate glasses $\mathrm{Sr}\left(\mathrm{PO}_{3}\right)_{2}$ and $11 \mathrm{~K}_{2} \mathrm{O}$ $28 \mathrm{BaO}-6 \mathrm{Al}_{2} \mathrm{O}_{3}-55 \mathrm{P}_{2} \mathrm{O}_{5}$ doped with between about 1 and $10 \times 10^{20} \mathrm{Nd}^{3+} / \mathrm{cm}^{3}$. The decay rates vary linearly with the square of the $\mathrm{Nd}$ concentration as predicted via a dipolar relaxation mechanism (see Eq. (14)) similar to that reported above for other metaphosphates. In agreement with the work discussed above, Ebendorff-Heidepriem et al. [45] also conclude that using low field strength modifiers, such as $\mathrm{K}$ and $\mathrm{Ba}$, reduces the concentration quenching. They suggest that the large difference in field strength between $\mathrm{K}^{+}$(and $\mathrm{Ba}^{2+}$ ) and $\mathrm{Nd}^{3+}$ produces a regular alteration in positions of the two cation polyhedra ( $\mathrm{Nd}$ and $\mathrm{K}$ ) along the metaphosphate chains and thus maximizes the separation between $\mathrm{Nd}^{3+}$ ions. They propose that such an alteration would not occur for modifiers having field strengths comparable to $\mathrm{Nd}^{3+}$ (e.g., $\mathrm{Y}^{3+}$ ).

The data from the above studies $[40,45,81,96]$ show that laser glass compositions with the smallest concentration quenching effects are those glasses that use groups I and II cations with the smallest electric field strengths. The data indicate that $\mathrm{K}$ and $\mathrm{Ba}$ should give the best results and indeed one or both of these two modifiers are used in commercial laser glass compositions (see Section 2).

\subsection{Auger up-conversion losses ( $k_{\text {Aug }}$ )}

Until recently, Auger up-conversion loss had not been reported in Nd-doped laser glasses. Auger up-conversion occurs when two excited $\mathrm{Nd}$ ions, both in the metastable ${ }^{4} \mathrm{~F}_{3 / 2}$ state, interact such that one ion returns to a lower-lying ${ }^{4} I_{J}$ state while the other is excited to an energetically equivalent higher state (see Fig. 4). Payne et al. [98] have recently measured up-conversion losses in two phosphate laser glasses (APG-2 and LG-770), a silicate (LG-660) and the heavy metal fluoride glass, ZBLAN. They report that the product of the emission lifetime $(\tau)$ and the $\mathrm{Nd}$ up-conversion constant $\left(\gamma_{A}\right)$ (i.e., $\left.\gamma_{A} \tau\right)$ is nearly constant for these materials and between 1 and $2 \times 10^{20} \mathrm{~cm}^{3}$. The $\gamma$ for LG-770 is $8.1 \times 10^{-17}\left(\mathrm{~cm}^{3} / \mathrm{s}\right) \pm 30 \%$ [98].

The kinetic equation describing the decay from the ${ }^{4} F_{3 / 2}$ state depends on the $\mathrm{Nd}$ excited state concentration [98]. The contribution of the upconversion process to increased $\mathrm{Nd}$ decay rate, $k_{\text {Aug }}$, can be approximated as

$k_{\text {Aug }} \approx \gamma_{A} N^{*}$,

where $N^{*}$ is the excited state density. $N^{*}$ is about $10^{18} \mathrm{~cm}^{-3}$ in glasses used in most high-energy laser applications (i.e., stored energy about $0.25 \mathrm{~J} / \mathrm{cm}^{3}$ [88]). Thus, the increased decay rate due to upconversion loss (via Eq. (16)) is less than $100 \mathrm{~Hz}$. 
4.4. Hydroxyl group effects on non-radiative decay rate $\left(k_{O H}\right)$

A number of researchers have reported either $\mathrm{OH}$ quenching rates or data from which it can be easily derived $[20,32,94,96,99]$. In several cases the measurements have been made as a function of $\mathrm{Nd}$ concentration in various phosphate glasses; Fig. 9 summarizes these data. The data are valid for $-\mathrm{OH}$ concentrations (as measured by the absorption at $\sim 3000 \mathrm{~cm}^{-1}$ ) up to about $10 \mathrm{~cm}^{-1}$.

A simple empirical relation that can be used for estimating the magnitude of $\mathrm{OH}$ quenching in $\mathrm{Nd}-$ phosphate glasses at a given Nd concentration is [47]

$k_{\mathrm{OH}}=Q_{\mathrm{OH}}\left(\alpha_{\mathrm{OH}}\right)$

where $\alpha_{\mathrm{OH}}$ is the absorption coefficient at 3000 $\mathrm{cm}^{-1}$ due to $\mathrm{OH}$ and $Q_{\mathrm{OH}}$ is the quenching coefficient $\left(\mathrm{Hz} / \mathrm{cm}^{-1}\right)$ determined from Fig. 9. The $\mathrm{OH}$ quenching rate increases nearly linearly with $\mathrm{Nd}$ concentration at doping levels $\geqslant 3 \times 10^{20} \mathrm{ions} / \mathrm{cm}^{3}$. However at doping levels $<1 \times 10^{20}$ ions $/ \mathrm{cm}^{3}$ the quenching rate approaches a constant of about 60 $\mathrm{Hz} / \mathrm{cm}^{-1}$. The trend at low doping is unexpected. Based on a simple dipolar relaxation mechanism $[22,63]$ for uniformly distributed donor $(\mathrm{Nd})$ and acceptor $(\mathrm{OH})$ centers one would expect the $\mathrm{OH}$ quenching rate to vary linearly with $\mathrm{Nd}$ concentrations at low dopings and to pass through the

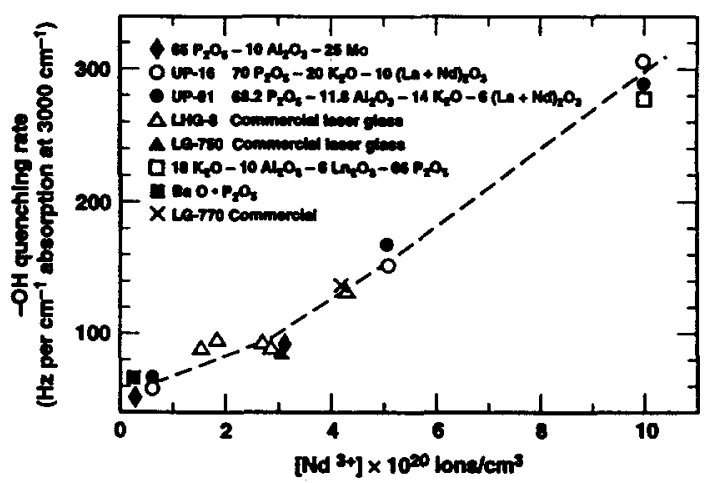

Fig. 9. Nd fluorescence quenching rate $\left(Q_{\mathrm{OH}}\right)$ due to $-\mathrm{OH}$ contamination for phosphate glasses with various Nd concentrations. The dashed line is fit to the data using an empirical expression discussed in the text. Sources: $[20,32,47,94,96,99]$. origin. The data in Fig. 9 are fit to an empirical expression $Q_{\mathrm{OH}}=a+b[\mathrm{Nd}]^{3 / 2}$, where $a$ is $62.8 \mathrm{~Hz}$ $\mathrm{cm}$ and $b$ is $7.26 \times 10^{-30} \mathrm{~Hz} \mathrm{~cm} /\left(\text { ions } / \mathrm{cm}^{3}\right)^{3 / 2}$. This expression has no theoretical significance and simply represents a best-fit to the data over the range shown.

To achieve optimum laser performance, the hydroxyl group absorption should be less than $2.0 \mathrm{~cm}^{-1}$ at $3000 \mathrm{~cm}^{-1}[7,43]$. An absorption of $2 \mathrm{~cm}^{-1}$ corresponds to about $200 \mathrm{ppmw}$ of $\mathrm{OH}$ [7], however, absolute measurements of $\mathrm{OH}$ content in phosphate glasses are difficult, particularly at concentrations less than $1000 \mathrm{ppmw}$. Conversion factors for relating the absorption coefficient at $\sim 3000 \mathrm{~cm}^{-1}$ to absolute $\mathrm{OH}$ concentrations vary from about 30 to nearly $400 \mathrm{ppmw} / \mathrm{cm}^{-1}$ with most factors between about 60 and $130 \mathrm{ppmw} / \mathrm{cm}^{-1}$ [100]. This range of data has prompted EbendorffHeidepreim and Ehrt [101] to suggest that only absorption measurements should be used as a measure of the relative $-\mathrm{OH}$ content in glasses.

4.5. Fluorescence quenching by rare earth and transition metal ions

The absorption bands of some rare earth (RE) and transition metal (TM) ions overlap the $\mathrm{Nd}^{3+} 1053 \mathrm{~nm}$ emission band. This spectral overlap leads to fluorescence quenching as described by the Förster/Dexter theory [76,77] for dipolar energy transfer. Some RE and TM ions absorb enough at $1053 \mathrm{~nm}$ that they affect the Nd fluorescence decay rate at concentrations less than 10 ppmw $[20,89,90]$. Stokowski and Krashkevich [89] examined the effects of transition metal ions $(\mathrm{Cu}, \mathrm{Fe}, \mathrm{V}, \mathrm{Cr}, \mathrm{Co}$ and $\mathrm{Ni}$ ) doped at $300 \mathrm{ppmw}$ on $\mathrm{Nd}$ quenching in an ultraphosphate glass at different Nd-doping levels. Ehrmann et al. [90] report quenching rates for $\mathrm{Cu}$ and $\mathrm{Fe}$ at one Nd-doping concentration but for a range of impurity levels from about 30 to 1000 ppmw. The $\mathrm{Cu}$ quenching rate (reported in $\mathrm{Hz}$ / ppm impurity) is constant at all impurity concentrations. In contrast, the $\mathrm{Fe}$ quenching rate decreases at doping levels $<300$ ppmw; Ehrmann et al. [90] attribute this decrease to a change in the $\mathrm{Fe}^{2+} / \mathrm{Fe}^{3+}$ ratio.

\section{Al}

$\mathrm{T}\}$

funct

the

glass

$[66,9$

laser

$\alpha_{\text {total }}$

wher

abso

popu

trans

impu

spect

the $\mathrm{g}$

or il

sourc cally

than

syste

flash]

$4 \times 1$

Ther

great.

loss 1

as $\mathrm{m}$

centr.

pendi

Tr

to ${ }^{4} \mathrm{~F}$

phos]

$\alpha_{\mathrm{Nd}}(1$

wher

sorpt

ion ,

provi

$\mathrm{Nd}^{3+}$

glasse

Er

coeffi

laser

and $I$ 
empirical

$62.8 \mathrm{~Hz}$

, $3 / 2$. This

nce and

jver the

ince, the

iess than

ption of

, $\mathrm{OH}$ [7],

content in

larly at

nversion

fficient at

ons vary

ith most

$\mathrm{mw} / \mathrm{cm}^{-1}$

isbendorff-

hat only

sed as a

glasses.

earth and

are earth verlap the spectral $1 g$ as de[76,77] for

TM ions affect the ations less and Kratransition , doped at ultraphosvels. Ehres for $\mathbf{C u}$ on but for 30 to 1000 ed in $\mathrm{Hz}^{\prime}$ surity conching rate Ehrmann change in

\section{Absorption and scattering losses}

The net gain of a glass laser amplifier is a function not only of the gain coefficient but also the combined passive transmission losses in the glass due to impurity absorption and scattering $[66,90]$. The total static absorption loss, $\alpha_{\text {total, }}$, in laser glass at $1053 \mathrm{~nm}$ is a sum of contributions

$\alpha_{\mathrm{total}}=\alpha_{\mathrm{Nd}}+\sum_{i=1}^{n} \alpha_{\mathrm{TM}_{i}}+\sum_{j=1}^{m} \alpha_{\mathrm{RE} j}+\alpha_{\mathrm{OH}}$,

where the four terms on the right side refer to absorption losses due to: (1) $\mathrm{Nd}^{3+}$ ions thermally populating the terminal laser level $\left({ }^{4} I_{11 / 2}\right)$, (2) transition metal ion impurities, (3) rare earth ion impurities and (4) residual hydroxyl groups, respectively. These impurities may originate from the glass raw materials, the melter refractory and/ or impurities from an outside contamination source. Commercially supplied laser glasses typically have an un-pumped absorption loss of less than $0.0015 \mathrm{~cm}^{-1}$ at $1053 \mathrm{~nm}$ [31]. For ICF laser systems, the typical gain coefficient through a flashlamp pumped laser slab doped with 2$4 \times 10^{20} \mathrm{Nd}^{3+} / \mathrm{cm}^{3}$ is about $0.05 \mathrm{~cm}^{-1}$ [88]. Therefore, the ratio of gain-to-loss coefficients is greater than about 30:1. To achieve these gain-toloss levels requires the use of raw materials as well as melter wall materials with the impurity concentrations typically less than $10-100$ ppmw, depending on the TM or RE ion [7,90,102].

The $\mathrm{Nd}^{3+}$ absorption cross-section for the ${ }^{4} \mathrm{I}_{11 / 2}$ to ${ }^{4} F_{3 / 2}$ transition at room temperature in a metaphosphate glass is reported as [94]

$\alpha_{\mathrm{Nd}}(T)=1.03 \times 10^{-20} \exp (-2576 / T)\left[\mathrm{Nd}^{3+}\right]$,

where $\alpha_{\mathrm{Nd}}(T)$ is the temperature-dependent absorption coefficient $\left(\mathrm{cm}^{-1}\right)$ and $\left[\mathrm{Nd}^{3+}\right]$ is the $\mathrm{Nd}$ ion concentration (ions $/ \mathrm{cm}^{3}$ ). Eq. (19) should provide reasonable estimates $( \pm 15 \%)$ for static $\mathrm{Nd}^{3+}$ absorption losses in other meta-phosphate glasses in the absence of direct measurements.

Ehrmann et al. [90] have compiled extinction coefficients at $1053 \mathrm{~nm}$ reported for phosphate laser glasses doped with various transition metal and rare earth ion impurities $[89,90,102-104]$ and melted under oxidizing conditions (1 atm $\mathrm{O}_{2}$ ). Currently most phosphate laser glasses are processed under oxidizing conditions so iron contamination tends to occur mainly as $\mathrm{Fe}^{3+}$ in metaphosphate laser glasses $[90,104,105]$. $\mathrm{Fe}^{3+}$ absorbs in the visible and UV [106-109] and has insignificant absorption near the $1053 \mathrm{~nm}$ laser transition. Nevertheless, some equilibrium amount of $\mathrm{Fe}^{2+}$ is usually present which has an absorption band near $1000 \mathrm{~nm}[105,110-112]$. The $\mathrm{Fe}^{2+} / \mathrm{Fe}^{3+}$ distribution in LHG-8 and LG-770 melted under oxidizing conditions ( $1 \mathrm{~atm} \mathrm{O}_{2}$ ) is reported to be concentration dependent at impurity concentrations $<300$ ppmw Fe [90].

Scatter losses are due to inhomogeneities within the glass plus residual surface roughness after polishing. Scatter loss measurements have been reported [113] on polished pieces of LHG-8 and LG-750 meta-phosphate laser glasses (typical of the polished surfaces of glasses installed in an amplifier) using an integrating sphere scatterometer. The scatterometer is capable of measuring fractional losses to $10^{-5}$ of the incident intensity. Combined surface and interior scatter losses of less than $10^{-4}$ are reported [113].

\section{Optical properties}

\subsection{Non-linear refractive index}

A propagating laser beam can develop phase aberrations induced by changes in the glass refractive index at operating intensities greater than about $1 \mathrm{GW} / \mathrm{cm}^{2}$. This effect degrades the beam focal spot, reduces the energy extraction efficiency of the laser and increases the risk of laser-induced damage [114-116].

The change in refractive index with laser intensity is given by $[117,118]$

$n=n_{0}+\gamma I$,

where $\gamma$ is the non-linear refractive index coefficient $\left(\mathrm{m}^{2} / \mathrm{W}\right)$ and $I$ is the laser intensity $\left(\mathrm{W} / \mathrm{m}^{2}\right)$. Most commercial phosphate laser glasses have a non-linear index coefficient $\leqslant 3.5 \times 10^{-20} \mathrm{~m}^{2} / \mathrm{W}$. The intensity-dependent index causes amplitude ripples (noise), that occur at certain spatial 
frequencies, to grow as $\exp (B)[116,119]$. Here ' $B$ ' is the cumulative non-linear phase retardation integrated over the optical path length $(z)$

$B=\frac{2 \pi}{\lambda} \int \gamma I \mathrm{~d} z$

Past experience has shown that for $B$ greater than about 2 radians, unacceptable noise ripple growth can cause optical damage and also degrade the beam focus on large aperture laser systems $[114,115]$.

Direct measurement of $\gamma$ is difficult, so empirical correlations have been developed. The expression developed by Boling et al. [120] a number of years ago predicts $\gamma$ from the refractive index $\left(n_{d}\right)$ and the Abbe number ( $v$ ) of the glass

$$
\begin{aligned}
\gamma= & K\left(n_{d}-1\right)\left(n_{d}^{2}+2\right)^{2} /\left\{n _ { d } v \left[1.52+\left(n_{d}^{2}+2\right)\right.\right. \\
& \left.\left.\times\left(n_{d}+1\right) v / 6 n_{d}\right]^{1 / 2}\right\},
\end{aligned}
$$

where $K=2.8 \times 10^{-10} \mathrm{~m}^{2} / \mathrm{W}$ is an empirically determined constant. The non-linear refractive index, $n_{2}$ (in esu) is related to $\gamma$ by $n_{2}=\gamma(n c / 40 \pi)$, where $c$ is light speed.

Fig. 10 shows the effect of a systematic change in modifiers from $\mathrm{Be}$ to $\mathrm{Ba}$ on $n_{2}$ for the meta-phosphate glass series $55 \mathrm{P}_{2} \mathrm{O}_{5}-40 \mathrm{RO}$ $4.7 \mathrm{La}_{2} \mathrm{O}_{3}-0.3 \mathrm{Nd}_{2} \mathrm{O}_{3}$ as reported by $\mathrm{Gan}$ [28]. The data are correlated with the radius of the cation modifier. Also shown, for comparison, are the $n_{2}$ s reported by Hayden et al. [39]. The results show the same trend as the work by Gan in that $n_{2}$ decreases, going from $\mathrm{Ba}$ to $\mathrm{Mg}$. Based on these results, phosphate laser glasses with the smallest $n_{2}$ are those in which $\mathrm{K}$ and $\mathrm{Mg}$ are used as modifiers (assuming that the toxicity of Be makes it impractical). The laser glass, LG770 , has the smallest reported $n_{2}$ (and $n_{d}$ ) of any commercial phosphate laser glass; as discussed in Section 2, the modifiers used in LG-770 are $\mathrm{Mg}$ and $K[7]$.

\subsection{Thermal-optical properties}

Laser glass must have optical homogeneity $(\Delta n)$ of $< \pm 2 \times 10^{-6}$ to achieve the beam quality necessary to propagate and focus the output laser
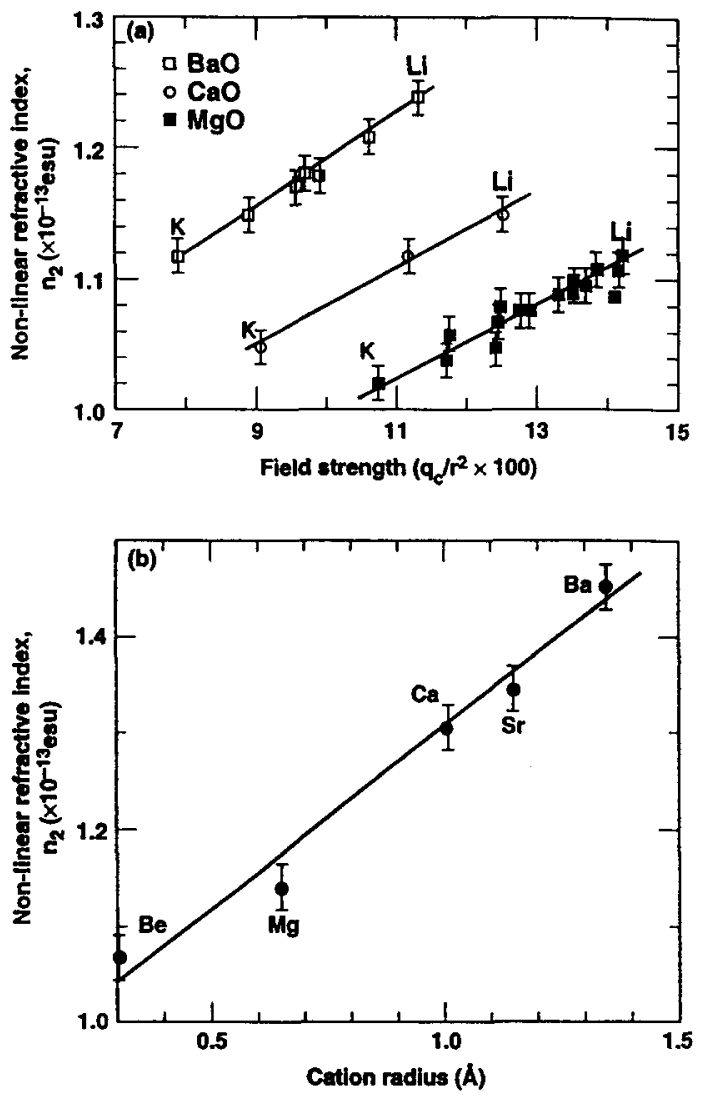

Fig. 10. Effect of systematic changes in combinations of group I and II modifiers on the non-linear index of phosphate laser glasses based on data from (a) Ref. [39] and (b) Ref. [28].

beam [7]. Thermal variations in the laser glass, caused by residual heat from the optical pumping process, can produce optical distortion by changing the optical path length. Therefore it is desirable to have a glass for which the temperature coefficient of the optical path length is zero (athermal glass). The change in the optical path length, $\Delta O_{\mathrm{L}}$ (m), resulting from a temperature variation, $\Delta T$ (K), is given by [121]

$\Delta O_{\mathrm{L}}=\delta L \Delta T$.

where $L$ is the total path length (m) and $\delta$ is the temperature coefficient of the optical path length

$\delta=\mathrm{d} n / \mathrm{d} T+(n-1) \alpha_{\mathrm{e}}$.

The temperature change in refractive index $(\mathrm{d} n l$ $\mathrm{d} T$ ) is defined by $\mathrm{d} n / \mathrm{d} T=$

where $\phi$ of electr volumetr For an i: where $\alpha_{c}$ pansion. plying, $f$ where $n$ thumb, a $\mathrm{d} n / \mathrm{d} T$ at expansio:

Torat: report a phate an. on an ar temperat ability, $\phi$

$\phi=\sum$

where $\phi_{i}$ compone tion. Tat in silicat These da a numbe: in good

Table 2).

Table 2

Additivity $[32,122]$ an

\begin{tabular}{l} 
Compone \\
\hline $\mathrm{SiO}_{2}$ \\
$\mathrm{PO}_{0.5}$ \\
$\mathrm{BO}_{1.5}$ \\
$\mathrm{AlO}_{1.5}$ \\
$\mathrm{LiO}_{0.5}$ \\
$\mathrm{NaO}_{0.5}$ \\
$\mathrm{KO}_{0.5}$ \\
$\mathrm{MgO}$ \\
$\mathrm{CaO}$ \\
$\mathrm{BaO}$ \\
$\mathrm{PbO}$ \\
$\mathrm{TiO}$ \\
$\mathrm{ZnO}$ \\
\hline
\end{tabular}


$\mathrm{d} n / \mathrm{d} T=\left[\left(n^{2}-1\right)\left(n^{2}+2\right) / 6 n\right](\phi-\beta)$,

where $\phi$ is the temperature-dependent coefficient of electronic polarizability $\left(K^{-1}\right)$ and $\beta$ is the volumetric thermal expansion coefficient $\left(K^{-1}\right)$. For an isotropic material, such as glass, $\beta=3 \alpha_{e}$, where $\alpha_{c}$ is the linear coefficient of thermal expansion. An ideal athermal glass has $\delta=0$ implying, from Eq. (24) that $\mathrm{d} n / \mathrm{d} T=(n-1) \alpha_{\mathrm{e}}$, where $n$ is usually $\sim 1.5$. Therefore, as a rule-ofthumb, a good athermal laser glass must have a $\mathrm{d} n / \mathrm{d} T$ about half the coefficient of linear thermal expansion.

Toratani [32] and Izumitani and Toratani [122] report a method for calculating $\mathrm{d} n / \mathrm{d} T$ for phosphate and silicate laser glasses, respectively, based on an additivity relationship for estimating the temperature coefficient of the electronic polarizability, $\phi$ :

$\phi=\sum \phi_{i} X_{i}$

where $\phi_{i}$ is the additive contribution from glass component $i$ and $X_{i}$ is the component mole fraction. Table 2 lists $\phi_{i}$ s for various common oxides in silicate [122] and phosphate [32] laser glasses. These data have been used to estimate $\mathrm{d} n / \mathrm{d} T$ for a number of laser glasses [94] and in general, are in good agreement with measured data (see Table 2).

\section{Thermal-mechanical properties}

The figure-of-merit parameter commonly used to characterize the thermal-mechanical performance of laser glass is the well-known thermal shock resistance, $R_{\mathrm{s}}$ [93]:

$R_{\mathrm{s}}=k(1-\mu) K_{\mathrm{IC}} /\left(E \alpha_{\mathrm{e}}\right)$,

where $E$ is Young's modulus, $k$ the thermal conductivity, $K_{\mathrm{IC}}$ the fracture toughness, $\mu$ Poisson's ratio and $\alpha_{e}$ is the coefficient of linear thermal expansion. $R_{\mathrm{S}}$ has units of $\mathrm{W} / \mathrm{m}^{1 / 2}$ and the larger $R_{\mathrm{s}}$ the greater the thermal loading without failure. Laser glasses can be subjected to thermal loads during handling and processing [123] as well as during operation $[7,124]$.

There have been relatively few reported systematic studies of composition effects on thermalmechanical properties of phosphate laser glasses. Hayden et al. [39] report the affects of varying alkali and alkaline earth modifiers in a meta-phosphate laser glass in which the $\mathrm{Al}_{2} \mathrm{O}_{3}$ and $\mathrm{P}_{2} \mathrm{O}_{5}$ contents are held constant. In an extension of this work, Elder et al. [123] systematically varied the network former; particularly the $\mathrm{Al}_{2} \mathrm{O}_{3} / \mathrm{P}_{2} \mathrm{O}_{5}$ ratio and the $\mathrm{O} / \mathrm{P}$ ratio and also examined the effects of replacing $\mathrm{P}_{2} \mathrm{O}_{5}$ and $\mathrm{Al}_{2} \mathrm{O}_{3}$ with either $\mathrm{SiO}_{2}$ or $\mathrm{B}_{2} \mathrm{O}_{3}$. In a study of glasses for repetition-rate lasers, Marion [124] analyzed data from Stokowski $[20]$ in terms of a figure-of-merit similar to that

Table 2

Additivity factors, $\phi_{i}\left(10^{-6} / \mathrm{K}\right)$, for estimating the temperature coefficient of electronic polarizability from the glass composition $[32,122]$ and comparison of predicted vs. measured $\mathrm{d} n / \mathrm{d} T$ reported for several phosphate laser glasses using these values [94]

esirable

: coeffi-

hermal

th, $\Delta O_{\mathrm{L}}$

ion, $\Delta T$

$\delta$ is the . length

\begin{tabular}{|c|c|c|c|c|c|}
\hline \multirow[b]{2}{*}{ Component } & \multicolumn{2}{|c|}{$\phi_{i}\left(10^{-6} / \mathrm{K}\right)$} & \multicolumn{3}{|c|}{$\mathrm{d} n / \mathrm{d} T\left(10^{-6} / \mathrm{K}\right)$} \\
\hline & Silicates & Phosphates & Glass & Predicted & Measured \\
\hline $\mathrm{SiO}_{2}$ & 17.4 & 20 (est.) & LHG-8 & -4.8 & -5.3 \\
\hline $\mathrm{PO}_{0.5}$ & - & 20 & LHG-80 & -3.6 & -3.8 \\
\hline $\mathrm{BO}_{1.5}$ & 13.8 & 16 & LG-750 & -6.0 & -6.8 \\
\hline $\mathrm{AlO}_{1.5}$ & 22.2 & 26 & LG-760 & -4.9 & -5.1 \\
\hline $\mathrm{LiO}_{0.5}$ & - & 36 (est.) & HAP-3 & 1.0 & 1.9 \\
\hline $\mathrm{NaO}_{0.5}$ & 50.0 & 44 & APG-1 & 1.3 & 1.2 \\
\hline $\mathbf{K O}_{0.5}$ & 43.9 & 45 & & & \\
\hline $\mathrm{MgO}$ & - & 45 (est.) & & & \\
\hline $\mathrm{CaO}$ & 42.0 & 42 (est.) & & & \\
\hline $\mathrm{BaO}$ & 36.1 & 35 & & & \\
\hline $\mathrm{PbO}$ & 50.2 & 47 & & & \\
\hline $\mathrm{TiO}_{2}$ & 19.3 & 15 & & & \\
\hline $\mathrm{ZnO}$ & 39.4 & - & & & \\
\hline
\end{tabular}


given in Eq. (27). Jiang et al. [96] investigated the effects of groups I and II modifiers $(\mathrm{K}, \mathrm{Na}, \mathrm{Li}, \mathrm{Ba}$, $\mathrm{Sr}$ and $\mathrm{Ca}$ ) on the thermal expansion coefficients of different phosphate laser glasses and report a correlation with cation electric field strength. Their data also show that glasses containing larger field strength cations (e.g., Li) have smaller thermal expansion coefficients. The above studies $[39,96,123]$ all show that using modifiers with greater field strengths (particularly Li) increases Young's modulus and thermal conductivity and decreases the thermal expansion (e.g., see Fig. 11).

Improvements in thermal-mechanical properties tend to follow composition trends opposite to that for improved laser properties (see Sections 3 and 4). In general, optimizing the laser properties

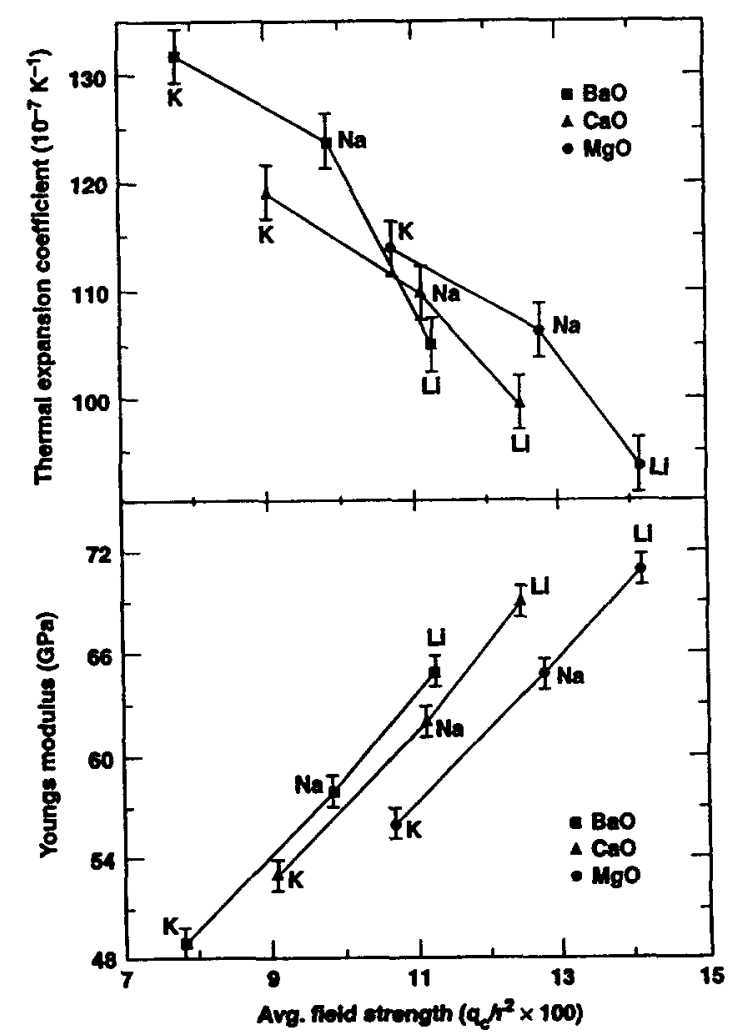

Fig. 11. Variation of linear thermal expansion coefficient and Young's modulus with the compositionally averaged field strength for phosphate laser glasses containing combinations of groups $\mathrm{I}$ and II modifiers ( $\mathrm{Li}, \mathrm{Na}, \mathrm{K}, \mathrm{Mg}, \mathrm{Ca}$ and $\mathrm{Ba}$ ). Plot generated from data by Hayden et al. [39]; the lines connect the data points and are added to distinguished data sets. takes precedence over improving the mechanical properties so low field strength cations (e.g., K) are usually the dominant modifiers in a glass. The one exception is laser glass used in repetitively pulsed lasers (so-called HAP lasers). Here the need for good thermal shock resistance is critical therefore these glasses tend to contain larger field strength ions such as $\mathrm{Li}[32,33]$.

\section{Fracture toughness and sub-critical crack growth}

The size of the laser glass plates used in multikilojoule energy applications increases the threat of fracture due to increased thermal or mechanical-induced stress during handling and processing [7]. In addition, it is our experience- that surface flaws ( $\leqslant 1 \mathrm{~mm}$ ) may develop during operation due to laser or flashlamp-induced damage.

The fracture strength of phosphate laser glasses is less than that for silicate counterparts as indicated by fracture toughness measurements given in Table 3. In general, the fracture toughness for phosphate laser glasses is about one-half to twothirds those for silicates.

Table 3

Fracture toughness values reported for common commercial phosphate and silicate laser glasses $[94,125]$

\begin{tabular}{lll}
\hline $\begin{array}{l}\text { Glass (by vendor } \\
\text { code name) }\end{array}$ & Vendor & $\begin{array}{l}\text { Fracture tough- } \\
\text { ness }^{\mathrm{b}}\left(\mathrm{MPa} \mathrm{m} \mathrm{m}^{1 / 2}\right)\end{array}$ \\
\hline $\begin{array}{l}\text { Phosphates } \\
\text { LHG-8 }\end{array}$ & Hoya & $0.51 \pm 0.02^{\mathrm{a}}$ \\
LG-770 & Schott & $0.43^{\mathrm{a}}$ \\
LG-750 & Schott & $0.45^{\mathrm{c}}$ \\
APG-1 & Schott & $0.61^{\mathrm{a}}$ \\
APG-2 & Schott & $0.64 \pm 0.03^{\mathrm{a}}$ \\
IOG-1 & Schott & $0.54^{\mathrm{a}}$ \\
LHG-80 & Hoya & $0.46^{\mathrm{a}}$ \\
LHG-5 & Hoya & $0.42^{\mathrm{c}}$ \\
Silicates & & \\
LG-680 & Schott & $0.86^{\mathrm{a}}$ \\
IOG-10 & Schott & $0.71^{\mathrm{a}}$ \\
LG-670 & Schott & $0.83^{\mathrm{c}}$ \\
LSG91H & Hoya & $0.88^{\mathrm{c}}$ \\
\hline
\end{tabular}

Measured by the authors using chevron notch method [126].

${ }^{b}$ Error is \pm 0.01 unless otherwise noted.

'Data from [125]; measured by indentation technique.

${ }^{d}$ Formerly ED-2 by Owens-Illinois.
Elc

varies

glasse

show

great

Slc

repor

Surat

phate

Both

of $t$

press

et al

drox:

analy

[129]

kinet

port

porte

predi

[127,

blun

from

mod:

\section{9. $\mathrm{L}$ :}

for $i$

pros

próa

abol

duce

of $d$

ther

proc

met:

mel

incl.

dan

app

met

cen i

tha

For

(79

the 
sochanical g., K) are is. The one rely pulsed need for therefore Id strength

ck growth

$x$ in multi-

the threat mechani- processing hat surface ration due

aser glasses

ts as indits given in ughness for alf to two-

1 commercial

ure tough-

(Pa m ${ }^{1 / 2}$ )

$0.02^{*}$

$=0.03^{a}$

method [126]. nnique.
Elder et al. [47] reported that fracture toughness varies with $\mathrm{O} / \mathrm{P}$ ratio for a series of phosphate glasses containing $\mathrm{Al}, \mathrm{K}$ and $\mathrm{Ba}$. Their results show that the ultra-phosphates $(\mathrm{O} / \mathrm{P}<3)$ have greater fracture toughness.

Slow crack growth measurements have been reported recently by Crichton et al. [127] and Suratwala et al. [128] on the commercial phosphate glasses, LG-770 and LHG-8, respectively. Both studies have been carried out as a function of temperature $\left(23-300^{\circ} \mathrm{C}\right)$ and water vapor pressure $(0.3-355 \mathrm{~mm} \mathrm{Hg})$. In addition, Suratwala et al. [128] examined the effect of residual hydroxyl content in the laser glass. The results are analyzed using Wiederhorn's reaction rate model [129] for slow crack growth in region I (reaction kinetic limited region) and region II (mass transport limited region). Model parameters are reported for these two glasses that can be used to predict slow crack growth at different stress levels $[127,128]$. Both studies report regions of crack tip blunting where the crack growth rates depart from predictions made using the reaction rate model.

\section{Laser-induced damage}

The mega-joule lasers now under construction for inertial confinement fusion (ICF) research will produce peak fluences in the laser glass approaching $18-20 \mathrm{~J} / \mathrm{cm}^{2}$ with a peak irradiance of about $5.0 \mathrm{GW} / \mathrm{cm}^{2}[130,131]$. To avoid laser-induced optical damage the laser glass must be free of defects, specifically microscopic inclusions (either metallic or ceramic) left from the melting process. The most common inclusion source is metallic Pt inclusions from the Pt liners used in the melting system [7,132]. Prior to about 1990, Pt inclusion damage represented the major source of damage in laser glass used for high-peak-power applications [132,133]. However new processing methods effectively reduce the Pt inclusion concentration in phosphate laser glasses by more that 1000-fold to less than 0.1/litre [134-136]. For example, $50 \%$ of the large laser slabs $\left(79 \times 45 \times 4 \mathrm{~cm}^{3} ; 14\right.$ litre of glass each) used on the Beamlet laser at LLNL [130] are reported to have had no inclusions at all and the average for all the slabs produced is $<0.1 /$ itre [31]. Similar results have been reported for the several hundred replacement glass disks manufactured for the Nova and Phebus lasers $[132,137]$; each of those disks contained 7 litre of glass.

Inclusions in the laser glass damage at about between 2 and $5 \mathrm{~J} / \mathrm{cm}^{2}$ at the $1-10$ pulse lengths typical of most HPP applications [132,138]. Although very small to begin with, inclusion damage can grow with successive laser shots to several millimeters or even centimeters in size eventually making the laser glass unusable [138]. Also large damage spots $(>300 \mu \mathrm{m})$ in the laser glass can seed damage in other optics in the laser chain [114].

The new processing techniques used for eliminating $\mathbf{P t}$ inclusions in phosphate glasses $[132,134,135]$ rely on the intrinsic property of many phosphate glasses to dissolve Pt metal under oxidizing conditions. The effects of glass composition on platinum solubility have been reported to follow the trend: phosphate $>$ silico-phosphate $\gg$ fluorophosphate $>$ silicate [139]. In a similar study Hayden et al. [140] have examined the effects of the $\mathrm{Al}_{2} \mathrm{O}_{3}$ concentration in phosphate glasses on $\mathrm{Pt}$ solubility. They chose three commercial phosphate laser glasses (LG-770, LG-760 and APG-1) each having different $\mathrm{Al}_{2} \mathrm{O}_{3}$ content. These researchers report that the larger the $\mathrm{Al}_{2} \mathrm{O}_{3}$ content the smaller the $\mathrm{Pt}$ solubility. The effects of $\mathrm{Al}_{2} \mathrm{O}_{3}$ content on $\mathrm{Pt}$ solubility tend to parallel those reported by Izumitani et al. for $\mathrm{SiO}_{2}$ content in phosphate glasses [139].

If inclusions inside the glass are eliminated then the damage threshold is limited only by the surface finish. The pulse length dependence of the surface damage threshold for polished glass samples (Fig. 12) can be represented by the empirical expression [131]

$D_{\mathrm{S}}\left(\mathrm{J} / \mathrm{cm}^{2}\right)=22 t_{\mathrm{P}}^{0.4}$,

where $t_{\mathrm{P}}$ is the laser pulse length (ns). The surface damage threshold approximately follows the $t^{1 / 2}$ relationship predicted by a thermal diffusion heat transport model [66,132]. For comparison, the damage threshold reported by Gonzales and 


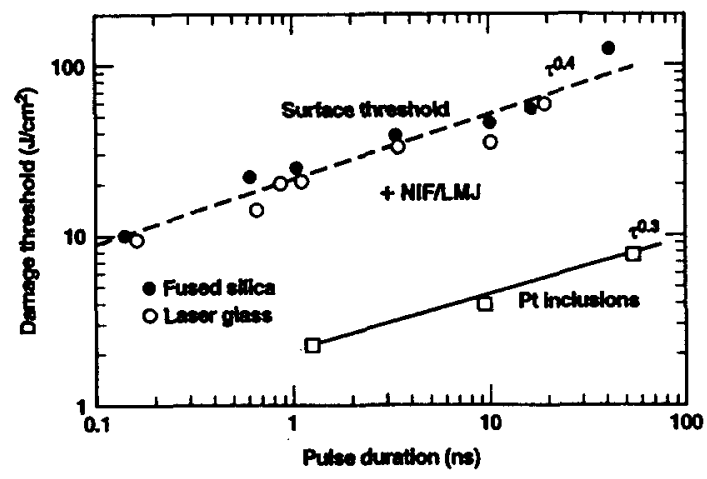

Fig. 12. Measured damage threshold at $1053 \mathrm{~nm}$ for $\mathrm{Pt}$ inclusions in laser glass as a function of laser pulse length; data are from [138]. Also shown, for comparison, are the measured damage thresholds at $1053 \mathrm{~nm}$ for highly polished laser glass and fused silica surfaces [131] and the design peak operating fluence of the NIF and LMJ mega-joule lasers currently under construction $[1,130]$.

Milam [138] for Pt inclusions (Fig. 12) follows the approximate pulse length scaling relationship

$D_{\mathrm{Pt}}\left(\mathrm{J} / \mathrm{cm}^{2}\right)=2 t_{\mathrm{P}}^{0.3}$

Thus the presence of $\mathrm{Pt}$ inclusions reduces the operating limit of a laser glass by about 10 -fold.

Jiang et al. [141] have investigated the redox equilibrium $\left[\mathrm{Pt}^{4+} \leftrightarrows \mathrm{Pt}^{2+} \leftrightarrows \mathrm{Pt}^{0}\right]$ in a $\mathrm{R}_{2} \mathrm{O}-\mathrm{BaO}-$ $\mathrm{P}_{2} \mathrm{O}_{5}$ glass as a function of oxidizing environment and temperature. They assign absorption bands near $290,360 \mathrm{~nm}$ and $320,390 \mathrm{~nm}$ to $\mathrm{Pt}^{2+}$ and $\mathrm{Pt}^{4+}$, respectively. By monitoring the relative peak amplitudes for these bands they report the ratio of $\mathrm{Pt}^{4+} / \mathrm{Pt}^{2+}$ as a function of increasing oxygen partial pressure; $\left[\mathrm{Pt}^{4+} / \mathrm{Pt}^{2+}\right] \beta=P_{\mathrm{O}_{2}}$ where $\beta$ is about 0.75 . They relate this same ratio to the observed Ptinclusion density.

The tail of the ionic Pt absorption bands in the near UV extends into the visible, giving detectable absorption up to about $400 \mathrm{~nm}$. This absorption can affect the energy storage of the laser glass because the absorption blocks some of the flashlamp radiation and reduces the pumping efficiency. The $400 \mathrm{~nm}$ absorption coefficient due to ionic Pt is generally specified not to exceed 0.25 $\mathrm{cm}^{-1}$ [31]; this coefficient corresponds to a $\mathrm{Pt}$ ion concentration of less than about $150 \mathrm{ppm}$ [132]. For rods or slabs doped with $\mathrm{Nd}^{3+}>1 \times 10^{20}$ $\mathrm{cm}^{-3}$ the effect of the ionic Pt absorption is negligible as long as the absorption at $400 \mathrm{~nm}$ does not exceed about $0.25 \mathrm{~cm}^{-1}$. Kelly et al. [142], however, have analyzed the effect of ionic Pt absorption on the flashlamp pumping of rods with smaller Nd-dopings. They estimate that an ionic $\mathrm{Pt}$ absorption at or near $0.25 \mathrm{~cm}^{-1}$ can reduce the pumping efficiency by up to $15 \%$ for $9.9 \mathrm{~cm}$ diameter laser glass rods doped with about $5 \times 10^{19}$ $\mathrm{Nd}$ ions $/ \mathrm{cm}^{3}$.

\section{Summary and directions for future work}

We conclude this review with a summary (Table 4) of the properties and compositions of the Nd-doped phosphate laser glasses in use on major multi-kilojoule lasers in the US, Europe and Japan $[8,94]$. Glasses having optimal laser performance and acceptable thermal-physical properties are meta-phosphates having the approximate base composition: $60 \mathrm{P}_{2} \mathrm{O}_{5}-10 \mathrm{Al}_{2} \mathrm{O}_{3}-30 \mathrm{~K}_{2} \mathrm{O} / \mathrm{MO}$, where $\mathrm{MO}$ is either $\mathrm{BaO}$ or $\mathrm{MgO} . \mathrm{Nd}_{2} \mathrm{O}_{3}$ is generally added at doping levels of $<2 \mathrm{~mol} \%$ (i.e., $\lesssim 5 \times 10^{20} \mathrm{Nd}^{3+} / \mathrm{cm}^{3}$ ). Small variations in composition and modifiers about this base glass composition have only minor effects $( \pm 10 \%)$ on most glass properties (see Table 4).

Non-radiative energy losses from the ${ }^{4} \mathrm{~F}_{3 / 2}$ upper laser level are reasonably well understood. The one exception is $\mathrm{OH}$ quenching. Although an empirical relationship can be used to accurately estimate $( \pm 10 \%)$ the quenching effect, a theoretical formulation describing the unusual $\mathrm{OH}$ quenching affects at smaller Nd-doping is lacking and is worthy of further study. In addition, the mechanism and kinetics of dehydroxylation of phosphate glasses have received little attention despite the adverse effects of ppm levels of $\mathrm{OH}$ on many glass properties.

The development of processing technology for making inclusion-free phosphate glass has enabled lasers to be built and operated at fluences 5-10 times greater than was possible 10 years ago. However a detailed understanding of the mechanism of $\mathrm{Pt}$ dissolution in glasses bubbled with $\mathrm{O}_{2}$
Table 4

Properties lasers [8]

Sources

\begin{tabular}{r}
\hline Glass de \\
\hline Optical \\
Refracti \\
$@ 587$ \\
$@ 10 \leq$ \\
Non-line \\
$\left(10^{-13}\right.$ \\
$\left(10^{-20}\right.$ \\
Abbe nu \\
Temp-cr \\
Temp-cc \\
Laser \\
Emissior \\
Saturatic \\
Radiativ \\
Judd-Of \\
Judd-Ot \\
( $\pm 5 \%)$
\end{tabular}

Emissior

Conc. q1

$( \pm 0.3)$

Fluoresc

Thermal

Thermal

Thermal

Specific

Coeff. tt

Glass tr:

Mechani

Density

Poisson'

Fracture

Hardnes

Young's

"LHG-8:

10) $\mathrm{MgO}-$

${ }^{b}$ Values vi

' $Q$ definec

d $20-300^{\circ} \mathrm{C}$

or $\mathrm{Cl}_{2}$ i composi process 
a [132].

$\times 10^{20}$

s neg-

$m$ does

[142],

Pt abds with un ionic ice the $\mathrm{cm}$ di$5 \times 10^{19}$

ummary as of the I major .J Japan ormance ies are e base J, where senerally 'o (i.e., in comass comin most

${ }^{\prime} F_{3 / 2}$ upod. The ugh an ocurately eoretical enching 3 and is e mechaIosphate pite the any glass

logy for $s$ enabled ices 5-10 ars ago. - mecha1 with $\mathrm{O}_{2}$

Table 4

Properties and compositions (when reported) of Nd-doped phosphate laser glasses in common use on high-energy/high-peak-power lasers [8]

\begin{tabular}{|c|c|c|c|c|c|c|}
\hline \multirow[t]{3}{*}{ Sources } & & \multicolumn{5}{|c|}{ Glass manufacturer } \\
\hline & & \multicolumn{2}{|l|}{ Hoya } & \multicolumn{2}{|l|}{ Schott } & \multirow{2}{*}{$\frac{\text { Kigre }}{[23,145]}$} \\
\hline & & {$[23,143]$} & {$[7,23,143]$} & [7] & {$[23,144]$} & \\
\hline Glass designation" & Symbol & LHG-80 & LHG-8 & LG-770 & LG-750 & Q88 \\
\hline \multicolumn{7}{|l|}{ Optical } \\
\hline \multicolumn{7}{|l|}{ Refractive index } \\
\hline @ $587.3 \mathrm{~nm}( \pm 0.00002)^{\mathrm{b}}$ & $n_{d}$ & 1.5429 & 1.5296 & 1.5067 & 1.5257 & 1.5449 \\
\hline @ $1053 \mathrm{~nm}( \pm 0.00015)^{\mathrm{b}}$ & $n_{1}$ & 1.5329 & 1.5201 & 1.4991 & 1.5160 & 1.5363 \\
\hline \multicolumn{7}{|l|}{ Non-linear refractive index } \\
\hline$\left(10^{-13} \mathrm{esu}\right)$ & $n_{2}$ & 1.24 & 1.12 & 1.01 & 1.08 & 1.14 \\
\hline$\left(10^{-20} \mathrm{~m}^{2} / \mathrm{W}\right)$ & $\gamma$ & 3.36 & 3.08 & 2.78 & 2.98 & 3.11 \\
\hline Abbe number $( \pm 0.05)$ & y & 64.7 & 66.5 & 68.4 & 68.2 & 64.8 \\
\hline Temp-coeff. refract. index $\left(10^{-6} / \mathrm{K}\right)( \pm 0.5)$ & $\mathrm{d} n / \mathrm{d} T$ & -3.8 & -5.3 & -4.7 & -5.1 & -0.5 \\
\hline Temp-coeff. optical path $\left(10^{-6} / \mathrm{K}\right)( \pm 0.2)$ & $\delta$ & 1.8 & 0.6 & 1.2 & 0.8 & 2.7 \\
\hline \multicolumn{7}{|l|}{ Laser } \\
\hline Emission cross-section $\left(10^{-20} \mathrm{~cm}^{2}\right)( \pm 0.2)$ & $\sigma_{\mathrm{em}}$ & 4.2 & 3.6 & 3.9 & 3.7 & 4.0 \\
\hline Saturation fluence $\left(\mathrm{J} / \mathrm{cm}^{2}\right)($ calc.) & $F_{\text {sat }}$ & 4.5 & 5.2 & 4.8 & 5.1 & 4.7 \\
\hline Radiative lifetime (zero-Nd) $(\mu s)( \pm 3)$ & $\tau_{0}$ & 337 & 365 & 372 & 383 & 326 \\
\hline Judd-Ofelt radiative lifetime $(\mu s)( \pm 10 \%)$ & $\tau_{\mathrm{r}}$ & 327 & 351 & 349 & 367 & 326 \\
\hline \multirow{3}{*}{$\begin{array}{l}\text { Judd-Ofelt parameters }\left(10^{-20} \mathrm{~cm}^{2}\right) \\
( \pm 5 \%)\end{array}$} & $\Omega_{2}$ & 3.6 & 4.4 & 4.3 & 4.6 & 3.3 \\
\hline & $\Omega_{4}$ & 5.0 & 5.1 & 5.0 & 4.8 & 5.1 \\
\hline & $\Omega_{6}$ & 5.5 & 5.6 & 5.6 & 5.6 & 5.6 \\
\hline Emission band width $(\mathrm{nm})( \pm 0.1)$ & $\Delta \lambda_{\text {eff }}$ & 23.9 & 26.5 & 25.4 & 25.3 & 21.9 \\
\hline $\begin{array}{l}\text { Conc. quenching factor }\left(\times 10^{20} \mathrm{~cm}^{-3}\right) \\
( \pm 0.3)\end{array}$ & $Q$ & 10.1 & 8.4 & 8.8 & 7.4 & 6.6 \\
\hline Fluorescence peak $(\mathrm{nm})( \pm 0.3)$ & $\lambda_{\mathrm{L}}$ & 1054 & 1053 & 1053 & 1053.5 & 1054 \\
\hline \multicolumn{7}{|l|}{ Thermal } \\
\hline Thermal conduct. $(\mathrm{W} / \mathrm{m} \mathrm{K})( \pm 0.03)$ & $k$ & 0.59 & 0.58 & 0.57 & 0.60 & 0.84 \\
\hline Thermal diffusivity $\left(10^{-7} \mathrm{~m}^{2} / \mathrm{s}\right)$ & $\alpha$ & 3.2 & 2.7 & 2.9 & 2.9 & - \\
\hline Specific heat $(J / g ~ K)( \pm 0.02)$ & $C_{\mathrm{p}}$ & 0.63 & 0.75 & 0.77 & 0.72 & 0.81 \\
\hline Coeff. thermal expan. $\left(10^{-7} / K\right)( \pm 3)$ & $\alpha_{e}$ & 130 & 127 & 134 & 132 & 104 \\
\hline Glass transition temp $\left({ }^{\circ} \mathrm{C}\right)( \pm 5)$ & $T_{\mathrm{g}}$ & 402 & 485 & 461 & 450 & 367 \\
\hline \multicolumn{7}{|l|}{ Mechanical } \\
\hline Density $\left(\mathrm{g} / \mathrm{cm}^{3}\right)( \pm 0.01)$ & $\rho$ & 2.92 & 2.83 & 2.59 & 2.83 & 2.71 \\
\hline Poisson's ratio $( \pm 0.01)$ & $\mu$ & 0.27 & 0.26 & 0.25 & 0.26 & 0.24 \\
\hline Fracture toughness $\left(\mathrm{Mpa} \mathrm{m}^{0.5}\right)( \pm 0.02)$ & $\mathbf{K}_{\mathbf{I C}}$ & 0.46 & 0.51 & 0.43 & 0.45 & - \\
\hline Hardness $(\mathrm{GPa})( \pm 0.10)$ & $H$ & 3.35 & 3.43 & 3.58 & 2.85 & - \\
\hline Young's modulus $(\mathrm{GPa})( \pm 1.0)$ & $E$ & 50 & 50 & 47 & 50 & 70 \\
\hline
\end{tabular}

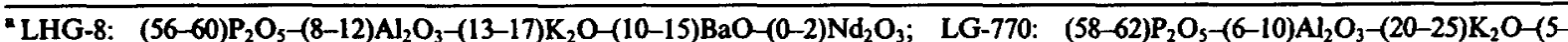
10) $\mathrm{MgO}-(0-2) \mathrm{Nd}_{2} \mathrm{O}_{3}$; LG-750: (55-60) $\mathrm{P}_{2} \mathrm{O}_{5}-(8-12) \mathrm{Al}_{2} \mathrm{O}_{3}-(13-17) \mathrm{K}_{2} \mathrm{O}-(10-15) \mathrm{BaO}-(0-2) \mathrm{Nd}_{2} \mathrm{O}_{3}$.

Values vary slightly with Nd-doping levels.

${ }^{c} Q$ defined by Eq. (14).

${ }^{d} 20-300^{\circ} \mathrm{C}$

or $\mathrm{Cl}_{2}$ is lacking. In addition, the effects of glass composition and structure on the dissolution process are poorly understood. For example, the reasons why $\mathrm{SiO}_{2}$ and $\mathrm{Al}_{2} \mathrm{O}_{3}$ additions to metaphosphate glasses retard $\mathrm{Pt}$ inclusion dissolution is not well understood. 
Finally, glass compositions have been developed with good laser performance properties but a corresponding quantitative understanding (i.e., able to be reduced to calculation) of the relationship between glass structure and performance is lacking and remains a continuing challenge.

\section{Acknowledgements}

The authors gratefully acknowledge the many helpful discussions with co-workers, Dr J. Hayden and Dr A. Marker at Schott Glass Technologies, Inc. and $\mathrm{Dr} \mathrm{H}$. Toratani and $\mathrm{Mr} \mathrm{K}$. Takeuchi at Hoya Corporation. The assistance by Ms G. Martinez in the literature search for this review and by Ms A. Clasen in the preparation of the manuscript is also deeply appreciated. Work was performed under the auspices of the US Department of Energy by Lawrence Livermore National Laboratory under Contract No. W7405-Eng-48.

\section{References}

[1] J.R. Murray, A walk through the National Ignition Facility, ICF Quarterly Report, Lawrence Livermore National Laboratory Report UCRL-LR-105821-97, 7, 1997 , p. 95.

[2] M. Andre, M. Novaro, D. Schirmann, Chocs. Rev. Sci. Techn. Direct. Appli. Milit. 13 (1995) 73.

[3] S. Nakai, Optoelectron. Devices Technol. 8 (1993) 147.

[4] G. Theill, H. Graillot, P. Joly, A. Boscheron, L. Videau, A. Adolf, Fusion Eng. Des. 44 (1999) 157.

[5] T.R. Boehly, D.L. Brown, R.S. Craxton, R.L. Keck, J.P. Knauer, J.H. Kelly, T.J. Kessler, S.A. Kumpan, S.J. Loucks, S.A. Letzring, F.J. Marshall, R.L. McCrory, S.F.B. Morse, W. Seka, J.M. Soures, C.P. Verdon, Opt. Commun. 133 (1997) 495.

[6] J. Lindl, Phys. Plasmas 2 (1995) 3933.

[7] J. Campbell, T. Suratwala, C. Thorsness, J. Hayden, A. Thorne, A. Marker, K. Takeuchi, M. Smolley, G. FiciniDorn, these Proceedings, p. 342.

[8] J.H. Campbell, 25 years of laser glass development leading to a $1.8 \mathrm{MJ}, 500 \mathrm{TW}$ laser for fusion ignition, Lawrence Livermore National Laboratory Report, UCRLJC-129507, 1998, p. 1.

[9] H. Ebendorff-Heidepriem, D. Ehrt, M. Bettinelli, A. Speghini, J. Non-Cryst. Solids 240 (1998) 66.
[10] H. Ebendorff-Heidepriem, D. Ehrt, Glastech. Ber. Glass Sci. Technol. 71 (1998) 289.

[11] H. Ebendorff-Heidepriem, W. Seeber, D. Ehrt, Glastech. Ber. Glass Sci. Technol. 66 (1993) 235.

[12] S. Jiang, M. Myers, N. Peyghambarian, J. Non-Cryst. Solids 239 (1998) 143.

[13] S. Jiang, T. Luo, B.C. Hwang, G. Nunzi-Conti, M. Myers, D. Rhonehouse, S. Honkanen, N. Peyghambarian, Opt. Eng. 37 (1998) 3282.

[14] G.K.D. Mohapatra, Phys. Chem. Glasses 40 (1999) 57.

[15] S.T. Davey, B.J. Ainslie, R. Wyatt, in: M.J. Weber (Ed.), CRC Handbook of Laser Science and Technology, CRC, Boca Raton, FL, 1995, p. 635.

[16] M.J. Weber, J. Non-Cryst. Solids 123 (1990) 208.

[17] K. Church, R. Zanoni, D. Sapak, J. Hayden, SPIE 2287 (1994) 97.

[18] P.R. Morkel, K.P. Jedrzejewski, E.R. Taylor, IEEE J. Quantum Electron. 29 (1993) 2178.

[19] N. Neuroth, Opt. Eng. 26 (1987) 96.

[20] S.E. Stokowski, Laser glass: an engineered material, Lawrence Livermore National Laboratory Report UCRL-96331, 1987, p. 1.

[21] R. Reisfeld, M. Eyal, C.K. Jorgensen, J. Less Common Met. 126 (1986) 187.

[22] M.J. Weber, Laser glasses, Lawrence Livermore National Laboratory Report UCRL-UC-109922, 1992.

[23] S.E. Stokowski, R.A. Saroyan, M.J. Weber, Laser glass Nd-doped glass spectroscopic and physical properties, Lawrence Livermore National Laboratory Report M095, Rev. 2, vols. 1\&2, 1981.

[24] N.E. Alekseev, V.P. Gapontsev, M.E. Zhabotinskii, V.B. Kravchenko, Y.P. Rudnitskii, Laser Phosphate Glasses, Nauka, Moscow, 1980 (English Translation, Lawrence Livermore National Laboratory Report UCRL-Trans11817, 1983).

[25] S.E. Stokowski, in: M.J. Weber (Ed.), Handbook of Laser Science and Technology, vol. 1, CRC, Boca Raton, FL, 1982, p. 1.

[26] J.E. Marion, M.J. Weber, Eur. J. Solid-State Inorg. Chem. 28 (1991) 271.

[27] C.F. Rapp, in: M.J. Weber (Ed.), CRC Handbook of Laser Science and Technology, CRC, Boca Raton, FL, 1995, p. 619 (Sect. 17.1).

[28] F. Gan, Chin. Phys. 5 (1985) 145.

[29] E.V. Uhlmann, M.C. Weinberg, N.J. Kreidl, L.L. Burgner, R. Zanoni, K.H. Church, J. Non-Cryst. Solids 178 (1994) 15.

[30] J.L. Emmett, W.F. Krupke, J.B. Trenholme, The future development of high-power solid state laser systems, Lawrence Livermore National Laboratory Report UCRL-53344, 1982.

[31] J.H. Campbell, L.J. Atherton, J.J. DeYoreo, M.R. Kozlowski, R.T. Maney, R.C. Montesanti, L.M. Sheehan, C.E. Barker, Large-aperture, high-damage-threshold optics for beamlet, ICF Quarterly Report, Lawrence Livermore National Laboratory Report UCRLLR105821-95-1, 1994, p. 52.
[32] :

[33]

[34]

[35]

[36]

[37]

[38]

[39]

[40]

[41]

[42]

[43]

[44]

[45]

[46]

[47]

[48]

[49]

[50]

[51]

[52]

[53]

[54]

[56!

[57]

[58. 
er. Glass

lastech.

on-Cryst.

nti, $M$.

snambar-

a99) 57.

: $($ Ed.),

${ }_{5} \mathrm{~J}, \mathrm{CRC}$,

.n.

IE 2287

गr, IEEE

naterial,

Report

'ommon

: National

ser glass operties, eport M-

kii, V.B.

Glasses,

Lawrence

RL-Trans-

of Laser aton, FL,

e Inorg.

Idbook of aton, FL,

Burgner, 178 (1994)

he future r systems, y Report

o, M.R. .M. Shee-threshold Lawrence CRLLR-
[32] H. Toratani, PhD thesis, Kyoto University, Kyoto, Japan, 1989.

[33] T. Izumitani, M. Matsukawa, C. Hata, K. Tanaka, H. Toratani, Laser Induced Damage in Optical Materials, 1986, NIST Publication 752, 1988, p. 13.

[34] H. Takebe, Y. Nageno, K. Morinaga, J. Am. Ceram. Soc. 78 (1995) 1161.

[35] H. Takebe, K. Morinaga, T. Izumitani, J. Non-Cryst. Solids 178 (1994) 58.

[36] Y. Lu, N. Ming, J. Mater. Sci. 30 (1995) 5705.

[37] M. Sen, M. Hanfen, Chin. Phys. 6 (1986) 657.

[38] S. Jiang, Y. Jiang, Glastech. Ber. Glass Sci. Technol. 64 (1991) 291.

[39] J.S. Hayden, Y.T. Hayden, J.H. Campbell, SPIE 1277 (1990) 121.

[40] J.O. Byun, B.H. Kim, K.S. Hong, H.J. Jung, S.W. Lee, K.S. Ryoo, A.A. Izyneev, V.B. Kravchenko, Jpn. J. Appl. Phys. 33 (1994) 4907.

[41] L.M. Cook, A.J. Marker, SPIE 505 (1984) 102.

[42] S.P. Tandon, Y.K. Sharma, N.B. Bishnoi, K. Tandon, Def. Sci. J. 47 (1997) 225.

[43] Z. Jiang, X. Song, J. Zhang, Studies of Laser Phosphate Glasses, Glass Division Meeting, Conference of the Chinese Silicates Society, October 1980 (English translation, Lawrence Livermore National Laboratory Report UCIR-1683, 1987, p. 1).

[44] A.R. Kuznetsov, S.G. Lunter, S.I. Nikitina, A.G. Plyukhin, Y.K. Fedrov, J. Appl. Spectrosc. 56 (1992) 68.

[45] H. Ebendorff-Heidepreim, W. Seeber, D. Ehrt, J. NonCryst. Solids 183 (1995) 191.

[46] A.Z. Dietzel, Z. Electrochem. 48 (1942) 9.

[47] S. Payne, M.L. Elder, J.H. Campbell, G.D. Wilke, M.J. Weber, in: A.J. Bruce, B.V. Hiremath (Eds.), Solid-State Optical Materials, vol. 28, American Ceramic Society, Westerville, OH, 1991, p. 253.

[48] R. Brow, R. Kirkpatrick, G. Turner, J. Am. Ceram. Soc. $73(1990) 2293$.

[49] R. Brow, J. Am. Ceram. Soc. 76 (1993) 913.

[50] R. Brow, R. Kirkpatrick, G. Turner, J. Am. Ceram. Soc. 76 (1993) 919.

[51] H.B. Senin, Q. Wang, G.A. Saunders, R.C. Draper, E.F. Lambson, M. Cankurtaran, F.J. Ford, H.M. Farok, H.A.A. Sidek, W.A. Lambson, Glass Technol. 34 (1993) 75.

[52] J.J. Hudgens, R.K. Brow, D.R. Tallant, S.W. Martin, J. Non-Cryst. Solids 223 (1998) 21.

[53] Y. Jin, X. Chen, X. Huang, J. Non-Cryst. Solids 112 (1989) 147.

[54] R.K. Brow, D.R. Tallant, Z.A. Osborne, Y. Yang, D.E. Day, Phys. Chem. Glasses 32 (1991) 188.

[55] R. Brow, C. Phifer, G. Turner, R. Kirkpatrick, J. Am. Ceram. Soc. 74 (1991) 1287.

[56] D. Day, J. Non-Cryst. Solids 112 (1989) 7.

[57] R.K. Brow, D.R. Tallant, J.J. Hudgens, S.W. Martin, A.D. Irwin, J. Non-Cryst. Solids 177 (1994) 221.

[58] R.K. Sato, R.J. Kirkpatrick, R.K. Brow, J. Non-Cryst. Solids 143 (1992) 257.
[59] R.K. Brow, D.R. Tallant, J. Non-Cryst. Solids 222 (1997) 396.

[60] R.J. Kirkpatrick, R.K. Brow, Solid-State Nucl. Magn. Reson. 5 (1995) 9.

[61] W. Seeber, D. Ehrt, Silikattechnik 41 (1990) 230.

[62] T. Izumitani, H. Toratani, H. Kuroda, J. Non-Cryst. Solids 47 (1982) 87.

[63] R.C. Powell, Physics of Solid-State Laser Materials, Springer, New York, 1998.

[64] M. Gerloch, Orbitals, Terms and States, Wiley, Chichester, 1986

[65] S. Hufner, Optical Spectra of Transparent Rare Earth Compounds, Academic Press, New York, 1978.

[66] W. Koechner, Solid-State Laser Engineering, 4th Ed., Springer, New York, 1996.

[67] H.T. Powell, A.C. Erlandson, K.S. Jancaitis, J.E. Murray, SPIE 1277 (1990) 103.

[68] A.C. Erlandson, K.S. Jancaitis, R.W. McCracken, M.D. Rotter, Gain uniformity and amplified spontaneous emission in multi-segment amplifiers, ICF Quarterly Report, Lawrence Livermore National Laboratory Report UCRL-JC-111172, 1992, p. 105.

[69] R. Beach, Laser Tech. Briefs 2 (1994) 32.

[70] J.K. Crane, M. Martinez, R.J. Beach, S. Mitchell, F. Penko, D. Browning, R. Wilcox, Diode-pumped regenerative amplifier for the NIF laser system, ICF Quarterly Report, Lawrence Livermore National Laboratory Report UCRL-LR-105821-97-4, 1997, p. 246.

[71] C.B. Layne, W.H. Lowdermilk, M.J. Weber, Phys. Rev. B 16 (1977) 110.

[72] C. Bibeau, S. Payne, H. Powell, J. Opt. Soc. Am. B 12 (1995) 1981.

[73] C. Bibeau, S. Payne, Terminal-level relaxation in nddoped laser materials, ICF Quarterly Report, Lawrence Livermore National Laboratory Report UCRL-LR105821-95-2, 1995, p. 119.

[74] C. Bibeau, J. Trenhome, S. Payne, IEEE J. Quantum Electron. 32 (1996) 1487.

[75] S. Payne, C. Bibeau, J. Lumin. 79 (1998) 143.

[76] T. Förster, Ann. Phys. 2 (1948) 56.

[77] D.L. Dexter, J. Chem. Phys. 21 (1953) 836.

[78] W. Krupke, IEEE J. Quantum Electron. QE-10 (1974) 450.

[79] B.R. Judd, Phys. Rev. B 127 (1962) 750.

[80] G.S. Ofelt, J. Chem. Phys. 37 (1962) 511.

[81] S. Lunter, A. Dymnikov, A. Przhevuskii, Y. Federov, SPIE 1513 (1991) 349.

[82] Y. Nageno, H. Takebe, K. Morinaga, J. Am. Ceram. Soc. 76 (1993) 3081.

[83] H. Takebe, Y. Nageno, K. Morinaga, J. Am. Ceram. Soc. 77 (1994) 2132.

[84] H. Ebendorff-Heidepriem, D. Ehrt, M. Bettinelli, A. Speghini, SPIE 3622 (1999) 19.

[85] R.R. Jacobs, M.J. Weber, IEEE J. Quantum Electron. QE-12 (1976) 102.

[86] X.J. Xu, C.S. Ray, Solid-State Opt. Mater. 28 (1992) 297.

[87] J. Caird, A. Ramponi, P. Staver, J. Opt. Soc. Am. B 8 (1991) 1391. 
[88] A.C. Erlandson, M.D. Rotter, D.N. Frank, R.W. McCracken, Design and performance of the beamlet amplifiers, ICF Quarterly Report, Lawrence Livermore National Laboratory Report UCRL-LR-105821-95-1, 1994, p. 18.

[89] S.E. Stokowski, D. Krashkevich, Mater. Res. Soc. Symp. 61 (1986) 273.

[90] P. Ehrmann, J.H. Campbell, T.I. Suratwala, J.S. Hayden, D. Krashkevich, K. Takeuchi, J. Non-Cryst. Solids, 1999, this conference.

[91] C.B. Layne, M.J. Weber, Phys. Rev. B 16 (1977) 3259.

[92] S.A. Payne, C.D. Marshall, A. Bayramian, G.D. Wilke, J.S. Hayden, Appl. Phys. B 61 (1995) 257.

[93] S.E. Stokowski, L. Cook, H. Mueller, M.J. Weber, J. Lumin. $31 \& 32$ (1984) 823.

[94] J.H. Campbell, SPIE CR 64 (1996) 3.

[95] A.I. Burshtein, Soviet Phys., JETP 35 (1972) 882.

[96] Y. Jiang, S. Jiang, Y. Jiang, J. Non-Cryst. Solids 112 (1989) 286.

[97] J.O. Byun, B.H. Kim, K.S. Hong, H.J. Jung, S.W. Lee, K.S. Ryoo, A.A. Izyneev, V.B. Kravchenko, Jpn. J. Appl. Phys. 33 (1994) 4907.

[98] S.A. Payne, G.D. Wilke, L.K. Smith, W.F. Krupke, Opt. Commun. 111 (1994) 263.

[99] D. Zhuo, W. Xu, Y. Jiang, Chin. Phys. 6 (1986) 157.

[100] J. Shelby, Handbook of Gas Diffusion in Solids and Melts, ASM International, Materials Park, OH, 1996, p. 217.

[101] H. Ebendorff-Heidepriem, D. Ehrt, Glastech. Ber. Glass Sci. Technol. 68 (1995) 139.

[102] H. Toratani, H.E. Meissner, T. Izumitani, S.E. Stokowski, J. Non-Cryst. Solids 95\&96 (1987) 701.

[103] A. Matthai, D. Ehrt, C. Rüssel, Glastech. Ber. Glass Sci. Technol. 71 (1998) 187.

[104] D. Sapak, J. Ward, J. Marion, SPIE 970 (1988) 107.

[105] K. Zirkelbach, R. Bruckner, Glastech. Ber. Glass Sci. Technol. 60 (1987) 312.

[106] L.B. Glebov, E.N. Boulos, J. Non-Cryst. Solids 242 (1998) 49.

[107] C.R. Kurkjian, E.A. Sigety, Phys. Chem. Glasses 9 (1968) 73.

[108] D. Ehrt, W. Seeber, J. Non-Cryst. Solids 129 (1991) 19.

[109] D. Ehrt, M. Leister, A. Matthai, Molten Salt Forum 5\&6 (1998) 547.

[110] B. Camara, Glastech. Ber. Glass Sci. Technol. 51 (1978) 87.

[111] U. Kolberg, in: H. Bach, N. Neuroth (Eds.), The Properties of Optical Glass, Springer, Berlin, 1995, p. 351 (Chapter 8.8).

[112] A.M. Bishay, L. Makar, J. Am. Ceram. Soc. 52 (1969) 605.

[113] J.A. Caird, F.P. Milanovich, N.D. Nielsen, H.T. Powell, J.E. Marion, A.J. Pertica, J.N. Roe, in: Conference on Lasers and Electro-Optics (CLEO), 1989, p. 1.

[114] J.T. Hunt, K.R. Manes, P.A. Renard, Appl. Opt. 32 (1993) 5973.

[115] J.T. Hunt, D.R. Speck, Opt. Eng. 28 (1989) 461.

[116] J. Hunt, J. Glaze, W. Simmons, P. Renard, Appl. Opt. 17 (1978) 2053.
[117] D.C. Brown, High-Peak-Power Nd: Glass Laser Systems, Springer, New York, 1981.

[118] B.E.A. Saleh, M.C. Teich, Fundamentals of Photonics, Wiley, New York, 1991.

[119] W. Simmons, J. Hunt, W. Warren, IEEE J. Quantum Electron. QE-17 (1981) 1727.

[120] N. Boling, A. Glass, A. Owyoung, IEEE J. Quantum Electron. QE-14 (1978) 601.

[121] D.R. Uhlmann, N.J. Kreidl, Optical Properties of Glass, American Ceramic Society, Westerville, OH, 1991.

[122] T. Izumitani, H. Toratani, J. Non-Cryst. Solids 49 (1980) 611.

[123] M.L. Elder, Y.T. Hayden, J.H. Campbell, S.A. Payne, G.D. Wilke, in: A.J. Bruce, B.V. Hiremath (Eds.), SolidState Optical Materials, vol. 28, American Ceramic Society, Westerville, OH, 1991, p. 261.

[124] J.E. Marion, SPIE 1128 (1989) 318.

[125] W.F. Krupke, M.D. Shinn, J.E. Marion, J.A. Caird, S.E. Stokowski, J. Opt. Soc. Am. B 3 (1986) 102.

[126] K.P.R. Reddy, E.H. Fontana, J.D. Helfinstine, J. Am. Ceram. Soc. 71 (1988) C310.

[127] S. Crichton, M. Tomozawa, J. Hayden, T. Suratwala, J. Campbell, J. Am. Ceram. Soc. 82 (1999) 3097.

[128] T.I. Suratwala, R.A. Steele, G.D. Wilke, J.H. Campbell, K. Takeuchi, these Proceedings, p. 213.

[129] S. Wiederhorn, J. Am. Ceram. Soc. 50 (1967) 407.

[130] B.M. Van Wonterghem, J.R. Murray, J.H. Campbell, D.R. Speck, C.E. Barker, I.C. Smith, D.F. Browning, W.C. Behrendt, Appl. Opt. 36 (1997) 4932.

[131] J.H. Campbell, F. Rainer, M. Kozlowski, C.R. Wolfe, I.M. Thomas, F. Milanovich, SPIE 1441 (1990) 444.

[132] J.H. Campbell, E.P. Wallerstein, J.S. Hayden, D.L. Sapak, D.E. Warrington, A.J. Marker, H. Toratani, H. Meissner, S. Nakajima, T. Izumitani, Elimination of platinum inclusions in phosphate laser glasses, Lawrence Livermore National Laboratory Report UCRL-53932, 1989 , p. 1.

[133] Fundamentals of Damage in Laser Glass, National Materials Advisory Board, Division of Engineering, National Research Council, NMAB-271, 1970.

[134] J.H. Campbell, E.P. Wallerstein, J.S. Hayden, D.L. Sapak, D.E. Warrington, A.J. Marker, Glastech. Ber. Glass Sci. Technol. 68 (1995) 11.

[135] J.H. Campbell, E.P. Wallerstein, H. Toratani, H.E. Meissner, S. Nakajima, T.S. Izumitani, Glastech. Ber. Glass Sci. Technol. 28 (1995) 59.

[136] J.H. Campbell, Glastech. Ber. Glass Sci. Technol. 68 (1995) 96.

[137] C.L. Weinzapfel, G.J. Greiner, C.D. Walmer, J.K. Kimmons, E.P. Wallerstein, F.T. Marchi, J.H. Campbell, J.S. Hayden, K. Komiya, T. Kitiyama, Laser Induced Damage in Optical Materials, National Institute of Standards and Technology Special Publication, 756, 1987 , p. 112.

[138] R. Gonzales, D. Milam, Easer Induced Damage in Optical Materials, National Bureau of Standards Special Publication, 745, 1988, p. 128.
[139] T

$\mathrm{d}$
[140] $\mathrm{Y}$
$\mathrm{A}$
$\mathrm{N}$
$\mathrm{v}$
$[141] \mathrm{C}$

C 
ıser Systems,

Photonics,

J. Quantum

. Quantum

ties of Glass, -1991 .

is $49(1980)$

S.A. Payne, (s.ds.), Solid-

in Ceramic

1. Caird, S.E.

ine, J. Am

Suratwala, J.

17.

I. Campbell,

i7) 407.

Campbell,

Browning,

C.R. Wolfe, 190) 444

ayden, D.L. Toratani, $\mathrm{H}$. limination of es, Lawrence JCRL-53932,

ass, National Engineering, 70. Hayden, D.L. Glastech. Ber.

ratani, H.E. Glastech. Ber.

Technol. 68

Walmer, J.K I.H. Campbell, -aser Induced Institute of dication, 756,

1 Damage in Idards Special
[139] T. Izumitani, M. Matsukawa, H. Miyade, Laser Induced Damage in Optical Materials, National Institute of Standards and Technology Special Publication, 756, 1988, p. 29.

[140] Y.T. Hayden, J.H. Campbell, S.A. Payne, G.D. Wilke, in A.J. Bruce, B.V. Hiremath (Eds.), Solid-State Optical Materials, vol. 28, American Ceramic Society, Westerville, $\mathrm{OH}, 1992$, p. 283.

[141] C. Jiang, D. Zhuo, J. Zhang, Chin. J. Lasers A 23 (1996) 1047.
[142] J.H. Kelly, M.H. Shoup, SPIE 1627 (1992) 175.

[143] Laser Glass Product Catalog, Hoya Corporation USA, Fremont, CA, 1994, p. 1.

[144] Laser Glass Product Catalog, Schott Glass Technologies, Duryea, PA, 1999, p. 1.

[145] Laser Glass Product Catalog, Kigre, Hilton Head, SC, 1990, p. 1. 


\section{PROCEEDINGS OF SPIE REPRINT}

Reprinted from

\section{Inorganic Optical Materials II}

1-3 August 2000

San Diego, USA 


\title{
Dehydroxylation of Phosphate Laser Glass
}

\author{
C. B. Thorsness, T. I. Suratwala ${ }^{*}$ R. A. Steele, J. H. Campbell \\ University of California, Lawrence Livermore National Laboratory, 7000 East Avenue, L-500, \\ Livermore, California 94550 \\ J. S. Hayden, S. A. Pucilowski \\ Schott Glass Technologies Inc., 400 York Ave., Duryea, PA 18642 \\ K. Suzuki \\ Hoya Corporation USA, 3400 Edison Way, Fremont, CA 94538
}

Rates of dehydroxylation of two Nd-doped metaphosphate laser glasses (LG-770 and LHG-8) are measured and modeled. Glass melts ranging in size from $100 \mathrm{~g}$ to $2.8 \mathrm{~kg}$ were bubbled with $\mathrm{O}_{2}$ containing various $\mathrm{H}_{2} \mathrm{O}$ partial pressures $\left(\mathrm{P}_{\mathrm{H}_{2}} \mathrm{O}\right)$ and with $\mathrm{O}_{2} / \mathrm{Cl}_{2}$ mixtures at temperatures ranging from $925-1300^{\circ} \mathrm{C}$. The $\mathrm{OH}$ content in the glass was measured by monitoring the $\mathrm{OH}$ absorption at $3.333 \mu \mathrm{m}$ at various bubbling times. The $\mathrm{OH}$ removal by inert gas bubbling (e.g. $\mathrm{O}_{2}$ bubbling) is governed by the transport (diffusion) of $\mathrm{OH}$ to the glass liquid/vapor interface and by the chemical equilibrium between $\mathrm{OH}$ at the surface and $\mathrm{H}_{2} \mathrm{O}$ in the gas phase. The equilibrium $\mathrm{OH}$ content in glass melts bubbled with $\mathrm{O}_{2}$ containing different $\mathrm{P}_{\mathrm{H}_{2} \mathrm{O}}$ varies as $\mathrm{P}_{\mathrm{H}_{2} \mathrm{O}}{ }^{1 / 2}$. Reactive gas dehydroxylation (using $\mathrm{Cl}_{2}$ bubbling) is enhanced by the reverse Deacon reaction where $\mathrm{Cl}_{2}$ gas reacts with $\mathrm{H}_{2} \mathrm{O}$ in the gas phase to form $\mathrm{HCl}$. A time-dependent, one-dimensional bubble-column dehydroxylation model is developed and used to describe the rates of dehydroxylation for glasses. The model uses measured or literature values for the diffusion coefficient of $\mathrm{OH}$ in the melt $\left(D_{\mathrm{COH}}\right)$, the $\mathrm{H}_{2} \mathrm{O} / \mathrm{OH}$ equilibrium constant $\left(\mathrm{K}_{\mathrm{w}}\right)$, and the equilibrium constant for the reverse Deacon reaction $\left(\mathrm{K}_{\mathrm{d}}\right)$. The model does a good job simulating/predicting dehydroxylation rates of small-scale test melts and production-scale continuous melting operations.

Keywords: dehydroxylation, dehydration, phosphate laser glass, $\mathrm{O}_{2} / \mathrm{Cl}_{2}$ bubbling, glass melting, reverse Deacon reaction, bubble column

\section{INTRODUCTION}

Rare earth-doped glasses, such as $\mathrm{Nd}^{3+}$ and $\mathrm{Er}^{3+}$ in silicate and phosphate glasses, are used in a wide variety of applications ranging from high power laser systems to fiber or planar waveguide amplifiers ${ }^{1-7}$. The presence of hydroxyl $(\mathrm{OH})$ groups quenches the fluorescence of the rare earth ion, which reduces laser gain and adversely affects laser performance ${ }^{2}$. In the case of $\mathrm{Nd}^{3+}$, this quenching transfers energy from the upper laser level $\left(\mathrm{F}_{3 / 2}\right.$ state of $\left.\mathrm{Nd}^{3+}\right)$ to the second vibrational overtone of $\mathrm{OH}^{2}$. For most laser applications, it is desirable to reduce the $\mathrm{OH}$ concentration to $<200 \mathrm{ppm}$ 8 .

The $\mathrm{H}_{2} \mathrm{O}$ and $\mathrm{OH}$ present in the raw materials and the $\mathrm{H}_{2} \mathrm{O}$ present in the environment are the source of $\mathrm{OH}$ in manufactured glass. A variety of techniques can be employed to reduce the amount of $\mathrm{OH}$ in the glass that include: 1) thermal drying of raw materials (i.e. calcining); 2) addition of non-reactive dehydroxylation agents; and 3) addition of reactive dehydroxylation agents.

The thermal drying of the raw materials is simply performed by calcining the powder before melting. However, it is still difficult to remove all hydroxyls from the powders, and the small residual amounts often lead to $100-1000 \mathrm{ppm} \mathrm{OH}$ levels in the final glass. Non-reactive dehydroxylation is commonly performed by bubbling inert gases through a melt (e.g. $\mathrm{O}_{2}, \mathrm{~N}_{2}$ ) 1, 9-15. Reactive dehydroxylation involves reaction between a halide (such as $\mathrm{Cl}$ and $\mathrm{F}$ ) with $\mathrm{OH}$ or $\mathrm{H}_{2} \mathrm{O}$. Two common methods that have been utilized are exposing a porous glass preform to $\mathrm{Cl}_{2}$ gas or bubbling a glass melt with $\mathrm{Cl}_{2}$ gas 12-17. Other reactive agents (solids, liquid or gases) can also be used 18.

Despite the great general interest in the dehydroxylation of glasses, surprisingly little is understood or published about details of the mechanism and kinetics. In the present paper, we explore the rate of dehydroxylation using $\mathrm{O}_{2}$ and $\mathrm{Cl}_{2}$ bubbling in glass melts of two commercial Nd-doped phosphate laser glasses (LG-770 from Schott Glass Technologies Inc. and LHG-8 from Hoya Corporation USA). First, the results for the $\mathrm{OH}$ content of glass melts bubbled with $\mathrm{O}_{2}$ containing

\footnotetext{
'Correspondance: Suratwalal @llnl.gov: Telephone: 925-422-1884; Fax:925-423-0792
} 
various $\mathrm{H}_{2} \mathrm{O}$ partial pressures $\left(\mathrm{P}_{\mathrm{H}_{2} \mathrm{O}}\right)$ and with $\mathrm{O}_{2} / \mathrm{Cl}_{2}$ mixtures at various temperatures, melt sizes, bubbling flow rates, and cover gas flows are reported (Section 3). Next, we describe a proposed mechanism of dehydroxylation (Section 4.1) which involves three steps: (1) mass transport of $\mathrm{OH}$ to the melt/vapor interface; (2) thermal dehydroxylation (governed by $\mathrm{H}_{2} \mathrm{O} / \mathrm{OH}$ equilibrium), and (3) reactive $\mathrm{Cl}_{2}$ dehydroxylation (governed by $\mathrm{H}_{2} \mathrm{O} / \mathrm{HCl}$ equilibrium). Then, a description of the onedimensional, time-dependent, bubble-column dehydroxylation model is given (Section 4.2). Specifically, we discuss the governing balance equations for the model and the relationships describing mass transfer at the bubble and top surface interfaces. Also, the limiting cases of the model are described. Finally, in Section 5, we apply the model to experimental melt data and discuss how the various experimental parameters affect the dehydroxylation kinetics, and how well the model describes the dehydroxylation kinetics for both small-scale test melts and production-scale continuous melting operations.

\section{EXPERIMENTAL}

Two commercial glasses, LG-770 (from Schott Glass Technologies, Inc.) and LHG-8 (from Hoya Corporation, USA) were used in the melting experiments. The base glasses are near meta-phosphate glasses, which have the molar compositions of (58-62) $\mathrm{P}_{2} \mathrm{O}_{5}-(6-10) \mathrm{Al}_{2} \mathrm{O}_{3}-(20-25) \mathrm{K}_{2} \mathrm{O}-(10-15) \mathrm{MgO}-(0-2) \mathrm{Nd}_{2} \mathrm{O}_{3}$ for LG-770 and (55-60) $\mathrm{P}_{2} \mathrm{O}_{5}-(8-12) \mathrm{Al}_{2} \mathrm{O}_{3}-$ $(13-17) \mathrm{K}_{2} \mathrm{O}-(10-15) \mathrm{BaO}-(0-2) \mathrm{Nd}_{2} \mathrm{O}_{3}$ for LHG-8. The starting materials for each of the melts were either pre-made glass cullet or the raw materials which when melted have the compositions described above.

Three series of glass melts were conducted. The first series of glass melts, called $\mathrm{H}_{2} \mathrm{O} / \mathrm{OH}$ equilibrium melts, were conducted to determine the equilibrium amount of $\mathrm{OH}$ in the glass with different amount of $\mathrm{H}_{2} \mathrm{O}$ in a bubbling gas stream. These melts were conducted by bubbling $\mathrm{O}_{2}$ containing varying $\mathrm{P}_{\mathrm{H}_{2}} \mathrm{O}$ into a glass melt until equilibrium was reached in the melt. The second series of glass melts were performed to examine the dehydroxylation rates of LHG-8 glass; this was performed by bubbling dry $\mathrm{O}_{2}$ gas into the glass melts and then measuring the $\mathrm{OH}$ content as a function of time. The third and final series of glass melts was performed to measure the dehydroxylation rates of LG-770 glass. These melts were bubbled with dry $\mathrm{O}_{2}$ or $\mathrm{O}_{2} / \mathrm{Cl}_{2}$ gas mixtures and the $\mathrm{OH}$ content was measured as a function of time.

\section{$2.1 \mathrm{H}_{2} \mathrm{O} / \mathrm{OH}$ Equilibrium melts}

A schematic of the experimental setup used to perform the $\mathrm{H}_{2} \mathrm{O} / \mathrm{OH}$ equilibrium melts is shown in Fig. 1 . Approximately $100 \mathrm{~g}$ of crushed glass cullet (LG-770 or LHG-8) was melted in a Pt crucible (250-ml capacity, 3-cm diameter) within a box furnace (Thermolyne 1400 or 47900 ) at temperatures ranging from $925^{\circ} \mathrm{C}$ to $1200^{\circ} \mathrm{C}$; a round $\mathrm{Pt}$ sheet (10-cm diameter with a $1.0-\mathrm{cm}$ hole) was used as a cover for the crucible. A quartz tube was dipped into the glass melt through a hole at the top of the furnace, and $\mathrm{O}_{2}$ gas enriched with various $\mathrm{H}_{2} \mathrm{O}$ partial pressures $\left(\mathrm{P}_{\mathrm{H}_{2}} \mathrm{O}\right)$ was bubbled into the melt. $\mathrm{P}_{\mathrm{H}_{2} \mathrm{O}}$ was established by bubbling dry $\mathrm{O}_{2}$ gas $\left(-57^{\circ} \mathrm{C}\right.$ dew point) through a fritted tube in a water bath set to temperatures ranging from $3.5^{\circ} \mathrm{C}$ to $29.7^{\circ} \mathrm{C}$. A portion of the gas was fed into an optical dew point sensor (General Eastern Model 1311DR) which measured the actual $\mathrm{P}_{\mathrm{H}_{2} \mathrm{O}}$ (see Fig. 1). The $\mathrm{Cu}$ lines were heated by heating tape to avoid water condensation in the lines. Bubbling in the glass melt was performed for $2-4$ hours, typically at a flow rate of 5 standard $\mathrm{ft}^{3} / \mathrm{h}$ (scfh). After bubbling, the quartz tube was removed and the glass melt was poured into steel molds $\left(4 \times 4 \times 1 \mathrm{~cm}^{3}\right)$ coated with boron nitride (preheated to $550^{\circ} \mathrm{C}$ ). The mold was then placed into an annealing furnace (Thermolyne 1500 ) set at $550^{\circ} \mathrm{C}$ and cooled at a rate of $60^{\circ} \mathrm{C} / \mathrm{h}$. The $\mathrm{OH}$ content in the glass samples was measured by cutting the samples into 0.5-2.0-mm slices and measuring the $3000 \mathrm{~cm}^{-1}(3.333 \mu \mathrm{m})$ transmission in a FTIR spectrometer (Perkin Elmer Spectrum 2000). The OH content is reported as $\mathrm{OH}$ absorptivity $\left(\alpha\right.$ in $\left.\mathrm{cm}^{-1}\right)$. The $\mathrm{OH}$ content of the starting cullet was low $\left(-2 \mathrm{~cm}^{-1}\right)$ for all melts. The samples from the melts are identified as L-1 to L-31.

\subsection{LHG-8 dehydroxylation melts}

LHG-8 raw materials $(2.8 \mathrm{~kg})$ was placed into a fused quartz crucible $(11 \mathrm{~cm}$ diameter $\times 17.5 \mathrm{~cm}$ depth) preheated in a resistively-heated furnace at temperatures ranging from $1000^{\circ} \mathrm{C}$ to $1165^{\circ} \mathrm{C}$. A fused quartz square plate $\left(15 \times 15 \times 0.7 \mathrm{~cm}^{3}\right)$ with a $1.0-\mathrm{cm}$ hole in the center was used as a cover for the crucible. After heating for one hour, approximately $30 \mathrm{~g}$ of the melt was poured into a graphite mold $\left(4 \times 4 \times 1 \mathrm{~cm}^{3}\right)$ preheated to $490^{\circ} \mathrm{C}$. The mold was then stored in an annealing furnace set at $490^{\circ} \mathrm{C}$. This first scoop sample represents the zero bubbling time sample $(t=0 \mathrm{~h})$. The crucible was then reinserted into the furnace, and a fused silica tube (8-mm OD, 4-mm ID) was inserted into the glass melt through the hole in the fused quartz cover. $\mathrm{O}_{2}$ was then bubbled at various flow rates ranging from 0.54 to $1.1 \mathrm{scfh}$. Note no cover gas was used. Scoop samples were taken at various bubbling times $(0.5,1,1.5,2$, and 3 hours). All six scoop samples were placed within an 


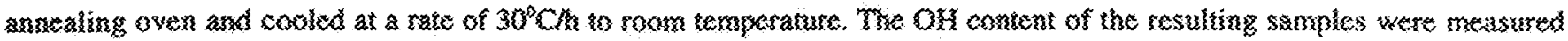

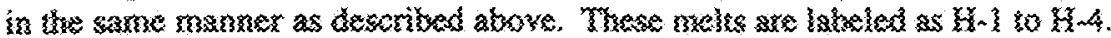

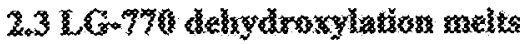

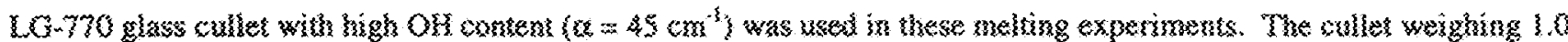

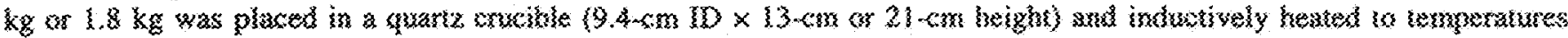

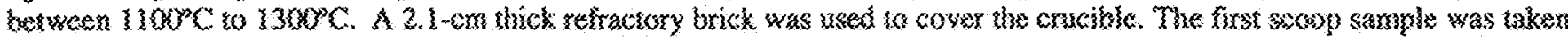

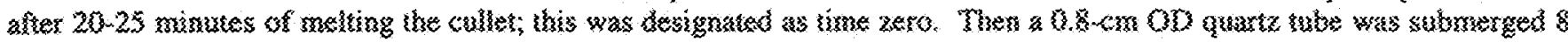

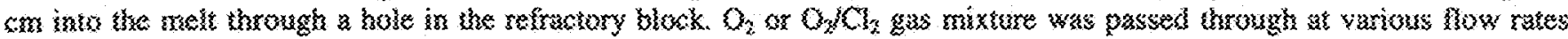

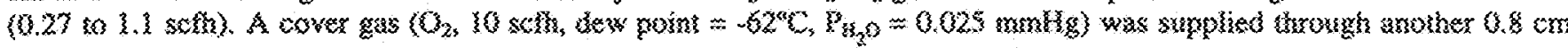

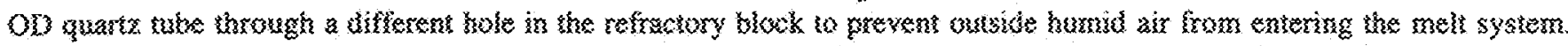

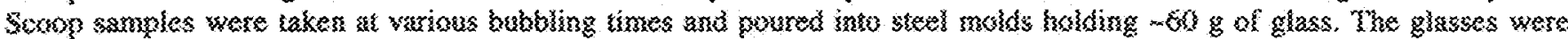

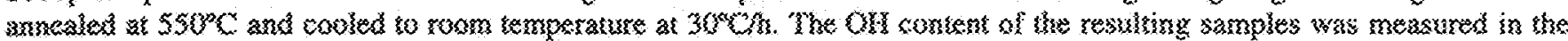

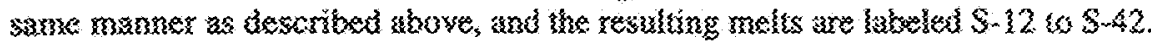

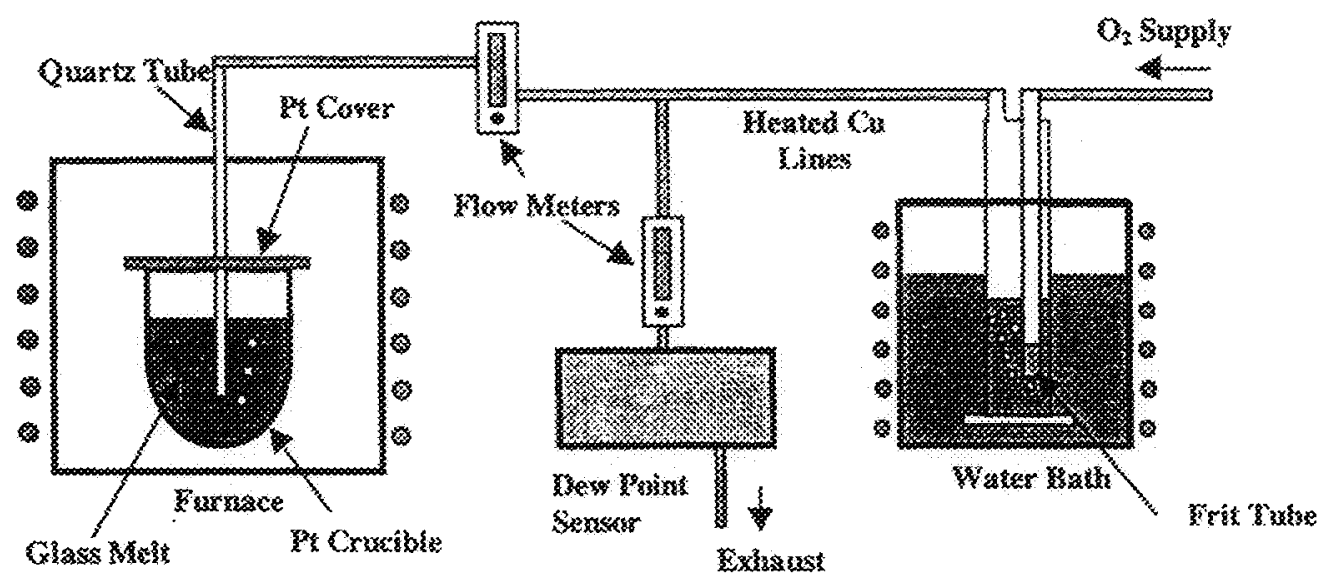

by

\section{3.}

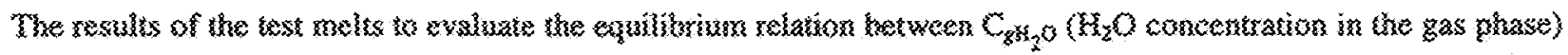
and $C_{\text {oxs }}$ (OF⿱

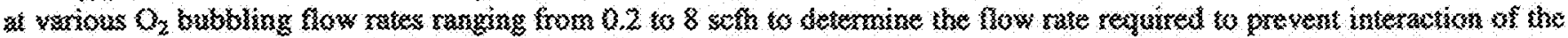

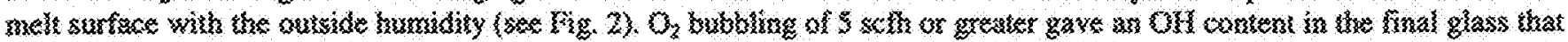

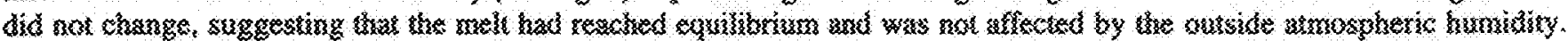

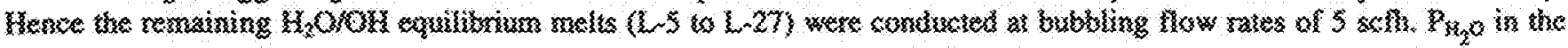

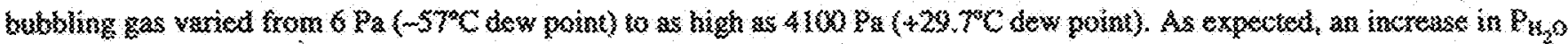
resulut \{ay

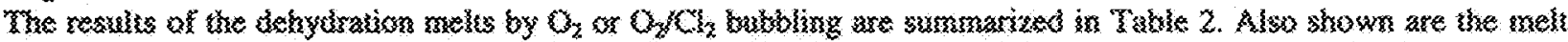

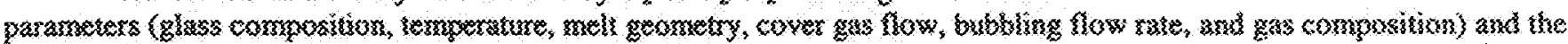

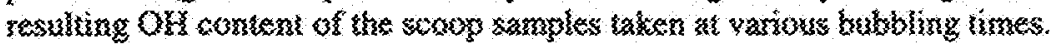


Table 1: Summary of $\mathrm{H}_{2} \mathrm{O} / \mathrm{OH}$ equilibrium experiments

\begin{tabular}{|c|c|c|c|c|c|c|c|c|}
\hline Melt * & Glass & Melt Temp. ( $\left.{ }^{\circ} \mathrm{C}\right)$ & $\begin{array}{l}\text { Melt Stze } \\
\text { (g) }\end{array}$ & $\begin{array}{l}\mathrm{O}_{2} \text { Bubbliling } \\
\text { rate (scth) }\end{array}$ & $\begin{array}{l}\text { Bubbling } \\
\text { time (h) }\end{array}$ & $\begin{array}{c}\alpha \\
\left(\mathrm{cm}^{-1}\right)\end{array}$ & $\begin{array}{l}P_{\mathrm{P}_{2} \mathrm{O}} \\
(\mathrm{Pa})\end{array}$ & $\left(\mathrm{Pa}^{\left.\frac{K_{2} / 2 \mathrm{~cm}^{-1}}{2}\right)}\right.$ \\
\hline \multicolumn{9}{|c|}{ Variable bubbling rate } \\
\hline $\mathrm{L}-1$ & LHG-8 & 1100 & 100 & 0.4 & 2 & 4.6 & 6 & na \\
\hline L-2 & LHG-8 & 1100 & 100 & 2 & 2 & 0.8 & 6 & \\
\hline L-3 & LHG-8 & 1100 & 100 & 5 & 2 & 0.4 & 6 & \\
\hline $\mathrm{L}-4$ & LHG-8 & 1100 & 100 & 8 & 2 & 0.4 & 6 & \\
\hline \multicolumn{9}{|c|}{ Variable water vapor pressure $\&$ temperature } \\
\hline L-5 & LHG-8 & 925 & 100 & 5 & 2 & 4.20 & 6 & \multirow{4}{*}{1.40} \\
\hline L-6 & LHG-8 & 925 & 100 & 5 & 2 & 17.20 & 638 & \\
\hline L-7 & LHG-8 & 925 & 100 & 5 & 2 & 25.30 & 1184 & \\
\hline L-8 & LHG-8 & 925 & 100 & 5 & 2 & 29.60 & 1756 & \\
\hline L-9 & LHG-8 & 1000 & 100 & 5 & $\overline{4}$ & 1.10 & 6 & \multirow{6}{*}{1.63} \\
\hline L-10 & LHG-8 & 1000 & 100 & 5 & 4 & 16.00 & 625 & \\
\hline L-11 & LHG-8 & 1000 & 100 & 5 & 2 & 18.70 & 927 & \\
\hline L-13 & LHG-8 & 1000 & 100 & 5 & 4 & 23.20 & 1131 & \\
\hline L-14 & LHG-8 & 1000 & 100 & 5 & 2 & 26.50 & 1942 & \\
\hline L-15 & LHG-8 & 1000 & 100 & 5 & 4 & 27.80 & 2008 & \\
\hline L-16 & LHG-8 & 1100 & 100 & 5 & 2 & 1.00 & 6 & \multirow{4}{*}{1.96} \\
\hline L-17 & LHG-8 & 1100 & 100 & 5 & 2 & 13.80 & 798 & \\
\hline L-18 & LHG-8 & 1100 & 100 & 5 & 2 & 18.60 & 1330 & \\
\hline L-19 & LHG-8 & 1100 & 100 & 5 & 2 & 25.00 & 2328 & \\
\hline $\mathrm{L}-20$ & LG-770 & 1050 & 100 & 5 & 2 & 2.88 & 6 & \\
\hline L-21 & LG-770 & 1050 & 100 & 5 & 2 & 29.50 & 1915 & 1.48 \\
\hline L.22 & LG-770 & 1100 & 100 & 5 & 2 & 0.90 & 6 & \multirow{3}{*}{1.56} \\
\hline L 23 & LG-770 & 1100 & 100 & 5 & 2 & 18.80 & 971 & \\
\hline L-24 & LG-770 & 1100 & 100 & 5 & 2 & 29.10 & 1968 & \\
\hline L-25 & LG-770 & 1200 & 100 & 5 & 2 & 2.20 & 6 & \multirow{3}{*}{2.01} \\
\hline L-26 & LG-770 & 1200 & 100 & 5 & 2 & 17.10 & 1250 & \\
\hline L-27 & LG-770 & 1200 & 100 & 5 & 2 & 27.20 & 2939 & \\
\hline L-28 & LG-770 & 1300 & 1000 & 0.5 & 2.5 & 9.65 & 610 & \multirow{4}{*}{2.18} \\
\hline L-29 & LG-770 & 1300 & 1000 & 0.5 & 2.5 & 23.13 & 2980 & \\
\hline L-30 & LG-770 & 1300 & 1000 & 0.5 & 6 & 29.89 & 3990 & \\
\hline L-31 & LG-770 & 1300 & 1000 & 0.5 & 6 & 30.38 & 4100 & \\
\hline
\end{tabular}

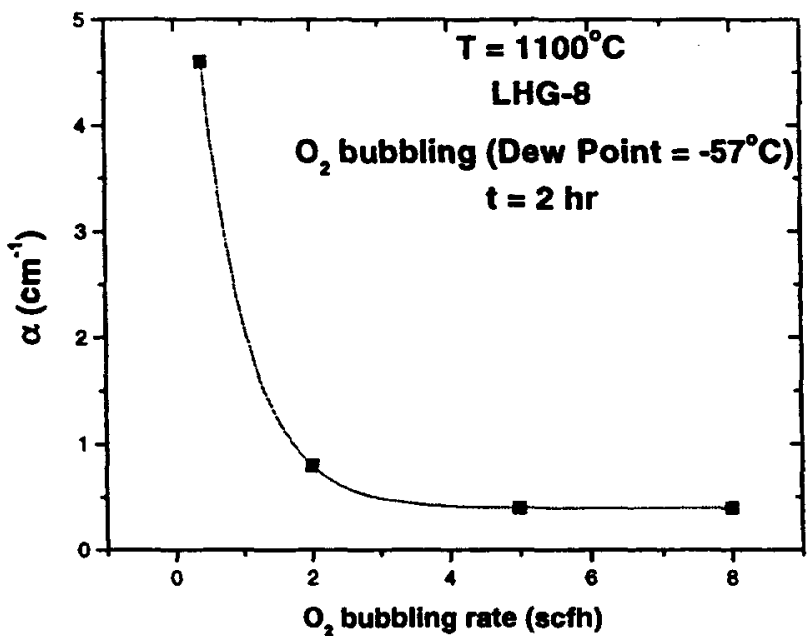

Fig. 2. $\mathrm{OH}$ content in LHG-8 laser glass as function of $\mathrm{O}_{2}$ bubbling rate during melting. $\left(100 \mathrm{~g}\right.$ melts, $\left.\mathrm{T}=1100^{\circ} \mathrm{C}, \mathrm{t}=2 \mathrm{~h}\right)$. The line represents a single exponential fit added as a guide to the eye. 
Table 2: Summary of dehydration experiments by $\mathrm{O}_{2}$ or $\mathrm{O}_{2} / \mathrm{Cl}_{2}$ bubbling.

\begin{tabular}{|c|c|c|c|c|c|c|c|c|c|c|c|c|c|c|c|}
\hline \multirow{3}{*}{$\begin{array}{c}\text { Melt } \\
\#\end{array}$} & \multirow{3}{*}{$\begin{array}{l}\text { Glass } \\
\text { Type }\end{array}$} & \multirow{3}{*}{$\begin{array}{c}\text { Melt } \\
\text { Diam and } \\
\text { height } \\
\text { (cm) }\end{array}$} & \multirow{3}{*}{$\begin{array}{c}\text { Melt } \\
\text { Temp } \\
\text { ('C) }\end{array}$} & \multirow{3}{*}{$\begin{array}{l}\text { Cover } \\
\text { Gas } \\
\text { Flow } \\
\text { (sefh) }\end{array}$} & \multirow{3}{*}{$\begin{array}{c}\text { Total } \\
\text { Bubble } \\
\text { Flow } \\
\text { (sch) }\end{array}$} & \multirow{3}{*}{$\begin{array}{c}\text { Bubble } \\
\text { Flow } \\
(\% \\
\left.\mathrm{Cl}_{2}\right)\end{array}$} & \multicolumn{9}{|c|}{ Scoop sampling time } \\
\hline & & & & & & & $\begin{array}{l}\text { o } \\
\text { h }\end{array}$ & $\begin{array}{c}0.5 \\
\text { h }\end{array}$ & $\begin{array}{c}1.0 \\
\mathrm{~h}\end{array}$ & $\begin{array}{c}1.5 \\
h\end{array}$ & $\begin{array}{c}2.0 \\
h\end{array}$ & $\begin{array}{c}2.5 \\
\text { h }\end{array}$ & $\begin{array}{c}3.0 \\
h\end{array}$ & $\begin{array}{c}4.0 \\
h\end{array}$ & $\begin{array}{c}6.0 \\
h\end{array}$ \\
\hline & & & & & & & \multicolumn{9}{|c|}{$\alpha\left(\mathrm{cm}^{-1}\right)$} \\
\hline $\mathrm{H}-\mathrm{I}$ & LHG-8 & $11 \times 12.7$ & 1100 & 0 & 0.54 & 0 & 141 & 115 & 99.9 & 87.2 & 76.1 & & 59.2 & & \\
\hline $\mathrm{H}-2$ & LHG-8 & $11 \times 12.7$ & 1100 & $\mathbf{0}$ & 1.1 & 0 & 139 & 76.6 & 73.9 & 61.9 & 51.0 & & 37.4 & & \\
\hline $\mathrm{H}-3$ & LHG-8 & $11 \times 12.7$ & 1000 & 0 & 1.1 & 0 & 154 & 126 & 99.6 & 85.8 & 73.8 & & 47.6 & & \\
\hline$S-13$ & LG-770 & $9.4 \times 8.5$ & 1300 & 20 & 0.5 & 0 & 36.1 & & 6.71 & & & & & & \\
\hline$S-14$ & LG-770 & $9.4 \times 8.5$ & 1300 & 20 & 0.5 & 0 & 34.8 & & & & 4.57 & & & & \\
\hline$S-31$ & LG-770 & $9.4 \times 8.5$ & 1300 & 20 & 0.54 & 21.2 & 46.6 & 4.35 & 0.70 & 0.51 & & & & 0.46 & 0.41 \\
\hline S-32 & LG-770 & $9.4 \times 8.5$ & 1250 & 20 & 0.54 & 21.2 & 48.9 & 5.47 & 0.85 & & 0.44 & & & 0.39 & 0.32 \\
\hline S-33 & LG-770 & $9.4 \times 8.5$ & 1200 & 20 & 0.54 & 21.2 & 48.5 & 6.80 & 0.92 & & 0.51 & & & 0.46 & 0.41 \\
\hline S-34 & LG-770 & $9.4 \times 8.5$ & 1300 & 20 & 0.52 & 11.0 & 44.2 & 10.7 & 2.60 & & 0.73 & & & 0.68 & 0.39 \\
\hline S-36 & LG-770 & $9.4 \times 8.5$ & 1300 & 20 & 0.50 & 0.0 & 46.4 & 8.43 & 2.82 & & 1.53 & & & 0.90 & 0.73 \\
\hline S-37 & LG-770 & $9.4 \times 8.5$ & 1300 & 20 & 1.08 & 21.2 & 46.7 & 3.13 & 1.24 & & 0.73 & & & 0.41 & 0.41 \\
\hline S-38 & LG-770 & $9.4 \times 17.0$ & 1300 & 20 & 1.08 & 21.2 & 42.1 & 2.45 & 1.19 & & 0.41 & & & & \\
\hline S-39 & LG-770 & $9.4 \times 17.0$ & 1300 & 20 & 0.54 & 21.2 & 42.3 & 6.66 & 1.41 & & 0.46 & & & & \\
\hline$S-40$ & LG-770 & $9.4 \times 17.0$ & 1200 & 20 & 1.08 & 21.2 & 47.8 & 6.22 & 1.31 & & 0.46 & & & & \\
\hline$S-41$ & LG-770 & $9.4 \times 17.0$ & 1200 & 20 & 0.27 & 21.2 & 45.6 & 17.3 & 6.78 & & 1.29 & & & & \\
\hline S-42 & LG-770 & $9.4 \times 17.0$ & 1200 & 20 & 0.54 & 21.2 & 46.9 & 11.5 & 3.52 & & 0.70 & & & & \\
\hline
\end{tabular}

\section{DEHYDROXYLATION MECHANISM AND MODEL}

\subsection{Mechanism}

The glass compositions of the two phosphate glasses used in this study (listed in experimental section) both have near meta-phosphate compositions (O/P -3$)$. The basic structure of phosphate glasses has been well studied, and nearmetaphosphate glasses can be described structurally as linear phosphate chains ${ }^{19}$. Molten phosphate glass readily reacts with $\mathrm{H}_{2} \mathrm{O}$ which is believed to hydrolyze a $\mathrm{P}-\mathrm{O}-\mathrm{P}$ bond creating two chain terminating $\mathrm{P}-\mathrm{OH}$ bonds 15,20 . For dehydroxylation to occur, the reverse reaction takes place at a liquid/gas interface (such as the bubble or top surface interface).

The detailed mechanism describing dehydroxylation of phosphate laser glass is not well understood. However, we have had reasonable success in analyzing dehydroxylation data using a model that assumes the two most important aspects of the dehydroxylation process involve 1) a mass transport step and 2) two chemical equilibrium constraints. This is shown schematically in Fig. 3.

The transport step (step 1 in Fig. 3) is the diffusion of the $\mathrm{OH}$ carrying component from the bulk glass melt to a melt/vapor interface. The migrating species is likely a proton 21 ; however for simplicity we treat the diffusion as an effective $\mathrm{OH}$ migration which is characterized by an effective $\mathrm{OH}$ diffusion coefficient $\left(\mathrm{D}_{\mathrm{ROH}}\right)$. We assume that the mass transport rate is proportional to the gradient in the $\mathrm{OH}$ concentration. $\mathrm{D}_{\mathrm{OOH}}$ has been previously measured for LG-770 at temperatures ranging from $200-1000^{\circ} \mathrm{C}^{22}$; an empirical fit to the data gives

$$
D_{\text {COH }}=\left(2.09 \frac{m^{2}}{\mathrm{sec}}\right) \exp \left(\frac{-3.45 \times 10^{4}}{T}+\frac{8.0 \times 10^{6}}{T^{2}}\right),
$$

where $T$ is the temperature in $K$. 


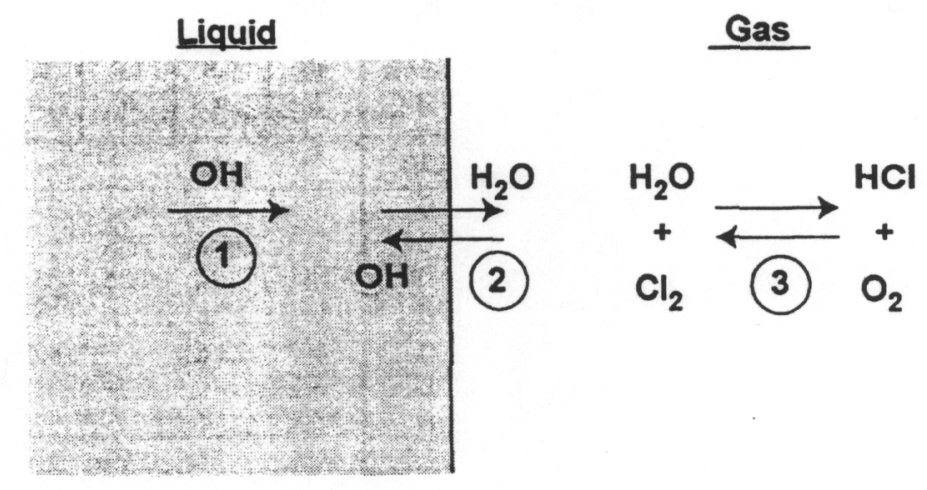

(1) Mass transport to liquid surface $\left(D_{\ell O H}\right)$

$$
(\mathrm{P}-\mathrm{OH})_{\ell} \rightarrow(\mathrm{P}-\mathrm{OH})_{s}
$$

(2) $\mathrm{H}_{2} \mathrm{O} / \mathrm{OH}$ Equilibrium

$$
\begin{aligned}
& \left.2(\mathrm{P}-\mathrm{OH})_{\mathrm{s}} \rightleftarrows \quad \mathrm{P}-\mathrm{O}-\mathrm{P}\right)_{\ell}+\mathrm{H}_{2} \mathrm{O}_{\mathrm{g}} \\
& \mathrm{K}_{\mathrm{w}}=\frac{\sqrt{\mathrm{C}_{\mathrm{OH}_{2} \mathrm{O}}}}{\mathrm{C}_{\mathrm{OH}_{\mathrm{s}}}}
\end{aligned}
$$

(3) $\mathrm{H}_{2} \mathrm{O} / \mathrm{HCl}$ Equilibrium

$$
\begin{aligned}
& 2 \mathrm{H}_{2} \mathrm{O}+2 \mathrm{Cl}_{2} \rightleftharpoons 4 \mathrm{HCl}+\mathrm{O}_{2} \\
& \mathrm{~K}_{\mathrm{d}}=\frac{\mathrm{C}_{\mathrm{gHCl}^{4}} \mathrm{C}_{\mathrm{gO}_{2}}}{\mathrm{C}_{\mathrm{gH}_{2} \mathrm{O}^{2} \mathrm{C}_{\mathrm{gCl}_{2}}{ }^{2}}}
\end{aligned}
$$

Fig. 3. Schematic of liquid melt / gas interface illustrating the proposed physical and chemical processes that govern thermal and chemical dehydroxylation.

At the interface, which may be the exposed top surface of the melt or a bubble surface, it is assumed that the governing reaction is 2

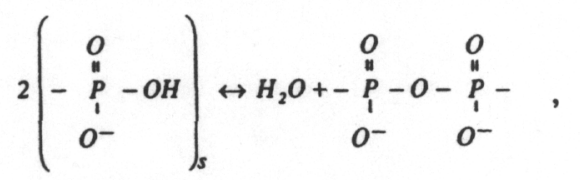

where the $\mathrm{OH}$ concentration at the gas/liquid interface $\left(\mathrm{C}_{\mathrm{eOH}_{\mathrm{s}}}\right.$ in $\left.\mathrm{mol} / \mathrm{m}^{3}\right)$ is in equilibrium with the water concentration in the gas phase $\left(\mathrm{C}_{\mathrm{gH}_{2} \mathrm{O}}\right.$ in $\left.\mathrm{mol} / \mathrm{m}^{3}\right)$ according to the equilibrium relation:

$$
\mathrm{K}_{\mathrm{w}}=\frac{\sqrt{\mathrm{C}_{\mathrm{gH}_{2} \mathrm{O}}}}{\mathrm{C}_{\mathrm{CH}_{\mathrm{s}}}},
$$

where $\mathrm{K}_{\mathrm{w}}$ is the equilibrium constant $\left(\left(\mathrm{mol} / \mathrm{m}^{3}\right)^{-1 / 2}\right)$. Because these reactions take place at high temperatures, kinetics for reaction (3) are assumed to be so fast that the material concentrations can be described by chemical equilibrium. 
If the bulk melt has obtained equilibrium with $\mathrm{C}_{\mathrm{BH}_{2}} \mathrm{O}$, then the surface $\mathrm{OH}$ concentration $\left(\mathrm{C}_{\mathrm{OH}_{s}}\right)$ is equal to the bulk $\mathrm{OH}$ concentration ( $\left.\mathrm{C}_{\mathrm{OH}}\right)$. However, we can only measure the bulk $\mathrm{OH}$ content by optical absorption $(\alpha)$. Then by the same token, when the bulk equilibrium has been reached, then $\alpha=\alpha_{3}$ where $\alpha_{2}$ is the absorption coefficient for OH at the surface. Therefore the surface equilibrium relation given by Eq. (4) is more conveniently given as

$$
K_{w p}=\frac{\sqrt{P_{H_{2} O}}}{\alpha_{s}} \text {, }
$$

and when bulk equilibrium is reached, it is given by

$$
K_{w p}=\frac{\sqrt{P_{\mathrm{H}_{2} \mathrm{O}}}}{\alpha} .
$$

The values for $K_{w p}$ as a function of temperature can be determined from the $\mathrm{H}_{2} \mathrm{O} / \mathrm{OH}$ equilibrium melts (see Table 1). When $\alpha$ is plotted versus $P_{\mathrm{H}_{2}} \mathrm{O}^{1 / 2}$, it yields a straight-line for both LG-770 and LHG-8 suggesting Eq. 6 is valid (see Figs. $4 \mathrm{a}$ and $\mathrm{b}$ ). The reciprocals of the line slopes in Figs. $4 \mathrm{a}$ and $\mathrm{b}$ give values for $\mathrm{K}_{\mathrm{wp}}$ which are reported in the last column of Table 1. At higher temperatures, the slopes are lower which leads to higher $\mathrm{K}_{w p}$ values. In other words, the equilibrium $\mathrm{OH}$ content of the glass is lower at higher temperatures. At an equivalent temperature, the equilibrium $\mathrm{OH}$ content of LHG-8 is slightly lower than LG-770. This is shown in Fig. $4 \mathrm{c}$ where both glasses are compared at $1100^{\circ} \mathrm{C}\left(\mathrm{K}_{\mathrm{wp}}=1.96 \mathrm{~Pa} / \mathrm{cm}^{-1}\right.$ for LHG-8 and $\mathrm{K}_{\mathrm{wp}}=1.56 \mathrm{~Pa}^{1 / 2} / \mathrm{cm}^{-1}$ for LG-770).

Figure $4 \mathrm{~d}$ is an Arrhenius plot of the equilibrium constant $\left(\mathrm{K}_{\mathrm{wp}}\right)$ determined for both glasses; a linear fit to the data gives the expression

$$
\mathrm{K}_{\text {wp }}=\mathrm{K}_{\mathrm{o}} \exp \left(\frac{-\Delta G}{\mathrm{RT}}\right) \text {, }
$$

where $\Delta G$ is the free energy, $K_{0}$ is the pre-exponential constant, and $R$ is the ideal gas constant. The two glasses are found to have similar free energies (28.9 kJ/mol (LG-770) and $26.0 \mathrm{~kJ} / \mathrm{mol}(\mathrm{LHG}-8)$ ), and the values for $\mathrm{K}_{0} \operatorname{are~} 20.4 \mathrm{~Pa}^{1 / 2} / \mathrm{cm}^{-1}(\mathrm{LG}-$ 770) and $19.14 \mathrm{~Pa}^{1 / 2} / \mathrm{cm}^{-1}$ (LHG-8).

In the presence of $\mathrm{Cl}_{2}$, a vapor phase reaction between $\mathrm{Cl}_{2}$ gas and $\mathrm{H}_{2} \mathrm{O}$ vapor occurs,

$$
2 \mathrm{H}_{2} \mathrm{O}+2 \mathrm{Cl}_{2} \rightarrow 4 \mathrm{HCl}+\mathrm{O}_{2} \text {. }
$$

As written (left to right), Eq. (8) is known as the reverse Deacon reaction ${ }^{23}$, with the $\mathrm{Cl}_{2}$ acting to dehydrate the vapor. The equilibrium constant for this reaction is given by

$$
K_{d}=\frac{C_{2 \mathrm{HCl}}{ }^{4} C_{\mathrm{gO}_{2}}}{C_{\mathrm{gH}_{2} \mathrm{O}}{ }^{2} C_{\mathrm{BCl}_{2}}^{2}},
$$

where $\mathrm{C}_{8 \mathrm{O}}, \mathrm{C}_{\mathrm{gHC}}, \mathrm{C}_{\mathrm{gC}_{2}}$ are the $\mathrm{O}_{2}, \mathrm{HCl}$, and $\mathrm{Cl}_{2}$ concentrations in the gas phase ( $\mathrm{mol} / \mathrm{m}^{3}$ ), and $\mathrm{K}_{\mathrm{d}}$ is the equilibrium constant $\left(\mathrm{mol} / \mathrm{m}^{3}\right)$. The equilibrium constant for Eq. (9) has been reported as 23 :

$$
K_{d}=\frac{\left(10^{\frac{-6104}{T}+7.099}\right) \cdot a t m}{R T} .
$$

$\mathrm{K}_{d}$ has a value of 3996 and $7463 \mathrm{~mol} / \mathrm{m}^{3}$ at $1100^{\circ} \mathrm{C}$ and $1200^{\circ} \mathrm{C}$, respectively 23 . These relatively large $\mathrm{K}_{d}$ values lead to low concentrations of water vapor in equilibrium mixtures. As a consequence, in systems containing chlorine in the bubbling gas, the driving force for mass transfer between the bulk glass and the glass/bubble interface remains high (i.e. $\mathrm{C}_{1 \mathrm{OH}}$ is low). In contrast, in systems where only $\mathrm{O}_{2}$ is present, the bubbles tend to reach saturation because of the equilibrium imposed by Eq. (5). In this case, the driving force for transport of $\mathrm{OH}$ out of the melt becomes small (i.e. $\mathrm{C}_{\mathrm{NOH}_{s}}$ is high), and the dehydration rate is correspondingly slower.

Although the details of the reaction mechanism between $\mathrm{Cl}_{2}$ and $\mathrm{H}_{2} \mathrm{O}$ are not well known, it is likely that $\mathrm{Cl}_{2}$ dissociates to form $\mathrm{Cl}$ radicals at these high temperatures 16 . Regardless of the mechanism, the overall reaction can still be described by Eq. (8). Note also that the current model assumes that the potential reaction of $\mathrm{OH}$ at the glass interface with $\mathrm{Cl}$ or $\mathrm{Cl}_{2}$ is negligible. 

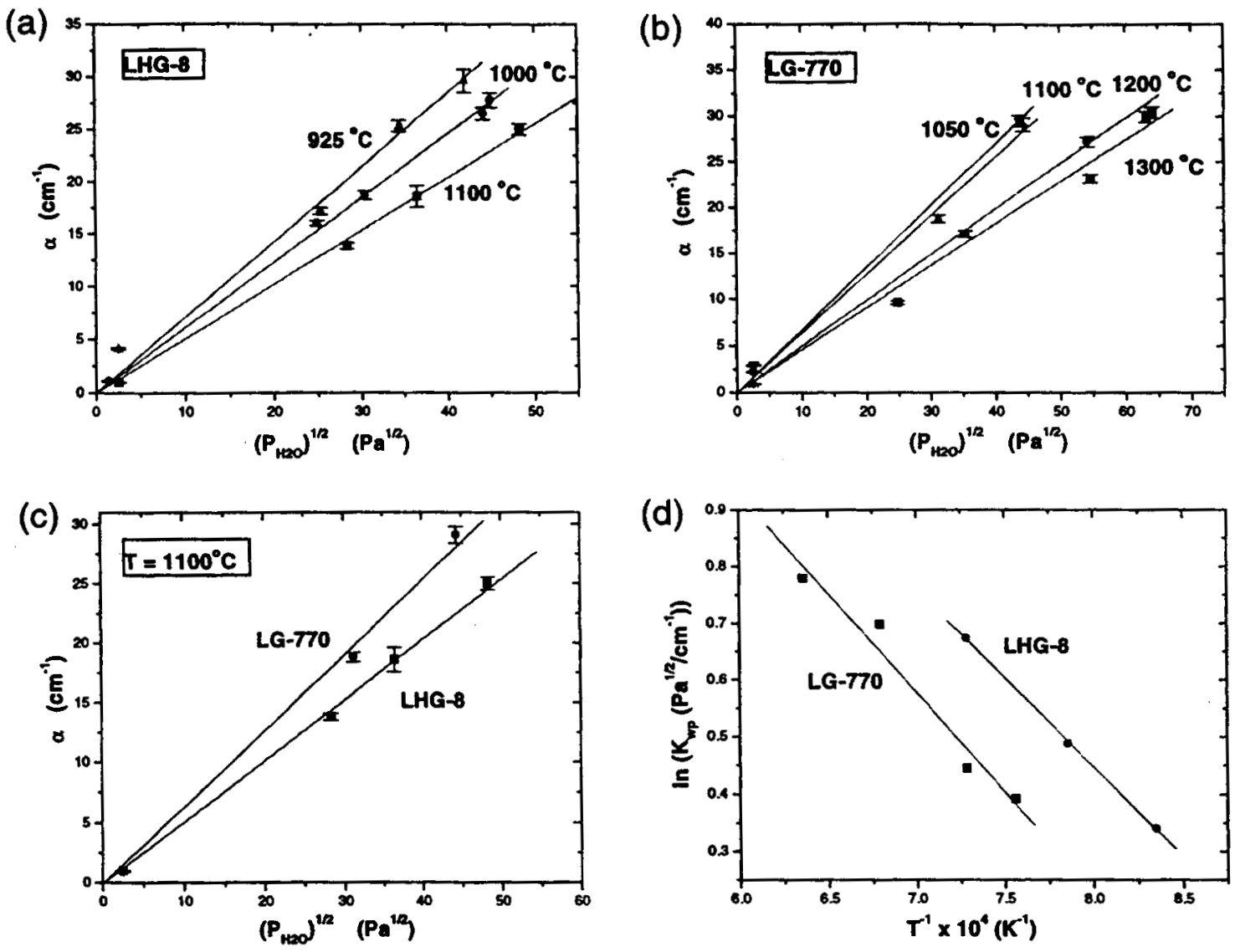

Figure 4. (a) OH content $(\alpha)$ as a function of the $\mathrm{P}_{\mathrm{H}_{2}} \mathrm{O}^{1 / 2}$ for LHG-8 glass melts at various temperatures. The melting conditions and data points are reported in Table 1 . The lines represent fits to the data where the inverse of the slope is $K_{w p}$. (b) Same as (a) for LG-770 glass melts. (c) $\mathrm{OH}$ content ( $\alpha$ ) as a function of the $\mathrm{P}_{\mathrm{H}_{2}} \mathrm{O}^{1 / 2}$ at $1100^{\circ} \mathrm{C}$ for both glasses. (d) Arthenius plot of the determined $\mathrm{K}_{\mathrm{wp}}$ values (points) at various temperatures for LG-770 and LHG-8. The lines represent fits to the data points using Eq. (9).

\subsection{Model Description}

\subsubsection{Balance Equations}

A computer model has been developed that describes the removal rate of $\mathrm{OH}$ groups from phosphate laser glass using either an inert (e.g. $\mathrm{O}_{2}$ ) or reactive (e.g. $\mathrm{Cl}_{2}$ ) gas employing mass transfer constraints and reaction equilibriums discussed in the previous section. The model assumes the system can be described by equations appropriate for a timedependent, one-dimensional bubble column (see Fig. 5).

The concentration of species (e.g. $\mathrm{H}_{2} \mathrm{O}, \mathrm{OH}, \mathrm{Cl}_{2}, \mathrm{O}_{2}$ etc) in this model can be described mathematically by a system of coupled partial differential equations where the concentration is both a function of time (t) and height $(z)$ in the bubble column. The generic set of equations used to describe a time-dependent, one-dimensional bubble column are simply the balance equations of each of chemicals species of interest in the gas and liquid phase 24 :

$$
\begin{aligned}
& \frac{-\partial C_{\ell}}{\partial t}=E_{\ell} \frac{\partial^{2} C_{\ell}}{\partial z^{2}}-U_{\ell} \frac{\partial C_{\ell}}{\partial z}-\frac{k A_{b}}{1-\phi}\left(C_{\ell}-C_{\ell}^{*}\right)-R_{\ell} \\
& \frac{-\partial C_{g}}{\partial t}=E_{8} \frac{\partial^{2} C_{g}}{\partial z^{2}}-U_{8} \frac{\partial C_{g}}{\partial z}+\frac{k A_{b}}{1-\phi}\left(C_{\ell}-C_{\ell}^{*}\right)-R_{g}
\end{aligned}
$$

The subscript $\ell$ represents parameters or species in the liquid phase and $g$ represents parameters or species in the gas phase. $\mathrm{C}$ is the concentration of particular species at time $(\mathrm{t})$ and height $(\mathrm{z}), \mathrm{C}^{*}$ is the gas/liquid interface concentration, $\mathrm{E}$ is the 
dispersion coefficient $\left(\mathrm{m}^{2} / \mathrm{sec}\right), U$ is the average velocity $(\mathrm{m} / \mathrm{sec}), \mathrm{kA}_{\mathrm{b}}$ is the overall mass transport $\left(\mathrm{sec}^{-1}\right), \phi$ is the melt porosity, and $R$ is the source or sink term from bulk reaction $\left(\mathrm{mol} / \mathrm{m}^{3} \mathrm{sec}\right)$. Equations (11) and (12) state that the net flux of a particular chemical species at a certain time and height in the bubble column is determined by transport of species in and out of plane $\mathrm{Z}$ by dispersion (or diffusion) (first term on right-hand side of Eqs. (11) and (12)), by transport of species in and out of plane $\mathbf{Z}$ by convection (second term), mass transport to another phase (from liquid to vapor or vapor to liquid) (third term), and by the change in concentration from reaction with other species (fourth term). Using several assumptions, the balance equations can be simplified for the case of glass dehydroxylation. First, we assume that the liquid phase (i.e. the glass melt) is well mixed because gas bubbling is used in the melt. This means that the concentration of the liquid does not change with position, and therefore, all the liquid dispersion terms $\left(E_{\ell} \frac{\partial^{2} C_{l}}{\partial z^{2}}\right)$ and the convection terms $\left(U_{\ell} \frac{\partial C_{l}}{\partial z}\right)$ for each of the chemical species go to zero. Secondly, the gas concentration as a function of position is dominated by convection (not diffusion), hence $E_{g} \frac{\partial^{2} C_{z}}{\partial z^{2}}=0$. Finally, we assume there is no bulk reaction in the liquid phase, $\mathrm{R}_{\ell}=0$. With the following constraints, the balance equations for $\mathrm{OH}$ in the liquid and $\mathrm{H}_{2} \mathrm{O}$ in the gas phase can be written as:

$$
\begin{gathered}
\frac{-\partial C_{\ell \mathrm{OH}}}{\partial t}=-\frac{k A_{b}}{1-\phi}\left(C_{\mathrm{COH}}-C_{\mathrm{COH}_{s}}\right) \\
\frac{-\partial C_{\mathrm{gH}_{2} \mathrm{O}}}{\partial t}=-U_{g} \frac{\partial C_{g \mathrm{H}_{2} \mathrm{O}}}{\partial z}+\frac{k A_{b}}{2 \phi}\left(C_{\mathrm{COH}}-C_{\mathrm{COH}_{\mathrm{s}}}\right)-R_{\mathrm{H}_{2} \mathrm{O} / \mathrm{HCl}}
\end{gathered}
$$

where $\mathrm{R}_{\mathrm{H}_{2} \mathrm{O} / \mathrm{HCl}}$ is the reaction rate of the reverse Deacon reaction (Eq. 8) which is given by:

$$
R_{\mathrm{H}_{2} \mathrm{O} / \mathrm{HCl}}=r_{d}\left(C_{8 \mathrm{Cl}_{2}}\right)^{2}\left(C_{\mathrm{gH}_{2} \mathrm{O}}\right)^{2}
$$

where $r_{d}$ is the reaction rate constant for the reverse Deacon reaction. The balance equations can also be written for other chemical species $\left(\mathrm{Cl}_{2}, \mathrm{O}_{2}\right.$, and $\left.\mathrm{HCl}\right)$ in a similar manner as was done for $\mathrm{H}_{2} \mathrm{O}$ and $\mathrm{OH}$.

The dehydroxylation model treats all the balance equations, and numerically solves the set of partial differential equations. The $\mathrm{H}_{2} \mathrm{O} / \mathrm{OH}$ equilibrium constraint is imposed by using Eq. (4) and the computed gas phase $\mathrm{H}_{2} \mathrm{O}$ concentration to set $\mathrm{C}_{\mathrm{OH}_{3}}$. In the gas phase, the $\mathrm{H}_{2} \mathrm{O} / \mathrm{HCl}$ equilibrium is imposed by defining a simple mass action rate for the reverse Deacon reaction (Eq. (15)) which is fast. A rate for the forward reaction is defined using this rate and the equilibrium relation given by Eq. (9). In the model, competition between these rates enforces the $\mathrm{H}_{2} \mathrm{O} / \mathrm{HCl}$ equilibrium.

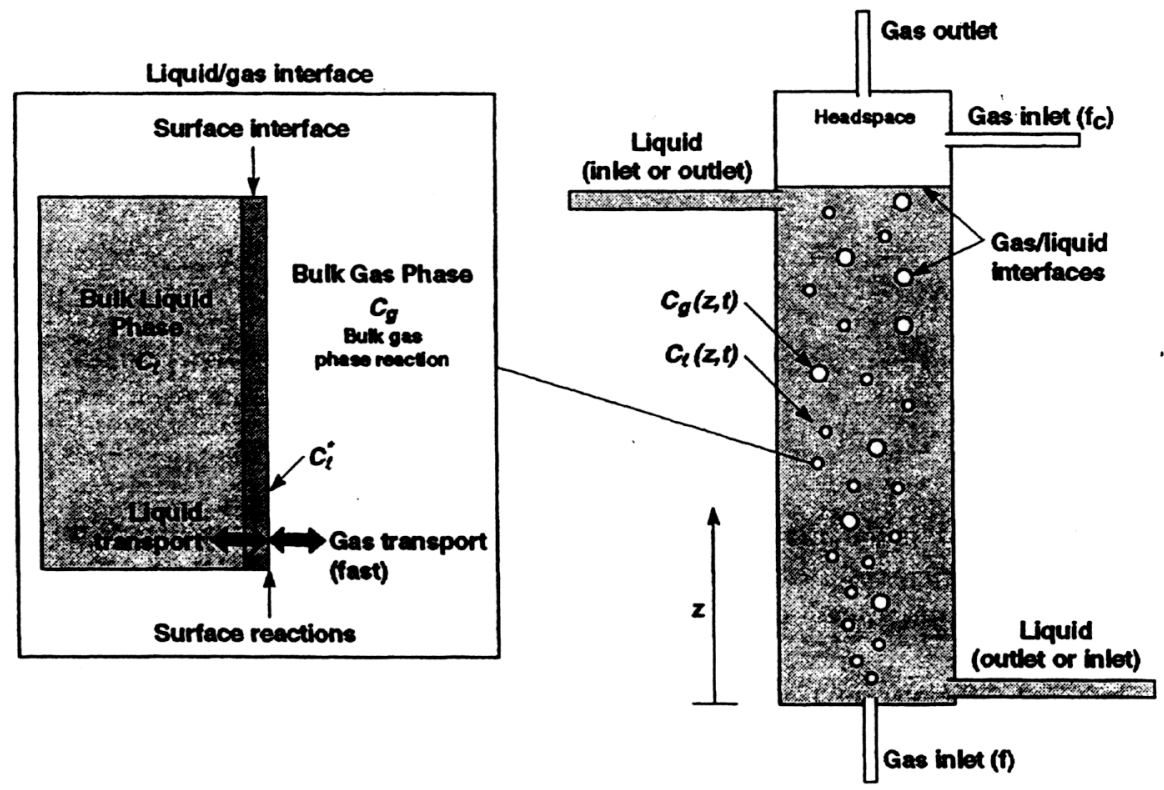

Fig. 5. Physical representation of the time-dependent, one-dimensional dehydroxylation model for $\mathrm{OH}$ removal using gas bubbling through a phosphate glass melt. The model treats both inert and reactive gases. 


\subsubsection{Mass transport at the melt/vapor interface}

Transport of $\mathrm{OH}$ can occur at two types of interfaces, the bubble and top surface of the melt. When bubbles are formed in a bubble column, a large distribution of bubble sizes is typically observed. Hence there is not a simple representation of the interfacial area. Transport at the bubble interface is characterized in the model by an effective transport parameter, $\mathbf{k A}_{b}$, which is the product of the mass transfer coefficient, $k$, and the interfacial area of the bubbles per unit volume, $A_{b}$. There are a large number of approaches and correlations used to estimate transport between the vapor phase inside a bubble and a surrounding liquid. The approach taken is dictated by the type of bubbling regime present. Bubbling regimes are often categorized by the nature of the bubble flow:

1. Homogeneous regime - Low bubble concentrations where the bubbles tend to move from the their origin to the surface with little interaction.

2. Heterogeneous regime - Moderate bubble concentrations where considerable interaction between bubbles occur.

3. Slug flow regime - Relatively high gas throughputs where large slugs of vapor and liquid are present.

We have chosen to use a bubble mass transfer correlation proposed by Deckwer 25 which can be employed over a large range of flow conditions. The effective bubble mass transfer is defined as

$$
k A_{b}=\frac{D_{\mathrm{COH}} S h}{d_{c}^{2}}
$$

where $d_{c}$ is the diameter of the bubble column $(m)$, and

$$
S h=0.6 S c^{0.5} B o^{0.62} G a^{0.31} \varphi^{1.1} .
$$

The four dimensionless numbers appearing in Eq. (17) are the Sherwood (Sh), Schmidt (Sc), Bond (Bo) and Galilei (Ga) numbers, where

$$
S c=\frac{\mu_{\ell}}{\rho_{\ell} D_{\ell O H}}, B o=\frac{g d_{c}^{2} \rho_{\ell}}{\sigma}, \text { and } G a=\frac{g d_{c}^{3} \rho_{\ell}^{2}}{\mu_{\ell}^{2}} .
$$

Here $\mu_{\ell}$ is the liquid viscosity $(\mathrm{Pa} \mathrm{sec}), \rho_{\ell}$ is the liquid density $\left(\mathrm{kg} / \mathrm{m}^{3}\right), \sigma$ is the surface tension $(\mathrm{N} / \mathrm{m})$ of the liquid melt, and $\mathrm{g}$ is the acceleration of gravity $\left(\mathrm{m} / \mathrm{sec}^{2}\right)$.

The fourth term in Eq. (17) is the melt porosity, $\phi$, or void volume created by the bubbling. For viscous fluids Deckwer suggests using the following correlation to obtain the porosity,

$$
\phi=0.2 B o^{-0.13} \mathrm{Ga}^{0.11} \mathrm{Fr}^{0.54} \text {. }
$$

Here $F r$ is the Froude number and is given by

$$
F r=\frac{u_{g}}{\sqrt{g d_{c}}},
$$

where $u_{g}$ is the superficial gas velocity $(\mathrm{m} / \mathrm{s})$ which is given by

$$
u_{g}=\frac{4 f R T}{\pi P d_{c}^{2}}
$$

where $f$ is the gas flow in $\mathrm{mol} / \mathrm{sec}$ and $\mathrm{P}$ is the total gas pressure $(\mathrm{Pa})$. Notice the correlation makes no explicit use of bubble diameter or rise velocity, nor does it compute these values. However, Eq. (16) does allow the necessary transport parameter $\mathbf{k A}_{b}$ for the bubble interfaces, to be computed. Also, note that the superficial gas velocity $\left(u_{g}\right)$ is just the average velocity $\left(\mathrm{U}_{2}\right)$ divided by the melt fraction $(1-\phi)$. obtained

By substituting Eqs. (17)-(23) into Eq. (16) the following dependence of the transport factor on process variables is

$$
k A_{b} \propto d_{c}^{-0.05} u_{g}^{0.6} D_{\ell O H}{ }^{0.5} \rho_{\ell}^{0.84} \mu_{\ell}^{-0.36} \sigma^{-0.48} .
$$


Based on this correlation, one sees that the transport factor is a very weak function of vessel diameter, increases as superficial gas velocity or diffusivity increases and decreases as viscosity or surface tension increases.

The transport to/from a liquid column to an overlying gas at the top of a bubble column has received little attention in the literature because for many systems it is not important. However, in small systems it can be as important as the bubble phase transport. Unfortunately, we do not know of any established correlations for estimating surface transport coefficients from system variables. Consequently, we have employed a simple correlation using surface renewal theory which introduces two parameters surface velocity, $v_{s}$, and a characteristic length, $l_{s}$. Surface renewal theory can be used to relate these parameters and diffusivity to the transport coefficient at the surface is

$$
k=\sqrt{\frac{4 D_{\mathrm{COH}} v_{s}}{\pi l_{s}}} .
$$

Parameterized in this fashion it is possible to make at least limiting estimates of the magnitude of the transport by choosing reasonable values of $v_{s}$ and $l_{s}$. Notice, however, that the transport coefficient actually depends only on the ratio of these two parameters.

As mentioned above, the characterization of the surface transport is the most difficult to deal with. In the following, we assume that $l_{s}$ is a measure of the activity of bubbles breaking at the surface and that this activity is proportional to the flux of gas in the bubbles, with higher flux leading to more violent action and thus a smaller effective length scale. We further assume that this behavior can be approximated using the simple relation

$$
l_{s}=\frac{L_{s}}{u_{\varepsilon}}
$$

where $\mathrm{L}_{s}$ is a constant. Since the surface transport actually depends on the ratio of $v_{s}$ and $l_{s}$ (Eq. (25)), we choose a reasonable but arbitrary value for $v_{s}(0.3 \mathrm{~m} / \mathrm{sec})$, a value equal to the rise velocity of the larger bubbles in the system. We allow $L_{2}$ to be a parameter to be determined by fitting of model results to the experimental data.

\subsubsection{Limiting cases}

The partial differential equations described in Section 4.2.1 can only be solved numerically. However, it is instructive to explore limiting cases where the differential equations yield analytical solutions. For example, if the system is limited only by mass transfer of $\mathrm{OH}$ in the liquid to the liquid/vapor interface, the following equation applies:

$$
\frac{d C_{\ell O H}}{d t}=-\frac{k A_{v}}{1-\phi} C_{\text {lOH }} \text {. }
$$

Here it is assumed that the equilibrium constant $K_{w}$ is sufficiently large, or sufficient chlorine is present, such that the effective equilibrium concentration of $\mathrm{OH}$ 'at the vapor/liquid interface $\left(\mathrm{C}_{\mathrm{eH}}\right)$ is zero. Equation (27) can be easily integrated giving:

$$
\frac{C_{\mathrm{COH}}}{C_{\mathrm{lOH}}}=\exp \left[-\frac{k A_{v}}{1-\phi} t\right] \text {. }
$$

A simplified set of equations can also be developed for the case in which transport is fast and the system is controlled by the two previously defined equilibrium relations. This is done by writing the overall hydrogen balance for the system:

$$
V(1-\phi) \frac{d C_{\ell O H}}{d t}=-f\left(2 y_{H_{2} \mathrm{O}}+y_{H C l}\right) \text {. }
$$

where $\mathrm{V}$ is the melt volume. $\mathrm{y}_{\mathrm{H}_{2} \mathrm{O}}$ and $\mathrm{y}_{\mathrm{HC}}$ are gas mole fractions of $\mathrm{H}_{2} \mathrm{O}$ and $\mathrm{HCl}$, respectively, exiting the system. For simplicity we assume that no $\mathrm{H}_{2} \mathrm{O}$ or $\mathrm{HCl}$ enter the system in the gas phase. Using the ideal gas law and Eq. (9) and (4), the gas mole fractions can then be described as:

$$
y_{\mathrm{H}_{2} \mathrm{O}}=\frac{C_{8 \mathrm{H}_{2} \mathrm{O}}}{C_{8}}=\frac{R T K_{w}{ }^{2} C_{\mathrm{COH}}{ }^{2}}{P},
$$




$$
y_{H C l}=\frac{C_{g H C l}}{C_{8}}=\frac{R T K_{w} C_{l O H}}{P}\left(\frac{K_{d} C_{g C l_{2}}{ }^{2}}{C_{8 O_{2}}}\right)^{1 / 4}
$$

where $P$ is the total gas pressure ( $P a$ ). Note, because mass transfer is fast, $\mathrm{C}_{\mathrm{fOH}} \approx \mathrm{C}_{\mathrm{OOH}_{\mathrm{s}}}$. Combining the equilibrium relations with this hydrogen balance gives

$$
\frac{d C_{\mathrm{ZOH}}}{d t}=-\frac{f R T}{P V(1-\phi)}\left(2 K_{w}{ }^{2} C_{\mathrm{ZOH}}{ }^{2}+\left(\frac{K_{d} C_{8 C_{2}}{ }^{2}}{C_{g O_{2}}}\right)^{1 / 4} K_{w} C_{\mathrm{COH}}\right)
$$

If no chlorine is present $\left(\mathrm{C}_{\mathrm{gC}_{2}}=0\right)$ then Eq. (32) can be integrated to give the result

$$
\frac{1}{C_{\mathrm{COH}}}=\frac{1}{C_{\mathrm{COH}}}+\frac{2 f K_{w}{ }^{2} R T t}{P V(1-\phi)}
$$

In cases where significant amounts of $\mathrm{Cl}_{2}$ are present and the water vapor levels in the exiting gas are small compared to the $\mathrm{HCl}$ levels, the right hand side of Eq. (32) will be dominated by the second term in the bracket. In this case Eq. (32) can be integrated to give

$$
\frac{C_{\mathrm{OOH}}}{C_{\mathrm{COH}}}=\exp \left[\frac{-f R T K_{w}}{P V(1-\phi)}\left(\frac{K_{d} C_{8 C_{2}}^{2}}{C_{\mathrm{gO}_{2}}}\right)^{1 / 4} t\right]
$$

Notice that in the presence of $\mathrm{Cl}_{2}$, the form of the equation describing the evolution of $\mathrm{OH}$ levels in the melt has the same exponential form for both the mass transfer controlled (Eq. (28)) and the equilibrium controlled (Eq. (34)) cases. In either case, if data are plotted on a semi-log plot a straight line should result if the limiting case applies. In one case the slope of the line would be proportional to the overall transport coefficient, whereas in the other case it yields information on the magnitude of the equilibrium constants.

On the other hand, in the absence of chlorine, a semi-log plot of the data would only be a straight line if the system were dominated by mass transport (Eq. (28)). If equilibrium constraints dominate the system then a plot of the reciprocal of

\begin{tabular}{|c|c|c|}
\hline Limiting Case & Differential Form & Solution \\
\hline Mass transfer limited & $\frac{d C_{\ell O H}}{d t}=-\frac{k A_{v}}{1-\phi} C_{\ell O H}$ & $\frac{C_{\mathrm{COH}}}{C_{\mathrm{COH}}}=\exp \left[-\frac{k A_{v}}{1-\phi} t\right]$ \\
\hline $\begin{array}{l}\mathrm{H}_{2} \mathrm{O} / \mathrm{OH} \text { Equilibrium } \\
\text { limited } \\
\left(\text { no } \mathrm{Cl}_{2}\right)\end{array}$ & $\frac{d C_{\ell O H}}{d t}=\frac{-2 f R T K_{w}^{2}}{P V} C_{\ell O H}^{2}$ & $\frac{1}{C_{\mathrm{COH}}}=\frac{1}{C_{\mathrm{COH}}}+\frac{2 f K_{w}{ }^{2} R T t}{P V(1-\phi)}$ \\
\hline $\begin{array}{c}\mathrm{H}_{2} \mathrm{O} / \mathrm{OH} \text { Equilibrium } \\
\text { limited } \\
\text { (high } \mathrm{Cl}_{2} \text { levels and } \\
\mathrm{C}_{2 \mathrm{CO}_{2}} \gg \mathrm{C}_{\mathrm{EH}_{2} \mathrm{O}} \text { ) }\end{array}$ & $\frac{d C_{\mathrm{lOH}}}{d t}=-\frac{f R T K_{\mathrm{w}}}{P V(1-\phi)}\left(\frac{K_{1} C_{\mathrm{PC}_{2}}{ }^{2}}{C_{\mathrm{SO}_{2}}}\right)^{1 / 4} C_{\mathrm{eOH}}$ & $\frac{C_{\text {eOH }}}{C_{\text {COHo }}}=\exp \left[\frac{-f R T K_{w}}{P V(1-\phi)}\left(\frac{K_{d} C_{8} \mathrm{C}_{2}{ }^{2}}{C_{8 O_{1}}}\right)^{1 / 4} t\right.$ \\
\hline
\end{tabular}
$\mathrm{OH}$ concentration versus time would yield a straight line (Eq. (33)). Table 3 summarizes the limiting cases described in this section.

Table 3: Limiting cases of dehydration model 


\section{DISCUSSION}

\subsection{Application of the dehydration model to small scale melts}

Using the determined or literature values for $\mathrm{D}_{\mathrm{COH}}, \mathrm{K}_{\mathrm{wp}}$, and $\mathrm{K}_{\mathrm{d}}$ as a function of temperature, the known melt properties, and the known experimental parameters (see Table 4), the full dehydration model (described in Section 4) was used to compute the $\mathrm{OH}$ removal rates from LG-770 melts. Two values that are not well known, the $\mathrm{OH}$ extinction coefficient $(\varepsilon)$ and $L_{2}$ were used as fitting parameters in the model. Limits on reasonable values were set for both of these parameters. The extinction coefficient relates the absorption coefficient of $\mathrm{OH}$ at $3.333 \mu \mathrm{m}$ to the $\mathrm{OH}$ concentration in the glass in ppm by weight. Reported values for the $\mathrm{OH}$ extinction coefficient vary from about 30 to $400 \mathrm{ppm} / \mathrm{cm}^{-1}$ with most factors ranging from 50 to $130 \mathrm{ppmw} / \mathrm{cm}^{-1} 15$. The $\mathrm{H}_{2} \mathrm{O} / \mathrm{OH}$ extinction coefficient that best fits the data was determined to be $52 \mathrm{ppmw} / \mathrm{cm}^{-1}$ (see Table 4).

The value of the other fitting parameter, $L_{3}$, effects the relative amount of mass transfer at the bubble interface to that at the top surface. The ratio $L_{\mathbf{s}} / \mathrm{v}_{\mathbf{s}}\left(=\mathrm{I}_{\mathbf{s}}\right)$ gives the length scale over which a packet of fluid is assumed to remain on the surface. The value of $\mathrm{L}_{8}$ found during the fitting procedure results in values of $\mathrm{l}_{8}$ on the order of $1 \mathrm{~cm}$. One would expect the length scale to be bounded by the diameter of the vessel at the high end and the characteristic bubble size at the low end, and, indeed, the determined values of $l_{s}$ fit within these bounds.

A similar fitting procedure was performed for LHG-8, except that values for $D_{\mathrm{OOH}}$ were not available. Assuming that the $\mathrm{H}_{2} \mathrm{O} / \mathrm{OH}$ extinction coefficient $(\varepsilon)$ is the same for both glasses, the data was fit using two fitting parameters $\left(\mathrm{D}_{\rho \mathrm{OH}}\right.$ and $\left.\mathrm{L}_{s}\right)$. The $D_{\text {COH }}$ values that best fit the data were $D_{\mathrm{COH}}=2.0 \times 10^{-11} \mathrm{~m}^{2} / \mathrm{sec}\left(1000^{\circ} \mathrm{C}\right), 3.0 \times 10^{-11} \mathrm{~m}^{2} / \mathrm{sec}\left(1100^{\circ} \mathrm{C}\right)$, and $4.3 \times 10^{-11}$ $\mathrm{m}^{2} / \mathrm{sec}\left(1165^{\circ} \mathrm{C}\right)$. Note that different combinations of $\mathrm{D}_{\mathrm{eOH}}$ and $\mathrm{L}_{3}$ can be used to fit the data; however the values we ultimately chose appear to reasonably fit both the small-scale test melts and large-scale continuous production melts the best (see section 5.5).

Table 4. Parameters used in dehydration model

\begin{tabular}{|c|c|c|}
\hline & LG-770 & LHG-8 \\
\hline \multicolumn{3}{|l|}{ Experimental Parameters } \\
\hline Column diam. $\left(\mathrm{d}_{\mathrm{c}}\right)$ & $9.4 \mathrm{~cm}$ & $11.2 \mathrm{~cm}$ \\
\hline Column height & $17 \mathrm{~cm}$ or $9.5 \mathrm{~cm}$ & $12.7 \mathrm{~cm}$ \\
\hline Cover gas $\left(f_{c}\right)$ & $20 \mathrm{scfh}$ & 0 \\
\hline Temperature (T) & $1200-1300^{\circ} \mathrm{C}$ & $1000-1165^{\circ} \mathrm{C}$ \\
\hline Flow rate $(f)$ & $0-1.08 \mathrm{scfh}$ & $0.54-1.1 \mathrm{scfh}$ \\
\hline \multicolumn{3}{|l|}{ Melt Parameters } \\
\hline Viscosity $\left(\mu_{\ell}\right)$ & $0.30 \mathrm{~Pa} \bullet \sec$ & $0.96 \mathrm{~Pa} \bullet \sec$ \\
\hline Surface tension $(\sigma)$ & $0.15 \mathrm{~N} / \mathrm{m}$ & $0.15 \mathrm{~N} / \mathrm{m}$ \\
\hline Melt density $\left(\rho_{\ell}\right)$ & $2.12 \mathrm{~g} / \mathrm{cm}^{3}$ & $2.32 \mathrm{~g} / \mathrm{cm}^{3}$ \\
\hline $\mathbf{K}_{\mathbf{d}}$ & Eq. (10) & Eq. (10) \\
\hline $\mathbf{K}_{\mathbf{w p}}$ & Eq. (7) & Eq. (7) \\
\hline $\mathrm{D}_{\mathrm{CH}}$ & $\mathrm{Eq}(2)$ & see Section 5.1* \\
\hline OH extinction coefficient $(\varepsilon)$ & $52 \mathrm{ppm} / \mathrm{cm}^{-1} *$ & $52 \mathrm{ppm} / \mathrm{cm}^{-1}$ \\
\hline $\mathrm{L}_{3}$ & $3 \times 10^{-5} \mathrm{~m}^{2} / \mathrm{s}^{*}$ & $15 \times 10^{-5} \mathrm{~m}^{2} / \mathrm{s}^{*}$ \\
\hline
\end{tabular}

\subsection{Effect of experimental parameters on dehydration kinetics}

To fairly compare the dehydration rates for different melts, the data in Figs. 6 and 7 are plotted in terms of the normalized OH content (i.e. $\alpha$ at time t over $\alpha$ at time zero $\left(\alpha_{0}\right)$ ). In addition, a log scale abscissa is used because it best illustrates small changes over an extended range of water content. However, care should be exercised when viewing the data 
on such semi-log plots so that too much weight is not given to very low values of the ratio $\alpha / \alpha_{0}$.

The solid lines in Figures $6 \mathrm{a}-6 \mathrm{f}$ represent the predictions of the full dehydration model to the data using the parameters summarized in Table 4. Considering all the plots, the fits to the data are reasonably good, remembering that all the data is shown on semi-log plots. Figure 6a illustrates the effect of temperature on the rate of dehydroxylation for LG-770 glass during bubbling with $\mathrm{O}_{2}$ and $\mathrm{Cl}_{2}$. The rate of dehydroxylation increases with an increase in temperature. This is not surprising since both the mass transport $\left(\mathrm{D}_{\mathrm{O}} \mathrm{H}\right)$, and the equilibrium constraints $\left(\mathrm{K}_{\mathrm{d}}, \mathrm{K}_{\mathrm{w}}\right)$ are driven toward values that would increase the dehydroxylation rate. However, the temperature effect is relatively small over the temperature range explored in this study. As seen in Fig. 6b, the effect of bubbling flow rate is much greater. After one hour of bubbling, a $4 \times$ increase in flow rate resulted in about a $5 \times$ improvement in the degree of dehydroxylation. Without any bubbling (i.e. where all dehydration takes place at the melt top surface), a noticeable amount of dehydration still takes place (see Fig. $6 \mathrm{c}$ ). The addition of $\mathrm{O}_{2}$ bubbling at $0.54 \mathrm{scfh}$ (shown on the same plot) increases the amount of dehydroxylation by $7 \times$ after one hour. The addition of $\mathrm{Cl}_{2}$ to the gas bubbling (also shown in the same plot) increases the amount of dehydroxylation by $29 \times$ after one hour (compared to no bubbling). Clearly, to achieve fast rates of dehydroxylation, the use of higher flow rates and the presence of $\mathrm{Cl}_{2}$ are preferred.

While the $\mathrm{OH}$ concentration in the glass melt is still high, changing the amount of $\mathrm{Cl}_{2}$ in the bubbling gas compositions should also have a strong effect on the amount of dehydroxylation. Remember that $\mathrm{Cl}_{2}$ acts as a getter which chemically removes $\mathrm{H}_{2} \mathrm{O}$ from the gas phase and increases the driving force for more $\mathrm{OH}$ to come out of the liquid. At low $\mathrm{OH}$ concentrations in the liquid, the amount of $\mathrm{Cl}_{2}$ present does not play as strong of a role, because there is more $\mathrm{Cl}_{2}$ than $\mathrm{H}_{2} \mathrm{O}$ present in the gas phase. However, the presence of at least a small amount of $\mathrm{Cl}_{2}$ is needed to enhance the rate of dehydroxylation. This is because without $\mathrm{Cl}_{2}$, even small amount of $\mathrm{H}_{2} \mathrm{O}$ in the vapor will saturate the gas (see Eq. (5)); hence, the $\mathrm{OH}$ removal will be slow.

The results of the glass melts performed by bubbling at various $\mathrm{Cl}_{2}$ concentrations are shown in Fig. $6 \mathrm{~d}$. The model predictions to the data are not as good for this set of experiments. The experimental data, specifically those taken with high $\mathrm{Cl}_{2}$, show less dehydration than predicted by the model. There are two possible explanations for the data: 1) the mechanism for $\mathrm{Cl}_{2}$ reaction is not accurate, or 2) the experimental measurements may have had error in the amount of $\mathrm{Cl}_{2}$ that was added. Further study is required to determine the cause of this discrepancy.

Figure 6e shows the results for the dehydroxylation of the LHG-8 glass melts. Similar trends to the LG-770 melts are observed; the dehydroxylation rate increase at higher temperatures and flow rates. The initial OH content in the LHG-8 glass was about $3 \times$ higher than LG-770, and only $\mathrm{O}_{2}$ bubbling was performed in these melts. Hence the relative amount of dehydroxylation was less than that observed with LG-770 for the same amount of bubbling time. The mass transport of $\mathrm{OH}$ in the LHG-8 glass melts was significantly lower than in the LG-770 $\left(D_{\mathrm{COH}}=3.0 \times 10^{-11} \mathrm{~m}^{2} / \mathrm{sec}\right.$ for LHG-8 and $\mathrm{D}_{\mathrm{eOH}}=1.7 \times$ $10^{-9} \mathrm{~m}^{2} / \mathrm{sec}$ at $1100^{\circ} \mathrm{C}$ ). The lower diffusivity may be related to the lower viscosity of LG-770 compared to LHG-8 at equivalent temperatures (see Table 4). However, a $3 \times$ change in viscosity can not account for such a large diffusivity change $(-100 \times)$. This may mean that mass transport is not driven specifically by $\mathrm{OH}$ diffusion, but by some other mechanism. Despite the fact that the true mechanism for $\mathrm{OH}$ mass transport is not well understood, the determined values for $\mathrm{D}_{\text {POH }}$ do a reasonable job at predicting $\mathrm{OH}$ removal rates in both small-scale melts as well as production size melts (see section 5.5).

Figure $6 \mathrm{f}$ illustrates the effect of melt height on the rates of dehydration. As the melt height increases, so does the volume; therefore, the dehydroxylation should decrease. Our results match this observation. Another feature of using different melt heights is that it changes the ratio of the amount of mass transport that takes place at the top surface of the melt compared to that of the bubble surfaces. So the model fit to these experiments is a good test of whether these two mass transport terms are valid. The model prediction agrees fairly well with the data suggesting that our chosen value for $L_{3}$ is reasonable.

\subsection{Role of cover gas and cover gas humidity}

Two important considerations in the fitting the full dehydration model are the effect of using a cover gas $\left(f_{c}\right)$ and the partial pressure of $\mathrm{H}_{2} \mathrm{O}\left(\mathrm{P}_{\mathrm{H}_{2}} \mathrm{O}\right)$ in the cover gas. Figure 7a illustrates the dehydroxylation kinetics with and without a cover

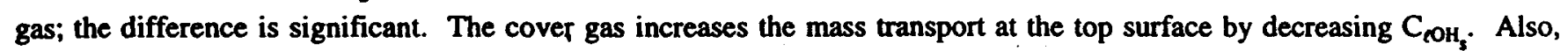
this effect is large because the melt size is small; for larger size melts, the effect of cover gas would be much smaller because the surface area to volume ratio would be much smaller.

The presence of a trace amounts of moisture in the gas supply will prevent the $\mathrm{OH}$ content in the glass melt from reaching zero. Without any humidity in the cover gas or bubbling gas, the model predicts the water content to drop to very low values $\left(\alpha / \alpha_{0}<10^{-3}\right)$ (see Fig. 7b). However, the measured $\mathrm{OH}$ content does not drop to such levels. A probable explanation for this behavior is that some trace amounts of $\mathrm{H}_{2} \mathrm{O}$ are in the gas supply. The dew point of the $\mathrm{O}_{2}$ source is $-62^{\circ} \mathrm{C}(0.025 \mathrm{mmHg})$. This level of humidity still results in a much lower $\mathrm{OH}$ content in the glass at long times than 
measured. However, a possible source of additional moisture is from ambient air leaking into the melting system. This is very possible because no provisions were present to seal the cover of the melting crucible. Knowing the humidity and temperature of the outside room air where the melts were conducted, all the data was fit to the full dehydration model by leaking a constant amount of ambient air into melting system (i.e. into the cover gas). Using $0.3 \%$ leakage of ambient air provided the best fits to the data at long times (see Fig. 7b).

\subsection{Mass transfer versus equilibrium}

In section 4.2.2 the analytical expressions for limiting cases in the dehydration model were derived. Figure $7 \mathrm{c}$ shows that the LG-770 melts were not governed by either limiting case (mass transport or equilibrium). Line 1 in Fig. 7c represents the mass transport limited case calculated using Eq. (28). Remember that this represents the case where mass transport of $\mathrm{OH}$ is slow enough that equilibrium is not reached. Line 2 represents the equilibrium case (Eq. (34) when $\mathrm{Cl}_{2}$ is high and $\mathrm{C}_{\mathrm{gC}} \mathrm{P}_{2} \mathrm{C}_{\mathrm{gH}_{2} \mathrm{O}}$. Line 3 represents the full dehydration model whose calculation is described in Section 4.2. In fact the full dehydration model lies about half-way between both limiting cases for the LG770 melt $\left(\mathrm{T}=1200^{\circ} \mathrm{C}, \mathrm{f}=0.54 \mathrm{scfh}\right.$, $21.2 \% \mathrm{Cl}_{2}$ ). Hence, the small-scale tests can not be described solely by the limiting cases.

\subsection{Simulation of large scale glass melts}

The full dehydration model does a reasonable job of calculating the rate of $\mathrm{OH}$ removal in small-scale test melts $(<1$ liter). The small-scale test melts are discontinuous or batch melts, while production scale melts are carried out by a continuous melting operation. The details of the continuous melting process are described elsewhere 1 . Continuous melting operations have the key features of using larger melt volumes and continuous melt flow through the bubble column. Both of these features increase the difficulty of removing $\mathrm{OH}$ from the melt.

The dehydration model has been used to predict dehydration levels for both discontinuous and continuous melting processes; in Fig. 8 the computed relative $\mathrm{OH}$ levels are compared to measured levels in the product glass from both melting processes. The continuous melting data represent operating regimes for which the bubbling flow rate and $\mathrm{Cl}_{2}$ content differed by more than $10 x$ and thus is a good test of the model. The ability to predict the dehydration in both discontinuous and continuous melts suggests that the basic model assumptions capture the primary physics and chemistry involved in dehydration of phosphate glass by gas bubbling.

\section{CONCLUSIONS}

The rates of dehydroxylation resulting from bubbling $\mathrm{O}_{2}$ or $\mathrm{Cl}_{2}$ into glass melts have been measured for two commercial laser phosphate glasses (LG-770 and LHG-8). The effect of various gas compositions, temperatures, bubbling flow rates, melt geometries, cover gas flow rates have been evaluated. A time-dependent, one-dimensional bubble column model describing dehydroxylation rates of phosphate glass melts by bubbling $\mathrm{O}_{2}$ or $\mathrm{O}_{2} / \mathrm{Cl}_{2}$ mixtures has been utilized to describe dehydroxylation of small-scale test melts and large-scale continuous melting processes. In the model, the dehydroxylation process is governed by (1) transport of $\mathrm{OH}$ to the liquid/vapor interface $\left(\mathrm{D}_{\mathrm{OOH}}\right)$, (2) the $\mathrm{H}_{2} \mathrm{O} / \mathrm{OH}$ equilibrium $\left(K_{\mathrm{wp}}\right)$, and (3) the equilibrium for the reverse Deacon reaction $\left(\mathrm{K}_{\mathrm{d}}\right)$. Using measured or literature values for $\mathrm{D}_{\ell \mathrm{OH}}, \mathrm{K}_{\mathrm{wp}}$ and $\mathrm{K}_{d}$, the model is fit to the data using two parameters $\varepsilon\left(\mathrm{OH}\right.$ extinction coefficient (in ppm/cm ${ }^{-1}$ )) and $\mathrm{L}_{3}$ (parameter related to the mass transfer at the top surface).

\section{ACKNOWLEDGEMENTS}

The work was performed under the auspices of the US Department of Energy by Lawrence Livermore National Laboratory under contract No. W-7405-Eng-48. The assistance of Ms. Alene Clasen in the preparation of this manuscript is greatly appreciated. 

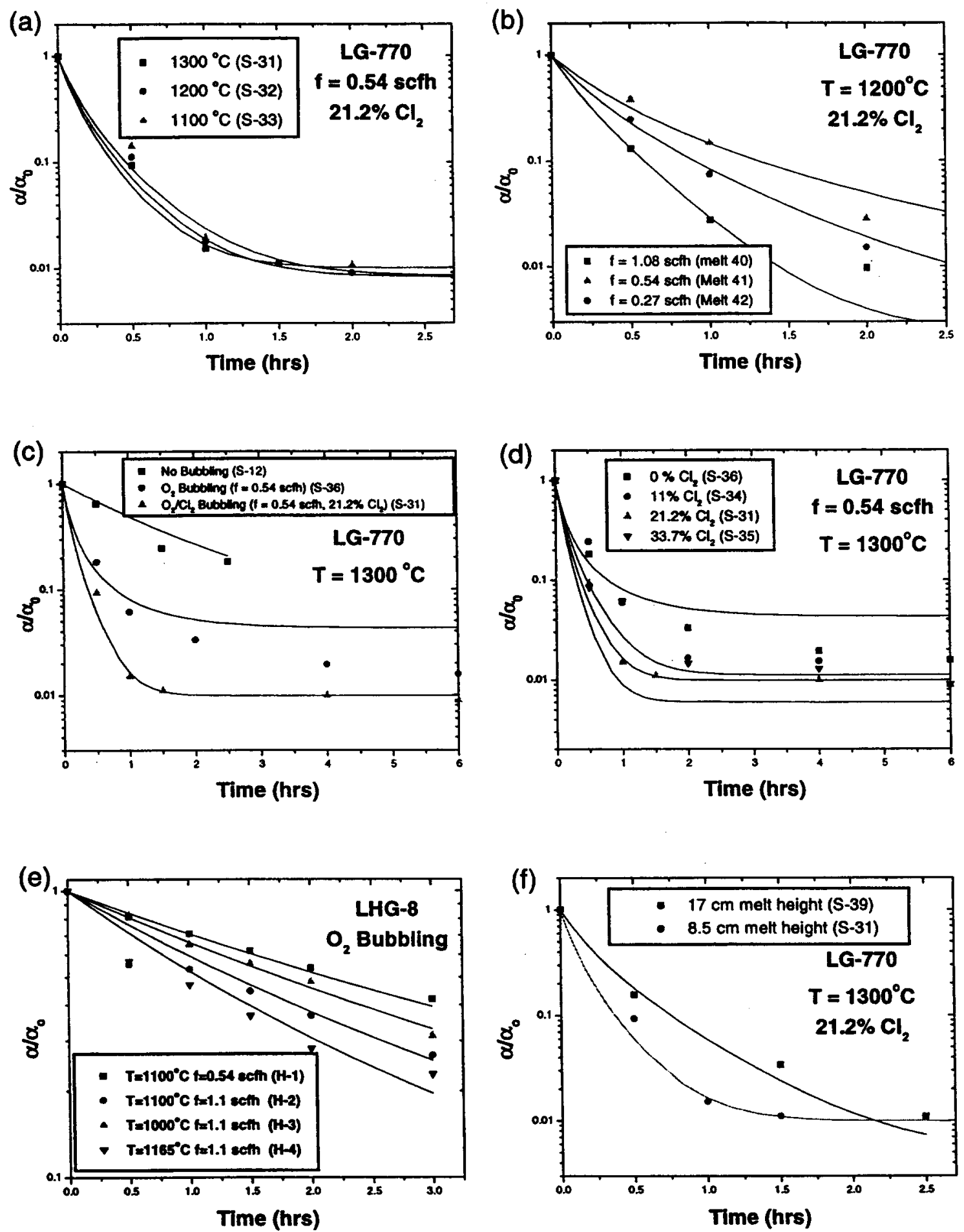

Fig. 6. Comparison of full dehydration model with experimental data. (a) Normalized OH content as function of bubbling time in LG-770 glass melts at various temperatures ( $f=0.54 \mathrm{scth}, 21.2 \% \mathrm{Cl}_{2}$ ). (b) Normalized $\mathrm{OH}$ content as function of bubbling time in LG-770 glass melts at various bubbling flow rates $\left(\mathrm{T}=1200^{\circ} \mathrm{C}, 21.2 \% \mathrm{Cl}_{2}\right)$. (c) Normalized $\mathrm{OH}$ content as function of bubbling time in LG-770 glass melts at different bubbling conditions (no bubbling, $0.54 \operatorname{scth}\left(\mathrm{O}_{2}\right.$ only), and $0.54 \operatorname{scth}\left(21 \% \mathrm{Cl}_{2}\right)$ ). (d) Normalized $\mathrm{OH}$ content as function of bubbling time in LG-770 glass melts at various $\mathrm{Cl}_{2}$ concentrations $\left(\mathrm{T}=1300^{\circ} \mathrm{C}, \mathrm{f}=0.54 \mathrm{scfh}, 21.2 \% \mathrm{Cl}_{2}\right)$. (e) Normalized $\mathrm{OH}$ content as function of bubbling time in LHG-8 glass melts at various temperatures $\left(1000\right.$ to $\left.1165^{\circ} \mathrm{C}\right)$ and flow rates $(0.54$ to 1.1 scfh). (f) Normalized $\mathrm{OH}$ content as function of bubbling time in LG-770 glass melts with different melt heights $(8.5 \mathrm{~cm}$ and $17 \mathrm{~cm})\left(\mathrm{T}=1300^{\circ} \mathrm{C}, \mathrm{f}=0.54 \mathrm{scfh}\right.$, $21.2 \% \mathrm{Cl}_{2}$ ). 

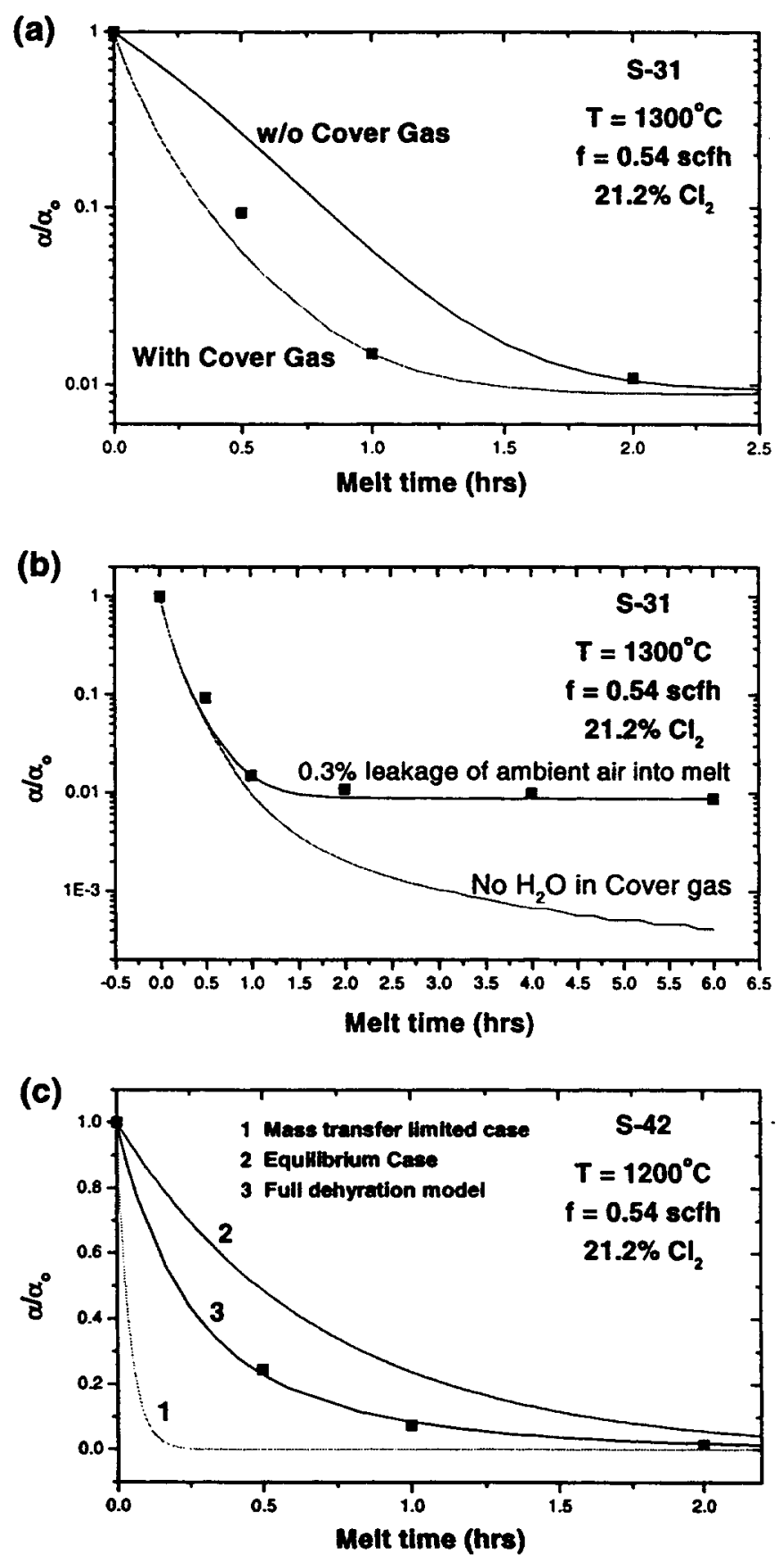

Fig. 7. (a) Normalized OH content as function of time in LG-770 glass $\left(\mathrm{T}=1300^{\circ} \mathrm{C}, \mathrm{f}=0.54 \mathrm{scfh}, 21.2 \% \mathrm{Cl}_{2}\right)$. The lines represent the model fit to the data with and without cover gas. (b) Same as (a) except that the lines represent model fits to the data when no $\mathrm{P}_{\mathrm{H}_{2} \mathrm{O}}$ is present in the cover gas, and when $\mathrm{P}_{\mathrm{H}_{2}} \mathrm{O}$ is $64 \mathrm{~Pa}$ (i.e. $0.3 \%$ of outside air is leaking into melt system). (c) Normalized OH content as function of time in LG-770 glass $\left(\mathrm{T}=1200^{\circ} \mathrm{C}, \mathrm{f}=0.54 \mathrm{scfh}, 21.2 \% \mathrm{Cl}_{2}\right)$. Line 1 represents the mass transport limited case calculated using Eq. (28); line 2 represents equilibrium case calculated using Eq. (34); and line 3 represent full dehydration model case as described in Section 4. 

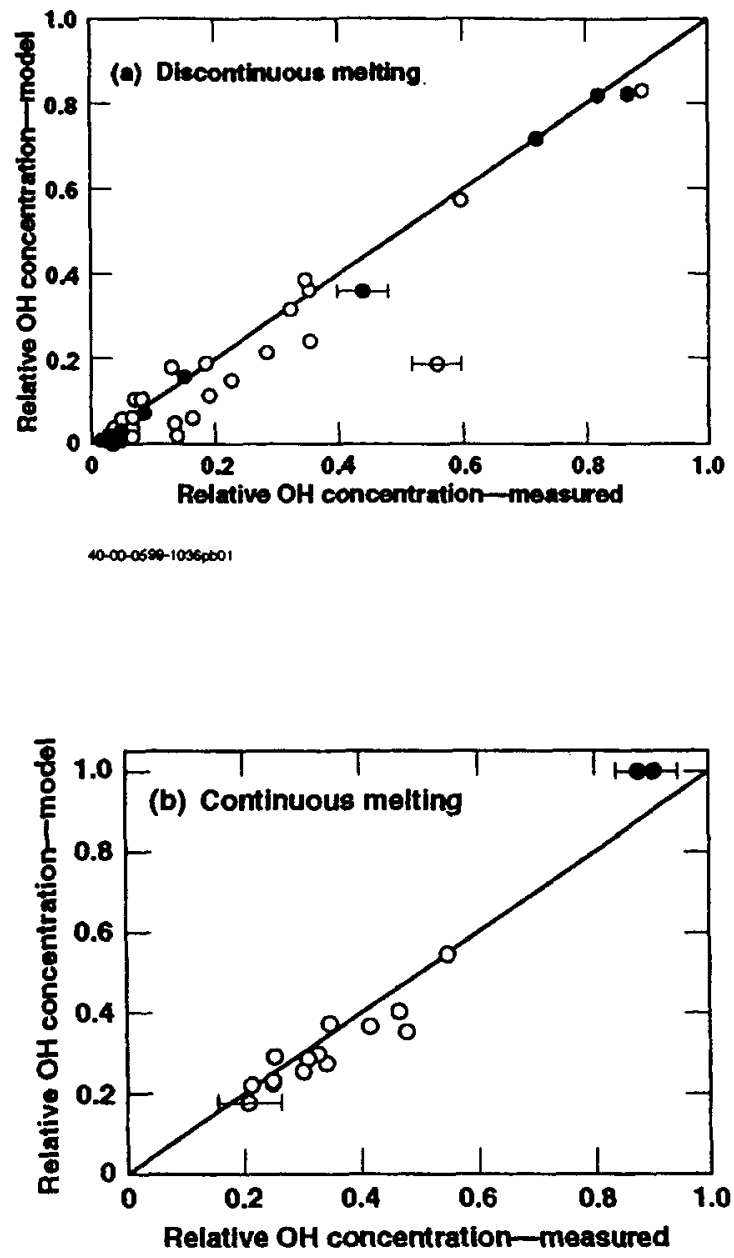

Fig. 8. Comparison of measured versus predicted $\mathrm{OH}$ concentrations in glass produced by (a) small-scale test melts (<1 $\ell$ ) and (b) production-scale continuous melting operations. The solid circles are using $\mathrm{O}_{2}$ bubbling only, while open circles represent bubbling with $\mathrm{O}_{2}$ and variable amounts of $\mathrm{Cl}_{2}(<50 \%)$.

\section{REFERENCES}

[1] J. H. Campbell, T. I. Suratwala, C. B. Thorsness, J. S. Hayden, A. J. Thorne, J. M. Cimino, A. J. Marker, K. Takeuchi, M. Smolley, and G. F. Ficini-Dorn, "Continuous Melting of Nd-doped Phosphate Laser Glasses," J. NonCryst. Solids, Vol. 263\&264, pp. 342-357, 2000.

[2] J. H. Campbell and T. I. Suratwala, "Nd-doped Phosphate Glasses for High-Energy/ High-Peak-Power Lasers," $J$. Non-Cryst. Solids, Vol. 263\&264, pp. 318-341, 2000.

[3] J. T. Rantala, S. Honkanen, and N. Peyghambarian, "Potential and Challenges of Sol-Gel Materials for ErbiumDoped Amplifiers," SPIE 3622, pp. 52-57, 1999.

[4] P. Becker, N. Olsson, and J. Simpson, Erbium-Doped Fiber Amplifiers. San Diego: Academic Press, 1999.

[5] M. Dejneka and B. Samson, "Rare-Earth-Doped-Fibers for Telecommunications Applications," MRS Bulletin, Vol. 24, 9, pp. 39-45, 1999.

[6] S. I. Najafi, "Overview of Nd- and Er- Doped Glass Integrated Optics Amplifiers and Lasers," SPIE 2996, pp. 5461, 1997.

[7] D. W. Hewak, "Progress Towards a 1300 nm Fibre Amplifier," IEEE Colloquium New Developments in Optical Amplifiers 492, pp. 1-5, 1998. 
[8] T. I. Suratwala, R. A. Steele, G. D. Wilke, J. H. Campbell, and K. Takeuchi, "Effects of OH Content, Water Vapor Pressure, and Temperature on Slow Crack Growth Behavior in Phosphate Laser Glass," J. Non-Cryst. Solids, Vol. 263\&264, pp. 213-227, 2000.

[9] R. Adams, "Some Experiments on the Removal of Water from Glass," Phys. Chem. Glasses, Vol. 2, 2, pp. 50-54, 1961.

[10] J. Chun, Z. Junzhou, and Z. Dunshui, "Investigation on Removal of -OH Group in $\mathrm{BaO}-\mathrm{P}_{2} \mathrm{O}_{5}$ and $\mathrm{R}_{2} \mathrm{O}-\mathrm{BaO}-\mathrm{P}_{2} \mathrm{O}_{5}$ System Phosphate Laser Glasses by Means RAP Method," Chin. J. Lasers, Vol. A23, pp. 182-185, 1996.

[11] F. Gomez, P. Vast, P. Llewellyn, and F. Rouquerol, "Dehydroxylation Mechanisms of Polyphosphate Glasses in Relation to Temperature and Pressure," J. Non-Cryst. Solids, Vol. 222, pp. 415-421, 1997.

[12] T. Elmer, "Dehydroxylation of Porous Glass by Means of Chlorine," J. Am. Ceram. Soc., Vol. 64, 3, pp. 150-154, 1981.

[13] T. Elmer, "Chlorine Treatment of Nitrided PorousGlass," Glastech. Ber. Glass Sci. Technol., Vol. 61, 1, pp. 24-27, 1988.

[14] E. Boulos and N. Kreidl, "Water in Glass: A Review," J. Canadian Ceram. Soc., Vol. 41, pp. 83-90, 1972.

[15] J. Shelby, "Water in Glasses and Melts," in Handbook of Gas Diffusion in Solids and Melts. Materials Park, $\mathrm{OH}$ ASM International, 1996, pp. 217-234.

[16] C. J. Brinker and G. W. Scherer, Sol-Gel Science: The Physics and Chemistry of Sol-Gel Processing. San Diego: Academic Press, 1990.

[17] T. Elmer, "Dehydroxylation of Porous Glass by Means of Chlorine," J. Am. Ceram. Soc., Vol. 64, 3, pp. 150-154, 1980.

[18] H. Ebendorff-Heidepriem, W. Seber, and D. Ehrt, "Dehydration of Phosphate Glasses," J. Non-Cryst. Solids, Vol. 163, pp. 74-80, 1993.

[19] S. Martin, "Review of the Structures of Phosphate Glasses," Eur. J. Solid State Inorg. Chem., Vol. 28, pp. 163-205, 1991.

[20] R. M. Wenslow and K. T. Mueller, "Structural Details of Aqueous Attack on a Phosphate Glass by ${ }^{1} \mathrm{H} /{ }^{31} \mathrm{P}$ Cross Polarization NMR," J. Phys. Chem. B, Vol. 102, 45, pp. 9033-9038, 1998.

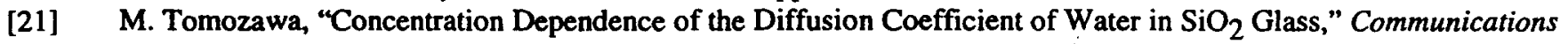
of the American Ceramic Society, September, pp. C251-C252, 1985.

[22] J. S. Hayden, M. Tomozawa, and S. Crichton, "OH Diffusion Measurements in Phosphate Laser Glasses," Schott Glass Technologies, Duryea, PA UCRL-ID-136007 (Renssealaer Polytechnic Institute), 1997.

[23] C. W. Arnold and K. A. Kobe, "Thermodynamics of the Deacon Process," Chem. Eng. Prog., Vol. 48, pp. 293-266, 1952.

[24] C. Y. Wen and L. T. Fan, Model for Flow Systems and Chemical Reactors. New York: Marcel Dekker Inc., 1975.

[25] W. D. Deckwer and A. Schumpe, "Improved Tools for Bubble Column Reactor Design and Scale-Up," Chem. Eng. Sci., Vol. 48, 5, pp. 889-991, 1993.

\section{APPENDIX: VARIABLE LIST FOR DEHYDROXYLATION MODEL}

$\begin{array}{lll}\alpha & = & \text { Absorption coefficient of bulk glass at } 3.333 \mu \mathrm{m}\left(\mathrm{cm}^{-1}\right) \\ \alpha_{0} & = & \text { Absorption coefficient of bulk glass at } 3.333 \mu \mathrm{m}\left(\mathrm{cm}^{-1}\right) \text { at time zero } \\ \alpha_{s} & = & \text { Absorption coefficient of glass melt at } 3.333 \mu \mathrm{m}\left(\mathrm{cm}^{-1}\right) \text { at liquid/vapor interface } \\ \Delta G & = & \text { free energy for } \mathrm{K}_{\mathrm{wp}}(\mathrm{kJ} / \mathrm{mol}) \\ \sigma & = & \text { Liquid surface tension }(\mathrm{N} / \mathrm{m}) \\ \phi & = & \text { Melt porosity or void volume } \\ \mu_{\ell} & = & \text { Viscosity of liquid }(\mathrm{Pa} \mathrm{sec}) \\ \rho_{\ell} & = & \text { Density of liquid }\left(\mathrm{kg} / \mathrm{m}^{3}\right) \\ \mathrm{A}_{\mathrm{b}} & = & \text { Total bubble surface area per unit volume }\left(\mathrm{m}^{-1}\right) \\ \mathrm{A}_{\mathrm{v}} & = & \text { Effective interface area per unit volume of melt, includes bubble and top surface }\left(\mathrm{m}^{-1}\right) \\ \mathrm{Bo} & = & \text { Bond number } \\ \mathrm{C}_{g}, \mathrm{C}_{\ell}= & \text { Concentration of a particular species in gas or liquid }\left(\mathrm{mol} / \mathrm{m}^{3}\right) \\ \mathrm{C}_{8 \mathrm{C}_{2}}= & \mathrm{Cl}_{2} \text { concentration in gas phase }\left(\mathrm{mol} / \mathrm{m}^{3}\right) \\ \mathrm{C}_{g \mathrm{H}_{2} \mathrm{O}} \mathrm{O}= & \mathrm{H}_{2} \mathrm{O} \text { concentration in gas phase }\left(\mathrm{mol} / \mathrm{m}^{3}\right) \\ \mathrm{C}_{8 \mathrm{HCl}}= & \mathrm{HCl} \text { concentration in gas phase }\left(\mathrm{mol} / \mathrm{m}^{3}\right)\end{array}$




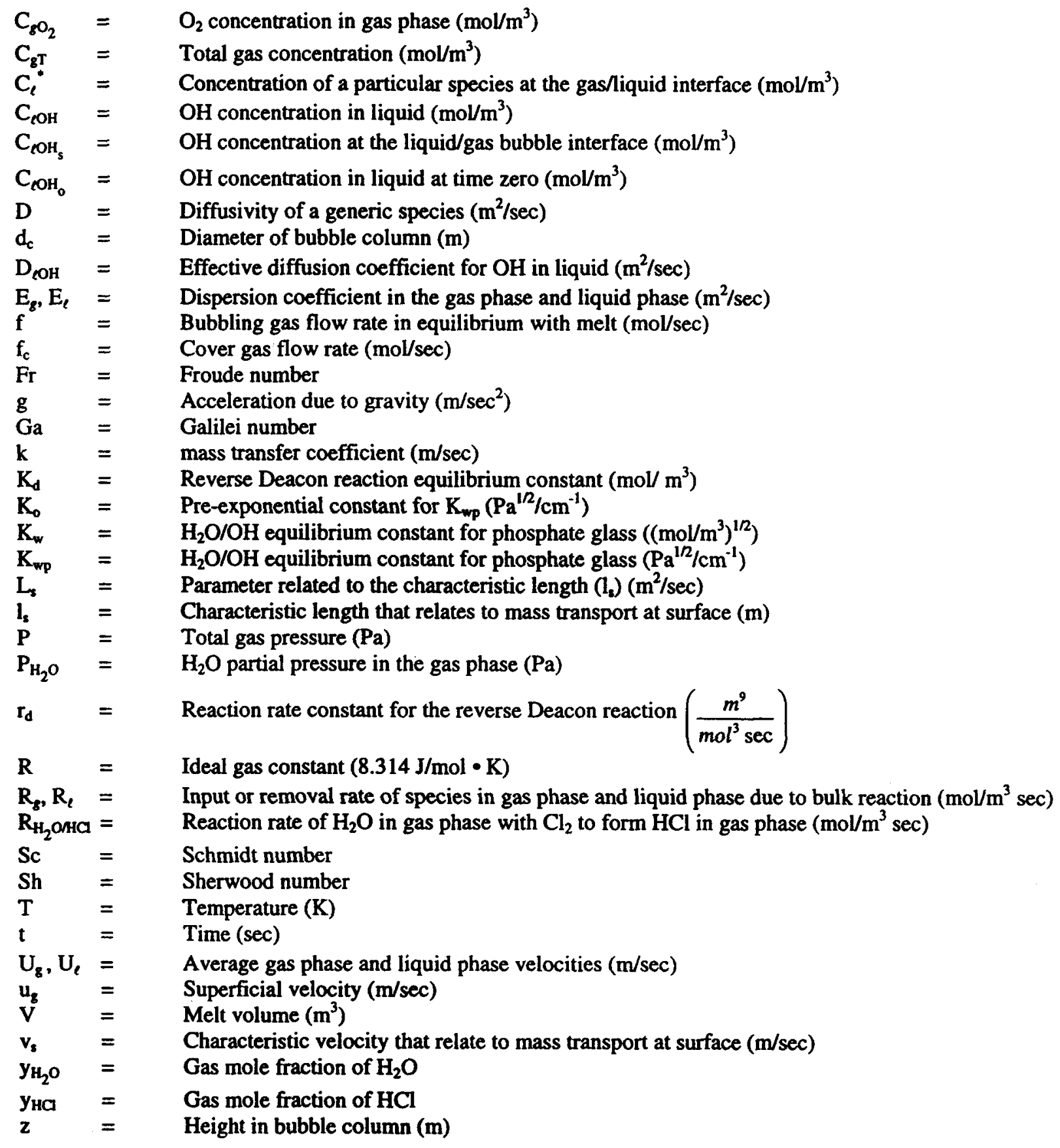




\title{
Development of continuous glass melting for production of Nd-doped phosphate glasses for the NIF and LMJ laser systems
}

\author{
J. H. Campbell \\ M. J. McLean \\ R. Hawley-Fedder \\ T. Suratwala \\ G. Ficini-Dorn \\ J. H. Trombert
}

This paper was prepared for submittal to the Third Annual International Conference on Solid State Lasers for Application (SSLA)

to Inertial Confinement Fusion (ICF)

Monterey, California

June 7-12, 1998

August 14, 1998

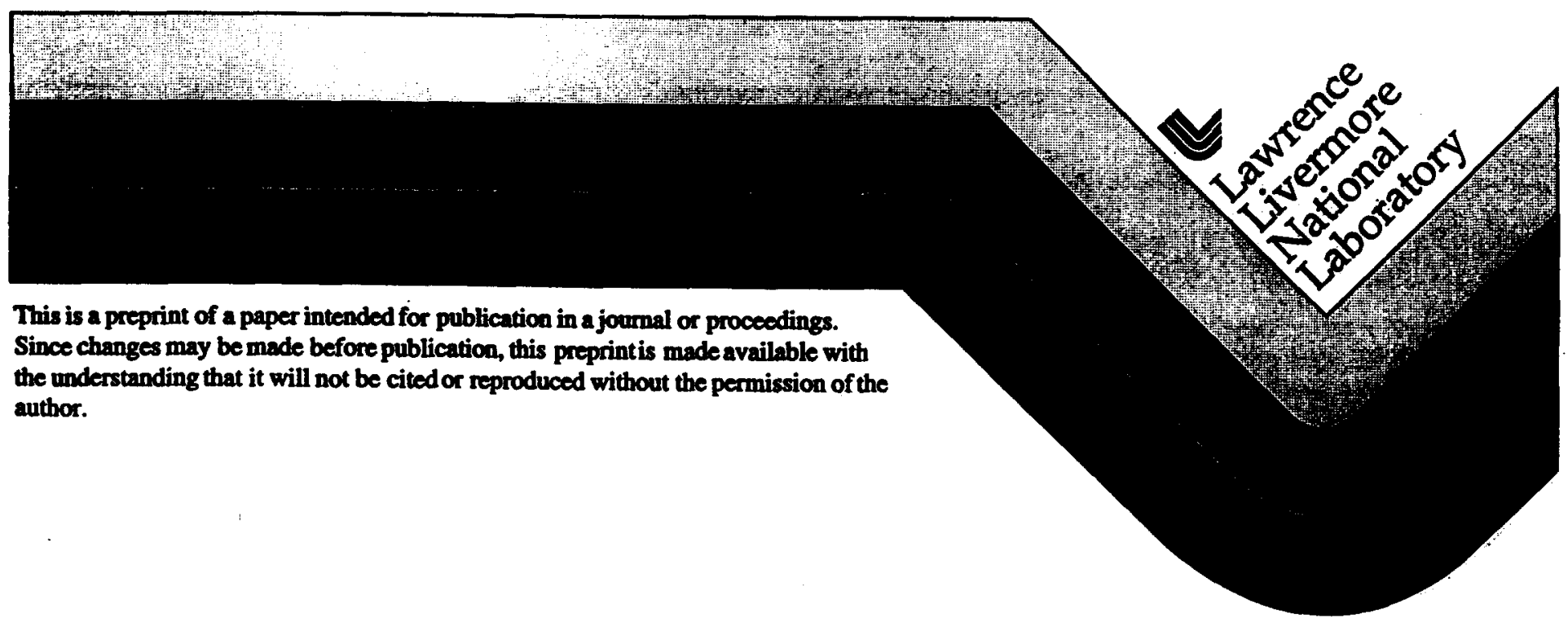




\section{DISCLAIMER}

This document was prepared as an account of work sponsored by an agency of the United States Government. Neither the United States Government nor the University of Califormia nor any of their employees, makes any warranty, express or implied, or assumes any legal liability or responsibility for the accuracy, completeness, or usefulness of any information, apparatus, product, or process disclosed, or represents that its use would not infringe privately owned rights. Reference herein to any specific commercial product, process, or service by trade name, trademark, manufacturer, or otherwise, does not necessarily constitute or imply its endorsement, recommendation, or favoring by the United States Government or the University of Califomia. The views and opinions of authors expressed herein do not necessarily state or reflect those of the United States Government or the University of California, and shall not be used for advertising or product endorsement purposes. 
Development of continuous glass melting for production of Nd-doped phosphate glasses
for the NIF and LMJ laser systems

\author{
J. H. Campbell, M. J. McLean, R. Hawley-Fedder, and T. Suratwala \\ Lawrence Livermore National Laboratory, P. O. Box 808 Livermore, CA 94550, USA \\ G. Ficini-Dorn and J. H. Trombert \\ Centre d'Etudes de Limeil-Valenton, EME/ECO, 94795 Villeneuve St. Georges Cedex, France
}

\begin{abstract}
The NIF and LMJ laser systems require about 3380 and $4752 \mathrm{Nd-doped} \mathrm{laser} \mathrm{glass} \mathrm{slabs,} \mathrm{respectively.} \mathrm{Continuous} \mathrm{laser} \mathrm{glass}$ melting and forming will be used for the first time to manufacture these slabs. Two vendors have been chosen to produce the glass: Hoya Corporation and Schott Glass Technologies. The laser glass melting systems that each of these two vendors have designed, built and tested are arguably the most advanced in the world. Production of the laser glass will begin on a pilot scale in the fall of 1998.
\end{abstract}

\title{
1. INTRODUCTION
}

The laser systems that comprise the US Department of Energy (DOE) National Ignition Facility (NIF) and the French Commissariat à l'Energie Atomique (CEA) Laser Megajoule (LMJ), each consist of 192 and 240 laser beamlines, respectively. ${ }^{1-4}$ Each beamline contains either 16 (NIF) or 18 (LMJ) large, Nd-doped laser glass slabs and each finished laser glass slab is about $81 \times 46 \times 4.1 \mathrm{~cm}^{3}$. A total of 3072 and 4380 slabs will be installed on the NIF and LMJ, respectively (Table 1). In addition, each facility plans to purchase approximately $10 \%$ more slabs as construction and operation spares. Thus, nearly 8150 laser glass slabs will be needed for the two laser systems: this represents a volume of about $125 \mathrm{~m}^{3}$ (330 metric tons) of finished high optical quality glass. Note that the quantity of raw glass that must be melted is significantly larger than 330 metric tons to account for various processing losses.

Both the NIF and LMJ use a compact laser amplifier design called the "multi-segment amplifier" (MSA). 5.6,7 These amplifiers consist of stacked $4 \times 1$ arrays of laser glass slabs inside a flashlamp pumped cavity (Fig 1). By using square apertures (i.e. square beams) it is possible to tightly pack the individual laser glass amplifiers into a compact matrix and greatly reduce the size and cost of the system. This design requires that the laser glass be manufactured in rectangular slabs. Note that although the laser aperture is square, the laser slabs are rectangular because they are mounted at Brewster's angle to the propagation direction of the beam. Mounting the glass at Brewster's angle minimizes the Fresnel reflection losses at the surfaces of the slabs. In addition, mounting at an angle increases the coupling efficiency of the flashlamp light with the slabs. Erlandson et al ${ }^{56.7}$ have recently described in detail the design and operating characteristics of flashlamp pumped multisegment amplifiers. The measured small signal gain coefficient is typically about $0.05 / \mathrm{cm}$ and the stored energy density about $0.25 \mathrm{~J} / \mathrm{cm}^{3}$ for phosphate laser glass doped at about $4 \times 10^{20} / \mathrm{cm}^{3}$ and pumped at a lamp explosion fraction of 0.20 .

A prototype laser closely resembling one of the NIF beamlines has recently been built and tested. ${ }^{8}$ This laser, called "Beamlet", uses 11 amplifiers in the main cavity and 5 in the booster section, the same configuration as the NIF. A series of large phosphate glass slabs $\left(767 \times 428 \times 44 \mathrm{~mm}^{3}\right)$ having a doping of $3.5 \times 10^{20} / \mathrm{cm}^{3}$ were produced for this laser.9 Although slightly smaller than required for LMJ and NIF, these prototype glass slabs were made to nearly identical specifications as required for the NIF and LMJ. Therefore, to a great extent, the quality and size of the laser glass pieces needed for NIF and LMJ have been demonstrated. What remains is to develop the manufacturing capability for producing a large number of these high quality glass slabs at a high rate and at a significantly lower cost. In this paper we briefly describe the advanced melting methods that are being developed to produce the glass for the NIF and LMJ. Although details of the production processes are proprietary, we will highlight the changes involved in changing from the one-at-a-time discontinuous production process used in the past to the continuous melting process of the future. Our cost goal is to manufacture the laser glass for about $\$ 1000$ hiter $(\$ 350 / \mathrm{kg})$; this is roughly a factor of three lower than the cost with the current one-at-a-time production methods. Given the size of the laser glass order, this level of cost reduction represents a total cost savings of about $\$ 200$ to $\$ 300$ million over the price that could be achieved with current manufacturing methods. 


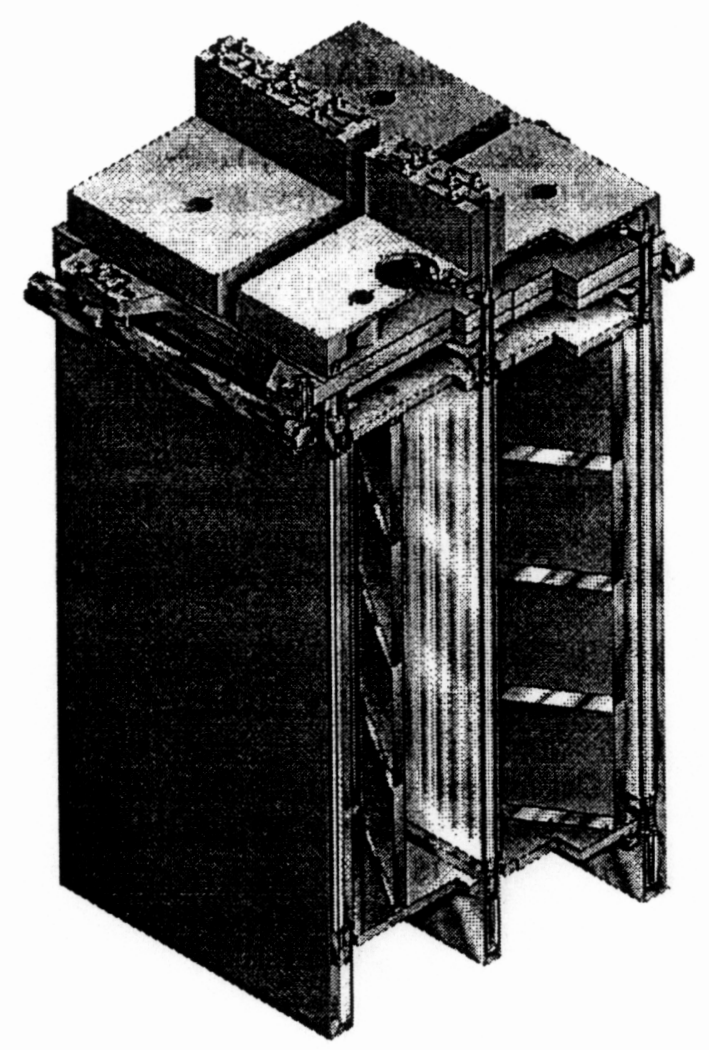

Figure 1. Assembly drawing of two $4 \times 2$ amplifier units to be used on NIF. The laser slabs are mounted in the amplifiers in a frame that contains four (4) vertically stacked laser slabs.

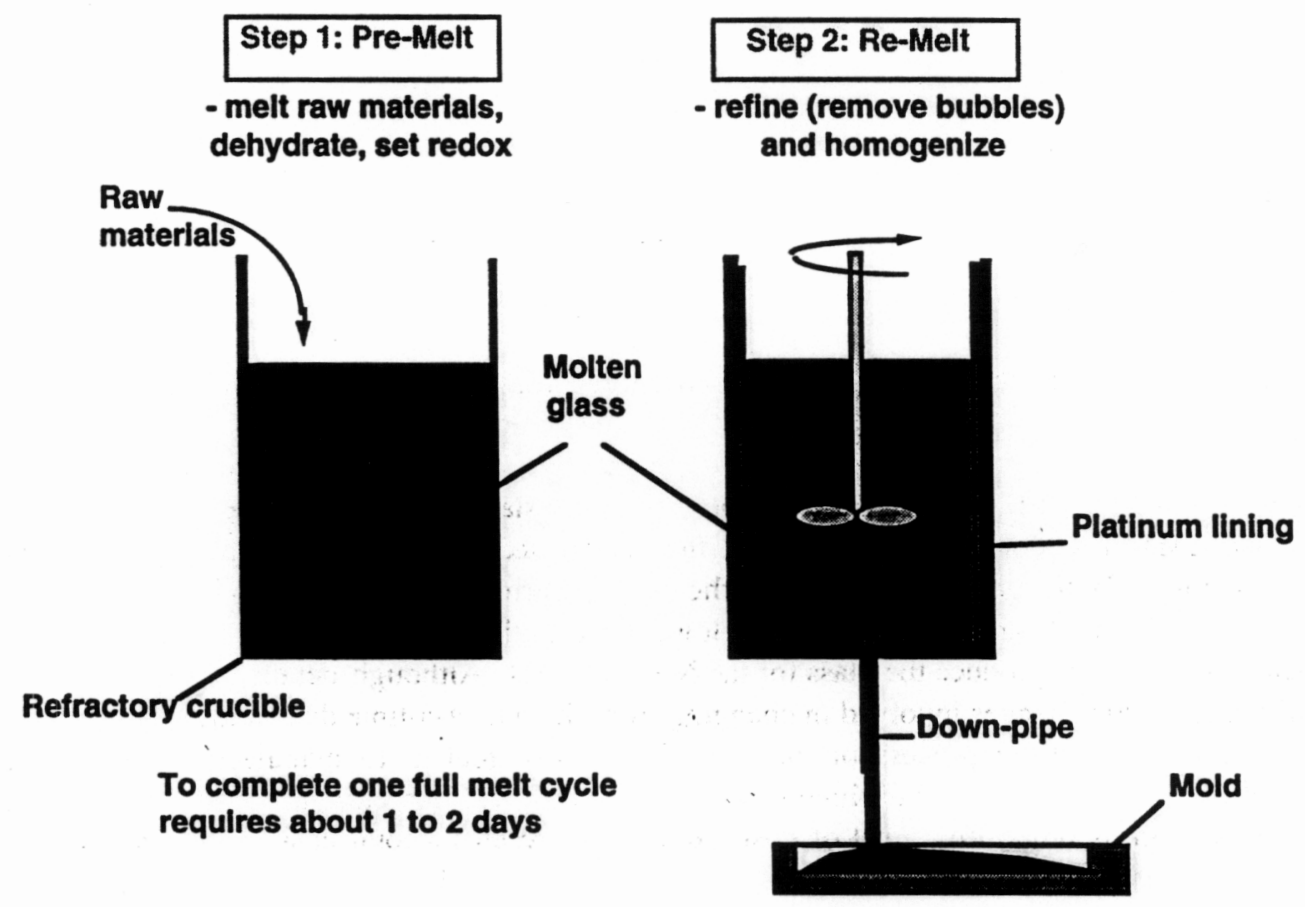

Figure 2. Schematic representation of the current discontinuous, 2-step process used to melt and form laser glass castings. 
Table 1: Quantity of laser glass required for the LMJ and NIF projects.

Variable

Number of beamlines

Number of slabs / beamline

Spares

Total number of slabs (including spares)

Finished slab dimensions $\left(\mathrm{cm}^{3}\right)$

Volume per slab (liter)

Total volume $\left(\mathrm{m}^{3}\right)$

Mass (metric tons)

$\begin{array}{cc}\text { NIF } & \text { LMJ } \\ 192 & 240 \\ 16 & 18 \\ 10 \% & 10 \% \\ 3380 & 4752 \\ \times 46 \times 4.1 & 81 \times 46 \times 4.1 \\ 15.3 & 15.3 \\ 52 & 73 \\ 136 & 190\end{array}$

\section{LASER GLASS SPECIFICATIONS AND PROPERTIES}

\subsection{Optical quality}

Some of the most critical specifications of the laser glass relate to its optical quality and are strongly dependent on the processing conditions. In particular, there are three main characteristics of the glass that impact optical quality:

- optical homogeneity

- inclusions

- bubbles

Optical homogeneity refers to the refractive index variation in the optical material and for laser glass this is typically less than $2 \mathrm{ppm}$ (i.e. $\Delta \mathrm{n}< \pm 2 \times 10^{-6}$ ). The homogeneity is generally specified in terms of a maximum amount of allowed aberration due to sphere, coma, astigmatism and a smaller amount of higher-order terms (see Table 2). For NIF and LMJ we intend to keep this same specification. However the final, finished (that is, polished) laser glass will be specified using a more sophisticated procedure designed to monitor aberrations at specific spatial frequencies that are known to seed non-linear-growth of intensity noise in the laser beam.

The homogeneity of the laser glass is critical in order to maintain wavefront uniformity of the laser beam. Recall that there are a total of 16 laser slabs in the laser beamline and during the four passes through the amplifier chain the beam passes through the equivalent of 64 laser slabs. Therefore, even small optical inhomogeneities can lead to significant wavefront aberration in the output of the beam, potentially causing significant degradation in both frequency conversion and focusability of the beam.

Inclusions from ceramic refractory materials, unmelted raw materials, $\mathrm{Pt}$ metal, crystallites or impurities can cause optical damage in the glass when exposed to high laser fluences. The most common inclusion source is metallic $\mathrm{Pt}$ inclusions from the Pt liners used in the melting system. Improved processing conditions have lead to a dramatic reduction in $P t$ inclusions in recent years such that the average inclusion density is less than $\mathbf{0 . 1}$ per liter of glass or less than an average of 1 to 2 per glass slab. ${ }^{10.11}$ Inclusions in the laser glass typically damage at about $2-5 \mathrm{~J} / \mathrm{cm}^{2}$ at the NIF and LMJ pulse lengths. ${ }^{12}$ Although very small to begin with, inclusion damage can grow with successive laser shots to several millimeters or even centimeters in size making the laser glass unusable. Also large damage spots in the laser glass can seed damage in other optics in the laser chain. In general, if the inclusions are small they can be tolerated as long as the optical damage they produce does not exceed about $250 \mu \mathrm{m}$ in size. This is the basis for the specification given in Table 2. Currently we scan each piece of laser glass with a high fluence laser beam and measure the size of any damage site after a specified number of shots at fluences between 7 to $14 \mathrm{~J} / \mathrm{cm}^{2}(8 \mathrm{~ns}) .{ }^{13}$ If the Pt-damage size remains below the specified size limit given in Table 2, then it is acceptable.

The laser glass bubble specification is based on two requirements: first, the need to minimize the amount of light loss due to the obscurations caused by the bubbles and second, the need to keep the size below a certain value that may induce 
non-linear growth of intensity noise. The obscuration loss is not to exceed $0.01 \%$ of the beam area per slab and therefore sets the total number of bubbles of a given size allowed in any given slab. The maximum size bubble allowed is currently $100 \mu \mathrm{m}$. The diffracted light from bubbles that exceed $100 \mu \mathrm{m}$ can, at high intensities, imprint a holographic diffraction pattern in the next optic that, in turn, can bring that portion of the beam to focus at another downstream optic and potentially damage it. Because of the regular spacing of many of the optics in the laser chain this non-linear imaging effect could lead to propagation of laser damage throughout the beamline. In general, bubbles have not been a significant problem for laser glass. For example, only one of the Beamlet slabs had bubbles and these were so few in number and so small as to be insignificant. ${ }^{9}$ Similar results were observed for the Nova and Phebus laser glass disks.

Table 2: Several key technical specifications for the NIF pre-finished laser glass slabs. These pre-finished slabs will be clad, ground and polished into the finished slabs by the finishing vendor.

\section{Parameter}

1. Nd doping

2. Homogeneity (expressed as wavefront error at @ $632 \mathrm{~nm}$, normal incidence)

Sphere

Astigmatism

Higher order aberrations

3. Fluorescence Lifetime

(measured on $5 \times 5 \times 0.5 \mathrm{~cm}^{3}$ sample)

4. Absorption coefficients:

$$
\begin{aligned}
& \text { at } 1053 \mathrm{~nm} \\
& \text { at } 400 \mathrm{~nm} \text { (due to } \mathrm{Pt}^{\mathrm{n}+} \text { ) } \\
& \text { at } 3333 \mathrm{~nm} \text { (due to }-\mathrm{OH} \text { ) }
\end{aligned}
$$

5. Bubbles:

max. number (per $100 \mathrm{~cm}^{2}$ area) maximum diameter

6. Birefringence

7. Pt inclusions:

max. number for any one slab average for all slabs

max. size after laser irradiation

\section{NIF specifications}

$4.2 \times 10^{20} \pm 0.1 \mathrm{Nd}^{3+} / \mathrm{cm}^{3}$

$<0.425 \lambda$

$<0.220 \lambda$

$<0.142 \lambda$

$>320 \mu \mathrm{sec}$

$\leq 0.0019 \mathrm{~cm}^{-1}$

$\leq 0.25 \mathrm{~cm}^{-1}$

$\leq 2 \mathrm{~cm}^{-1}$

total cross section $<0.15 \mathrm{~mm}^{2}$

$\leq 100 \mu \mathrm{m}$

$\leq 5 \mathrm{~nm} / \mathrm{cm}$

$\leq 5$ in Clear Aperture

$\leq 2$ per slab

$\leq 100 \mu \mathrm{m}$.

\subsection{Properties of the NIF and LMJ laser glasses}

Laser glasses are specially formulated to give the desired laser, optical, thermal-mechanical and physical-chemical properties needed for a specific laser application. Some of these properties are strongly affected by the processing conditions (as discussed in the preceding sections), however, most are controlled by the base glass composition.

We have chosen two glasses for use on the NIF and LMJ that meet the gain, energy storage, extraction efficiency, and damage resistance requirements: LHG-8 (Hoya Corporation) and LG-770 (Schott Glass Technologies Inc.). LHG-8 is the same glass used on the Nova and Phebus lasers, however, LG-770 is a new formulation developed to replace LG-750 that was used on Nova, Phebus and Beamlet.

The key properties of these laser glasses are summarized in Table 3. The importance of these properties for ICF highpeak-power applications has been recently reviewed. ${ }^{14}$ Consequently, we will not discuss laser glass properties further here. 
Table 3 : Properties of LHG-8 (Hoya) and LG-770 (Schott), the two laser glasses selected for use on LMJ and NIF.

\begin{tabular}{|c|c|c|}
\hline \multicolumn{3}{|l|}{$\begin{array}{l}\text { Optical } \\
\text { Refractive index }\end{array}$} \\
\hline $\mathrm{n}_{d}(589.3 \mathrm{~nm})$ & 1.52962 & 1.50674 \\
\hline$n_{1}(1053 \mathrm{~nm})$ & 1.52005 & 1.49908 \\
\hline \multicolumn{3}{|l|}{ Non-linear refractive index } \\
\hline $\mathrm{n}_{2}\left(10^{-13} \mathrm{esu}\right)$ & 1.12 & 1.01 \\
\hline$\gamma\left(10^{-20} \mathrm{~m}^{2} / \mathrm{W}\right)$ & 3.08 & 2.78 \\
\hline Abbe number & 66.5 & 68.4 \\
\hline \multicolumn{3}{|l|}{ Laser } \\
\hline Emission cross-section $\left(10^{-20} \mathrm{~cm}^{2}\right)$ & 3.6 & 3.9 \\
\hline Radiative lifetime at zero- $N d$ concentration ( $\mu$ s) & 365 & 372 \\
\hline Judd-Ofelt radiative lifetime $(\mu s)$ & 351 & 349 \\
\hline Emission band width (nm) & 26.5 & 25.4 \\
\hline \multicolumn{3}{|l|}{ Thermal } \\
\hline Thermal conductivity, $90^{\circ} \mathrm{C}(\mathrm{W} / \mathrm{mK})$ & 0.58 & 0.57 \\
\hline Thermal diffusivity $\left(10^{-7} \mathrm{~m}^{2} / \mathrm{s}\right)$ & 2.7 & 2.9 \\
\hline Specific heat, Cp (J/gK) & 0.75 & 0.77 \\
\hline Coefficient of thermal expansion, $20-300^{\circ} \mathrm{C}\left(10^{-7} / \mathrm{K}\right)$ & 127 & 134 \\
\hline Glass transition temperature, $\mathrm{Tg}\left({ }^{\circ} \mathrm{C}\right)$ & 485 & 460 \\
\hline \multicolumn{3}{|l|}{ Mechanical } \\
\hline Density $\left(\mathrm{g} / \mathrm{cm}^{3}\right)$ & 2.83 & 2.59 \\
\hline Poisson's ratio & 0.26 & 0.25 \\
\hline Fracture toughness $\left(\mathrm{MPa} \cdot \mathrm{m}^{1 / 2}\right)$ & 0.51 & 0.48 \\
\hline Hardness (GPa) & 3.43 & 3.58 \\
\hline Young's modulus (GPa) & 50.1 & 47.3 \\
\hline
\end{tabular}

\section{GLASS MELTING DEVELOPMENT}

The glasses made for the present large ICF laser systems (e.g. Nova [LLNL], Phebus [CEA], Beamlet [LLNL] Gekko [Osaka] and Omega [Univ. of Rochester]) were manufactured using a one-at-a-time, discontinuous melting process. In this section we briefly describe this older manufacturing method and the new advanced processes that have been developed for NIF and LMJ.

\subsection{The "old" technology: one-at-a-time, discontinuous laser glass melting and forming}

The first step of the discontinuous process is a pre-melting step designed melt and mix (on a large scale length) the raw starting materials (Fig. 2). A bubbling gas is often added to remove unwanted volatile products, particularly water and, if necessary adjust the melt redox state. The pre-melt is carried out in a relatively inert refractory crucible. The walls of the refractory vessel corrode over time eventually requiring the vessel to be replaced. The glass from the pre-melter generally contains bubbles, striae, and possibly some small particles of unmelted starting material.

The product glass from the pre-melt stage is next processed in a physically separate unit called the "re-melter". The remelter consists of a platinum lined vessel that also has provisions for stirring and gas bubbling. The main purpose of the remelter is to dissolve any platinum inclusions, remove any bubbles and finally, homogenize the glass to provide the striaefree, high-optical-quality glass necessary for laser applications. This process involves several stages. ${ }^{15}$ During the first stage 
of the re-melt cycle the redox state of the glass is adjusted to enhance platinum particle dissolution. This followed by a refining or "fining" process conducted at high temperatures where the viscosity of the glass is low, allowing bubbles to rise to the surface. The third stage is a stirring process which is generally conducted at temperatures lower than either the melting or the refining stages. The continuous stirring thoroughly distributes all components within the glass melt, eliminating striae and thus ensuring uniformity of the refractive index over the entire casting. Finally, the melt is cooled to a temperature such that the viscosity of the glass is proper for casting into a mold of the appropriate size and shape. After casting, the glass undergoes a coarse annealing step, is inspected for inclusions and striae, and then is fine annealed to remove residual thermal stresses due to the forming process.

\subsection{Advanced technology: continuous laser glass melting and forming}

Advanced laser glass melting processes have been developed separately by Schott Glass Technologies (Duryea, PA) and Hoya Corporation (Fremont, CA) under work funded jointly by the Lawrence Livermore National Laboratory and the Centre d' Etudes de Limeil-Valenton. The two glass companies have chosen different development approaches. Schott has chosen to design and develop a full-scale melting system that will then become the production melter. This approach allowed for one development run to verify the equipment design and the melting and forming process; this was completed in November and December 1997. In contrast Hoya chose to carry out development using a sub-scale continuous melter. Because of the smaller size and lower operating costs of this equipment Hoya was able to carry out several melting and forming campaigns which were completed in March 1998. We are pleased to state that both vendors have successfully completed their development efforts and are preparing for a first production run that we term the "pilot". This will be followed by several years of production, approximately 2-3 years for the NIF and about 3-4 years for LMJ.

Many of the details of the manufacturing process are highly proprietary to each company. Therefore, we give only a generic description of the melting, forming and coarse annealing process. Nevertheless, this description should give an idea of the progress in laser glass manufacturing technology that has occurred as a result of the NIF and LMJ projects. The laser glass melting systems developed by Schott and Hoya are arguably the most advanced optical glass melting systems in the world.

A continuous optical glass melting system is generally divided into several interconnected zones (Fig. 3). Each zone consists of one or more vessels designed to carry out a specific aspect of the process. In the case of the laser glass continuous melters there are six main processing zones ${ }^{16}$ (Fig 3): (1) raw material batching, (2) melting, (3) conditioning, (4) refining, (5) homogenization and, (6) continuous strip forming. These regions are interconnected allowing for the continuous flow of glass from one zone to the next.

It is desirable that the raw materials be batched together and then thoroughly mixed in a dry atmosphere. The batch is then delivered continuously to the melter with precautions to avoid water uptake by hydroscopic raw materials. The batch powder that enters the melter dissolves in the molten glass and undergoes large-scale mixing. Off-gas handling equipment collects any gas emissions from the melter (or other vessels) and treats the effluent to meet environmental regulations.

The glass continuously flows from the melter into the conditioning unit where the redox state of the melt is adjusted to enhance Pt-inclusion dissolution. If required, steps may also be taken to remove any excess "water" (i.e. $-\mathrm{OH}$ ) in the glass. The glass from the conditioning unit then flows to the refiner section where the temperature is generally elevated to reduce the glass viscosity and thereby increase the bubble rise velocity to promote bubble removal.

Finally, the glass from the refiner enters the homogenization section where $\mathrm{Pt}$ stirrers thoroughly mix the glass to achieve the part-per-million index homogeneity required for ICF laser applications. Just as in the discontinuous process, the temperature of the homogenizing section is reduced to adjust the glass viscosity to give the desired flow characteristics needed to form a wide, thick, homogeneous strip of glass. The width and thickness of the glass strip produced during the forming operation is greater than any optical glass ever produced prior to NIF/LMJ-driven glass development. 


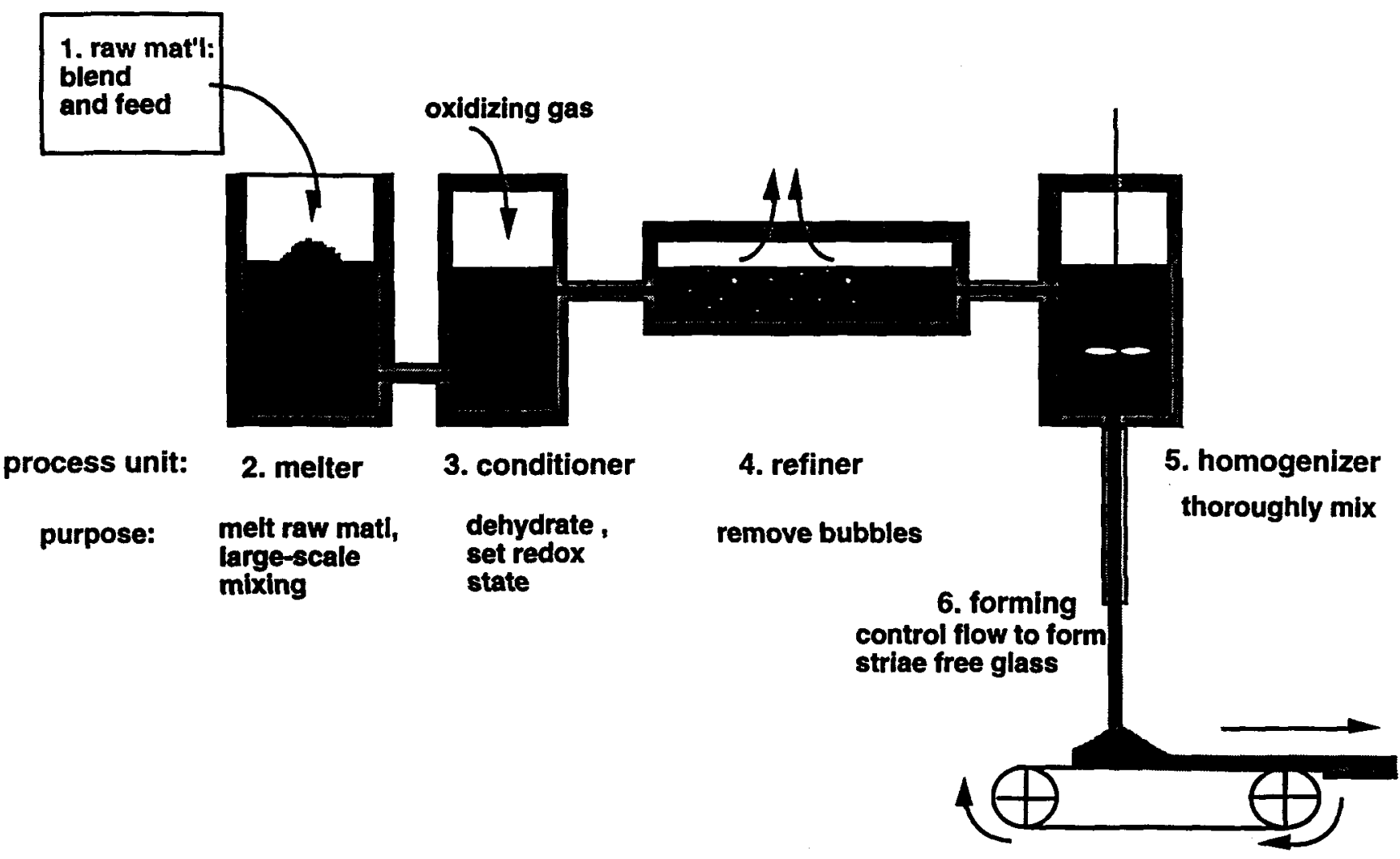

Figure 3. Schematic representation of the continuous laser glass melting systems to be used for manufacture of NIF and LMJ laser glass. Shown are the various process zones that are discussed further in the text.

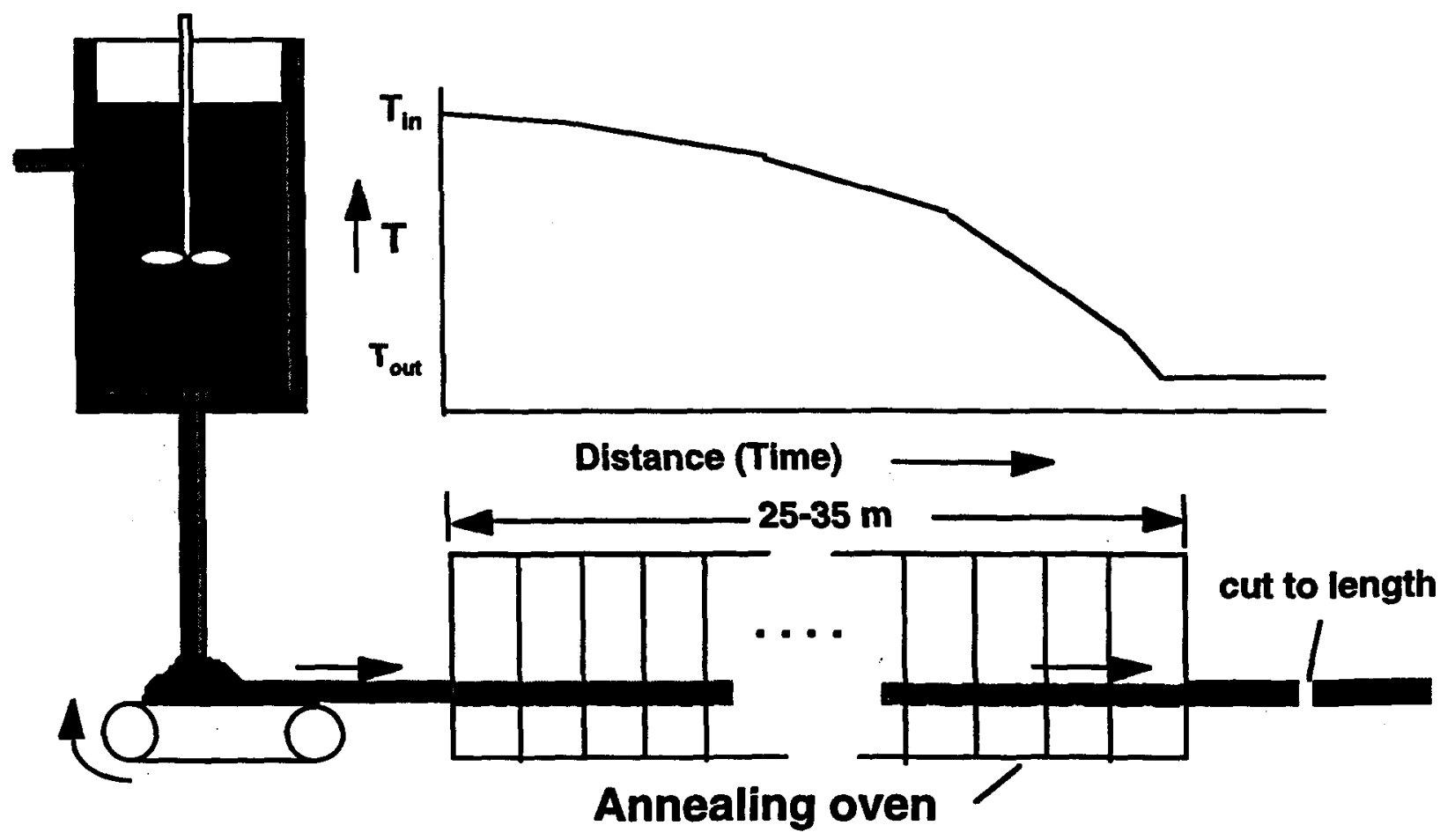

Figure 4.Schematic representation of the system used to coarse anneal the as-cast, continuous laser glass strip. 
The glass manufacturers have highly proprietary technology that they employ to "form" (i.e. cast) the glass into a homogeneous continuous strip free of sharp index variations (striae). Once successfully formed, the cast strip moves by conveyer belt through a long $(25-35 \mathrm{~m})$ coarse annealing oven (Fig. 4) where the temperature is ramped down at a rate to avoid generating unacceptable thermal stresses in the glass. Finally, at the end of the lehr, the cast strip is cut into pieces that are then individually post-processed to give the desired laser slab blank.

Both manufacturers will use advanced processing conditions designed to minimize the formation of Pt inclusions in the laser glass. Prior to 1986, Pt inclusion damage represented the major source of damage in laser glass used for high peak power applications. However new processing methods effectively reduce the Pt inclusion concentration by more that 1000 -fold to fewer than an average of 1 to 2 per laser glass slab (i.e. less than 0.1 per liter). ${ }^{g .12}$

\subsection{Post-processing}

Once the laser glass has been melted and formed into plates, there remains a number of other process steps before the glass can be shipped to the final finishing vendor. Specifically the laser glass needs to undergo pre-fabrication to a size suitable for inspection for striae and Pt inclusions. Following this the glass is slowly annealed to remove any residual strain; this process alone can take many days. Finally the glass is fabricated to the final dimensions required by the glass finishing, inspected for homogeneity and prepared for shipping.

\section{MANUFACTURING SCHEDULE}

The NIF and LMJ laser glass manufacturing is divided into two main phases: pilot and production. Pilot refers to the first production run; the results from the pilot run will be used to establish yield and costs. In addition, the glass from the pilot run will be used by the finishing vendors to demonstrate the advanced laser glass finishing and polishing methods to be used in final production.

The production phase immediately follows pilot. The first stage of laser glass production will be primarily for the NIF facility because NIF construction will occur earlier than the LMJ. The NIF production will take place over approximately three years at a rate of about 1200 slabs per year. This production will be followed by the LMJ production that will last 3 to 4 years. On the third year of production the NIF and LMJ may overlap somewhat causing a short term increase in the annual production rate.

CEA is building an intermediate facility called the "Integrated Laser Line" (LIL). The LIL will consist of 8 beams identical to those on the LMJ (which contains 240). The first goal of this laser is to validate the design of the LMJ including the performance of the various laser components and optics. Some of the laser slabs produced during pilot operations will be used on the LIL.

\section{ACKNOWLEDGMENTS}

The authors gratefully acknowledge the efforts by J. Hayden, A. Thorne, H. Pankratz and their colleagues at Schott Glass Technologies, Inc. and by K. Takeuchi, M. Smolley, and J. Storms and their colleagues at Hoya Corporation for their fine efforts in the development of the advanced laser glass processes needed to produce the laser glass for the NIF and LMJ. This work is supported in the US by the Department of Energy by Lawrence Livermore National Laboratory under contract W-7405-ENG-48 and in France by the Commissariat a l'Energie Atomique (CEA).

\section{REFERENCES}

1. J. Paisner and J.R. Murray, "Overview of the National Ignition Facility Project”, SPIE Conference on Solid State Laser Applications to ICF (this proceedings), Monterey (1998).

2. M. Andre "LMJ and LIL" SPIE Conference on Solid State Laser Applications to ICF (this proceedings), Monterey (1998). 
3. National Ignition Facility Conceptual Design Report, Vol. 2 and 3, Lawrence Livermore National Laboratory, Livermore, CA, Report No. UCRL-PROP-117093, May 1994

4. M. Andre, "Pour une chaine laser de grande puissance", Chocs, Revue scientifique et technique de la Direction de Applications Militaires, Vol. 11, pp.82-85, July 1994.

5. A. C. Erlandson, M. D. Rotter, D. N. Frank and R. W. McCracken, "Design and performance of the Beamlet amplifiers", Inertial Confinement Fusion Quarterly Report, Vol. 5, No. 1, pp. 18-28, Lawrence Livermore National Laboratory, Livermore, CA, UCRL-LR-105821-95-1, October-December 1994.

6. A. Erlandson, J. Horvath, K. Jancaitis, J. Lawson, K. Manes, C. Marshall, E. Moor, S. Payne, L. Pedrotti, S. Rodriguez, M. Rotter, S. Sutton, L. Zapata, S. Seznec, J. Beullier, O. Carbourdin, E. Grebot, J. Guenet, M. Guenet, and X. Maille, "Flashlamp-pumped Nd:glass Amplifiers for the National Ignition Facility", Proceedings of the 13th Embedded Topical Meeting on the Technology of Fusion Energy, American Nuclear Society (1998).

7. L. Zapata, C. Marshall, M. Rotter, K. Jancaitis, A. Erlandson, E. Grebot, J. Beuiller, J.L. Guenet and S. Seznec, "Gain and wavefront measurements performed on the NIF/LMJ prototype amplifiers", SPIE Conference on Solid State Laser Applications to ICF (this proceedings), Monterey (1998).

8. B. M. VanWonterghem, J. R. Murray, J. H. Campbell, D. R. Speck, C. E. Barker, I. C. Smith, D. F. Browning and W. C. Behrendt, "Performance of a Proto-type for a Large-aperture Multi-pass Nd:Glass Laser for Inertial Confinement Fusion", Applied Optics, Vol. 36 (1997) p.4932.

9. J. H. Campbell, R. T. Maney, L. J. Atherton, R. C. Montesanti, J. J. DeYoreo, L. M. Sheehan, M. R. Kozlowski, and C. E. Barker, "Large-aperture high-damage threshold optics for Beamlet", Inertial Confinement Fusion Quarterty Report, Vol. 5, No. 1, pp. 29-41, Lawrence Livermore National Laboratory, Livermore, CA, UCRL-LR-105821-95-1, October-December 1994.

10. J. H. Campbell, E. P. Wallerstein, J. S. Hayden, D. L. Sapak, and A. J. Marker, "Effects of melting conditions on platinum-inclusion content in phosphate laser glasses", Glastech. Ber. Glass Sci. Technol., Vol. 68, No. 1, pp. 11-21, 1995.

11. J. H. Campbell, E. P. Wallerstein, H. Toratani, H. Meissner, and T. Izumitani , "Effects of process gas environment on platinum-inclusion density and dissolution rate in phosphate laser glasses", Glastech. Ber. Glass Sci. Technol., Vol. 68, No. 2, pp. 1-11, 1995.

12. J. H. Campbell, E. P. Wallerstein, J. S. Hayden, D. L. Sapak, D. Warrington, A. J. Marker, H. Toratani, H. Meissner, S. Nakajima, and T. Izumitani, "Elimination of platinum inclusions in phosphate laser glasses", Lawrence Livermore National Laboratory Report UCRL-53932, Livermore, CA, , 1989, pp. 1-80.

13. C. L. Weinzapfel, G. J. Greiner, C.D. Walmer, J. K. Kimmons, E. P. Wallerstein, F. T. Marchi, J. H. Campbell, J. S. Hayden, K. Komiya, and T. Kitiyama, "Large scale damage testing in a production environment", Laser Induced Damage in Optical Materials: 1987, NIST Special Publication 756, National Institute of Standards and Technology, 1987, pp. 112-122

14. J. H. Campbell, "Recent Advances in Phosphate Laser Glasses for High-power Applications, in Inorganic Optical Materials, P Klocek Ed. SPIE Vol. CR64, pp. 3-39, 1996.

15. A. J. Marker, "Optical glass technology", Geometrical Optics, SPIE proceedings Vol. 531, pp. 2-10, 1985.

16. T. S. Izumitani, "Optical Glass", Chap. 3, American institute of Physics translation series, New York, 1986.

17. S. Schwartz, R. T. Jennings, J. F. Kimmons, R. P. Mouser, C. L. Weinzapfel M. R. Kozlowski, C. J. Stolz, and J. H. Campbell, "Vendor-based laser damage metrology equipment supporting the National Ignition Facility", SPIE Conference on Solid State Laser Applications to ICF (this proceedings), Monterey (1998). 
UCRL-JC-129507

PREPRINT

\title{
25 Years of Laser Glass Development Leading to a $1.8 \mathrm{MJ}, 500 \mathrm{TW}$ Laser for Fusion Ignition
}

\author{
John H. Campbell
}

This paper was prepared for submittal to the

18th International Congress on Glass

San Francisco, California, USA

July 5-10, 1998

January 26, 1998

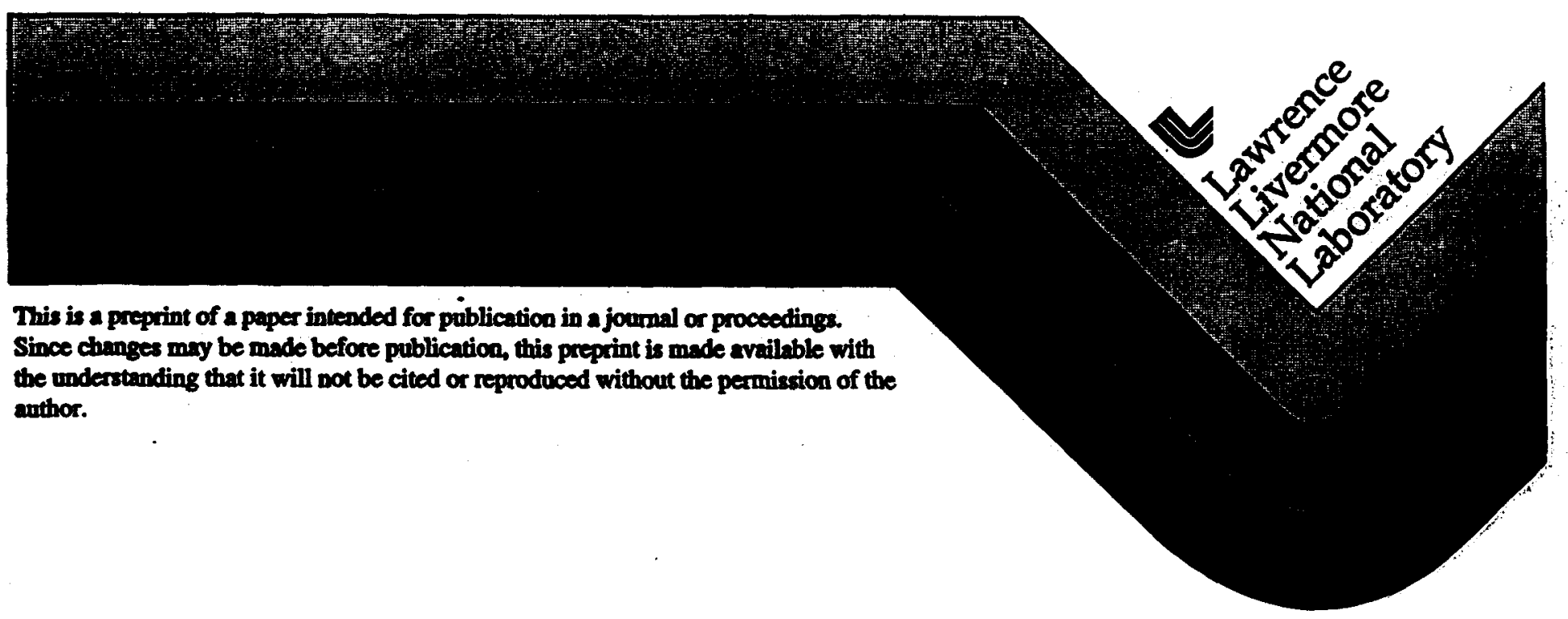




\section{DISCLAIMER}

This document was prepared as an account of work sponsored by an agency of the United States Government. Neither the United States Government nor the University of California nor any of their employees, makes any warranty, express or implied, or assumes any legal liability or responsibility for the accuracy. completeness, or usefulness of any information, apparatus, product, or process disclosed, or represents that its use would not infringe privately owned rights. Reference herein to any epecific commercial product, process, or service by trade name, trademark, manufacturer, or otherwise, does not necessarily constitute or imply its endorsement, recommendation, or favoring by the United States Government or the University of California. The views and opinions of authors expressed herein do not necessarily state or reflect those of the United States Government or the University of California, and shall not be used for advertising or product endorsement purposes.

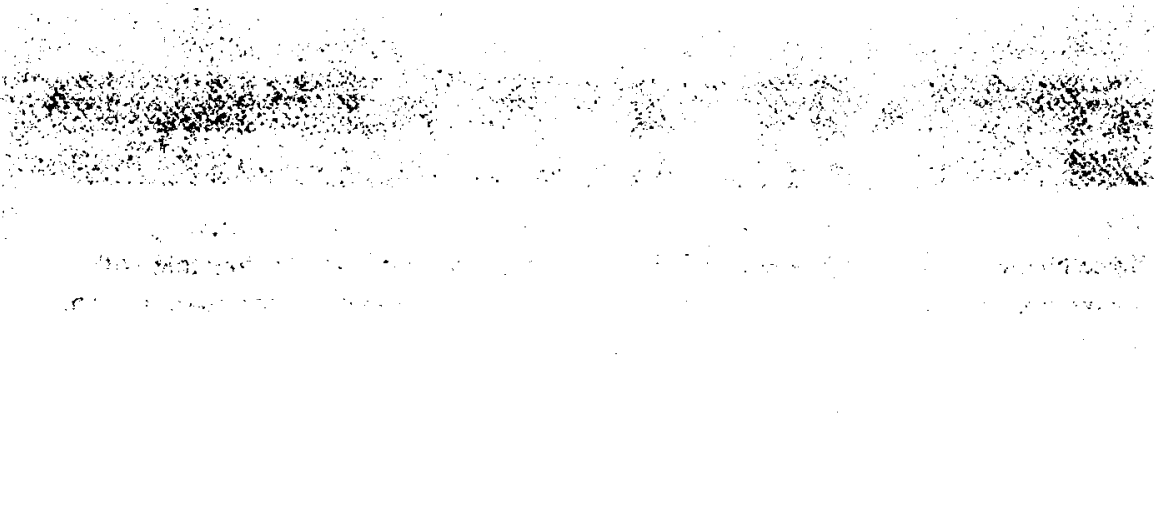




\section{YEARS OF LASER GLASS DEVELOPMENT LEADING TO A $1.8 \mathrm{MJ}, 500$ TW LASER FOR FUSION IGNITION}

John H. Campbell

Lawrence Livermore National Laboratory

L-500, Laser Program

P. O. Box 808 Livermore, CA 94550 , USA

\section{ABSTRACT}

Nd-doped phosphate glasses are the preferred gain medium for high-peak-power (HPP) lasers used for Inertial Confinement Fusion (ICF) research because they have excellent energy storage and extraction characteristics. In addition, these glasses can be manufactured defect-free in large sizes and at relatively low cost. The current laser glasses for ICF are the result of more than 20 years technological development. The key scientific and technical advances in ICF laser glasses during this period are reviewed. Properties of the glasses to be used in the $1.8 \mathrm{MJ}$, 500 TW ICF laser systems currently under construction are discussed. The laser glasses for these new lasers will be produced in sizes 30 times larger, quantities 3000 times greater and at rates more than 1000 times faster than laser glasses for the ICF lasers built in the mid to late 1970's.

\section{INTRODUCTION}

The US Department of Energy is currently constructing a $1.8 \mathrm{MJ}, 500 \mathrm{TW}$, frequency-tripled, Nd-glass laser designed to drive a roughly $1 \mathrm{~mm}^{3}$ capsule containing liquid DT to nuclear fusion ignition.' The 192-beamline laser, plus associated target facility is called the National Ignition Facility (NIF) (Figure 1). NIF will be housed in a building approximately the size of a small municipal sports stadium and, at an estimated cost of $\$ 1.2$ billion, will require about 8 years to design, build and activate. Construction of a prototype of one of the 192-laser beamlines (called "Beamlet") was completed in 1994 and demonstrated the required laser output energy, fluence and beam quality needed for the NIF.'

The NIF design and laser component development began in 1995 and will be completed by October 1998. Construction of the building to house the laser and the target facility was started in the spring of 1997 and will be completed in stages, with stage 1 being done by October 1999 and the final stage by October 2001. The laser will become fully operational by 2003 , following a three year schedule of laser activation and early target shots.

The heart of the NIF laser is a series of nearly 3100 flashlamp-pumped amplifier segments, arranged in $2 \times 4$ arrays (Figure 2) that rely on plates of high optical quality Nd-doped phosphate laser glass as the energy storage and laser gain media. Each glass plate is about $81 \times 46 \times 4.1 \mathrm{~cm}^{3}$ in size with an Nd doping density of $4.2 \times$ $10^{20}$ ions $/ \mathrm{cm}^{3}$.

A fusion ignition facility similar to the NIF is also being designed by the French Commissariat a l'Energie Atomique (CEA). This system, called the "Laser Megajoule" (LM), is planned to be constructed and activated in stages beginning in 2005 and being fully operational by about 2010 . The LMJ will require about 4000 laser slabs for the 240 beamline system. The CEA and LLNL are presently sharing the cost for development and facilitization needed to produce the laser glass for these two systems. In addition both laser designs use glass slabs of the same size, Nd-doping and material specifications.

This brief review covers major advances in laser glasses over approximately the last 25 years that have occurred in parallel with the design and construction of larger and more powerfil solid-state fusion laser systems. Perhaps more than any other optical material, it has been the advances in betied Jarger and Jess expensive laser glasses that have paced the development and construction of the high-peak-power (HPP) laser yystems needed for Inertial Confinement Fusion (ICF) research. Twenty-five years was chosen as a starting point because it coincides roughly with the 1974 publication of Krupke's classic work ${ }^{3}$ on the use of the Judd-Ofelt $t^{3}$ theory for the determination of key laser properties by analysis of laser glass spectroscopic data.

The manuscript is divided into four main parts:

1. a summary of laser glass properties important for high-peak-power ICF research applications,

2. major advances in laser glass chemistry and physics that have lead to the development of the current commercial laser glasses

3. a compilation of the properties of current laser glasses used in fusion systems

4. a summary of major improvements in the manufacturing technology that have lead to better performance and lower cost HPP laser glasses. 


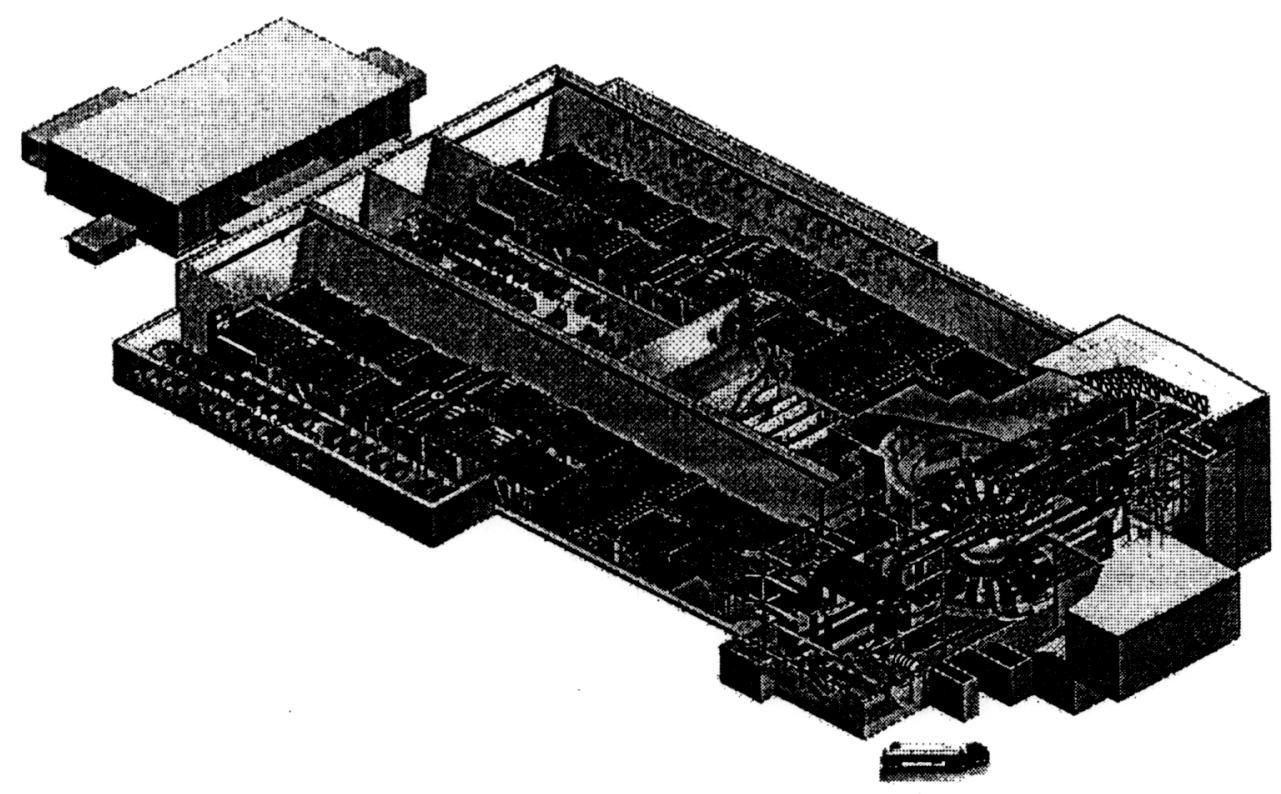

Figure 1. Artist's drawing of the 192-beamline National Ignition Facility (NIF).

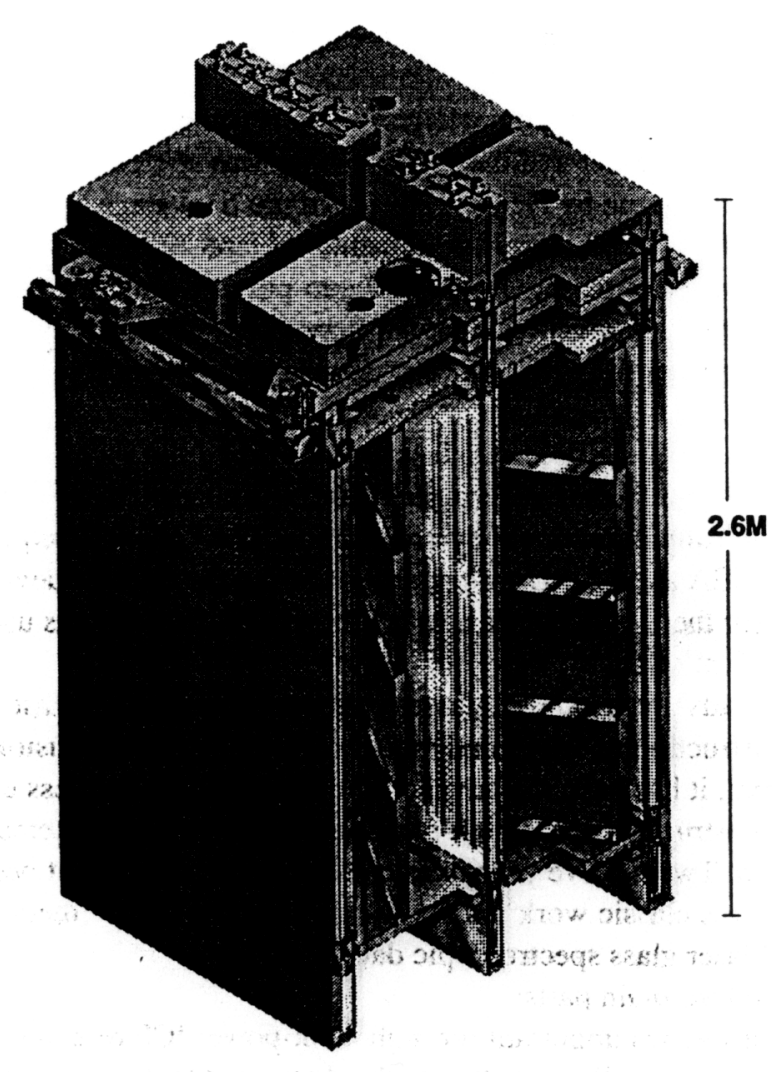

Figure 2. Section through a NIF $2 \times 4$ amplifier array containing 8 laser glass plates $81 \times 46 \times 4.1 \mathrm{~cm}^{3}$ 
The article deals only with the neodymium-doped laser glasses used in fusion research laser systems since they represent the most common and largest volume of laser glass produced today. Note however that there have been a number of exciting developments in the area of active glasses used for high-average-power applications and also for fiber optics and waveguided structures; the reader is referred to reviews by others in this field. ${ }^{6.7}$ Similarly, in the past there have been many excellent periodic reviews on the chemistry and physics of all classes of laser glasses (phosphates, silicates, borates, fluorides, aluminates, germanates, chalcogenides, and sulfates) ${ }^{7.17}$ and thus the reader is referred to these sources for more detailed information.

\section{GLASS PROPERTIES IMPORTANT FOR LASER FUSION APPLICATIONS}

To meet the performance requirements for Inertial Confinement Fusion (ICF) research applications, there are several important characteristics the laser glass must have:

- high net gain,

- efficient energy storage at a high energy density,

- efficient extraction of the stored energy,

- resistance to laser induced damage and

- high optical quality to allow the light to propagate with little or no wavefront aberration.

It can be argued that the most important spectroscopic and optical properties for ICF applications are the emission cross-section, fluorescence lifetime, and non-linear index of refraction. The emission cross-section and the fluorescence lifetime largely control the gain, energy storage and extraction efficiency of the laser glass. The nonlinear index strongly impacts beam quality, particularly noise growth at the high operating intensities required for ICF.

ICF laser systems tend to be essentially "single shot" devices with several minutes or even hours between shots, therefore the glass physical properties tend to be of less importance for the end use application. However the glass physical properties can be very important to the successful manufacture and handling of ICF laser glasses.

Gain, Stored Energy and Extraction Efficiency.

The amplification of a laser pulse passing through a laser gain medium (e.g. laser glass) of length, $z$, can be modeled using the well-known Frantz-Nodvik equation. ${ }^{18}$ This equation relates the output fluence $\left(F_{\text {out }}\right)$ to the input fluence $\left(F_{\mathrm{ta}}\right)$ given the small signal gain $\left(G_{0}\right)$ and saturation fluence $\left(F_{m i}\right)$ of the laser medium:

$$
F_{\text {out }}=F_{\text {sut }} \ln \left[1+G_{0}\left(\exp \left(F_{\text {tan }} / F_{\text {sact }}\right)-1\right)\right]
$$

The small-signal gain of the laser glass is described by:

$$
G_{0}=\exp \left(z\left[\left(\sigma N^{*}\right)-\alpha\right]\right)
$$

where $\sigma$ is the emission cross section $\left(\mathrm{cm}^{2}\right), \mathrm{N}^{*}$ the Nd-ion inversion density $\left(1 / \mathrm{cm}^{3}\right)$ and $\alpha$ is the transmission loss coefficient $\left(\mathrm{cm}^{-1}\right)$. To achieve a high net gain requires a high emission cross section coupled with a large population inversion density. In addition, transmission losses due to absorption by impurities or scattering from defects in the glass (or on the polished surfaces) must be kept low relative to the gain.

The term $\sigma \mathrm{N}^{*}$ is the gain coefficient, $\mathrm{g}_{\mathrm{L}}$, and is related to the stored energy density ( $\mathrm{G}_{2}=\mathrm{hvN}$ ) and the saturation fluence $\left(F_{\mathrm{eur}}=h v_{1} / \sigma\right)$ of the material:

$$
\begin{gathered}
g_{L}=N^{*} \sigma \\
=\left(h v_{1} N^{*}\right) \cdot\left(\sigma / h v_{\nu}\right) \\
=E_{3} / F_{\text {out }}
\end{gathered}
$$

where $h$ is Planck's constant $(\mathrm{J}-\mathrm{s})$, and $\mathrm{v}_{1}$ the laser frequency $(\mathrm{Hz})$. Experimentally the gain coefficient $(\mathrm{g} \mathrm{U})$ is measured directly by monitoring the signal gain of a probe beam passing through the glass as it is being pumped in a laser amplifier. ${ }^{1920}$ For example, the large flash-lamp pumped, glass laser amplifiers used in fusion energy applications typically operate with a gain coefficient of about $0.05 \mathrm{~cm}^{-1}$. The emission cross-section is determined 
independently from spectroscopic measurements. The phosphate glasses used in fusion applications nominally have an emission cross-section of about 3.5 to $4.0 \times 10^{20} \mathrm{~cm}^{2}$ corresponding to a saturation fluence of about $5 \mathrm{~J} / \mathrm{cm}^{2}$. The stored energy in the laser glass is computed from equation (3) to be about $0.25 \mathrm{~J} / \mathrm{cm}^{3}$.

Energy extraction from the glass is most efficient at high laser fluences, particularly fluences in excess of twice the saturation fluence. Having a glass with a high emission cross-section is desirable because efficient extraction can be achieved at lower fluence, thereby reducing the chance of laser-induced damage to the optics. Unfortunately, not all of the stored energy in the glass can be extracted even at very high fluences. ${ }^{21}$ This is due to the inhomogeneous broadening of the Nd emission. The cross-section calculated from measurements of gain saturation using the Frantz-Nodvik equation give higher emission cross-sections $\left(\sigma_{\mathrm{gs}}\right)$ than those determined spectroscopically $\left(\sigma_{\mathrm{em}}\right)$. This is because the Nd-site inhomogeneities in the glass lead to hole-burning, causing the glass to saturate at a lower fluence corresponding to a higher effective cross-section. The extraction efficiency then can be defined by the ratio of the two cross-sections:

$$
\eta_{\mathrm{ext}}=\sigma_{\mathrm{em}} / \sigma_{\mathrm{gs}}
$$

Phosphate laser glasses tend to saturate much more homogeneously than do silicates and therefore the efficiency with which the energy is extracted is much higher. ${ }^{21.22}$ This is one of the reasons for the wide use of phosphate glasses in ICF applications. To be more specific, a large fraction of the cost of the large fusion research lasers is in the cost of the amplifiers. Therefore simultaneously achieving a high stored energy and efficient extraction is essential to keep the number (and cost) of the amplifiers at a minimum.

A high $\mathbf{N d}^{3+}$ gain cross-section is often desirable for ICF laser applications however it can also lead to some undesirable effects. For example, for large aperture laser systems, a high gain coefficient can lead to low energy storage efficiency and large spatial variations in the gain distribution across the aperture due to amplified spontaneous emission. The general rule-of-thumb is that the product of the gain coefficient and longest dimension of the laser glass piece should not exceed a value of about 4.2. In addition, the Nd doping and fluorescence lifetime must be optimized to achieve maximum energy storage efficiency. This trade-off between high gain, good spatial gain uniformity and efficient energy storage is quite complex and is usually optimized with the use of sophisticated laser design computer codes. ${ }^{23}$

\section{Non-radiative Energy Losses}

In most practical applications the quantum yield is never $100 \%$ due to non-radiative relaxation mechanisms that significantly shorten the lifetime. These non-radiative losses are affected by the intrinsic properties of the laser glass as well as the care with which the glass is manufactured. ${ }^{924}$ Figure 3 presents a schematic view of the most important non-radiative mechanisms.

The two most important intrinsic processes are multi-phonon relaxation and concentration quenching. Concentration quenching refers to the radiation exchange between a pair of $\mathrm{Nd}$ ions. Nd concentration quenching results from the contributions of two relaxation mechanisms. One is cross relaxation in which the two ions share the energy and the second is migration of the excitation energy from one ion to the next (the so-called "hopping" mechanism). In theory the rate of relaxation due to concentration quenching varies as $1 r^{6}$ where $r$ is the inter-ion distance; note that this is equivalent to the square of the $\mathrm{Nd}^{3+}$ concentration. In reality the effect of the $\mathrm{Nd}$ concentration on relaxation rate is highly glass dependent and varies from nearly linear to quadratic in phosphates and from quadratic to cubic in silicates. ${ }^{2426}$ Stokowski and more recently Payne et. al. ${ }^{26}$ bave proposed an empirical relationship to characterize concentration quenching in HPP metaphosphate glasses:

$$
\tau_{\text {ea }}=\tau_{0} /\left(1+(\mathrm{N} / \mathrm{Q})^{2}\right)
$$

where $\tau_{\mathrm{o}}$ is the zero concentration lifetime $(\mu \mathrm{s}), \mathrm{N}$ is the $\mathrm{Nd}^{3+}$ ion concentration $\left(\mathrm{cm}^{-3}\right)$ and $\mathrm{Q}\left(\mathrm{cm}^{-3}\right)$ is an empirically determined quantity for a given glass; $Q$ is physically equivalent to the $N d$ concentration needed to reduce the lifetime to one-half its zero concentration limit.

The rate of multi-phonon relaxation depends on how closely the ${ }^{4} F_{32} \cdot$ to ${ }^{4} I_{15 / 2}$ energy transition $\left(5500 \mathrm{~cm}^{-1}\right)$ matches the maximum vibration energy of the glass matrix. ${ }^{9242}$ For phosphate glasses the maximum vibration energy is about $1170-1200 \mathrm{~cm}^{-1}$, 2a, thus suggesting the absence of any significant multi-phonon effects. Careful 
measurements by Caird et. al. ${ }^{24}$ on two commercial phosphate glasses ( LG-750 and LG-760) support this observation; the measured multi-phonon relaxation rate is about $200 \mathrm{~s}^{-1}$.

(a) Intrinate proceseses

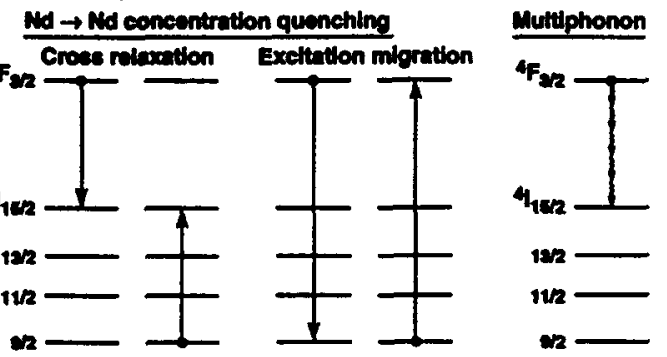

(b) Extrinalc proceseses Nd $\rightarrow$ translition-matel ion
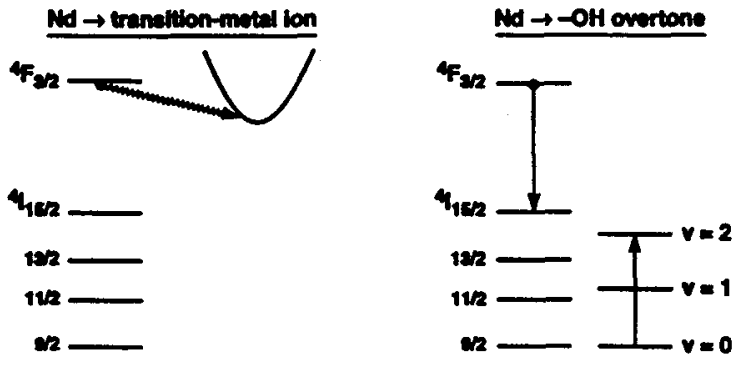

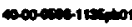

monom

Figure 3. Non-radiative $\mathrm{Nd}^{3+}$ relaxation processes in laser glasses can be divided into (a) intrinsic processes that depend on the glass structure during manufacturing and (b) extrinsic processes that depend on impurities in the laser glass (e.g. - OH and transition metal ions).

It is well known that impurities that enter the glass during manufacturing (particularly - $\mathrm{OH}$ and transition metal ions) can cause significant non-radiative relaxation. Some useful correlations have recently reported for estimating the impact of various impurities on the non-radiative relaxation rate in phosphate glasses. ${ }^{17}$ We hasten to add however that the problems associated with impurities have been largely eliminated in modern laser glass manufacturing by the proper chose of raw material and melting equipment.

\section{Non-linear Refractive Index}

The energy extraction efficiency for ICF laser systems is also limited by non-linear propagation effects, particularly at very short pulse lengths. The refractive index increases with the laser intensity:

$$
n=n_{0}+\gamma I
$$

where $\gamma$ is the non-linear refractive index coefficient $\left(\mathrm{m}^{2} / \mathrm{W}\right)$ and $\mathrm{I}$ is the laser intensity $\left(\mathrm{W} / \mathrm{m}^{2}\right)$. The intensity dependent index can cause amplitude ripples (noise), that occur at certain spatial frequencies, to grow exponentially:

$$
I=I_{0} \exp (B)
$$

where the "B" factor (or "break-up integral") is the cumulative non-linear phase retardation over the optical path length:

$$
B=2 \pi / \lambda \int \gamma I d z
$$


Past experience has shown that B needs to be less than about 2 radians to avoid unacceptable noise ripple growth. ${ }^{30,31}$ Such growth can cause optical damage and/or degrade the beam focus. Therefore laser glasses with low non-linear indices are required for ICF applications.

Direct measurement of $\gamma$ is difficult, so empirical correlations have been developed. The expression developed by Boling et. al. ${ }^{32}$ number of years ago accurately predicts $\gamma$ from the refractive index $\left(n_{d}\right)$ and the Abbe number $(v)$ of the glass:

$$
\gamma=K\left(n_{d}-1\right)\left(n_{d}^{2}+2\right)^{2} /\left[n_{d} v\left[1.52+\left(n_{d}^{2}+2\right)\left(n_{d}+1\right) v / 6 n_{d}\right]^{1 / 2}\right\}
$$

where $K=2.8 \times 10^{-10} \mathrm{~m}^{2} / \mathrm{W}$ is an empirically determined constant. The non-linear refractive index, $\mathrm{n}_{2}$ (in esu) is related to $\gamma$ by $n_{2}=\gamma(n c / 40 \pi)$ where $c$ is light speed.

\section{BRIEF OVERVIEW OF THE EVOLUTION OF LASER GLASS TECHNOLOGY}

Arguably, one of the most important contributions to the development of laser glasses for fusion lasers was the work by Krupke ${ }^{3}$ in 1974 who applied the Judd-Ofelt ${ }^{4.5}$ approach to understanding the spectra of rare earths to $\mathrm{Nd}^{3+}$ in a glass matrix. Krupke's approach allowed researchers to use small laboratory samples of Nd-doped glasses to determine key laser properties. Laser performance could then be predicted from these properties. Systematic studies of the effects of glass composition on emission cross-section, radiative lifetime, emission peak wavelength and bandwidth, and radiative branching ratios were begun at universities, national laboratories and glass manufacturers (see for example References 7-17) and continue even to this day. These efforts led to compilations of data on a large number of laser glasses.

The glass of choice in the mid-seventies was a silicate glass code named ED-2 and developed by OwensIllinois. ${ }^{16}$ It soon became clear that silicates, although manufactured with relative ease, had several problems: a low to moderate gain cross-section, poor extraction efficiency, high nonlinear index and a high level of platinum inclusion contamination. (The inclusion problem is discussed later.)

Glass composition studies have spanned nearly the entire range of glass forming systems (silicates, phosphates, fluorophosphates, fluorides, borates, aluminates, chalcogenides, tellurites, and titanates) and, in many cases, within each system the effects of the variations in the network modifiers have also been studied (for example see References 9, 12, 16, 17, 28, 29). Many of the glasses were simply scientific curiosities but nevertheless provided a basic understanding from which more practical glass forming systems evolved. For example, Weber and co-workers showed that perhaps the best glass composition for use in ICF laser systems is $\mathrm{Nd}^{3+}$-doped $\mathrm{BeF}_{2}{ }^{11}$ because of its good laser properties and perhaps most important, low nonlinear refractive index. However the reactivity and toxicity of the material presently make it prohibitive to manufacture. Nevertheless, from this evolved fluorophosphate laser glasses which combined some of the key laser property advantages of the fluoride systems with the better melting characteristics of phosphates. Unfortunately, the problem of very high levels of platinum inclusions in fluorophosphates soon precluded their use in high fluence laser systems.

The composition work in the 1970's and 80's soon lead to phosphates as the glass of choice and today they continue to be the compositions in use in all major fusion laser systems around the world. ${ }^{15-17}$ The current commercial phosphate glasses have high gain cross-section, modest fluorescence lifetime, good extraction efficiency and relatively low nonlinear index. In addition, as will be discussed in the next section, they can be manufactured in large sizes, free of platinum inclusions and at a modest cost.

In the last ten years an enormous number of different phosphate glass compositions have been melted in an effort to simultaneously optimize the laser properties and also the thermal-mechanical and physical-chemical properties. In addition, much of this work has focused on improved and low-cost manufacturing. As a result of these past efforts, the level of scientific understanding of laser glasses has become quite sophisticated and the manufacturing technology has evolved to a mature state. 


\section{PROPERTIES OF LASER GLASSES USED IN CURRENT FUSION LASER SYSTEMS}

The key properties of commercial laser glasses used in current ICF laser are summarized in Table I. Although there are other HPP glasses that are being manufactured, the ones listed in Table I are the most widely used glasses in the US, Japan and Europe. Table II lists the major large Nd-glass ICF laser systems in the western world and the type and maximum size of laser glass installed.

The largest pieces of laser glass in use today are the approximately $79 \times 45 \times 4 \mathrm{~cm}^{3}$ slabs installed on the LLNL Beamlet laser (Fig 5): ${ }^{2}$ recall that Beamlet is a prototype of the design of one NIF laser beamline.

The newest glass to join the list for use on ICF lasers is LG-770. Compared to its predecessor, LG-750, LG-770 has a lower non-linear index, improved laser and thermal-mechanical properties and also some improved characteristics important for high volume manufacturing. LG-770 and LHG-8 are the glasses chosen for use on the LMJ and NIF laser systems and also the prototype LMJ laser that is presently under construction (LIL) (see Table II).

\section{MANUFACTURING DEVELOPMENT} Improved Laser Damage Threshold

The operating fluence and irradiance of the future ICF mega-joule scale lasers will be higher than any current laser system. Peak fluences in the laser glass will approach 18 to $20 \mathrm{~J} / \mathrm{cm}^{2}$ with a peak irradiance of about $5.0 \mathrm{GW} / \mathrm{cm}^{2}$. To avoid any optical damage the laser glass must be free of defects, specifically any microscopic inclusions (either metallic or ceramic) left from the melting process. The most common inclusion source is metallic $\mathrm{Pt}$ inclusions from the Pt liners used in the melting system. ${ }^{33}$ Prior to 1986, Pt inclusion damage represented the major source of damage in laser glass used for high-peak-power applications. However new processing methods effectively reduce the $\mathrm{Pt}$ inclusion concentration by more that 1000 -fold to less than 0.1 per liter. ${ }^{33-35}$ For example, $50 \%$ of the large laser slabs (79 $\times 45 \times 4 \mathrm{~cm}^{3} ; 14$ liters of glass each) used on the new Beamlet laser at LLNL had no inclusions at all and the average for all the slabs produced was about 1 per slab. Similar results have been achieved for the several hundred replacement glass disks manufactured for the Nova and Phebus laser, each of those disks contained 7 liters of glass. ${ }^{34,37}$

Inclusions in the laser glass damage at about 2-5 J/cm at the 1-10 pulse lengths typical of most HPP applications. ${ }^{38}$ Although very small to begin with, inclusion damage can grow with successive laser shots to several millimeters or even centimeters in size eventually making the laser glass unusable. Also large damage spots $(>300 \mu \mathrm{m})$ in the laser glass can seed damage in other optics in the laser chain. ${ }^{31}$ In general, if the inclusions are small they can be tolerated as long as the optical damage they produce does not exceed $300 \mu \mathrm{m}$ in size. Inspection methods have been developed and put into production to scan each piece of laser glass with a high fluence laser beam and measure the size of any damage site after 100 shots at fluences between 7 to $14 \mathrm{~J} / \mathrm{cm}^{2}(8 \mathrm{~ns}) .^{37}$

The new processing techniques for eliminating Pt inclusions rely on the intrinsic property of many phosphate glasses to dissolve $\mathrm{Pt}$ metal under oxidizing conditions. Izumitani et. al. ${ }^{39}$ have reported the use of gaseous $\mathrm{POCl}_{3}$ as an oxidizing additive and Campbell and co-workers at Hoya and Schott ${ }^{3,35}$ have reported the effects of $\mathrm{O}_{2}, \mathrm{Cl}_{2}, \mathrm{CCl}_{4}$ and $\mathrm{N}_{2} / \mathrm{O}_{2}$ mixtures. Model predictions of $\mathrm{Pt}$ inclusion dissolution rates agree well with results from glass melting tests. ${ }^{.0}$

The effects of glass composition on platinum solubility have been reported to follow the trend: phosphate $>$ silica-phosphate $\gg$ fluorophosphate > silicate. ${ }^{39}$ These results are based on solubility measurements using LHG-5 and LHG-8 (phosphates), HAP-3 (silica-phosphate), LHG-10 (fluorophosphate) and LSG-91H (silicate).

If inclusions are eliminated from the bulk laser glass, the damage threshold is limited only by the quality of the surface finish. ${ }^{36}$ This is shown in Fig. 4 where the surface damage threshold is plotted versus pulse length for various laser glasses as well as fused silica. The pulse length dependence of the surface damage threshold for finely polished samples can be accurately represented by the empirical expression:

$$
D_{S}\left(J / \mathrm{cm}^{2}\right)=22 t_{p}^{0.4}
$$

where $t_{p}$ is the pulse length (ns). The surface damage threshold approximately follows the $t^{1 / 2}$ relationship predicted by a thermal diffusion heat transport model. For comparison the damage threshold reported by Gonzales and Milam ${ }^{38}$ for Pt inclusions is also shown in Fig. 4; it follows the approximate pulse length scaling relationships:

$$
D_{\mathrm{Pt}}\left(\mathrm{J} / \mathrm{cm}^{2}\right)=2 \mathrm{tp}^{0.3} \text {. }
$$


Table I: Properties of commercially available HPP glasses in common use on ICF lasers.

\begin{tabular}{|c|c|c|c|c|c|c|}
\hline \multicolumn{2}{|l|}{ Glass Manufacturer } & \multicolumn{2}{|c|}{ Hoya } & \multicolumn{2}{|c|}{ Schott } & Kigre \\
\hline Glass Properties & Symbol & LHG-80 & LHG-8 & LG-770 & LG-750 & Q88 \\
\hline $\begin{array}{l}\text { Optical } \\
\text { refractive index } \\
\text { @ } 587.3 \mathrm{~nm} \\
\text { @ } 1053 \mathrm{~nm} \\
\text { non-linear refractive index } \\
\quad\left(10^{-13} \mathrm{esu}\right) \\
\quad\left(10^{-20} \mathrm{~m}^{2} / \mathrm{W}\right) \\
\text { Abbe number } \\
\text { Temp-coeff. refract. index }\left(10^{-6} / \mathrm{K}\right) \\
\text { Temp-coeff. optical path }\left(10^{-6} / \mathrm{K}\right) \\
\end{array}$ & $\begin{array}{c}\mathrm{n}_{\mathrm{d}} \\
\mathrm{n}_{1} \\
\\
\mathrm{n}_{2} \\
\gamma \\
\mathrm{v} \\
\mathrm{dn} / \mathrm{dT} \\
\delta\end{array}$ & $\begin{array}{c}1.54291 \\
1.53289 \\
\\
1.24 \\
3.36 \\
64.7 \\
-3.8 \\
1.8 \\
\end{array}$ & $\begin{array}{c}1.52962 \\
1.52005 \\
1.12 \\
3.08 \\
66.5 \\
-5.3 \\
0.6 \\
\end{array}$ & \begin{tabular}{c|}
1.50674 \\
1.49908 \\
\\
1.02 \\
2.78 \\
68.5 \\
-4.7 \\
1.2 \\
\end{tabular} & $\begin{array}{c}1.526 \\
1.516 \\
\\
1.08 \\
2.98 \\
68.2 \\
-5.1 \\
0.8 \\
\end{array}$ & $\begin{array}{l}1.5449 \\
1.5363 \\
\\
1.14 \\
3.11 \\
64.8 \\
-0.5 \\
2.7 \\
\end{array}$ \\
\hline $\begin{array}{l}\text { Laser } \\
\text { emission cross-section }\left(10^{-20} \mathrm{~cm}^{2}\right) \\
\text { saturation fluence }\left(\mathrm{J} / \mathrm{cm}^{2}\right) \\
\text { radiative lifetime (zero-Nd) }(\mu \mathrm{s}) \\
\text { Judd-Ofelt radiative lifetime }(\mu \mathrm{s}) \\
\text { Judd-Ofelt parameters }\left(10^{-20} \mathrm{~cm}^{2}\right)\end{array}$ & $\begin{array}{c}\sigma_{\text {em }} \\
F_{\text {att }} \\
\tau_{0} \\
\tau_{\mathrm{r}} \\
\Omega_{2} \\
\Omega_{4} \\
\Omega_{6} \\
\Delta \lambda_{\text {eff }} \\
Q \\
\lambda_{L} \\
\end{array}$ & $\begin{array}{c}4.2 \\
4.5 \\
337 \\
327 \\
- \\
- \\
- \\
23.9 \\
10.1 \\
1054 \\
\end{array}$ & $\begin{array}{c}3.6 \\
5.3 \\
365 \\
351 \\
4.4 \\
5.1 \\
5.6 \\
26.5 \\
8.4 \\
1054 \\
\end{array}$ & $\begin{array}{c}3.9 \\
4.8 \\
372 \\
350 \\
4.3 \\
5.0 \\
5.6 \\
25.4 \\
8.8 \\
1053\end{array}$ & $\begin{array}{c}3.7 \\
5.1 \\
383 \\
367 \\
4.6 \\
4.8 \\
5.6 \\
25.3 \\
7.4 \\
1053.5\end{array}$ & $\begin{array}{c}4.0 \\
4.7 \\
326 \\
326 \\
3.3 \\
5.1 \\
5.6 \\
21.9 \\
6.6 \\
1054\end{array}$ \\
\hline $\begin{array}{l}\text { Thermal } \\
\text { thermal conduct, (W/mK) } \\
\text { thermal diffusivity }\left(10^{-7} \mathrm{~m}^{2} / \mathrm{s}\right) \\
\text { specific heat, (J/gK) } \\
\text { Coeff. thermal expan. }{ }^{*}\left(10^{-7} / \mathrm{K}\right) \\
\left.\text { Glass transition temp }{ }^{\circ} \mathrm{C}\right)\end{array}$ & $\begin{array}{l}k \\
\alpha \\
C_{b} \\
\alpha_{e} \\
T_{e}\end{array}$ & $\begin{array}{l}0.59 \\
3.2 \\
0.63 \\
130 \\
402 \\
\end{array}$ & $\begin{array}{l}0.58 \\
2.7 \\
0.75 \\
127 \\
485 \\
\end{array}$ & $\begin{array}{c}0.57 \\
2.9 \\
0.77 \\
135 \\
460 \\
\end{array}$ & $\begin{array}{c}0.60 \\
2.9 \\
0.72 \\
132 \\
450 \\
\end{array}$ & $\begin{array}{c}0.84 \\
- \\
0.81 \\
104 \\
367 \\
\end{array}$ \\
\hline $\begin{array}{l}\text { Mechanical } \\
\text { density }\left(\mathrm{g} / \mathrm{cm}^{3}\right) \\
\text { Poisson's ratio } \\
\text { Fracture toughness }\left(\mathrm{MPa} \mathrm{m}^{0.5}\right) \\
\text { Hardness }(\mathrm{GPa}) \\
\text { Young's modulus }(\mathrm{GPa}) \\
\text { Stress optic coeff. } \mathrm{Pa}) \\
\end{array}$ & $\begin{array}{c}\rho \\
\mu \\
\mathbf{K}_{1 \mathrm{C}} \\
\mathbf{H} \\
\mathrm{E} \\
\Delta \mathrm{B} \\
\end{array}$ & $\begin{array}{l}2.92 \\
0.27 \\
0.46 \\
3.35 \\
50.0 \\
1.77\end{array}$ & $\begin{array}{l}2.83 \\
0.26 \\
0.51 \\
3.43 \\
50.1 \\
1.93\end{array}$ & $\begin{array}{c}2.59 \\
0.25 \\
0.48 \\
3.58 \\
47.3 \\
2.2 \\
\end{array}$ & $\begin{array}{l}2.83 \\
0.26 \\
0.48 \\
2.85 \\
50.1 \\
1.80 \\
\end{array}$ & $\begin{array}{l}2.71 \\
0.24 \\
- \\
- \\
69.8 \\
2.07\end{array}$ \\
\hline $\begin{array}{l}\text { measured by LLNL } \\
\text { estimated } \\
\text { Q defined by guadratic relation }\end{array}$ & & & & & & \\
\hline
\end{tabular}


Thus, the presence of Pt inclusions reduces the operating limit of the laser glass by about 10-fold.

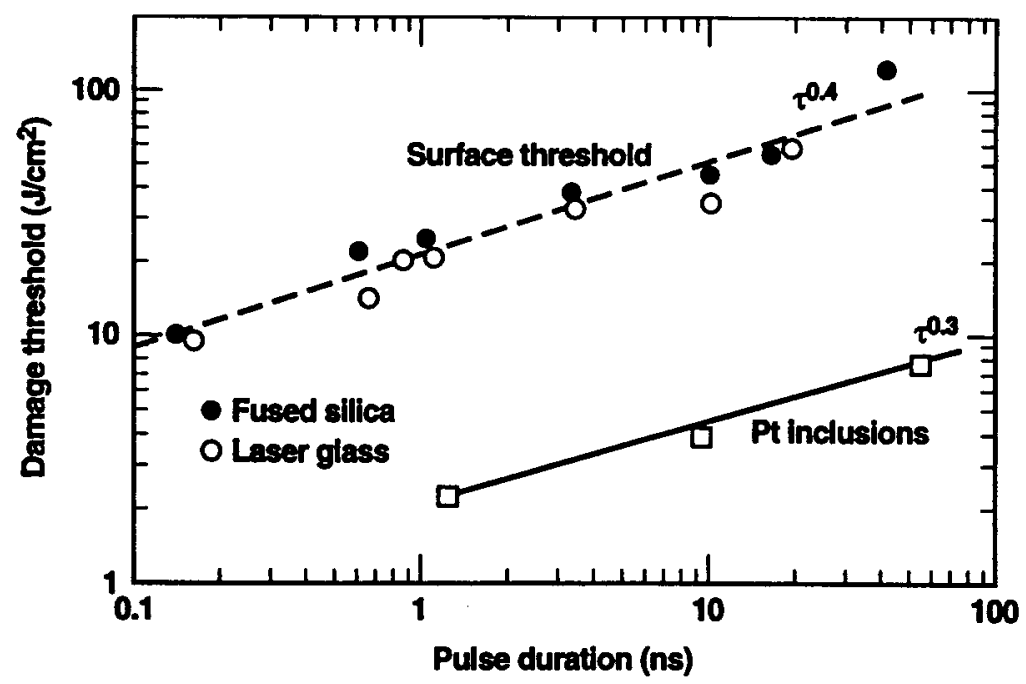

Figure 4. Measured surface damage threshold for various polished laser glasses and fused silica vs. pulse length. Also shown are bulk laser glass damage thresholds due to Pt inclusions as reported by Gonzales and Milam.

\section{Edge cladding development}

Edge claddings are used to suppress parasitic oscillations of amplified spontaneous emission (ASE) during flashlamp pumping of large pieces of laser glass. ${ }^{41}$ Edge cladding consists of a refractive-index-matched glass that is doped (usually with $\mathrm{Cu}^{+2}$ ) to absorb at the laser wavelength. The cladding is bonded to the edges of the laser glass disks or slabs and absorbs the ASE, thereby preventing parasitics from developing. Adhesively-bonded edge claddings have been developed and are now widely in the US and Europe. This new edge cladding process replaces the difficult and costly high temperature molten glass and sintered frit-glass processes used in the late 70's and early 80's. In addition the adhesively bonded cladding, because it is applied at room temperature, is free of residual strain and optical distortion commonly produced near the edges of the glass fabricated using high temperature cladding processes. The adhesive that is used is a two part optical epoxy that, after curing, has a Tg slightly above room temperature. The refractive index match to the laser glass is about \pm 0.003 and can be tuned somewhat by changing the ratio of two epoxide resins; one of the resins is a high index aromatic based material while the other is a lower index epoxide largely comprised of straight chain hydrocarbons. ${ }^{4}$

\section{Advances in Melting Technology}

Most recent laser glass process developments have been driven by the needs of the planned ICF National Ignition Facility (NIF) and Laser Mega-joule (LM) projects. As discussed earlier, these advanced lasers use a compact amplifier design called the "multi-segment amplifier" (MSA) that consists of a stacked-array of rectangular laser glass plates inside a flashlamp pumped cavity (Fig. 2). By using square apertures (i.e. square beams) it is possible to tightly pack the individual laser glass amplifiers into a compact matrix and thereby greatly reduce the size and cost of the system. Each of the laser glass slabs is about $81 \times 46 \times 4.1 \mathrm{~cm}^{3}$. The approximate $3000-4000$ slabs required for each megajoule-scale laser, represents a total volume of $60-70 \mathrm{~m}^{3}$ (150 to $200 \mathrm{ton}$ ) of high optical quality glass.

To meet the requirements of the mega-joule size lasers, advanced laser glass manufacturing methods are being developed that would enable laser glass to be continuously produced at the rate of about one thousand glass slabs per year. This represents more than a 10 to 100 -fold improvement in the scale of the present manufacturing technology while meeting the same high optical quality requirements. To illustrate the magnitude of growth in the scale of melting activities, Table III summarizes the increase in size and volume of laser glass produced for the LLNL ICF laser systems starting in 1975. 
Table II: Summary of laser glass type and maximum sizes installed on operating and planned ICF laser systems

\begin{tabular}{|c|c|c|c|c|}
\hline \multirow[b]{2}{*}{ Laser System } & \multicolumn{4}{|c|}{ Largest Glass Size (finished) } \\
\hline & Glass & $\begin{array}{l}\text { Dimensions } \\
\left(\mathrm{cm}^{3}\right)\end{array}$ & $\begin{array}{l}\text { Volume } \\
\text { (liter) }\end{array}$ & $\begin{array}{l}\text { Nd-doping } \\
\left(\times 10^{20} / \mathrm{cm}^{3}\right)\end{array}$ \\
\hline \multicolumn{5}{|c|}{ I. Operational } \\
\hline Nova $a^{a}$ & $\begin{array}{c}\text { LG-750 } \\
\text { LHG-8 } \\
\text { Q-88 }\end{array}$ & $\begin{array}{l}62.9 \times 34.2 \times 4.3 \\
48 \times 45.4 \times 4.3 \\
30.9 \times 16.4 \times 3^{f}\end{array}$ & $\begin{array}{l}7 \\
7 \\
1.2\end{array}$ & $\begin{array}{l}2.0 \\
3.0 \\
2.0\end{array}$ \\
\hline Beamlet $^{a}$ & LG-750 & $78.8 \times 44.8 \times 4$ & 14 & 3.4 \\
\hline Omega & LHG-8 & $44.8 \times 27.6 \times 3$ & 2.0 & 3.0 \\
\hline Upgrade $^{b}$ & LHG-8 & $9.0 \phi \times 37.0^{\circ}$ & 2.3 & 2.0 \\
\hline Phebus ${ }^{c}$ & $\begin{array}{l}\text { LG-750 } \\
\text { LHG-8 } \\
\text { Q-88 }\end{array}$ & $\begin{array}{l}63 \times 34 \times 4.3 \\
48 \times 45.4 \times 4.3 \\
30.9 \times 16.4 \times 3^{t}\end{array}$ & $\begin{array}{l}7 \\
7 \\
1.2\end{array}$ & $\begin{array}{l}2.0 \\
3.0 \\
2.0\end{array}$ \\
\hline Gekko XII ${ }^{d}$ & $\begin{array}{l}\text { LHG-80\&-8 } \\
\text { LHG-80\&-8 }\end{array}$ & $\begin{array}{l}40.0 \times 21.4 \times 3.2^{1} \\
50.0 \phi \times 37^{\mathrm{e}}\end{array}$ & 0.7 & $\begin{array}{l}2.0 \\
0.6\end{array}$ \\
\hline
\end{tabular}

\section{Planned}

Osaka "Petawatt" LHG-80

$69.4 \times 38 \times 4.5^{f}$

3.0

LIL (2002) $\quad$ LG-770+LHG-8

$80.2 \times 45.7 \times 4.115 .0$

3.6-4.0

NIF (2003) LG-770+LHG-8

$80.2 \times 45.7 \times 4.115 .0$

3.6-4.0

LMJ (2008) ${ }^{c}$ LG-770+LHG-8

$80.2 \times 45.7 \times 4.115 .0$

3.6-4.0

- LLNL, USA; 'LLE, USA; 'CEA, France; 'Osaka Univ., Japan;

- rod;

${ }^{i}=$ molten glass cladding; all others are epoxy bonded

Table III. Comparison of laser glass needs for past, present, and future LLNL ICF lasers.

\begin{tabular}{|c|c|c|c|c|c|c|c|c|}
\hline Laser/Year & $\begin{array}{l}\text { Total no. } \\
\text { disks or } \\
\text { slabs } \\
\text { (all sizes)* }\end{array}$ & $\begin{array}{l}\text { No. } \\
\text { of } \\
\text { sizes }\end{array}$ & \multicolumn{3}{|c|}{$\begin{array}{l}\text { Max. finished disk } \\
\text { or slab size } \\
\text { (cm) }\end{array}$} & $\begin{array}{l}\text { Max. disk } \\
\text { volume } \\
\text { (L) }\end{array}$ & \multicolumn{2}{|c|}{$\begin{array}{l}\text { Total glass } \\
\text { volume Mass }\end{array}$} \\
\hline Janus/1975 & 48 & 2 & 18.5 & 10.0 & 2.2 & 0.33 & 12.6 & 0.04 \\
\hline 78 & 60 & 2 & & 21.0 & 2.6 & 1.7 & 55.2 & 0.17 \\
\hline Shiva/1980 & 500 & 3 & 41.8 & 22.3 & 3.2 & 2.3 & 400 & 1.26 \\
\hline Nova & 510 & 5 & 62.9 & 34.2 & 4.3 & 7.0 & 2,130 & 6.7 \\
\hline Beamlet/1994 & 16 & 1 & 78 & 44.8 & 4.0 & 14.1 & 226.0 & 0.7 \\
\hline NIF/2003 & 3072 & 1 & 80.0 & 45.7 & 4.1 & 15.0 & 46,000 & 145 \\
\hline
\end{tabular}

* Installed on laser (not including spares).

** $\quad 1, w, t=$ length, width, thickness 
The glasses made for the existing large ICF laser systems (e.g. Nova [LLNL], Phebus [CEA], Beamlet [LLNL] and Omega [Univ. of Rochester] see Table II) were all manufactured using a one-at-a-time, discontinuous melting process. In the final two sections of this review, the current manufacturing method is compared and contrasted with the advanced melting processes now under development.

\section{Current Technology: Discontinuous. Melting Process}

In the first step of the discontinuous process (Fig. 5), a cullet glass is made by melting the raw starting materials. The cullet glass is usually melted in a relatively inert ceramic refractory crucible, and a bubbling gas is often added to remove unwanted volatile products, particularly water. The cullet melt is cast and then broken into smaller pieces. The cullet is generally full of bubbles, striae, and possibly some small particles of undissolved starting material.

Discontinuous laser glass melting process

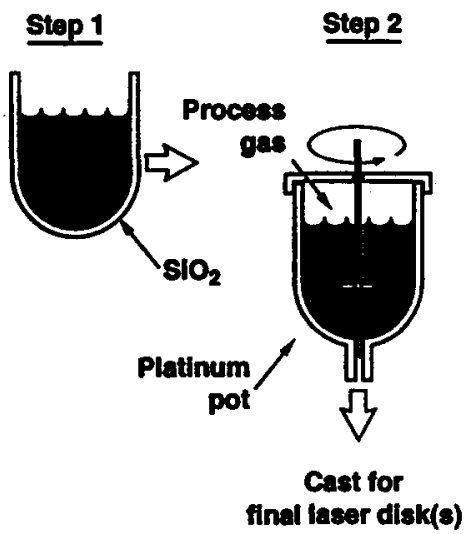

Figure 5. Schematic drawing of the one-at-a-time laser glass melting process currently used to manufacture large slabs of laser glass.

The glass produced from the cullet melt is used in the final melting step which is conducted in large platinum crucibles. During this second melt step, the glass is homogenized to provide the striae-free, high optical quality glass necessary for laser applications. This homogenizing process involves two stages." The first is a refining or "fining" process conducted at high temperatures where the viscosity of the glass is low, allowing bubbles to rise to the surface. The second stage is a stirring process which is generally conducted at temperatures lower than either the melting or the refining stages. The continuous mixing thoroughly distributes all components within the glass melt, eliminating striae and thus ensuring uniformity of the refractive index over the entire casting. Finally, the melt is cooled to a temperature such that the viscosity of the glass is proper for casting into a mold of the appropriate size and shape. After casting, the glass undergoes a coarse annealing step, is inspected for inclusions and striae, and then is fine annealed to remove residual thermal stresses due to the forming process.

\section{Advanced Technology: Continuous Melting Process}

In contrast to the discontinuous process, the advanced glass melting method will continuously produce large rectangular plates of laser glass at a rate that could exceed 10 per day. A continuous melting system for optical glass is nominally divided into several processing zones ${ }^{43.4}$, for example (Fig. 6 ): (1) melting, (2) conditioning, (3) refining, (4) homogenization, and (5) forming. These regions are interconnected allowing for the continuous flow of glass from one zone to the next. The glass is cast as one continuous "strip" during the forming process; this strip is coarse annealed and then cut to the desired length. Unlike the discontinuous process, the raw material will feed directly to the melter, eliminating the need to make a cullet melt. 


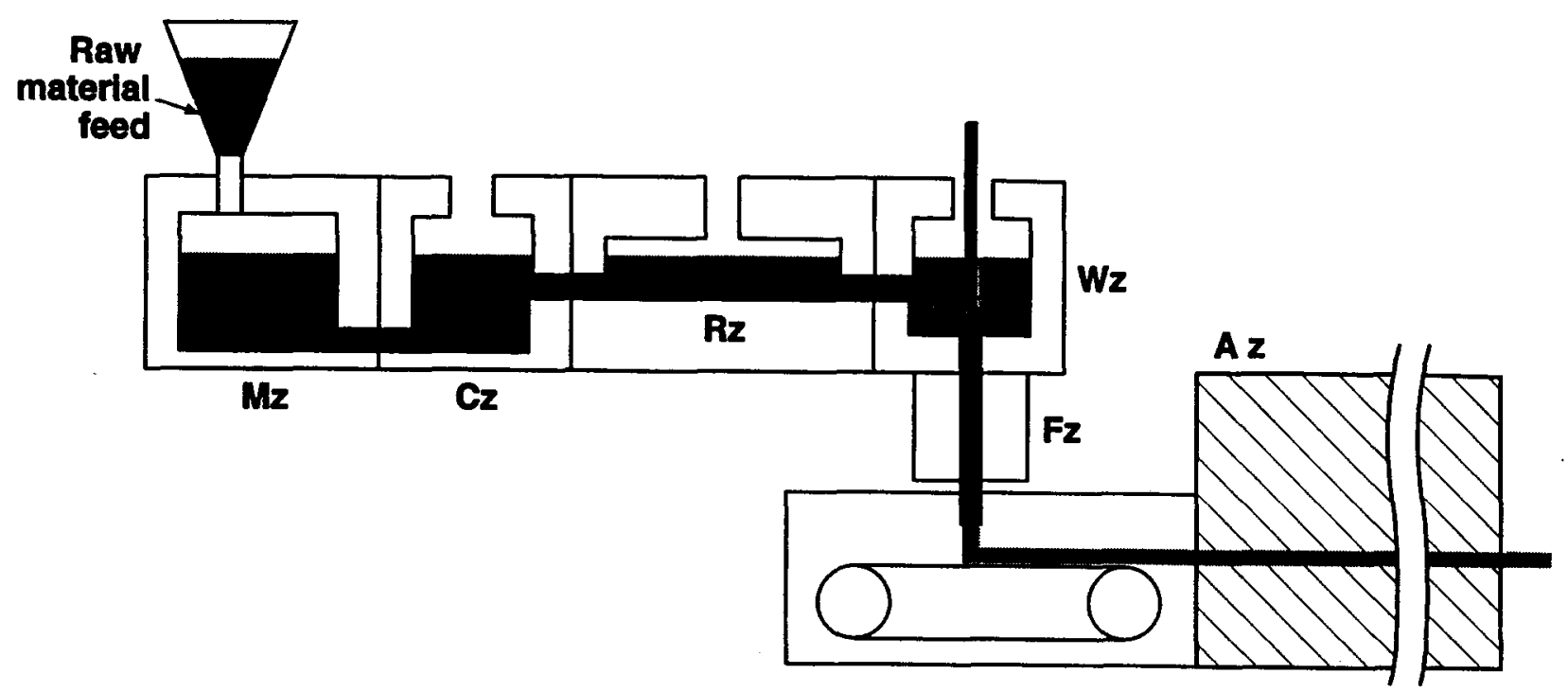

Figure 6. Highly schematic drawing of a continuous glass melting system typical of those being developed to produce the nearly $\mathbf{8 0 0 0}$ slabs needed for the US NIF and the French LMJ laser systems. The various process zones shown in the drawing include: melting (MZ), conditioning (CZ), refining (RZ), homogenization (HZ), forming (FZ), and annealing (AZ).

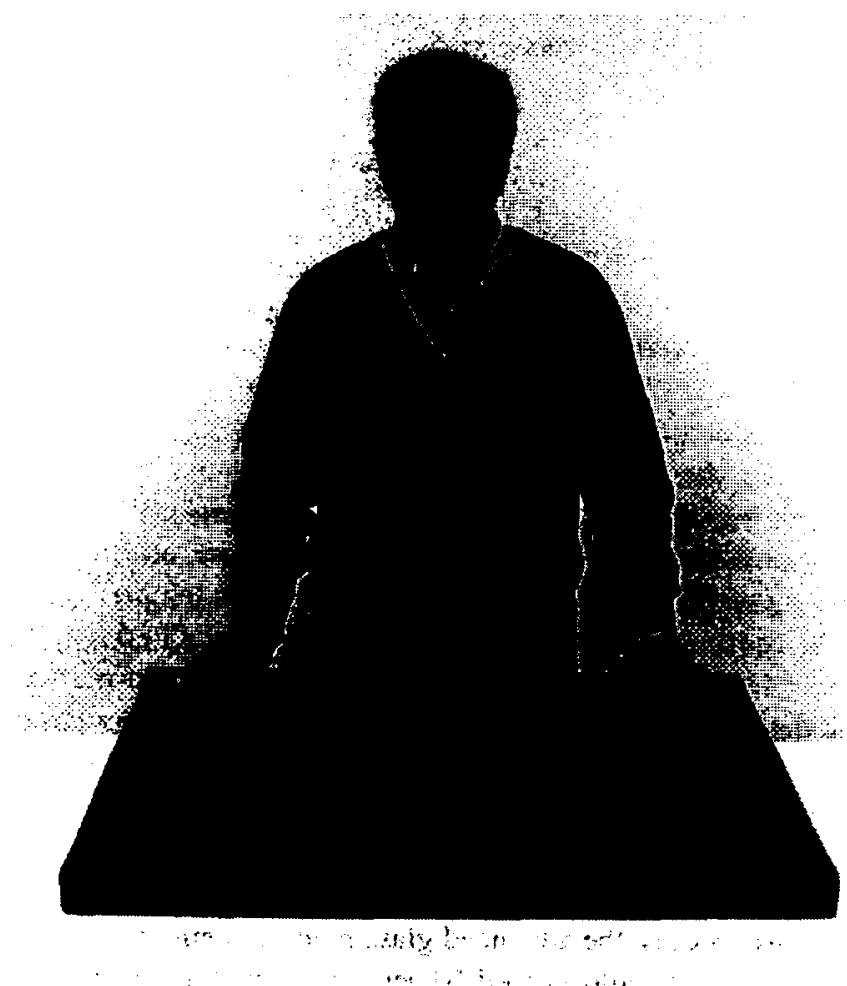

Figure 7. Photograph of a full-size laser glass slab blank cut from an approximately 30-meter-long continuous glass strip produced during a test run of the Schott Glass Technologies' continuous laser glass melting system. 
Once the laser glass has been melted and formed into plates, there remains a number of other process steps before the glass can be shipped to the final finishing vendor. Specifically the laser glass needs to undergo prefabrication into a size suitable for inspection for striae and $\mathrm{Pt}$ inclusions. Following this the glass in slowly annealed to remove any residual strain; this process alone can take several weeks. Finally the glass is fabricated to the final dimensions required by the polishing vendors, inspected for homogeneity and prepared for shipping. Research is under way to develop advanced inspection techniques and/or reliable statistical inspection methods that will reduce the time and cost for inspection.

Significant progress has been made in developing the continuous processing method for production of laser glass. Hoya Corporation (Fremont, Ca.) has designed, built and tested a sub-scale melter that has melted and formed laser glass into a continuous strip with a cross-section of $28 \times 240 \mathrm{~mm}^{2}$. This strip is roughly half the size of that required for the NIF and LMJ. During initial test runs several tons of laser glass have been produced from each run. Scale-up to full size will occur in 1998.

Schott Technologies Incorporated (Duryea, PA) has designed a continuous laser glass melting system and has just completed a demonstration run that produced full-sized Nd-doped test slabs of LG-770. Figure 7 shows a prefinished, full-sized slab cut from a continuous strip of laser glass produced by Schott's melter system. Evaluation and testing of these laser glass slabs are presently underway.

\section{ACKNOWLEDGMENTS}

The author gratefully acknowledges the many helpful discussions with his colleagues particularly Joe Hayden and Alex Marker at Schott Glass Technologies, Inc., and Yoshi Toratani and Kunio Takeuchi at Hoya Corporation.. Work performed under the auspices of the U.S. Department of Energy by Lawrence Livermore National Laboratory under Contract No. W-7405-Eng-48.

\section{REFERENCES}

1. W. A. Bookless, Ed., "The National Ignition Facility," Energy and Technology Review, Vol. 12, Lawrence Livermore National Laboratory, Livermore, CA, Report UCRL-52000-94-12, December 94,.

2. B. M. Van Wonterghem, J. R. Murray, J. H. Campbell, D. R. Speck, C. E. Barker, I. C. Smith, D. F. Browning and W. C. Behrendt, "Performance of a Proto-type for a Large-aperture Multi-pass Nd:Glass Laser for Inertial Confinement Fusion", Applied Optics, 36 (1997) p.4932.

3. W. Krupke, "Induced-Emission Cross Sections in Neodymium Laser Glasses", IEEE Quantum Electron. QE10 (1974), 450.

4. B. R. Judd, "Optical absorption intensities of rare-earth ions," Phys. Rev., 127. 750 (1962).

5. G. S. Ofelt, "Intensities of crystal spectra of rare-earth ions," J. Chem. Phys., 37,511 (1962).

6. S. T. Davey, B. J. Ainslie and R. Wyatt, "Waveguide glasses", Handbook of Laser Science and Technology, M. J. Weber Ed., p. 635-668, CRC Press Inc. 1995.

7. M. J. Weber, "Science and technology of laser glass," J. of Non-Cryst. Solids, Vol. 123, p. 208-222 (1990).

8. N. Neuroth, "Laser glass: status and prospects," Optical Engineering, vol. 26, 1987, 96.

9. S. E. Stokowski, "Laser glass: an engineered material," LLNL Report UCRL-96331 (1987).

10. R. Reisfeld, M. Eyal, C. K. Jorgensen, "Comparison of laser properties of rare-earths in oxide and fluoride glasses," J. Less-Common Met., 126, p. 187-194 (1986).

11. C. F. Cline and M. J. Weber, "Beryllium Fluoride Optical Glasses: preparation and Properties", Proc. 1st OHO Schott Colloquium, Wiss. Zttschr. Friedrich-Schiller-Univ. Jena, Math.-Natl. R., 28, J.G.H. 2/3 (1979), 351.

12. S. E. Stokowski, R. A. Saroyan and M. J. Weber, "Nd-doped laser glass spectroscopic and physical properties," Lawrence Livermore National Laboratory Report M-095, Rev. 2 Vol. 1 and 2, 1981.

13. N. E. Alekseev, V. P. Gapontsev, M. E. Zhabotinskii, V. B. Kravchenko, and Yu. P. Rudnitskii, "Laser phosphate glasses" (Nauka, Moscow, 1980); English translation in report UCRL-TRANS-11817, Lawrence Livermore National Laboratory, (1983), pp. 3-97.

14. S. E. Stokowski, "Glass lasers," Handbook of Laser Science and Technology, Vol. 1, Lasers and Masers, M J. Weber ed., CRC press, Boca Raton, Fl, 1982, p. 215.

15. J. E. Marion and M. J. Weber, "Phosphate laser glasses," European Journal of Solid State and Inorganic Chemistry, Vol. 28, p. 271-287 (1991). 
16. C. F. Rapp "Laser Glasses: Bulk Glasses, “ CRC Handbook of Laser Science and Technology, M. J. Weber, Ed., Section 17.1 pp. 619-634, 1995.

17. J. H. Campbell, "Recent Advances in Phosphate Laser Glasses for High-power Applications, in Inorganic Optical Materials, P Klocek Ed. SPIE Vol. CR64, pp. 3-39, 1996.

18. L. M. Frantz and J. S. Nodvik, "Theory of pulse propagation in a laser amplifier, " J. Appl. Phys., Vol. 34, pp. 2346-2349 (1963).

19. H. T. Powell A. C. Erlandson. K. S. Jancaitis and J. E. Murray, "Flashlamp pumping of Nd: glass disk amplifiers," High power Solid State Lasers and Applications, SPIE proceedings Vol. 1277, pp. 103-120, Bellingham, WA, 1990.

20. A. C Erlandson, K. S. Jancaitis, R. W. McCracken and M. D. Rotter, "Gain uniformity and Amplified Spontaneous Emission in Multi-segment Amplifier," ICF quarterly report, Vol. 2, No 3, April-June 1994

21. W. E. Martin and D. Milam, "Gain saturation in Nd: doped laser materials," IEEE J. Quantum Electron. OE18. 1155 (1982).

22. W. E. Martin and D. Milam, "Gain Saturation in Nd: doped laser materials," IEEE J. Quantum Electron., Vol. QE-18, pp. 1155-1163 (1982).

23. National Ignition Facility Conceptual Design Report, Vol. 2 and 3, Lawrence Livermore National Laboratory, Livermore, CA, Report No. UCRL-PROP-117093, May 1994

24. J. A. Caird, A. J. Ramponi, and P. R. Staver, "Quantum efficiency and excited state relaxation dynamics in neodymium-doped phosphate laser glasses," J. Opt. Soc. Am. B 8, 1391 (1991).

25. S. A. Payne, C. D. Marshall, A. Bayramian, G. D. Wilke, J. S. Hayden, "Laser properties of a new averagepower Nd-doped phosphate glass," Appl. Phys. B (Lasers and Optics),Vol. B61, p. 257-266, 1995.

26. S. A. Payne, M. L. Elder, J. H. Campbell, G. D. Wilke, M. J. Weber, and Y. T. Hayden, "Spectroscopic properties of $\mathrm{Nd}^{3+}$ dopant ions in phosphate laser glass," Ceramic Transactions: Solid State Optical Materials, Vol. 28, pp. 253-260, American Ceramic Society Press., 1992.

27. C. B. Layne, W. H. Lowdermilk and M. J. Weber; "Multiphonon relaxation of rare-earth ions in oxide glasses," Phys. Rev. B, vol. 16 p. 10 (1977).

28. H. Toratani, "Properties of laser glasses," Ph.D. Thesis, Kyoto University, Japan, (1989), pp. 1-187.

29. H. Toratani, I. Izumitani, and H. Kuroda "Compositional dependence of non-radiative decay rate in Nd laser glasses," J. Non-Cryst. Solids, Vol. 52, pp. 303-313, 1982.

30. J. T. Hunt and D. R. Speck, "Present and future performance of the Nova laser system," Optical Engineering, Vol. 28, pp. 461-468, 1989.

31. J. T. Hunt, K. R. Manes and P. A. Renard, "Hot images from obscurations," Applied Optics, Vol. 32, pp. 5973-5982 (1993).

32. N. L. Boling, A. J. Glass and A. Owyoung, "Empirical relationships for predicting non-linear refractive-index changes in optical solids," IEEE J. Quantum Electron. QE-14, 601 (1978).

33. J. H. Campbell, E. P. Wallerstein, J. S. Hayden, D. L. Sapak, D. Warrington, A. J. Marker, H. Toratani, H. Meissner, S. Nakajima, and T. Izumitani, "Elimination of platinum inclusions in phosphate laser glasses," Lawrence Livermore National Laboratory Report UCRL-53932, Livermore, CA, 1989, pp. 1-80.

34. J. H. Campbell, E. P. Wallerstein, J. S. Hayden, D. L. Sapak, and A. J. Marker, "Effects of melting conditions on platinum-inclusion content in phosphate laser glasses," Glastech. Ber. Glass Sci. Technol., Vol. 68, No. 1, pp. 11-21, 1995.

35. J. H. Campbell, E. P. Wallerstein, H. Toratani, H. Meissner, and T. Izumitani , "Effects of process gas environment on platinum-inclusion density and dissolution rate in phosphate laser glasses," Glastech. Ber. Glass Sci. Technol, Vol. 68, No. 2, pp. 1-11, 1995.

36. J. H. Campbell, F. Rainer, M. Kozlowski, C. R. Wolfe, I. M. Thomas, F. Milanovich, "Damage resistant optics for a mega-joule solid-state laser," Laser Induced Damage in Optical Materials: 1990, SPIE, Vol. 1441, p. 444-456,1990:

37. C. L. Weinzapfel, G. J. Greiner, C.D. Walmer, J. K. Kimmons, E. P. Wallerstein, F. T. Marchi, J. H. Campbell, J. S. Hayden, K. Komiya, and T. Kitiyama, "Large scale damage testing in a production environment," Laser Induced Damage in Optical Materials: 1987, NIST Special Publication 756, National Institute of Standards and Technology, 1987, pp. 112-122 
38. R. Gonzales and D. Milam "Evolution during multiple-shot irradiation of damage surrounding isolated platinum inclusions in phosphate laser glasses," Laser Induced Damage in Optical Materials; 1985, NBS special pub. No. 745, (1988) pp. 128-137.

39. T. Izumitani, M. Matsukawa and H. Miyade, "Solubility of Pt in Nd Phosphate laser glass," Laser Induced Damage in Optical Materials: 1987, NIST special publication 756, pp. $29-34$ (1988).

40. J. H. Campbell, "Modeling platinum-inclusion dissolution in phosphate laser glasses," Glass Sci. Technol., Vol. 68, pp. 91-101, 1995.

41. J. H. Campbell et. al "Development of Composite Polymer-glass Edge Claddings for Nova Laser Disks," Laser Induced Damage in Optics Materials: 1986, NIST special publication 752, pp. 19-41 (1988).

42. A. J. Marker, "Optical glass technology," Geometrical Optics, SPIE Proceedings Vol. 531, pp. 2-10, 1985.

43. T. Izumitani, Optical Glass, Chap. 3. Am. Instit. of Phys. translation series, New York, 1986.

44. T. Izumitani, "Continuous melting of phosphate laser glass," SPIE, Vol. 2633, p. 386, 1995. 


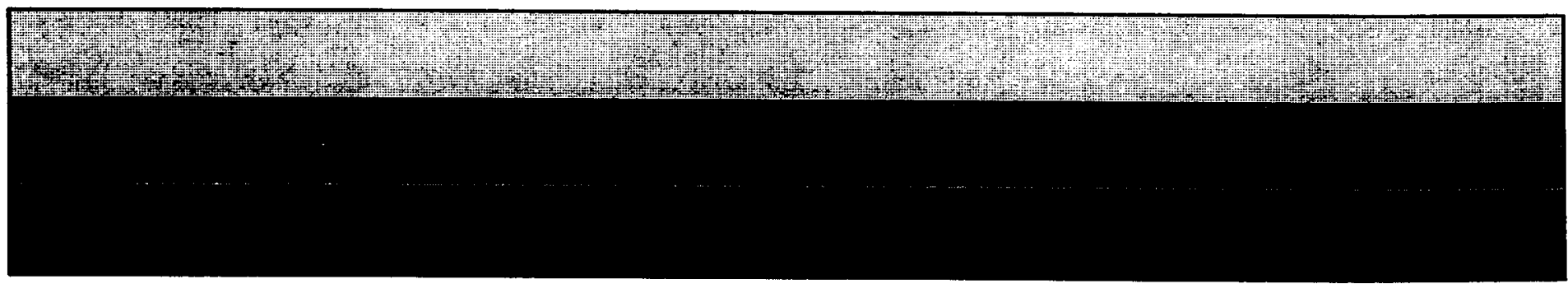




\section{CONTINUOUS MELTING OF PHOSPHATE LASER GLASS BY HOYA CORPORATION}

\section{MARK SMOLLEY and KUNIO TAKEUCHI - Hoya Corporation USA}

Abstract Continuous melting is being used to produce phosphate laser glass for the first time. The continuous melting has increased the production rate of laser glass and offers more steady-state operating conditions when compared to previous methods.

\subsection{Introduction}

HOYA CORPORATION USA began producing phosphate laser glass using a new continuous melting system in January 1999. Hoya and one other US glass manufacturer (Schott Glass Technologies) are the first companies to produced large-size laser glass slabs using continuous melting systems. The glass is being produced for two large laser systems that are designed for fusion energy research. The laser systems are the National Ignition Facility, under construction at Lawrence Livermore National Laboratory (LLNL) in the United States, and the Laser Megajoule Facility (LMJ), planned for construction in Bordeaux, France.

The NIF and LMJ laser projects require Hoya to deliver rectangular glass slabs that are 790 millimeters (mm) x $440 \mathrm{~mm}$ x $45 \mathrm{~mm}$ thick. The production rate of laser glass needed for these systems is approximately 50 to 100 times the production capacity of glass previously produced for the Nova laser (Lawrence Livermore National Laboratory) and Omega laser (University of Rochester).

Hoya has previously produced LHG-8 laser glass for the Nova, Omega, and Phebus laser systems. This glass was produced using discontinuous or batch-type methods. Hoya's discontinuous melting system is limited in the quantity of glass that can be produced. The high volume of glass needed by the NIF and LMJ systems presented Hoya with the challenge to develop methods for continuous melting which would substantially increase the production capacity of laser glass. Hoya successfully met this challenge and has constructed a continuous melting system, which has produced laser glass at higher production rates. In addition, the continuous melting technology offers the benefits of more consistent slab-to-slab composition, higher production yields, and significantly lower costs than discontinuous methods.

This paper provides a historical perspective on laser glass production within Hoya, briefly describes the discontinuous melting process, and then presents a discussion of the new continuous melting system. 


\subsection{History of Laser Glass Production at Hoya Corporation}

Hoya has been involved with laser glass since the early 1960's and has commercially produced laser glass since 1970. Hoya's first type of laser glass was LSG-91H, a silicate glass, which was used by LLNL in the SHIVA laser in 1978. As a result of studies conducted on fluorescent intensity and fluorescence lifetime, it was discovered that phosphate glass had a much higher efficiency for these properties than silicate glass. Studies in the late 1980's led to the development of the current composition of laser glass (LHG-8), being produced for the NIF and LMJ projects. The composition of LHG-8 glass is shown on Table 1.

In addition to producing LHG-8 laser glass by the continuous melting process, Hoya will also produce CG-8 cladding glass utilizing this same process. The cladding glass will be used by the NIF and LMJ projects, to band the outer edge of the LHG-8 glass slabs. The CG-8 glass will absorb emission from the spontaneous fluorescent decay of neodymium in the excited state. The basic composition of CG-8 glass is essentially the same as LHG-8 glass as shown on Table 1. The differences are that CG- 8 glass does not contain neodymium oxide, but does contain a small amount of copper oxide (CuO).

Hoya has continued to expand our laser glass production capabilities to meet increasingly stringent customer requirements for laser glass. The following shows the laser systems that utilize Hoya glass and the various sizes produced over the years by Hoya.

Year/Laser System

1982-83/Gekko, Osaka Univ.

1982-88/Nova, LLNL

1982-88/Phebus, France

1992-93/Omega, Univ. of Rochester

1997/NIF \& LIL Prototypes

1999/NIF \& LMJ

\begin{tabular}{ll} 
Glass Size Produced & Glass Volume \\
\hline $450 \times 250 \times 34 \mathrm{~mm}$ & 3.5 Liters \\
$493 \times 468 \times 48.4 \mathrm{~mm}$ & 9.7 Liters \\
$634 \times 343 \times 48.4 \mathrm{~mm}$ & 8.9 Liters \\
$438 \times 266 \times 34 \mathrm{~mm}$ & 3.2 Liters \\
$790 \times 440 \times 45 \mathrm{~mm}$ & 15.3 Liters \\
$790 \times 440 \times 45 \mathrm{~mm}$ & 15.3 Liters
\end{tabular}

In May 1997, Hoya began the construction of the Laser Glass Production Facility in Fremont, California. Construction of the 32,000 square-foot facility was completed at the end of 1997. The equipment used for melting and processing laser glass was installed in 1998 and production operations began in January 1999. 


\subsection{Discontinuous Melting Process}

To understand the advantages of the continuous melting process, it is necessary to first understand the older, discontinuous melting process. From 1981, Hoya used the discontinuous melting process to produce laser glass for the Nova, Phebus, and Omega lasers. Figure 1 shows the various steps that are necessary in the discontinuous process. Step 1 is the Pre-Melt phase of the process, where large-scale mixing of the raw batch material occurs. At this step, oxygen is bubbled into the melt to promote dehydration and large-scale mixing. After the glass is melted, it is removed from the oven, cast into a mold, and quick-cooled (Step 2).

In Step 3, the glass is manually crushed into 10 -mm size fragments. As the glass is being crushed, it is visually inspected to remove any fragments that contain visible particles of platinum or other inclusions. In Step 4, the glass is re-melted. The re-melt process is shown in more detail in Figure 2. The initial step is to feed crushed glass into the furnace. Gas is bubbled into the melted glass to promote dehydration and ionization of platinum inclusions. The glass is then refined to remove the bubbles, mixed to homogenize the batch, and cast into a mold.

After the glass is cast, it is coarse annealed and then visually inspected for bubbles and large inclusions. The various steps that are required for the final processing of the slabs are shown on Table 2. After passing the visual inspection step, the glass is then sawed, milled, and polished for inspection. The polished surface is necessary to inspect the slab for platinum and striae. After passing the platinum and striae inspection steps, the glass is fine annealed for 35 days. The fine annealed slab is then sawed to the final shape, milled and hand-ground before completing the final inspection. The final step involves inspecting the slab for stress birefringence and homogeneity.

Hoya has successfully used the discontinuous melting process since 1981 to produce limited quantities of laser glass, including prototype slabs for the NIF and LMJ projects. However, the number of blank slabs that can be melted and cast from Hoya's batch-type furnace is generally less than 5 per week. Platinum inclusions, various inspection steps, and material losses further reduce the number of slabs that are available for shipment. In addition, the consistency of the melted glass can vary significantly with each successive melt due to daily variations in process conditions. The primary advantages offered by the continuous melting process are significantly higher production rates and less variability in glass composition.

\subsection{Continuous Melting Process}

The continuous melting process can produce glass slabs at a rate approximately 10 times greater than the discontinuous method described above. The continuous melting system consists 
of several interconnected functional zones, with each zone performing a different purpose in the glass melting process. Figure 3 shows the various zones that form the continuous melting system. The zones are (1) dry material mixing unit, (2) automatic feed hopper, (3) melting zone, (4) conditioning zone, (5) refining zone, (6) working zone, (7) feeding zone, (8) forming zone, and (9) the lehr oven. Each of these is described below.

\subsection{Dry Material Mixing Unit}

Hoya utilizes a computer-controlled mixing unit that prepares dry batch material. The unit can be programmed to prepare various batch mixtures, while controlling the weight of each 100-kilogram batch to \pm 10.0 grams. The chemicals are placed in individual feed-hoppers, which then dispense predetermined weights of chemicals based on programs stored in the computer of the mixing unit. The chemicals are dispensed to a single collecting-hopper, which then delivers the entire batch of chemicals to a V-Blender. The V-Blender then homogenizes the dry batch material. After the batch is blended, it is placed in a small mobile hopper, which is then sealed to reduce any potential uptake of water from the atmosphere. The mobile hopper is then stored to await transfer into the automatic feed hopper at the melting furnace.

The purity specifications for the dry material are very stringent, with metals being a particular concern as a contaminant. In particular, only a trace amount of iron is permitted in the final product. This concern was factored into the design of all components that come in contact with the batch material. Feed screws and mixing stirrers are generally constructed from ceramic material. Metal components are lined with rubber or Teflon. The water content of the batch material is also a concern. Chemicals are delivered from the manufacturer in moisture-resistant packages. These packages are opened and placed in the individual feed hoppers on a Just-InTime basis, before being mixed and then added to the melting furnace.

\subsection{Automatic Feed Hopper}

Mixed chemical batches are placed into the automatic feed hopper. This feed hopper dispenses chemical batch material into the melting zone of the furnace at rates that are controlled by a programmable computer. The flow rate can be varied depending on the required output at the forming zone. The feed hopper contains a unique internal stirring mechanism that prevents bridging of the chemicals while they are in the hopper. To avoid any contamination of the batch material, the interior of the feed hopper is rubber-lined and any internal work parts are made of ceramic material. 


\subsection{Melting Zone}

The batch material enters the melting zone and is transformed into molten glass. The interior of the melting zone is a silica-lined "bath-tub" where large-scale mixing by convection current circulation occurs. The melting zone is heated to temperatures in excess of 1,000 degrees centigrade by electrical heating elements.

Chemically absorbed water is present in the melted glass in the form of $-\mathrm{OH}$ ions. The $\mathrm{OH}$ ions adversely affect the performance of the laser system. Therefore, Hoya employs measures to remove - $\mathrm{OH}$ ions that may be present in the melt. Oxygen is bubbled into the melted glass to aid in the removal of the $-\mathrm{OH}$ ions and begin the dehydration process. All vapors that off-gas from the melting zone and other parts of the furnace are captured by a central exhaust system. These vapors are then treated to comply with environmental regulations.

\subsection{Conditioning Zone}

Melted glass flows from the melting zone to the conditioning zone through interconnecting piping, constructed from platinum. From this point forward in the furnace, all crucibles, interconnecting piping, and stirrers are constructed of platinum.

In the conditioning zone, oxygen and chlorine gases are bubbled into the melted glass. The oxygen causes platinum inclusions that may be present to dissolve into the melt. The chlorine gas aids in the removal of $-\mathrm{OH}$ ions, thereby dehydrating the melt.

\subsection{Refining Zone}

Glass flows from the conditioning zone into the refining zone, where the temperatures are increased. The increased temperature reduces the viscosity of the glass. The reduced viscosity allows any entrained gases that were introduced in the conditioning zone to rise and off-gas. This results in the formation of bubble-free glass.

\subsection{Working Zone}

In the working zone, the glass is stirred to homogenize the melt. The size of the crucible, and the shape and size of the stirrers control the degree of mixing that occurs within this zone.

\subsection{Feeding Zone}

The feeding zone controls the rate of glass flow from the furnace. The feeding zone consists of a narrow diameter feed pipe, which is surrounded by heating elements and insulation. 
Varying the temperature of the heating elements controls the rate of glass flow from the feed pipe.

\subsection{Forming Zone}

Molten glass is cast into a forming mold that is set to the desired width for the as-cast strip of glass. Glass is fed from the mold onto the conveyor belt at the beginning of the lehr oven.

\subsection{Lehr Oven}

Glass enters the lehr oven and begins the rough annealing process. The lehr oven consists of several electrically heated chambers where the temperature is closely controlled. Within the lehr oven, the glass is a single, continuous strip, which varies in length from 10 to 35 meters, depending on the oven in which the glass is being formed. The rough annealing process requires between one and several days, depending on the glass type and thickness. When the glass exits the lehr oven, it is cut into the desired lengths and transported for final processing.

\subsection{Final Processing}

Hoya utilized our extensive experience developed during the discontinuous melting process to design the methods currently used to process laser glass derived from continuous melting. The increased production volume generated by continuous melting required new and innovative methods for handling and processing. Table 2 presents a detailed list of the various steps that are necessary for the final processing of the slabs. This section describes these various post-melting processes.

\subsection{Visual Inspection/Platinum Testing}

Slabs from the lehr oven are immediately inspected for bubbles, large inclusions, and cracks. After visual inspection, the slabs are then tested for platinum inclusions. This routing is a significant improvement when compared to the routing utilized in the discontinuous melting. Previously, the glass required significant fabrication (milling and polishing) before the platinum testing could be conducted. Performing this inspection step earlier in the process cycle allows Hoya to more efficiently reject slabs that do not meet platinum specifications, thereby making more effective use of limited processing resources.

The reason for this change in routing is the improved surface quality of the glass as it exits the lehr oven. The discontinuous melting process yielded a glass slab with a surface finish 
that did not readily transmit the laser light needed for platinum testing. Therefore, the slab required milling and polishing before platinum testing could be performed. Conversely, the glass slab from the lehr oven is essentially transparent, eliminating the need for these fabrication steps before qualifying the slab at the platinum inspection step.

\subsection{Fabrication}

Glass blanks are sawn to the size required for fine annealing. The sawing is conducted on a computer-controlled diamond saw that is equipped with a cutting surface that can rotate 90 degrees. This rotating surface allows the operator to position the slab, make an initial cut, rotate the slab, and make a second cut without lifting the slab. This reduces the amount of handling, thereby reducing the potential for breaking the slab.

\subsection{Fine Annealing}

Slabs are fine annealed in ovens that were specifically constructed for the continuous melting process. The ovens have the capacity to hold up to $10 \mathrm{NIF/LMJ}$ sized slabs. Previously, Hoya utilized ovens that had the capacity for 4 slabs of this type. Oven temperatures are closely monitored with internal thermocouples, allowing Hoya to control the temperature to within 1.0 degree centigrade of the desired level.

The current annealing cycle is 25 days, which is 10 days less than the annealing cycle used during discontinuous melting. This reduction is a result of newly designed ovens which have improved temperature controls and heating elements, thereby providing a more consistent annealing temperature profile.

Another improvement in the fine annealing cycle is the elimination of the initial milling step, which was required in the discontinuous melting process. To achieve proper stress reduction in the slab during fine annealing, the slabs need to be flat. As described in Section 3.0, the discontinuous melting process involved casting the slab in a mold. This casting generally produced a slab with an irregular top surface. However, when the slabs are formed in the lehr oven, they are virtually flat. The flat shape of the continuously formed slab has allowed Hoya to eliminate the initial milling step.

\subsection{Final Sawing \& Milling}

When the slabs are removed from the fine annealing oven, they are sawn to the final shape and then milled flat on top and bottom. Sawing is done using the equipment described in 
Section 5.2. Milling is conducted on a 42-inch-diameter blanchard milling machine using standard glass milling procedures.

\subsection{Grinding and Polishing}

The final fabrication step is performed on 120-inch-diameter $(305 \mathrm{~cm})$ continuous grinding and polishing machines developed specifically for the NIF/LMJ slabs by Lapmaster International. Slabs are placed flat on the working surfaces of these machines, and liquid slurries are added. These machines then grind and polish the glass to the desired flatness and surface condition. Hoya can process up to 3 slabs at one time on these machines, which is a significant improvement over the single slab processing equipment previously used by Hoya.

\subsection{Final Inspection}

After slabs are polished to the desired flatness and surface condition, they are inspected for stress birefringence, striae, and homogeneity. The stress birefringence and striae equipment are similar to equipment previously used for these inspections by Hoya. The homogeneity testing is done on a 24 -inch-diameter $(61-\mathrm{cm})$ phase interferometer developed by Vecco Metrology, Inc. The interferometer measures the spatial variation in the phase of the transmitted wavefront of the slab. Because of the size of the slab, measurements are collected separately on the right and left sides.

\subsection{Handling Equipment}

The need to move and handle laser glass slabs throughout the production process presented new challenges to Hoya as the Laser Glass Facility was being constructed. The laser glass slabs weigh between 120 and 150 pounds (55 to 70 kilograms), are extremely fragile, and are somewhat awkward because of the length and width. It was Hoya's goal to utilize methods that did not require significant physical strength and would allow an individual operator to safely move slabs. In addition, these methods also needed to be able to repeatedly move and handle slabs without damaging them. Hoya successfully met these challenges with the installation of vacuum-assisted lifting equipment and roller-topped carts for transporting the slabs.

The vacuum-assisted lifting equipment allows a single operator to lift a slab and place it on any of the various fabrication or inspection equipment described in this section. Slabs can be vacuum-lifted from the top surface or the side edge. In addition, slabs can be rotated from horizontal to vertical with a vacuum lifter. 
Slabs are moved throughout the facility on roller-topped carts. These carts were specifically developed to handle laser glass slabs, based on conceptual designs from Hoya. The top of the cart consists of five rubber-coated rollers that each span the full width (550-mm) of the cart. These rollers allow slabs to be easily pushed on or off the cart. The height of the top of the cart is adjustable with a hand crank, allowing the cart to access processing equipment at varying heights. These carts allow individual operators to safely and consistently move slabs between the various pieces of equipment.

\subsection{Inspection Results}

Hoya tested laser glass slabs produced during the recent continuous melting campaign for a range of optical and laser performance criteria. The four most significant criteria are; residual $\mathrm{OH}$ content, platinum, stress birefringence, and homogeneity. Results of the tests for these four parameters are discussed briefly.

\subsection{Residual - OH Content}

The residual $-\mathrm{OH}$ content (hereafter referred to as water content) was determined by measuring the absorption coefficient at 3,333 nanometers (nm). The following are the water contents obtained for selected dates during the continuous melting campaign.

$\begin{array}{lclll}\text { Date } & \text { Absorption (Value } / \mathrm{cm}) & & \text { Date } & \text { Absorption (Value } / \mathrm{cm}) \\ 2 / 5 / 99 & 17.5 \text { or } 525 \mathrm{ppm} & 5 / 20 / 99 & 4.8 \text { or } 144 \mathrm{ppm} \\ 2 / 25 / 99 & 9.8 \text { or } 294 \mathrm{ppm} & 6 / 5 / 99 & 4.6 \text { or } 138 \mathrm{ppm} \\ 3 / 10 / 99 & 6.3 \text { or } 190 \mathrm{ppm} & 6 / 20 / 99 & 4.6 \text { or } 138 \mathrm{ppm}\end{array}$

The data show a downward trend for glass produced during the recent campaign. The high result in early February was at the very beginning of the campaign, when dehydration agents were not being fully utilized. The most notable change in the data can be seen in the results from May-June. The decrease in water contents, as compared to the data from February-March, is a result of obtaining dryer batch material from the raw material suppliers.

Although the results presented above do not meet the requirements of the NIF/LMJ projects $(<.0 / \mathrm{cm})$, laser glass slabs have been conditionally accepted by both projects. Hoya is presently working on improvements that will allow dryer glass to be produced. 


\subsection{Platinum}

Laser glass is tested for platinum with an inspection system provided by Lawrence Livermore National Laboratory. Each individual laser glass slab is scanned with a high fluence laser beam. This system can measure the size of platinum sites at fluences between 6 to 14 Joules $/ \mathrm{cm}^{2}$, with a pulse length of $\leq 8$ nanoseconds. This is similar to actual operating conditions that will be used in the NIF/LMJ lasers.

The following summarizes the information on platinum testing conducted on slabs from the continuous melting campaign at Hoya. The first category includes slabs that did not contain any inclusions and slabs that contained inclusions that are less than 100 microns. The second category includes slabs that had from 1 to 5 inclusions; with sizes generally ranging from 200 to 600 microns. Because yields are proprietary information, Hoya has not presented the actual numbers of slabs that are within each of these categories.

$\begin{array}{lcc}\text { Time Period } & \text { Slabs - No Pt or }<100 \text { um. } & \text { Slabs with 1 to 5 Inclusions } \\ \text { Feb-March, } 1999 & 27 \% & 36 \% \\ \text { May-June, } 1999 & 54 \% & 46 \%\end{array}$

The data are presented for two time periods of the campaign, Feb-March and May-June. These time periods were selected to compare data when different flow rates of chlorine gas were being used. As described in Section 4.4, chlorine gas is used as a dehydrating agent. Hoya was able to reduce the flow rate of chlorine gas in the May-June time period, because of the dryer batch material that was obtained from the supplier as described in Section 6.1. The reduction in chlorine flow rates resulted in lower platinum contents for the May-June time period.

\subsection{Stress Birefringence}

Stress birefringence was measured at 9 locations on each slab. The measurements for all slabs are $\leq 3.8 \mathrm{~nm} / \mathrm{cm}$, which meet the specification of $\leq 5.0 \mathrm{~nm} / \mathrm{cm}$. These measurements indicate that the current annealing cycle of 25 days reduces residual stress in the glass to acceptable levels.

\subsection{Homogeneity}

Hoya tested slabs produced during the continuous melting campaign for index homogeneity. The slabs were testing for inferred full power, astigmatism, residual phase, slope error, and surface flatness. Figure 4 presents one of the homogeneity test results. Because yields 
are proprietary information, Hoya has not presented the actual numbers or the percentages of slabs that pass each of the test parameters listed here.

\subsection{Conclusion}

Hoya has successfully manufactured large-size laser glass slabs using the continuous melting process. The process has significant advantages over the older, discontinuous melting process. The advantages are (1) significantly increased production rates and capacity, (2) more consistent slab-to-slab compositions, and (3) lower production costs. In 1999, Hoya gained significant information on the necessary melting and forming conditions required for producing laser glass using the continuous melting process. Based on the information gained, Hoya will now make modifications to selected equipment to optimize production yields and improve the overall quality of the glass.

\section{ACKṄOWLEDGEMENTS}

The authors gratefully acknowledge the support, both financial and technical, provided by our colleagues at Lawrence Livermore National Laboratory (Dr. J.H. Campbell and Dr. T. I. Suratwala) and Centre d'Etudes de Limeil-Valenton (Ms. G. Ficini-Dorn).

\section{REFERENCES}

J.H. Campbell, T.I. Suratwala, C.B. Thorsness, J.S. Hayden, A.J. Thorne, A.J. Marker III, K. Takeuchi, M.Smolley, G. Ficini-Dorn, "Continuous Melting of Phosphate Laser Glass" $15^{\text {th }}$ University Conference on Glass Science: Structure, Properties and Applications of Phosphate and Phosphate Containing Glasses, (1999). 


\section{IABLE 1. Composition \& Properties of LHG-8 Nd-Doped phosphate laser glass, Produced by HOYA Corporation, USA}

Composition" or Property

$\mathrm{P}_{2} \mathrm{O}_{5}$

$\mathrm{Al}_{2} \mathrm{O}_{3}$

$\mathrm{K}_{2} \mathrm{O}$

$\mathrm{BaO}$

$\mathrm{Nd}_{2} \mathrm{O}_{3}{ }^{b}$

Other

O/P
LHG-8
$55-60$
8-12
13-17
10-15
$0-2$
$<2$
$\sim 3$

Optical

Refractive Index

$n_{0}(589.3 \mathrm{~nm})$

1.52962

1.52005

Non-linear refractive index

$\mathrm{n}_{2}\left(10^{-13}\right.$ esu $)$

$\gamma\left(10^{-20} \mathrm{~m}^{2} \mathrm{~N}\right)$

Abbe number

1.12

3.08

66.5

Laser

Emission cross-section $\left(10^{-20} \mathrm{~cm}^{2}\right)$

Radiative lifetime (zero- $\mathrm{Nd}$ ) ( $\mu \mathrm{s})$

3.6

365

351

26.5

Emission band width $(\mathrm{nm})$

Thermal

Thermal conductivity, $90^{\circ} \mathrm{C}(\mathrm{W} / \mathrm{mK})$

Thermal diffusivity $\left(10^{-7} \mathrm{~m}^{2} / \mathrm{s}\right) \quad 2.7$

Specific heat, $\mathrm{Cp}(\mathrm{J} / \mathrm{gK})$

Coeff. Thermal expansion $20-300^{\circ} \mathrm{C}\left(10^{-7} \mathrm{~K}\right) \quad 127$

Glass transition temperature, $\mathrm{Tg}\left({ }^{\circ} \mathrm{C}\right)$

\section{Mechanical}

Density $\left(\mathrm{g} / \mathrm{cm}^{3}\right)$

Poisson's ratio $\quad 0.26$

Fracture toughness $\left(\mathrm{MPa} \bullet \mathrm{m}^{1 / 2}\right) \quad 0.51$

Hardness (GPa) $\quad 3.43$

Young's modulus (GPa) $\quad 50.1$

a Range in composition values reflect variations duc to Nd-doping concentration, melt volatility, and batching variantions

b Nd-doping levels typically $\leq 2$ mole\% $\mathrm{Nd}_{2} \mathrm{O}_{3}\left(\leq 5 \times 10^{200} \mathrm{Nd}\right.$ ions $\left./ \mathrm{cm}^{3}\right)$; the NIF and LMJ use a doping of $4.2( \pm 0.1) \times 10^{200}$ ions/ $\mathrm{cm}^{3}$ 


\section{IABLE 1. Composition \& Propenties of LHG-8 Nd-Doped phosphate laser alass, Produced by HOYA Corporation, USA}

$\begin{array}{cc}\text { Composition" or Property } & \text { LHG-8 } \\ \mathrm{P}_{2} \mathrm{O}_{5} & 55-60 \\ \mathrm{Al}_{2} \mathrm{O}_{3} & 8-12 \\ \mathrm{~K}_{2} \mathrm{O} & 13-17 \\ \mathrm{BaO}^{\circ} & 10-15 \\ \mathrm{Nd}_{2} \mathrm{O}_{3}^{\circ} & 0-2 \\ \mathrm{Other} & <2 \\ \text { O/P } & -3\end{array}$

\section{Optical}

Refractive Index

$n_{\mathrm{d}}(589.3 \mathrm{~nm})$

1.52962

$n_{1}(1053 \mathrm{~nm})$

Non-linear refractive index

1.52005

$\mathrm{n}_{2}\left(10^{-13}\right.$ esu)

$y\left(10^{-20} \mathrm{~m}^{2} \mathrm{M}\right)$

1.12

3.08

Abbe number

66.5

Leser

Emission cross-section $\left(10^{-20} \mathrm{~cm}^{2}\right)$

Radiative lifetime. (zero-Nd) ( $\mu s)$

Judd-Ofelt radiative lifetime ( $\mu s$ )

3.6

365

351

Emission bend width ( $\mathrm{nm}$ )

26.5

\section{Thermal}

Thermal conductivity, $90^{\circ} \mathrm{C}(\mathrm{N} / \mathrm{mK}) \quad 0.58$

Thermal diffusivity $\left(10^{-7} \mathrm{~m}^{2} / \mathrm{s}\right) \quad 2.7$

Specific heat, $C_{p}(\mathrm{~J} / \mathrm{gK}) \quad 0.75$

Coeff. Thermal expansion $20-300^{\circ} \mathrm{C}\left(10^{-7} / \mathrm{K}\right) \quad 127$

Glass transition temperature, $\mathrm{Tg}\left({ }^{\circ} \mathrm{C}\right) \quad 485$

Mechanical

Density $\left(\mathrm{g}^{\mathrm{cm}} \mathrm{cm}^{3}\right)$

2.83

Polsson's ratio

0.26

Fracture toughness $\left(\mathrm{MPa} \bullet \mathrm{m}^{1 / 2}\right)$

Hardness (GPa) 3.43

Young's modulus (GPa)

\footnotetext{
a Rage in composition values reflect variations due 10 Nd-doping concentrution, melt volatility, and batching variantions

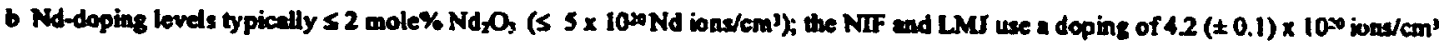




\section{TABLE 2. Comparison of Final Processing Methods}

\section{Discontinuous Melting Process}

1. Coarse Annealing up to 7 days

2. Visual Inspection

3. Initial Sawing \& Milling

4. Inspection Polishing

5. Striae Testing

6. Damage Testing for Platinum

7. Fine Annealing up to 35 days

8. Final Sawing, Milling \& Grinding

9. Inspection for Stress Birefringence \&

Homogeniety
Continuous Melting

1. Visual Inspection/ Testing for Platinum

2. Initial Sawing

3. Fine Annealing up to 25 days

4. Final Sawing \& Milling

5. Polishing

6. Inspection for Stress Birefringence, Striae, \& Homogeniety 


\section{FIGURE 1: DISCONTINUOUS MELTING PROCESS}
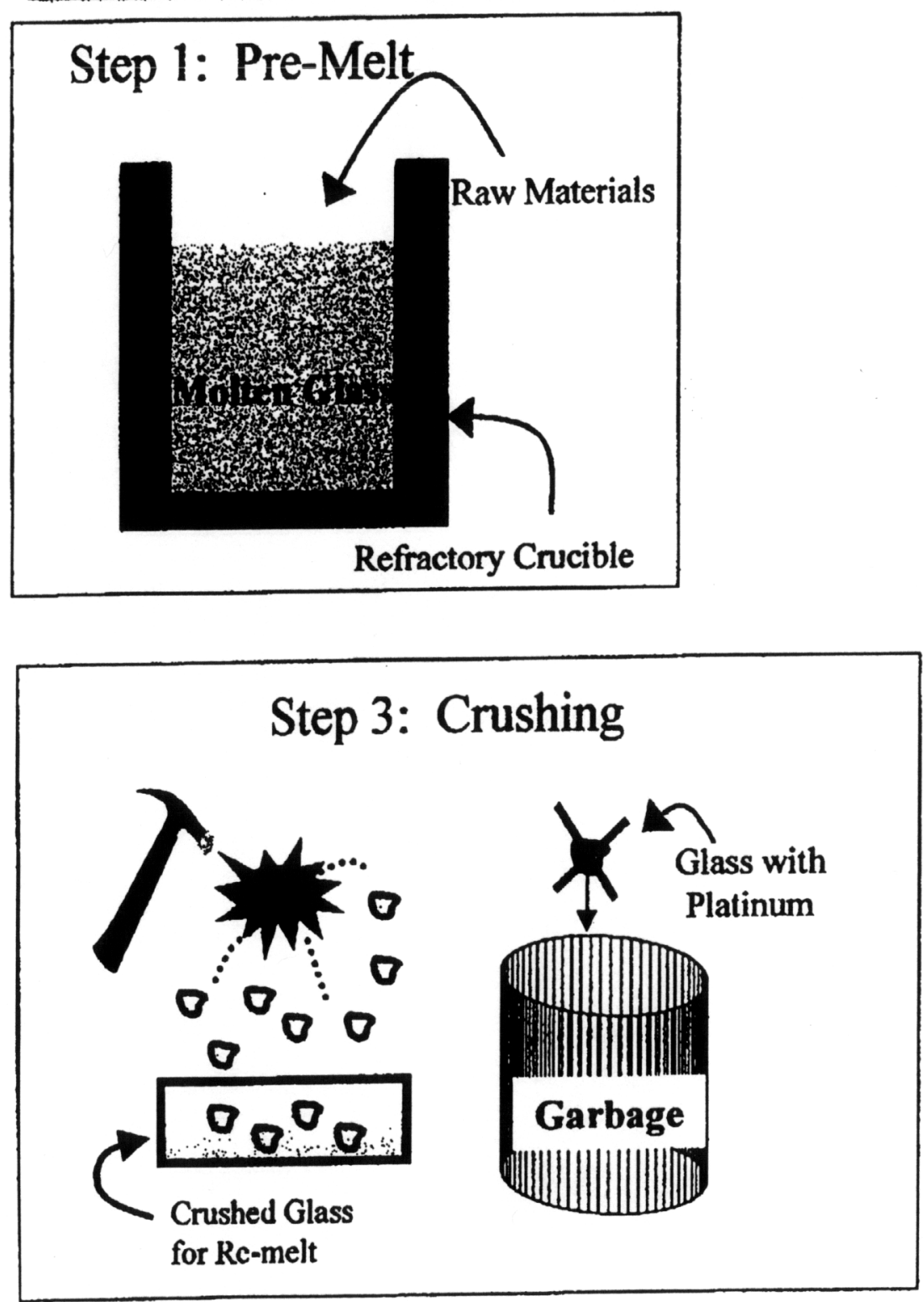

Continuous melting process. ppt 8/30/99
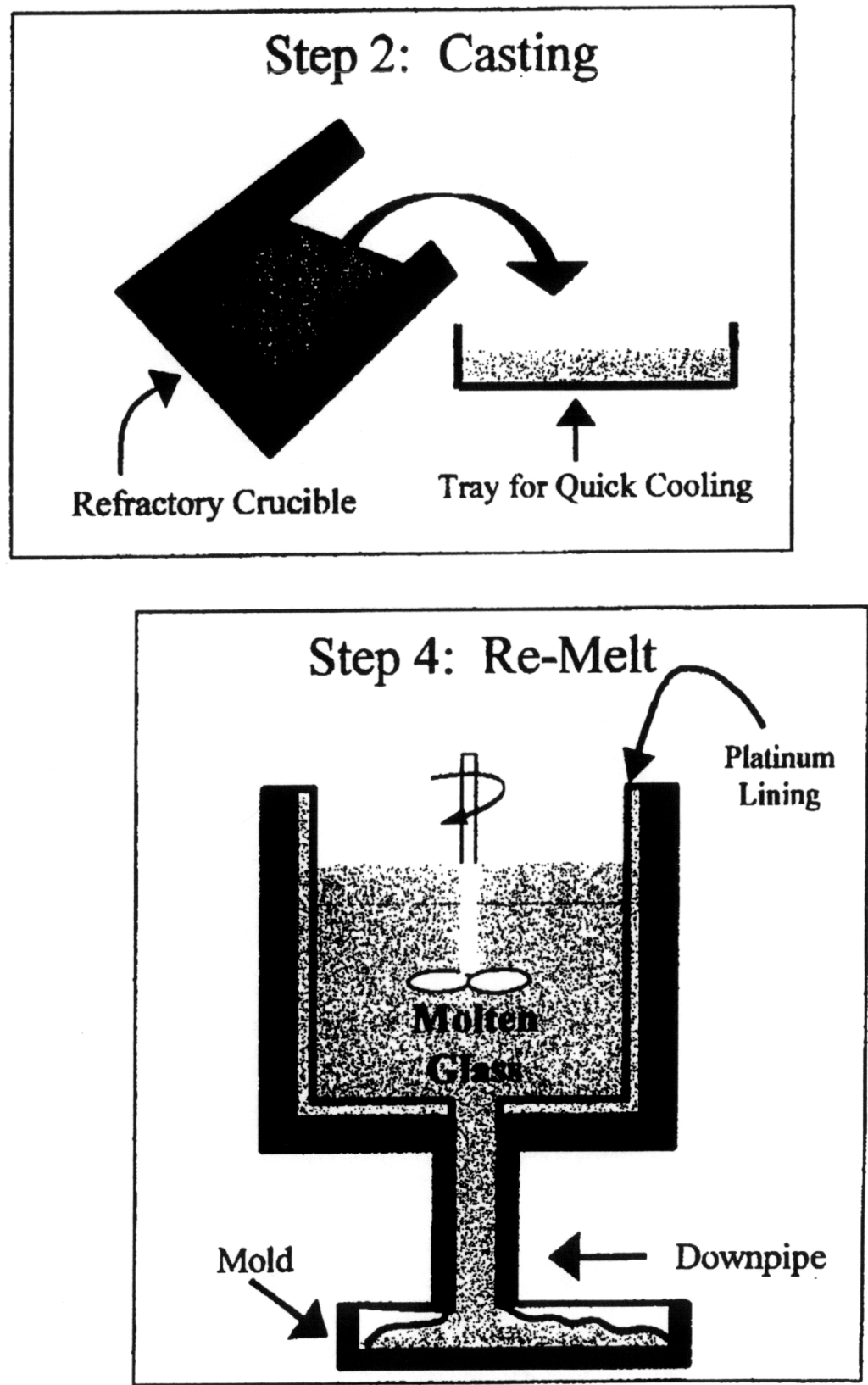


\section{FIGURE 2. Time Line for Re-Melt of Glass in Discontinuous Melting}

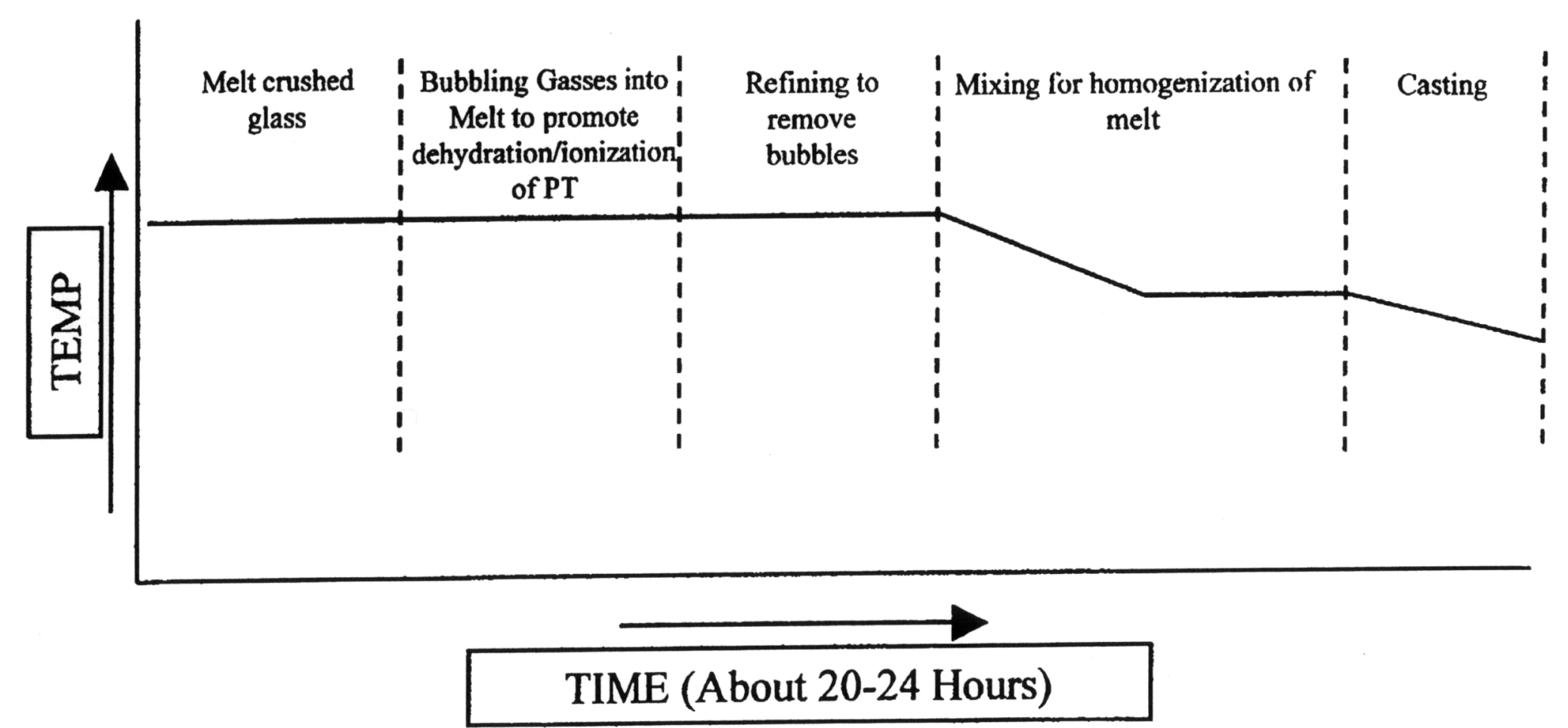




\section{FIGURE 3. Continuous Melting Process \\ Functional Zone: \\ Dry Material Mixing Unit \\ Automatic Feed Hopper \\ Melting Zone \\ Conditioning Zone \\ Refining Zone \\ Working Zone \\ Feeding Zone \\ Forming Zone \\ Lehr Oven \\ Purpose: \\ Consistent mixing of chemicals \\ Consistent delivery of Dry Batch Material to the Melting Zone \\ Vitrification of batch and large-scale mixing \\ Ionization of Pt inclusions and de-hydration \\ De-Bubbling \\ Homogenization \\ Control of flow rate \\ Controls width and thickness of glass \\ Coarse annealing of glass strip}

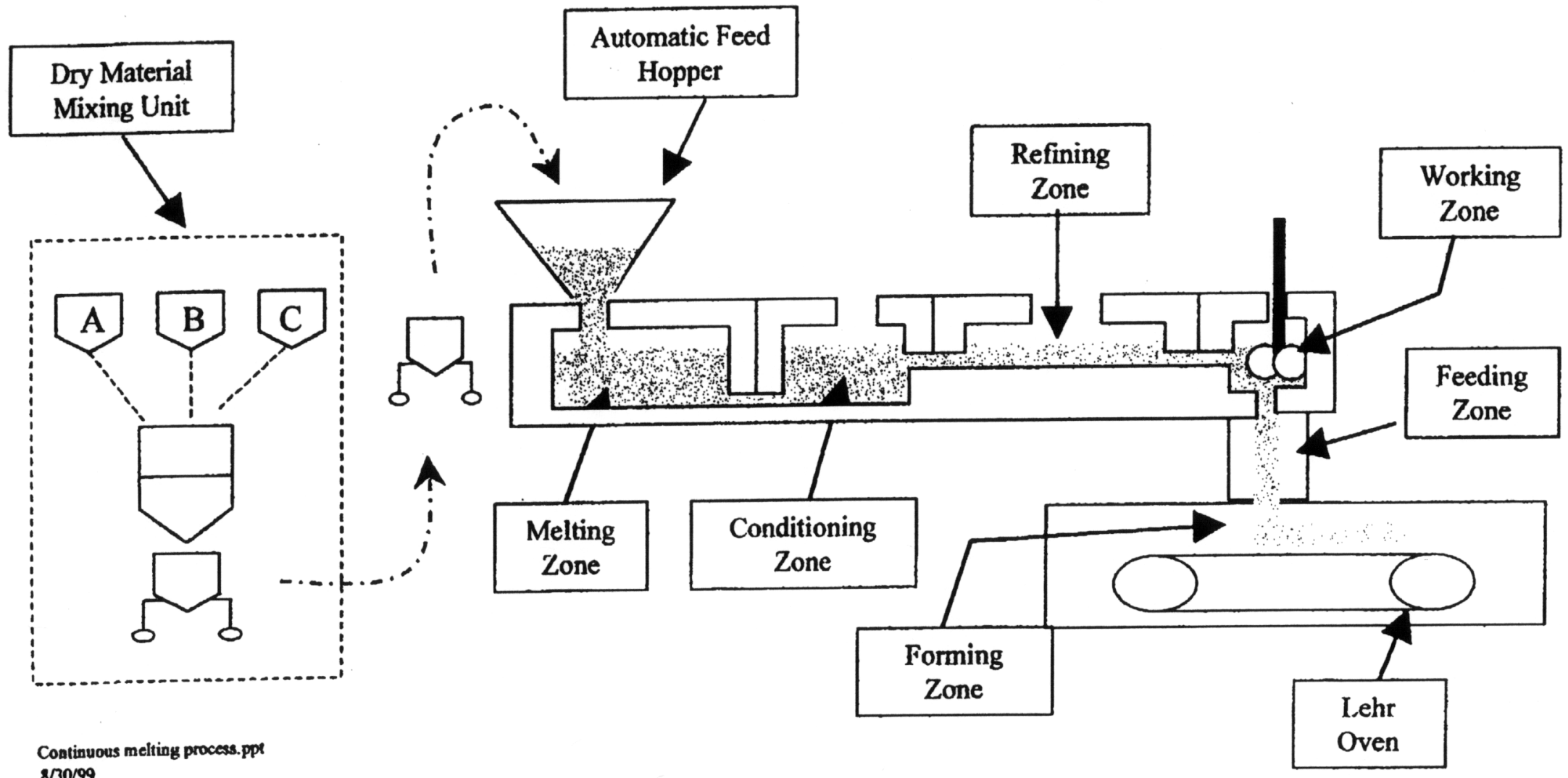



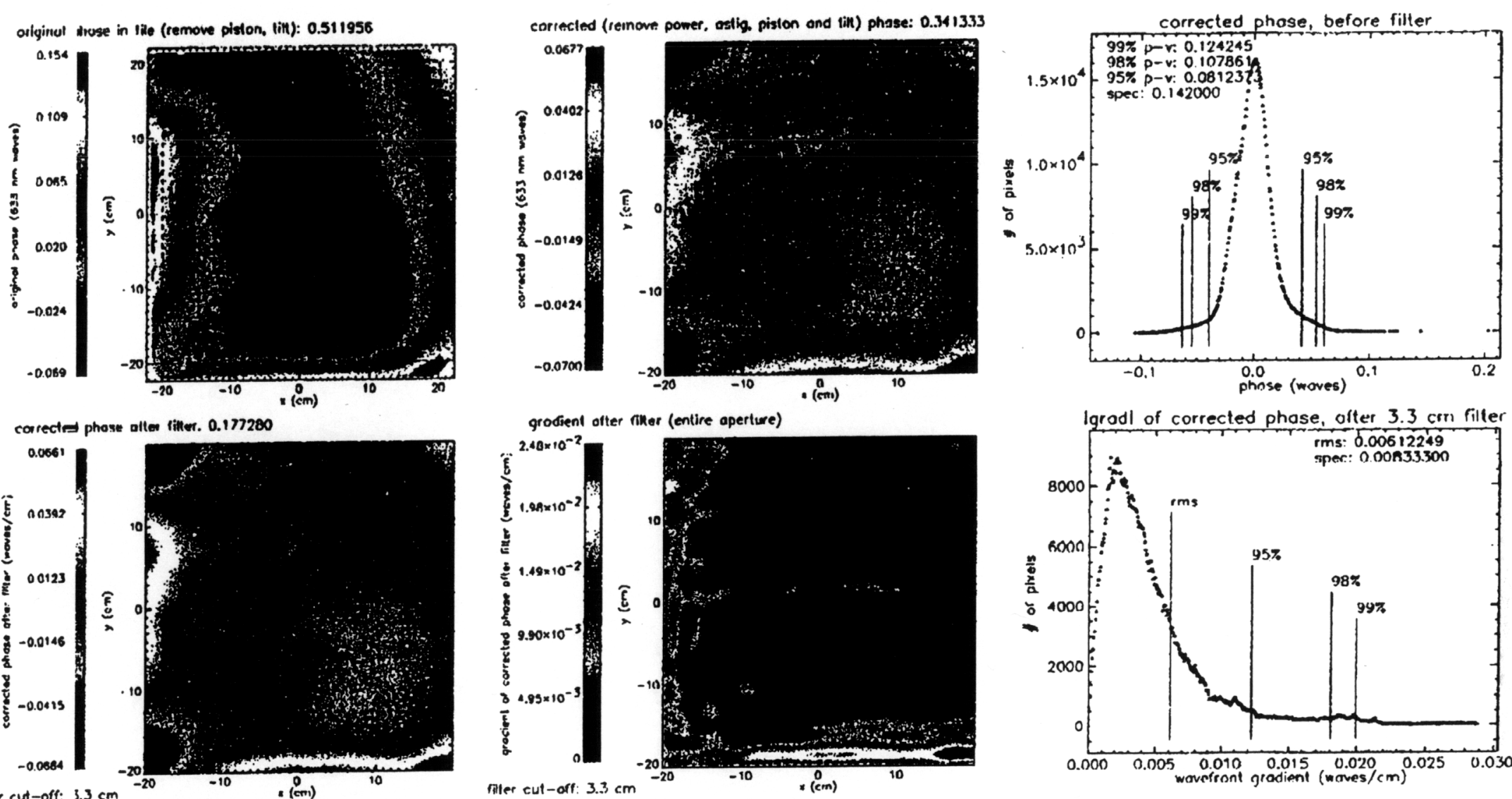

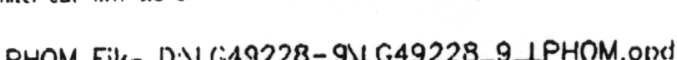
inter cut-off: $3.3 \mathrm{~cm}$

PIIOM Mensured: 05/04/19 10:50.03 Surfoce Mcosured: $5 / 04 / 19 ; 1: 17: 2$ Surioce Fle: D:LG49228-9YLG49228.9.LS1.opd Filcs Anol zed: Mon Auq 30 U9:28:56 1999 Anolysis Mode: Final poss/fo

PHOM file comments:

PHOM tile lills:

Anolysis omments: $1 \mathrm{C} 49228-9$ Left side PHOM

(one wove is $33 \mathrm{~nm}$. PHOM filc urruy sile: $1024 \times 1024$; HHOM colc. arroy size: $1024 \times 1024$ )

LLNL. PHICM - Inferred full-.slab power / sign ( $p-v$. woves):

LINL, PHCM -. Inferred full.. slab astigmotism ( $p-v$, woves):

I.INI, PHCM - Residual phase, unfiltered (99\%) ( $p-v_{1}$, waves):

LLNL, PHCM. RMS filtered ('s mm) phase grodient

LLNi, Sur ace - Inferred full-slah Pa (

Meosured PHOM power / siun ( $p-v$ woves):

Measured PHOM ostig. mag. / angle: ( $p-v$ waves / deg)

Measured surfoce P... (99\%, waves):

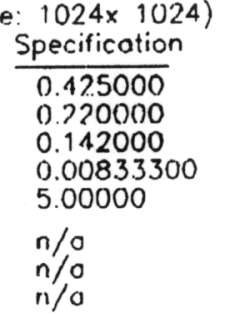

$\frac{\text { Meosured }}{0.2243 .30 /+}$
0.201505
0.124245
0.00612249
1.55056
$0.0990013 /+$
$0.0890767 /-7$
0.684292

\begin{tabular}{l} 
POSS/roil \\
\hline PASS \\
PASS \\
PASS \\
PASS \\
PASS \\
$n / 0$ \\
$n 10$ \\
$n / 0$
\end{tabular}

phomglosy. iev-1.30

FIGURE 4 - Typical Homogeneity Test Result 


\title{
Effects of melting conditions on platinum-inclusion content in phosphate laser glasses
}

\author{
John H. Campbell and Edward P. Wallerstein \\ Lawrence Livermore National Laboratory, Livermore, CA (USA) \\ Joseph S. Hayden, David L. Sapak, David E. Warrington and Alex J. Marker III \\ Schott Glass Technologies, Inc., Duryea, PA (USA)
}

\begin{abstract}
Results from small-scale glass melting experiments aimed at reducing the density of platinum particles in phosphate laser glasses are discussed. The platinum particles originate from the crucibles used to melt the laser glass and can cause optical damage in glasses used in high-peak-power lasers. The melting experiments examine the effects of a) temperature and temperature gradients; b) processing time; and c) $\mathrm{O}_{2}$ atmosphere on the formation and dissolution of platinum inclusions in LG-750 phosphate laser glass. Results show that most platinum inclusions originate early in the melt cycle, with thermal gradients within the melter being one of the major causes. By using oxidizing conditions $\left(\mathrm{O}_{2}\right)$, the platinum inclusions can be dissolved into the glass during the course of the melt cycle. Results from the laboratory-scale meiting experiments have been incorporated into a proprietary laser-glass melting process. The laser glass prepared under these conditions has an average of less than 0.1 platinum inclusions/1, which represents a 1000 -fold reduction over the previously available phosphate laser glasses.
\end{abstract}

\section{Einfluß der Schmelzbedingungen aưf den Gehalt an Platineinschlūssen in Phosphatlasergläsern}

Es werden die Ergebnisse von Glasschmelzversuchen im Labormaßstab diskutiert, deren Ziel es war, den Anteil von Platineinschlüssen in Phosphatlasergläsern zu reduzieren. Die Platinteilchen stammen von den zur Laserglasschmelze verwendeten Tiegeln und können in optischen Gläsern, wie sie in Hochleistungslasern eingesetzt werden, zu Fehlern führen. Durch die Schmelzversuche wurde der Einfluß von a) Temperatur und Temperaturgradienten, b) Behandlungsdauer und c) Sauerstoffatmosphäre auf die Entstehung und Auflösung von Platineinschlüssen in LG-750-Phosphatlaserglas untersucht. Die Ergebnisse zeigen, daß sich die meisten Platineinschlüsse recht früh während des Schmelzvorganges bilden, wobei Temperaturunterschiede im Schmelzaggregat eine der Hauptursachen sind. Unter oxidierenden Bedingungen $\left(\mathrm{O}_{2}\right)$ können die Platineinschlüsse während des Schmelzablaufs im Glas gelöst werden. Die aus den Schmelzversuchen gewonnenen Erkenntnisse wurden in einem patentrechtlich geschützten Laserglasschmelzverfahren angewendet. Ein unter diesen Bedingungen hergestelltes Laserglas weist im Durchschnitt weniger als 0,1 Platineinschlüsse/ auf, was eine 1000 fache Reduzierung gegenüber herkömmlichen Phosphatlasergläsern bedeutet.

\section{Introduction}

Platinum and platinum alloys have been successfully used as container materials in the glass melting industry since the 1940s. In contrast to most ceramic refractories, platinum is largely chemically inert to a wide range of glass compositions; consequently, very high-quality, homogeneous optical glasses can be produced in platinum melters [1].

Although relatively inert, platinum still produces some level of contamination in the glasses. This contamination is in the form of either microscopic platinum particles (inclusions) and/or low levels (ppb to $\mathrm{ppm}$ ) of dissolved platinum. In most applications, the level of contamination is sufficiently small not to affect the optical performance of the glass. However, with the advent of high-peak-power lasers in the 1960s, it was discovered that platinum inclusions produced fracture sites when irradiated above a certain fluence threshold [2 to 4]. Since

Roceived September 12, 1994. that time, considerable effort has gone into trying to reduce or eliminate platinum inclusions in both laser glasses and other laser optical components (e.g., lenses).

In 1985, when the LLNL (Lawrence Livermore National Laboratory) $120 \mathrm{~kJ}$ Nova laser (used for Inertial Fusion Research) was first operated, the large (71) phosphate glass laser disks experienced isolated, bulk damage due to platinum inclusions [5 to 7]. Most of the damage sites are distinguished by a series of radial fractures that form a circular pattern perpendicular to the beam direction. This damage morphology is shown in the schematic drawing and photographs given in figures $1 a, b$ and $2 a, b$, respectively. The damage occurred at fluences above about $2.5 \mathrm{~J} / \mathrm{cm}^{2}$ (at normal incidence) at a pulse length of $1 \mathrm{~ns}$. Further details of the mechanism of laser damage due to platinum inclusions are discussed elsewhere $[4,5$, and 8 to 18$]$.

To verify that the damaging inclusions were indeed platinum, glass samples were core-drilled from several damage sites in the laser disks The cores were then 


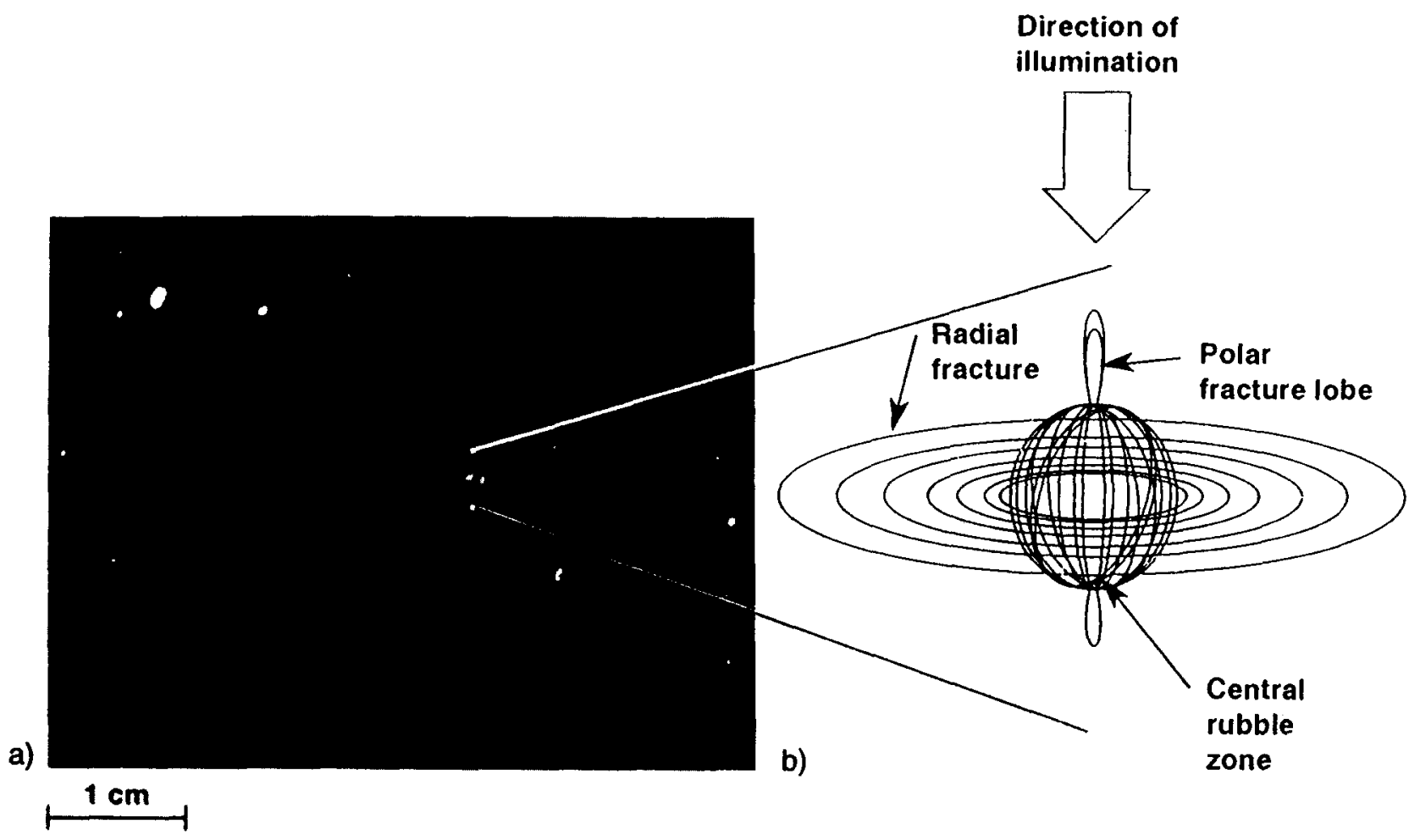

Figures la and $b$. Schematic representation of the typical morphology of laser-induced damage in laser glasses caused by a platinum inclusion. Generally, there is a major radial fracture normal to the direction of beam propagation, with two minor lobes extending above and below the radial fracture plane; a) photograph of damage sites in laser glass, b) typical geometry of many fracture sites.

cleaved at the plane of the damage fracture and submitted for Scanning Electron Microscopy (SEM) analysis. Figures $3 a$ and $b$ show a typical Back-Scattered Electron (BSE) image of one such sample at two different levels of magnification, with the typical conchoidal fracture pattern of the laser damage site. At the center of the photograph is a high-atomic-number particle that can be clearly seen by the white image it produces in the highmagnification BSE photograph. Energy dispersive $x$-ray analysis of several such particles verified that they were platinum.

It was anticipated that use of a phosphate laser glass in the design of high-peak-power lasers would reduce the risk of platinum-inclusion damage because of the greater solubility of platinum in phosphate than in silicate or fluorophosphate laser glasses. Platinum present in the dissolved (ionic) state represents no damage threat. Unfortunately, even though the phosphate glass was far superior to both silicate and fluorophosphate alternatives, it still contained platinum inclusions in concentrations of about 10 to $1000 / 1$ and in size from less than about 5 (visual detection limit) to approximately $100 \mu \mathrm{m}[6$ and 7$]$.

The occurrence of platinum in glass has been the subject of study for many years and has recently been reviewed [5]. In prior work related specifically to laser glasses, two general approaches were used to try to reduce or eliminate the source of platinum inclusions. The first was to develop glasses and melting conditions that minimize platinum levels, and the second was to melt in a platinum-free environment. Following the first approach, Ginther [19] attempted to develop a silicate glass of a composition that would be resistant to platinum contamination. His approach was to eliminate volatile alkali and alkaline earth oxides from the glass formulation. Experiments by Ginther showed that oxygen, produced by the dissociation of these components under reducing conditions, contributed to vapor-phase transport of platinum to the glass melt. Thus, he reasoned that by eliminating these components the platinum content in the glass could be significantly reduced. His experiments indeed showed reduction in platinum although no large-scale melting experiments were conducted nor was the glass ever laser damage tested. Ginther prepared his samples by induction heating and noted that induction heating will produce greater levels of platinum contamination than does resistance heating, simply because induction heating heats the platinum surface to a higher temperature than the rest of the melt. Ginther suggests that the lower thermal gradients produced by resistance heating should lead to lower platinum contamination.

One of the most significant studies of platinum in clusions in silicate glasses was reported by Hornyak and Abendroth [20] who worked primarily with the ED-2 silicate laser glass formulation. ED-2 is a proprietary silicate glass composition that is essentially a lithium disilicate also containing $\mathrm{CaO}, \mathrm{Al}_{2} \mathrm{O}_{3}$, and $\mathrm{CeO}_{2}$. In their study, Hornyak and Abendroth investigated the effects 
a)

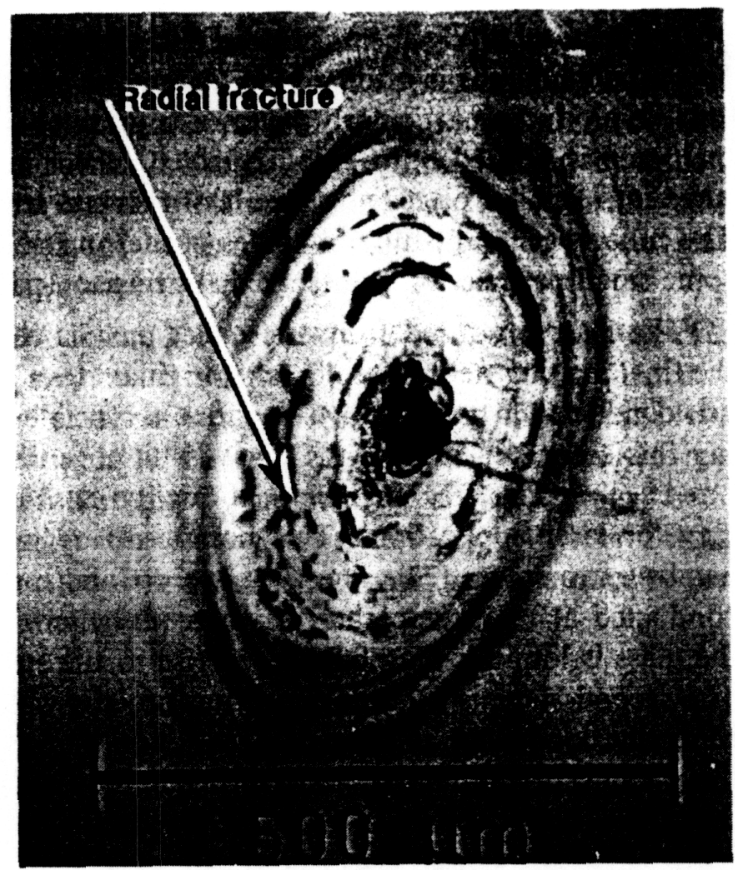

b)

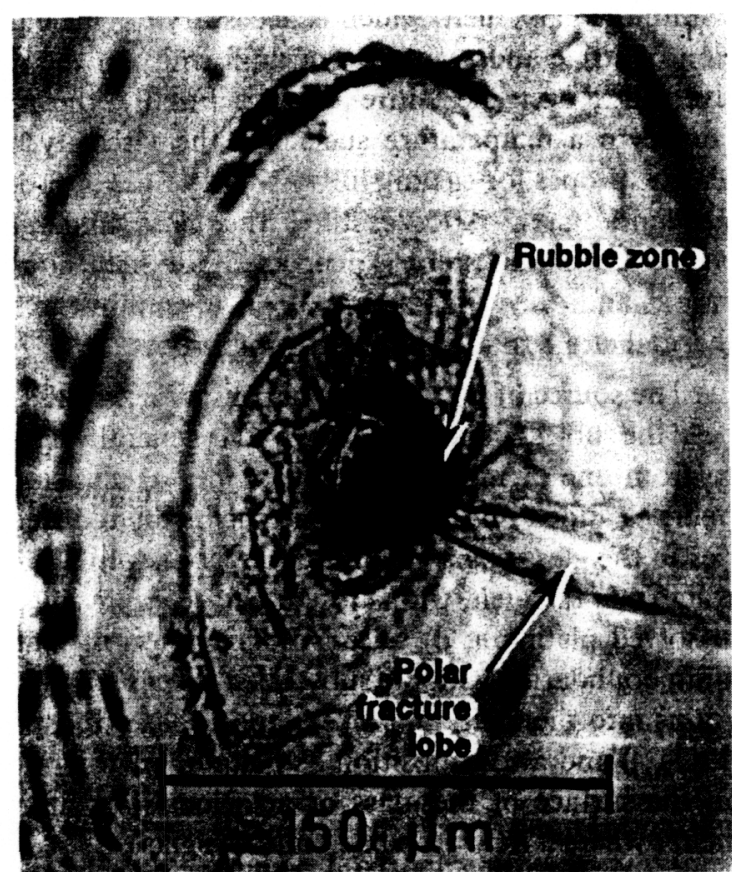

Figures $2 a$ and $b$. Optical photographs of damage sites (figure a taken at low magnification, figure $b$ taken at higher magnification) showing the characteristic radial fracture and lobes as discussed in figures $1 a$ and $b$. The highly fractured spherical region surrounds the location of the original inclusion.

of $\mathrm{O}_{2}$ partial pressure on platinum solubility in ED-2. They reported that platinum particles were not observed in ED-2 glass melted in air or $\mathrm{O}_{2}$ but that use of a neutral atmosphere produced massive numbers of metallic inclusions. Hence, their work indicated that the melt redox conditions control the solubility of platinum in the silicate glass melts.

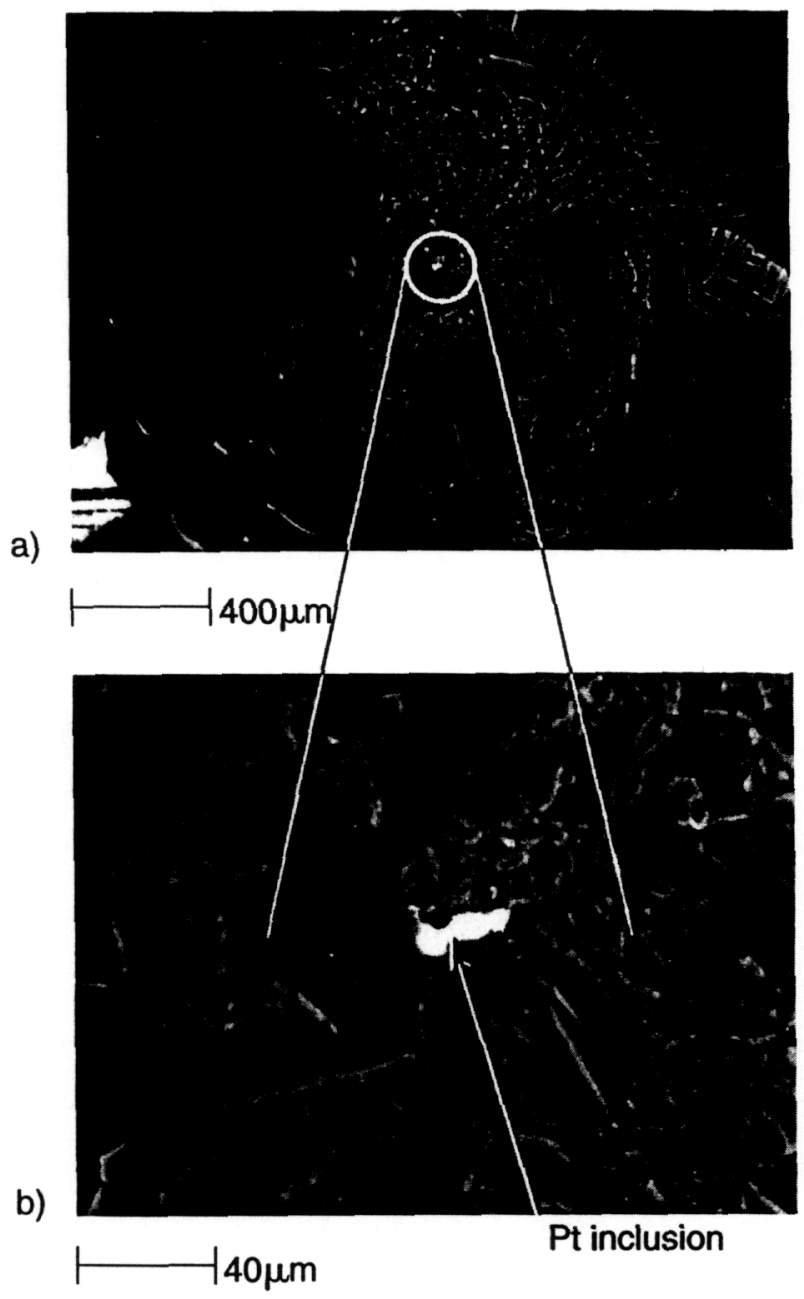

Figures $3 a$ and $b$. SEM back-scattered electron images of a cleaved damage site (figure a taken at low magnification, figure b taken at higher magnification). The remaining kernel from the original platinum inclusion is the small white particle that can be seen near the center of figure $b$.

Hornyak and Abendroth proposed the following reaction mechanism to account for the effects of $\mathrm{O}_{2}$ partial pressure on the incorporation of platinum in the glass:

$\mathrm{Pt}(\mathrm{s})+\frac{n}{4} \mathrm{O}_{2} \leftrightarrow \mathrm{PtO}_{n / 2}(\mathrm{~g})$

$\mathrm{PtO}_{n / 2}(\mathrm{~g}) \leftrightarrow \mathrm{Pt}^{\mathrm{n}+}$ (glass) $+\frac{n}{2} \mathrm{O}^{2-}$ (glass)

$\mathrm{Pt}^{n^{+}}+\frac{n}{2} \mathrm{O}^{2^{-}} \leftrightarrow \mathrm{Pt}(\mathrm{s})+\frac{n}{4} \mathrm{O}_{2}(\mathrm{~g})$

They measured the solubility of platinum in ED-2 glass at $1450^{\circ} \mathrm{C}$ as a function of oxygen partial pressure and correlated the solubility with the oxidation state in the melt by simultaneously measuring the $\mathrm{Ce}^{3+} / \mathrm{Ce}^{4+}$ ratio in the glass. Assuming a constant $\mathrm{O}^{2-}$ activity in the melt, the equilibrium constant for equation (3) is simply: 
$K_{\mathrm{eq}}=\frac{k\left(P_{\mathrm{O}_{2}}\right)^{n / 4}}{\left[\mathrm{Pt}^{n^{+}}\right]}$

Thus, the slope of the platinum solubility data can be related to the valence state of platinum by

$\lg \left[\mathrm{Pt}^{n^{+}}\right]=\frac{n}{4} \lg \left[P_{\mathrm{O}_{2}}\right]-\lg k^{\prime}$

where $n=$ valence state of the dissolved platinum, $P_{\mathrm{O}_{2}}=$ oxygen partial pressure (in bar), $k^{\prime}=$ a constant.

From their data, Hornyak and Abendroth [20] determined a value of $n$ of approximately 1.6 to 1.9 which, they suggest, indicates an oxidation state of 2 . Hornyak and Abendroth then applied their observations to ED-2 glass production. By using the $\mathrm{Ce}^{3^{+}} / \mathrm{Ce}^{4^{+}}$couple as an indicator of platinum solubility, they measured the rate of platinum incorporation in the glass during the melting, refining, and homogenization cycles. Their results showed that most $(70 \%)$ of the platinum entered the glass during the charging cycle, and only a small increase in platinum was observed during refining and homogenization. However, they also found that, if the cycle time of the process was increased, the platinum might exceed the solubility limit and be precipitated.

As mentioned, the second approach to eliminate platinum inclusions from laser glass was to perform the melt in non-platinum systems. For example, workers at Sovirel in France [3], used ceramic melters to prepare platinum inclusion-free glass. Dielectric inclusions from the ceramic still produced laser damage although at a somewhat higher threshold (about $22 \mathrm{~J} / \mathrm{cm}^{2}$ at $30 \mathrm{~ns}$ ); the damage density was greater than $300 / 1$.

Perhaps the most recent report of a platinum-free glass is that by Wilson [21] of BK-7 silicate glass being melted in ceramic melters. The authors procured a large blank of this glass and subjected it to laser damage testing at approximately $8 \mathrm{~J} / \mathrm{cm}^{2}$ at $8 \mathrm{~ns}(1.05 \mu \mathrm{m})$. The density of damage sites was greater than $100 /$ and, in one instant, resulted in a massive 3-cm-diameter fracture region that propagated through the entire glass thickness. The source of the damage is apparently dielectric inclusions originating from the ceramic melter.

Although ceramic pot melters in principle eliminate the problem of platinum inclusions, ceramic melters commonty adversely affect several other factors such as ceramic inclusions, optical homogeneity, absorption loss, and cost.

\section{Preparation of phosphate laser glass and sources of platinum inclusions}

The original phosphate laser glass used in the Nova laser was prepared in a two-step batch melting process. Although the details of the process are proprietary, the following description highlights the key steps of the process In the first step, a cullet glass is made by melting the raw starting materials. The cullet glass is usually melted in a relatively inert ceramic refractory crucible, and a bubbling gas is often added to remove unwanted volatile products, particularly water. The product of this melt step is poured onto a cold surface, where it fractures into smaller pieces as a result of thermal stresses. The cullet is generally full of bubbles, striae, and possibly some small particles of undissolved starting material.

The glass produced from the cullet melt is used in the final melting step which (for the original Nova glass) was conducted in a nominal 40-1 platinum crucible. During this second melt step, the glass is homogenized to provide the striae-free, high optical quality glass necessary for laser applications. This homogenizing process involves two stages [22]. The first is a refining process conducted at high temperatures where the viscosity of the glass is low, allowing bubbles to rise to the surface. The second stage is a homogenization process which is generally conducted at temperatures lower than either the melting or refining stages. During homogenization the melt is continuously stirred. The continuous mixing provides a thorough distribution of all components within the glass melt, which is necessary for the elimination of striae and assurance of uniformity of the refractive index over the entire casting. Finally, the melt is cooled to a temperature such that the viscosity of the glass is proper for casting into a mold of the appropriate size and shape. After casting, the glass undergoes a coarse annealing step, is inspected for inclusions and striae, and then is fine-annealed to remove residual thermal stresses due to the forming process.

The source of platinum inclusions in laser glasses has been the subject of many studies and is generally agreed to be from one or more of the following: a) abrasion and wear; b) attack on the platinum crucible by reduced species in the glass (e.g., silicon); c) direct dissolution of the crucible in the melt, with subsequent precipitation of the dissolved platinum; d) selective dissolution of platinum grain boundaries, with the subsequent release of platinum grains into the melt; and/or e) vapor-phase transport as $\left(\mathrm{PtO}_{2(\mathrm{Bg})}\right)$ and a re-deposition as metallic platinum either on the surface of the glass or at a location within the melter where it may drop back into the glass.

In principle, abrasion and wear can be eliminated as a source by care in processing. Also, in the case of phosphate glasses, the oxygen fugacity in the melt is sufficiently high that reduced species are not formed that can attack the crucible. Therefore, precipitation, selective dissolution of grain boundaries, and vapor-phase transport are the three most likely sources of platinum inclusions in phosphate laser glasses. Consequently, the primary focus of this study is to differentiate between these three mechanisms and to understand the processing conditions that affect either inclusion formation or solubility in the melt.

Platinum inclusions formed by vapor-phase transport stem from the peculiar properties of platinum metal. Platinum is an unusual metal in that it forms a volatile oxide $\left(\mathrm{PtO}_{2(\mathrm{~g})}\right)$ when heated above approximately $700^{\circ} \mathrm{C}$ 
in an oxygen-containing atmosphere [ 23 and 24]. Above this temperature, platinum oxide exists only as a gas; upon contact with a solid or liquid surface, it deposits platinum metal. The vapor pressure of platinum oxide in equilibrium with platinum (at $1 \mathrm{bar} \mathrm{O}_{2}$ ) is much greater than that of the pure platinum metal at typical glass melting temperatures.

Alcock and Hooper [24] and Schäfer and Tebben [25] have studied the thermodynamics of $\mathrm{PtO}_{2}$ formation over a temperature range from 1000 to $1600^{\circ} \mathrm{C}$ and from 1000 to $1200^{\circ} \mathrm{C}$, respectively. Alcock and Hooper showed that, for $\mathrm{O}_{2}$ pressures at or below atmospheric, the oxide formed is $\mathrm{PtO}_{2}$ (versus e.g., $\mathrm{PtO}$ or $\mathrm{Pt}_{3} \mathrm{O}_{4}$ ); thus, at equilibrium the amount formed is directly proportional to the oxygen partial pressure:

$\mathrm{Pt}^{0}+\mathrm{O}_{2} \leftrightarrow \mathrm{PtO}_{2}$

The equilibrium constant for this reaction is simply

$K_{\mathrm{eq}}=\frac{P_{\mathrm{PtO}_{2}}}{\left(\alpha_{\mathrm{Pt}}\right)\left(P_{\mathrm{O}_{2}}\right)}$

where $P_{\mathrm{PtO}_{2}}=\mathrm{PtO}_{2}$ partial pressure, $P_{\mathrm{O}_{2}}=$ oxygen partial pressure, and $a_{\mathrm{Pt}}=$ platinum activity (which for the pure metal is unity).

The equilibrium constant is related to the Gibbs free energy $\left(\Delta G^{0}\right)$ of the reaction via the classic thermodynamic expression:

$\Delta G^{0}=-R T \ln K_{\mathrm{eq}}$

which, upon substitution of equation (7) for $K_{\text {eq }}$, gives

$\Delta G^{0}=-R T \ln \frac{P_{\mathrm{PtO}_{2}}}{\left(P_{\mathrm{O}_{2}}\right)}$

where $R=$ the molar Boltzmann constant $(=8.315 \mathrm{~J} /(\mathrm{mol} \cdot \mathrm{K}))$ and $T=$ temperature in $\mathrm{K}$.

Alcock and Hooper [24] measured the $\mathrm{PtO}_{2}$ vapor pressure in 1-bar $\mathrm{O}_{2}$ between 1100 and $1500^{\circ} \mathrm{C}$ and found the data could be accurately represented by

$\lg \left(P_{\mathrm{PtO}_{2}}\right)=-\left(\frac{8585-0.204 T}{T}\right)$

giving a Gibbs free energy (in $\mathrm{J} / \mathrm{mol}$ ) of

$\Delta G^{0}=164400-3.91 T$.

Thus, from equation (9), the equilibrium $\mathrm{PtO}_{2}$ pressure at other oxygen partial pressures and temperatures can be easily calculated:
$P_{\mathrm{PtO}_{2}}=P_{\mathrm{O}_{2}} \cdot \exp \left[\frac{-164400+3.91 T}{R T}\right]$

For comparison, the corresponding vapor pressure (in bar) of the pure platinum metal can be calculated using the following expression from Hampson and Walker [26]:

$P_{\mathrm{Pt}}=1.333 \cdot 10^{-3} \cdot \exp \left[\frac{-63494+22.20 T}{T}\right]$.

Note that over the temperature range of interest (1000 to $1200^{\circ} \mathrm{C}$ ) and at $1 \mathrm{bar} \mathrm{O}_{2}$, the vapor pressure of $\mathrm{PtO}_{2}$ is more than about $10^{6}$ greater than that of platinum. Therefore, in the presence of an oxygen-containing atmosphere, the rate of platinum transport (as $\mathrm{PtO}_{2}$ ) is greatly accelerated. Since the oxide vapor pressure depends linearly on the $\mathrm{O}_{2}$ pressure (equation (13)) then $P_{\mathrm{O}_{2}}$ would have to be $10^{-6}$ bar to have the $\mathrm{PtO}_{2}$ vapor pressure equivalent to that of the metal. Thus, in oxidizing systems, platinum can be transported to the molten glass as $\mathrm{PtO}_{2}$ and then redeposited on the glass as pure platinum metal.

The notion that $\mathrm{PtO}_{2}$ transport can lead to $\mathrm{Pt}^{0}$ inclusion formation in optical glasses was clearly illustrated by Ginther [19]. He conducted a series of experiments in which a silicate glass was melted in a ceramic crucible that was in close proximity but physically separated from platinum metal. When the melt was carried out in $\mathrm{O}_{2}$, platinum inclusions were found in the glass; when an inert gas $\left(\mathrm{N}_{2}\right)$ was used, no platinum particles were observed.

Based on these experiments, it would appear that preparing glass in an inert gas environment would eliminate platinum-inclusion formation. Unfortunately, this is not the case. The oxygen partial pressure produced by decomposition of oxide-glass components is often sufficient to produce platinum transport and inclusion formation. This, of course, was the basis for the work by Ginther [19] on low oxygen pressure glasses that was discussed in section 1 .

\section{Experimental procedures}

All experiments were conducted using small-scale melts of LG-750 laser glass in either 0.5 or 21 platinum pots. LG-750 is a commercial metaphosphate laser glass manufactured by Schott Glass Technologies, Inc., Duryea, PA (USA). Although the composition of LG750 is proprietary to Schott, the essential ingredients are phosphorous, aluminum, barium, potassium and neodymium with some additional minor additives. The starting material (i.e., cullet glass) for most of these experiments was prepared in one large melt to ensure uniformity among the experiments. For convenience, most of the melts were heated inductively. However, to test the suggestion by Ginther [19], that induction heating leads to greater temperature gradients and hence 

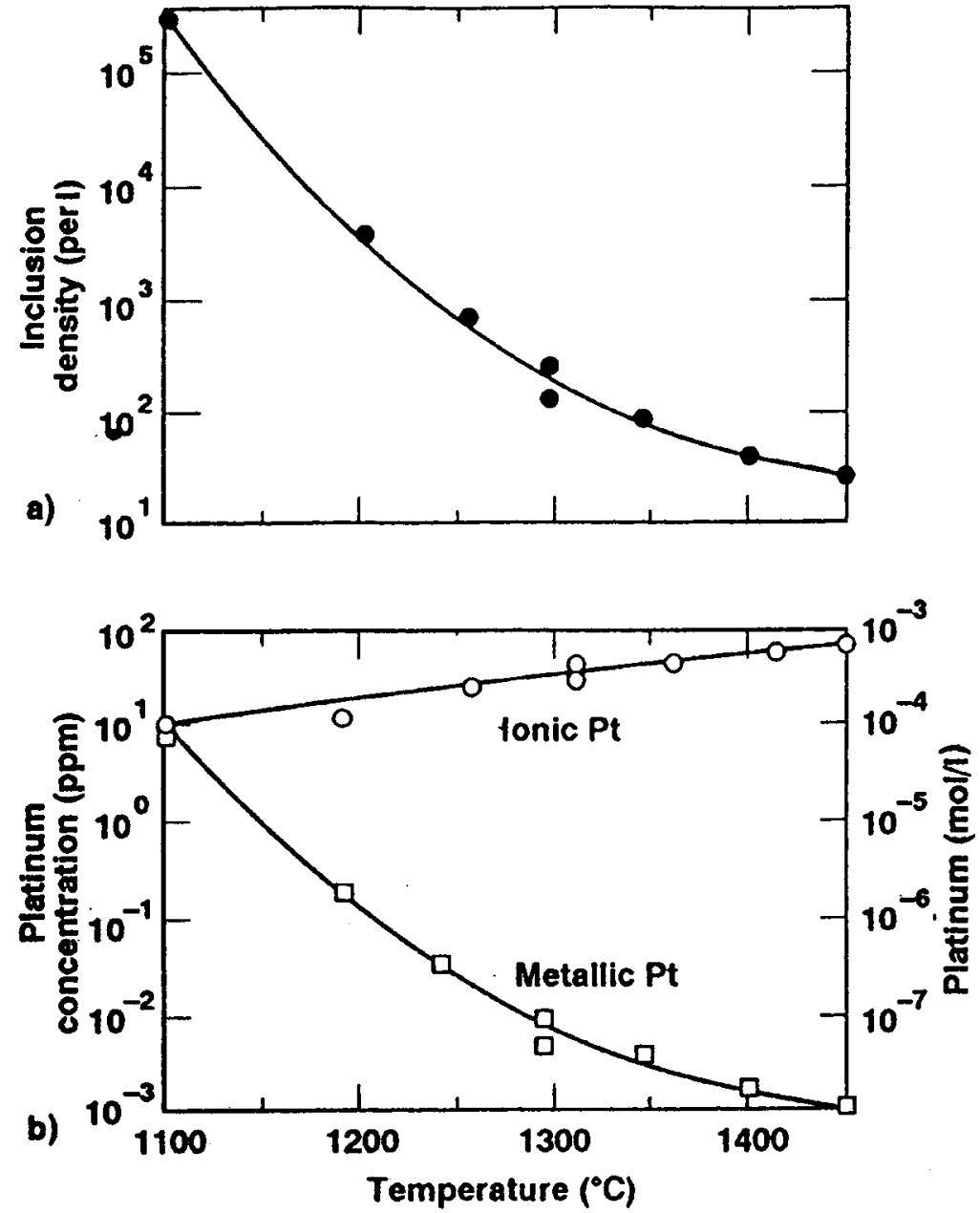

Figures $4 a$ and $b$. Platinum-inclusion density (figure a) and metallic ( $\square$ ) and ionic (O) platinum concentration (figure b) versus refining temperature for a series of 0.5-1 melts of LG-750 phosphate laser glass. The metallic platinum concentration was calculated from the inclusion density shown in figure $a$ and assuming an inclusion radius of $10 \mu \mathrm{m}$. higher platinum-inclusion density, several melts were also prepared by resistance heating.

The increase in platinum transport caused by temperature gradients also implies that the method of cullet addition to the platinum pot would affect the melt experiments. Consequently, in nearly all experiments a standard technique was used to add cullet to the melt.

First, the cullet was placed in the platinum melting crucible at room temperature. Second, the crucible was then heated to the desired experimental temperature, and finally additional room-temperature cullet was added until the proper glass level was reached.

In later experiments, the method of cullet addition (for a given melting condition) was varied to determine whether the method of addition had an effect on the platinum-inclusion density.

Each melt was cast into a steel mold and annealed to produce a glass slab for analysis of platinum content. From this casting, two transmission samples were prepared for monitoring the ionic platinum content. The concentration of ionic platinum was related to absorption in the $400-\mathrm{nm}$ region, using the correlation developed by Campbell et al. [5].

The bulk of the casting was used to produce an inspection block through which a $3.5-\mathrm{mm}$ diameter,
50-mW HeNe laser beam was systematically scanned. Every inclusion observed was marked and then inspected under suitable illumination and magnification to independently verify the identity of the site. Inspection blocks that contained large numbers of particles were analyzed by counting the total number of sites found in a specific volume element. The concentration of metallic platinum resulting from each melt was then estimated by assuming a uniform size distribution for $10-\mu \mathrm{m}$-radius spherical particles. This estimate probably represents an upper bound for the actual metallic content. Most inclusions were in the 5 to $10 \mu \mathrm{m}$ size range, although the observed size distribution was quite large.

\section{Results and discussion from phosphate laser glass melting experiments}

\subsection{Influence of refining temperature on platinum-inclusion density}

The melts used to investigate the impact of refining temperature on platinum content of phosphate glass all employed an identical refining procedure, which consisted of a $2 \mathrm{~h}$ treatment under a nitrogen cover gas followed by $2 \mathrm{~h}$ under oxygen. The refining temperature was varied from 1100 to $1450^{\circ} \mathrm{C}$. 


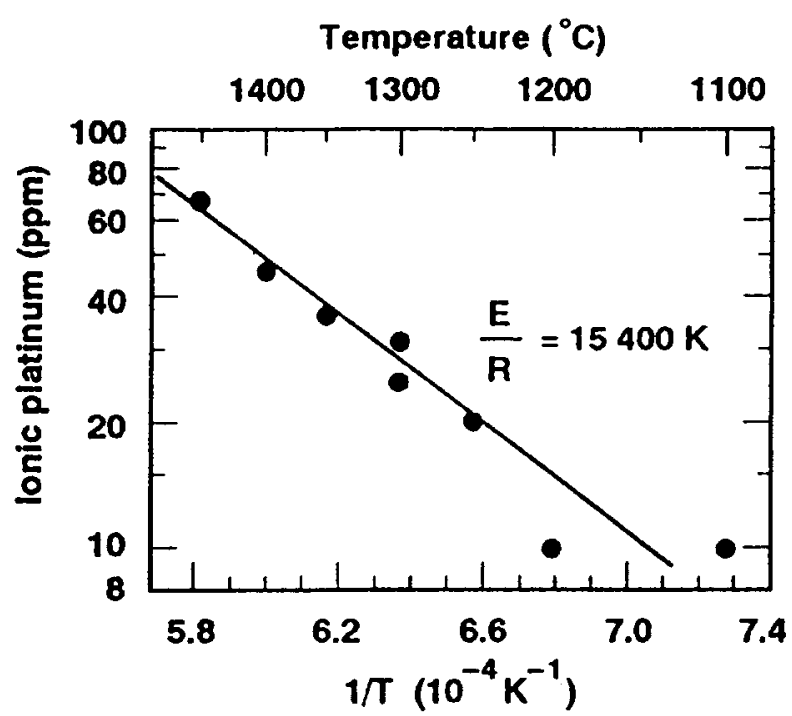

Figure 5. Ionic platinum concentration versus $1 / T$ for $L G-750$ phosphate laser glass; data from figures $4 a$ and $b$. The activation energy. $E$, can be determined from the slope of the curve, $E / R$, where $R$ is the gas constant.

Figures $4 a$ and $b$ display the metallic and ionic platinum contents resulting from these melts. Immediately obvious from these data is the large disparity between the ionic and metallic platinum concentrations except with the melt at $1100^{\circ} \mathrm{C}$. Three conclusions can be drawn from these experiments:

a) The metallic platinum concentration decreases dramatically with increases in refining temperature.

b) The ionic platinum concentration increases with temperature.

c) In general, if ionic platinum producing even a modest 400-nm absorption were converted into metallic platinum, a typical melt refined at $1300^{\circ} \mathrm{C}$ would have more than $10^{6}$ inclusions/1.

The observed increase in ionic platinum has been shown to come mainly from direct dissolution of the crucible walls [5]. Consequently, the increased dissolution of platinum inclusions with higher refining temperatures is expected to have only a minor effect on the ionic platinum content of the melt.

Figure 5 is an Arrhenius-type plot of the logarithm of ionic (dissolved) platinum content versus $T^{-1}$. The data at higher temperatures show a linear relationship characterized by an activation energy, $E$, of about $126 \mathrm{~kJ} / \mathrm{mol}$.

\subsection{Influence of oxygen content in the melt atmosphere}

A series of 0.5-1 pot melts were prepared in which the oxygen content of the gas flowing over the melt was varied from approximately $10^{-3}$ to 1.0 bar. The inclusion densities were determined by the microscopic examination techniques mentioned in section 3. Figures $6 a$
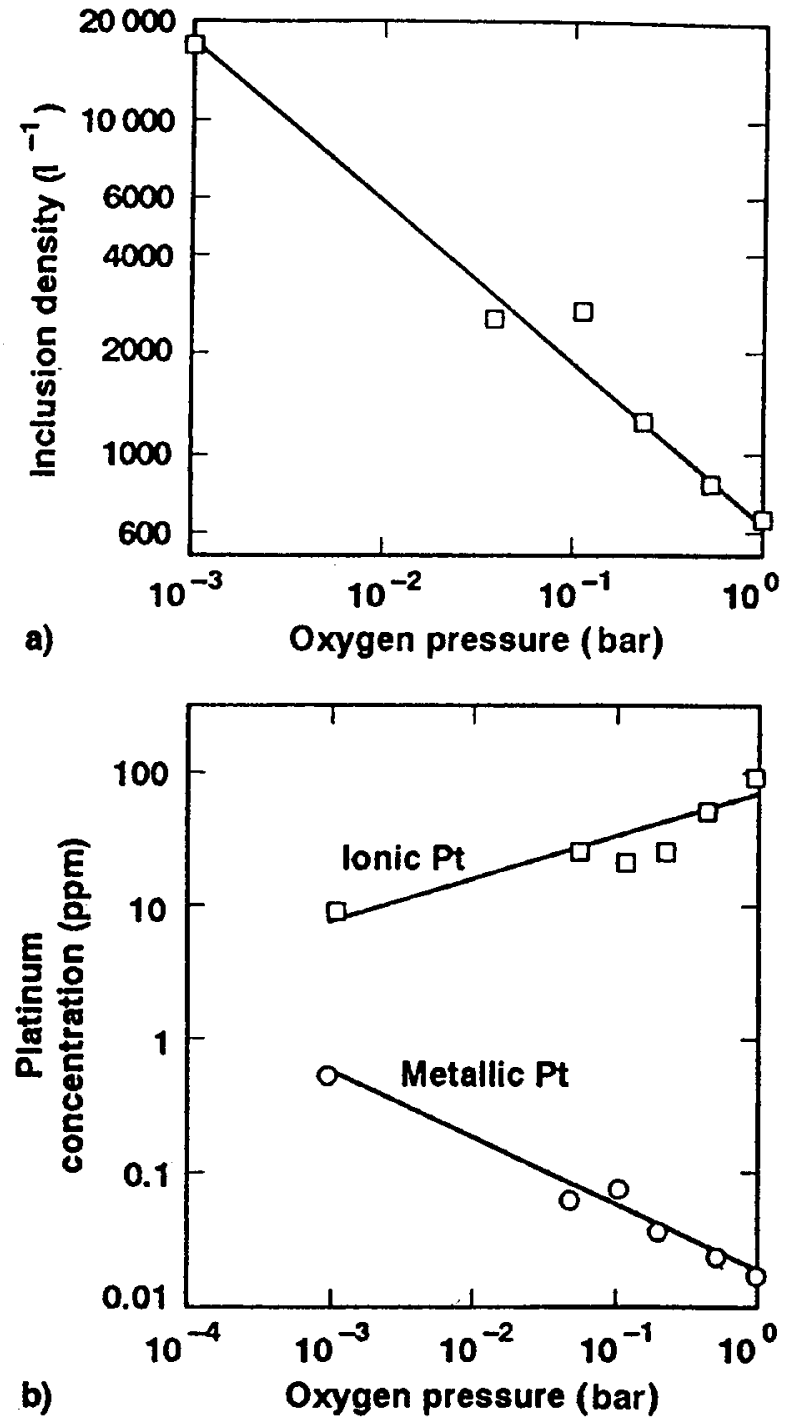

Figures $6 a$ and $b$. Platinum-inclusion density (figure a) and metallic (O) and ionic ( $\square$ ) platinum concentrations in LG-750 phosphate laser glass (figure b) as a function of oxygen partial pressure used during the melt refining step. The metallic platinum concentration was calculated from the inclusion density given in figure a and assuming an inclusion radius of $10 \mu \mathrm{m}$.

and $b$ summarize the data graphically and clearly show the dramatic improvement that strongly oxidizing conditions have on reducing the number of platinum inclusions. The disadvantage in using highly oxidizing conditions is the increase in absorption, particularly below $400 \mathrm{~nm}$, due to optical absorption by ionic platinum. For high platinum-ion concentrations, the corresponding 400-nm absorption could affect the efficiency of neodymium pumping by xenon flashlamps. The effect of ionic platinum on the transmission is clearly shown in the spectra in figure 7 of a sample of LG-750 glass melted under oxidizing conditions. The transmission was measured for three sample thicknesses. Note the main $\mathrm{Pt}^{\mathrm{n}^{+}}$absorption is in the $\mathbf{4 0 0}$ to $\mathbf{4 5 0} \mathrm{nm}$ region, in agreement with that reported by earlier researchers [27 to 32]. 


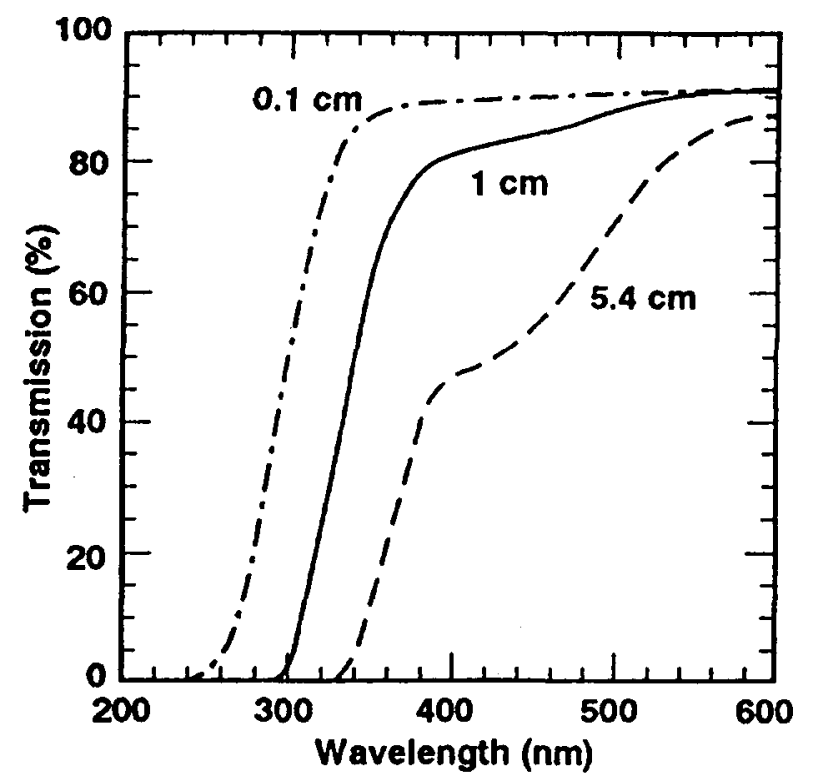

Figure 7. Effect of ionic platinum on the transmission spectra for three different thicknesses of LG-750 phosphate laser glass melted under oxidizing conditions $\left(\mathrm{O}_{2}\right.$ gas environment).

The relatively large background concentration of inclusions observed even under the most highly oxidizing conditions is probably an artifact of the procedure used to charge the crucible at the beginning of the experiment. In these small-scale experiments, it is difficult to control all the melt variables during the melt cycle, which can lead to higher than normal background levels of inclusions.

\subsection{Effect of refining time under oxygen}

A series of 2-1 melts was completed to investigate the affect of refining time under $100 \%$ oxygen on the resultant platinum-inclusion density (table 1). The standard conditions for this series of melts used two sequential refining periods. The first period was conducted under $100 \% \mathrm{~N}_{2}\left(P_{\mathrm{O}_{2}} \approx 10^{-3} \mathrm{bar}\right)$ for about $2 \mathrm{~h}$. This was followed by a second period under $100 \% \mathrm{O}_{2}$ and of variable duration. The exceptions to this pattern are melt 40.2 , which had only one 2 -h refining period under $100 \% \mathrm{O}_{2}$, and melt 83.2, which had a single 2-h refining time under $100 \% \mathrm{~N}_{2}$. All melts were refined at $1300^{\circ} \mathrm{C}$.

For these melts, the platinum crucible had a total surface area of approximately $1145 \mathrm{~cm}^{2}$, of which $920 \mathrm{~cm}^{2}$ was submerged below the melt and $225 \mathrm{~cm}^{2}$ was exposed to the atmosphere above the melt. The ionic platinum was calculated from the $400-\mathrm{nm}$ absorption, using a correlation developed previously [5]:

$\left[\mathrm{Pt}^{n^{+}}\right]=637 \cdot \alpha_{400 \mathrm{~nm}}$

where $\left[\mathrm{Pt}^{n^{+}}\right]$is the ionic platinum content in ppm and $\alpha_{400 \mathrm{~nm}}$ is the absorption coefficient at $400 \mathrm{~nm}$ in $\mathrm{cm}^{-1}$. Note that the ionic platinum concentration increases nearly linearly with time at a rate of approximately $2.8 \cdot 10^{-4}$ mole platinum per liter per hour or, when expressed in terms of the platinum area exposed to the melt, $6.1 \cdot 10^{-7}$ mole $\mathrm{Pt} /\left(\mathrm{cm}^{2} \cdot \mathrm{h}\right.$ ) (figure 8).

The metallic (platinum inclusion) concentration showed considerable variability in this series of melts. As mentioned before, this is believed to be a consequence of the procedure used to charge the crucible. Nevertheless, the highest inclusion density was observed for the melt prepared under $100 \% \mathrm{~N}_{2}$ (no $\mathrm{O}_{2}$ refining); this melt also had the lowest dissolved (ionic) platinum content. Thus, refining under $\mathrm{N}_{2}$ favors platinum-inclusion formation.

These results also suggest that a substantial number of platinum inclusions enter the melt during the fill procedure (approximately 5000/ for these particular melts). Exposure to oxygen appears to result in the dissolution

Table 1. Effect of variable refining time at $1300^{\circ} \mathrm{C}$ and an oxygen pressure of 1 bar on platinum content in $2-1$ melts of $L G-750$ phosphate glass

\begin{tabular}{|c|c|c|c|c|c|c|c|}
\hline \multirow{3}{*}{$\begin{array}{l}\text { melt } \\
\text { number }\end{array}$} & \multirow{3}{*}{$\begin{array}{l}\text { time in } h \\
\text { at } 1 \text { bar } \mathrm{O}_{2}\end{array}$} & \multicolumn{3}{|c|}{ metallic platinum } & \multicolumn{3}{|l|}{ ionic platinum } \\
\hline & & \multirow{2}{*}{$\begin{array}{l}\text { particles } \\
\text { in } I^{-1}\end{array}$} & \multicolumn{2}{|c|}{ concentration ${ }^{1}$ ) } & \multirow{2}{*}{$\begin{array}{l}\text { absorption coefficient } \\
\text { (in } \mathrm{cm}^{-1} \text { ) at } 400 \mathrm{~nm}\end{array}$} & \multicolumn{2}{|c|}{ concentration } \\
\hline & & & in ppb & in $\mathrm{mol} / \mathrm{l}$ & & in $\mathrm{mol} / 1$ & in $\mathrm{ppm}$ \\
\hline 83.2 & 0 & 4900 & 157 & $2.3 \cdot 10^{-6}$ & 0.016 & $1.5 \cdot 10^{-4}$ & 10 \\
\hline 39.2 & 1 & 725 & 23 & $3.3 \cdot 10^{-7}$ & 0.055 & $5.1 \cdot 10^{-4}$ & 35 \\
\hline 65.2 & 1.5 & 78 & 2.5 & $3.6 \cdot 10^{-8}$ & 0.061 & $5.7 \cdot 10^{-4}$ & 39 \\
\hline $37.2 / 2$ & 2 & 950 & 30 & $4.4 \cdot 10^{-7}$ & 0.071 & $6.6 \cdot 10^{-4}$ & 45 \\
\hline $37.2 / 3$ & 2 & 410 & 13 & $1.9 \cdot 10^{-7}$ & 0.093 & $8.6 \cdot 10^{-4}$ & 59 \\
\hline $37.2 / 4$ & 2 & 56 & 1.7 & $2.6 \cdot 10^{-8}$ & 0.078 & $7.3 \cdot 10^{-4}$ & 50 \\
\hline $37.2 / 5$ & 2 & 12 & 0.4 & $5.5 \cdot 10^{-9}$ & 0.086 & $8.0 \cdot 10^{-4}$ & 55 \\
\hline $37.2 / 6$ & 2 & 38 & 1.2 & $1.8 \cdot 10^{-8}$ & 0.093 & $8.6 \cdot 10^{-4}$ & 59 \\
\hline 40.2 & 2 & 96 & 3.0 & $4.4 \cdot 10^{-8}$ & 0.081 & $7.5 \cdot 10^{-4}$ & 52 \\
\hline $66.2 / 1$ & 3 & 185 & 5.8 & $8.5 \cdot 10^{-8}$ & 0.128 & $12 \cdot 10^{-4}$ & 82 \\
\hline $66.2 / 3$ & 3 & 205 & 6.5 & $9.5 \cdot 10^{-8}$ & 0.119 & $11 \cdot 10^{-4}$ & 76 \\
\hline $38.2 / 1$ & 4 & 810 & 25 & $3.7 \cdot 10^{-7}$ & 0.108 & $\cdot 10^{-4}$ & 69 \\
\hline $38.2 / 2$ & 4 & 37 & 1.2 & $1.7 \cdot 10^{-8}$ & 0.140 & $13 \cdot 10^{-4}$ & 89 \\
\hline
\end{tabular}

1) Calculated from the platinum-inclusion density assuming a particle radius of $10 \mu \mathrm{m}$. 


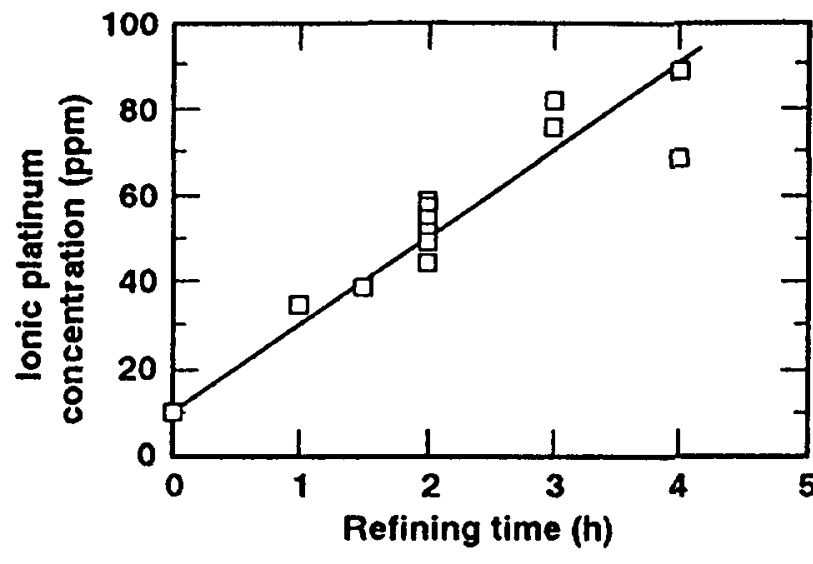

Figure 8. Ionic platinum concentration versus refining time at $1300^{\circ} \mathrm{C}$ and 1-bar $\mathrm{O}_{2}$ pressure for LG-750 phosphate laser glass.

of platinum inclusions as well as continued introduction of ionic platinum into the melt due to dissolution of the crucible walls. The increased ionic platinum is primarily from dissolution of the crucible walls, with only a very small contribution from the dissolution of inclusions [5].

\subsection{Effect of temperature gradients on platinum- inclusion formation}

Temperature gradients can lead to transport of platinum (as $\mathrm{PtO}_{2}$ ), with the subsequent formation of inclusions: In typical melting experiments, thermal gradients often exist, first, during the start of melting when cold cullet is being added to the melt and, second, between different hot and cold regions of the melter. As a consequence, platinum inclusions can form directly on the glass, when cold cullet is added to a melter, or indirectly, when platinum condenses in some cooler region and then falls or refluxes back into the crucible.

In these particular experiments, there are two main sources of thermal gradients that could lead to platinum-inclusion formation:

a) induction heating,

b) addition of cold cullet to a hot platinum crucible.

As pointed out by Ginther [19], induction heating can lead to sizable temperature gradients between the heated (receptor) platinum crucible and the glass melt. Resistance heating, on the other hand, produces smaller gradients and should produce less $\mathrm{PtO}_{2}$ transport and hence fewer inclusions.

Similarly, addition of cold cullet to a hot platinum crucible can, in principle, cause solid platinum to condense on the relatively cool surface of the cullet. This is illustrated schematically in figure 9. Here, a cold piece of cullet added to a hot platinum crucible "sweeps" through a volume $\left(V_{a}\right)$ of gas within the crucible. Assuming all the $\mathrm{PtO}_{2}$ within that volume precipitates as

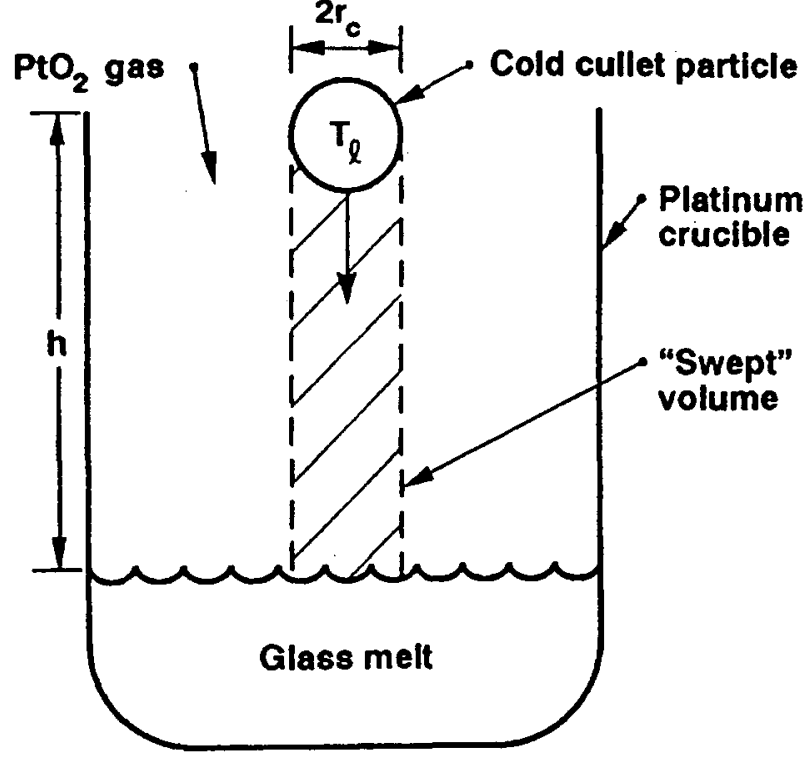

Figure 9. Schematic diagram of a cold cullet particle dropping into a heated platinum crucible (temperature $\approx 1100$ to $1200^{\circ} \mathrm{C}$ ) containing an equilibrium $\mathrm{PtO}_{2}$ pressure of $\approx 10^{-6}$ bar.

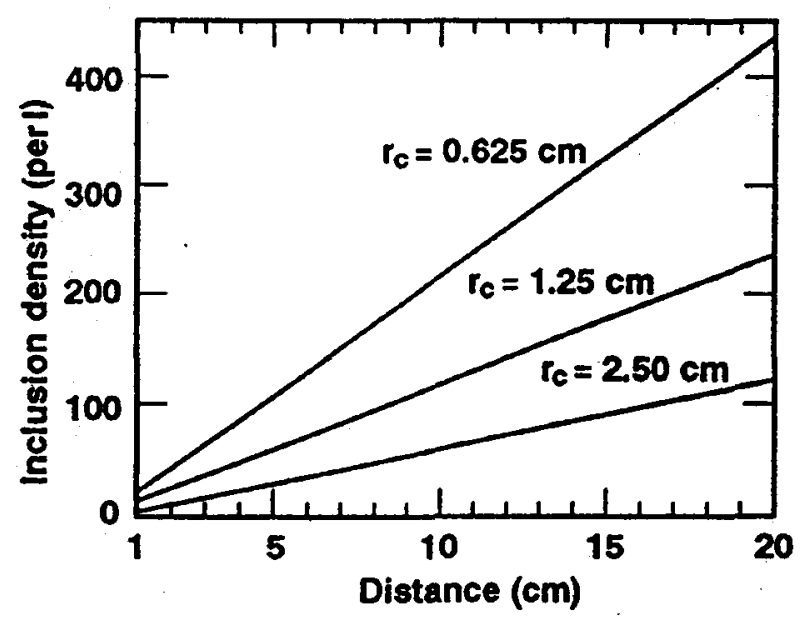

Figure 10. Calculated density of inclusions, $10 \mu \mathrm{m}$ in radius, resulting from metallic platinum accumulation on a cold cullet particle of radius $r_{c} 0.625,1.25$, and $2.50 \mathrm{~cm}$ as the particle falls a given distance through a heated platinum crucible.

$\mathrm{Pt}^{0}$ on the cullet, then it is possible to calculate an inclusion density in the glass. The volume of gas "swept" $V_{\mathrm{s}}\left(\right.$ in $\left.\mathrm{cm}^{3}\right)$ is simply

$V_{\mathrm{s}}=\pi r_{\mathrm{c}}^{2} h$

where $r_{\mathrm{c}}=$ radius of the cullet (in $\mathrm{cm}$ ), $h=$ height (in cm) of the free fall.

Assuming the platinum oxide behaves as an ideal gas, then the number of moles $\left(N_{\mathrm{Pu}}\right)$ of platinum in the swept volume is 
Table 2. Effect of thermal gradients on platinum-inclusion density in small-scale experimental melts of LG-750 phosphate glass

\begin{tabular}{llllr}
\hline $\begin{array}{l}\text { melt } \\
\text { number }\end{array}$ & $\begin{array}{l}\text { heating } \\
\text { method }\end{array}$ & $\begin{array}{l}\text { cullet } \\
\text { temperature }\end{array}$ & $\begin{array}{l}\text { relative } \\
\text { thermal gradient }\end{array}$ & platinum inclusions/l \\
\hline 34.5 & induction & cold & greatest & 1700 \\
35.5 & resistive & cold & - & 38 \\
81.5 & resistive & hot $\left(1050^{\circ} \mathrm{C}\right)$ & smallest & 6 \\
\hline
\end{tabular}

$\frac{P_{\mathrm{PtO}_{2}} V_{\mathrm{s}}}{R T_{\mathrm{H}}}=\frac{P_{\mathrm{PtO}_{2}} \pi r_{\mathrm{c}}^{2} h}{R T_{\mathrm{H}}}$

where $P_{\mathrm{PtO}_{2}}=$ equilibrium partial pressure (in bar) of $\mathrm{PtO}_{2}$ at temperature $T_{\mathrm{H}}$ (in $\mathrm{K}$ ), and $R=$ gas constant $\left(83 \mathrm{~cm}^{3} \cdot \mathrm{bar} /(\mathrm{K} \cdot \mathrm{mol})\right)$.

Assuming an average inclusion radius of $r_{\mathrm{i}}$ (in $\mathrm{cm}$ ), then the inclusion density $\left(\varrho_{i}\right.$, (in $\left.1^{-1}\right)$ ) in the cullet glass is

$\varrho_{\mathrm{i}}=\frac{N_{\mathrm{Pt}}}{V_{\mathrm{c}}}\left(\frac{M_{\mathrm{w}}}{V_{\mathrm{Pt}} \varrho_{\mathrm{Pt}}}\right)$,

where $M_{\mathrm{w}}=$ molecular weight (in $\mathrm{g} / \mathrm{mol}$ ) of platinum, $Q_{\mathrm{Pt}}=$ density (in $\mathrm{g} / \mathrm{cm}^{3}$ ) of platinum, $V_{\mathrm{c}}=$ volume (in $\mathrm{cm}^{3}$ ) of the glass cullet particle, and $V_{\mathrm{Pt}}=$ volume (in $\mathrm{cm}^{3}$ ) of the platinum inclusion.

Combining equations (16 and 17) gives the desired result:

$\varrho_{\mathrm{i}}=\left(\frac{9}{16 \pi}\right)\left(\frac{P_{\mathrm{PtO}_{2}} h M_{\mathrm{w}}}{R T_{\mathrm{H}} r_{\mathrm{c}} r_{\mathrm{i}}^{3} \varrho_{\mathrm{Pt}}}\right)$.

This function (equation (18)) is plotted in figure 10 versus free-fall distance for three different cullet sizes. An inclusion radius of $10 \mu \mathrm{m}$ and a crucible temperature of $1100^{\circ} \mathrm{C}$ containing 1 bar $\mathrm{O}_{2}$ was assumed. This model, of course, is greatly simplified. Nevertheless, it illustrates the potential impact of cold cullet additions on the initial platinum-inclusion concentration in the melt. Thus, the thermal gradients due to cullet addition and induction heating used in these experiments can lead to a sizable background of platinum inclusions.

To quantify the impact of thermal gradients on platinum-inclusion density, several $0.5-1$ melts were prepared with the aim of reducing the thermal gradients to a minimum. This was done by using resistance heating, by preheating the cullet, or both. The results (table 2) show that minimizing the thermal gradients reduces the platinum-inclusion density.

\subsection{Results from production melts of platinum- free laser glass}

Results of the research reported here and a companion article [33] have been incorporated into large-scale melting processes that have lead to essentially platinum inclusion-free phosphate laser glass. Although the specific processing details and melter designs are proprietary, the underlying basis for platinum removal is largely: eliminate the source of platinum inclusions as best as possible (i.e., erosion, wear, temperature gradients, etc.); and use oxidizing conditions to dissolve any remaining inclusions in the glass.

Production-scale melting of replacement glass for the Nova laser took place over approximately 18 months. The total production run involved about 350 large laser disks, each having a finished volume of about 71 .

During production, each laser glass casting was subjected to $100 \%$ quality assurance (QA) testing for the presence of platinum inclusions. This was accomplished by scanning the entire glass casting with a small-diameter laser beam whose output fluence (in $\mathrm{J} / \mathrm{cm}^{2}$ ) exceeded that of the Nova laser. The QA system used a commercial, Q-switched, YAG laser and movable $x-y$ stage to automatically scan the entire glass volume. The system is fully automated and operates unattended; further details of the system design and operation are given by Weinzapfel et al. [34]. Each glass vendor was supplied with a complete damage-test system that was fully integrated into the production schedule.

The manufacturing goal was to have no more than an average of two inclusions per disk; each disk contains about 71 of glass, so this translates to an inclusion density of less than $0.3 /$. In actual operation, a density of approximately 0.1 inclusion/ (i.e., less than 1 platinum inclusion per disk) was achieved. For comparison, the original Nova laser glass contained, on the average, about 100 inclusions $/ 1$. Thus, the replacement glass represents almost a 1000 -fold reduction in platinum-particle density. More specifically, $62 \%$ of all the $7-1$ laser glass disks had zero platinum inclusions and no disks had more than 8 .

\section{Summary and conclusions}

There are two important conclusions from melting experiments designed to examine the affect of various process parameters on the formation and dissolution of platinum inclusions in phosphate laser glasses. First, most platinum inclusions originate early in the melt cycle. This suggests that the major source of platinum inclusions is not the erosion or wear of the platinum crucible but the condensation of $\mathrm{PtO}_{2}$ vapor as $\mathrm{Pt}^{\mathbf{0}}$ particles due to thermal gradients or other non-equilibrium conditions. Second, platinum inclusions can be dissolved into the phosphate glass during the course of the melt 
cycle by using oxidizing conditions (e.g., $100 \% \mathrm{O}_{2}$ ). These results have been incorporated into production melting processes to produce laser glass containing approximately 0.1 platinum inclusion $/$.

Work performed under the auspices of the U. S. Department of Energy by Lawrence Livermore National Laboratory under Contract No. W-7405-ENG-48.

\section{References}

[1] Fischer, B; Gerth, K.: Platinum for glass making at Jena. Platin. Met. Rev. 38 (1994) no. 2, p. 74-82.

[2] Young, C. G.: Glass lasers. Proc. IEEE 57 (1969) no. 7, p. 1267-1289.

[3] Fundamentals of damage in laser glass. National Materials Advisory Board, Division of Engineering, National Research Council, Washington, DC. Report NMAB-271. 1970.

[4] Bliss, E. S.: Damage in laser glass. American Society for Testing and Materials, Philadelphia, PA. Spec. Tech. Publ. No. 469.1970.

[5] Campbell, J. H.; Wallerstein, E. P.; Hayden, J. S. et al.: Elimination of platinum inclusions in phosphate laser glasses. Lawrence Livermore National Laboratory. Report UCRL-53932. 1989.

[6] Hatcher, C. W.: Assessment of laser glass damage on the Nova system. Lawrence Livermore National Laboratory, Livermore, CA. Report UCRL-50021-85. 1986. p. 6-4-6-6.

[7] Campbell, J.: Eliminating platinum inclusions in laser glass. Lawrence Livermore National Laboratory. Report UCRL-52000-86-4/5. 1986

[8] Hopper, R. W.; Uhlmann, D. R.: Mechanism of inclusion damage in laser glass. J. Appl. Phys. 41 (1970) no. 10, p. 4023-4037.

[9] Hopper, R. W.; Uhlmann, D. R.: Vaporization of inclusions during laser operation. J. Appl. Phys, Commun. (1970) p. 5356-5357.

[10] Hopper, R. W.; Lee, C.; Uhlmann, D. R.: The inclusion problem in glass. In: Laser Induced Damage in Optical Materials. Boulder Damage Symposium, Boulder, CO (USA) 1970.

[11] Sparks, M.; Duthler, C. J.: Theory of infrared absorption and material failure in crystals containing inclusions. $\mathrm{J}$. Appl. Phys. 44 (1973) no. 7, p. 3038-3045.

[12] Danileiko, Y. K.; Manenkov, A. A.; Nechotailo, V. S. et al.: The role of absorbing impurities in laser-induced damage of transparent dielectrics, Sov. Phys. JETP 36 (1973) no. 3, p. $541-543$.

[13] Alekseev, N. E.; Gapontsev, V. P.; Zhabotinskii, M. E. et al.: Laser phosphate glasses. Lawrence Livermore National Laboratory, Livermore, CA. Report UCRL-Trans-11817. 1983.

[14] Avizonis, P. V.; Farrington, T.: Internal self-damage of ruby and Nd-glass lasers. Appl. Phys. Lett. 7 (1965) p. 205-206.

[15] Yamanaka, C.; Saski, T.; Hongyo, M. et al.: Investigations of damage in laser glass. In: Laser Induced Damage in Optical Materials. Boulder Damage Symposium, Boulder, CO (USA) 1971. p. 104-112.
[16] Stokowski, S.; Milam, D.; Weber, M.: Laser induced damage in fluoride glasses: a status report. In: Laser Induced Damage in Optical Materials. Boulder Damage Symposium, Boulder, CO (USA) 1978. p. 99-108.

[17] Gonzales, R. P.; Milam, D.: Evolution during multipleshot irradiation of damage surrounding isolated platinum inclusions in phosphate laser glass. In: Laser Induced Damage in Optical Materials. Boulder Damage Symposium, Boulder, CO (USA) 1985. p. 128.

[18] Pitts, J. H.: Modeling laser damage caused by platinum inclusions in laser glass. In: Laser Induced Damage in Optical Materials. Boulder Damage Symposium, Boulder, CO (USA) 1985. p. 537.

[19] Ginther, R. J.: The contamination of glass by platinum. J. Non-Cryst. Solids 6 (1971) p. 294-306.

[20] Hornyak, E. J.; Abendroth, R. P.: Problems of melting laser glass in platinum. Preprint. Toledo, $\mathrm{OH}$ : Owens-Illinois, Inc. 1970.

[21] Wilson, D. K.: Glass research. Photonics Spectra 22 (1988) p. 16.

[22] Marker, A. J. III: Optical glass technology. Proc. SPIE: Geometrical Optics 531 (1985) p. 2-10.

[23] Chaston, J. C.: The oxidation of the platinum metals. Platin. Met. Rev. 19 (1975) no. 4, p. 135-140.

[24] Alcock, C. B.; Hooper, G. W.: Thermodynamics of the gaseous oxides of the platinum group metals. Proc. R. Soc. 254A (1960) p. 551-561.

[25] Schäfer, V. H.; Tebben, A.: Gleichgewichtsmessungen im System Platin-Sauerstoff. Gasförmiges Platindioxyd. Z. Anorg. Allg. Chem. 304 (1960) p. 317-321.

[26] Hampson, R. F.; Walker, R. F.: Vapor pressures of platinum, iridium and rhodium. J. Res. Nat. Bur. Stand. 65A (1961) p. 289-295.

[27] Rindone, G. E.; Rhoads, J. L.: The colors of platinum, palladium and rhodium in simple glasses, $\mathrm{J}$. Am. Ceram. Soc. 39 (1956) no. 5, p. 173-180.

[28] Ryder, R. J.; Rindone, G. E.: Color and light scattering of platinum in some lead glasses. J. Am. Ceram. Soc. 41 (1958) no. 10, p. 415-422.

[29] Smith, H. L.; Cohen, A. J.: Absorption spectra of cations in alkali-silicate glasses of high ultra-violet transmission. Phys. Chem. Glasses 4 (1963) no. 5, p. 173-187.

[30] Stroud, J. S.: Optical absorption and color caused by selected cations in high-density, lead silicate glass, J. Am. Ceram. Soc. 54 (1971) no. 8, p. 401-406.

[31] Jorgensen, C. K.: Complexes of the 4d- and 5d-groups II. Crystal field and electron transfer spectra of ruthenium (II) and (III), iridium (IV) and platinum (IV). Acta Chem. Scand. 10 (1956) p. 518-534.

[32] Brown, R. N.; Bendow, B.; Drexhage, M. G.: Ultraviolet absorption edge studies of fluorozirconate and fluorohafnate glass. Appl. Opt. 21 (1982) no. 3, p. 361-363.

[33] Campbell, J. H.; Wallerstein, E. P.; Toratani, H. et al.: Effects of process gas environment on platinum inclusion density and dissolution rate in phosphate laser glasses. Glastech. Ber. 68 (1995) no. 2. (In prep.).

[34] Weinzapfel, C. L.; Greiner, G. J.; Walmer, C. D. et al.: Large scale damage testing in a production environment. In: Laser Induced Damage in Optical Materials. Boulder Damage Symposium, Boulder, CO (USA) 1987. p. 112-122.

$0195 \mathrm{P} 002$ 


\title{
Original Paper
}

\section{Effects of process gas environment on platinum-inclusion density and dissolution rate in phosphate laser glasses}

\author{
John H. Campbell and Edward P. Wallerstein \\ Lawrence Livermore National Laboratory, Livermore, CA (USA) \\ Hisayoshi Toratani, Helmuth E. Meissner ${ }^{1}$ ), Sadahiro Nakajima and Tetsuro S. Izumitani \\ Hoya Optics, Inc., Freemont, CA (USA)
}

\begin{abstract}
The effects of process gas environment on reducing the density of platinum inclusions in phosphate laser glasses are examined. The platinum inclusions originate from the crucibles used to melt the laser glass and can lead to optical damage in glasses used in highpeak-power lasers. The melting experiments examine the effects of $\mathrm{N}_{2}, \mathrm{O}_{2}$ and $\mathrm{Cl}_{2}$ gases on inclusion density and platinum dissolution rates. The more oxidizing the process gas conditions, the greater the dissolution rate $\left(\mathrm{O}_{2}+\mathrm{Cl}_{2}>\mathrm{O}_{2}>\mathrm{N}_{2}\right)$. A thin-film mass transport model is used to analyze dissolution rate data for small plates of platinum over a range of temperatures from 1000 to $1200^{\circ} \mathrm{C}$ and oxygen fugacity of $10^{-3}$ to 1 bar. At $1200^{\circ} \mathrm{C}$ the platinum dissolution rate is approximately $3.0 \cdot 10^{-8}\left(P_{\mathrm{O}_{2}}\right)^{0.7}$ (in $\mathrm{g} /\left(\mathrm{cm}^{2} \cdot \mathrm{s}\right)$ ) where $P_{\mathrm{O}_{2}}$ is the oxygen fugacity of the process gas in bar. Using $\mathrm{Cl}_{2}$ rather than $\mathrm{O}_{2}$ causes a measurable increase in the optical absorption of the glass that may be due to either a red-shift and/or a greater absorption coefficient for the platinumchlorine complex.
\end{abstract} Einfluß der ProzeBgasatmosphăre aư die Dichte und Auflosungsgeschwindigkeit von Platineinschlüssen in Phosphat-
laserglăsern

Der Einfluß der Prozeßgasatmosphäre auf die Verringerung des Gehaltes an Platineinschlüssen in Phosphatlasergläsern wird untersucht. Die Platineinschlüsse stammen von den zur Laserglasschmelze verwendeten Tiegeln und können in Gläsern, wie sie in Hochleistungslasern eingesetzt werden, zu optischen Fehlern führen. Durch die Schmelzversuche wurde der EinfluB von gasförmigem $\mathrm{N}_{2}, \mathrm{O}_{2}$ und $\mathrm{Cl}_{2}$ auf den Gehalt an Einschlüssen und die Auflösungsgeschwindigkeit von Platin untersucht. Je stärker die oxidierende Wirkung der ProzeBgase ist, um so höher ist die Auflösungsgeschwindigkeit $\left(\mathrm{O}_{2}+\mathrm{Cl}_{2}>\mathrm{O}_{2}>\mathrm{N}_{2}\right)$. Um die Werte der Auflösungsgeschwindigkeit von kleinen Platinplättchen über einen Temperaturbereich von 1000 bis $1200^{\circ} \mathrm{C}$ und bei Sauerstoffugazitäten von $10^{-3}$ bis 1 bar zu analysieren, wird ein Dünnschicht-Massentransportmodell angewendet. Bei $1200^{\circ} \mathrm{C}$ beträgt die Auflösungsgeschwindigkeit von Platin ungefăhr $3,0 \cdot 10^{-8}\left(P_{\mathrm{O}_{2}}\right)^{0,7}$ (in $\mathrm{g} /\left(\mathrm{cm}^{2} \cdot \mathrm{s}\right)$ ), wobei $P_{\mathrm{O}_{2}}$ die Sauerstoffugazität des ProzeBgases in bar bedeutet. Der Einsatz von $\mathrm{Cl}_{2}$ mehr noch als der von $\mathrm{O}_{2}$ ruft einen meBbaren Anstieg der optischen Absorption des Glases hervor, was entweder auf eine Rotverschiebung und/oder einen größeren Absorptionskoeffizienten des Platin-Chlorkomplexes zurückzuführen ist.

\section{Introduction}

In a companion paper [1], results were presented showing the impact of melting conditions on the density of platinum inclusions in Schott's LG-750 phosphate laser glass. In this paper the authors examine the effects of different oxidizing gas environments on platinum-inclusion formation and dissolution rate in Hoya's LHG-8 phosphate glass. LHG-8 is a metaphosphate glass. Details of the composition are proprietary, however, the basic components of the glass are $\mathrm{P}_{2} \mathrm{O}_{5}, \mathrm{Al}_{3} \mathrm{O}_{3}, \mathrm{BaO}$, $\mathrm{K}_{2} \mathrm{O}$ and $\mathrm{Nd}_{2} \mathrm{O}_{3}$ plus other miscellaneous components.

Platinum and platinum alloys that are often used as container materials in optical glass melting produce small levels of contamination in the form of either microscopic inclusions or low levels of dissolved (ionic) platinum. Glasses used in high-peak-power laser applications, such as the large lasers used for fusion research,

Received September 19, 1994.

1) Currently with Onyx Optics, Dublin, CA (USA). require platinum inclusion-free glass. This is because the high laser fluences cause the platinum inclusions to heat to the point they volatilize and fracture the laser glass, thereby rending it useless. Further details of the mechanisms of laser-induced damage due to platinum inclusions are discussed elsewhere [2 and 3].

The occurrence of platinum in glass has been the subject of study for many years and is briefly reviewed in the companion study [1]. It has been shown that most platinum inclusions in laser glasses form by vapor-phase transport as $\mathrm{PtO}_{2}(\mathrm{~g})$ with subsequent deposition of metallic particles on a free surface. The metallic particles may form either on the surface of the glass melt or on surfaces within the melter where they may then transport back into the glass melt.

The results from this study show that by using various oxidizing gas conditions $\left(\mathrm{O}_{2}, \mathrm{Cl}_{2}\right.$ or $\left.\mathrm{O}_{2}+\mathrm{Cl}_{2}\right)$ the platinum inclusions can be dissolved in the glass melt. The dissolution rate of platinum under oxidizing conditions is measured in a series of small-scale melts and 


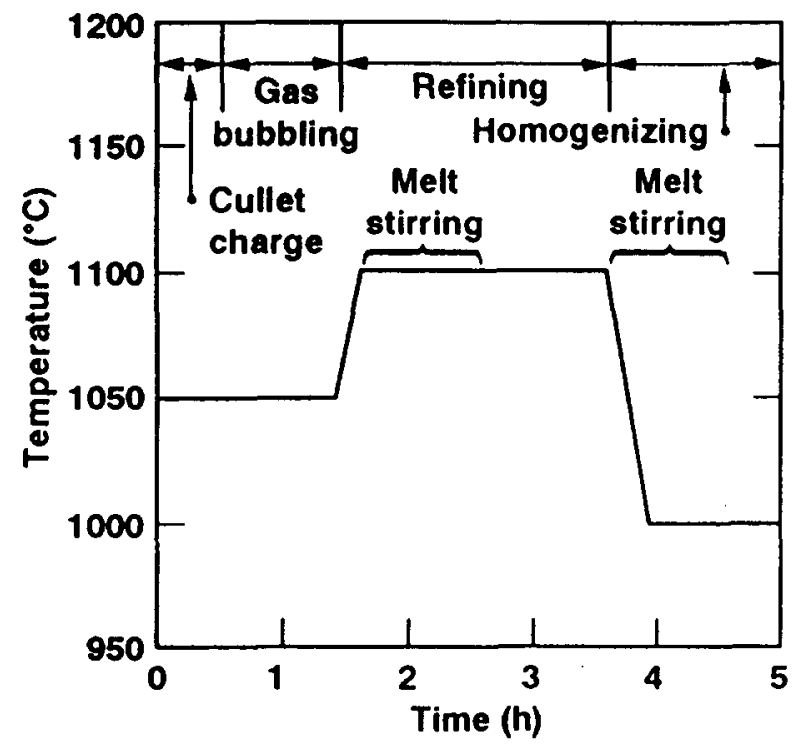

Figure 1. Glass processing schedule used to prepare 0.5-1 melts of LHG-8 glass.

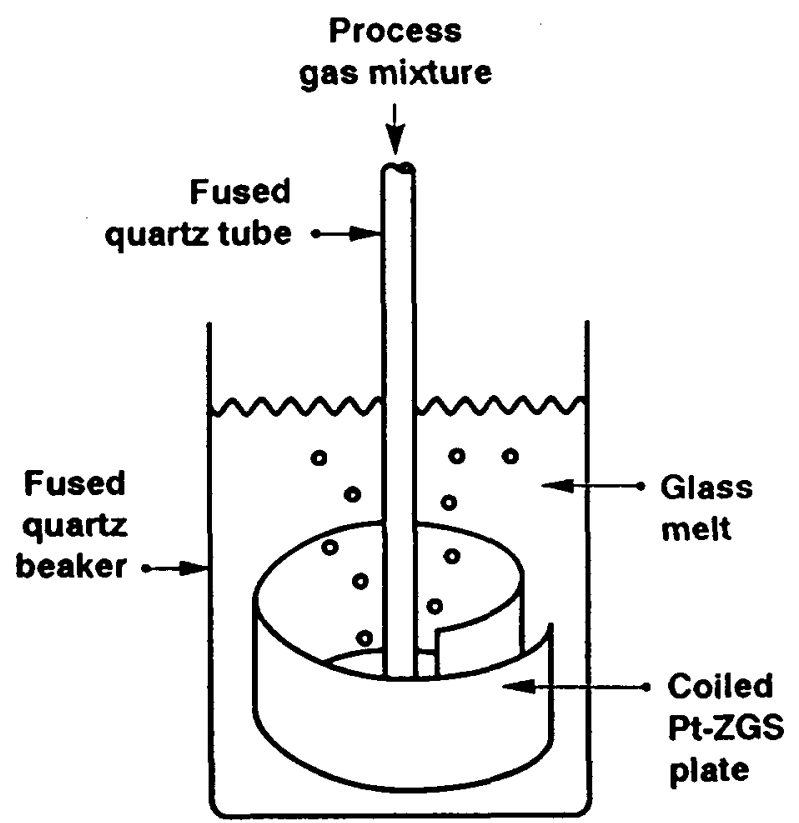

Figure 2. Schematic drawing of melting set-up used to measure the platinum solubility rate in LHG-8 phosphate glass.

a model is used to quantify the description of the dissolution process. The effect of ionic platinum on the transmission spectra of the LHG-8 phosphate laser glass produced under various oxidizing conditions has also been measured. The small-scale melt experiments on LHG-8 glass are broken into two main areas: a) understanding the effects of an oxidizing gas used at various temperatures and over different lengths of time on platinum-inclusion formation and platinum metal dissolution rate, and b) investigation of chlorine additives on platinum solubility.
The experiments on the use of chlorine were in part motivated by the earlier work by Rindone and Rhoads [4] and Ryder and Rindone [5]; the purpose is to understand the effects of chlorine on platinum solubility and the formation of chloroplatinum complexes in phosphate glass systems.

It should be added that the study of the effects of oxidizing conditions on platinum solubility in silicate melts has been a subject of recent interest to the earth sciences [6 and 7].

\section{Experimental procedures}

\subsection{Preparation of $0.5-1$ test melts}

Nominal half-liter-scale melts of LHG-8 glass were prepared to study the effects of oxidizing process gas on the ionic platinum and metallic platinum inclusion content in the glass. All melts were prepared in a resistanceheated furnace designed to allow for introduction of a flowing cover gas over the melt as well as an option for gas bubbling through the melt.

The platinum crucible had a volume of $550 \mathrm{~cm}^{3}$ and a total exposed surface area of about $350 \mathrm{~cm}^{2}$, of which $290 \mathrm{~cm}^{2}$ was submerged below the melt and $60 \mathrm{~cm}^{2}$ was exposed to the environment above the melt.

Cullet glass, melted in a fused quartz crucible, was used as a raw material. Enough cullet was prepared in one laser glass melt to provide feed stock for 80 experiments. Figure 1 shows the approximate melting schedule used in most of the experimental melts. After homogenization, the melt was cast into a graphite mold and then annealed.

The platinum-inclusion density was usually measured using dark field microscopy. A small polished sample from each melt was also used to measure the transmission spectrum and the platinum ion concentration was calculated using the correlation developed by Campbell et al. [8].

\subsection{Determination of platinum-dissolution rate}

The dissolution rate of platinum in the glass was determined using a platinum metal plate of known surface area submerged in a fixed volume of molten LHG-8 glass (figure 2). The plate has a surface area of $70 \mathrm{~cm}^{2}$ and was fabricated from zirconia-grain-stabilized (ZGS) platinum. The melt volume was $46 \mathrm{~cm}^{3}$, and gas was bubbled through the melt at a rate of $50 \mathrm{~cm}^{3} / \mathrm{min}$ for up to $15 \mathrm{~h}$. The temperature was varied between 1000,1100 , and $1200^{\circ} \mathrm{C}$.

Cullet glass was first charged to the quartz crucible and approximately $15 \mathrm{~min}$ later the coiled Pt-ZGS plate and quartz bubbling tube were inserted. Process gas of the desired composition was then bubbled through the melt for a given time and then both the bubbling tube and Pt-ZGS plate were removed. The glass melt was allowed to sit for $15 \mathrm{~min}$ and then cast into a graphite mold. The glass sample was then cut and inspectionpolished for subsequent transmission measurements. 
Table 1. Effect of oxygen partial pressure on platinum-inclusion density and ionic platinum content of LHG-8 phosphate glass

\begin{tabular}{|c|c|c|c|c|c|c|}
\hline \multirow[b]{2}{*}{$\begin{array}{l}\text { melt } \\
\text { number }\end{array}$} & \multicolumn{2}{|c|}{ gas composition ${ }^{2}$ ) } & \multicolumn{2}{|c|}{ metallic platinum } & \multicolumn{2}{|c|}{ ionic platinum } \\
\hline & $\begin{array}{l}\mathrm{O}_{2} \\
\text { in } \%\end{array}$ & $\begin{array}{l}\mathrm{N}_{2} \\
\text { in } \%\end{array}$ & $\begin{array}{l}\text { inclusion } \\
\text { density } \\
\text { in } 1^{-1}\end{array}$ & $\begin{array}{l}\text { equivalent } \\
\text { concentration }{ }^{3} \text { ) } \\
\text { in } \mathrm{ppb}\end{array}$ & $\begin{array}{l}\text { absorption } \\
\text { at } 400 \mathrm{~nm} \text {, } \\
\text { in } \mathrm{cm}^{-1}\end{array}$ & $\begin{array}{l}\left.\text { concentration }{ }^{4}\right) \\
\text { in ppm }\end{array}$ \\
\hline DT-500-24 & 100 & 0 & 15 & 0.5 & 0.090 & 57 \\
\hline DT-500-26 & 30 & 70 & 45 & 1.4 & 0.040 & 26 \\
\hline DT-500-27 & 10 & 90 & 40 & 1.3 & 0.034 & 21 \\
\hline DT-500-44 & 3 & 97 & 243 & 7.6 & 0.017 & 11 \\
\hline DT-500-47 & 1 & 99 & 586 & 18 & 0.018 & 11 \\
\hline DT-500-48 & $\approx 0.1$ to 0.5 & $\approx 99.5$ to 99.9 & 1203 & 38 & 0.014 & 9 \\
\hline
\end{tabular}

2) The cover gas and the gas bubbled through the melt had the same composition; the total gas pressure was 1 bar.

3) Calculated assuming a platinum-inclusion radius of $10 \mu \mathrm{m}$.

$\left.{ }^{4}\right)$ Calculated using the correlation given by equation (1).

The ionic platinum content was determined by measuring the glass absorption at $400 \mathrm{~nm}$ and the relating that to the platinum concentration using the expression [8]:

$\left[\mathrm{Pt}_{\text {ionic }}\right]=637 \cdot \alpha_{400 \mathrm{~nm}}$

where $\alpha_{400 \mathrm{~nm}}$ is the measured absorptivity (in $\mathrm{cm}^{-1}$ ) of the glass melt and $\left[\mathrm{Pt}_{\text {ionic }}\right]$ is the platinum content in ppm.

\subsection{Melts prepared using $\mathrm{O}_{2} / \mathrm{Cl}_{2}$ gas addition}

The effects of $\mathrm{O}_{2}$ and $\mathrm{Cl}_{2}$ gas addition on platinum solubility was measured using a method similar to that described in section 2.2 . About $120 \mathrm{~g}$ of LHG-8 cullet was melted in a $75-\mathrm{cm}^{3}$ quartz crucible. A strip of platinum metal having a surface area of about $52 \mathrm{~cm}^{2}$ and weighing approximately $28 \mathrm{~g}$ was carefully cleaned, dried, and weighed. It was then bent into a cylinder so that it could be easily placed in the glass melt. Prior to the addition of the platinum strip, the glass melt was preconditioned by bubbling the desired gas composition through the melt for $10 \mathrm{~min}$. The bubbler tube was then removed, the platinum metal strip added, and the gas bubbler replaced. The bubbler tube was placed in the center of the crucible (and center of the cylindrical platinum strip), about $1.5 \mathrm{~cm}$ from the bottom. After $2 \mathrm{~h}$ at $1200^{\circ} \mathrm{C}$, the bubbler and platinum strip were removed and the melt was returned to the furnace for a 20-min refining period. After that, the melt was poured into a mold and annealed. The platinum strip was cleaned and reweighed to determine the mass loss.

A carrier gas of either $\mathrm{N}_{2}, \mathrm{O}_{2}$, or a combination of both was fed through the bubbler at a total flow rate of $100 \mathrm{~cm}^{3} / \mathrm{min}$ at standard conditions. To this was added $\mathrm{Cl}_{2}$ either in the form of $\mathrm{Cl}_{2}$ or $\mathrm{CCl}_{4}$; the flow rate of the added gas was adjusted such that the final $\mathrm{Cl}_{2}$ output was always $20 \mathrm{~cm}^{3} / \mathrm{min}$. $\mathrm{CCl}_{4}$ was chosen as an additive to assess the effect of a different $\mathrm{Cl}_{2}$ source. At the melt temperatures, $\mathrm{CCl}_{4}$ reacts with $\mathrm{O}_{2}$ from either the added gas or the melt to give $\mathrm{Cl}_{2}$ :
$\mathrm{CCl}_{4}+\mathrm{O}_{2} \rightleftarrows \mathrm{CO}_{2}+2 \mathrm{Cl}_{2}$.

Thus, to produce $20 \mathrm{~cm}^{3} / \mathrm{min}$ of $\mathrm{Cl}_{2}, 10 \mathrm{~cm}^{3} / \mathrm{min}$ of $\mathrm{O}_{2}$ must be consumed.

\section{Results and discussion}

\subsection{Effect of oxygen partial pressure on platinum} content

The oxygen partial pressure of both the melt cover gas and the gas bubbled through the melt was varied from about $10^{-3}$ to $1 \mathrm{bar}$, as given in table 1 ; the melting schedule was the same as shown in figure 1 . The measured platinum-inclusion density and ionic platinum content versus oxygen partial pressure are plotted in figures $3 a$ and $b$. The inclusion density decreases with increasing $\mathrm{O}_{2}$ pressure and can be represented by the approximate empirical expression:

$Q_{\mathrm{Pt}}=15 P_{\mathbf{O}_{2}^{-}}^{-0.77}$

where $Q_{\mathrm{Pt}}=$ inclusion density (in $1^{-1}$ ), and $P_{\mathrm{O}_{2}}=$ oxygen partial pressure (in bar).

The platinum-inclusion density in a series of "washmelt" glasses was also measured. These glasses were melted for just $1 \mathrm{~h}$ without atmosphere control in order to wash out the platinum crucible prior to melting the test samples. The inclusion densities measured in these samples were almost the same as those of the glass melted under $\mathrm{N}_{2}\left(\approx 10^{-3}\right.$ bar $\left.\mathrm{O}_{2}\right)$. This observation suggests that most of the platinum inclusions are formed during the early stages of the melting process. In addition, it appears that oxygen does not reduce the number of inclusions formed but rather enhances their dissolution during the melting process. In general, the higher the oxygen partial pressure of the melt atmosphere, the greater the dissolution rate. These conclusions agree with experiments on Schott's LG-750 metaphosphate laser glass that were reported in the companion paper [1] as well as the observations reported by earlier 

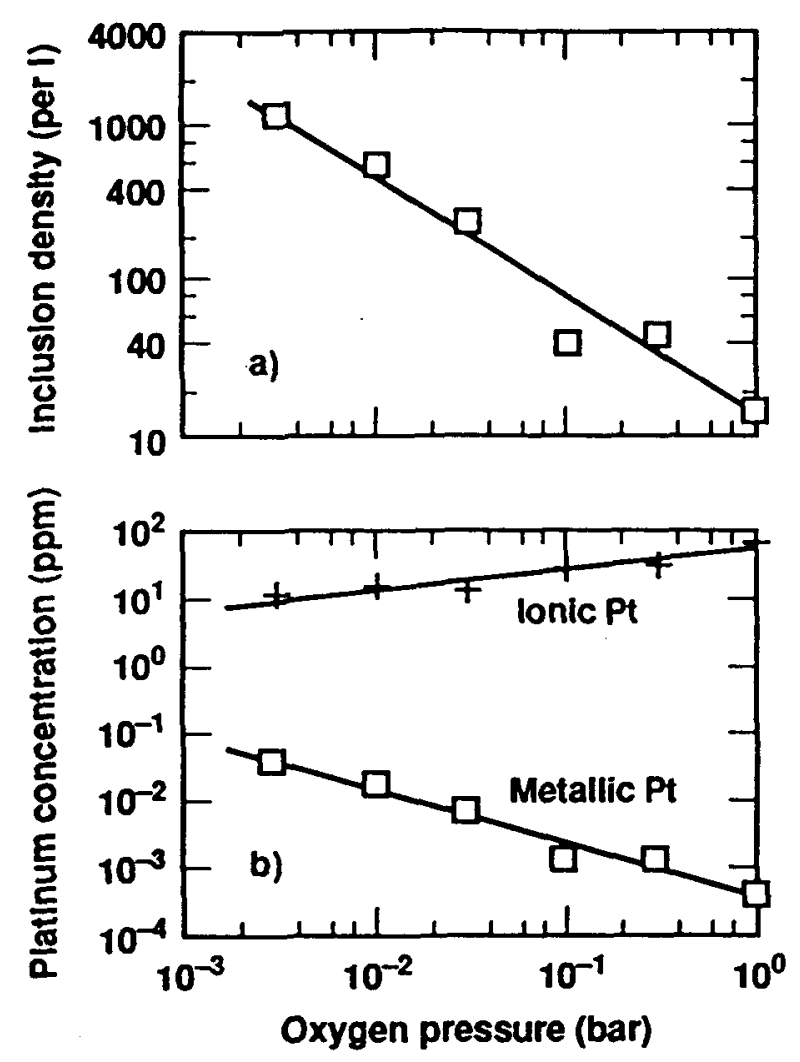

Figures $3 a$ and $b$. Platinum-inclusion density (figure $a)$ and metallic $(\square)$ and ionic $(+)$ platinum content (figure b) versus oxygen partial pressure used in melting. The metallic platinum concentration was calculated from the inclusion density given in figure a) and assuming an inclusion radius of $\approx 10 \mu \mathrm{m}$.

investigators $[4,5$, and 8$]$. For comparison with the results given here for LHG-8 glass, the plot of inclusion density versus oxygen partial pressure for the Schott LG-750 melting experiments [1] gives the approximate relationship

$Q_{P_{1}}=610 P \mathrm{O}_{2}^{-0.49}$,

where $e_{\mathrm{P}}$ and $P_{\mathrm{O}_{2}}$ are the same as defined for equation (3). With the LG-750 glass, the effect of oxygen partial pressure is not as great; the exponents of equations ( 3 and 4 ) differ by approximately $50 \%$ between the two glasses. Furthermore, the LG-750 glass has a greater background concentration of inclusions than in the Hoya experiments; this is apparent comparing the proportionality constants given in equations ( 3 and 4). This difference might be due to induction heating being used in most of the LG-750 experiments, giving greater thermal gradients [1].

The ionic platinum content versus oxygen partial pressure is plotted in figure 4 for both LHG-8 and LG750 glass melts. Using the model proposed by Hornyak and Abendroth [9], the slope of this $\mathrm{lg}$ plot is equal to

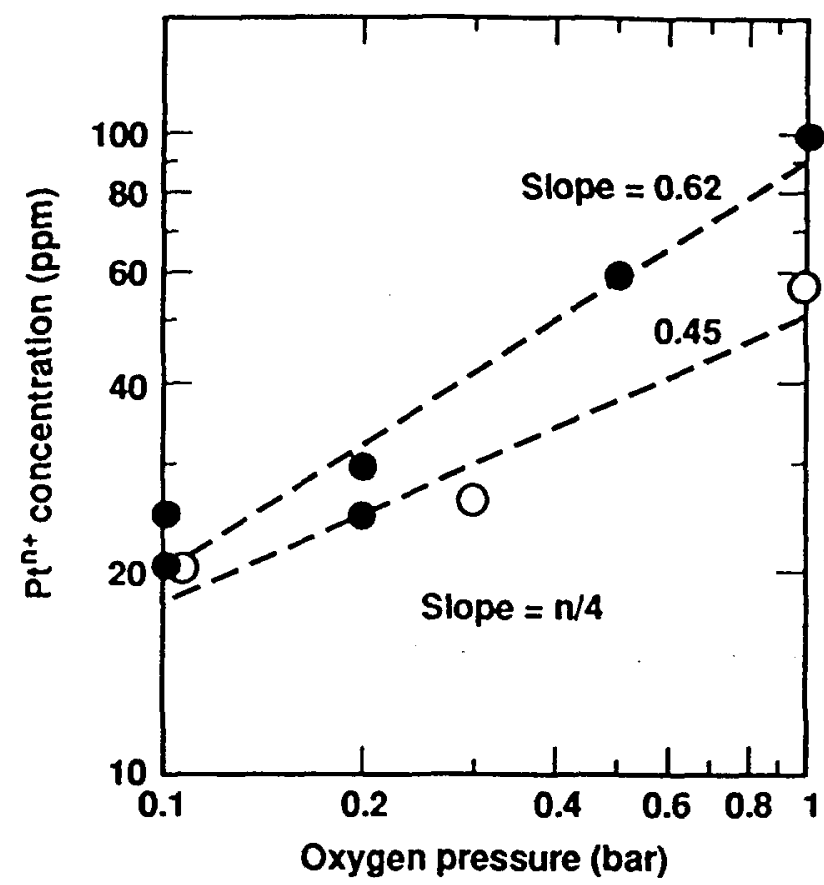

Figure 4. Ionic platinum concentration versus oxygen partial pressure for LHG-8 (O: $n=1.8)$ and LG-750 (O: $n=2.5)$ laser glasses. The dashed lines are least-squares fit to the two data sets. The slopes of the curves are related to one-fourth the oxidation state $(n)$ of the dissolved platinum, i.e., $n / 4$. Average value of $n=2.1$.

$n / 4$, where $n$ is the oxidation state of platinum [1, equation (3)]. The data are somewhat nonlinear over the range of oxygen partial pressure $\left(10^{-3}\right.$ to $\left.1 \mathrm{bar}\right)$, so the slope was measured only in the high pressure region $\left(10^{-1}\right.$ to 1 bar $\mathrm{O}_{2}$ ). (This nonlinear behavior might be from evolution of $\mathrm{O}_{2}$ from volatile alkali or alkaline earth oxides in the melt giving a higher effective $\mathrm{O}_{2}$ pressure. Also, it requires some time for the $\mathrm{O}_{2}$ concentration in the melt to equilibrate with that of the surrounding process gas environment.) The slopes of the curves range from about 0.45 to 0.62 , indicating a value for $n$ between 1.8 and 2.5. Thus, the result seems to indicate platinum dissolving into the glass as $\mathrm{Pt}^{2+}$, which agrees with the results of Hornyak and Abendroth [9], who measured an $n$ value of $\approx 1.5$ to 2.0 for $\mathrm{O}_{2}$ treatment of silicate glasses.

Figure 5 shows the transmission spectra for LGH-8 glass melted in $100 \% \mathrm{O}_{2}$ versus $100 \% \mathrm{~N}_{2}$ gas atmosphere. The ionic platimum absorption in the $360-\mathrm{nm}$ region (for the $\mathrm{O}_{2}$-treated glass) is clearly evident. Additional data on the transmission characteristics of platinum-containing glasses treated with various gases are discussed in a later section.

\subsection{Effect of temperature}

The temperature of both the gas bubbling and homogenizing step was varied to determine its effects on platinum dissolution in LHG-8 glass. The results are summarized in table 2. Except for the variation in temperature, the melt cycle used is identical to that shown in figure 1 . 
Table 2. Effect of temperature during the gas bubbling and homogenization steps on ionic and metallic platinum concentration in LHG-8 laser glass

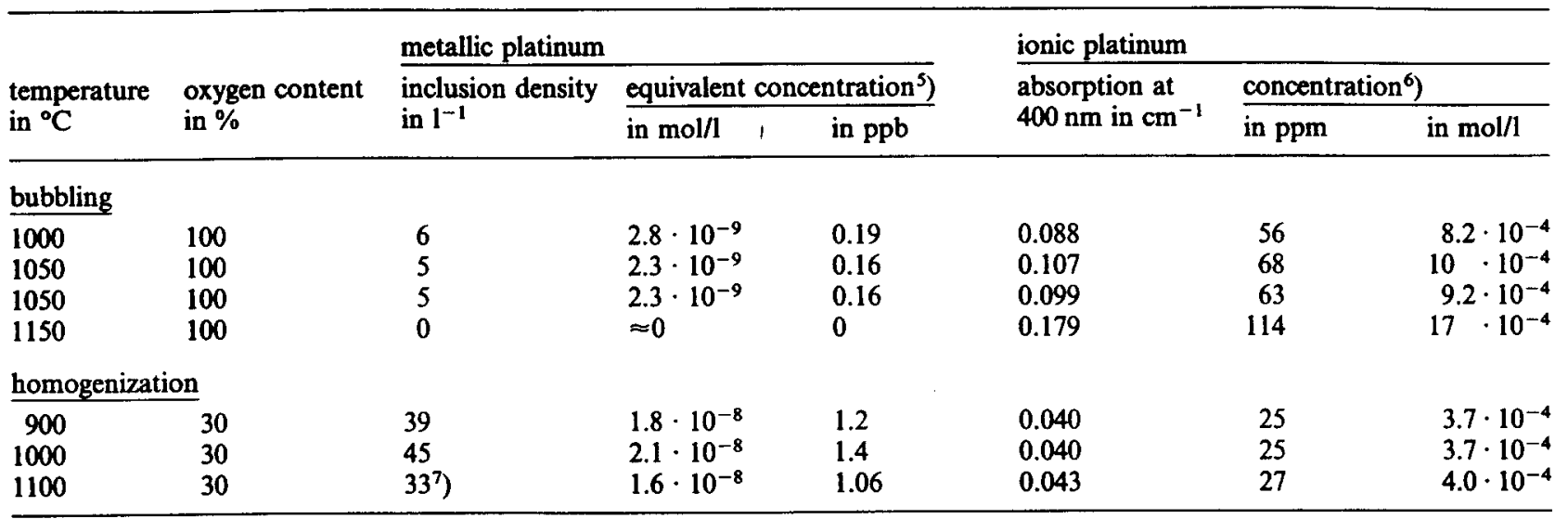

5) Calculated assuming a platinum-inclusion radius of $10 \mu \mathrm{m}$.

6) Determined from the correlation of ionic platinum versus absorption given in equation (1).

7 There is a large uncertainty in this value because of the large number of small bubbles appearing in the melt.

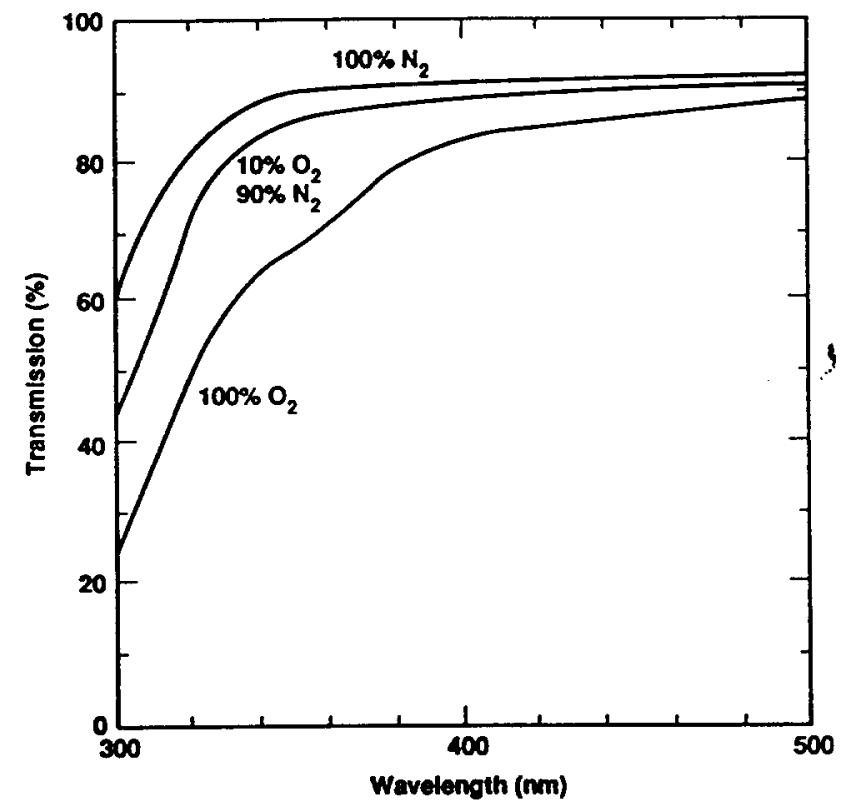

Figure 5. Transmission spectra for LHG-8 glass melted in $100 \%$ $\mathrm{O}_{2}, 90 \% \mathrm{~N}_{2} / 10 \% \mathrm{O}_{2}$ and $100 \% \mathrm{~N}_{2}$. Sample thickness is $1.3 \mathrm{~cm}$.

The temperature of the gas bubbling step has a much greater impact on the dissolved platinum content than the temperature used during homogenization. Plotted in figure 6 is the ionic platinum content (as determined from the $400-\mathrm{nm}$ absorption) versus $1 / T$ for the bubbling experiments. The slope of the curve gives an activation energy characteristic of the dissolution process; for LHG-8 glass, this is about $80 \mathrm{~kJ} / \mathrm{mol}$. This is approximately $35 \%$ lower than the value of $125 \mathrm{~kJ} / \mathrm{mol}$ measured for platinum dissolution in LG-750 glass [1]. The different activation energies might be due to a difference in the melt viscosity and melt structure due to the compositional differences between the Schott LG-750 and Hoya LHG-8 glasses.

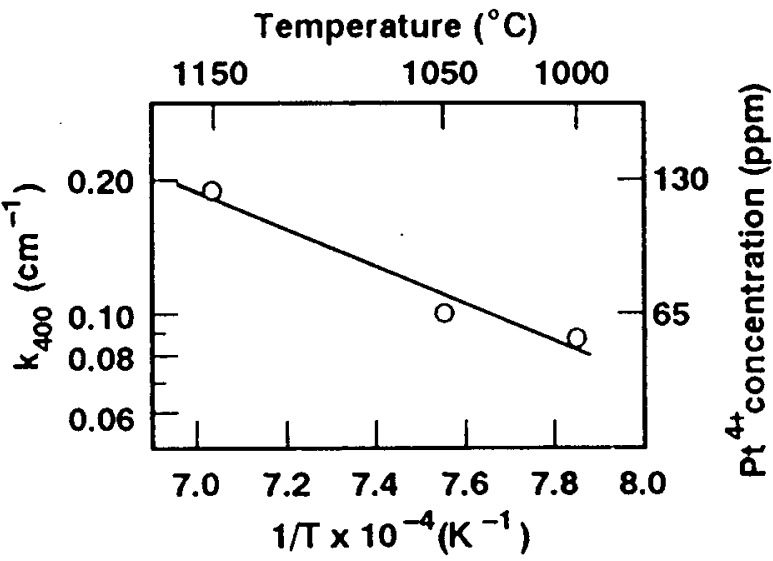

Figure 6. Arrhenius plot of $400-\mathrm{nm}$ absorption $\left(k_{400}\right)$ and corresponding ionic platinum concentration in LHG-8 glass.

The results in table 2 show little effect of the homogenization temperature on platinum dissolution in LHG-8 glass. Neither the inclusion density nor the ionic platinum content changed significantly in these meits. The gas mixture used in these experiments had $30 \% \mathrm{O}_{2}$ and was used for the bubbling step as well as atmosphere control.

\subsection{Effect of processing time}

Using the same melt schedule as shown in figure 1, the durations of the bubbling and homogenization steps were varied to assess the impact of process time on platinum content in the LHG-8 glass. The results are summarized in table 3; in all cases, $100 \% \mathrm{O}_{2}$ was used as both the bubbling and cover gas. Increasing the bubbling time from 1 to $3 \mathrm{~h}$ increases the ionic platinum content by about 40 to $50 \%$. On the other hand, increasing the homogenization time seems to have little if any effect on the amount of dissolved platinum. 
Table 3. Effect of processing time (during gas bubbling and homogenization) on the platinum content in LHG-8 laser glass

\begin{tabular}{|c|c|c|c|c|c|c|}
\hline \multirow{3}{*}{$\begin{array}{l}\text { time } \\
\text { in } h\end{array}$} & \multicolumn{3}{|l|}{ metallic platinum } & \multicolumn{3}{|l|}{ ionic platinum } \\
\hline & \multirow{2}{*}{$\begin{array}{l}\text { inclusion density } \\
\text { in } 1^{-1}\end{array}$} & \multicolumn{2}{|c|}{ concentration ${ }^{8}$ ) } & \multirow{2}{*}{$\begin{array}{l}\text { absorption at } \\
400 \mathrm{~nm} \text { in } \mathrm{cm}^{-1}\end{array}$} & \multicolumn{2}{|c|}{ concentration ${ }^{9}$ ) } \\
\hline & & in $\mathrm{ppb}$ & in $\mathrm{mol} / \mathrm{l}$ & & in $\mathrm{ppm}$ & in $\mathrm{mol} / 1$ \\
\hline \multicolumn{7}{|c|}{ bubbling } \\
\hline $\begin{array}{l}1 \\
3 \\
3\end{array}$ & $\begin{array}{r}15 \\
\approx 0 \\
\approx 0\end{array}$ & $\begin{aligned} & 0.5 \\
\approx & 0 \\
\approx & 0\end{aligned}$ & $\begin{aligned} & 7.3 \cdot 10^{-9} \\
\approx & 0 \\
\approx & 0\end{aligned}$ & $\begin{array}{l}0.082 \\
0.114 \\
0.117\end{array}$ & $\begin{array}{l}52 \\
73 \\
75\end{array}$ & $\begin{array}{r}7.6 \cdot 10^{-4} \\
11 \cdot 10^{-4} \\
11 \cdot 10^{-4}\end{array}$ \\
\hline \multicolumn{7}{|c|}{ homogenization } \\
\hline $\begin{array}{l}1 \\
1.7 \\
2.5\end{array}$ & $\begin{array}{r}15 \\
46 \\
6\end{array}$ & $\begin{array}{l}0.5 \\
1.5 \\
0.2\end{array}$ & $\begin{array}{l}7.3 \cdot 10^{-9} \\
2.2 \cdot 10^{-8} \\
2.9 \cdot 10^{-9}\end{array}$ & $\begin{array}{l}0.082 \\
0.064 \\
0.077\end{array}$ & $\begin{array}{l}52 \\
41 \\
49\end{array}$ & $\begin{array}{l}7.6 \cdot 10^{-4} \\
6.0 \cdot 10^{-4} \\
7.2 \cdot 10^{-4}\end{array}$ \\
\hline
\end{tabular}

8) Calculated assuming a platinum-inclusion radius of $10 \mu \mathrm{m}$.

9) Calculated using the correlation in equation (1).

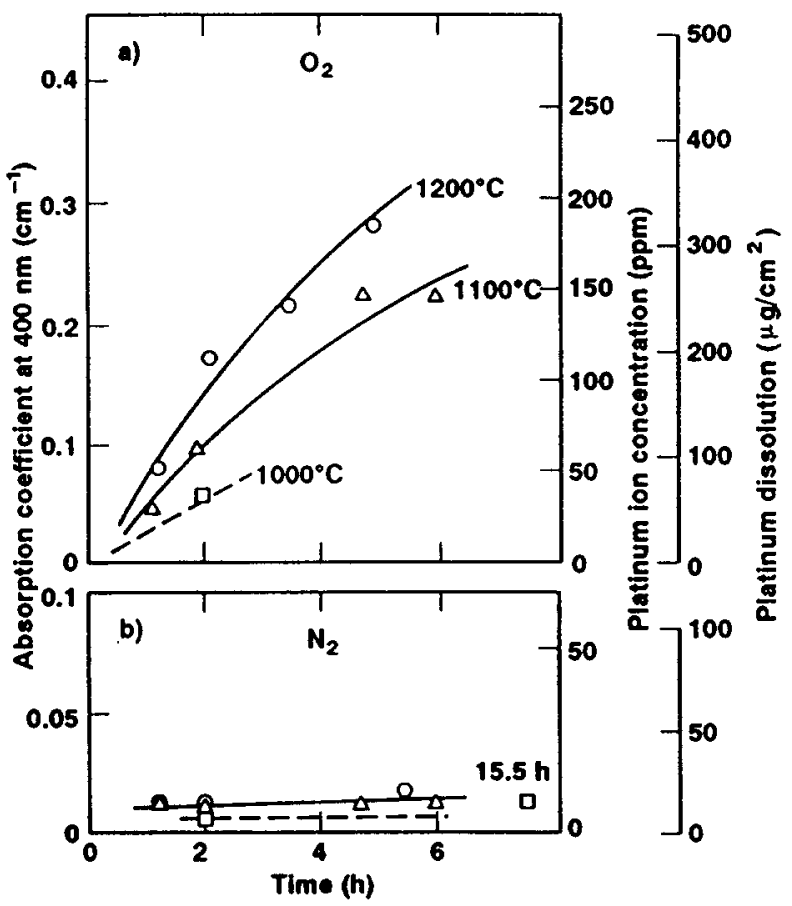

Figures $7 a$ and $b$. Platinum-ion concentration in the melt as a function of time and temperature in melts bubbled with $100 \%$ $\mathrm{O}_{2}$ (figure a) and $100 \% \mathrm{~N}_{2}$ (figure b). $1200^{\circ} \mathrm{C}: \mathrm{O}, 1100^{\circ} \mathrm{C}: \triangle$, $1000^{\circ} \mathrm{C}: \square$.

There are three main conclusions from the described work on LHG-8 glass. First, the oxygen fugacity of the melt has a strong impact on both the platinum-inclusion and ionic platinum concentrations; the greater the oxidizing conditions, the fewer platinum inclusions observed in the melt. Most of the inclusions appear to arrive early in the melting process (similar to that observed in the companion study of LG-750 glass [1] and are dissolved as the melt cycle progresses. The walls of the crucible also dissolve during processing, giving rise to an increased background of ionic platinum much larger than observed from dissolution of just the platinum inclusions (see figure 3b).
A second conclusion is that higher processing temperatures accelerate the dissolution of the platinum inclusions as well as the crucible walls. The result is that the inclusion density decreases but ionic content increases sharply with temperature. As might be expected, the increase in ionic platinum seems to be governed by an Arrhenius process with an activation energy of $\approx 85 \mathrm{~kJ} / \mathrm{mol}$. Decreasing the temperature during the homogenization step has little impact on the inclusion concentration. Since homogenization occurs near the end of the melt cycle, the platinum concentration is still below the solubility limit in LHG-8 glass since no inclusions are precipitated. Any precipitation would be readily apparent since there would be a massive increase in inclusion density. For example, the ionic platinum content in the glass is about 10 to $100 \mathrm{ppm}$ (see figure $3 b)$. If only $1 \%$ of this platinum precipitated (i.e., 0.1 to $1 \mathrm{ppm}$ ), between 2500 and 25000 inclusions $/ 1$ would be produced, far more than observed in these experiments.

Finally, the increase in processing time leads to some increase in ionic platinum content, but, as might be expected, the effect is smaller than that from changes in either process temperature or oxygen fugacity.

\subsection{Platinum-dissolution rate}

Quantifying the rate of dissolution of platinum and its solubility limits in phosphate glass is important for evaluating both the dissolution rate of inclusions as well as the possibility of platinum precipitation during melting. Consequently, a series of experiments was conducted in an attempt to determine both rate and solubility limit in the LHG-8 glass.

In some initial experiments, $\mathrm{H}_{2} \mathrm{PtCl}_{6}$ was added to the glass melt; however, the platinum colloids formed by decomposition of $\mathrm{H}_{2} \mathrm{PtCl}_{6}$ consolidated into large particles with an unknown particle size distribution. Since the dissolution rate of particles varies as $r^{2}$, quantifying the platinum-dissolution rate using this technique is difficult. 
Consequently, the solubility of platinum using a platinum metal plate of known surface area submerged in a fixed volume of molten LHG-8 glass was studied (figure 2) using the procedure outlined in section 2.

The variation of ionic platinum content in the melt as a function of time and temperature is plotted in figures $7 a$ and $b$ for both $\mathrm{O}_{2}$ and $\mathrm{N}_{2}$ bubbling gases. The $\mathrm{O}_{2}$ treatment leads to significant platinum dissolution whereas $\mathrm{N}_{2}$ bubbling shows no increase in the ionic platinum content, even when extended up to $15 \mathrm{~h}$. This correlates with the observation on small-scale melts.

The rate of platinum dissolution for a platinum metal plate is given by Fick's law:

$q=j \cdot A=A D(\nabla C)$,

where $q=$ dissolution rate (in $\mathrm{g} / \mathrm{s}$ ) for the whole plate, $j=$ flux (in $\mathrm{g} /\left(\mathrm{cm}^{2} \cdot \mathrm{s}\right)$ ), $A$ = surface area of the metal plate (in $\mathrm{cm}^{2}$ ), $D=$ diffusion coefficient of $\mathrm{Pt}^{n+}$ in glass (in $\mathrm{cm}^{2} / \mathrm{s}$ ), and $C=$ concentration (in $\mathrm{g} / \mathrm{cm}^{3}$ ). Equation (5) is usually written in terms of a mass transfer coefficient for systems in which convection determines the rate of dissolution:

$q=k_{\mathrm{m}} A\left(C_{\mathrm{S}}-C_{\mathrm{b}}(t)\right)$

where $k_{\mathrm{m}}=$ mass transfer coefficient (in $\mathrm{cm} / \mathrm{s}$ ), $C_{\mathrm{S}}=$ $=$ platinum solubility limit (in $\left.\mathrm{g} / \mathrm{cm}^{3}\right)$, and $C_{\mathrm{b}}(t)=$ timedependent ionic platinum concentration in the bulk glass (in $\mathrm{g} / \mathrm{cm}^{3}$ ).

Although conceptually simple, equation (6) is often difficult to use since $k_{\mathrm{m}}$ might depend in a rather complex (and unpredictable) way on the diffusion coefficient, system geometry, flow rate, etc. Fortunately, some rather simple physical models do exist that relate $k_{\mathrm{m}}$ to the molecular diffusion and fluid flow in a convective system [10]. One of these is the thin-film model that assumes a stagnant film boundary layer near the fluid/solid interface in which the concentration varies linearly across the layer (figure 8). The rate of dissolution is then simply controlled by diffusion across this thin film:

$q=(A D / l)\left(C_{\mathrm{S}}-C_{\mathrm{b}}(t)\right)$

Here the mass transfer coefficient is given by $D / l$ where $D$ is the molecular diffusion coefficient (in $\mathrm{cm}^{2} / \mathrm{s}$ ) and $l$ is the film (boundary layer) thickness (in $\mathrm{cm}$ ). The dissolution rate, $q$, is $V_{\mathrm{m}}\left(\mathrm{d} C_{\mathrm{b}} / \mathrm{d} t\right)$, where $V_{\mathrm{m}}$ is the melt volume (in $\mathrm{cm}^{3}$ ). Equation (7) can be rewritten as

$\frac{\mathrm{d} C_{\mathrm{b}}}{\mathrm{d} t}=\frac{D A}{V_{\mathrm{m}} l}\left(C_{\mathrm{s}}-C_{\mathrm{b}}(t)\right)$,

which, when integrated, leads to the desired expression:

$C_{\mathrm{b}}(t)=C_{\mathrm{S}}\left(1-\exp \left[\frac{-D A t}{V_{\mathrm{m}} l}\right]\right)$

or by taking the logarithm:
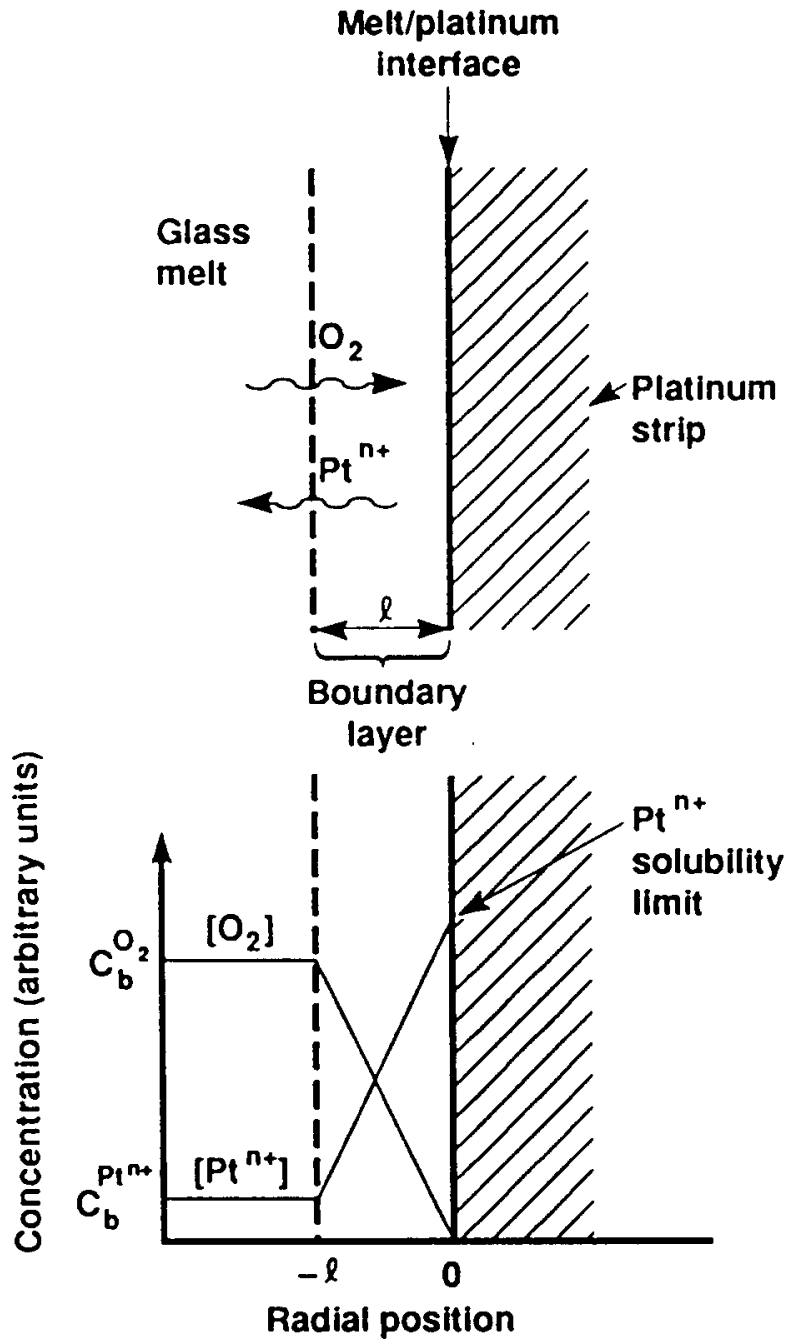

Figure 8. Schematic representation of the simple thin-film model used to analyze the platinum-dissolution data.

$\ln \left[1-\frac{C_{\mathrm{b}}(t)}{C_{\mathrm{s}}}\right]=-\frac{D A t}{V_{\mathrm{m}} l}$

Using equation (10) requires that the platinum solubility limit $\left(C_{S}\right)$ be known; a lower limit for this solubility value was determined at $1100^{\circ} \mathrm{C}$ for a glass melt that was treated for up to $45 \mathrm{~h}$ with 1 bar $\mathrm{O}_{2}$. The platinumion concentration was determined to be about 1050 to $1100 \mathrm{ppm}$ at $1100^{\circ} \mathrm{C}$. (The saturation concentration of $\mathrm{Pt}^{n+}$ might be somewhat higher than this since no platinum inclusions were observed in these melts.) In the analysis that follows, $C_{S} \approx 1070 \mathrm{ppm}$ at $1100^{\circ} \mathrm{C}$ is assumed. This value of $\mathrm{Pt}^{\mathrm{n}}$ is in the range of values observed by Ryder and Rindone [5] in sodium metaphosphate glasses.

As shown in figure 9, a plot of the $\mathrm{Pt}^{n+}$ concentration data at $1100^{\circ} \mathrm{C}$ using equation (10) gives a straight line with the slope, $D A /\left(V_{\mathrm{m}}\right)$, equal to approximately $8.3 \cdot 10^{-6} \mathrm{~s}^{-1}$. From the known values of $A$ and $V_{\mathrm{m}}$, the mass transfer coefficient $\left(k_{\mathrm{m}}=D / l\right)$ is then estimated to be approximately $5.5 \cdot 10^{-6} \mathrm{~cm} / \mathrm{s}$. The bound- 


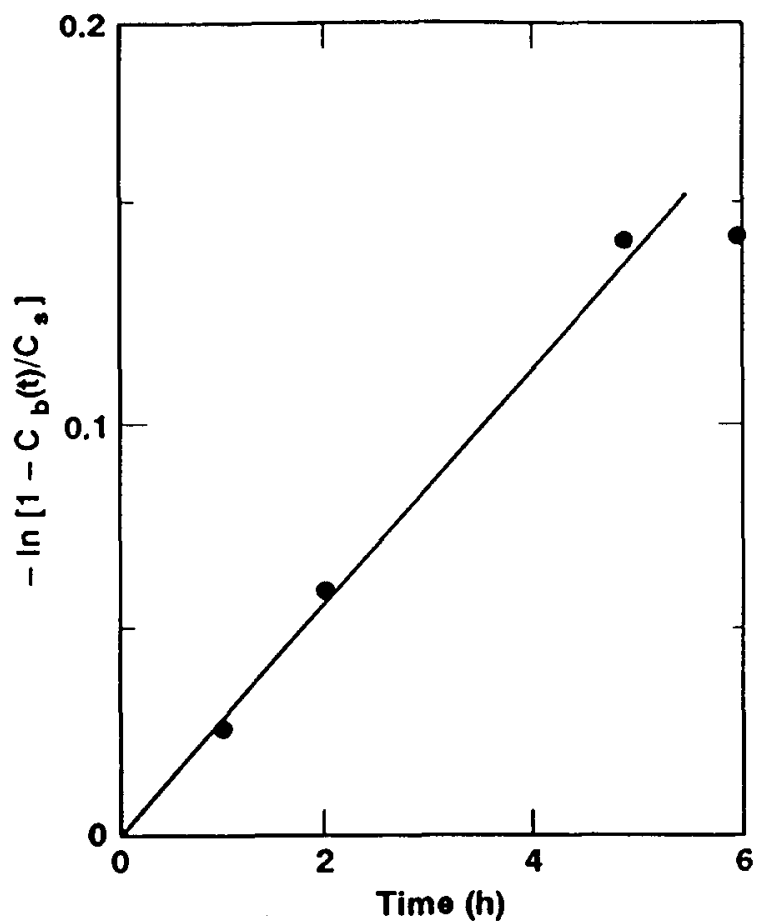

Figure 9. Plot of platinum-plate dissolution data according to the thin-film mass transport model (equation (10)). $V=46 \mathrm{~cm}^{3}$ and $A=70 \mathrm{~cm}^{2} ; k_{\mathrm{m}} A / V=0.030 \mathrm{~h}^{-1}$.

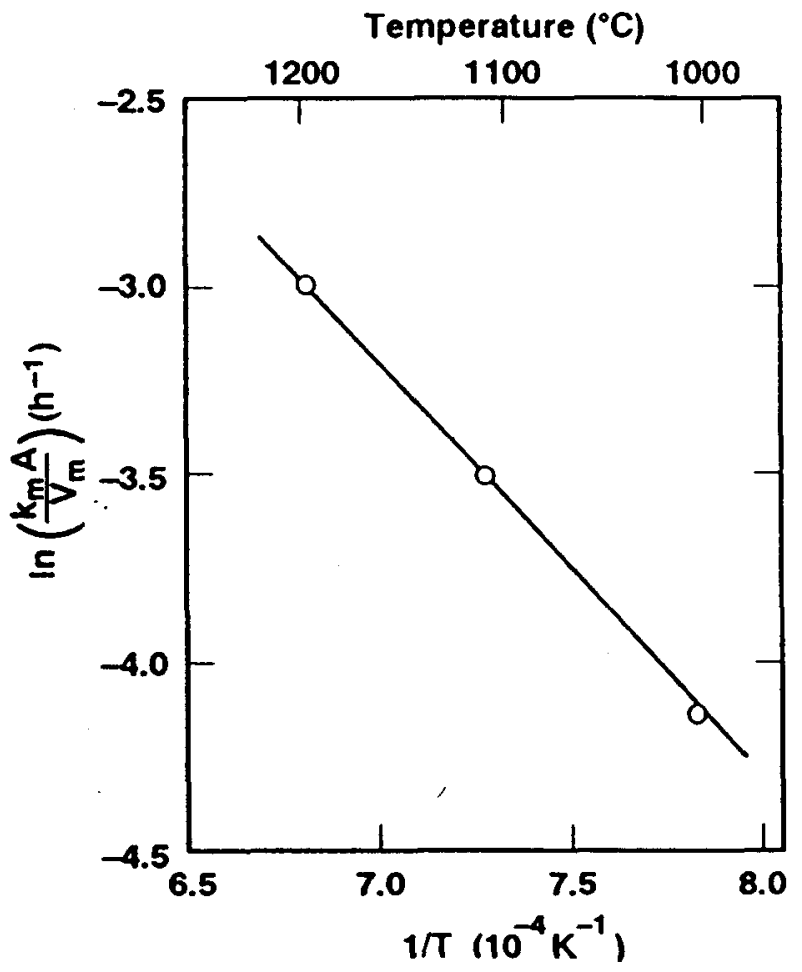

Figure 10. Arrhenius plot of rate constant for platinum dissolution $\left(D A /\left(V_{m} l\right)\right)$ determined from data in figures $7 a$ and $b$. The rate constants are in units of $h^{-1}$.

ary layer thickness is estimated from the literature [10] to be about $10^{-2} \mathrm{~cm}$, implying a diffusion constant of

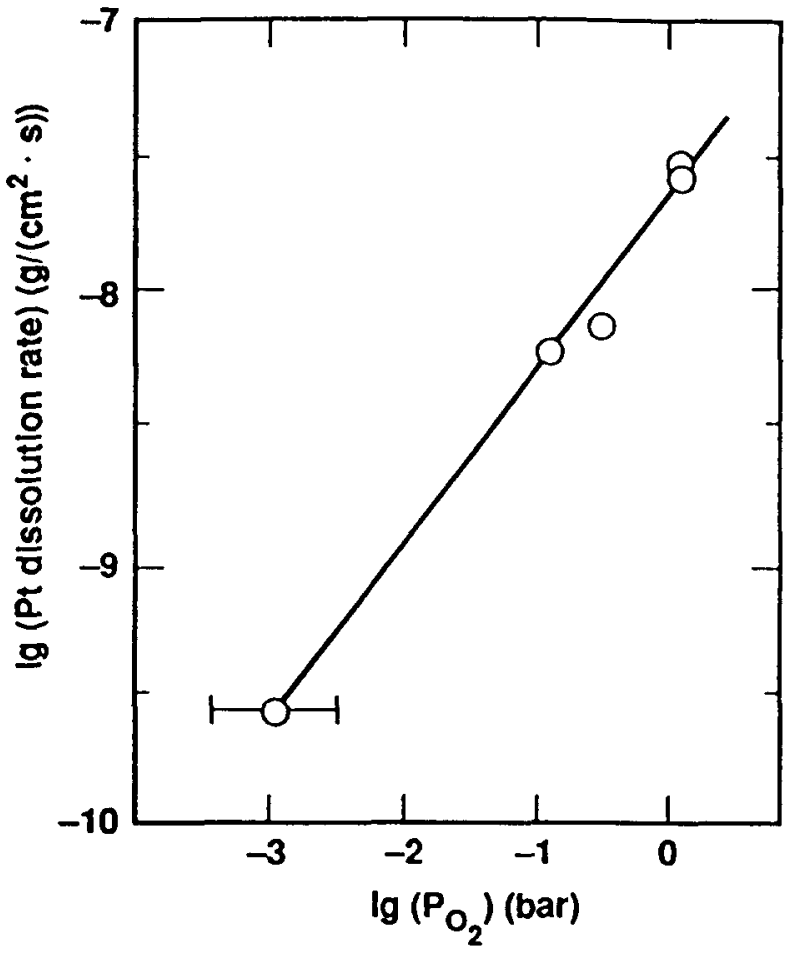

Figure 11. Platinum-dissolution rate in LHG-8 glass at $1200^{\circ} \mathrm{C}$ versus $\mathrm{O}_{2}$ partial pressure in the process gas. The rate is proportional to $\left(P_{\mathrm{O}_{2}}\right)^{0.7}$.

about $5 \cdot 10^{-8} \mathrm{~cm}^{2} / \mathrm{s}$. The $\mathrm{Pt}^{n+}$ diffusion constant can also be estimated from the glass viscosity. The diffusion constants in many liquid systems are inversely proportional to the viscosity and generally range from about 0.5 to $1 \cdot 10^{-5} \mathrm{~cm}^{2} / \mathrm{s}$ for fluid viscosities of 0.001 to $0.005 \mathrm{~Pa} \cdot \mathrm{s}$; (in units common to melting technology, $1 \mathrm{~Pa} \cdot \mathrm{s}=10$ Poise). The viscosity of phosphate laser glass during melting is typically in the range 0.1 to 1.0 Pa $\cdot \mathrm{s}$; thus, a reasonable estimate of the $\mathrm{Pt}^{{ }^{n+}}$ diffusion coefficient is about $10^{-7} \mathrm{~cm}^{2} / \mathrm{s}$. This agrees to within a factor of 2 with the approximate value determined from the mass transfer coefficient.

An Arrhenius plot of the measured rate constants (i.e, $D A /\left(V_{\mathrm{m}} l\right)$ ) versus $1 / T$ gives an activation energy of $88 \mathrm{~kJ} / \mathrm{mol}$ for the platinum-dissolution process (figure 10). Assuming that the change in the boundary layer thickness with temperature is negligible, then the results imply that the activation energy for $\mathrm{Pt}^{n+}$ diffusion is also about $88 \mathrm{~kJ} / \mathrm{mol}$. This activation energy is similar to that for diffusion of non-alkali species in silicate melts and also that for oxygen diffusion in soda-lime-silica glass melts. Thus, although diffusion seems to control the rate of platinum dissolution, whether it is $\mathrm{O}_{2}$ diffusion to the $\mathrm{Pt}^{\circ}$ or $\mathrm{Pt}^{\mathrm{nt}}$ diffusion away from it (or both) that is the rate-controlling step is not clear.

The effect of oxygen partial pressure on the rate of platinum dissolution is shown in figure 11. The melt temperature for these experiments is $1200^{\circ} \mathrm{C}$. The dissolution rate increases dramatically with $\mathrm{O}_{2}$ partial pressure and, for the conditions used in these experiments, can be characterized by the approximate rate expression: 


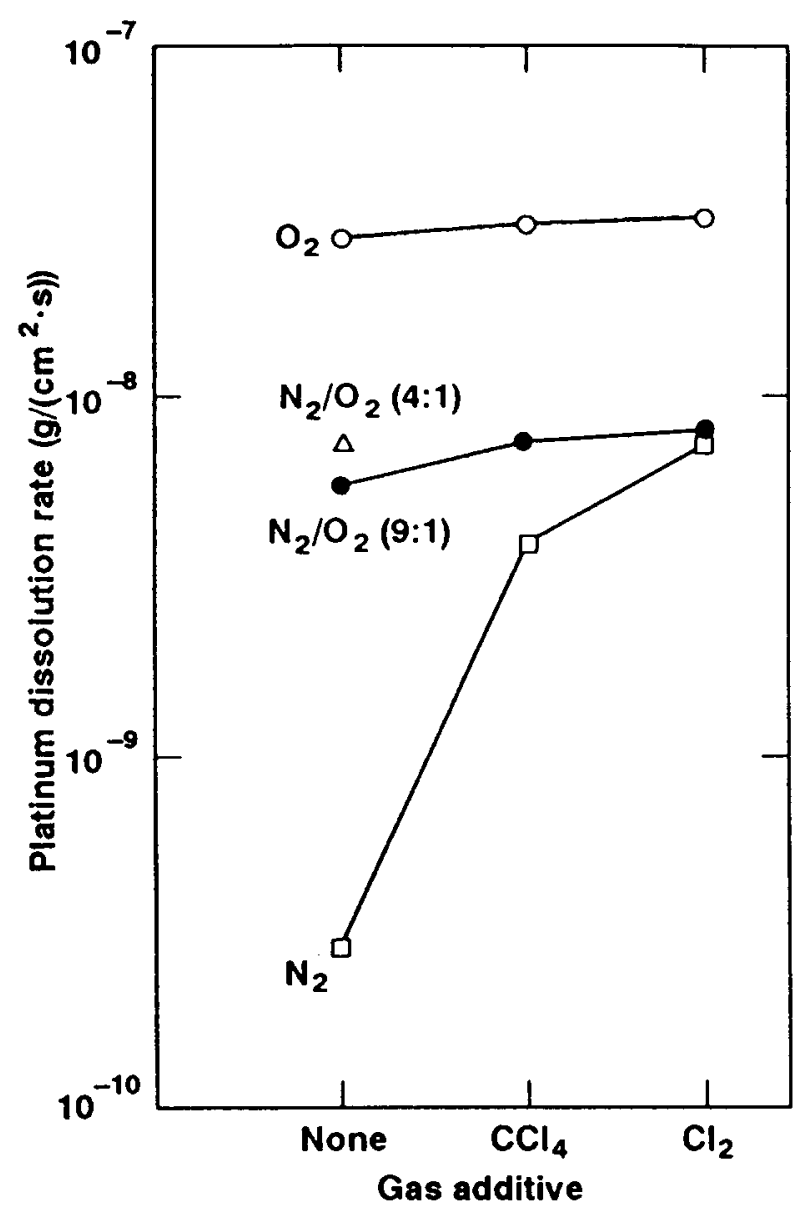

Figure 12. Effect of $\mathrm{Cl}_{2}$ and $\mathrm{CCl}_{4}$ on platinum dissolution when added to various $\mathrm{N}_{2} / \mathrm{O}_{2}$ process gas mixtures; $\mathrm{O}_{2}: \mathrm{O}, \mathrm{N}_{2} / \mathrm{O}_{2}$ in 4:1 ratio: $\Delta, \mathrm{N}_{2} / \mathrm{O}_{2}$ in 9:1 ratio: $O, \mathrm{~N}_{2}: \square$. The glass melt temperature was $1200^{\circ} \mathrm{C}$.

$r_{\mathrm{d}} \approx 3 \cdot 10^{-8}\left(P_{\mathrm{O}_{2}}\right)^{0.7}$

where $r_{\mathrm{d}}$ is the platinum-dissolution rate per unit area of exposed metal (in $\mathrm{g} /\left(\mathrm{cm}^{2} \cdot \mathrm{s}\right)$ ) and $P_{\mathrm{O}_{2}}$ is the oxygen partial pressure given in bar.

One might expect that the platinum-dissolution rate and the number of platinum inclusions appearing in the melt would be inversely related. In other words, the number of platinum inclusions in the melt might be expected to vary as $P_{O_{2}}^{-0.7}$. Note that this prediction is in very good agreement with experimental observation (figures $3 a$ and b). Here the inclusion density in the LHG-8 glass was observed to decrease as $P_{\mathrm{O}_{2}}^{-0.77}$ (equation (3)).

\subsection{Effects of $\mathrm{Cl}_{2}$ on platinum dissolution}

Rindone and Rhoads [4] and Ryder and Rindone [5] reported enhanced platinum dissolution in phosphate glasses with addition of $\mathrm{O}_{2}$ and $\mathrm{Cl}_{2}$. The authors of the present paper also investigated the addition of $\mathrm{Cl}_{2}$ during melting of LHG-8 phosphate laser glass to determine its effect on reducing platinum-inclusion density. Experiments were conducted using both $\mathrm{O}_{2}$ and $\mathrm{Cl}_{2}$ so

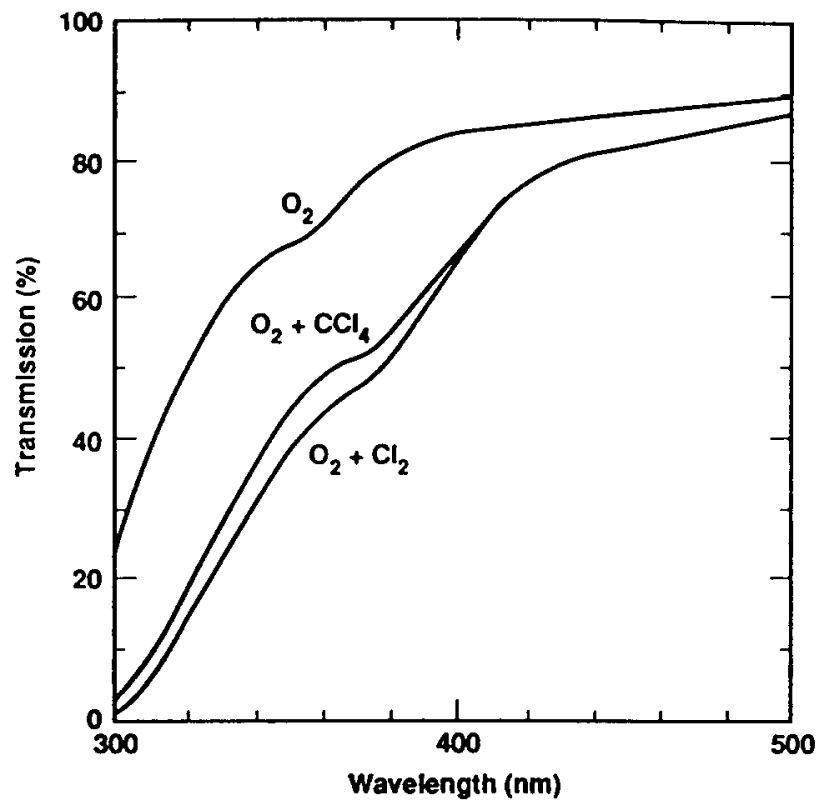

Figure 13. Transmission spectra for LHG-8 phosphate glass melted in the presence of platinum and using $\mathrm{O}_{2}, \mathrm{O}_{2}+\mathrm{Cl}_{2}$, and $\mathrm{O}_{2}+\mathrm{CCl}_{4}$ bubbling gas treatments.

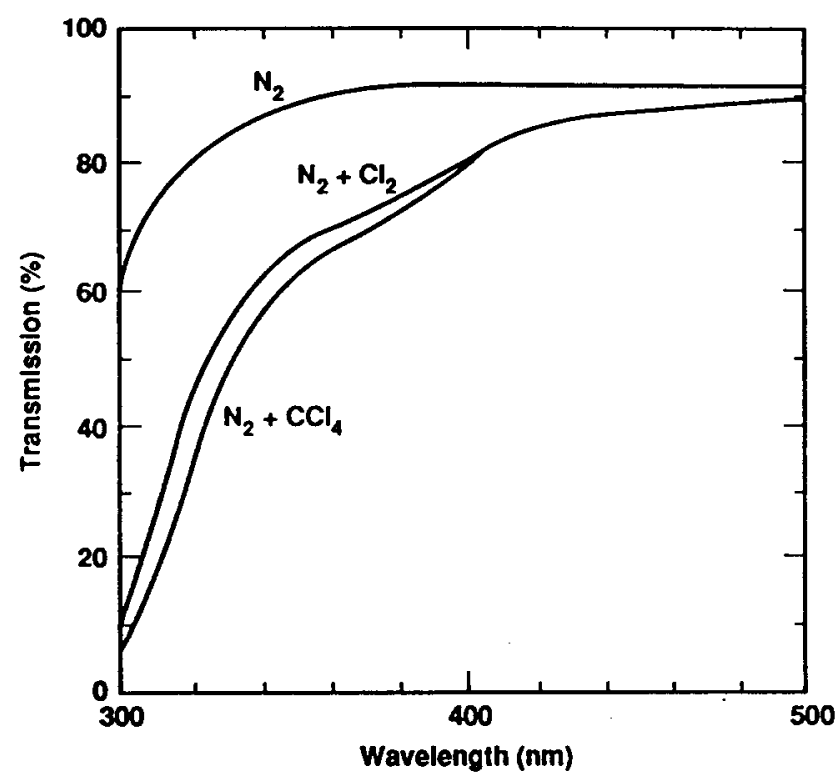

Figure 14. Transmission spectra for LHG-8 phosphate glasses melted in the presence of platinum and using $\mathrm{N}_{2}, \mathrm{~N}_{2}+\mathrm{Cl}_{2}$, and $\mathrm{N}_{2}+\mathrm{CCl}_{4}$ as bubbling gas treatments. Sample thickness $=1.3 \mathrm{~cm}$.

as to directly compare the effects of the two different oxidizing gases. The melting procedure used for these experiments is outlined in section 2.3 .

The effects of $\mathrm{Cl}_{2}$ and $\mathrm{CCl}_{4}$ on platinum dissolution, when added to $\mathrm{N}_{2}, \mathrm{~N}_{2} / \mathrm{O}_{2}: 9 / 1$, or $\mathrm{O}_{2}$ are shown in figure 12. These results show that $\mathrm{Cl}_{2}$ has approximately the same effect on enhancing the dissolution of platinum as does $\mathrm{O}_{2}$. Furthermore, the effect of $\mathrm{CCl}_{4}$ is not as great as that of $\mathrm{Cl}_{2}$ when it is used with $\mathrm{N}_{2}$ alone, probably because of the need for additional $\mathrm{O}_{2}$ to convert $\mathrm{CCl}_{4}$ to $\mathrm{Cl}_{2}$ (equation (2)). Presumably, in the absence 

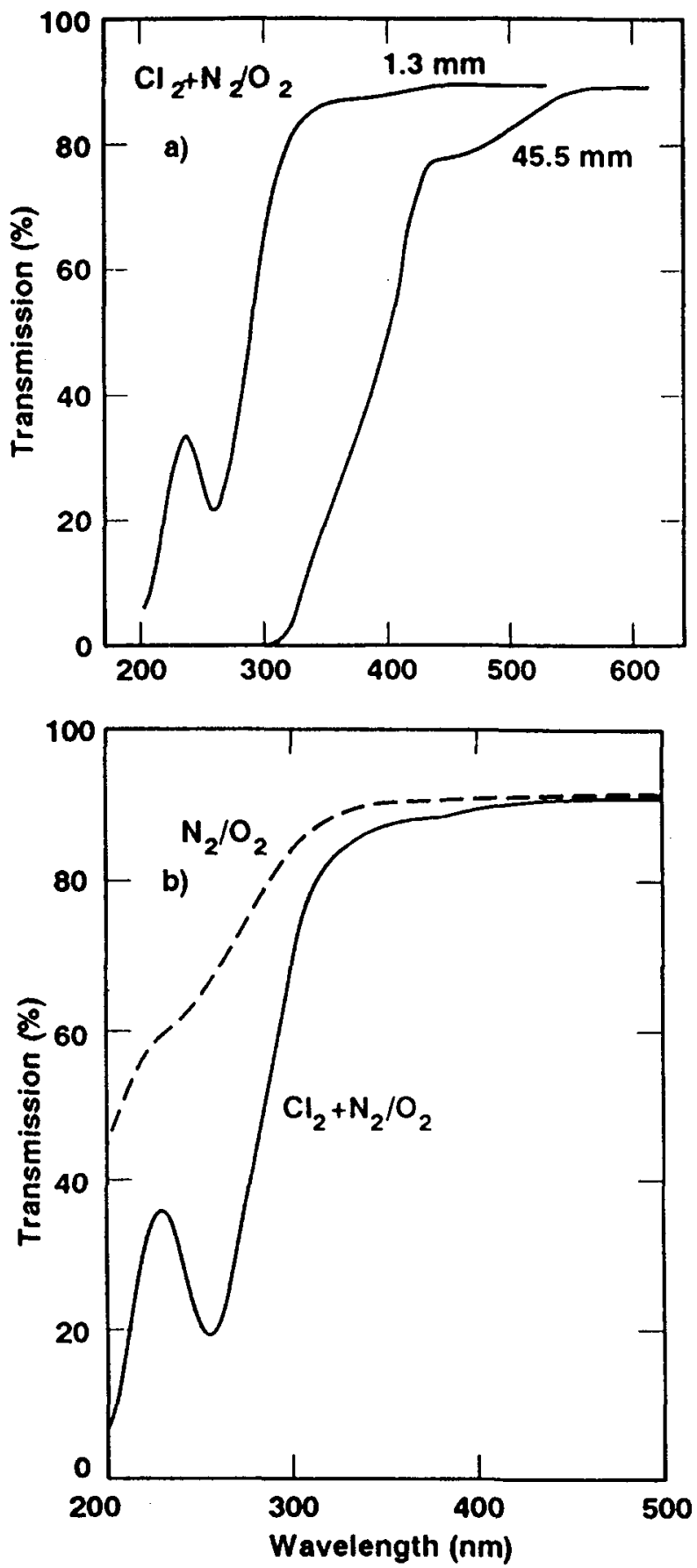

Figures $15 a$ and $b$. Transmission spectra for two different thicknesses of LHG-8 phosphate laser glass melted in the presence of a platinum strip using $\mathrm{Cl}_{2}+\mathrm{N}_{2} / \mathrm{O}_{2}$ gas bubbling treatment (figure a), and for glasses melted using $\mathrm{Cl}_{2}+\mathrm{N}_{2} / \mathrm{O}_{2}$ versus $\mathrm{N}_{2} / \mathrm{O}_{2}$ (figure b) the ratio of $\mathrm{N}_{2} / \mathrm{O}_{2}$ to $\mathrm{Cl}_{2}$ is about $5: 1$ and the sample thickness $=(0.92 \pm 0.02) \mathrm{mm}$.

of added $\mathrm{O}_{2}$ gas, the oxygen must be supplied by the melt. Chlorine has the advantage that it probably also acts as a drying agent for the laser glass. Chlorine is a commonly used drying agent in the manufacture of lowloss optical wave guides (e.g. [11 and 12]).
Figure 13 compares the transmission spectra for glass samples in which $\mathrm{O}_{2}$ and $\mathrm{O}_{2}$ plus either $\mathrm{Cl}_{2}$ or $\mathrm{CCl}_{4}$ (ratio $5: 1$ ) were used as the bubbling gas. The addition of the chlorine gases causes a dramatic increase in absorption in the region below $500 \mathrm{~nm}$. A similar effect is observed for $\mathrm{Cl}_{2}$ and $\mathrm{CCl}_{4}$ addition to $\mathrm{N}_{2}$ (figure 14). The increased absorption probably comes from a combination of two effects: a) the increased dissolution rate of platinum in the glass with use of chlorine-containing gases and b) a red-shift and/or a greater absorption coefficient for the platinum-chlorine complex.

The effect of $\mathrm{Cl}_{2}$ on the $\mathrm{Pt}^{\text {n+ }}$ absorption coefficient at $400 \mathrm{~nm}$ is shown in figures $15 \mathrm{a}$ and $\mathrm{b}$. The addition of $\mathrm{Cl}_{2}$ causes a pronounced increase in the absorption at $400 \mathrm{~nm}$ for a comparable amount of platinum dissolution. $400 \mathrm{~nm}$ is a wavelength limit of interest in laser applications since absorption at wavelengths greater than that degrades the pumping efficiency of the laser. The neodymium-absorption bands that are important to laser energy storage lie in the region 400 to $950 \mathrm{~nm}$. Thus, limits on absorption values at the $400-\mathrm{nm}$ region were set for the glass to be an acceptable laser medium.

To evaluate the stability of the platinum-chlorine complex, a two-stage gas bubbling treatment was conducted. First, the melt containing the platinum strip was treated with a 5:1 mixture of $\mathrm{Cl}_{2}+\mathrm{N}_{2}$ for $2 \mathrm{~h}$ and then the platinum strip was removed. A small sample of this glass melt was then cast. The remainder of the melt was treated with $\mathrm{O}_{2}$ bubbling for $1 \mathrm{~h}$, with no platinum strip in the melt, and was then cast. The absorption due to ionic platinum in the region 300 to $425 \mathrm{~nm}$ was reduced significantly after the second stage of treatment.

The decrease in absorption might be due to either decomposition of the platinum-chlorine complex followed by an associated blue shift or partial vaporization of platinum compounds from the melt or both. Previous work by Izumitani et al. [13] using $\mathrm{POCl}_{3}$ as a $\mathrm{Cl}_{2}$ source suggests that evaporation of a platinum-chlorine complex is indeed likely. Platinum evaporation also seems to have occurred in this study, as indicated by a simple mass balance that compares the measured platinum mass-loss from the strip with the measured amount taken up in the laser glass (table 4). These data indicate that the degree of platinum evaporation from the melt is $20 \%$ or more for the $\mathrm{Cl}_{2}+\mathrm{O}_{2}$ treatment. In general, the degree of platinum evaporation as affected by gas treatment seems to follow the trend:

$\mathrm{Cl}_{2}+\mathrm{O}_{2}>\mathrm{O}_{2}>\mathrm{N}_{2}$

where the degree of vaporization for $\mathrm{N}_{2}$ is almost zero.

The roughly 10 to $20 \%$ observed platinum vaporization (table 4) does not seem sufficient to explain the very large change in transmission near 350 to $400 \mathrm{~nm}$. Consequently, this change in transmission is probably mainly due to a shift in the absorption bands to shorter wavelengths as $\mathrm{Cl}_{2}$ is removed from the melt. 
Table 4. Comparison of platinum weight loss (expressed as ppm in melt) versus measured platinum-ion concentration in the melt ${ }^{10}$ )

\begin{tabular}{lcll}
\hline process gas & $\begin{array}{c}\text { platinum mass } \\
\text { loss in ppm }\end{array}$ & $\begin{array}{l}\text { analyzed platinum } \\
\text { content in ppm }\end{array}$ & $\begin{array}{l}\text { difference } \\
\text { in } \%\end{array}$ \\
\hline $\mathrm{N}_{2} / \mathrm{O}_{2}(9: 1)$ & 16 & 16 & $\approx 0$ \\
$\mathrm{O}_{2}$ & 90 & 82 & $\approx 10$ \\
$\mathrm{O}_{2} / \mathrm{Cl}_{2}(5: 1)$ & 103 & 82 & $\approx 20$ \\
\hline
\end{tabular}

19) The difference between the two is proposed to be lost via evaporation from the melt.

Transmission spectra for a glass treated with $\mathrm{Cl}_{2}+\mathrm{N}_{2} / \mathrm{O}_{2}(9: 1)$ are shown in figures $15 \mathrm{a}$ and $\mathrm{b}$ and contrasted with that of just $\mathrm{N}_{2} / \mathrm{O}_{2}(9: 1)$. A strong absorption band at $\approx 260 \mathrm{~nm}$ is particularly evident. Similar bands in the 260 to $270 \mathrm{~nm}$ region have been reported by Izumitani et al. [13] in their work with $\mathrm{POCl}_{3}$.

In conclusion, $\mathrm{Cl}_{2}$ addition, whether as $\mathrm{Cl}_{2}$ gas or $\mathrm{Cl}_{2}$ liberated from some chlorine-containing compound, increases the platinum-dissolution rate and leads to greater absorption in the region below $450 \mathrm{~nm}$.

\section{Conclusions}

The presence of platinum inclusions in phosphate laser glasses can lead to optical damage when used in highpeak-power lasers. Oxidizing process gas conditions, particularly the use of $100 \% \mathrm{O}_{2}$ or $\mathrm{O}_{2}+\mathrm{Cl}_{2}$ can be used to dissolve the platinum inclusions in Hoya's LHG-8 metaphosphate laser glass. The dissolution rate of platinum is found to be proportional to $\mathrm{PQ}_{2}$. The rate of dissolution is sufficiently fast that, under oxidizing conditions and with modest melt temperatures $\left(1100\right.$ to $\left.1200^{\circ} \mathrm{C}\right)$, nearly all platinum inclusions can be dissolved during the normal glass melting, fining and homogenization cycle. This process has successfully been used to produce large plates of phosphate laser glass ( $Z 71$ ) with an inclusion density less than $0.1 / 1$ [8]. This is a 1000 -fold improvement over glasses made using previous process conditions.
This work was performed under the auspices of the U.S. Department of Energy by Lawrence Livermore National Laboratory under contract number W-7405-ENG-48. The authors also gratefully acknowledge the contributions of Mr. H. Kitayama and Mr. K. Takeuchi, Hoya Corp., Tokyo (Japan), to certain aspects of this work.

\section{References}

[1] Campbell. J. H.; Wallerstein, E. P; Hayden, J. S. et al. Effects of melting conditions on platinum-inclusion content in phosphate laser glasses. Glastech. Ber. Glass Sci. Technol. 68 (1995) no. 1, p. 11-21.

[2] Gonzales, R. P.; Milam, D.: Evolution during multipleshot irradiation of damage surrounding isolated platinum inclusions in phosphate laser glass. In: Laser Induced Damage in Optical Materials. Boulder Damage Symposium, Boulder, CO (USA) 1985. (National Institute of Standards, spec. publ. no. 746, p. 128.)

[3] Pitts, J. H.: Modeling laser damage caused by platinum inclusions in laser glass. In: Laser Induced Damage in $\mathrm{Op}$ tical Materials. Boulder Damage Symposium, Boulder, CO (USA) 1985. (National Institute of Standards, spec. publ. no. 746 , p. 537 .)

[4] Rindone, G. E.; Rhoads, J. L.: The colors of platinum, palladium, and rhodium in simple glasses. J. Am. Ceram. Soc. 39 (1956) no. S, p. 173-180.

[5] Ryder, R. J.; Rindone, G. E.: Color and light scattering of platinum in some lead glasses. J. Am. Ceram. Soc. 41 (1958) no. 10, p. 415-422.

[6] Borisov, A.; Palme, H.; Spettel, B.: The solubility of platinum in silicate melts: experiments under oxidizing conditions. Lunar Planet. Sci. 25 (1994) p. 141-142.

[7] Borisov, A.; Palme, H.; Spettel, B.: Solubility of palladium in silicate melts: implications for core formation in the earth. Geochim. Cosmochim. Acta 57 (1993) p. 1-12.

[8] Campbell. J. H.; Wallerstein, E. P.; Hayden, J. S. et al.: Elimination pf platinum inclusions on phosphate laser glasses. Lawrence Livermore National Laboratory. Report UCRL-53932. 1989.

[9] Hornyak, E. J.; Abendroth, R. P.: Problems of melting laser glass in platinum. Preprint. Toledo, OH (USA): Owens-Illinois, Inc. 1970.

[10] Cussler, E.: Diffusion and mass transfer in fluid systems. Cambridge: Cambridge Univ. Press 1984. p. 230-231.

[11] Nagel, S.; MacChesney, J. B.; Walker, K. L.: An overview of the modified chemical vapor deposition (MCVD) process and performance. IEEE J. Quantum Electron. QE-18 (1982) p. 459-476.

[12] Schultz, P. C.: Vapor phase materials and processes for glass wave guides. In: Bendow, B.; Mitra, S. S. (eds): Fiber optics: Advances in research and development. New York: Plenum Publ. Corp. 1979.

[13] Izumitani, T.; Matsukawai, M.; Miyade, H.: Solubility of Pt in Nd-phosphate laser glass. In: Laser Induced Damage in Optical Materials. Boulder Damage Symposium, Boulder, CO (USA) 1987. (National Institute of Standards and Technology, spec. publ. no. 756, p. 29-34.)

0295P003 


\title{
Modeling platinum-inclusion dissolution in phosphate laser glasses
}

\author{
John H. Campbell \\ Lawrence Livermore National Laboratory, Livermore, CA (USA)
}

\begin{abstract}
An analytic model is developed describing the dissolution of platinum inclusions in LHG-8 and LG-750 metaphosphate laser glasses. The model assumes a spherical geometry and a diffusion-limited rate process in a quiescent fluid. The time for complete dissolution of a platinum inclusion is proportional to the square of the inclusion radius and is computed to be about $10 \mathrm{~h}$ at $1100^{\circ} \mathrm{C}$ for inclusions $10 \mu \mathrm{m}$ in diameter in these glasses. This agrees with experimental results. When melting in a platinum vessel, the dissolution of the crucible walls limits the size of the platinum inclusion that can be dissolved because of the background contribution to the ionic platinum content. This effect is included in the model and is related to the exposed surface-area-to-volume ratio of the platinum vessel.
\end{abstract}

\section{Modell der Auflösung von Platineinschlūssen in Phosphatlaserglāsem}

Es wird ein analytisches Modell entwickelt, das die Auflösung von Platineinschlüssen in LHG-8- und LG-750-Metaphosphatlasergläsern beschreibt. Das Modell setzt Kugelgeometrie und einen durch Diffusion begrenzten Geschwindigkeitsverlauf in einer ruhenden Flūssigkeit voraus. Die Zeit bis zur vollständigen Auflösung eines Platineinschlusses ist proportional dem Quadrat des Radius des Einschlusses; sie wurde für Einschlüsse mit einem Durchmesser von $10 \mu \mathrm{m}$ in diesen Gläsern zu etwa $10 \mathrm{~h}$ bei $1100^{\circ} \mathrm{C}$ errechnet. Dieser Wert stimmt mit experimentellen Ergebnissen überein. Bei der Schmelze in einem Platintiegel ist die GröBe der Platineinschlüsse, die sich noch auflösen lassen, wegen des Beitrages der sich auflösenden Tiegelwände zum ionaren Platingehalt begrenzt. Dieser Effekt wird im Modell berücksichtigt und hängt vom exponierten Oberflächen/Volumenverhältnis des Platintiegels ab.

\section{Introduction}

Platinum inclusions are well known to cause optical damage in glasses used for high-power-laser applications [1 to 3]. In two companion papers [4 and 5] it has been shown that in the case of certain commercial metaphosphate laser glasses (LG-750 from Schott Glass Technologies, Duryea, PA (USA), and LHG-8 from Hoya Corporation, Tokyo (Japan)), these inclusions can be successfully dissolved in the glass matrix using oxidizing gas conditions applied during the course of melting. The inclusions are generally less than $10 \mu \mathrm{m}$ in radius and consequently their dissolution rate is difficult to directly measure. Experiments have been carried out to determine the dissolution rate of a platinum metal sheet in phosphate glasses over a range of temperatures and oxygen partial pressures [5]. What is lacking is a simple model that can be used to estimate the length of time to fully dissolve inclusions under a given set of process conditions.

In this paper a particle dissolution model is developed and used to estimate the rate of platinum-inclusion dissolution with current processing conditions. The model predicts dissolution times of between 2 and $10 \mathrm{~h}$ for 10- to 20- $\mu \mathrm{m}$ diameter platinum particles (typically the maximum size observed in the glass) at a temperature of $1100^{\circ} \mathrm{C}$. This prediction agrees with melt results discussed here and in previous work [5].

Received September 19, 1994.
The analysis is extended to include the dissolution of the crucible walls and a discussion of the implications of crucible dissolution on the ionic platinum content of the glass. The results show that the dissolution of the crucible walls, not the inclusions, dominates ionic content of the glass. This is important in laser applications because the ionic platinum absorbs in the 300 to $450 \mu \mathrm{m}$ region and thereby reduces the flashlamp-pumping efficiencies of the laser glass.

\section{Model of platinum-particle dissolution}

\subsection{Model assumptions}

The model representation of a dissolving platinum particle in a molten glass system (figure 1) includes three major assumptions:

a) The particles (inclusions) can be treated as spheres.

b) The terminal velocity of the particles in the molten glass is very low; thus, the effects of stirring on mass transport to and from the particles can be neglected.

c) The temperature of the system is sufficiently high that molecular diffusion, rather than reaction kinetics, dominates the dissolution process.

Assumption a) is straightforward and does not require further explanation. In assumption b), the flow velocity past the particle is presumed to the slow; therefore, the mass removal rate is controlled by simple molecular diffusion into an infinite reservoir, rather than 


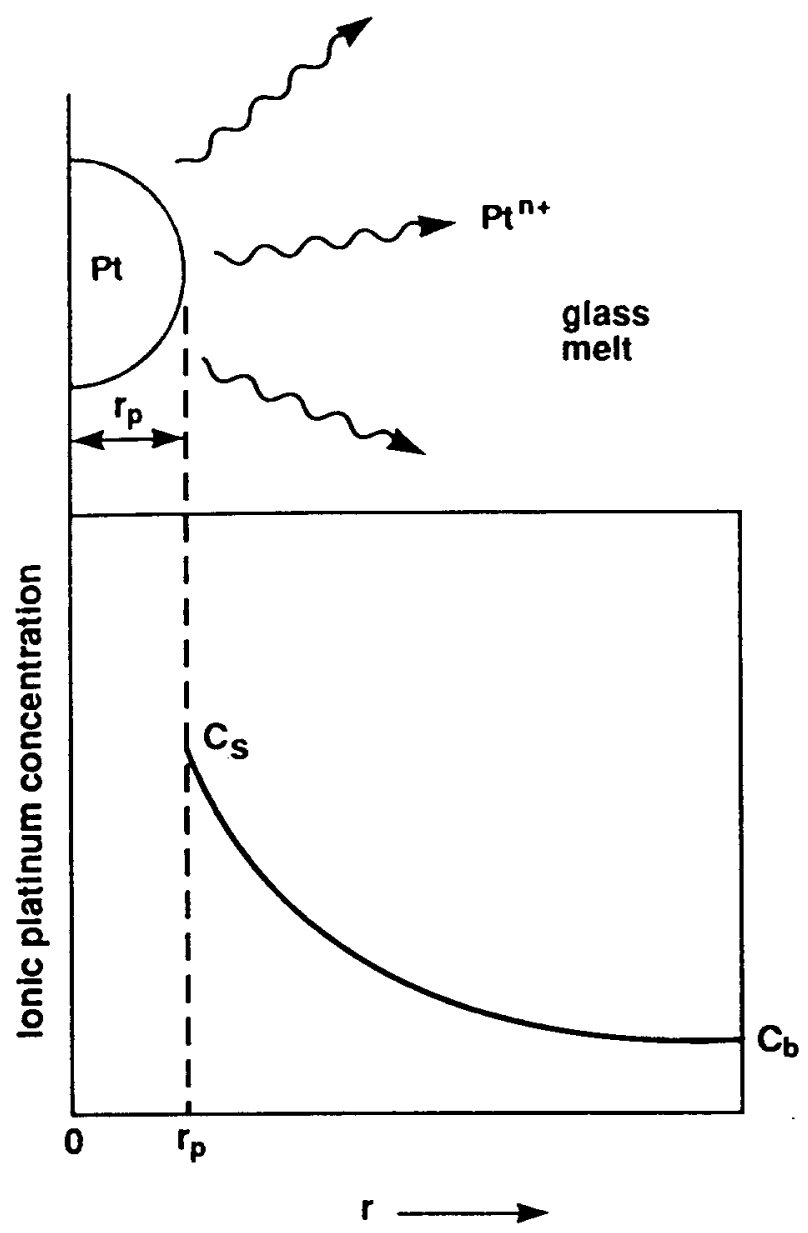

Figure 1. Model representation of platinum-particle dissolution.

by mass transport across some boundary layer. Figure 2 shows the termininal velocity, $v_{t}$, of small, spherical platinum particles in a viscous fluid as a function of particle diameter. These curves are for low Reynolds numbers $(R e \leq 0.5)$ and are governed by the Stokes equation [6]:

$v_{\mathrm{t}}=\frac{g\left(\varrho_{\mathrm{i}}-\varrho_{\mathrm{g}}\right) d_{\mathrm{p}}^{2}}{180 \eta}$

where $d_{\mathrm{p}}=$ particle diameter (in $\mathrm{cm}$ ), $\varrho_{\mathrm{i}}=$ platinum density (in $\mathrm{g} / \mathrm{cm}^{3}$ ), $e_{\mathrm{g}}=$ glass density (in $\mathrm{g} / \mathrm{cm}^{3}$ ), $g=$ gravitational acceleration $\left(=980 \mathrm{~cm} / \mathrm{s}^{2}\right)$, and $\eta=$ glass viscosity (in $\mathrm{Pa} \cdot \mathrm{s}$ ). For a typical phosphate glass melt viscosity of 0.1 to $1.0 \mathrm{~Pa} \cdot \mathrm{s}(1 \mathrm{~Pa} \cdot \mathrm{s}=10$ Poise), the terminal velocity of a $10-\mu \mathrm{m}$-diameter particle is only $10^{-3}$ to $10^{-4} \mathrm{~cm} / \mathrm{s}$, corresponding to a Reynolds number of less than $10^{-6}$. Thus, assumption $b$ ) is valid.

Assumption c) is concerned with the reaction of the $\mathbf{P t}^{\mathbf{0}}$ particle with dissolved oxygen:

$\mathrm{Pt}^{0}+\frac{n}{4} \mathrm{O}_{2} \rightarrow \mathrm{Pt}^{n+}+\frac{n}{2} \mathrm{O}^{2-}$.

In these calculations, the reaction is assumed to be fast and the dissolution rate therefore depends on the rate of

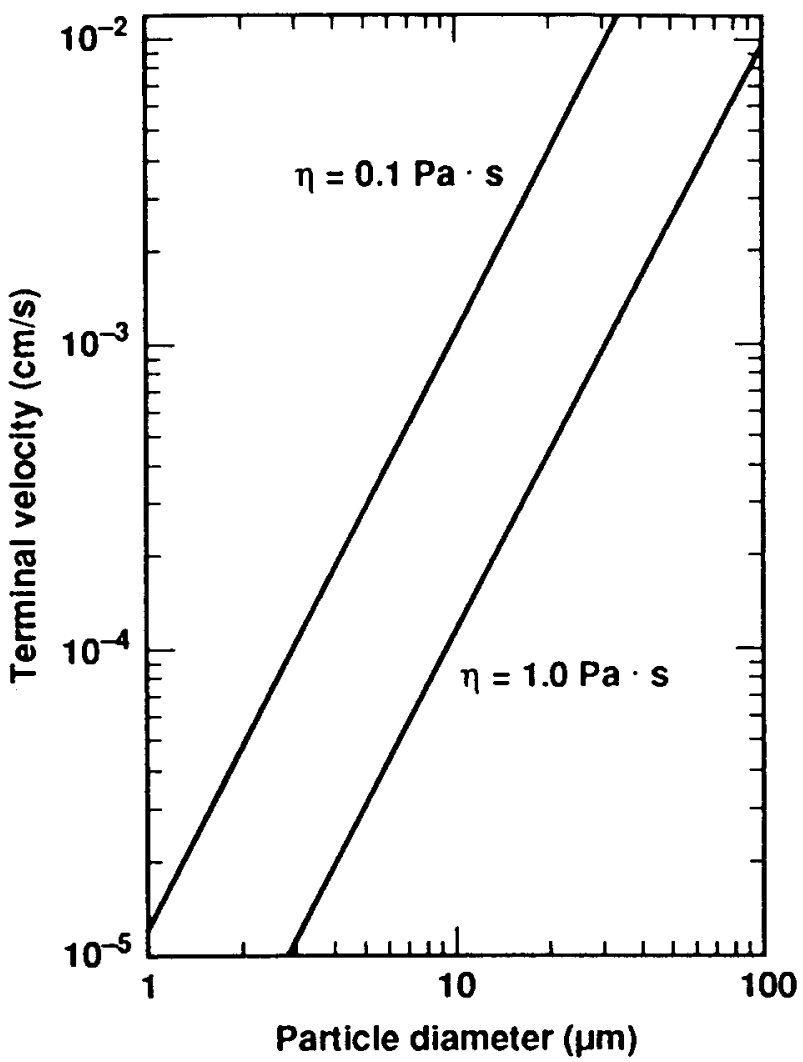

Figure 2. Terminal velocity $\left(v_{t}\right)$ of spherical platinum particle as a function of particle diameter $\left(d_{p}\right)$ at melt viscosities of 0.1 and $1.0 \mathrm{~Pa} \cdot \mathrm{s}$.

diffusion of either $\mathrm{O}_{2}$ toward or $\mathrm{Pt}^{\text {nt }}$ away from the particle surface. At high temperatures, most reactions become diffusion-limited. A good example is carbon oxidation; at high temperatures, the rate at which it burns depends on the rate of diffusion of oxygen to the surface (and $\mathrm{CO}$ and $\mathrm{CO}_{2}$ away from the surface), rather than on the actual reaction rate of $\mathrm{O}_{2}$ with carbon [7].

\subsection{Model description}

With these assumptions, a simple model to predict the dissolution of a platinum inclusion can be developed. The basic differential equation governing diffusion away from a spherical (one-dimensional) particle into an infinite homogeneous medium is

$\frac{\partial C}{\partial t}=\frac{1}{r^{2}}\left[\frac{\partial}{\partial r}\left(D r^{2} \frac{\partial C}{\partial r}\right)\right]$

where $t=$ time (in s), $r=$ radius (in $\mathrm{cm}$ ), $C=$ platinum concentration (in $\mathrm{g} / \mathrm{cm}^{3}$ ), and $D=$ platinum ion diffusion coefficient (in $\mathrm{cm}^{2} / \mathrm{s}$ ).

The concentration of $\mathrm{Pt}^{n+}$ is very dilute, so the diffusion coefficient is assumed to be independent of concentration, thus simplifying equation (3): 
$\frac{\partial C}{\partial t}=\frac{D}{r^{2}}\left[\frac{\partial}{\partial r}\left(r^{2} \frac{\partial C}{\partial r}\right)\right]$.

The boundary conditions governing this system (figure 1) are

$C\left(r_{0}, t\right)=C_{\mathrm{S}}$

and

$C(\infty, t)=C_{\mathrm{b}}$

where $r_{0}=$ radius of the inclusion (in $\mathrm{cm}$ ), $C_{\mathrm{S}}=$ platinum solubility limit (in $\mathrm{g} / \mathrm{cm}^{3}$ ), and $C_{\mathrm{b}}=$ platinum ion concentration in the bulk glass (in $\mathrm{g} / \mathrm{cm}^{3}$ ). For the model to be consistent with the experimental observations, the platinum solubility limit $\left(C_{\mathrm{S}}\right)$ must depend on the oxygen partial pressure. Thus,

$C_{\mathrm{S}}=k_{\mathrm{O}_{2}} P_{\mathrm{O}_{2}}$,

where $k_{\mathrm{O}_{2}}$ is a proportionality constant.

The solution to equations (4 to 7 ) is found in [8] and also in [9]. These authors use a method of variable substitution that converts equation (4) into the more easily soluble equation for a semi-infinite slab. The solution is

$\frac{C(r, t)-C_{\mathrm{b}}}{C_{\mathrm{S}}-C_{\mathrm{b}}}=\frac{r_{0}}{r}\left[1-\operatorname{erf}\left(\frac{r-r_{0}}{(4 D t)^{1 / 2}}\right)\right]$.

The flux of platinum at the inclusion surface is given by Fick's law:

$j=D\left(\frac{\partial C}{\partial r}\right)_{r=r_{0}}$

which, on substitution of equation (8), leads to [8]

$j=\frac{D\left(C_{\mathrm{s}}-C_{\mathrm{b}}\right)}{r_{0}}\left(1+\frac{r_{0}}{(\pi D t)^{1 / 2}}\right)$

Note that the flux becomes essentially constant for $t \geq r^{2} /(\pi D)$. Therefore, only a small fraction of particle mass is removed during the transient phase of the platinum-dissolution process. Consequently, the flux, $j$ (in $\left.\mathrm{g} /\left(\mathrm{cm}^{2} \cdot \mathrm{s}\right)\right)$, from the particle can be accurately estimated as

$j \approx D \frac{C_{\mathrm{S}}-C_{\mathrm{b}}}{r}$

or when expressed in terms of oxygen partial pressure:

$j=\frac{D}{r}\left(k_{\mathrm{O}_{2}} P_{\mathrm{O}_{2}}-C_{\mathrm{b}}\right)$
From equation (12), an analytic expression for the time it takes to completely dissolve a platinum inclusion can be obtained. The volumetric removal rate (in $\mathrm{cm}^{3} / \mathrm{s}$ ) of platinum is

$\frac{\mathrm{d} V_{\mathrm{i}}}{\mathrm{d} t}=\frac{M A_{\mathrm{i}}}{\varrho_{\mathrm{i}}} j=\frac{M}{\varrho_{\mathrm{i}}}\left[4 \pi D\left(C_{\mathrm{S}}-C_{\mathrm{b}}\right)\right]$,

where $V_{\mathrm{i}}=$ volume of platinum inclusion (in $\mathrm{cm}^{3}$ ), $M=$ gram-atomic weight of platinum, $A_{\mathrm{i}}=$ surface area of the inclusion (in $\mathrm{cm}^{2}$ ). The volumetric removal rate is related to the change in particle radius by

$\frac{\mathrm{d} V_{\mathrm{i}}}{\mathrm{d} t}=4 \pi r^{2}\left(\frac{\mathrm{d} r}{\mathrm{~d} t}\right)$

The concentration of platinum in the glass melt $\left(C_{\mathrm{b}}\right)$ increases slowly with time due to dissolution of the platinum crucible walls. A previous work [5] on the dissolution of flat platinum surfaces showed that the platinum concentration in the melt increases with time according to:

$C_{\mathrm{b}}(t)=C_{\mathrm{S}}\left(1-\exp \left[\frac{-D A t}{V l}\right]\right)$

where $V=$ volume of the melt (in $\mathrm{cm}^{3}$ ), $A=$ exposed area of the platinum crucible (in $\mathrm{cm}^{2}$ ) and $l=$ boundary layer thickness (in $\mathrm{cm}$ ).

Combining equations (13 to 15 ) and separating variables gives

$\int_{r_{0}}^{0} r \mathrm{~d} r=\int_{0}^{t_{\mathrm{d}}}\left[\frac{D\left(C_{\mathrm{S}}-C_{\mathrm{b}}(t)\right) M}{\varrho_{\mathrm{i}}}\right] \mathrm{d} t$,

where $C_{\mathrm{b}}(t)$ is given by

$C_{\mathrm{b}}(t)=C_{\mathrm{s}}(1-\exp [-\beta t])$

and $\beta$ is a constant used to represent the term $k_{\mathrm{m}} A / V$ where $k_{\mathrm{m}}$ is the mass transfer coefficient (in $\mathrm{cm} / \mathrm{s}$ ). Integrating equation (16) gives the desired expression for the inclusion-dissolution time $t_{\mathrm{d}}$ :

$t_{\mathrm{d}}=-\frac{1}{\beta} \ln \left(1-\frac{r_{0}^{2} \varrho_{\mathrm{i}} \beta}{2 M D C_{\mathrm{s}}}\right)$

For the special case in which $C_{\mathrm{b}}$ is constant (or zero), then equation (16) can be integrated to give

$t_{\mathrm{d}}=\frac{\varrho_{\mathrm{i}} r_{0}^{2}}{2 D\left(C_{\mathrm{s}}-C_{\mathrm{b}}\right) M}$

The dissolution time in equations (18 and 19) is a function of the square of the inclusion size. 


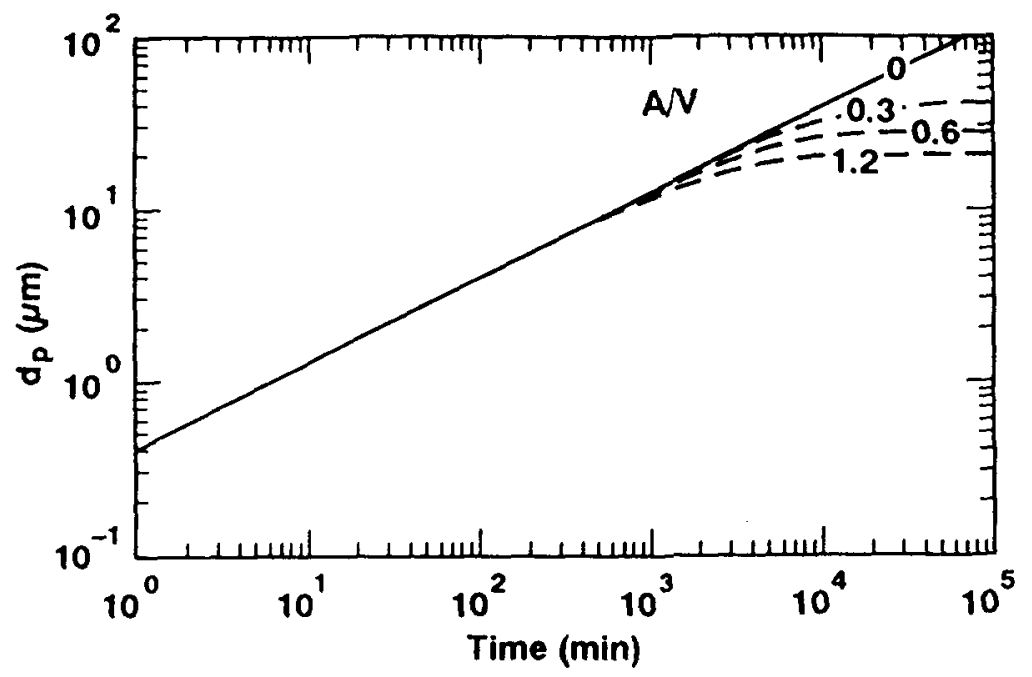

Figure 3. Results from model calculations showing the size of platinum particles that can be dissolved in a given melting time at $1100^{\circ} \mathrm{C}$. The solid line represents the case (equation (19)) in which there is negligible contribution from the crucible walls (for example, by melting in a quartz crucible). The dashed lines are for melts in platinum crucibles (equation (18)) that have different exposed surface-area-to-volume ratios $(A / V)$.

From equation (18), one can calculate the maximum particle size that can be dissolved by noting that this occurs when

$$
\frac{r_{0}^{2} Q_{\mathrm{i}} \beta}{2 C_{\mathrm{S}} M D}=1
$$

Thus, the maximum radius for complete dissolution is

$$
r_{0, \max }=\left(\frac{2 C_{\mathrm{S}} M D}{\varrho_{\mathrm{i}} \beta}\right)^{1 / 2}
$$

\section{Application of model to melt experiments}

\subsection{Half-liter melts}

In this section the model is compared to results from 0.5-1 experimental melts of phosphate laser glasses LHG-8 and LG-750. To use the platinum-inclusion dissolution model described in section 2., one must first estimate the diffusion constant and $\mathbf{P t}^{\text {nt }}$ solubility. Based on the experiments on LHG-8 glass reported in [5], the solubility limit, $C_{S}$, for $\mathrm{Pt}^{n+}$ in phosphate laser glass is about 1050 to $1100 \mathrm{ppm}\left(1 \mathrm{ppm} \mathrm{Pt}^{n+}=\right.$ $=1.46 \cdot 10^{-8} \mathrm{~mole} / \mathrm{cm}^{3}$ ) under typical processing conditions. In these calculations, a solubility limit of $1070 \mathrm{ppm}$ was assumed. For LHG-8 and LG-750 phosphate laser glasses melted in platinum crucibles, the concentration of $\mathrm{Pt}^{n+}$ in the final bulk glass $\left(C_{\mathrm{b}}\right)$ has been measured and typically has been found to be $\approx 100 \mathrm{ppm}$ for oxidizing conditions, thus they are far from saturation.

From equation (15), the increase in $\mathrm{Pt}^{\text {nt }}$ concentration (in ppm) in the melt at $1100^{\circ} \mathrm{C}$ is given by:

$$
C_{\mathrm{b}}(t)=1070\left(1-\exp \left[-5.5 \cdot 10^{-6}(A \cdot t / V)\right]\right) .
$$

For $0.5-1$ experimental melts, $A / V$ is approximately 0.6 , giving $\beta$ of $3.4 \cdot 10^{-6} \mathrm{~s}^{-1}$. Substituting this into equation (18) and assuming a $\mathrm{Pt}^{n+}$ diffusion constant of $10^{-7} \mathrm{~cm}^{2} / \mathrm{s} \mathrm{[5]} \mathrm{leads} \mathrm{to} \mathrm{the} \mathrm{following} \mathrm{expression} \mathrm{for} \mathrm{the}$ inclusion-dissolution time in the experimental melts: $t_{\mathrm{d}}=-\frac{1}{\beta} \ln \left(1-k r_{0}^{2}\right)$,

where $k$ (i.e., $\left.\varrho_{\mathrm{i}} \beta /\left(2 M D C_{\mathrm{S}}\right)\right)=1.1 \cdot 10^{5} \mathrm{~cm}^{-2}$. A plot of $t_{\mathrm{d}}$ versus $r_{0}$ is shown in figure 3. Also plotted is equation (19), for which $C_{\mathrm{b}}$ is assumed to be $\approx 0$ (i.e., platinuminclusion dissolution in a quartz or other nonplatinum crucible).

Unfortunately, platinum-particle dissolution rates are experimentally difficult to measure. Therefore, in the experiments only approximate dissolution times were obtained for a rather broad range of platinum-particle sizes. In one set of experiments, LG-750 premelts were doped with $1 \mathrm{ppm}$ of platinum (added as potassium chloroplatinate, which decomposes to metallic $\mathrm{Pt}^{0}$ ). The LG-750 premelt was prepared in a nitrogen atmosphere such that initially there was negligible platinum dissolution. The premelt was conducted in a quartz crucible. Although the exact particle size and density in the premelt could not be obtained, more than 30000 roughly spherical platinum particles existed in the 0.5-1 casting, with a size distribution up to about 10 to $20 \mu \mathrm{m}$. Next, the glass was remelted in a quartz crucible in an oxygen atmosphere at $\approx 1300^{\circ} \mathrm{C}$ for $4 \mathrm{~h}$. This melting reduced the particle count to $\approx 300 / 1$, indicating dissolution of most of the $\mathrm{Pt}^{0}$ particles. Note that the complete dissolution time predicted using the model (figure 3 ) is about $6 \mathrm{~h}$ for a $10-\mu \mathrm{m}$ particle, which is in reasonable agreement with the LG-750 melt experiments.

A second, similar set of experiments was also conducted on LHG-8 glass. In this case, a cullet was made from a laser glass with many $\mathrm{Pt}^{0}$ inclusions. The size of the inclusions was estimated to be less than or equal to about $10 \mu \mathrm{m}$. Various oxidizing conditions were then used in remelting the glass. All melts were done in a quartz crucible. Increasing the oxygen partial pressure accelerated the dissolution rate, and complete dissolution of the particles occurred in less than $4 \mathrm{~h}$ in a pure $\mathrm{O}_{2}$ atmosphere. This is also in reasonable agreement with the model predictions. 


\subsection{Dissolution of platinum-crucible walls}

A schematic representation of the platinum-crucible system during the melt cycle is shown in figure 4; this system is essentially a stirred-tank reactor. Because of the slight solubility of platinum in the glass, some platinum dissolution takes place at the crucible walls.

The equations governing the dissolution of the crucible walls are the same as those developed to describe the dissolution of a platinum plate [5].

The increase in platinum concentration is given by equation (15) where, for this particular case, $A$ is the area of the crucible that is exposed to the glass melt. Equation (15) shows that the lower the surface area-to-volume ratio, the slower the build-up of platinum in the melt. This suggests that large melts (low $A / V$ ratio) would have lower ionic platinum contents. However, in general, the melt cycle is longer for larger volume melts, which might off-set some or all of the advantage of the surface area-to-volume effect.

One might intuitively think that any attempts to dissolve a 5 to $10-\mu \mathrm{m}$-radius platinum particle would also result in dissolution of roughly $S$ to $10 \mu \mathrm{m}$ of the platinum crucible container. However, results from large LG-750 and LHG-8 glass melts show that this is not the case [4 and 5]. Particles with diameters of 10 to $20 \mu \mathrm{m}$ were dissolved while removing only $\approx 1 \mu \mathrm{m}$ of platinum from the crucible walls. (This $1-\mu \mathrm{m}$ estimate is based on the observed $\mathrm{Pt}^{\text {nt }}$ content of the glass.) Nevertheless, greater than $99 \%$ of the ionic platinum in the glass comes from the crucible walls because of the large relative area of the crucible compared with that of the $\mathbf{P t}^{\mathbf{0}}$ particles.

This apparent contradiction between dissolution rates for the crucible walls and platinum particles can be resolved by comparing fluxes (in $\mathrm{g} /\left(\mathrm{cm}^{2} \cdot \mathrm{s}\right.$ )) at the wall and particle surfaces:

particle flux $=j_{\mathrm{p}}=\frac{D}{r_{\mathrm{p}}}\left(C_{\mathrm{s}}-C_{\mathrm{b}}\right)$,

and

wall flux $=j_{\mathrm{w}}=\frac{D}{l}\left(C_{\mathrm{s}}-C_{\mathrm{b}}\right)$,

where $l=$ boundary layer thickness and $r_{\mathrm{p}}=$ radius of the particle. Thus, the ratio of the flux at the crucible wall to the flux at the particle surface is

$\frac{j_{\mathrm{w}}}{j_{\mathrm{p}}} \sim \frac{r_{\mathrm{p}}}{l}$

The boundary layer thickness is estimated to be 100 to $200 \mu \mathrm{m}$; therefore, for a 5 to 10 - $\mu \mathrm{m}$-radius particle, the predicted flux from the wall should only be $\approx 5$ to $10 \%$ of the flux from the particle. Thus, less than $1 \mu \mathrm{m}$ of crucible wall should be dissolved in the same period for complete dissolution of a 10 - to $20-\mu \mathrm{m}$-diameter inclusion, which agrees with the experimental data.

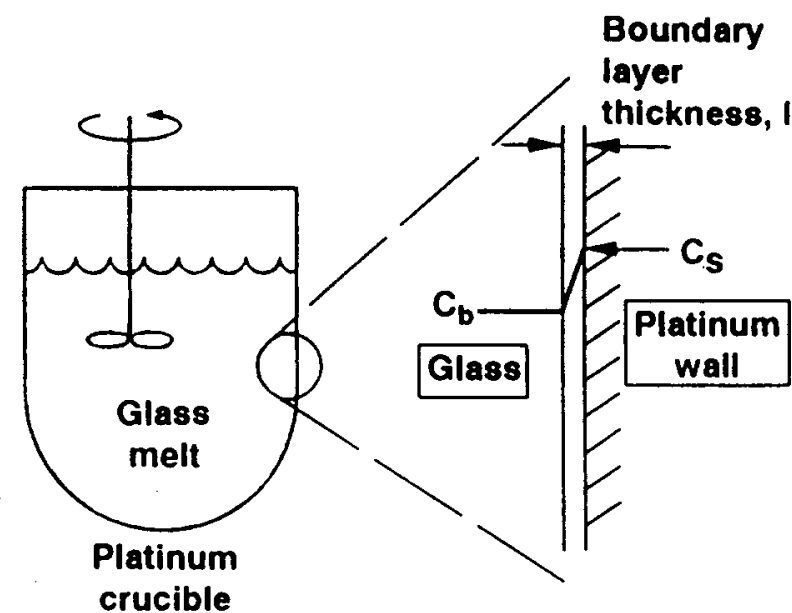

Figure 4. Schematic representation of platinum crucible wall dissolution.

\subsection{Effect of temperature on platinum-dissolution rate}

Raising the temperature of the melt should increase the inclusion-dissolution rate for two reasons: a) diffusion is an activated process and therefore generally follows an Arrhenius temperature dependence, increasing with temperature as $\exp \left(-E_{\mathrm{d}} / R T\right)$, where $E_{\mathrm{d}}$ is the associated activation energy; and $b$ ) the solubility also generally increases with temperature according to a similar expression, $\exp \left(-\Delta H_{\mathrm{s}} / R T\right)$, where $\Delta H_{\mathrm{s}}$ is the enthalpy of solution. Therefore, one would expect the particle and wall dissolution fluxes to have the following approximate temperature dependence:

$$
\begin{aligned}
J & \sim D\left(C_{\mathrm{S}}-C_{\mathrm{b}}\right) / l \\
& \sim \frac{D_{0}}{. l} \exp \left(-\frac{E_{\mathrm{d}}}{R T}\right)\left[C_{0} \exp \left(-\frac{\Delta H_{\mathrm{s}}}{R T}\right)-C_{\mathrm{b}}\right],
\end{aligned}
$$

where

$D=D_{0} \exp \left(-E_{\mathrm{d}} /(R T)\right)$

and

$C_{\mathrm{S}}=C_{0} \exp \left(-\frac{\Delta H_{s}}{R T}\right)$

where $D_{0}$ and $C_{0}=$ constants. Equation (27) shows that an increase in temperature should dramatically increase the dissolution rate.

The activation energy for the dissolution rate of platinum in LG-750 and LHG-8 glasses has been measured to be about 80 to $120 \mathrm{~kJ} / \mathrm{mol}$ [4 and 5]. Furthermore, some preliminary data on platinum solubility versus temperature for the LHG-8 glass showed that, over the range of interest $\left(\approx 1000\right.$ to $\left.1200^{\circ} \mathrm{C}\right)$, the solubility 
limit $C_{\mathrm{S}}$ changes rather slowly, which implies a low value for $\Delta H_{s}$. Thus, the temperature dependence of the dissolution rate is primarily dependent on the diffusion constant and scales approximately as

$j \sim \exp (-B / T)$

where $B$ is a constant with a value between about 10000 and $15000 \mathrm{~K}$.

\section{Conclusions}

The dissolution time of platinum inclusions in molten LHG-8 and LG-750 phosphate laser glasses can be estimated from equations (18 and 19). Under the nominal melt conditions used for commercial phosphate laser glasses, this time is estimated to be about $10 \mathrm{~h}$ for the maximum inclusion size $(10 \mu \mathrm{m})$ typically observed in the glass. The dissolution time is inversely proportional to the platinum-solubility limit and therefore is greatly reduced when using oxidizing conditions in phosphate glasses. The inherent low solubility of platinum in silicate glasses, even under oxidizing conditions, explains why these glasses have not been successfully manufactured inclusion-free.

When melting in a platinum container, the background contribution of ionic platinum from dissolution of the crucible walls limits the size of the inclusion that can be dissolved to less than $50 \mu \mathrm{m}$ for most practical crucible designs.
The many helpful discussions with Dr. H. Toratani at Hoya Corporation, Tokyo (Japan), and Dr. J. S. Hayden at Schott Glass Technologies, Duryea, PA (USA), are gratefully acknowledged.

This work was performed under the auspices of the U.S. Department of Energy by Lawrence Livermore National Laboratory under Contract No. W-7405-ENG-48.

\section{References}

[1] Gonzales, R. P.; Milam D.: Evolution during multiple-shot irradiation of damage surrounding isolated platinum inclusions in phosphate laser glass. In: Laser Induced Damage in Optical Materials. Boulder Damage Symposium, Boulder, CO (USA) 1985. p. 128.

[2] Pitts, J. H.: Modeling laser damage caused by platinum inclusions in laser glass. In: Laser Induced Damage in Optical Materials. Boulder Damage Symposium, Boulder, CO (USA) 1985. p. 537.

[3] Campbell, J. H.; Wallerstein, E. P.; Hayden, J. S. et al.: Elimination of platinum inclusions in phosphate laser glasses. Lawrence Livermore National Laboratory. Report UCRL-53932. 1989.

[4] Campbell, J. H.; Wallerstein, E. P.; Hayden, J. S. et al.: Effects of melting conditions on platinum-inclusion content in phosphate laser glasses. Glastech. Ber. Glass Sci. Technol. 68 (1995) no. 1, p. 11-21.

[5] Campbell, J. H.; Wallerstein, E. P.; Toratani, H. et al.: Effects of process gas environment on platinum-inclusion density and dissolution rate in phosphate laser glasses. Glastech. Ber. Glass Sci. Technol. 68 (1995) no. 2, p. 59-69.

[6] Kunii, D.; Levenspiel, O.: Fluidization engineering. Huntington, NY: Krieger 1977. p. 76.

[7] Levenspiel, O.: Chemical reaction engineering. 2nd ed. New York (et al.): Wiley 1972.

[8] Crank, J.: The mathematics of diffusion. 2nd ed. Oxford: Clarendon Press 1975.

[9] Carslaw, H. S.; Jaeger, J. C.: Conduction of heat in solids. Oxford: Clarendon Press 1975. p. 89.

$0395 \mathrm{P} 004$ 


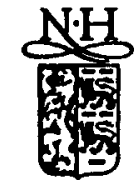

ELSEVIER

\title{
Surface tensile layer generation during thermal annealing of phosphate glass
}

\author{
J.S. Hayden ${ }^{\text {a,* }}$, A.J. Marker III ${ }^{a}$, T.I. Suratwala ${ }^{b}$, J.H. Campbell ${ }^{b}$ \\ - Schott Glass Tecturologies, Inc, 400 York Averwue, Duryea, PA 18642, USA \\ - Lawrence Lwermore National Laboracory, P.O. Box 808, Livermore, CA 94551, USA
}

\begin{abstract}
Surface tensile layers (up to $20 \mathrm{MPa}$ ) are generated during thermal annealing of metaphosphate glass in ambient air. The surface tensile stress is caused by changes in properties of the phosphate glass, particularty the glass transition temperature and the coefficient of thermal expansion, due to the glass reaction with water vapor and diffusion of $\mathrm{OH}$ groups into the region just below the surface $(<2 \mathrm{~mm})$. An increase in the OH content of the glass from about 80 to 5000 ppmw causes a decrease in the glass transition temperature from 468 to $405^{\circ} \mathrm{C}$ and an increase in the linear thermal expansion coefficient from 12.9 to $14.2 \times 10^{-6} \mathrm{~K}^{-1}$. A mechanism for the generation of the tensile surface layer is proposed and simulated experimentally by fusion-bonding at $500^{\circ} \mathrm{C}$ two samples of the same composition but with $\mathrm{OH}$ contents that differ by up to 50 . The stresses in the annealed fusion-bondod samples are determined from measured stress birefringence. Peak tensile stresses calculated by finite element analysis agree with measured values to within 30\%. 2000 Elsevier Science B.V. All rights reserved.
\end{abstract}

\section{Introduction}

Nd-doped meta-phosphate laser glasses are the preferred gain medium for use in high-peak-power lasers for fusion energy research [1,2]. Fusion lasers currently under construction $[3,4]$ will have output energies of nearly $2 \mathrm{MJ}$ and each requires more than 3000 slabs of laser glass; cach slab is nearly $81 \times 46 \times 4 \mathrm{~cm}^{3}$ in size and contain approximately 151 of glass. The phosphate glass slabs needed for these laser gystems can be made by either discontinuous or continuous melting processes [1]. In either case, the glass exiting the melter

\footnotetext{
Corresponding author. Tel.: +1-570 457 7485; fax: +1-570 4576960.

E-mail addrese: fhayden arachottedastechcom (J.S. Hayden).
}

system is formed into castings large enough to yield finished opties of the required size and shape; these castings are then thermally annealed [1].

Following thermal annealing, as-formed phosphate laser slabs are often observed to have surfaces with large tensile stresses. This is in contrast to most as-formed silicate glasses that exhibit compressive surface layers [S] after a similar annealing cycle. Tensile surfaces, in combination with available crack nucleation points, can result in the development of a network of shallow surface cracks. Surface cracks can become a production yield issue if they propagate and cause catastrophic fracture of processed glass.

The development of compressive surface stresses as a result of annealing, typically observed in silicate glasses, is well understood [J]. In brief, as the produced glass cools, a parabolic temperature

0022-3093001s - ee front matter \& 2000 Eleevier Science B.V. All rights reserved.

PUI: $50022-3093(99) 00672-9$ 
gradient is created through the glass with the surface temperature less than the interior. At temperatures above the glass transition temperature, $T_{2}$, stresses are relaxed by viscous flow. Once the glass cools below $T_{z}$, the thermal gradient through the glass causes a temporary stress with tension on the surface and compression in the interior simply because the surface has cooled more (i.e. shrunk more) than the interior. When the glass reaches room temperature, the thermal gradients are eventually removed and so are the temporary tensile stresses at the surface. The source of the residual surface compressive forces in silicate glasses can be traced to events near $T_{\boldsymbol{B}}$. Specifically, at temperatures near $T_{z}$, the glass relaxes (L.e. undergoes viscous flow) to yield a reduction in some of the temporary stress that is generated by the cooling-induced thermal gradient through the glass. Subsequently, what remains in the glass at room temperature is a permanent stress that is equal and opposite to the temporary stress relaxation that occurred near $T_{g}$. The result is a surface under compression and the interior under tension [5].

In contrast to the above mechanism, the formation of a tensile surface layer observed in phosphate glasses is different and the elucidation of the mechanism for this tensile layer formation is the purpose of this study. We show that water vapor from the atmosphere diffuses into the surface of the formed glass and significantly alters the properties of the surface. The result is that the OH-containing glass near the surface shrinks more than the interior and a tensile surface layer develops.

In this paper, we first describe some of the properties of the tensile layer and surface fractures in annealed phosphate glass slabs. Then we propose a mechanism for the generation of a tensile layer on phosphate glass surfaces based on the different shrinkage characteristics of the surface and interior of the glass. To illustrate the mochanism, fused laminates are made of two metaphosphate giass plates with the same composition but different OH contents and the maximum stresses near the laminate interface are measured. These stresses are compared with those predicted by finite element analysis (FEA). Finally, we discuss how stresses can be reduced or eliminated in annealed glass slabs.

2. Properties of observed tensile layer and surface fractures

Laser glasses are typically formed into large slabs of a near-rectangular shape (approximately $100 \times 50 \times 6 \mathrm{~cm}^{3}$ ) by pouring into a steel mold at completion of the discontinuous melt process [1]. The casting is then placed, while still above $T_{z}$, into an annealing oven that is also at a temperature just above $T_{8}$. The glass is then annealed at a cooling rate of $\leqslant 30^{\circ} \mathrm{C} / \mathrm{h}$ producing a glass with a stress at room temperature of $\leqslant 2 \mathrm{MPa}$ allowing it to be cut, polished and inspected. This glass blank is then annealed again at a slower rate ( $10-20^{\circ} \mathrm{C} /$ day) [1] to reduce stresses to a point that the birefringence is less than $5 \mathrm{~nm} / \mathrm{cm}(\leqslant 0.25$ MPa).

After the first annealing cycle, phosphate glass slabs often have cracks on the as-cast surfaces. Two types of crack patterns are frequently observed, which we term Type I and Type II cracks. Type I cracks, sometimes referred to as spider-web cracks because of their general appearance, cover nearly the entire top and side surfaces of castings. The areal density of cracks can vary and crack separation distances can be as small as a few millimeters. Also, Type I cracks rarely penetrate more than a few millimeters into the casting. The effected glass is normally removed in subsequent surface finishing (e.g. Blanchard grinding) and generally Type I cracking does not lead directly to catastrophic fracture.

Type II cracks are larger and often extend from the edges and sides of the casting into its center region and, on occasion, through the full casting thickness. Because Type II cracks penetrate a large fraction of the thickness of a casting, they make the product unusable.

Analysis of fractured glass surfaces, using a microscope equipped with polarizers and a compensating prism, indicates that there exists a surface tensile layer along the top, side, and to a lesser extent, the bottom surfaces of the phosphate glass castings. The magnitude of the stress varies, but in 
many cases excoeds $20 \mathrm{MPa}$ as determined from the stress birefringence near the glass surface.

Fractography analysis of the Type I and Type II cracks indicates that fracture origin is often small pits on the top surface of the castings [6], which are attributed to foreign material falling onto hot glass during or immediately after the castings operation. Fracture begins with the Type I crack pattern which is nucleated at these surface pits described above, but growth is limited to a shallow surface tensile region only a few $\mathrm{mm}$ in depth. Thermal gradients in the casting during subsequent annealing, handling and processing can then lead to propagation of Type I surface cracks into the much larger Type II fractures.

\section{Experimental}

\subsection{Glass melt preparation}

Six glass melts (labeled as glass samples A-F) having the same metaphosphate composition except with varying hydroxyl $(\mathrm{OH})$ contents were used in this study. The base glass is a commercial laser glass (LG-770) [7] and has the composition (mol\%): (58-62) $\mathrm{P}_{2} \mathrm{O}_{5}-(6-10) \mathrm{Al}_{2} \mathrm{O}_{3}-(20-25) \mathrm{K}_{2} \mathrm{O}$ (5-10) $\mathrm{MgO}$ and $(0-2) \mathrm{Nd}_{2} \mathrm{O}_{3}$. The composition is reported using ranges to account for volatile losses during melting, variations in Nd-doping (which depend on the intended laser application), batching variability and also to protect certain proprietary aspects of the composition. Note however, for the range of compositions shown above, the properties of the glass vary only slightly and do not affect the results of this study. For example, data reported by Campbell and Suratwala [2] show that for the glass properties important for this study (coefficient of thermal expansion, density, fracture toughness and Young's modulus), the variation is < $<15 \%$ over the composition range given above. Similarty, recent studies of phosphate giass manufacturing [1] show that the processing steps and conditions are nearly identical even though the product glasses have difierent compositions. Finally, and perhaps most important, a recent study of fracture growth in metaphosphate laser glasses shows that subcritical crack growth is relatively insensitive to small composition variations but much more dependent on the $\mathrm{OH}$ content in the glass and the water vapor content of the surrounding process atmosphere [8]. Therefore, we are confident that the results from this study are insensitive to the minor composition variations listed above.

All melts were prepared at $1250^{\circ} \mathrm{C}$, cast into steel molds and annealed at $500^{\circ} \mathrm{C}$ for two hours, and then cooled to room temperature at about $30^{\circ} \mathrm{C} / \mathrm{h}$. Glass sample $A$ is a production glass melt made using discontinuous melting [1]. This glass contains a low $\mathrm{OH}$ content (absorption at 3000 $\mathrm{cm}^{-1}$ of $\left.\sim 0.8 \mathrm{~cm}^{-1} ; \mathrm{OH} \leqslant 100 \mathrm{ppm}\right)$. Glasses B-F were from 0.51 melts prepared in inductively heated quartz crucibles using procedures described elsewhere [9]. The hydroxyl content in glasses B-F was varied by adjusting either the amount and duration of $\mathrm{O}_{2}$ bubbling through the melt (0-0.5 $\mathrm{y}$ $\min$ at STP) or the duration of the refining time $(2.5-3.5 \mathrm{~h})$, all of which decrease the hydroxyl content of the glass. Glass melts with larger hydroxyl content were generated by the direct addition of small amounts of water into the batch prior to melting (2-5 g H $\mathrm{H}_{2} \mathrm{O} / 1000 \mathrm{~g}$ batch). Details of relationship of the $\mathrm{H}_{2} \mathrm{O}$ content in the raw materials to the hydroxyl content in the glass, as well as the effect of processing parameters on the OH content in the glass, are described elsewhere [1].

\section{2. $O H$ concentration and concentration-profile measurements}

Glass samples $\left(10 \times 10 \times 2 \mathrm{~mm}^{3}\right)$ were cut from the exposed (top) surfaces of the melt glasses; the original exposed surface $\left(10 \times 10 \mathrm{~mm}^{2}\right.$ face) was untreated while the opposing surface was polished. The average $O H$ concentration through the glass was determined from the absorption band at 3.333 $\mu \mathrm{m}\left(3000 \mathrm{~cm}^{-1}\right)$ using a FIIR spectrometer (Perkin-Elmer Spectrum 2000) operated in the transmission mode. The $\mathrm{OH}$ concentration is expressed in terms of the OH absorptivity $\left(\alpha\right.$ in $\left.\mathrm{cm}^{-1}\right)$ which is calculated using

$\alpha=\frac{-\ln \left(T_{3000} / T_{5000}\right)}{t}$, 
where $T_{3000}$ and $T_{\text {s000 }}$ are the transmissions at 3000 and $5000 \mathrm{~cm}^{-1}$ wave numbers, respectively, and $t$ is the thickness of the sample $(\mathrm{cm}) . T_{\text {s000 }}$ serves as a background transmission and includes the Fresnel reflection losses.

We profiled the $\mathrm{OH}$ content near the original exposed surface of the glass, using the following procedure. The exposed surface was ground with SiC emery paper to remove between $10-200 \mu \mathrm{m}$ depending on the resolution desired and then polished first with $3 \mu \mathrm{m}$ and then $1 \mu \mathrm{m}$ diamond paste using a polishing oil (not water) as a lubricant. From the sample density and change in sample weight we determined the glass thickness removed. The $\mathrm{OH}$ absorptivity was re-measured using the FTIR spectrometer, and the absorptivity of the layer removed $\left(\alpha_{\Delta r}\right)$ was computed using the following expression

$\alpha_{\Delta t}=\frac{\alpha_{1} \cdot t-\alpha_{1-\Delta t} \cdot(t-\Delta t)}{\Delta t}$,

where $\Delta t$ is the thickness of the glass removed, and $\alpha_{1}$ and $\alpha_{1-\Delta s}$ are the absorptivities at thickness $t$ and $t-\Delta t$, respectively. This process was repeated by regrinding, polishing and re-measuring the $a b$ sorptivity until about $1 \mathrm{~mm}$ of the surface of the sample was removed. The error in our $\mathrm{OH} a b-$ sorptivity measurements ranges from $\pm 4 \%$ to $\pm 18 \%$ based on standard error analysis techniques [10]; the precision for the various measured quantities is as follows: thickness removed $( \pm 10$ $\mu \mathrm{m})$, weight difference $\left( \pm 2.5 \times 10^{-4} \mathrm{~g}\right)$ and optical transmission $( \pm 0.1 \%)$.

Determination of absolute $\mathrm{OH}$ concentration from the $\mathrm{OH}$ absorptivity of the sample depends on the value of the extinction coefficient. However, reported values for the extinction coefficients at $3000 \mathrm{~cm}^{-1}$ vary from 30 [11] to more than 100 ppmw/cm ${ }^{-1}$ [12]. For this study, an extinction coefficient of $100 \mathrm{ppmw} / \mathrm{cm}^{-1}$ is assumed.

\subsection{Measurement of physical and optical properties of the laser glass}

Thermal expansion of the glasses was measured using a dilatometer (Theta model 7214) and heat- ing cylindrical samples (5-mm diameter $\times 50-\mathrm{mm}$ length) at a rate of $2^{\circ} \mathrm{C} / \mathrm{min}$ from $20^{\circ} \mathrm{C}$ to a temperature just above $T_{z}$. Glass density was determined using the standard buoyancy method [13]. Fracture toughness was measured using both the Vickers indentation [14] and the chevron-notch [15] techniques. Vickers indentation measurements were carried out using a hardness testing machine (Zwick Werkstoff-Prüfmaschinen model 3212) on the polished surface of a $10 \times 10 \times 3 \mathrm{~mm}^{3}$ glass sample. Typically, a $0.6 \mathrm{~kg}$ load was applied to the glass surface for $15 \mathrm{~s}$; the surface was covered with hexane to prevent moisture enhanced sub-critical crack growth. Details of the chevron-notch method are described elsewhere [15]. Refractive index and dispersion were measured using a custom built V-block refractometer [16]. Young's modulus and Poisson's ratio were determined in the standard fashion from measured acoustic velocities in the glass [17].

\subsection{Preparation of glass laminates}

Test samples $25 \times 25 \times 10 \mathrm{~mm}^{3}$ were cut from each glass melt (A-F) and then one surface $\left(25 \times 25 \mathrm{~mm}^{2}\right)$ of each test sample was lightly ground using 600 grit emery paper and water. Next, the ground surface of each of the glasses A$F$ was placed in contact with the ground surface of glass sample A forming a bilaminate. There were a total of six different bilaminate samples (A-A through A-F). The samples were fused together by heating the bilaminates to $570^{\circ} \mathrm{C}\left(\sim 100^{\circ} \mathrm{C}\right.$ above $T_{\varepsilon}$ ) for one hour. The fused laminates (which we call fusion samples) were cooled to $500^{\circ} \mathrm{C}$ in about $40 \mathrm{~min}$. This was followed by a controlled $48^{\circ} \mathrm{C} / \mathrm{h}$ ramp to $300^{\circ} \mathrm{C}$ and an uncontrolled cooling ramp $\left(\sim 100^{\circ} \mathrm{C} / \mathrm{h}\right.$ ) from $300^{\circ} \mathrm{C}$ to room temperature (i.e. power was removed from the annealing furnace). The joined fusion parts were then cut and polished on each side 80 that inspection could be conducted in a direction parallel to the fused surface. The final sample thickness in the inspection direction was $5 \mathrm{~mm}$. The maximum stress birefringence in each fusion sample was measured using an optical microscope equipped with crossed polarizers and a compensating plate [18]. 


\section{Results}

\subsection{OH concentration profiles near glass surface}

Fig. 1 shows the measured $\mathrm{OH}$ profiles near the top surface of two identical meta-phosphate glass specimens (LG-770) subjected to the same annealing cycle but different ambient air environments. Both samples were annealed at $<10^{\circ} \mathrm{C} / \mathrm{h}$ from near $T_{8}\left(\sim 450^{\circ} \mathrm{C}\right)$ to $20^{\circ} \mathrm{C}$ but in one case the ambient air contained water vapor at a pressure of $7 \mathrm{mmHg}$ and in the other case $17 \mathrm{mmHg}$. In both cases, the hydroxyl concentration is greater near the surface than in the interior, however at equivalent depths, the $\mathrm{OH}$ content is greater for the glass annealed in the air having the greater water vapor pressure.

\subsection{Effect of $O H$ content on glass properties}

The effect of $\mathrm{OH}$ content on the thermal, mechanical and optical properties of LG-770 glass was determined using six glass samples with different $\mathrm{OH}$ contents (see Table 1). The OH content in the samples is expressed in terms of the optical absorption at $3333 \mathrm{~nm}$ (i.e. $3000 \mathrm{~cm}^{-1}$ ) and ranges from 0.8 to $50 \mathrm{~cm}^{-1}$; this corresponds to about 80 to 5000 ppmw OH, respectively.

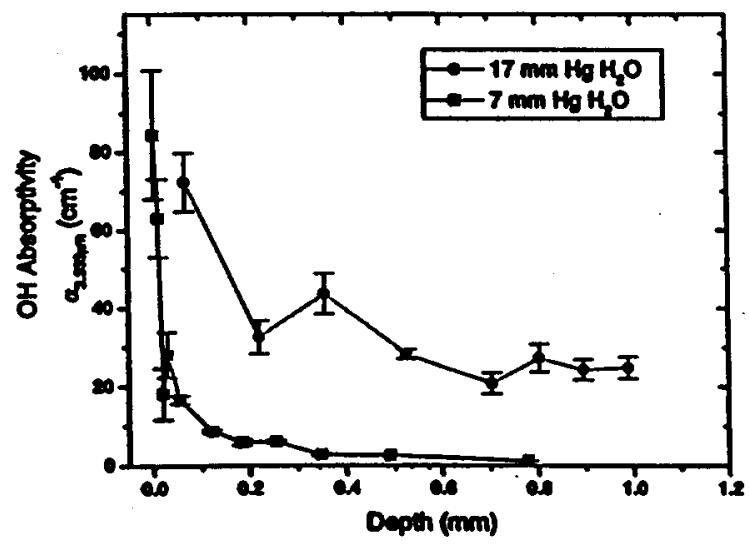

Fig. 1. Measured OH concentration as a function of the depth from the top surfece for two LO-770 haser phosphate ghases annealed in air conteining water vapor at pressure of 7 and 17 mmfig. The lines connect the data points.
Two key properties effected by glass $\mathrm{OH}$ content are the coefficient of thermal expansion (CTE) and the $T_{z}$ (Fig. 2). Specifically, $T_{z}$ decreases linearly by $63^{\circ} \mathrm{C}$ over the range of $\mathrm{OH}$ content investigated here. This decrease parallels the trend reported for silicates [12]. The CTE also increases approximately linearly with increase in $\mathrm{OH}$ content (Fig. 2). In contrast, Young's modulus (E) and Poisson's ratio ( $v$ ) remain essentially constant over the range of $\mathrm{OH}$ contents reported here, with $E=47( \pm 1) \mathrm{GPa}$ and $v=0.26( \pm 0.005)$ (Table 1). Also, the affect of $\mathrm{OH}$ content on the optical properties, such as the refractive index and the Abbe number, is negligible (Table 1).

The change in glass fracture toughness versus OH content was found to depend on the measurement technique. Fracture toughness measured by the chevron-notch technique showed no change with $\mathrm{OH}$ content to within the error of the measurement, however with the indentation tochnique a decrease in the fracture toughness with increase $\mathrm{OH}$ content was observed. The reason for this is not completely clear; however, we propose that samples measured using the indentation technique are more prone to stress-corrosion fracture (i.e. sub-critical crack growth) due to the presence of $\mathrm{OH}$ in the glass. Recent measurements of subcritical crack growth in phosphate laser glass showed that crack velocities increased with an increase in the $\mathrm{OH}$ content in the glass [8].

\subsection{Stress birefringence measurements}

The results of stress birefringence measurement on the six bilaminates (i.e. fusion samples) are summarized in columns 3 and 4 of Table 2. The stresses were estimated from the stress-induced birefringence, using a stress-optic coefficient of 21 $\mathrm{nm} / \mathrm{cm}$ per MPa [7]. The stress-optic coefficient is not a function of residual OH content in LG-770; two samples with $3333 \mathrm{~nm}$ absorption coefficients differing by more than a factor of 100 (i.e. 0.6 and about $100 \mathrm{~cm}^{-1}$ ) were both measured to have a stress-optic coefficient of $21( \pm 8 \%) \mathrm{nm} / \mathrm{cm}$ per $\mathrm{MPa}$

The stresses listed in Table 2 for the fusion laminates represent the maximum tension near the bond (fusion) interface. The peak tensile stress 
Table 1

Effect of OH content on the properties of the meta-phosphate laser glass, LG-770, used in this study"

\begin{tabular}{|c|c|c|c|c|c|c|c|c|c|}
\hline \multirow[t]{2}{*}{ Property } & \multirow[t]{2}{*}{ Symbol } & \multirow[t]{2}{*}{ Units } & \multirow[t]{2}{*}{ Error } & \multicolumn{6}{|c|}{ Sample designation } \\
\hline & & & & $\mathbf{A}$ & $\mathbf{B}$ & $\mathbf{C}$ & D & $\mathbf{E}$ & $\mathbf{F}$ \\
\hline $\begin{array}{l}\text { OH absorptivity at } \\
3333 \mathrm{~nm}\end{array}$ & $\alpha_{3.333} \mathrm{~mm}$ & $\mathrm{~cm}^{-1}$ & $\pm 0.4 \%$ & 0.8 & 1.6 & 10.6 & 21.4 & 24.2 & So.1 \\
\hline $\begin{array}{l}\text { Thermal } \\
\text { Softening Pt } \\
\text { Glass Transition } \\
\text { temp. }\end{array}$ & $\begin{array}{l}T_{\text {top }} \\
T_{\mathrm{s}}\end{array}$ & ${ }^{\circ} \mathrm{C}$ & $\begin{array}{l} \pm 5 \\
\pm 5\end{array}$ & $\begin{array}{l}566 \\
468\end{array}$ & $\begin{array}{l}562 \\
460\end{array}$ & $\begin{array}{l}547 \\
440\end{array}$ & $\begin{array}{l}548 \\
439\end{array}$ & $\begin{array}{l}531 \\
414\end{array}$ & $\begin{array}{l}524 \\
405\end{array}$ \\
\hline $\begin{array}{l}\text { Linear expansion } \\
\text { coefficient }{ }^{b}\end{array}$ & CTE & $\times 10^{-7} / \mathrm{K}^{-1}$ & \pm 0.5 & 129 & 130 & 131 & 130 & 136 & 142 \\
\hline $\begin{array}{l}\text { Mechanical } \\
\text { Young's modulus } \\
\text { Poisson's ratio } \\
\text { Fracture toughneass } \\
\text { Fracture toughness' } \\
\text { Density }\end{array}$ & $\begin{array}{l}E \\
v \\
K_{\mathrm{Lc}} \\
K_{\mathrm{k}} \\
\rho\end{array}$ & $\begin{array}{l}\text { GPa } \\
\mathrm{MPa} \mathrm{m} \mathrm{m}^{1 / 2} \\
\mathrm{MPa} \mathbf{m}^{1 / 2} \\
\mathrm{~g} / \mathrm{cm}^{3}\end{array}$ & $\begin{array}{l} \pm 1 \\
\pm 0.005 \\
\pm 0.02 \\
\pm 0.02 \\
\pm 0.02\end{array}$ & $\begin{array}{l}48 \\
0.259 \\
0.57 \\
0.43 \\
2.64\end{array}$ & $\begin{array}{l}47 \\
0.260 \\
0.56 \\
0.45 \\
2.63\end{array}$ & $\begin{array}{l}47 \\
0.259 \\
0.45 \\
0.43 \\
2.63\end{array}$ & $\begin{array}{l}48 \\
0.258 \\
0.48 \\
0.44 \\
2.62\end{array}$ & $\begin{array}{l}47 \\
0.260 \\
0.44 \\
0.43 \\
2.63\end{array}$ & $\begin{array}{l}47 \\
0.260 \\
0.38 \\
0.43 \\
2.62\end{array}$ \\
\hline $\begin{array}{l}\text { Optical } \\
\text { Refructive index } \\
\text { (587.6 nm) } \\
\text { Abbe number }\end{array}$ & $n_{d}$ & & $\begin{array}{l} \pm 0.00002 \\
\pm 0.02\end{array}$ & $\begin{array}{l}1.51225 \\
67.45\end{array}$ & $\begin{array}{l}1.51184 \\
67.30\end{array}$ & $\begin{array}{l}1.51070 \\
67.44\end{array}$ & $\begin{array}{l}1.51270 \\
67.63\end{array}$ & $\begin{array}{l}1.50902 \\
67.67\end{array}$ & $\begin{array}{l}1.51067 \\
67.69\end{array}$ \\
\hline
\end{tabular}

"LG-770 molar composition: (58-62) $\mathrm{P}_{2} \mathrm{O}_{5}-(6-10) \mathrm{Al}_{2} \mathrm{O}_{3}-(20-25) \mathrm{K}_{2} \mathrm{O}-(5-10) \mathrm{MgO}-(0-2) \mathrm{Nd}_{2} \mathrm{O}_{3}$.

Value from $20-300^{\circ} \mathrm{C}$.

'Measured by Vickor's indentation method [14].

¿Measured by chevron-notch method [15].

generally increases with an increase in difference between the $\mathrm{OH}$ content of the two laminated glasses. Based on repeated measurements, the

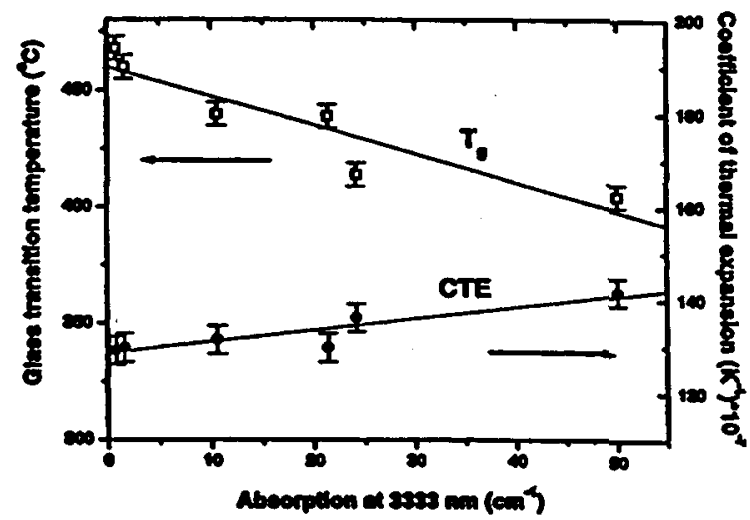

Fis. 2. Efioct of OH content on the giass transition temperature $\left(T_{3}\right)$ and the coeficicient of thermal expansion (CTE) of LQ-770 laser phosphate glasecs. The lines are from linear regrescion analyses of the data. standard deviation for measured stress at the bondline is $< \pm 15 \%$.

Despite repeated trials, all fusion samples prepared using samples of glasses $A$ and $E$ and $A$ and $F$ broke during cutting and polishing of inspection samples. Analysis of the fracture patterns indicated high tension at the fusion join for these samples (see Table 2).

\section{Discussion}

\subsection{Hydroxyl diffusion into the glass}

The presence of a much greater $\mathrm{OH}$ content near the surface versus interior of the as-cast glass is not surprising because phosphate glasses are generally hygroscopic [19]. The external water vapor reacts with the linear metaphosphate chains at the surface of the glass to form chain terminating hydroxyl groups $[1,12,20]$ 
Table 2

Results from fusion bonding tests and FEA model calculations of glass A with other glasses having different OH contents

\begin{tabular}{|c|c|c|c|c|c|}
\hline $\begin{array}{l}\text { Glass sample fusion } \\
\text { bonded to sample A }\end{array}$ & $\begin{array}{l}\text { OH content } \\
\alpha_{3,333}=\left(\mathrm{cm}^{-1}\right) \\
( \pm 0.4 \%)\end{array}$ & $\begin{array}{l}\text { Measured } \\
\text { birefringence } \\
(\mathrm{nm} / \mathrm{cm})\end{array}$ & $\begin{array}{l}\text { Implied } \\
\text { stress } \\
\text { (MPa) } \sigma_{x x}\end{array}$ & $\begin{array}{l}\text { Net strain from } \\
\text { thermal expansion curves } \\
(\Delta L / L) \times 10^{-6}( \pm 5 \%)\end{array}$ & $\begin{array}{l}\text { FEA predicted } \\
\text { stress } \\
(\mathrm{MPa}) \sigma_{x x}\end{array}$ \\
\hline $\mathbf{A}$ & 0.8 & $2.0 \pm 0.5$ & $\infty .1$ & 0 & \\
\hline B & 1.6 & $37 \pm 2$ & $1.8 \pm 0.1$ & -130 & \\
\hline C & 10.6 & $220^{4}$ & $10.5^{n}$ & -490 & 13 \\
\hline D & 21.4 & $156 \pm 20$ & $7.5 \pm 1$ & -460 & \\
\hline $\mathrm{E}$ & 24.2 & Fractured & Fractured & -700 & \\
\hline $\mathbf{F}$ & so.1 & Fractured & Fractured & -690 & 20.6 \\
\hline
\end{tabular}

Two other samples fractured.

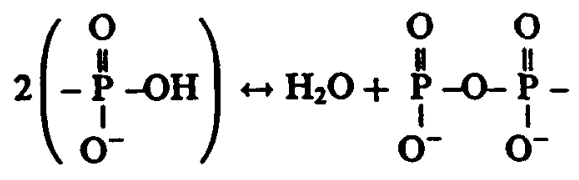

Ambient air can have a wide range of water contents depending on weather conditions and the level of process plant humidity control. Typically, the ambient water vapor pressure can vary from about 2 to $20 \mathrm{mmHg}(260-2600 \mathrm{~Pa})$. During processing, water vapor can react at the glass surface forming $\mathrm{OH}$ groups that diffuse into the bulk glass.

The rate of diffusion of $\mathrm{OH}$ into LG-770 between $400-1000^{\circ} \mathrm{C}$ has been previously reported [21]. These data, given in terms of diffusion coefficients $(D)$, can be represented using the relationship

$D \cong D_{0} \mathrm{e}^{-Q / R T}$,

where $R$ and $T$ have their usual meaning and $D_{0}$ and $Q$ are the pro-exponential constant and activation energy, respectively, and have values of $2.2 \pm 1.0 \mathrm{~cm}^{2} / \mathrm{s}$, and $141 \pm 7 \mathrm{~kJ} / \mathrm{mol}$ based on a linear regression analysis of the diffusion data. Thus, the $O H$ diffusion coefficients in LG-770 at 400 and $1000^{\circ} \mathrm{C}$ are about $2.5 \times 10^{-11}$ and $3.6 \times 10^{-6} \mathrm{~cm}^{2} / \mathrm{s}$, respectively; note that these values are about two to three orders of magnitude greater than values observed in soda-lime silicate glass at the same temperatures [22]. It is important to recognize that the diffusion coefficients given by Bq. (4) are probably not those for hydroxyl-groups per se, but rather the modifier, $\mathrm{H}^{+}$[12]. In addition, it is believed that the diffusion is concentration dependent, with the diffusion coefficient increasing as the $\mathrm{OH}$ content in the glass increases [23].
The time $(t)$ required for $O H$ to penetrate a given distance into the glass at a given temperature can be estimated using [24]

$t \cong \frac{x^{2}}{2 D}$

where $x$ is the penetration depth, defined as the depth where the OH concentration is half the surface concentration (i.e. $C(x) / C_{0}=0.5$ ) [24]. The measured $\mathrm{OH}$ penetration depth is about $0.5 \mathrm{~mm}$ in a typical laser glass slab annealed in air containing water vapor at a pressure of $17 \mathrm{~mm} \mathbf{~ g ~ ( s e e ~ F i g , ~ 1 ) . ~}$ At a typical annealing temperature of $500^{\circ} \mathrm{C}$ the diffusion coefficient is approximately $6.5 \times 10^{-10}$ $\mathrm{cm}^{2} / \mathrm{s}$, and hence 22 days would be required to achieve a penetration depth of $0.5 \mathrm{~mm}$. Exposure times in excess of 25 days are commonly used during the annealing of large phosphate glass slabs [1].

Note that the diffusion of $\mathrm{OH}$ into the glass (after $\mathrm{H}_{2} \mathrm{O}$ reaction at the surface) is an accumulation of the diffusion events that occur for all the temperatures and times to which the as-formed slab is exposed. OH penetration can occur in short exposure times (minutes) at temperatures $T \gg T_{g}$, as for example during casting [1]. It can also occur at lower temperatures $\left(T<T_{\varepsilon}\right)$ when the diffusion coefficient is smaller but the exposure times are much longer (days) as, for example, during annealing [1].

\subsection{Explanation for surface tensile stress develop- ment}

In Section 4.2, we showed that $O H$ incorporation in the laser phosphate glass affects some of the 
properties of the glass, specifically the thermal expansion coefficient and $T_{z}$. In this section, we describe how differences in these two properties result in stress in our glass laminates.

In a linear elastic solid, the stress $(\vec{\sigma})$ is related to the net strain $(\tilde{\delta})$ by

$\vec{\sigma}=\stackrel{\vec{c}}{\boldsymbol{\delta}}$,

where $\vec{\sigma}$ and $\vec{\delta}$ are six component vectors and $\vec{c}$ is the $6 \times 6$ elastic stiffness tensor [25]. The first three components of the stress and strain vectors describe the principal stresses and strains; the last three values describe shear components. For isotropic solids such as glass, $\vec{c}$ is described by two independent elastic moduli.

Consider an example using the two test glasses, sample A (a low $\mathrm{OH}$ content glass) and sample $\mathrm{F}$ (a high $\mathrm{OH}$ content glass) and having glass transition temperatures of $T_{\mathrm{aA}}$ and $T_{\mathrm{gF}}$, respectively. Assume the samples are fusion-bondod together by heating above temperature $T_{\text {en }}$. At this point there is no strain in the material; the strain/stress develops as the glass is cooled. For simplicity we assume cooling rate is slow enough that the thermal gradients in the glass part are negligible.

The mechanism for strain development during coling of a glass-to-glass laminate is illustrated in Figs. 3 and 4. Fig. 3(a) shows the measured shrinkage $(\Delta U L)$ for each of the two laminate glasses (samples $A$ and $F$ ) that contain different OH concentrations and Fig. 3(b) shows the differential shrinkage between these two glasses. During cooling a net strain develops as the temperature drops below $T_{\mathrm{ef}}$; the magnitude of the strain is determined from the magnitude of the differential shrinkage between the two glasses as shown in Fig. 3(b).

The net strain $(\delta)$ in the glass can be represented by the sum of two contributions

$\delta=\delta_{1}+\delta_{\text {ald }}$,

where $\delta_{1}$ is a linear contribution to the strain due to differences in the linear coefficient of expansion for the high and low OH containing glasses. The term $\delta_{\mathrm{v}}$ is the contribution due to nonlinear shrinkage and dominates the strain at temperatures just below $T_{z}$ (see Fig. 3(b)). The sign convention used in Fig. 3 is such that positive

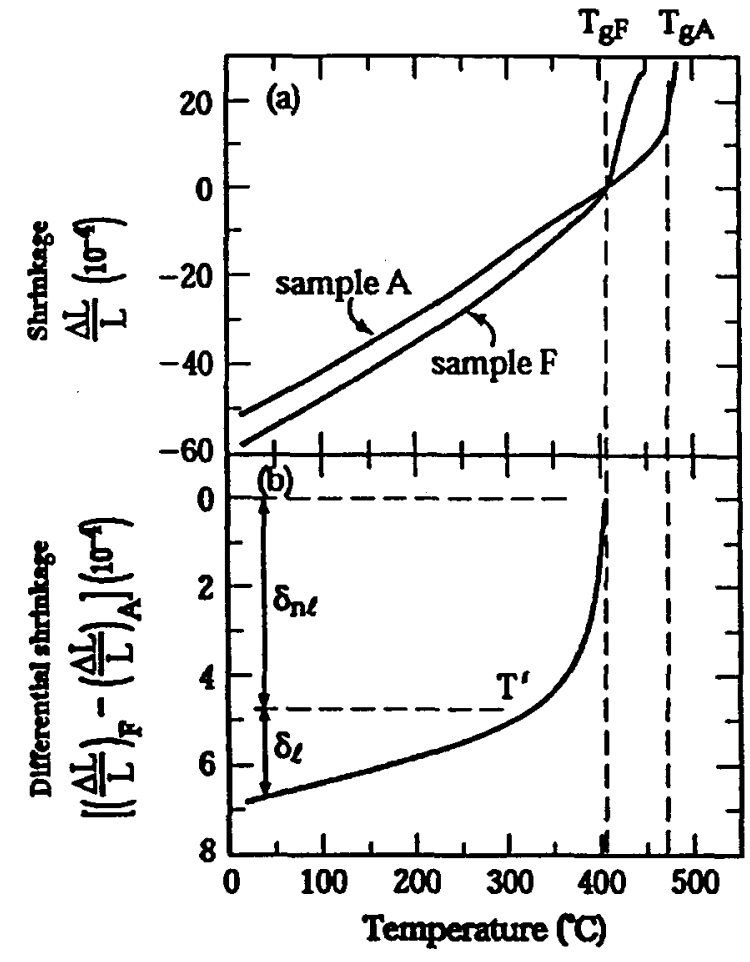

Fig. 3. (a) Dilatometer expansion curves of glass A (low OH) and $F$ (high $O H$ ) (see Table 1) shifted to intersect at the glass transition temperature of the high $\mathrm{OH}$ giass $\left(T_{\mathrm{zf}}\right)$. (b) Differential shrinkage during cooling of a buminate (fusion sample) comprised of glass A and F. The differential shrinkage is calculated from the difference between the two curves in (a).

differential strains lead to tension, and negative strains result in compression.

Fig. 4 schematically illustrates strain development during cooling of a sample laminate comprised of two glasses ( $A$ and $F$ ) with different $O H$ contents. When the laminated sample is above $T_{\mathrm{eF}}$, the glass transition temperature of sample $F$, there is no stress because sample $F$ relaxes viscoelastically to any differential shrinkage. When the laminate cools to temperature $T_{\mathrm{af}}$, the fusion join becomes stiff. At temperatures less than $T_{a x}$, the interface between the two glasses is constrained and stress develops as sample $F$ shrinks more than sample A. The differential shrinkage between the two samples ( $A$ and $F$ ) is dominated by the nonlinear portion of the glass shrinkage until reaching temperature, $T$, and the net strain developed in this temperature range is labeled $\delta_{\mathrm{n}}$ (Fig. 4). 


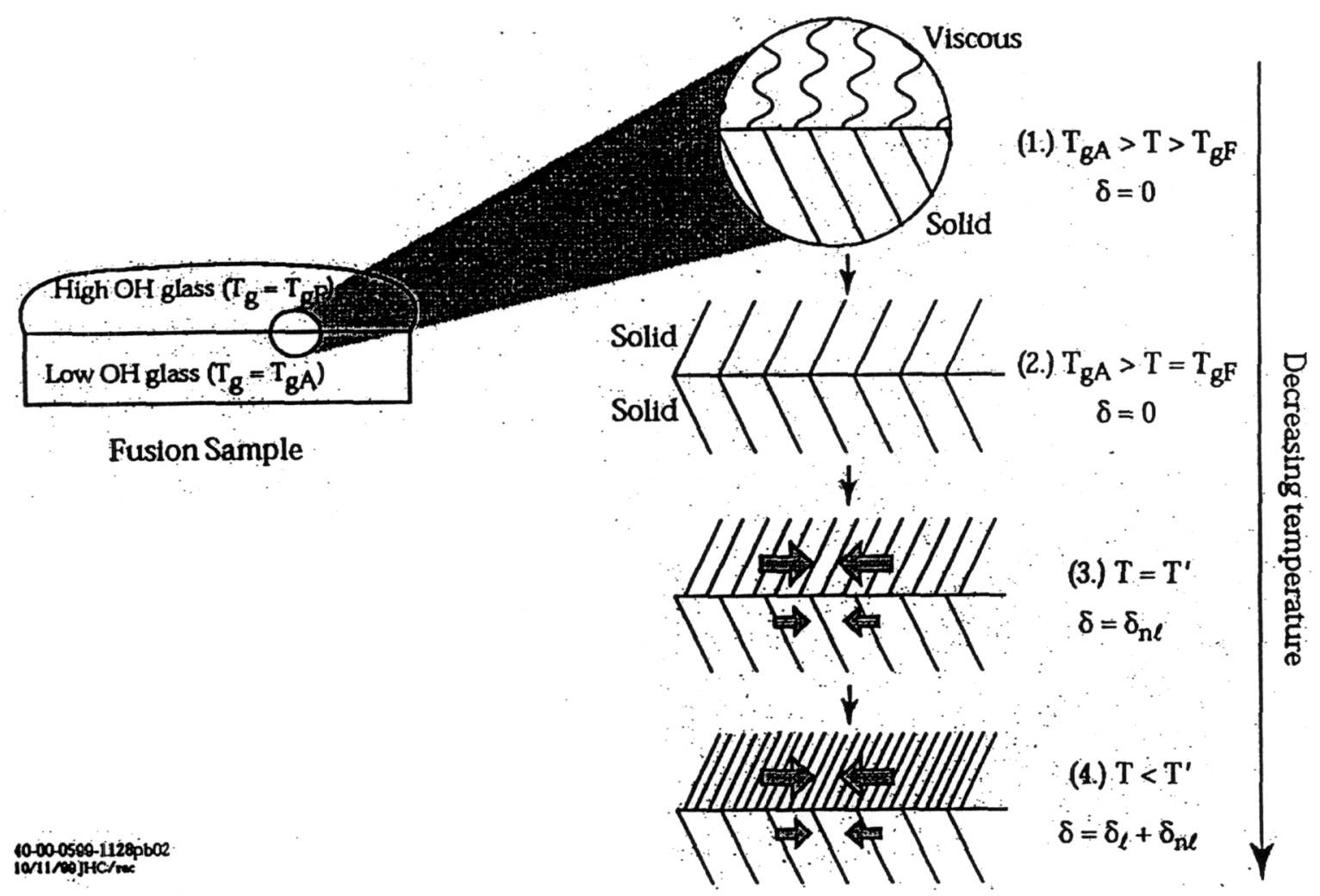

Fig. 4. Schematic illustration of the source of the differential shrinkage that develops during cooling of a fusion-bonded glass sample comprised of two glasses containing different hydroxyl contents.

Continued cooling below $T$ results in further differential shrinkage between the two samples, however in this region the shrinkage of both glasses is nearly linear with temperature and approximates the coefficient of thermal expansion. From the data in Table 1, the coefficient of linear thermal expansion is larger for the sample with the greater $\mathrm{OH}$ content, resulting in greater shrinkage of sample $F$ relative to $A$ and thus further increasing the net strain in the glass. The net strain continues to increase as the material is cooled to room temperature. The difference in shrinkage between the high and low $\mathrm{OH}$ content glasses produces a stress distribution near the fusion bond that is tensile in the high $\mathrm{OH}$ content glass and compressive in the low $\mathrm{OH}$ glass.

It is straightforward to estimate the net difference in linear shrinkage, $\delta_{1}$, from the coefficient of thermal expansions, $\mathrm{CTE}_{\mathrm{A}}$ and $\mathrm{CTE}_{\mathrm{F}}$, of sample $\mathrm{A}$ and sample $F$, respectively

$$
\delta_{1}=\left(\mathrm{CTE}_{\mathrm{F}}-\mathrm{CTE}_{\mathrm{A}}\right)\left(T^{\prime}-T_{\mathrm{RT}}\right) \text {, }
$$

where $T$ is the temperature below which the thermal expansion coefficient is independent of temperature and $T_{\mathrm{RT}}$ is room temperature. Developing an analytical expression for $\delta_{\text {nl }}$ is more difficult since the theoretical relationship for the shrinkage near $T_{\mathbf{g}}$ is not known. Therefore, we determined $\delta_{\text {nl }}$ graphically for all six fusion samples from the dilatometer curves as shown in Fig. 3.

The total differential shrinkages (i.e. net strains $(\delta))$ that develop during annealing of the six laminates are shown in Fig. 5. The data are plotted as a function of the difference in $\mathrm{OH}$ content between the two halves of the laminate. In general, the differential shrinkage increases with increasing difference in $\mathrm{OH}$ content between the two samples 


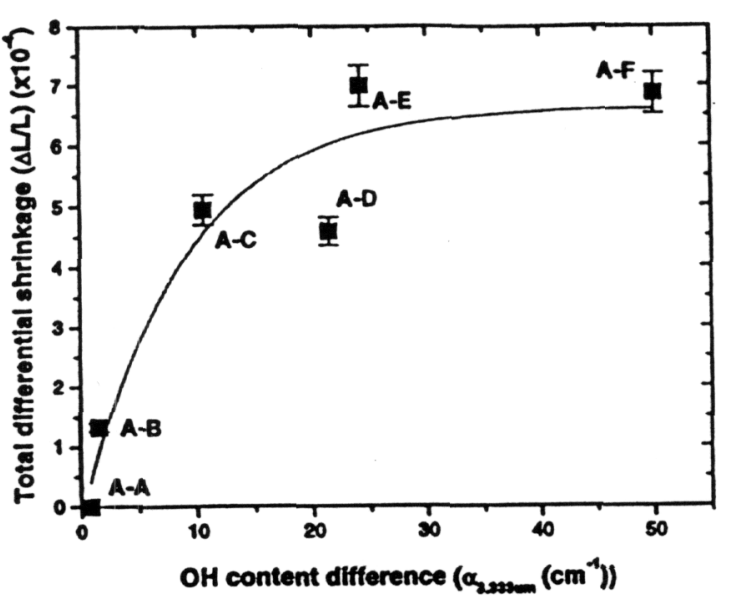

Fig. 5. Total differential shrinkage (strain) between two fusionbonded samples having different $\mathrm{OH}$ contents; the strains were estimated from dilatometer curves as discussed in the text and in Fig. 3. The line does not represent a theoretical relationship but is drawn to illustrate the data trend.

comprising the laminate. The differential shrinkage (net strain) varies from about $130 \mathrm{ppm}$ in laminate sample A-B to about $700 \mathrm{ppm}$ in samples A-E and A-F. Surprisingly, the total differential shrinkage appears to plateau at about $700 \mathrm{ppm}$ at the highest differential $\mathrm{OH}$ content.

\subsection{Calculated vs. measured stress}

The peak tensile stress and stress distribution were calculated by FEA using the stress/strain code NIKE2D [26] and assuming the mechanism for strain development in the fusion samples as described in Section 5.2. The grid size and coordinate orientation used in the analysis is shown in Fig. 6. The calculations assume that the glass density $\left(2.63 \mathrm{~g} / \mathrm{cm}^{3}\right)$, elastic modulus $(47 \mathrm{GPa})$ and Poisson's ratio $(0.26)$ are unaffected by $\mathrm{OH}$ content in the glass, as reported in Table 1 . As input, the FEA analysis uses the measured thermal expansion curves for the two samples in the bilaminate. Output from the FEA gives both the stress and strain distribution in the fusion sample. The simulations were carried out on two fusion samples; fusion samples A-C and A-F. As expected, the maximum tensile stress is computed to be near the fusion bond and just inside the sample with the

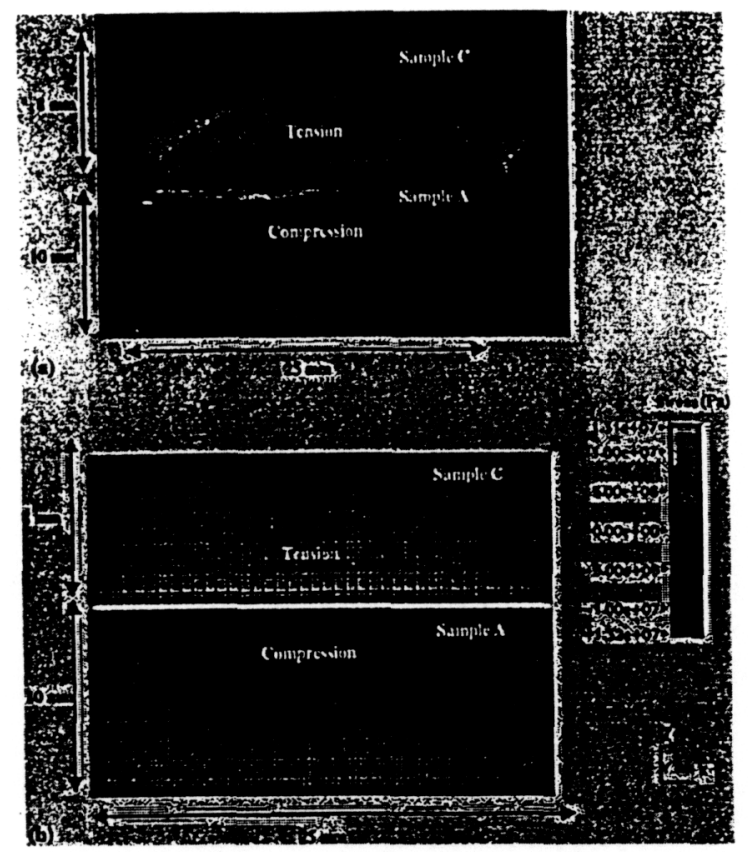

Fig. 6. (a) Photograph of fusion-bonded sample A-C with observed birefringence and (b) calculated stress distribution using a FEA model (via gray scale).

greater $\mathrm{OH}$ content. The predicted stress profile through the fusion sample $\mathrm{A}-\mathrm{C}$ is shown in Fig. 6 and visually compared with the observed birefringence in the sample. The calculated maximum tensile stress is $+13 \mathrm{MPa}$ for sample $\mathrm{A}-\mathrm{C}$ which is close to the measured value of $10.5 \mathrm{MPa}$, based on the measured stress birefringence (see Table 2). The maximum tensile stress predicted by FEA for fusion sample A-F is $20.5 \mathrm{MPa}$; unfortunately, stress birefringence measurements could not be carried out on this sample because it fractured. The fact that sample A-F fractured means the stress $(\sigma)$ exceeded the critical stress which depends on the glass fracture toughness $\left(K_{\mathrm{IC}}\right)$ and the critical flaw size $a_{\mathrm{c}}$ [27]:

$a_{\mathrm{c}}=\frac{1}{\pi}\left(\frac{K_{\mathrm{IC}}}{\sigma}\right)^{2}$.

Using Eq. (9) we estimate the critical flaw size of only $140 \mu \mathrm{m}$ needed to produce failure at 20.5 MPa tensile stress. The occurrence of such a small flaw is not unreasonable. 
5.4. Surface tensile stress generation and fracture in laser glass slabs

Using the strain data from the fusion samples, we can estimate the surface tensile stress in a typical phosphate laser glass slab that is annealed from a temperature slightly above $T_{\mathrm{g}}\left(\sim 500^{\circ} \mathrm{C}\right)$ to room temperature. We assume that the glass is a laminate comprised of a $60-\mathrm{mm}$-thick core [with properties the same as those of sample $A$ (see Table 1)] plus top and bottom surface layers 2-mm-thick and having properties the same as sample $\mathrm{E}$. The stress at the core $\left(\sigma_{\mathrm{c}}\right)$ and surface $\left(\sigma_{8}\right)$ for a part with this geometry are given by [25]

$\sigma_{\mathrm{c}}=\frac{-\delta E_{\mathrm{s}}}{1-v}\left(\frac{a}{2 c}+\frac{E_{\mathrm{z}}}{E_{\mathrm{c}}}\right)^{-1}$

$\sigma_{\mathrm{z}}=\frac{\delta E_{\mathrm{c}}}{1-v}\left(\frac{2 c}{a}+\frac{E_{\mathrm{c}}}{E_{\mathrm{z}}}\right)^{-1}$

where $E_{\mathrm{c}}$ and $E_{8}$ are Young's moduli of the core and surface material, respectively, $v$ is a composite Poisson's ratio, and $a$ and $c$ are the thickness of the surface and core glass, respectively. Since Young's modulus and Poisson's ratio do not vary with $\mathrm{OH}$ content, we assume $E_{s}=E_{c} \cong 47 \mathrm{GPa}$ and $v=0.26$. Also, we assume the average $O H$ concentration of the surface glass is about 3000 ppmw (L.e. $30 \mathrm{~cm}^{-1}$ absorption at $3.333 \mu \mathrm{m}$ ) based on measurements on annealed slabs. The expected net strain between the core glass and surface layers is about $700 \mathrm{ppm}$ based on the difference in $\mathrm{OH}$ content (Fig. 5). Using Eqs. (10) and (11) we calculate a tensile stress of $42 \mathrm{MPa}$ in the surface glass and less than -2.7 MPa compression in the thicker core plate. These values are consistent with our observations of tensile stresses near the slab surfaces of $\sim 20 \mathrm{MPa}$ based on measured stress birefringence. Stresses in slabs with $O H$ contents greater than $30 \mathrm{~cm}^{-1}$ at the surface have not been made because in all cases these slabs fractured.

Based on the estimated tensile stress, Eq. (9) can be used to calculate the minimum flaw size $\left(a_{c}\right)$ required to initiate fracture at the slab top surface [27]. Assuming a fracture toughness, $K_{\mathrm{IC}}$, based on the chevron-notch measurements, the minimum flaw size to initiate fracture is $32 \mu \mathrm{m}$. With such a small flaw size, fracture is very likely to oocur from minor defects or imperfections on the surface of the slabs in agreement with our observations.

Note that the above calculations are only approximate for the purpose of providing an estimate of surface stresses in phosphate laser slabs annealed in ambient air containing various concentrations of water vapor. The stress distribution in real production slabs is more complex for several reasons. First, the $\mathrm{OH}$ content is not constant over a given depth as assumed in the above calculation. Instead the $\mathrm{OH}$ content decreases with depth from the surfaces (as in Fig. 1) and therefore the stress developed will also decrease with depth. Second, the resistance to sub-critical crack growth also decreases with increasing $\mathrm{OH}$ content [8] resulting in a greater tendency for the glass exposed to water vapor during annealing to generate surface fractures. Finally, any tensile stresses that form due to the chemical modification of surface are in competition with the permanent compressive stress that is formed from thermal gradients in the glass during cooling. Nevertheless, the above simple calculation of surface tensile stress development during annealing of phosphate slabs gives a good approximation to our observations.

\section{Conclusions}

Tensile surface stresses and surface fractures have been observed after annealing slabs of metaphosphate laser glass in an ambient air containing water vapor. This is in sharp contrast to compressive surface layers generated during annealing of soda-lime silicate glasses under the same conditions.

Metaphosphate glasses have a chain-like structure consisting of $\mathrm{PO}_{4}$ tetrahedra. Water vapor in the ambient air of the annealing oven can chemically attack phosphate glass surfaces, cleaving P-O-P chains and leaving behind shorter chains that terminate in hydroxyl groups. As a result of such attack, the glass surfaces take on properties different from the interior of the material, including an increase in thermal expansion and a docrease of the glass transition temperature. Changes in these two properties cause the slab 
surface to shrink more during cooling than the interior, leading to castings with surfaces under tension. If suitable nucleation sites exist on the glass surface, this tensile layer can lead to a network of shallow surface cracks and, in extreme cases, catastrophic fracture of the slab.

To eliminate possible fracture problems associated with these surface stresses one must take steps to reduce or exclude water vapor from the annealing environment or at the end of the annealing cycle, immediately remove or pacify the stressed surface layer.

\section{Acknowledgements}

The authors gratefully acknowledge the contributions of $\mathrm{R}$. Steele ( $\mathrm{OH}$ profiles) and W. Miller (FEA modeling). This work was performed with funding provided by the US Department of Energy by Lawrence Livermore National Laboratory under Contract No. W-7405-Eng-48. The assistance of A. Flammini and A. Clasen in the preparation of the manuscript is deeply appreciated.

\section{References}

[1] J. Campbell, T. Suratwala, C. Thorsaess, J. Hayden, A. Thorne, J. Cimino, A. Marker, K. Takeuchi, M. Smolley, G. Ficini-Dorn, these Procoedings, p. 342.

[2] J. Campbell, T. Suratwala, these Proceedings, p. 318.

[3] J. Murray, SPIE 3492 (1998) 1.

[4] M. Andre, M. Novaro, D. Schirmann, Chocs. Rev. Sci. Techn. Direct. Appl. Milit. 13 (1995) 73.

[5] F.V. Tooley, The Handbook of Glass Manufacture, vol. II, Ashlee, New York, 1984, p. 801.
[6] V.D. Frechette, Failure Analysis of Brittle Materials, vol. 28, American Ceramics Society, 1990.

[7] Glass for Laser Applications, Schott Glass Technologies, Product Catalog, Duryea, PA, 1999, p. 1.

[8] T.I. Suratwala, R.A. Steele, G.D. Wilke, J.H. Campbell, K. Takeuchi, these Proceedings, p. 213.

[9] D. Sapak, J. Ward, J. Marion, SPIE 970 (1988) 107.

[10] D.A. Skoog. J.J. Leary, Principles of Instrumental Analysis, 4th Ed., Saunders College Publishing, Orlando, FL, 1992.

[11] H. Toratani, PhD thesis, Kyoto University, Kyoto, 1989.

[12] J. Shelby, Handbook of Gas Diffusion in Solids and Melts, ASM International, Materials Park, OH, 1996, p. 217.

[13] Annual Book of ASTM Standards, 15.02, C-693-93 (1998) 213.

[14] B. Lawn, Fracture of Brittle Solids, 2nd Ed., Cambridge University, Cambridge, 1993.

[15] K.P.R. Reddy, E.H. Fontana, J.D. Helfinstine, J. Am. Ceram. Soc. 71 (1988) C310.

[16] J.V. Hughes, J. Sci. Instrum. 18 (1941) 234.

[17] A.K. Varshneya, Fundamentals of Inorganic Glasses, Academic Press, Boston, MA, 1990, p. 164.

[18] A. Ehringhaus, Z. Kristallogr. 76 (1931) 315.

[19] J.V. Waxer, Phosphorus and its Compounds, New York, 1958.

[20] R.M. Wenslow, K.T. Mueller, J. Phys. Chem. B 102 (1998) 9033.

[21] J. Hayden, M. Tomozawa, S. Crichton, Lawrence Livermore National Laboratory Report, UCRL-ID-136007 (1997) 1.

[22] E.B. Shand, Glass Engineering Handbook, McGraw-Hill, New York, 1958.

[23] M. Tomozawa, Commun. Am. Ceram. Soc. (Sept. 1985) C2st.

[24] P. Atkins, Physical Chemistry, Sth Ed., Freeman, Oxford 1994.

[25] A.K. Varshneya, Treatise on Materials Science and Technology, Academic Press, New York, 1982.

[26] B. Engelmann, J.O. Hallquist, NIKE2D, A non-linear, implicit, two-dimensional finite element code for solid mechanics, Lawrence Livermore National Laboratory Report, UCRL-MA-105413, 1991.

[27] A. Griffith, Philos. Trans. R. Soc. A 221 (1920) 163. 


\title{
Subcritical Crack Growth in a Phosphate Laser Glass
}

\author{
Stephen N. Crichton ${ }^{*},+$ and Minoru Tomozawa* \\ Rensselaer Polytechnic Institute, Troy, New York \\ 12180
}

Joseph S. Hayden

Schott Glass Technologies, Inc., Duryea, Pennsylvania 18642

Tayyab I. Suratwala and John H. Campbell

Lawrence Livermore National Laboratory, Livermore, California 94551

The rate of subcritical crack growth in a metaphosphate Nd-doped laser glass was measured using the doublecleavage-drilled compression (DCDC) method. The crack velocity is reported as a function of stress intensity at temperatures ranging from 296 to $573 \mathrm{~K}$ and in nitrogen with water vapor pressures ranging from $40 \mathrm{~Pa}(0.3 \mathrm{mmHg})$ to $4.7 \times 10^{4} \mathrm{~Pa}(355 \mathrm{mmHg})$. The measured crack velocities follow region I, II, and III behavior similar to that reported for silicate glasses. A chemical and mass-transport-limited reaction rate model explains the behavior of the data except at high temperatures and high water vapor pressures where crack tip blunting is observed. Blunting is characterized by an arrest in the crack growth followed by the inability to reinitiate slow crack growth at higher stresses. A dynamic crack tip blunting mechanism is proposed to explain the deviation from the reaction rate model.

\section{Introduction}

$\mathrm{O}$ XIDE glass under tensile stress can exhibit enhanced slow crack growth in the presence of water or water vapor. Although there is considerable debate about the exact mechanism, it is generally accepted that water vapor attacks the region around the crack tips of surface flaws, weakening the structure in the vicinity of the crack tip. This allows cracks to grow at stress intensities below the critical value $\left(K_{\mathrm{Ic}}\right)$ for fracture in a dry environment.

The experimental characterization of this phenomenon was first accomplished by Wiederhorn ${ }^{1}$ on soda-lime silicate glasses. Wiederhorn used a geometry known as the double cantilever cleavage (DCC) technique (Fig. 1(a)) to measure crack velocity $(v)$ versus stress intensity $\left(K_{\mathfrak{Y}}\right)$. The stress intensity was calculated analytically from the sample geometry, the applied load, and the crack length. It is important to note that with this geometry, the stress intensity increases as the crack length increases under a constant applied load, so the crack velocity is continuously accelerating throughout the measurement. Wiedertorn found that the stress intensity needed for crack growth at a certain velocity increased as the water vapor pressure decreased, a strong indication that water was necessary to weaken the structure. This observation has been con-

S. W. Wiederhorn-contributing editor

Manuscript No. 189887. Received September 8, 1998; approved May 10, 1999. Member, American Ceramic Society.

'Now at Ferro Corporation, Cleveland, Ohio 44131. firmed many times in various mechanical test geometries and also for both gaseous and liquid water environments.

There is abundant literature on the crack growth of silicate glasses, but to our knowledge no data exist on phosphate glasses. Multicomponent phosphate glasses are important as hosts for laser ions, especially in applications where high output energy and high peak power are required. ${ }^{2}$ These glasses are excellent laser ion hosts, but suffer from several problems. One problem is that phosphate glasses are readily attacked by water, much more so than silicate glasses. Another problem is that these glasses have significantly lower fracture toughness than silicate glasses (approximately 0.4-0.5 $\mathrm{MPa}^{1 / 2}$ for metaphosphates $^{2,3}$ and $0.7-1.1 \mathrm{MPa}^{1 / 2}$ for silicates ${ }^{4}$ ).

Initially we attempted to measure slow crack growth in these glasses as a function of temperature and humidity using the DCC geometry. However, preliminary measurements proved unsuccessful. Whenever a crack formed in the specimen, it grew so rapidly that useful data could not be obtained. Therefore, a different approach was taken. An alternative geometry first proposed by Janssen 5 offered a solution. The geometry, known as the double-cleavage-drilled compression (DCDC) geometry (Fig. 1(b)), features a stress intensity that decreases as the cracks grow under a constant applied load. When this sample is loaded in compression, the top and bottom of the hole experience a tensile stress which, under sufficient load, leads to the formation and growth of a pair of opposing cracks. The stress intensity decreases as the crack tips move farther away from the hole, so the crack growth rate decelerates as the crack grows. Thus this geometry is more stable since the cracks are slowing down continuously. The one disadvantage of this geometry is that there is no analytical solution for calculating the stress intensity, $K_{\mathrm{I}}$, as a function of crack length, $\ell$. Janssen ${ }^{5}$ offered a solution by finite element analysis for determining $K_{\mathrm{I}}$. This solution was later confirmed by Michalske et al., ${ }^{6}$ who also found an empirical equation that described the stress intensity as a function of crack length for a substantial range of crack lengths. The empirical equation is accurate to within $10 \%$ of the "exact" solution offered by finite element analysis.

An important consideration in the strength of brittle materials is crack tip blunting. In the original Griffith theory, ${ }^{7}$ the strength of a sample is reciprocally proportional to the square root of the crack length, under the assumption that all crack tips have the same sharp radius of curvature. In the years that followed, the fracture mechanics community continued to assume that all crack tips are atomistically sharp. However, there are many indications that the crack tip of glasses can be made blunt. For example, it is known that the strength of abraded glass rods increases after soaking in water. Ito and Tomozawa ${ }^{8}$ showed that the strengthening of abraded silica glass by soaking in hot water is faster when the hot water contains silicic acid $\left(\mathrm{Si}(\mathrm{OH})_{4}\right)$, and proposed that crack tip blunting occurs by 
(a)

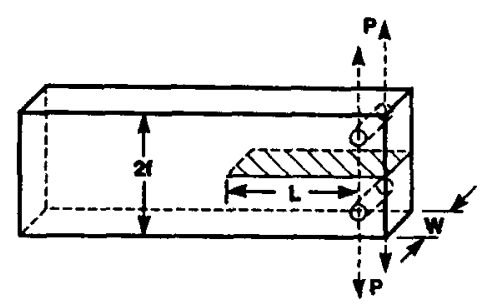

(b)

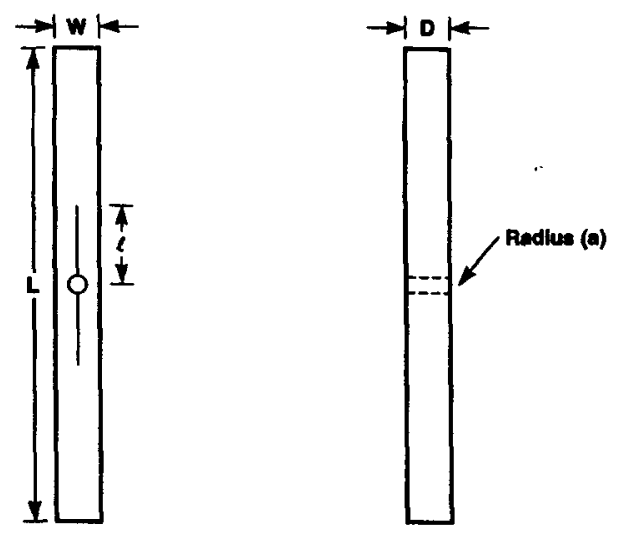

Fig. 1. Typical sample geometries used for slow crack growth measurements: (a) Wiederhom ${ }^{1}$ double-cantilever-cleavage (DCC) geometry, and (b) Janssen ${ }^{5}$ double-cleavage-drilled compression (DCDC) geometry. Geometry (b) was used exclusively in these experiments.

a dissolution and reprecipitation mechanism. Lawn et al. ${ }^{9}$ offered an alternative explanation for this strengthening of abraded glasses. They proposed that residual stress was created around the flaws during the abrasion process and that the residual tensile stress was released during the water soak, thus increasing the strength of the soaked samples. Later, Bando et al. ${ }^{10}$ showed electron micrographic evidence for the presence of a blunt crack tip in silica glass.

Since phosphate glass is generally more susceptible to water attack than most glasses studied to date, there is a possibility that crack tip blunting occurs more readily in phosphate glasses than in silicate glasses. Also, the relatively low $T_{g}$ of phosphate glasses could aid in crack tip blunting at a given temperature, especially if viscous flow is the mechanism by which blunting occurs.

In this study, the crack growth rate of the phosphate glass samples is measured and modeled as a function of temperature and humidity. Evidence for crack tip blunting is discussed.

\section{Experimental Procedure}

The glass used in this study (LG-770) is a multicomponent, near metaphosphate glass (O/P - 3). LG-770 is commercial laser glass developed by Schott Glass Technologies, Inc., that has the following approximate composition (mol\%): 58-62\% $\mathrm{P}_{2} \mathrm{O}_{5}, 6-10 \% \mathrm{Al}_{2} \mathrm{O}_{3}, 20-25 \% \mathrm{~K}_{2} \mathrm{O}$, and 5-10\% $\mathrm{MgO}$. The glass that we used had a doping of about $4 \times 10^{20} \mathrm{Nd}^{3+}$ ions/ $\mathrm{cm}^{3}$ or about $1.8 \mathrm{~mol} \% \mathrm{Nd}_{2} \mathrm{O}_{3}$. This glass composition is typical of commercially available laser glasses used in high-peakpower fusion laser systems (see, for example, Ref. 11). $T_{\mathrm{g}}$ for this glass, measured at the onset of the DTA peak, was $742 \mathrm{~K}$. The glass samples were fabricated into rectangular pieces $75 \mathrm{~mm} \times 7.5 \mathrm{~mm} \times 6.5 \mathrm{~mm}$ and a hole of $1 \mathrm{~mm}$ radius was core-drilled through each sample at the center of the $75 \mathrm{~mm} \times$ $7.5 \mathrm{~mm}$ face of the specimen (Fig. 1(b)). The two sample surfaces containing the hole were polished prior to core drilling. This is the same geometry used by Michalske et al. ${ }^{6}$ Two opposing starter cracks were cut at the top and bottom of the hole using a $0.3 \mathrm{~mm}$ diameter diamond-coated wire. Two stainless steel hemispheres were cut from ball bearings and secured to the top and bottom of the sample by mounting wax following the procedure employed by Helfinstine. ${ }^{12}$ This was done to ensure that the load was distributed evenly across the cross section of the sample, as opposed to the point or line loading possible if the end faces of the sample are not perfectly flat and aligned with the compression grips.

The samples were loaded in a Model 8562 Instron, capable of both load and position control, with a $500 \mathrm{~kg}$ load cell. A 0.095-m-diameter $\times 0.14-\mathrm{m}$-long cylindrical environment chamber was constructed with temperature control to within about $\pm 1.5 \mathrm{~K}$ at $296 \mathrm{~K}$ to about $\pm 3 \mathrm{~K}$ at $673 \mathrm{~K}$. The load was controllable to within $\pm 0.1 \mathrm{~kg}$, and the crosshead position to within $1 \mu \mathrm{m}$. The sample was loaded in compression between two flat plates by slowly bringing the plates closer to each other with the machine in position control. When a load of $-5-10 \mathrm{~kg}$ was reached, the machine was switched to load control, and the load was increased to $20 \mathrm{~kg}$. The sample was held at this point until the temperature and water vapor pressure conditions for that particular run were achieved. Most of the runs, unless otherwise noted, were done under controlled atmosphere conditions. In humid atmospheres, the desired water vapor pressure was generated by bubbling nitrogen gas through a water bath kept at a constant temperature within $\pm 1^{\circ} \mathrm{C}$ at low temperatures at $\pm 2^{\circ} \mathrm{C}$ at high temperatures. Dry atmospheres were achieved by using a nitrogen gas flow of $5 \times 10^{-7} \mathrm{~m}^{3} / \mathrm{s}$ from a standard compressed gas cylinder either used directly or by passing through a liquid nitrogen cryogenic trap. The $\mathrm{N}_{2}$ gas used from the compressed gas cylinder contained less than $2600 \mathrm{ppm} \mathrm{H}_{2} \mathrm{O}$ by volume (manufacturer's specification) whereas the cryogenically cooled $\mathrm{N}_{2}$ contained an estimated $395 \mathrm{ppm} \mathrm{H}_{2} \mathrm{O}$ by volume.

The position of the crack tip was monitored by use of a $14 x$ magnification cathetometer that could resolve a change in crack tip position of about $10 \mu \mathrm{m}$ (diffraction limit). The cathetometer crosshair was initially set at the bottom of the hole and the downward growing crack was monitored relative to this starting point. The cathetometer crosshair position was controlled by a micrometer. After the temperature and humidity had equilibrated in the chamber, the load was raised to $100 \mathrm{~kg}$, then raised in 10-kg increments until the crack was observed to grow. The crack was allowed to grow to at least $0.005 \mathrm{~m}$ in length, in order to minimize transient effects from the pre-crack and also because the crack must be at least that long before the empirical equation for the stress intensity becomes valid. ${ }^{6}$ The initial loads necessary to observe growing cracks ranged from 150 to $270 \mathrm{~kg}$, depending on temperature and humidity conditions.

When the crack reached the required minimum length, the load was raised an additional $10-20 \mathrm{~kg}$ and the data collection began. Initially the crack grew rapidly and data were taken in intervals as short as $15 \mathrm{~s}$, noting the crack length to a precision of $10 \mu \mathrm{m}$, and also recording the elapsed time. As the crack growth slowed, the time interval between readings was increased proportionately. For some samples, after the crack growth rates had been measured for a given load, the load was increased and another set of data was taken on the same sample.

Figure 2 shows a typical set of results obtained from a single sample that was subjected to two successive loadings. Because of the nature of the DCDC experimental method, successive loadings result in overlapping measurements of velocity vs $K_{\mathrm{I}}$. The data illustrate the excellent agreement between the velocity measurements vs $K_{1}$ achieved with this procedure.

For some samples, crack propagation appeared to stop completely. For these samples, after the crack had been stopped for a period of time (at least $30 \mathrm{~min}$ ), the load was increased in 10 $\mathrm{kg}$ increments until the crack growth started again. Usually the 


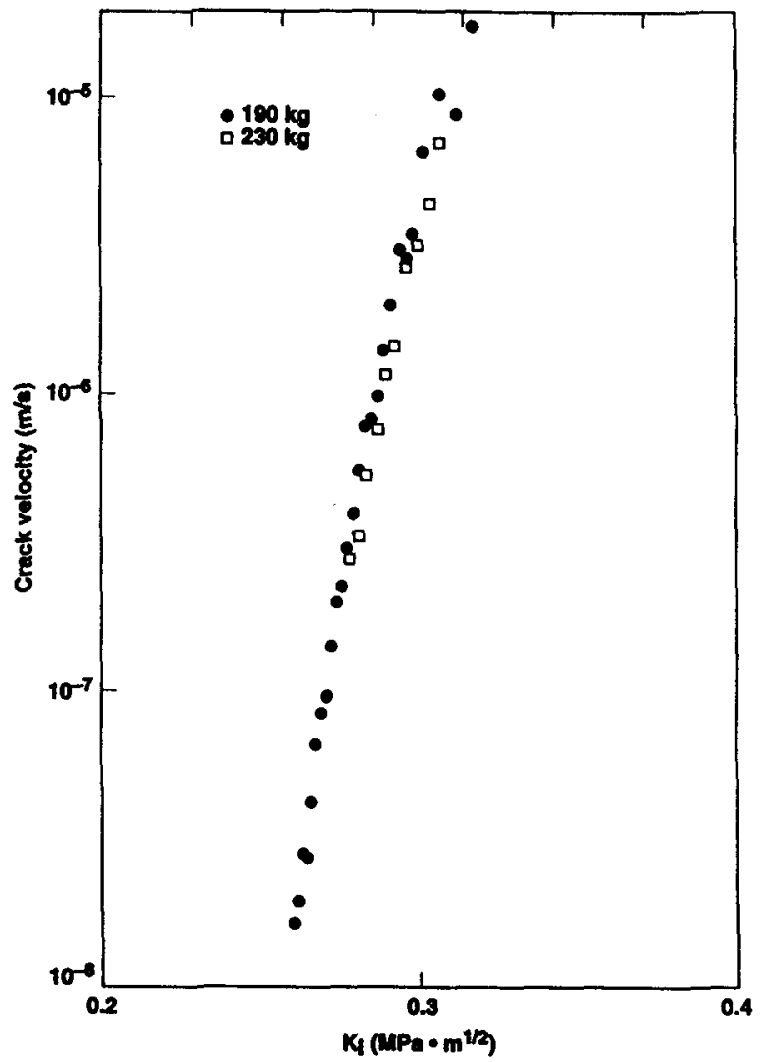

Fig. 2. Example of typical crack velocity data for phosphate glass obtained using the DCDC method and a sample subjected first to 190 and then $230 \mathrm{~kg}$ load $\left(23^{\circ} \mathrm{C}, P_{\mathrm{H}_{2} \mathrm{O}}=2.3 \times 10^{3} \mathrm{~Pa}(17 \mathrm{mmHg})\right)$.

increase in load needed to restart crack growth was substantial $(>30-50 \mathrm{~kg}$ ), and in several cases, additional crack growth did not take place even when the load was raised to the $500 \mathrm{~kg}$ limit of the load cell. For those samples in which additional crack growth did take place, the crack grew at a rate far too fast to be observable in the experimental setup and the final length was too long to be seen through the environmental chamber viewing port.

For many samples, the cracks were observed to heal over a period of several minutes after the load was removed. The growth rate for reopening a healed crack was measured on one of these samples using the procedure described above.

The crack growth data were analyzed by plotting the measured crack velocity vs stress intensity. The stress intensity for a given crack length is given by Michalske et al. ${ }^{6}$ for the sample geometry employed here:

$$
K_{1}=\frac{\sigma \sqrt{a}}{1.595+0.353 \frac{\ell}{a}}
$$

where $K_{1}$ is the stress intensity $\left(\mathrm{MPa}^{\mathrm{m}} \mathrm{m}^{1 / 2}\right), \sigma$ is the applied stress $(\mathrm{MPa}), \ell$ is the crack length (m) measured from the center of the hole, $a$ is the hole radius ( $m$ ), and the numbers are empirically determined constants. The above equation is valid in the range of $5<\ell / a<12$. The crack velocity was calculated by a simple finite difference between successive data points, i.e., $v=\Delta \ell / \Delta t$ where $\Delta \ell$ is the incremental crack length for the incremental time $\Delta t$.

\section{Results}

\section{(I) Dependence on Temperature and Water Vapor Pressure}

Slow crack growth experiments were carried out over a range of temperatures from 296 to $573 \mathrm{~K}$, water vapor pres- sures from $40 \mathrm{~Pa}(0.3 \mathrm{mmHg})$ to $4.7 \times 10^{4} \mathrm{~Pa}(355 \mathrm{mmHg})$ and stress intensities in the region between 0.2 to $0.4 \mathrm{MPa}^{1 / 2}$. The corresponding range in measured crack velocities varied from approximately $10^{-8}$ to $10^{-4} \mathrm{~m} / \mathrm{s}$.

The effect of temperature on crack growth rate for fixed water vapor pressures of $270 \mathrm{~Pa}(2 \mathrm{mmHg})$ and $2.3 \times 10^{3} \mathrm{~Pa}$ $(17 \mathrm{mmHg}$ ) are shown in Fig. 3. In contrast, Fig. 4 plots the effect of varying water vapor pressure on crack velocity for isothermal conditions of 348,423 , and $498 \mathrm{~K}$.

It is clear from the data in Figs. 3 and 4 that for a fixed stress intensity, changes in temperature have a far greater effect on crack growth velocity than do corresponding percent changes in water vapor pressure. This is expected since the velocity of crack growth is either reaction rate or diffusion limited, both of which are thermally activated processes having an exponential dependence with $T^{-1}$. Thus, for example, a change in temperature by $75 \mathrm{~K}$ can produce as much as a $10^{3}$ to $10^{4}$ change in crack velocity. In contrast, the effect of vapor pressure on crack velocity is more nearly linear, again in agreement with the commonly accepted chemical-reaction-driven crack growth models.

Slow crack growth of silicate glasses is generally characterized by three distinct regions ${ }^{1.13}$ (regions I, II, and III); these three regions are also clearly seen in the experimental data on phosphate glass (Fig. 3(a)). Region I refers to the range of conditions for which crack growth is reaction-rate limited and is characterized by an approximately linear increase in the logarithm of the crack velocity vs $K_{\mathrm{I}}$. Region II refers to the conditions over which the crack velocity appears to "plateau" to a constant value with increasing $K_{\mathrm{I}}$. In region II the crack velocity is mass-transport limited by the rate of diffusion of

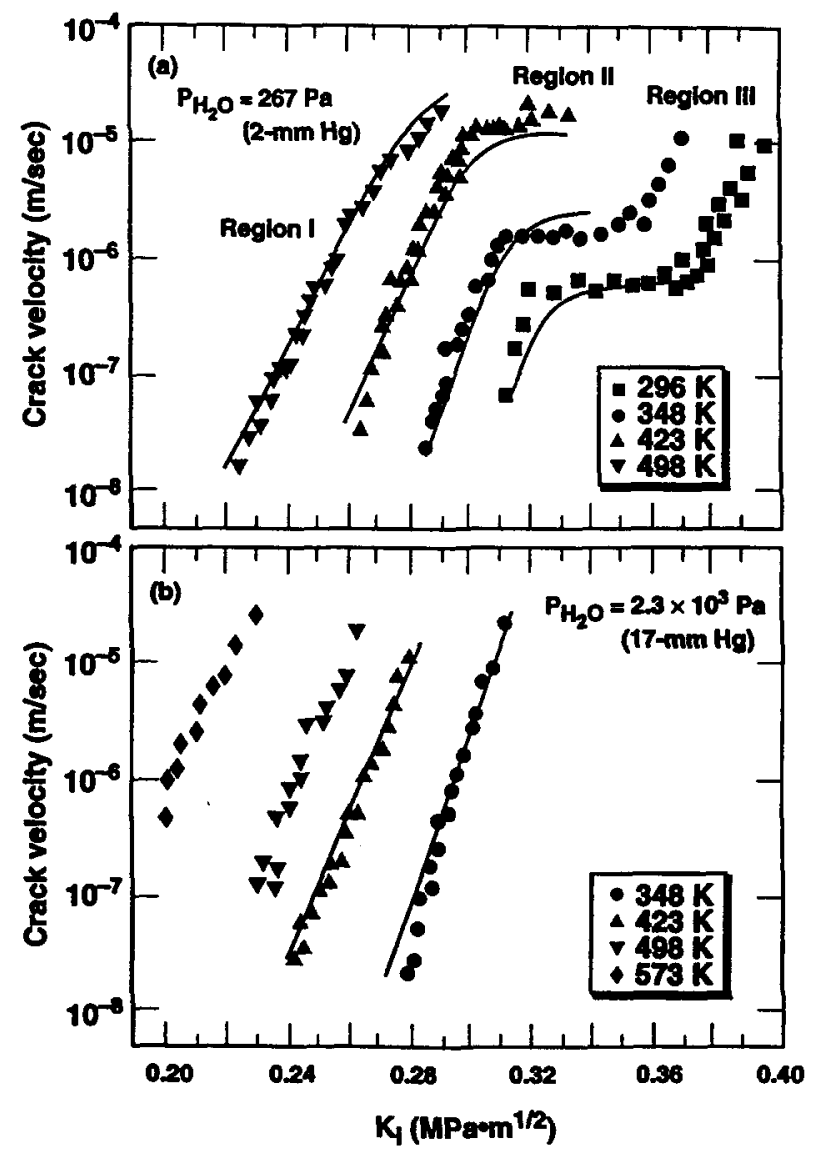

Fig. 3. Crack growth rate measured at various temperatures and con-

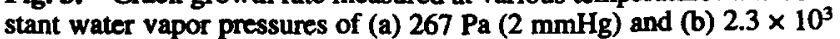
$\mathrm{Pa}(17 \mathrm{mmHg})$. The lines are fits to the data using the reaction rate model (Eq. (7)) and a single set of parameters. Only those data outside the region of significant crack blunting are fitted with the model. 


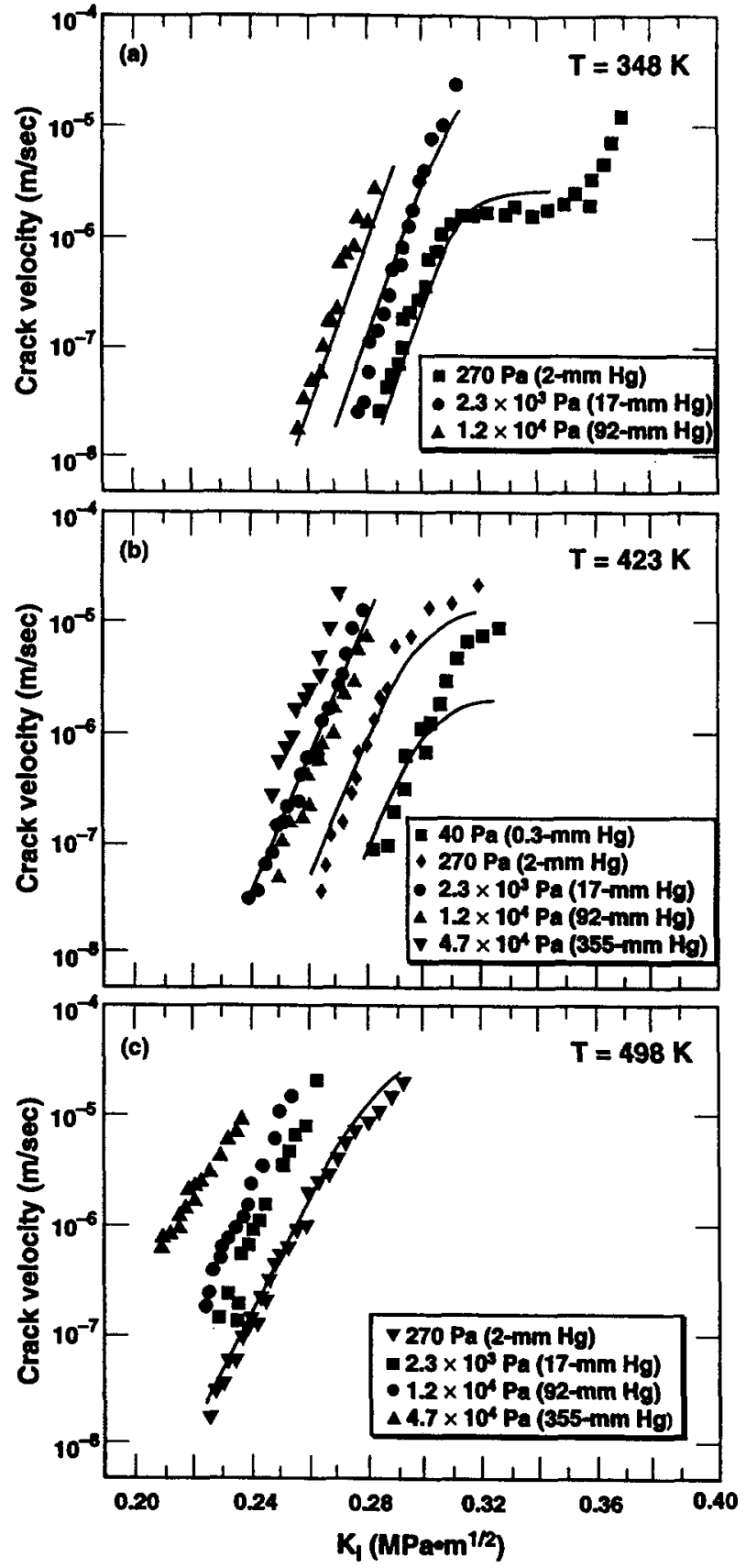

Fig. 4. Crack growth rate for various water vapor pressures at constant temperatures: (a) 348 , (b) 423 , and (c) $498 \mathrm{~K}$. The lines represent fits to the data using the reaction rate model (Eq. (7)) and the same set of parameters used in Fig. 3. Only those data outside the region of significant crack blunting are fitted with the model.

reactants (in this case $\mathrm{H}_{2} \mathrm{O}$ ) to the crack tip; the transition from region $I$ to region $I I$ is clearly shown in Fig. 3(a). Finally, region III refers to the conditions where crack velocity becomes independent of the chemical environment. Region III typically occurs at $K_{I}$ values approaching the fracture toughness limit and is evidenced by an abrupt increase in crack velocity at the end of region II.

Under isothermal conditions the transition from region II to III in silicate glasses is typically characterized by a rapid coalescence of the various growth curves into a single band of values in which the velocity is solely a function of $K_{1}{ }^{1}$ In our study only two of the measurements extended into region III (Fig. 3(a)). However, because these measurements were carried out at different temperatures, we do not see the coalescence of crack growth curves commonly seen under isothermal conditions.
Anomalously high crack velocities were observed at $296 \mathrm{~K}$ at a pressure of $2.3 \times 10^{3} \mathrm{~Pa}(17 \mathrm{mmHg})$. This is illustrated in Fig. 5 which compares measured crack velocities at 296, 348, and $423 \mathrm{~K}$ for a fixed vapor pressure of $2.3 \times 10^{3} \mathrm{~Pa}(17$ $\mathrm{mmHg}$ ). The high crack velocities at $296 \mathrm{~K}$ are actually higher than those at $348 \mathrm{~K}$ contrary to the expected temperature dependence. The $296 \mathrm{~K}$ measurements are reproducible. Later we suggest a possible explanation for this anomalous behavior.

\section{(2) Region of Crack Arrest under Load}

With the DCDC crack growth method (see Section II) the stress intensity at the crack tip decreases as the crack grows and moves away from the center hole under a constant applied load. Thus the crack velocity decelerates several orders of magnitude during the course of one test. Ordinarily, the crack velocity continues to decelerate to a low, but still measurable, level. However, at high temperatures and vapor pressures, crack growth was observed to slow and then stop abruptly (at least to within detection limits). Furthermore, when the load was increased to restart the crack growth, it was found that a very large increase was necessary to re-initiate growth. Once initiated, the new crack grows too rapidly to measure and often extending beyond the range of view of the cathetometer. For a typical DCDC measurement, the test load is in the range of 200 $\mathrm{kg}$; however, for two samples, increasing the load to $500 \mathrm{~kg}$ (the limit of the Instron load cell) still was insufficient to restart crack growth.

In this paper we refer to the failure to initiate slow crack growth upon application of a higher load as "crack tip blunting." Figure 6 shows the regions of temperature and pressure for this study where this crack blunting phenomenon is observed (defined as no measurable crack growth in $\sim 1800 \mathrm{~s}(-30$ $\mathrm{min})$ ). The dashed line indicates the approximately boundary of temperature and water vapor pressure conditions above which restart of crack growth becomes difficult once it has stopped. Under conditions where crack blunting is observed, the "timeto-blunt" decreases with increasing temperature and water vapor pressure. Here we define the time-to-blunt as the time difference between when crack growth has stopped under one load to the time when application of a higher load fails to reinitiate slow crack growth. Note that the observed time dependence associated with onset of blunting suggests that it is a dynamic process.

\section{(3) Crack Healing}

In a number of cases we observed that the crack closes to the point where it becomes visually undetectable a few minutes after removing the load. This suggests that the opposing faces

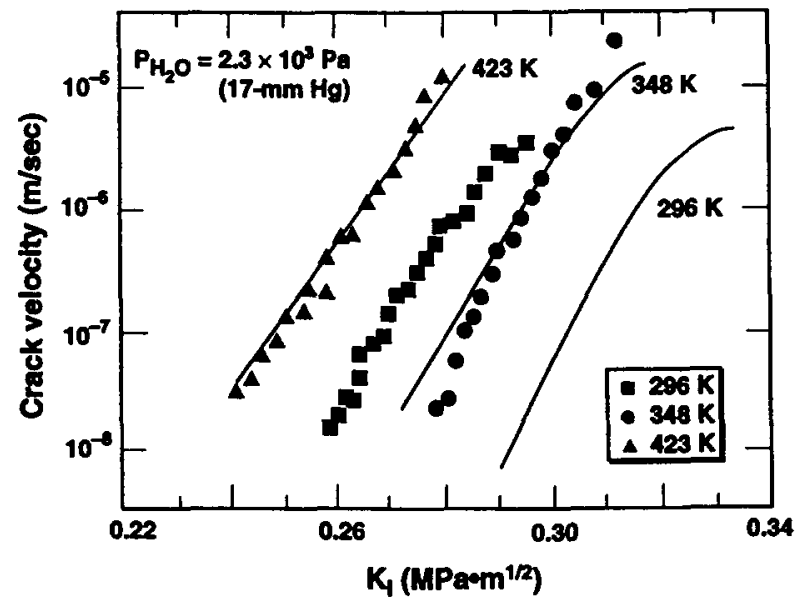

Fig. 5. Comparison of crack growth velocities measured at 296, 348, and $423 \mathrm{~K}$ and $2.3 \times 10^{3} \mathrm{~Pa}(17 \mathrm{mmHg})$ water vapor pressure showing the anomalous behavior at $296 \mathrm{~K}$ suspected to be the result of capillary condensation. The lines represent model predictions using Eq. (7). 


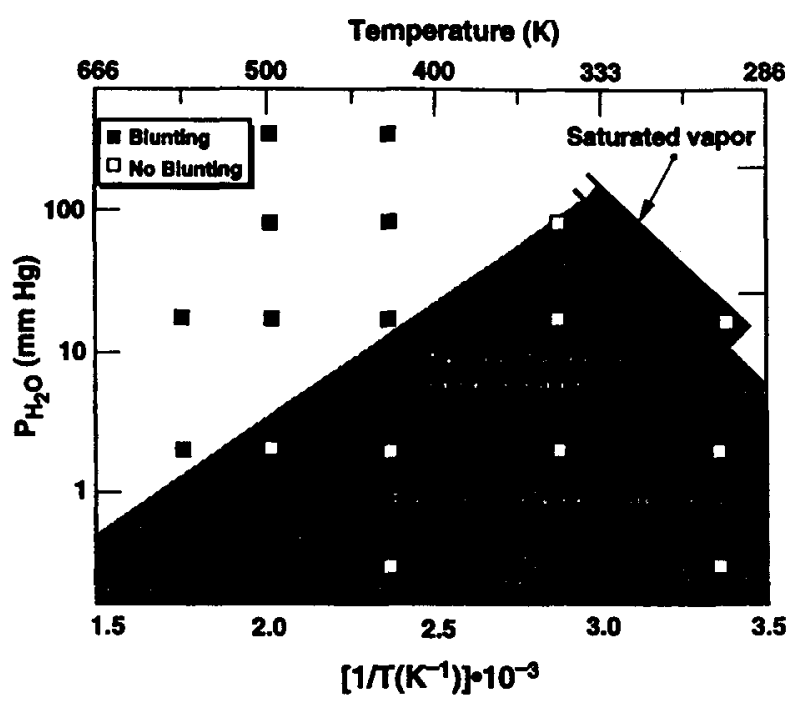

Fig. 6. Temperature and water vapor pressure regions where crack blunting is and is not significant; the dashed line is the approximate boundary between these two regions. In the region above the dashed line, crack tip blunting significantly influences crack growth whereas the region below the line shows negligible blunting and is accurately represented by the slow crack growth model (Eq. (7)). The shaded region between the two solid lines represents the $P_{\mathrm{H}_{2} \mathrm{O}}$ vs $T$ region of potential capillary condensation at the crack tip; the upper line is the water-saturated vapor pressure and the lower line represents the limit for capillary condensation for a crack tip radius of $1.5 \mathrm{~nm}$.

may have rebonded (i.e., the crack has "healed"). To test this, one such sample was retested in the Instron. The results show that the healed crack recovered a significant portion $(-80 \%)$ of the original glass strength, indicating substantial bonding between the crack faces. Wiederhorn and Townsend, ${ }^{14}$ Stavrinidis and Holloway, ${ }^{15}$ and Michalske and Fuller ${ }^{16}$ observed similar crack healing behavior for cracks in silicate glasses.

\section{Discussion}

As stated above, it is well known that slow crack growth measurements on silicate glasses show three characteristic regions of crack velocity versus stress intensity and the data presented here for phosphate glass show similar behavior. Although the exact chemical mechanism of crack propagation is not completely understood, it is generally accepted that the crack front movement in regions I and II involves the transport of $\mathrm{H}_{2} \mathrm{O}$ through the crack and the subsequent reaction between water and the crack tip. Hence it is believed that the rate of crack growth is governed by a combination of reaction kinetics and mass transfer. Various models have been developed to describe crack growth in regions I and II with the most widely accepted being that of Weiderhorn. ${ }^{1,17,18}$ In this section Wiederhorn's model is used to analyze the data over the range of conditions for which the model is valid (i.e., no change in crack tip radius). This analysis leads to two main results. First, a set of model parameters are derived that accurately predict crack growth under most experimental conditions. These model parameters can be used in engineering applications for predicting crack growth in phosphate glass over a broad range of process conditions. Second, the analysis shows that the model tends to break down at high temperature and high water vapor pressure where crack tip blunting is observed. This suggests a physical picture of the crack growth in phosphate glass in which crack propagation competes with crack blunting. This also suggests avenues of further experimental and modeling work needed to more accurately describe crack growth in phosphates.

\section{(1) Behavior in Region I}

Wiederhorn's model describes the dependence of crack growth on stress intensity, temperature, and water vapor pressure by the expression

$$
v_{\mathrm{l}}=A\left(\frac{p}{p_{0}}\right)^{m} \exp \left(\left[K_{\mathrm{l}} b-Q_{\mathrm{l}}\right] / R T\right)
$$

where $v_{I}$ is the crack velocity in region $I(\mathrm{~m} / \mathrm{s}), p$ is the water vapor pressure $(\mathrm{Pa}), K_{\mathrm{I}}$ is the stress intensity $\left(\mathrm{Pa} \cdot \mathrm{m}^{1 / 2}\right)$, and $R$ and $T$ have their usual meanings. We normalized the water vapor pressure to $1 \mathrm{~atm}$ (i.e., $1.013 \times 10^{5} \mathrm{~Pa}(760 \mathrm{mmHg})$ ); thus $p / p_{0}$ represents the relative variation in reactant concentration. The model includes four parameters- $A, m, b$, and $Q_{\mathrm{I}}$ - that have various physical meanings in the reaction process: $Q_{\mathrm{I}}$ is the activation energy $(\mathrm{kJ} / \mathrm{mol}), m$ is the "order" of the reaction in terms of the water vapor reactant, and $A(\mathrm{~m} / \mathrm{s})$ can be likened to the preexponential constant that often appears in reaction rate expressions. The parameter $b\left(\mathrm{~m}^{5 / 2} / \mathrm{mol}\right)$ is related to the activation volume and is discussed in more detail later.

Values for the four model parameters $\left(A=2.96 \times 10^{6} \mathrm{~m} / \mathrm{s}\right.$, $m=1.19, b=0.496 \mathrm{~m}^{2.5} / \mathrm{mol}$, and $Q_{\mathrm{I}}=216 \mathrm{~kJ} / \mathrm{mol}$ ) were determined by a multiple regression analysis of the data taken in the region where crack blunting effects are negligible (see Fig. 6). The value of $m$ was determined to be 1.19; this is close to 1.0 and suggests that crack tip bond breaking is governed by reaction kinetics first-order in $\mathrm{H}_{2} \mathrm{O}$. Wiederhorn's analysis of the crack growth in soda-lime silicate glass at moderate to high vapor pressures (similar to those used here) also showed $m=$ 1 ; however, at lower vapor pressures $m$ decreased to a value of about 0.5 in the soda-lime glass. Soga et al., ${ }^{19}$ on the other hand, observed $m=1$ by eliminating gases other than water vapor.

The activation energy, $Q_{\mathrm{I}}$, for crack growth in this phosphate glass is $216 \mathrm{~kJ} / \mathrm{mol}$, which is significantly greater than the value of $109 \mathrm{~kJ} / \mathrm{mol}$ reported for crack growth in soda-lime glass in liquid water. ${ }^{18}$ This partially explains the greater temperature sensitivity of crack growth in phosphate glass compared to silicates although the exact nature of the ratecontrolling reaction step remains unknown.

Physical insight into the significance of the parameter, $b$, can be gained by equating Wiederhorn's model for crack growth with a similar equation developed by Hillig and Charles to describe crack growth at a constant water vapor pressure:20,21

$$
\nu_{\mathrm{I}}=A^{\prime} \exp \left[\left(-Q_{\mathrm{I}}+\frac{2 V_{\mathrm{a}} K_{\mathrm{I}}}{3 \sqrt{\pi \rho}}\right) / R T\right]
$$

where $A^{\prime}$ is a preexponential constant $(\mathrm{m} / \mathrm{s}), V_{\mathrm{a}}$ is the activation volume $\left(\mathrm{m}^{3} / \mathrm{mol}\right)$, and $\rho$ is the crack tip radius $(\mathrm{m})$. Equating the Weiderhorn model (Eq.(2)) with that of Hillig and Charles (Eq. (3)) shows that $b$ is related to the activation volume and crack tip radius:

$$
b=\frac{2 V_{\mathrm{a}}}{3 \sqrt{\pi \rho}}
$$

The value of $b=0.496 \mathrm{~m}^{5 / 2} / \mathrm{mol}$ was determined by the regression analysis. This value is similar to the previously obtained values, ${ }^{21} 0.26-0.88$, for various different glasses. If we assume a crack tip radius of $1.5 \mathrm{~nm}$ as determined by electron micrograph for silica glass, ${ }^{10}$ then one can use Eq. (4) to estimate an activation volume for crack growth of $51.1 \times 10^{-6}$ $\mathrm{m}^{3} / \mathrm{mol}$ for this phosphate glass. If we use a crack tip radius of $0.5 \mathrm{~nm}$ (characteristic of an atomically sharp crack), the value used by Wiederhorn et al., ${ }^{21}$ we get an activation volume of $29.5 \times 10^{-6} \mathrm{~m}^{3} / \mathrm{mol}$.

\section{(2) Behavior in Region II}

As previously stated, the characteristic plateau region where the crack growth rate becomes nearly independent of the stress intensity is called region II. This occurs when the crack growth becomes limited by the rate at which water is transported to the crack tip. ${ }^{1}$ The region II crack velocities follow an Arrhenius temperature dependence indicative of a thermally activated mass transport process. Based on this observation and knowing the transport rate depends linearly on the water vapor pressure, 
the following expression can be used to model crack velocity $\left(v_{\mathrm{II}}\right)$ in region II:

$$
\nu_{\mathrm{II}}=C \cdot \frac{p}{p_{0}} \cdot \exp \left(\frac{-Q_{\mathrm{II}}}{R T}\right)
$$

where $C$ is a preexponential constant $(\mathrm{m} / \mathrm{s}), Q_{\mathrm{II}}$ is the activation energy for transport $(\mathrm{kJ} / \mathrm{mol})$, and the other terms have been defined previously. The values for $C$ and $Q_{\mathrm{II}}$, determined from the present crack growth data, are $8.21 \mathrm{~m} / \mathrm{s}$ and $26 \mathrm{~kJ} / \mathrm{mol}$, respectively.

The mechanism of $\mathrm{H}_{2} \mathrm{O}$ mass transport to the crack tip has been the subject of previous investigations. ${ }^{1.22}$ Wiederhorn $^{1}$ assumed $\mathrm{H}_{2} \mathrm{O}$ mass transport to be controlled by gas diffusion across a boundary layer at the crack tip in his study of crack growth in soda-lime glass. He further assumed that the water concentration outside the boundary layer remained constant and was continuously replenished by the bulk flow of the surrounding humid inert gas $\left(\mathrm{N}_{2}\right)$ into the void created by the growing crack. Lawn ${ }^{22}$ later extended Wiederhorn's gas diffusion concept to include Knudsen diffusion (molecular flow) by arguing that the mean free path between gas molecule collisions is greater than the assumed crack tip separation of $0.1 \mu \mathrm{m}$.

Bulk gas diffusion and Knudsen diffusion depend on temperature as $T^{3}$ and $T^{1 / 2}$, respectively. The crack velocity in region II is mass-transport limited and therefore dependent on the product of the diffusion coefficient and the water vapor concentration. Assuming the temperature dependence of the water vapor concentration follows the ideal gas law $\left(T^{-1}\right)$, then the crack velocity should show a $T^{1 / 2}$ and $T^{-1 / 2}$ dependence if controlled by bulk gas and Knudsen diffusion, respectively. In contrast, the data from this study show a much steeper temperature dependence suggesting that for phosphate glasses the gas diffusion mechanisms mentioned above are not the ratecontrolling step for mass transport to the crack tip.

One alternative explanation is mass transport by surface diffusion. The rate of surface diffusion is controlled by the activation energy separating adjacent adsorption sites and, therefore, would be expected to follow an Arrhenius-type temperature dependence. Morariu and $\mathrm{Mills}^{23}$ have studied the self-diffusion of adsorbed water on hydrated silica surfaces and report an activation energy of about $20-25 \mathrm{~kJ} / \mathrm{mol}$ for water in the second statistical monolayer. This is in reasonable agreement with the activation energy reported here $(26 \mathrm{~kJ} / \mathrm{mol})$. Note that energies less than about $40 \mathrm{~kJ} / \mathrm{mol}$ often correspond to weak bonds associated with physical absorption on a surface or hydrogen bonding. 24

Although it is tempting to conclude that surface diffusion is the controlling mass transport process in this study, there are other plausible mechanisms. For example, bulk gas diffusion that is modified by adsorption on the crack surface ${ }^{25}$ may also account for the observed temperature dependence. In such a case, the effective gas diffusion coefficient, $D_{\text {eff, }}$ is expressed as ${ }^{25}$

$$
D_{\text {eff }}=D /\left(1+K_{x} A / V\right)
$$

where $K_{\mathrm{a}}$ is an equilibrium constant describing the distribution of $\mathrm{H}_{2} \mathrm{O}$ adsorbed on the solid surface $v s$ that in the gas phase, and $V\left(\mathrm{~m}^{3}\right)$ and $A\left(\mathrm{~m}^{2}\right)$ represent the crack volume and the exposed surface area, respectively. According to Eq. (6) the adsorption of water on the crack surface has the effect of reducing the bulk diffusion rate and thus $K_{\mathrm{a}}$ is often referred to as the retardation factor. In general, the greater the degree of adsorption of water on the crack surface, the larger the overall reduction in the effective gas diffusion rate. Despite this retardation effect, the temperature dependence of $K_{\mathrm{a}}$ can cause $D_{\text {eff }}$ to increase with temperature, particularly if $K_{a}$ is an activated process.

Okamoto and $\mathrm{Tuzi}^{25}$ have used Eq. (6) to model the adsorption of water on soda-lime and borosilicate glasses at very low water vapor pressures $\left(-1.3 \times 10^{-3} \mathrm{~Pa}, \sim 10^{-5} \mathrm{mmHg}\right)$ and low coverage ( $\leq 1 \%$ of a monolayer) over a range of 273 to $403 \mathrm{~K}$. Their data show an exponential decrease in $K_{\mathrm{a}}$ with increased temperature (i.e., $D_{\text {eff }}$ increases exponentially) with an activation energy of $29 \mathrm{~kJ} / \mathrm{mol}$. This exponential dependence is similar to what we report here.

Unfortunately, it is not possible to define the exact mechanism that controls the rate of mass transport in these experiments. Therefore, to avoid further belaboring the issue, we simply conclude that our data show an Arrhenius-type temperature dependence that is not consistent with either bulk gas diffusion or molecular flow mechanisms. Surface diffusion is one possible explanation for this behavior although other mechanisms are also plausible. Nevertheless, Eq. (5), which has been empirically derived from our data, can be used to accurately predict region II crack velocities over the range of temperature and pressure conditions reported here.

The expressions for $v_{\mathrm{I}}$ and $v_{\mathrm{II}}$ (i.e., Eqs. (2) and (5)) describe the crack growth velocity in the limits of regions I and II, respectively. These two velocities can be combined into a single expression describing the composite slow crack growth velocity across both regions I and II.

$$
v=\frac{v_{\mathrm{I}} v_{\mathrm{II}}}{v_{\mathrm{I}}+v_{\mathrm{II}}}
$$

where the composite crack growth velocity $(v)$ is the wellknown harmonic mean of the crack velocity, $v_{I}$, in region I (Eq. (2)) and, $v_{\text {II }}$ in region II (Eq. (5)). Lawn ${ }^{22}$ has used a similar approach for describing the combined crack velocities of regions I and II. Note that in the limit of region I, Eq. (7) approaches $v \sim v_{\mathrm{l}}$, and similarly in region II, $v \sim v_{\mathrm{n}}$.

The velocities calculated by $\mathrm{Eq}$. (7) are compared to the experimental data in Figs. 3-5. Good agreement of the model with the data were obtained for temperatures and vapor pressures where crack tip blunting is negligible. In Section IV(4) we discuss the effects of blunting on the model predictions.

\section{(3) Crack Growth Enhanced by Capillary Condensation}

One possible explanation for the anomalous behavior of the crack growth at $296 \mathrm{~K}$ and $2.3 \times 10^{3} \mathrm{~Pa}(17 \mathrm{mmHg})$ is capillary condensation at the crack tip. Under such conditions the measured crack growth would tend to approach a growth rate expected in liquid water rather than in water vapor. The possibility of water condensation at the crack tip has been proposed by others, particularly for conditions in which the relative humidity exceeds $30 \% .1$ In addition, the presence of any glass corrosion products in the water phase would further reduce the equilibrium vapor pressure.

Capillary condensation implies a state of localized thermodynamic equilibrium between a liquid and vapor phase. Such conditions can exist even at a moving crack front as long as the rate of mass transport of water vapor to the crack tip exceeds the combined rate of crack tip motion and water consumption associated with bond breaking during fracture growth. Region I is the region of chemical-kinetic limited growth and therefore meets this requirement.

Capillary condensation is described by the well-known Kelvin equation, which relates the curvature of a surface to the associated equilibrium vapor pressure. For the present case of a line crack,

$$
\frac{p_{\mathrm{r}}}{p_{\mathrm{s}}}=\exp \left(\frac{\gamma M}{r d R T}\right)
$$

where $p_{\mathrm{r}}$ is the equilibrium vapor pressure ( $\mathrm{Pa}$ ) above a curved liquid surface of radius $r(\mathrm{~m})$, molecular weight $M(\mathrm{~kg} / \mathrm{mol})$, density $d\left(\mathrm{~kg} / \mathrm{m}^{3}\right)$ and having surface tension $\gamma\left(\mathrm{J} / \mathrm{m}^{2}\right) ; p_{z}$ is the equilibrium saturation vapor pressure $(\mathrm{Pa})$ above a flat surface.

The vapor pressure reduction (i.e., $p_{\mathrm{r}} / p_{\mathrm{s}}$ ) for water at a crack tip at $296 \mathrm{~K}$ is estimated to be about 0.5 (50\% relative humidity). Here we assume a crack tip radius of $1.5 \mathrm{~nm}$ as reported by Bando et al. ${ }^{10}$ based on TEM measurements of a crack in silica glass. The pressure reduction is more than sufficient to 
lead to capillary condensation at the crack tip when using a water vapor pressure of $2.3 \times 10^{3} \mathrm{~Pa}(17 \mathrm{mmHg})$ at $296 \mathrm{~K}$; the saturation pressure at this temperature is $2.8 \times 10^{3} \mathrm{~Pa}(21$ $\mathrm{mmHg}$ ), giving $p / p_{\mathrm{s}}$ of 0.83 ( $83 \%$ relative humidity). It is possible that this capillary condensation is the cause of the greater crack growth rate at this temperature.

In Fig. 6 we include the water saturation pressure (i.e., $100 \%$ relative humidity) versus temperature and also the corresponding vapor pressure estimated for the onset of capillary condensation at the crack tip. Our experimental condition of $296 \mathrm{~K}$ and $2.3 \times 10^{3} \mathrm{~Pa}(17 \mathrm{mmHg})$ falls within these two limits.

Alternately, the anomalous crack growth of the present glass at low temperature may be due to the nature of the phosphate glass surface which collects water from the atmosphere. Recent experiments by one of the authors indicate that the surface of this phosphate glass undergoes unusual reaction with water. ${ }^{26}$

\section{(4) Crack Tip Blunting}

The difficulty of reinitiating crack growth at high temperatures and water vapor pressures can be interpreted as an effective increase in the crack tip radius; in other words, the tip becomes blunt. As noted earlier, an alternative explanation of residual stress release was suggested ${ }^{9}$ for the similar strength increase. But in the present experiment no residual stress is involved. We use this crack tip blunting, i.e., change of crack tip radius, without change of crack length to analyze the results from our experiments.

The approximate temperature and pressure conditions where crack blunting becomes significant are shown in Fig. 6; the dashed line roughly separates the regions of significant vs negligible blunting. These data are for a holding time of $\sim 1800 \mathrm{~s}$ ( $-30 \mathrm{~min}$ ); the line would be shifted lower for longer holding times. In view of the large viscosity-reduction effect of water in glass, it is plausible that the blunting mechanism is glass viscous flow promoted by water entry into the glass from the atmosphere.

As noted above, we make the assumption that crack tip blunting is due to an effective change in radius of the crack tip. Therefore, we can estimate the relative change in the crack tip radius due to blunting from the relative increase in load needed to restart crack growth:

$$
\frac{\rho_{\mathrm{b}}}{\rho_{0}}=\left(\frac{\sigma_{\mathrm{b}}}{\sigma_{0}}\right)^{2}
$$

where $\rho_{0}$ and $\rho_{b}$ are the initial and blunted crack tip radii, respectively, and $\sigma_{0}$ and $\sigma_{b}$ are the corresponding preblunting and postblunting loads $(\mathrm{Pa})$. In some cases we found that the load needed to reinitiate crack growth was as much as 2 to 3 times the initial load, suggesting that during blunting the effective crack tip radius increased by as much as 4 to 9 times. This large increase in load necessary to reinitiate a sharp crack also explains why it then grows so quickly. The stress intensity at this new sharp crack tip would likely exceed $K_{I c}$ and thus rapid crack growth would be expected.

It is clear from the observed temporal dependence of the blunting process that some small change in the effective crack tip radius may occur even during crack propagation. This could explain why the standard crack growth model (Eq. (2)) fails to accurately predict crack propagation in the region where blunting was observed (Fig. 6). To test this hypothesis we used Eq. (2) and the previously determined values of $A, Q$, and $m$ to fit the crack velocity data in the region where the blunting was observed; however, we used $b$ as an adjustable parameter. Recall that $b$ is related to the square root of the crack tip radius (Eq. (4)). Therefore, under the assumption that the activation volume $\left(V_{2}\right)$ for the crack growth process is independent of crack tip radius, then any change in $b$ reflects a corresponding change in the crack tip radius. Figure 7 shows the results of such an analysis using the crack velocity data measured at $4.7 \times 10^{4} \mathrm{~Pa}(355 \mathrm{mmHg}$ ) and $498 \mathrm{~K}$. The solid lines represent the model predictions using Eq. (2) and with $b=0.496 \mathrm{~m}^{5 / 2}$ /

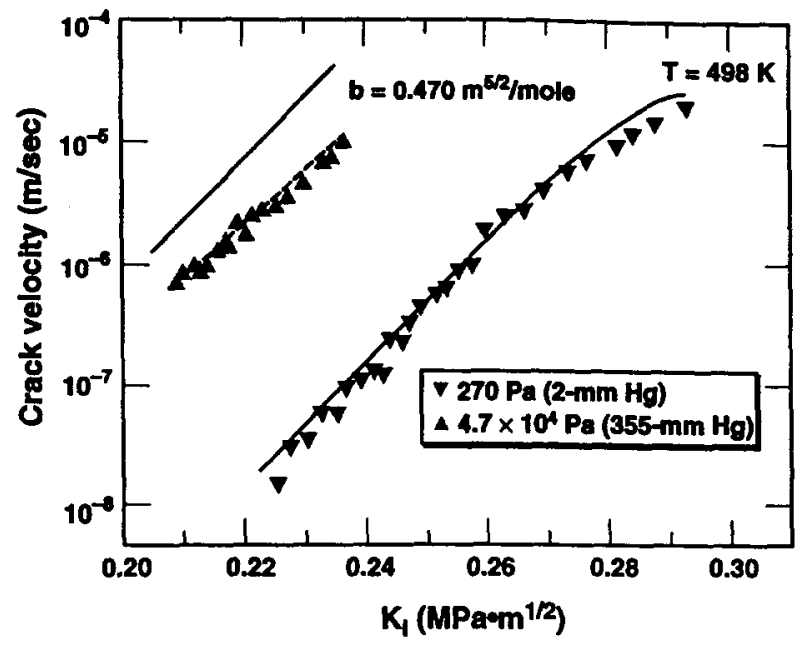

Fig. 7. Comparison of crack growth velocities measured at $267 \mathrm{~Pa}(2$ $\mathrm{mmHg})$ and $4.7 \times 10^{4} \mathrm{~Pa}(355 \mathrm{mmHg})$ and at $498 \mathrm{~K}$. The solid lines represent the predicted behavior using Eq. (7) and $b=0.496 \mathrm{~m}^{5 / 2} / \mathrm{mol}$. The dashed line also uses Eq. (7) but $b$ is reduced to $0.470 \mathrm{~m}^{5 / 2} / \mathrm{mol}$ to fit the data.

mol as determined from measurements made where there is no measurable blunting (see Fig. 6). As expected the model does not accurately predict the behavior at $498 \mathrm{~K}$ and $4.7 \times 10^{4} \mathrm{~Pa}$ (355 $\mathrm{mmHg}$ ) (i.e., the blunting region) but is in good agreement at $270 \mathrm{~Pa}$ ( $2 \mathrm{mmHg}$ ) (i.e., the nonblunting region). If $b$ is reduced to $0.470 \mathrm{~m}^{5 / 2} / \mathrm{mol}$, then Eq. (2) accurately fits the data at $4.7 \times 10^{4} \mathrm{~Pa}(355 \mathrm{mmHg})$. This change represents an increase in the effective crack radius by about $11 \%$. Similar fits to other crack velocity data taken in the blunting region all show an increase in the effective crack tip radius ranging from about $6 \%$ to $15 \%$. Note that the magnitude of the change in the crack tip radius observed under dynamic conditions is far less than that observed when the crack is stopped. This is not unexpected because under dynamic conditions the rate of crack blunting is always competing with crack propagation. Nevertheless, as this analysis showed, even very minor changes in the effective crack tip radius produce a significant change in the rate of crack growth because of the exponential dependence of crack velocity on $p^{-1 / 2}$ (see Eq. (3)). It has been suggested ${ }^{20}$ that the static fatigue limit often observed in soda-lime glasses represents the condition where the rate of blunting balances the rate of crack growth. This reasoning leads to the logical extension that the highest static fatigue limit is expected under conditions for the greatest rate of blunting.

One could also argue that the activation energy, $Q_{1}$ (see Eq. (3)), is changing in the blunting region, not the crack tip radius. Reducing the activation energy by the same relative amount as was done for $b$, would achieve the same quality of fit to the data shown in Fig. 7. However, this alternate explanation requires that a change in crack tip radius occurs only when crack propagation stops completely.

Crack blunting involving mass transport to the crack tip could occur by evaporation and condensation, surface diffusion, bulk diffusion, and/or viscous flow. In the case of mass transport by viscous flow, the range of change of the radius of the crack tip is inversely proportional to the viscosity of the glass in that region. In view of the large viscosity-reduction effect of water in glass, it is likely that the operating blunting mechanism is the viscous flow promoted by water entry into the glass from the atmosphere. A more detailed study of the kinetics and mechanism of crack blunting is currently under way.

\section{(5) Slow Crack Growth In Phosphate vs Silicate Glass}

Figure 8 compares our measured slow crack growth rates in a phosphate glass at $296 \mathrm{~K}$ and $\sim 10 \%$ relative humidity with 


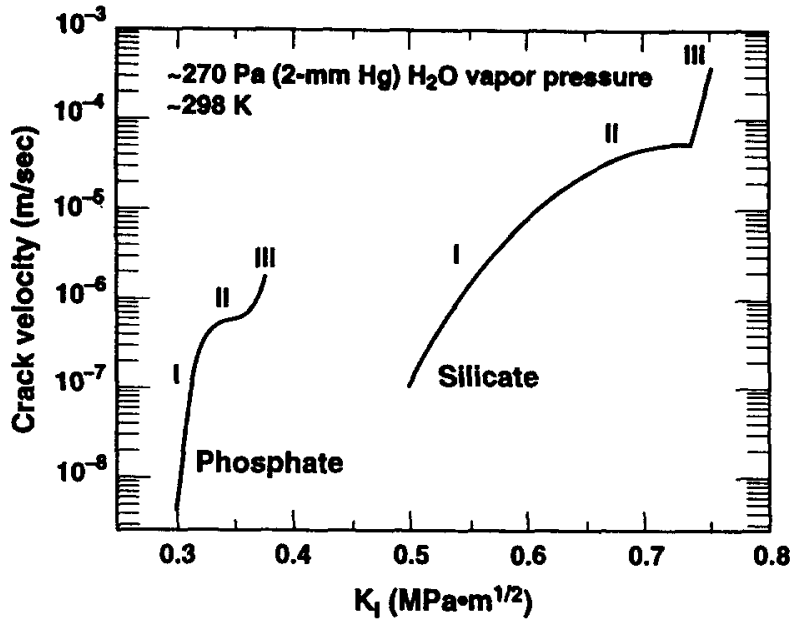

Fig. 8. Comparison of crack growth velocity measurement for phosphate glass (this study) and soda-lime silicate glass' at $296 \mathrm{~K}$ and approximately $267 \mathrm{~Pa}(2 \mathrm{mmHg})$ water vapor pressure.

corresponding data for a soda-lime silicate glass. ${ }^{1}$ In both cases the measurements extend over regions I, II, and III.

A number of interesting differences in slow crack growth behavior of the two glasses are immediately noticeable. First, and not surprising, the phosphate glass is significantly weaker than the silicate as indicated by the much lower stress intensity values needed to reach the same crack growth velocities. Also note that in region $I$, the slope of the crack velocity profile for the phosphate is much greater than that of the silicate. Thus, small increases in the stress intensity for the phosphate glass cause a greater increase in crack velocity compared to that for the silicate glass.

The onset of region $\amalg$ occurs at a crack velocity about $10^{2}$ lower for phosphates than for silicates. Since it is proposed that region II crack growth is controlled by diffusion of $\mathrm{H}_{2} \mathrm{O}$ to the crack tip modified by the adsorption, then this suggests that mass transfer rates are about $10^{2}$ slower in phosphates than silicates. The naturally higher affinity of phosphates for water compared to silicates may explain this large difference in diffusion rates. In other words, the stronger attraction of the water at the surface of the phosphate may tend to retard water transport to the crack tip; this process was discussed briefly in Section IV(2) (see Eq. (6)).

The onset of region III occurs as the stress intensity approaches the fracture toughness of the glass, i.e., about 0.45 $\mathrm{MPa}^{1 / 2}$ for phosphate compared to approximately 0.8 $\mathrm{MPa} \cdot \mathrm{m}^{1 / 2}$ for the soda-lime silicate. The onset of region III is much harder to measure using the DCDC method because the stress intensity (and hence growth rate) is greatest at the beginning of the measurement. Therefore, the measured transition from region II to region III behavior shown in Fig. 8 for the phosphate is probably only accurate to within stress intensity

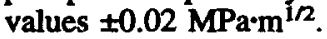

\section{Conclusions}

Crack growth velocities are reported for a phosphate laser glass over a range of temperatures and water vapor pressures. Wiederhorn's classic chemical and mass-transport-limited reaction rate model is used to explain crack growth behavior in regions I and II except when there is blunting. The results indicate that in region I the crack growth velocity varies approximately linearly with water concentration and has an activation energy, $Q_{\mathrm{l}}$, of $216 \mathrm{~kJ} / \mathrm{mol}$. In region II the crack velocity also exhibits a linear dependence on water vapor pressure and an Arrhenius temperature dependence but the activation energy, $Q_{\mathrm{n}}$, is only $26 \mathrm{~kJ} / \mathrm{mol}$. A set of model parameters are developed which can be used by glass process engineers to accurately predict the rate of slow crack growth in phosphate laser glasses over a wide range of operating environmental conditions. Blunting is interpreted as an increase in the effective radius of curvature of the crack tip. Our results suggest that under dynamic conditions, the effective crack tip radius may increase by about $10 \%$. Under static conditions (growth arrest), the crack tip radius increases by about 4 to 9 times. Anomalous crack growth near the point of water saturation at $296 \mathrm{~K}$ is discussed in terms of possible capillary condensation at the crack tip.

Acknowledgments: We gratefully acknowledge the assistance of the late Mr. William A. "Bill" Steele in the construction of the environmental chamber and fabrication of the glass samples used in this study. This research was funded by the U.S. Department of Energy by Lawrence Livermore National Laboratory under Contract No. W-7405-Eng-48.

\section{References}

'S. M. Wiederhorn, "Influence of Water Vapor on Crack Propagation in Soda-Lime Glass," J. Am. Ceram. Soc., 50 [8] 407-14 (1967).

${ }^{2}$ J. H. Campbell, "Recent Advances in Phosphate Laser Glasses for High Power Applications"; pp. 3-39 in Critical Reviews of Optical Science and Technology, Vol. CR64, Inorganic Optical Materials. Edited by P. Klocek. SPIE-The International Society for Optical Engineering, Bellingham, WA, 1996.

3J. E. Marion, "Fracture of Solid State Laser Slabs," J. Appl. Phys., 60 [1] 69-77 (1986)

4J. Mencik, "Fracture Toughness of Glass and Ceramics"; pp. 119-22 in Strength and Fracture of Glass and Ceramics. Elsevier, New York, 1992.

${ }^{5} \mathrm{Ch}$. Janssen, "Specimen for Fracture Mechanics Studies on Glass"; pp. 23-30 in Proceedings of the 10th International Congress on Glass, Vol. 10. Ceramic Society of Japan, Tokyo, Japan, 1974.

'T. A. Michalske, W. L. Smith, and E. P. Chen, "Stress Intensity Calibration for the Double Cleavage Drilled Compression Specimen," Eng. Fract. Mech. 45 [5] 637-42 (1993).

'A. A. Griffith, "Theory of Rupture," Philos. Trans. R. Soc. London, A221, 163-98 (1920).

${ }^{8}$ S. Ito and M. Tomozawa, "Crack Blunting of High Silica Glass," J. Am. Ceram. Soc., 65 [8] 368-71 (1982).

${ }^{9}$ B. R. Lawn, K. Jakus, and A. C. Gonzalez, "Sharp vs. Blunt Crack Hypothesis in the Strength of Glass: A Critical Study Using Indentation Flaws," J. Am. Ceram. Soc., 68 [1] 25-34 (1985).

${ }^{10} \mathrm{Y}$. Bando, S. Ito, and M. Tomozawa, "Direct Observation of Crack Tip Geometry of $\mathrm{SiO}_{2}$ Glass by High-Resolution Electron Microscopy," J. Am. Ceram. Soc., 67 [3] C-36-C-37 (1984).

"Y. T. Hayden, S. A. Payne, J. S. Hayden, J. H. Campbell, M. K. Aston, and M. L. Elder. "Phosphate Glass Useful in High Energy Lasers," U.S. Pat. No. 5526369 , June 11, 1996.

12J. D. Helfinstine, S. T. Gulati, and D. G. Pickels, "Slow Crack Growth in High Silica Glasses"; pp. 654-58 in The Physics of Non-Crystalline Solids. Edited by L. D. Pye, W. C. LaCourse, and H. J. Stevens. Taylor and Francis, London, U.K., 1992.

${ }^{13}$ S. W. Frieman, "Fracture Mechanics of Glass"; pp. 21-78 in Glass Science and Technology, Vol. 5, Elasticity and Strength in Glasses. Edited by D. R Uhimann and N. J. Kreidl. Academic Press, New York, 1980.

${ }^{14}$ S. M. Wiederhorn and P. R. Townsend, "Crack Healing in Glass," J. Am. Ceram. Soc., 53 [9] 486-89 (1970).

${ }^{15}$ B. Stavrinidis and D. G. Holloway, "Crack Healing in Glass," Phys. Chem. Glasses, 24 [1] 19-25 (1983).

${ }^{16}$ T. A. Michalske and E. R. Fuller, Jr., "Closure and Repropagation of Healed Cracks in Silicate Glass," J. Am. Ceram. Soc., 68 [11] 586-90 (1985).

${ }^{17}$ S. M. Wiederhorn, "Chemical Interaction of Static Fatigue," J. Am. Ceram. Soc., 55 [2] 81-85 (1971).

${ }^{18}$ S. M. Wiederhom and C. H. Bolz, "Stress Corrosion and Static Fatigue of Glass," J. Am. Ceram. Sac., 53 [10] 543-48 (1970).

${ }^{19} \mathrm{~N}$. Soga, T. Okamoto, T. Hanada, and M. Kunugi, "Chemical Reaction Between Water Vapor and Stressed Glass," J. Am. Ceram. Soc., 62 [5-6] 309 10 (1979).

${ }^{20}$ W. B. Hillig and R. J. Charles, "Surfaces, Stress-Dependent Surface Reactions, and Strength"; pp. 682-705 in High Strength Materials. Edited by V.F. Zackay. Wiley, New York, 1965.

${ }^{21 S}$. M. Wiedertorn, H. Johnson, A. M. Diness, and A. H., Heuer, "Fracture of Glass in Vacuum," J. Am. Ceram. Soc., 57 [8] 336-41 (1974)

22B. R. Lawn, "Diffusion-Controlled Subcritical Crack Growth in the Presence of a Dilute Gas Environment," Mater. Sci. Eng., 13 [3] 277-83 (1974).

${ }^{23}$ V. V. Morariu and R. Mills, "Self-Diffusion of Water Adsorbed on Silica," Z. Phys. Chem. Neue Folge, 79 [1/2] 1-9 (1972).

24A. W. Adamson "Adsorption of Gases and Vapors on Solids"; pp. 517-600 in Physical Chemistry of Surfaces. Wiley Interscience, New York, 1982.

${ }^{25} \mathrm{H}$. Okamoto and Y. Tuzi, “Adsorption of Water Vapor on Glass and Other Materials in Vacuum," J. Phys. Soc. Jpn., 13 [6] 649-55 (1958).

${ }^{26} Y$.-K. Lee and M. Tomozawa "Effect of Water Content in Phosphate Glasses on Slow Crack Growth Rate," J. Non-Cryst. Solids, 248, 203-10 (1999). 


\title{
Effects of $\mathrm{OH}$ content, water vapor pressure, and temperature on sub-critical crack growth in phosphate glass
}

\author{
T.I. Suratwala ${ }^{\text {a,* }}$, R.A. Steele ${ }^{\text {a }}$, G.D. Wilke ${ }^{\text {a }}$, J.H. Campbell ${ }^{\text {a }}$, K. Takeuchi ${ }^{\text {b }}$ \\ " Lawrence Livermore National Laboratory, P.O. Box 808, Livermore, CA 94551, USA \\ 'Hoya Corporation USA, 3400 Edison Way, Fremont, CA 94538, USA
}

\begin{abstract}
The effects of temperature and water vapor pressure on the rate of sub-critical crack growth in meta-phosphate laser glasses containing different $\mathrm{OH}$ concentrations (128 and $773 \mathrm{ppmw})$ are reported. The crack velocity was measured using the double-cleavage-drilled-compression method. When plotted as a function of stress intensity, the samples have the classic region I, II and III crack growth properties similar to that reported for silicate glasses. The glass containing the larger $\mathrm{OH}$ content has a 10-fold greater crack velocity in region I; crack velocities is region II are the nearly the same for both glasses. The crack velocities are analyzed using a chemical kinetic and mass-transport limited reaction rate model. At temperatures $>150^{\circ} \mathrm{C}$ and water vapor pressures $>10 \mathrm{mmHg}$, crack tip blunting is observed and the glass containing the larger $\mathrm{OH}$ content is more prone to blunting. () 2000 Published by Elsevier Science B.V. All rights reserved.
\end{abstract}

\section{Introduction}

Nd-doped metaphosphate glasses are the preferred gain medium for high-peak-power lasers used for fusion research mainly because they can store optical energy at greater densities than other glass-types and this energy can be efficiently extracted [1,2]. However, one problem with the use of phosphate glasses as laser ion hosts is that they have larger thermal expansion and lower fracture toughness than do, for example, silicates [3]. Consequently phosphates are more prone to fracture.

It is known that a crack can propagate from an existing flaw even at stresses less than that for

\footnotetext{
"Corresponding author. Tel.: 1-925 422 1884; fax: 1-925 423 0792.

E-mail address: suratwala 1@llnl.gov (T.I. Suratwala).
}

critical failure. This phenomenon is known as slow crack growth, stress corrosion cracking, or subcritical crack growth [4-15]. The velocity of the fracture can vary by orders of magnitude, from $<1$ $\mu \mathrm{m} / \mathrm{min}$ up to many meters per second. Consequently the time-to-failure for a given glass component can also vary by orders of magnitude. Because of their relatively poor mechanical properties, phosphate glasses are particularly susceptible to slow crack growth. However, despite the numerous studies on slow crack growth in silicate glasses [4-13], to our knowledge few studies have investigated this phenomenon in phosphate glasses $[14,15]$. Such information is of practical importance to the manufacture and use of phosphate glasses in mega-joule scale laser systems [16-18].

Crack growth has been hypothesized to occur by a stress-enhanced chemical reaction at the crack tip which for phosphate glass can be given by [14] 
$\mathrm{H}_{2} \mathrm{O}+\mathrm{P}-\mathrm{O}-\mathrm{P} \rightarrow 2(\mathrm{P}-\mathrm{OH})$

and/or

$\mathrm{H}_{2} \mathrm{O}+\mathrm{P}-\mathrm{O}-\mathrm{M} \rightarrow \mathrm{P}-\mathrm{OH}+\mathrm{M}-\mathrm{OH}$

where $\mathrm{M}$ is an metal cation. In Eq. (1a) the $\mathrm{H}_{2} \mathrm{O}$ reacts with the phosphorous-oxygen-phosphorous linkage at the crack tip and forms chain terminating hydroxyl groups; while in Eq. (1b) the $\mathrm{H}_{2} \mathrm{O}$ reaction does not break up the $\mathrm{P}-\mathrm{O}-\mathrm{P}$ backbone, but separates links between chains. With both reactions crack propagation takes place.

In a previous paper [14], we report slow crack growth velocities in phosphate glass having an $\mathrm{OH}$ content $<100 \mathrm{ppm}$. The measured crack growth velocities, when plotted as a function of stress intensity, have regions I, II and III velocities $[4,14]$. The data were analyzed using Wiederhorn's reaction rate model for slow crack growth [4]. This model includes a description of the $\mathrm{H}_{2} \mathrm{O}$ reaction kinetics at the crack tip as well as $\mathrm{H}_{2} \mathrm{O}$ mass transport to the reaction interface. By fitting this model to the data, a set of empirical parameters were developed that predicted slow crack growth over a range of temperatures, water vapor pressures, and stress intensities.

The work reported here expands the study of slow crack growth in phosphate glasses to include the effects of residual $\mathrm{OH}$ content in the glass. More specifically, the rate of crack growth as a function of stress intensity, temperature and water vapor pressure is reported in two glasses that have a six-fold difference in $\mathrm{OH}$ content. This difference is because during melting phosphate glasses readily react with water vapor in the ambient atmosphere producing chain terminating $\mathrm{OH}$ groups. The results of the present work are presented in several sections. First the data showing the region I, II and III slow crack growth are presented, and the region I and II data are fit using Wiederhorn's reaction rate model. The observed crack growth is compared with that reported for other glasses (phosphates and silicates). Next we discuss the effects of the hydroxyl content in the glass on the measured slow crack growth. Finally, the conditions that promote crack blunting are compared with predictions of models for slow crack propa- gation. Also, we suggest that water condensation may occur at the crack tip under certain test conditions.

\section{Experimental procedures}

Two phosphate laser glasses, LHG-8L and LHG-8H were prepared containing hydroxyl group contents of about 130 and 770 ppmw; here we use the designations ' $L$ ' and ' $H$ ' to denote the low and high $\mathrm{OH}$ content of the glasses, respectively. The base glass used in this study is a commercial metaphosphate laser glass, LHG-8 (Hoya Corporation), having the molar composition: (5560) $\mathrm{P}_{2} \mathrm{O}_{5}-(8-12) \mathrm{Al}_{2} \mathrm{O}_{3}-(13-17) \mathrm{K}_{2} \mathrm{O}-(10-15) \mathrm{BaO}-$ $(0-2) \mathrm{Nd}_{2} \mathrm{O}_{3}$.

The compositions are reported as ranges to account for variability due to doping and melting methods and to protect certain proprietary aspects of the composition [18]. There is little variation in glass properties over this range of compositions. For example, recently Campbell and Suratwala [3] have reported laser, optical and physical properties for a number of phosphate glasses having compositions that span the range given here and report that most properties vary by less than $\pm 20 \%$.

The glasses used in this study were prepared using the melt procedures discussed elsewhere [18]. The hydroxyl content was varied by changing the degree of $\mathrm{O}_{2}$ bubbling (1-atm) through the glass during the melting phase at $1400 \mathrm{~K} \mathrm{[18]}$. The cast glasses were cooled at a rate $<20 \mathrm{~K} / \mathrm{h}$ from $T_{\mathrm{g}}$ to room temperature giving a residual stress birefringence $<10 \mathrm{~nm} / \mathrm{cm}$ (i.e., residual stress $<0.5$ MPa).

The hydroxyl content of the glass was determined from the infrared absorption of the $-\mathrm{O}-\mathrm{H}$ stretching band at $3333 \mathrm{~nm}\left(3000 \mathrm{~cm}^{-1}\right)$ [19]. The measured $\mathrm{OH}$ absorption coefficient at $3000 \mathrm{~cm}^{-1}$ and some other properties for both LHG-8L and LHG-8H samples are shown in Table 1. To relate the $\mathrm{OH}$ absorption coefficient to the absolute $\mathrm{OH}$ concentration, the extinction coefficient must be known. However, reported extinction coefficients vary from 30 to $100 \mathrm{ppmw} / \mathrm{cm}^{-1}$ (from 70 to 230 $1 / \mathrm{mol} \mathrm{cm}$ ) at $3000 \mathrm{~cm}^{-1}$ [20]. An extinction coefficient of $30 \mathrm{ppmw} / \mathrm{cm}^{-1}(\approx 70 \mathrm{l} / \mathrm{mol} \mathrm{cm})$ is assumed 
Table 1

Hydroxyl content and glass transition temperature for the LHG-8 glasses used in this study

\begin{tabular}{llll}
\hline Glass & Optical absorption at & Implied $\mathrm{OH}$ content & $T_{\mathrm{g}}\left({ }^{\circ} \mathrm{C}\right)( \pm 5)$ \\
& $3333 \mathrm{~nm}\left(\mathrm{~cm}^{-1}\right)( \pm 4 \%)$ & 472 \\
\hline LHG-8L & 4.2 & 128 & 425 \\
LHG-8H & 25.5 & 773 &
\end{tabular}

based on earlier work by Toratani [21] on phosphate laser glasses.

The slow crack growth velocities were measured by the double-cleavage-drilled-compression (DCDC) technique. A schematic of the experimental setup is shown in Fig. 1. The details of the experimental procedure are described elsewhere [14]. Briefly, the technique utilizes rectangular glass samples $\left(75 \times 7.5 \times 6.5 \mathrm{~mm}^{3}\right)$ with a hole $(1 \mathrm{~mm}$ radius) drilled in the center of the $75 \times 7.5 \mathrm{~mm}^{2}$ face. The samples were mounted in a mechanical testing machine (Instron 8562) within an environmentally controlled chamber. The applied compressive stress was typically 400-500 psi. The velocity of the cracks originating from the sample hole (which is under tension) was determined by monitoring the position of the crack front as a function of time using a cathetometer. The diffraction limited resolution of the cathetometer was about $6 \times 10^{-5} \mathrm{rad}$ which, for our experimental geometry, allows measurement of the crack front position to within $\pm 10 \mu \mathrm{m}$. Crack velocities were measured for both glasses (LHG-8H and LHG-8L) at various temperatures ranging from $25^{\circ} \mathrm{C}$ to

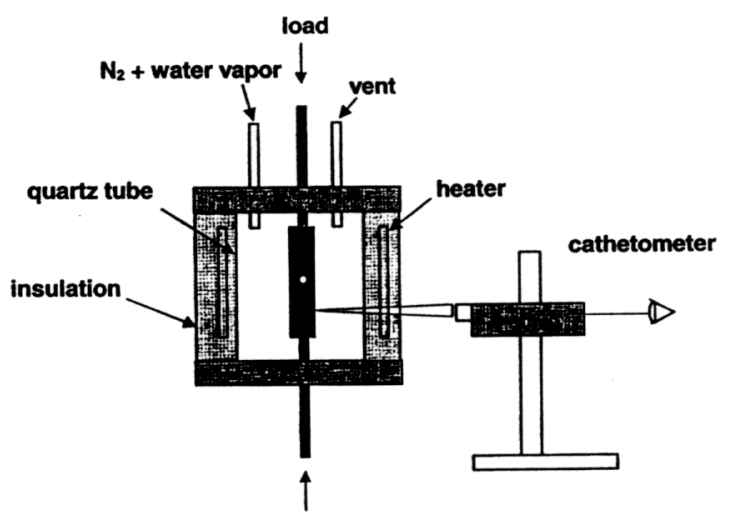

Fig. 1. Schematic of the experimental setup used to measure slow crack growth velocities using the DCDC method. $300^{\circ} \mathrm{C}$ and ambient water vapor pressures from 2 to $92 \mathrm{mmHg}$. Each set of data for a single set of conditions represents the measurements from a single sample. The water vapor pressure was generated by bubbling $\mathrm{N}_{2}$ gas through water contained in a temperature-controlled water bath. Stress intensities, $K_{\mathrm{I}}\left(\mathrm{MPa} \mathrm{m} \mathrm{m}^{1 / 2}\right)$, were calculated from the applied stress, $\sigma(\mathrm{MPa})$, measured crack length, $l$ $(\mathrm{m})$ and hole radius, $a(\mathrm{~m})$, using the relationship developed by Michalske et al. [22]

$K_{\mathrm{I}}=\frac{\sigma \sqrt{a}}{1.595+0.353(l / a)}$.

\section{Results}

Crack velocity measurements, when presented as plots of log velocity vs. $K_{\mathrm{I}}$, typically have three distinct regions, I, II and III. These regions have been observed in a number of glasses $[4,11,14,23]$. All three of these regions are observed in LHG-8 phosphate glass at $25^{\circ} \mathrm{C}$ and $2 \mathrm{mmHg}$ (see Fig. 2). Region I refers to the condition when crack growth is reaction-rate limited and has a linear relation between $\log v$ and $K_{\mathrm{I}}$. In other words, transport of $\mathrm{H}_{2} \mathrm{O}$ to the crack tip is rapid enough that crack growth is limited only by the rate of reaction between $\mathrm{H}_{2} \mathrm{O}$ and the $\mathrm{P}-\mathrm{O}-\mathrm{P}$ or $\mathrm{P}-\mathrm{O}-\mathrm{M}$ bond (Eq. (1)). For example, at $25^{\circ} \mathrm{C}$ and $2 \mathrm{mmHg} \mathrm{H}_{2} \mathrm{O}$ vapor pressure, the crack velocity in LHG-8L samples is $3.0 \pm 0.3 \times 10^{-7} \mathrm{~m} / \mathrm{s}(0.3 \mu \mathrm{m} / \mathrm{s})$ at a $K_{\mathrm{I}}$ of $0.405 \mathrm{MPa}$ $\mathrm{m}^{1 / 2}$. Increasing $K_{\mathrm{I}}$ to $0.420 \mathrm{MPa} \mathrm{m}^{1 / 2}$ results in about an order-of-magnitude increase in the crack velocity to $6.0 \pm 0.5 \times 10^{-6} \mathrm{~m} / \mathrm{s}(6 \mu \mathrm{m} / \mathrm{s})$. This exponential dependence of crack velocity with $K_{\mathrm{I}}$ is seen in Fig. 2; it is commonly observed in other glasses, ceramics and even polymers [4,5,24-29].

In region II, the crack velocity is no longer reaction-rate-limited but instead becomes limited by 


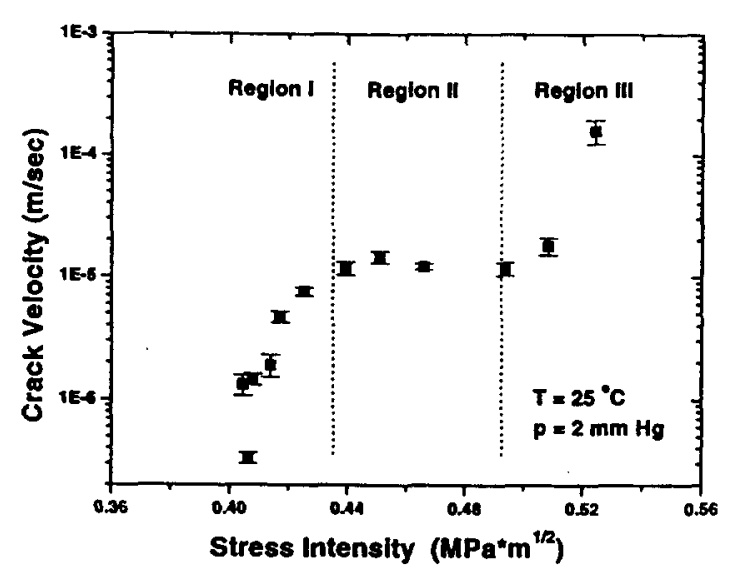

Fig. 2. Measured crack velocity (v) in LHG-8L (a low OH content glass) as a function of stress intensity $\left(K_{1}\right)$ illustrating region I, II and III slow crack growth. The measurements were carried out at $25^{\circ} \mathrm{C}$ and a water vapor pressure of $2 \mathrm{~mm} \mathrm{Hg}$.

mass-transport (diffusion) of $\mathrm{H}_{2} \mathrm{O}$ to the crack tip [6]. Consequently, region II is usually observed at smaller vapor pressures and lower temperatures where mass transport rates are slower. The measured crack velocities in region II remain nearly constant with increasing $K_{\mathrm{I}}$.

Finally, in region III the crack velocity becomes independent of the chemical environment and is limited by the intrinsic toughness of the glass [6]. The on-set of region III, as indicated by an increase in velocity at the end of region II (see Fig. 2), typically occurs as $K_{1}$ approaches the glass fracture toughness. The fracture toughness of LHG-8 samples has been measured by the chevron notch method [30] to be $0.51 \mathrm{MPa} \mathrm{m}^{1 / 2}$; notice in Fig. 2 that the onset of region III occurs just below this fracture toughness.

The measured slow crack velocities for LHG-8L glass at various temperatures and water vapor pressures are shown in Fig. 3. Crack velocities increase with both temperature (Fig. 3(a)) and water vapor pressure (Fig. 3(b)). In region I the crack velocity increases linearly with the $\mathrm{H}_{2} \mathrm{O}$ vapor pressure and can be fit with an Arrhenius-type temperature dependence $[4,5]$ with an activation energy of $253 \pm 3 \mathrm{~kJ} / \mathrm{mol}$.

The effect of the LHG-8 OH content on the slow crack growth velocities at different temperatures and water vapor pressures is shown in Fig. 4.

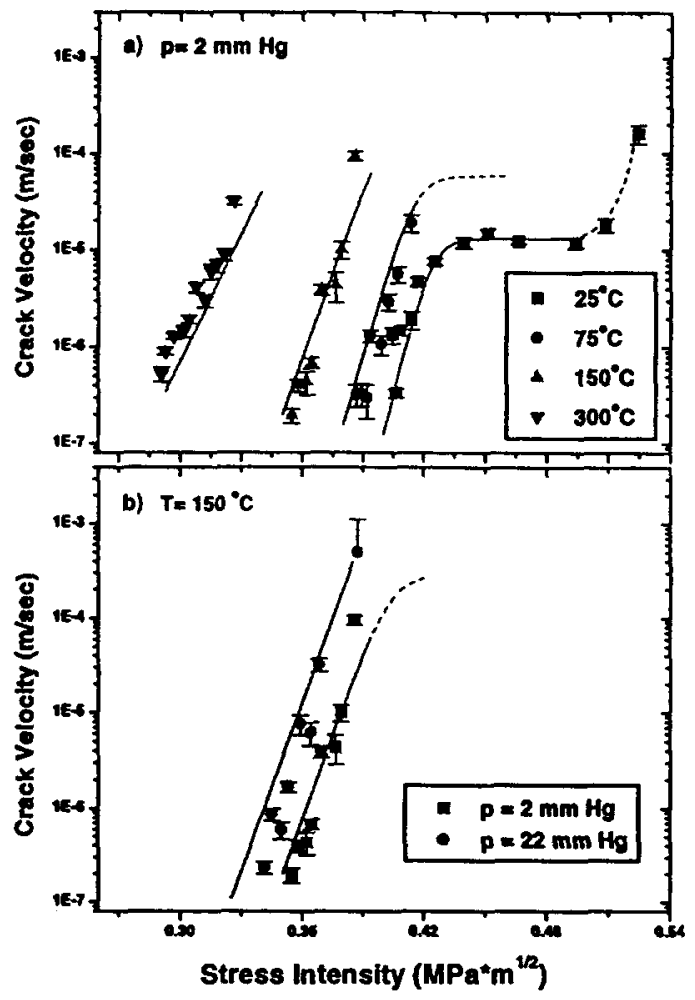

Fig. 3. Crack growth velocity $(v)$ in LHG-8L (a low OH content glass) as function of stress intensity $\left(K_{\mathrm{I}}\right)$ at (a) various temperatures and (b) water vapor pressures. The points represent measured velocities and the curves represent model predictions using Eq. (7) and the model parameters listed in Table 2.

The crack velocities in the low $\mathrm{OH}$ content glass, LHG-8L, are indicated by the solid data points, and in the high $\mathrm{OH}$ content glass, LHG-8H, by the open data points. At equivalent stress intensities $\left(K_{\mathrm{I}}\right)$, the larger $\mathrm{OH}$ content glass has faster crack velocities in both region I and III. Region II appears to be unaffected by the hydroxyl content of the glass (Fig. 4(a)).

\section{Discussion}

\subsection{Chemical and mass-transport-limited reaction rate model}

As described in Section 1, the proposed mechanism of slow crack growth in phosphate glass is 


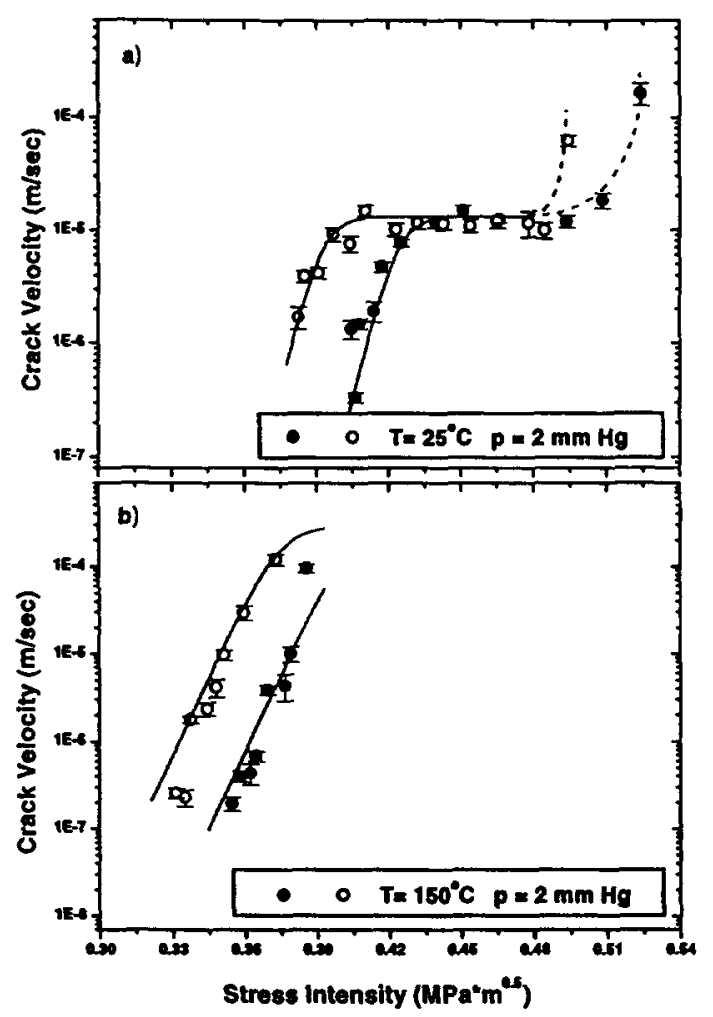

Fig. 4. Sub-critical crack growth velocities $(v)$ as a function of stress intensity $\left(K_{1}\right)$ for LHG-8 glasses containing low and high $\mathrm{OH}$ contents, i.e. LHG-8L $(\Theta)$ and LHG-8H $(O)$, respectively. The data are for (a) $25^{\circ} \mathrm{C}$ and (b) $150^{\circ} \mathrm{C}$. The curves are model calculations using Eq. (7) and the model parameters listed in Table 2. The smooth dashed curves are drawn through the points representing region III growth (the model does not treat region III).

the stress-enhanced reaction between $\mathrm{H}_{2} \mathrm{O}$ and $\mathrm{P}-$ $\mathrm{O}-\mathrm{P}$ or $\mathrm{P}-\mathrm{O}-\mathrm{M}$ at the crack tip. Hillig and Charles [12] and later Wiederhorn [6,31] have described the crack velocity in region $I$ by a reaction rate expression
$v_{\mathrm{I}}=A\left(\frac{p}{p_{0}}\right)^{m} \exp \left(\frac{K_{\mathrm{I}} b-Q_{\mathrm{I}}}{R T}\right)$,

where $v_{\mathrm{I}}$ is the crack velocity in region $\mathrm{I}(\mathrm{m} / \mathrm{s}), A$ a pre-exponential constant $(\mathrm{m} / \mathrm{s}), p$ the water vapor pressure $(\mathrm{mmHg}), p_{0}$ the atmospheric pressure $(760 \mathrm{mmHg}), b$ a parameter $\left(\mathrm{m}^{5 / 2} / \mathrm{mol}\right)$ related to activation volume and radius of curvature of the crack tip, $Q_{\mathrm{I}}$ the activation energy $(\mathrm{kJ} / \mathrm{mol})$, and $m$ is the 'order' of the reaction that often appears in reaction rate expressions. In our previous study [14] the above model described crack growth in LG-770 over the whole range of experimental conditions except in regions where crack blunting or capillary condensation occurred. The model uses a single set of fitting parameters: $A, m, b$ and $Q_{\mathrm{I}}$. The same model analysis that was done for LG-770 samples has also been carried out in this study for LHG-8L and 8H samples (see Section 4.3). The only exception is that $m$ is fixed at 1.2 as determined for LG-770. Setting $m$ equal to 1.2 assumes the reaction is nearly first-order in terms of the water vapor concentration; similar first-order reactions have been reported for other glasses, particularly silicates [6,31]. The magnitudes of the other three model parameters determined for the two LHG-8 glasses are summarized in Table 2.

The crack velocity in region II is constant at about $10^{-5} \mathrm{~m} / \mathrm{s}$ at $25^{\circ} \mathrm{C}$ and a water vapor pressure of $2 \mathrm{mmHg}$ (see Fig. 3(a)). In this region crack propagation is limited by the mass transport of $\mathrm{H}_{2} \mathrm{O}$ to the crack tip; given in terms of the flux, this is then

$v_{\text {II }} \propto D \frac{\partial C_{\mathrm{H}_{2} \mathrm{O}}}{\partial z}$,

where $D$ is the $\mathrm{H}_{2} \mathrm{O}$ diffusion coefficient and $\partial C_{\mathrm{H}_{2} \mathrm{O}} / \partial z$ is the concentration gradient in the direction, $z$, of crack propagation. Based on Eq. (4),

Table 2

Model parameters for predicting slow crack growth in LHG-8L and -8H in regions I and II in the absence of crack-tip blunting

\begin{tabular}{|c|c|c|c|}
\hline Parameter & Units & LHG-8L (128 ppmw OH) & LHG-8H (773 ppmw OH) \\
\hline$A$ & $10^{6} \mathrm{~m} / \mathrm{s}$ & 7.3 & 7.3 \\
\hline$m$ & unitless & 1.20 & 1.20 \\
\hline$Q_{\mathrm{I}}$ & $\mathbf{k J} / \mathbf{m o l}$ & 253 & 239 \\
\hline$b$ & $J /(\operatorname{mol~K})$ & 0.480 & 0.480 \\
\hline$C$ & $\mathrm{~m} / \mathrm{s}$ & 180 & 180 \\
\hline$Q_{\mathrm{d}}$ & $\mathrm{KJ} / \mathbf{m o l}$ & 26 & 26 \\
\hline
\end{tabular}

"Assumes 30 ppmw OH per $\mathrm{cm}^{-1}$ absorption at $3000 \mathrm{~cm}^{-1}$. 
the rate of crack growth should increase linearly with water vapor concentration (i.e., pressure) provided the diffusion constant is not concentration independent. The exact diffusion mechanism for $\mathrm{H}_{2} \mathrm{O}$ transport to the crack tip is not wellknown and could be either via gas phase, surface, and/or Knudsen (capillary) diffusion; all have been proposed at one time or another as the limiting diffusion mechanism for crack growth $[13,14]$. Determination of the mass transport mechanism is not attempted in this study. Therefore we simply note that the crack growth velocity is proportional to the water vapor pressure and best described by Wiederhorn's mechanism [4]

$v_{\mathrm{II}}=C^{\prime}(T) \frac{p_{\mathrm{H}_{2} \mathrm{O}}}{p_{0}}$

where $C^{\prime}(T)$ is temperature dependent and has units of $\mathrm{m} / \mathrm{s}$ and $p_{0}$ is a pressure normalization factor $(760 \mathrm{mmHg})$. $C^{\prime}(T)$ contains the temperature dependence of the diffusion constant which is assumed to have an Arrhenius dependence

$C^{\prime}(T)=C \exp \frac{Q_{\mathrm{II}}}{R T}$

where $C$ is a constant $(\mathrm{m} / \mathrm{s})$ and $Q_{\mathrm{II}}$ is the activation energy for $\mathrm{H}_{2} \mathrm{O}$ diffusion $(\mathrm{kJ} / \mathrm{mol})$. In the present work, region II was only observed at one experimental condition making it impossible to determine the activation energy, $Q_{\mathrm{II}}$. Therefore, because of the similar glass composition of LG770 and LHG-8, we assume that the activation energy for $\mathrm{H}_{2} \mathrm{O}$ transport for both glasses is about the same and use $26 \mathrm{~kJ} / \mathrm{mol}$ reported previously for LG-770 [14]. Thus, the $C$ in Eq. (6) is $180 \mathrm{~m} / \mathrm{s}$ based on the fit to the data.

The crack velocity expressions for region I (Eq. (3)) and region II (Eq. (5)) can be combined into a single expression given by the harmonic mean of $v_{I}$ and $v_{\mathrm{II}}$

$v=\frac{v_{\mathrm{I}} v_{\mathrm{II}}}{v_{\mathrm{I}}+v_{\mathrm{II}}}$

where $v$ is a 'composite' velocity that in the limit of region $I\left(v_{1} \ll v_{\mathrm{II}}\right)$ approaches $v_{\mathrm{I}}$ and in the limit of region II $\left(v_{\mathrm{II}} \ll v_{1}\right)$ approaches $v_{\mathrm{II}}$. In addition, it provides a smooth function for describing the transition between the two regions.
In Fig. 3, the composite velocities predicted using Eq. (7) (with the parameters listed in Table 2) are compared to the experimental data. The solid curves represent model prediction. In general the model agrees with the data within $\pm 10 \%$ at the temperatures and water vapor pressures shown (see Fig. 3). Considering that crack velocities vary by four orders of magnitude, the agreement between the model and the data is quite good. Therefore this model can be utilized to predict crack velocities and failure times in LHG-8 laser glass under various loads and environmental conditions. The one caveat is that, as presented, the model is only valid in regions where crack tip blunting is negligible and capillary condensation does not occur; the impact of these phenomena are discussed in Sections 4.4 and 4.5.

\subsection{Comparison with crack growth in silicate glasses}

Comparison of the model parameters describing crack growth in region I (i.e., $Q_{1}$ and $b$ ) of different glasses provides some insights into the relationship between crack growth and glass structure (Table 3). First notice that the activation energy for fracture propagation in meta-phosphate glasses $(216-253 \mathrm{~kJ} / \mathrm{mol})$ is less than for silicates $(275-705 \mathrm{~kJ} / \mathrm{mol})$. This difference is not surprising considering the smaller fracture toughness and the smaller resistance to crack growth in meta-phosphate as compared to those of silicate glasses [14]. Silica-based glasses have a larger cross-link density (mainly $\mathrm{Q}^{3}$ and $\mathrm{Q}^{4}$ species), whereas meta-phosphates are comprised mainly of phosphate chains and rings (mainly $Q^{2}$ species) and have fewer cross-links [32]. Decreasing the crosslink density decreases the number of covalent bonds to be broken during crack front propagation. Hence for a fixed energy input we expect cracks to grow further in metaphosphate than in silicate glasses.

There are other data that are consistent with the proposed connection between cross-link density and fracture toughness in phosphate glasses. We have observed that the fracture toughness decreases linearly with an increase in the $O / P$ ratio 
Table 3

Comparison of model parameters describing region I slow crack growth in different glasses in the presence of water vapor

\begin{tabular}{|c|c|c|c|c|}
\hline Glass & $Q_{1}(\mathrm{~kJ} / \mathrm{mol})$ & $b\left(\mathrm{~m}^{\mathrm{s} / 2} / \mathrm{mol}\right)$ & Activation volume $\left(10^{-6} \mathrm{~m}^{3} / \mathrm{mol}\right)$ & Refs. \\
\hline $61 \%$ Lead silicate & 348 & 0.510 & 52 & [45] \\
\hline Aluminosilicate & 705 & 0.770 & 79 & [45] \\
\hline Borosilicate crown & 275 & 0.260 & 27 & [45] \\
\hline Soda-lime silicate & 605 & 0.880 & 90 & [45] \\
\hline Phosphate (LG-770) & 216 & 0.496 & 51 & [14] \\
\hline Phosphate (LHG-8L) & 253 & 0.480 & 49 & This study \\
\hline Phosphate (LHG-8H) & 240 & 0.480 & 49 & This study \\
\hline
\end{tabular}

${ }^{a}$ Calculated from Eq. (8) assuming a crack tip radius of $1.5 \mathrm{~nm}$.

in a series of phosphate glasses [3]. The structure of phosphate glasses is determined in part by the $O / P$ ratio and the cross-link density and chain length decrease with increase in the $O / P$ ratio $[33,34]$.

The second model parameter which we compare between glasses is $b$ (Table 3). Both Wiederhorn and Bolz [5] and Hillig and Charles [12] showed that the parameter, $b$, is related to the crack tip radius $(\rho)$ and the activation volume for fracture propagation $\left(V_{\mathrm{a}}\right)$

$b=\frac{2 V_{\mathrm{a}}}{3 \sqrt{\pi \rho}}$.

The activation volume [35] can be thought of as the increase in volume of the transition-state in the stress corrosion reaction. $V_{\mathrm{a}}$ can be estimated from the measured $b=0.480 \mathrm{~m}^{5 / 2} / \mathrm{mol}$ for LHG-8 if the crack tip radius is known. Here we assume a crack tip radius of $1.5 \mathrm{~nm}$ based on work of Bando et al. [36]; the calculated activation volume via Eq. (8) is $49 \times 10^{-6} \mathrm{~m}^{3} / \mathrm{mol}$. Repeating the calculation for the other glasses in Table 3 gives activation volumes ranging from 49 to $90 \times 10^{-6} \mathrm{~m}^{3} / \mathrm{mol}$. The activation volume computed for LHG-8 corresponds to a characteristic length of $0.44 \mathrm{~nm}, 50 \%$ longer than the P-O-P bond length of $0.302 \mathrm{~nm}$. A volume increase in the activated state on the order of the bond length is not unreasonable; bimolecular reactions typically have activation volumes that correspond to $10-100 \%$ increase in the bond length [35]. However we must be cautious of a strict physical interpretation of this volume because it depends on the crack tip radius assumed in the calculation.

\subsection{Effect of $\mathrm{OH}$ content in glass}

The introduction of $\mathrm{OH}$ into the glass structure is known to affect a number of properties of both silicate [20] and phosphate [37] glasses. In particular, the glass transition temperature and the viscosity both decrease with increase in $\mathrm{OH}$ content. For example, in the case of LHG-8, an increase in $\mathrm{OH}$ content from 128 to $773 \mathrm{ppmw}$ results in a decrease in $T_{\mathrm{g}}$ from $472^{\circ} \mathrm{C}$ to $425^{\circ} \mathrm{C}$ (see Table 1).

As described in Section 3, increase in the -OH content in the glass increases crack growth velocities in regions I and III (see Fig. 4). We suggest that the crack growth results indicate an increase in the $\mathrm{OH}$ content of the glass decreases the overall strength (i.e., fracture resistance). Therefore, it is not surprising that both region I and III are affected by $\mathrm{OH}$ content in the glass; in region I crack growth is determined by the rate of the stress corrosion reaction and in region III the on-set of growth is determined by the glass fracture toughness. In contrast, the crack growth in region II is limited by $\mathrm{H}_{2} \mathrm{O}$ transport to the crack tip and thus the 'plateau' velocity is not expected to depend on glass $\mathrm{OH}$ content. Nevertheless, the onset of region II growth should be dependent on the glass $\mathrm{OH}$ content simply because of the shift in the region I (and III) velocities to a smaller $K_{1}$. This shift is shown in Fig. 4(a).

We propose that the observed increase in crack propagation velocities due to larger $\mathrm{OH}$ content are related to modification of the phosphate glass structure. The basic structure of phosphate glasses has been well studied and it is known [33] that near meta-phosphate glasses, such as LHG-8, can be structurally described as phosphate chains [34] 
(analogous to linear polymeric materials) with a repeating structural unit

$\left(\begin{array}{r}\mathrm{O} \\ \| \\ -\mathrm{O}-\mathbf{P}- \\ \mid \\ \mathbf{O} \\ \mathbf{M}\end{array}\right)_{m}$

where $M$ schematically represents the modifier cation and $m$ represents the number of structural units in a chain. During melting and forming, $\mathrm{H}_{2} \mathrm{O}$ from the atmosphere and from the raw materials are assumed to react with the glass structure by the reaction shown in Eq. (1a) [38]. The addition of $\mathrm{OH}$ reduces the average molecular weight of the phosphate chains. This reduction correlates with the observed decrease in viscosity and glass transition temperature. This same effect is observed in most linear polymers (i.e., as the average chain length decreases so does the $T_{\mathrm{g}}$ and viscosity) [39]. Several studies have shown that addition of $\mathrm{OH}$ to the structure of phosphate and silicate glasses reduces chain lengths and/or cross-link densities in the glass $[20,34,38]$.

The effects of different chain lengths (i.e., average molecular weights) on the slow crack growth velocities in linear organic polymers has been reported by several authors [24-29]. In all these studies the slow crack growth velocity was observed to increase with a decrease in the polymer mean molecular weight, similar to that observed here for the LHG-8 samples. Although most organic polymers undergo plastic deformation while glasses undergo 'brittle' fracture, some of their similarities can provide insight to the effect of $\mathrm{OH}$ content on glass structure and crack growth. Huang and Brown [25] measured crack velocities in polyethylene of different molecular weights and proposed that molecular weight reduction decreased the number of 'tie' molecules at the crack tip zone and thereby affected the crack velocity. A 'tie' molecule is one that bridges the walls of the crack near the tip. Similarly, Michel et al. [26] report the affects of polymer molecular weight on crack growth in PVC and PMMA and relate this to a change in the number of chain entanglements (per unit area) in the stressed region of the crack tip.

Assuming an 'ideal' meta-phosphate glass $(\mathrm{O} /$ $P=3$ ) with infinitely long chains, then the effect of added $\mathrm{OH}$ on the average 'molecular weight' (i.e., chain length) of LHG-8 glass can be estimated as

$\mathrm{MW}_{\text {glass }}=\frac{3.4 \times 10^{7}(\mathrm{gm} / \mathrm{mol}) / \mathrm{ppmw}}{[\mathrm{OH}]}$,

where $[\mathrm{OH}]$ is the $\mathrm{OH}$ concentration in ppmw and the constant $\left(3.4 \times 10^{7}\right)$ represents the molecular weight for a glass with $1 \mathrm{ppmw} \mathrm{OH}$ assuming all the $\mathrm{OH}$ molecules act as chain-terminating species. From Eq. (10) the average molecular weight of LHG-8L is $26 \times 10^{4} \mathrm{gm} / \mathrm{mol}$ (at $128 \mathrm{ppmw} \mathrm{OH}$ ) and of LHG-8H is $4.3 \times 10^{4} \mathrm{gm} / \mathrm{mol}$ (at $773 \mathrm{ppmw}$ $\mathrm{OH})$. The difference in the region I crack velocity caused by this change in molecular weight is about 60-fold based on using the crack growth data at $25^{\circ} \mathrm{C}$ and $2 \mathrm{mmHg}$ water vapor pressure (Fig. 4(a)). Using crack growth data taken under similar conditions for PMMA [25], 30-fold increase is observed. Note that the crack velocities are smaller at larger molecular weights. We suggest that the similarities between the effects of molecular weight on measured crack velocities in meta-phosphate glass and linear organic polymers indicate a similarity in fracture mechanism. In particular, an increase in the $\mathrm{OH}$ content in the glass likely decreases the number of bonds per unit area to be broken during fracture (i.e., the covalent $\mathrm{P}-\mathrm{O}-\mathrm{P}$ bonds). Consequently, the activation energy required for fracture $\left(Q_{\mathrm{I}}\right)$ should also decrease.

We used the same reaction rate model discussed in Section 4.1 to fit the data for the greater $\mathrm{OH}$ containing glass, LHG-8H. However, we kept all the model parameters equal to those determined for LHG-8L except the activation energy for region I crack growth, $Q_{1}$. We reasoned that the change in $\mathrm{OH}$ content should only affect the energy associated with the bond breaking process during fracture and therefore only affect $Q_{\mathfrak{l}}$. We suggest that the agreement between the model predictions and the data indicate that this assumption is valid. The $Q_{1}$ determined from a fit to the data for the LHG-8H glass is $239 \pm 3 \mathrm{~kJ} / \mathrm{mol}$ 
and, as expected, is less than the value for LHG-8L sample $(253 \pm 3 \mathrm{~kJ} / \mathrm{mol})$. The crack growth is very sensitive to the activation energy and thus the error limits, as reported above, are small. These limits were determined by fitting Eq. (7) to the upper and lower error bars of the data shown in Fig. 4.

In the remainder of this section, a simple model is described to quantify the relationship between $Q_{\mathrm{I}}$ and the glass $\mathrm{OH}$ content. This model is governed by the following assumptions: (1) the addition of $\mathrm{OH}$ to the glass reduces the number of $\mathrm{P}-\mathrm{O}-\mathrm{P}$ linkages in the structure; (2) the rate of crack propagation is dominated in part by cleavage of the covalent $\mathrm{P}-\mathrm{O}-\mathrm{P}$ bonds (see discussion in introduction); and (3) the activation energy for fracture $\left(Q_{1}\right)$ is proportional to the energy required for bond breaking. Note that assumption 2 implies the cation-to-oxygen bond energies are greater for $\mathrm{P}-\mathrm{O}$ bonds than for the modifiers. This implication is indeed the case for all the modifiers except $\mathrm{Al}^{3+}$. In the case of $\mathrm{Al}$ (four-fold coordination) the bond energy is approximately equivalent to that for the $\mathrm{P}-\mathrm{O}$ bond [40].

Consider a plane running through an unfractured glass; it contains a surface density of $n \mathrm{P}-\mathrm{O}$ $P$ bonds per unit area that must be broken when a crack propagates along that surface. Thus, the energy, $Q_{1}$, required for fracture is assumed to be proportional to the areal density of $\mathrm{P}-\mathrm{O}-\mathrm{P}$ bonds $(n)$

$Q_{\mathfrak{l}}=\frac{n}{n_{0}} E_{0}$

where, in the absence of glass, $n_{0}$ is the areal density of P-O-P bonds (hereafter simply called the 'bond density') and $E_{0}$ is the fracture activation energy. As discussed above, the P-O-P bond density decreases as the $\mathrm{OH}$ concentration increases.

The quantity, $n_{0}$, is related to the glass molar volume, $V_{\mathrm{m}},\left(\mathrm{m}^{3} / \mathrm{mol}\right)$ by

$n_{0}=\left(\frac{N_{\mathrm{A}}}{V_{\mathrm{m}} S}\right)^{2 / 3}$,

where $N_{\mathrm{A}}$ is Avogradro's number and $S$ is the number of atoms in a 'monomer' of the phosphate chain (Eq. (9)). We relate the $\mathrm{OH}$ concentration to the areal density of $\mathrm{OH}$ bonds using a simple $2 / 3$ power volume-to-area scaling relationship

$n_{\mathrm{OH}}=\left(\frac{[\mathrm{OH}] \rho_{\mathrm{gl}} N_{\mathrm{A}}}{\mathrm{MW}}\right)^{2 / 3}$,

where $n_{\mathrm{OH}}=n_{0}-n, \rho_{\mathrm{gl}}$ is the density of the glass $\left(\mathrm{g} / \mathrm{cm}^{3}\right)$ and $M W_{O H}$ is the hydroxyl group molecular weight ( $\mathrm{g} / \mathrm{mol})$. Substituting Eqs. (12) and (13) into Eq. (11), gives an expression that describes the activation energy of fracture as a function of $-\mathrm{OH}$ content in the glass

$Q_{\mathrm{I}}([\mathrm{OH}])$

$=\left(\frac{\left(N_{\mathrm{A}} /\left(V_{\mathrm{m}} S\right)\right)^{2 / 3}-\left([\mathrm{OH}] \rho_{\mathrm{g}} N_{\mathrm{A}} / \mathrm{MW}_{\mathrm{OH}}\right)^{2 / 3}}{\left(N_{\mathrm{A}} /\left(V_{\mathrm{m}} S\right)\right)^{2 / 3}}\right) E_{0}$,

where for LHG-8, $\quad V_{\mathrm{m}}$ is $39 \mathrm{~cm}^{3} / \mathrm{mol}, \rho_{\mathrm{gl}}$ is $2.83 \mathrm{~g} / \mathrm{cm}^{3}$ and $S$ is 5 .

The activation energies determined from the reaction rate model, fit to the measured crack growth velocities for $\mathrm{LHG}-8 \mathrm{~L}$ and $8 \mathrm{H}$, can be compared to the activation energy predicted by Eq. (14). Based on the $Q_{1}$ for LHG-8L (253 \pm 3 $\mathrm{kJ} / \mathrm{mol}$ ) and its hydroxyl content (128 ppmw), the activation energy, $E_{0}$, for fracture growth in a hydroxyl-free glasses is computed to be $260 \pm 3$ $\mathrm{kJ} / \mathrm{mol}$ using Eq. (14). Using this $E_{0}$, the calculated $Q_{\mathrm{I}}$ for LHG-8H (773 ppmw) is $238 \pm 3$ $\mathrm{kJ} / \mathrm{mol}$. This energy is in agreement with the energy obtained by fitting the reaction rate model (Eq. (7)) to the slow crack growth data $\left(Q_{\mathrm{I}}=239 \pm 3 \mathrm{~kJ} / \mathrm{mol}\right.$, see Table 2$)$.

A simple physical representation of the effect of $\mathrm{OH}$ content on the number P-O-P bonds to be broken on a fracture surface is given in Fig. 5. A hypothetical glass sample under tensile load and containing a pre-existing fracture is pictured at the bottom of Fig. 5 . Also shown is a $15 \times 15 \mathrm{~nm}^{2}$ plane extending beyond the crack front plane, into the unfractured glass. The expected $\mathrm{OH}$ density in this plane, for both LHG-8L and $8 \mathrm{H}$, is represented by the black dots in the grids in the top portion of Fig. 5 . The grid size $(0.7 \mathrm{~nm} \times 0.7 \mathrm{~nm})$ approximates the overall bond density $\left(n_{0} \cong 2\right.$ $\mathrm{nm}^{-2}$ from Eq. (12)), and the number of hydroxyl groups within each $15 \times 15 \mathrm{~nm}^{2}$ surface is 
ㅁ P-O-P

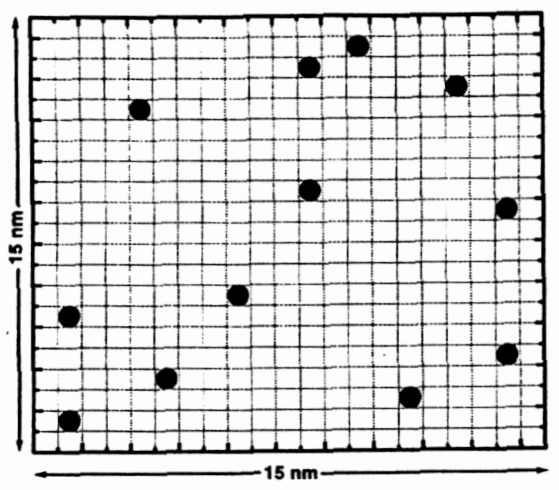

LHG-8L $-\mathbf{- O H}$

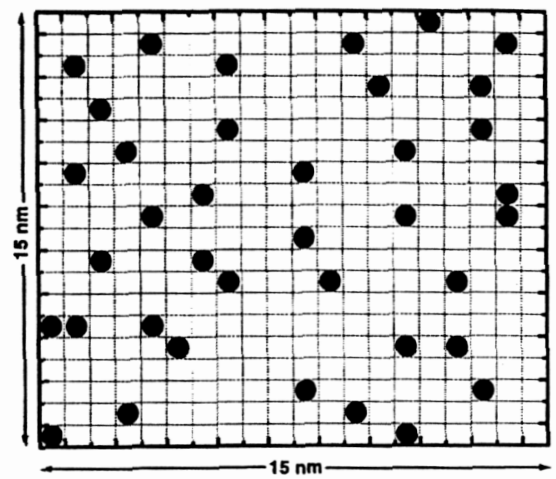

\section{LHG-8H}
773 ppmw $\mathrm{OH}$ $\mathrm{n}_{\mathrm{OH}}=0.18 \mathrm{~nm}^{-2}$ $\mathrm{n}_{\mathrm{OH}} / \mathrm{n}_{0}=9.1 \%$
$128 \mathrm{ppmw} \mathrm{OH}$ $\mathrm{nOH}=0.05 \mathrm{~nm}^{-2}$

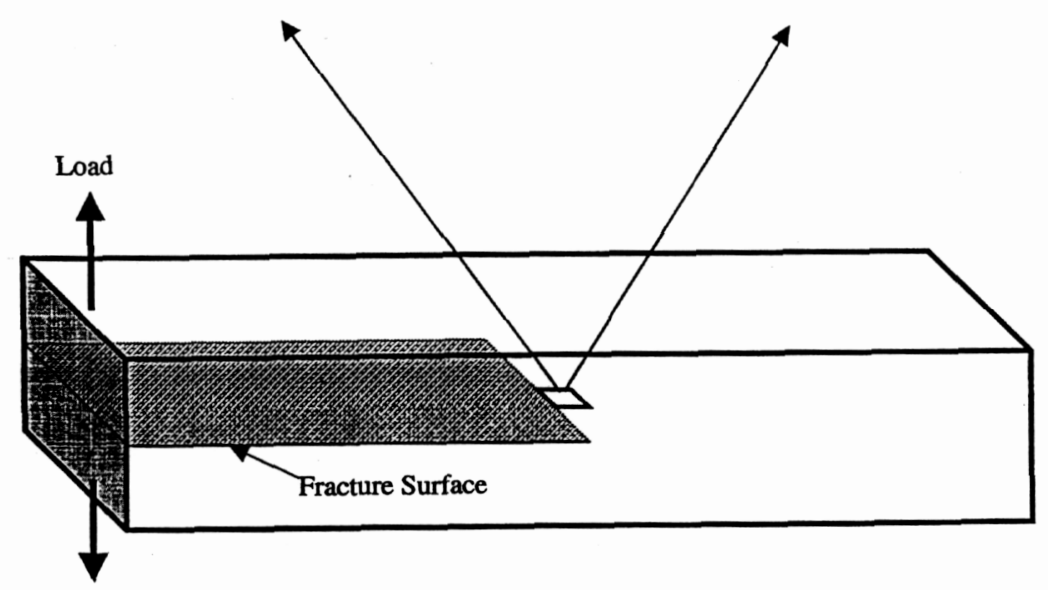

Fig. 5. Hypothetical representation of a glass sample undergoing brittle-fracture illustrating how a change in $-\mathrm{OH}$ content in the glass would alter the number of bonds to be broken as the crack propagates. The grid represents a cross-section of the potential fracture surface for both a low (LHG-8L) and high (LHG-8H) OH containing glass. Each square in the grid represents (on average) a bonding site, and each circle represents a bonding site on the fracture surface that has been broken due to a chain terminating $\mathrm{OH}$ group.

calculated using Eq. (13). Based on this simple picture, the increase in the $\mathrm{OH}$ content in going from LHG- $8 \mathrm{~L}$ to $8 \mathrm{H}$ reduces the $\mathrm{P}-\mathrm{O}-\mathrm{P}$ bond density across the fracture plane by about $7 \%$, in agreement with the $\sim 6 \%$ change in activation energy $\left(Q_{\mathrm{I}}\right)$ for crack growth in these two glasses. Note that this ability to measure small relative changes in activation energy is due to the sensitivity of the crack velocity to small changes in activation energy. For example, a change of $14 \mathrm{~kJ} /$ mol in activation energy governing crack growth (i.e., from 239 to $253 \mathrm{~kJ} / \mathrm{mol}$ ) produces a change in the crack velocity by a factor of 100 (see Fig. 4).

\subsection{Crack blunting}

Due to the geometry of the DCDC crack growth method (Fig. 1), the stress intensity 
decreases with increase in crack length (Eq. (2)); hence the crack velocity decreases over the course of the test. We observed that under conditions of relatively low temperatures and water vapor pressures, the crack velocity decreases; when the crack movement becomes undetectable, a small increase in load $(<40 \mathrm{~N}(\sim 10 \mathrm{lbf}))$ restarts crack propagation. However, at higher temperatures and water vapor pressures, we found that the propagating crack often stops abruptly. Furthermore, an increase in load, typically $>400 \mathrm{~N}(\sim 100 \mathrm{lbf})$, is required to restart crack growth, and once restarted the crack propagates at greater velocity, in many cases much greater than can be measured by our apparatus. We refer to this arrest in crack propagation as crack tip blunting where the term 'blunting' infers an increase in radius of curvature of the crack tip. The effect of crack tip radius $(\rho)$ on the local stress at the crack tip $\left(\sigma_{\max }\right)$ was first formulated by Inglis [41]

$\sigma_{\max } \propto \frac{1}{\sqrt{\rho}}$.

As the radius of curvature increases, the local stress at the crack tip decreases. This decrease in the local stress reduces the rate of crack propagation.

The conditions where blunting was observed during the course of this study are shown in Fig. 6. For comparison, also shown, is the complete range of conditions for which crack growth measurements were made. The edge of the shaded region represents the approximate transition from blunting to non-blunting conditions and compares well with the transition zone we observed in previous work [14].

We assume that the blunting process is the result of mass transport of glass to the crack tip; this is conceptually similar to the material transport that occurs during sintering of small particles [42]. A number of mass transport mechanisms are possible including viscous flow, evaporation-condensation, surface diffusion and bulk diffusion. Viscous flow near the crack tip is perhaps the most likely mass transport mechanism because of the decrease in phosphate glass viscosity with increasing hydroxyl content. Therefore at higher

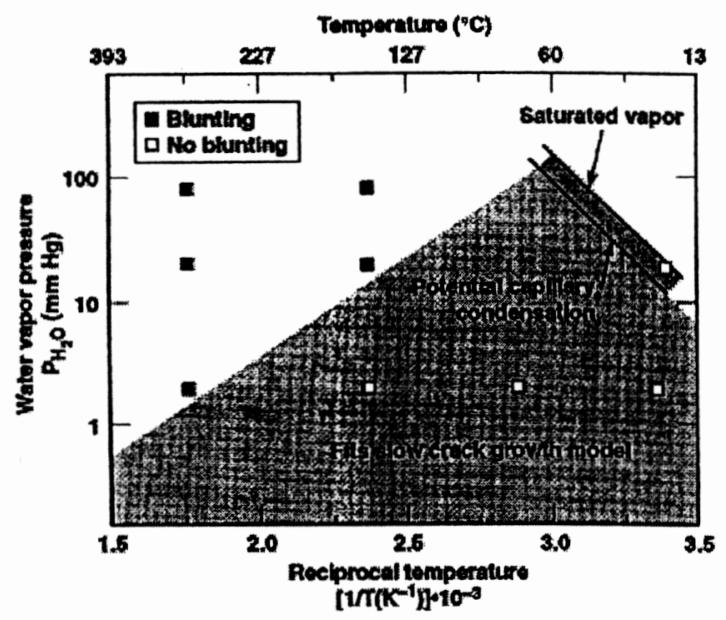

Fig. 6. Conditions (temperature and water vapor pressure), represented by the points, for which crack propagation measurements were made during the course of this work. Also shown are the regions where crack tip blunting was observed and the region for possible capillary condensation. The boundary separating the various regions is approximate.

temperatures and greater water vapor pressures, where $\mathrm{OH}$ diffusion into the glass surrounding the tip becomes more rapid, we expect to see a greater degree of blunting. This expectation agrees with our general observations (Fig. 6).

Up to this point, crack blunting (static blunting) is simply described as a decrease in the crack tip curvature that occurs after the crack has stopped. However, the driving force for blunting must also exist even while the crack is propagating; therefore, the propagating crack tip radius could differ depending on the temperature, water vapor pressure and stress intensity (i.e., velocity). We refer to this process as 'dynamic' crack tip blunting. Therefore, the size of the crack tip radius is determined by a balance between the rate of mass transport to the crack tip (leading to blunting) and the rate of crack propagation (leading to crack sharpening). In a moving crack, we expect a constant radius of curvature that can be described by

$\rho=\rho_{0}+\rho_{\mathrm{b}}([\mathrm{OH}], T, p, v)$,

where $\rho$ is the observed radius of curvature, $\rho_{0}$ the atomically sharp crack tip, and $\rho_{\mathrm{b}}$ is the contribution of mass transfer to the crack tip radius. In the case of crack propagation in an ideal brittle 
material, the observed crack tip radius is equal to $\rho_{0}$ and is expected to be on the order of a bond length $(\sim 0.15 \mathrm{~nm})$. In a material that is not per- fectly brittle, $\rho_{\mathrm{b}}$ contributes to the total crack tip radius. The degree of blunting that takes place is a function of the $\mathrm{OH}$ content in the glass, tempera-
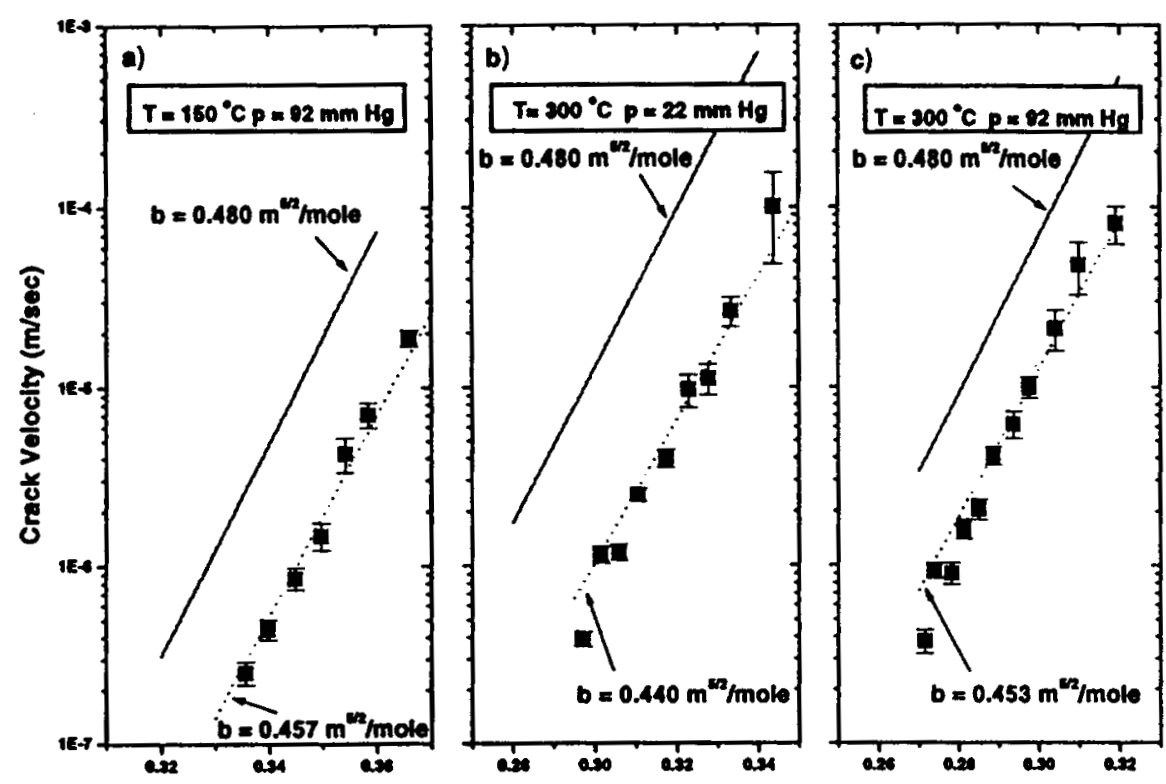

Stress intensity $\left(\mathrm{MPa}^{*} \mathrm{~m}^{\mathrm{kn}}\right)$
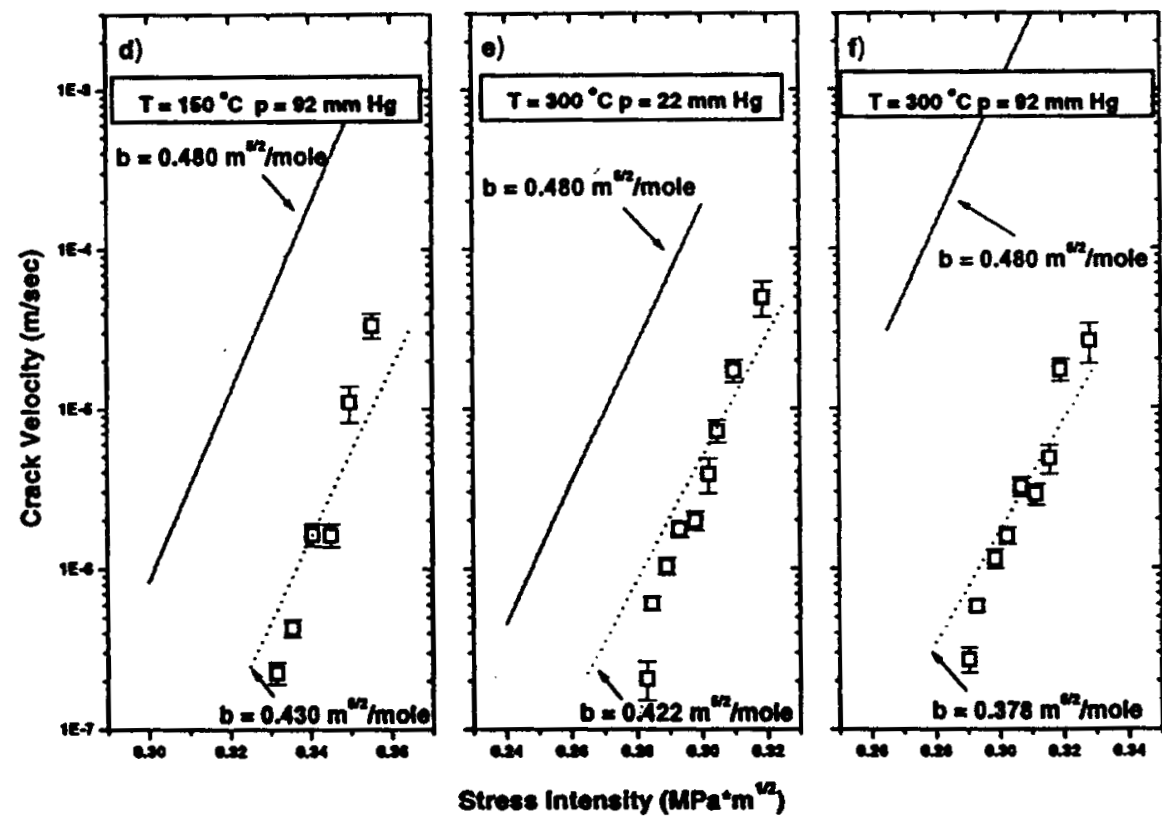

Fig. 7. Measured crack velocities for LHG-8L (a)-(c) and LHG-8H (d)-(f) at temperatures and water vapor pressures where crack-tip blunting was observed. The solid curves represent the predicted dependence using Eq. (3) and assuming no blunting $\left(b=0.480 \mathrm{~m}^{5 / 2} /\right.$ mol). The dash curves represent the predicted dependence using Eq. (3) but varying $b$ to account for crack tip blunting. 
ture, water vapor pressure, and, of course, the velocity of crack propagation (i.e., $K_{1}$ ). Note that crack blunting which occurs once the crack stops ('static' blunting) is simply a limiting case for the above conceptual model.

In instances where blunting is experimentally observed, the region I slow crack growth model (Eq. (3)) does not predict the crack velocity. Differences between model predictions of crack velocities and measured velocities in the blunting region are illustrated in Fig. 7 (a) $-(\mathrm{c})$. The solid curves in Fig. 7 represent crack velocities predicted by the region $I$ reaction rate model using the parameters in Table 2 . The crack velocity predicted using Eq. (3) is dependent on the crack tip radius through the constant $b$; based on Eq. (8), $b$ is proportional to $\rho^{-1 / 2}$. Note that because of the exponential dependence of $v_{1}$ on $b$, the velocity is affected by small changes in crack tip radius, $\rho$; a $10 \%$ increase in the radius of curvature typically causes 10 -fold reduction in the crack velocity.

The $b$ determined in the region of negligible blunting is $0.480 \mathrm{~m}^{5 / 2} / \mathrm{mol}$ and it predicts crack growth velocities in that region (see Fig. 6). However, using this $b$ the predicted crack velocity under blunting conditions does not agree with the data as shown in Fig. 7. The reduction in $b$ (while holding all other model parameters constant) needed to obtain a fit to the data corresponds to about a $12 \%$ increase in the crack tip radius for these temperatures and water vapor pressures (see dashed lines in Fig. 7). This increase in crack tip radius agrees with that reported from crack growth measurements on another phosphate glass under similar conditions [14].

In the glass containing the greater $\mathrm{OH}$ content (LHG-8H), blunting under the same experimental conditions as LHG-8L (see Fig. 6) was observed. A similar analysis of dynamic blunting was carried out on this glass and the results are shown in Fig. 7(d)-(f). Again the solid curves represent predicted crack velocities using Eq. (3) and Table 2 parameters, and the dashed lines are the best fits obtained by adjusting $b$. A larger adjustment in $b$ (corresponding to a radius of curvature change of between 25 and 60\%) was required for the greater $\mathrm{OH}$ content glass. We suggest that the larger the $\mathrm{OH}$ content of the glass, the more prone it is to blunting. Fig. 8 further illustrates this effect. Here the ratios of the LHG-8H/LHG-8L crack velocities (at the same stress intensity) are plotted as a function of water vapor pressure. At water vapor pressures of $2 \mathrm{mmHg}$, the $\mathrm{OH}$ content of the glass dominates the crack growth; notice that the velocities are approximately 30 times greater in the sample with the larger amount of $\mathrm{OH}$. On the other hand, at higher humidity $(92 \mathrm{mmHg})$ the LHG-8H sample has velocities only about three times greater than the LHG-8L sample. The much greater relative decrease in crack velocities observed in the high $\mathrm{OH}$ glass with increased vapor pressure indicates that this glass is more susceptible to blunting.

\subsection{Water condensation at crack tip}

At $25^{\circ} \mathrm{C}$ and $22 \mathrm{mmHg} \mathrm{H}_{2} \mathrm{O}$, the measured crack velocities for both $\mathrm{LHG}-8 \mathrm{~L}$ and $\mathrm{H}$ samples did not follow the expected temperature or $K_{I}$ dependence (see Fig. 9). The measured crack growth under these conditions may be affected by capillary condensation of liquid water at the crack tip as suggested by Crichton et al. [14]. Crack growth velocities are greater in liquid water compared to water vapor [5]. At $25^{\circ} \mathrm{C}$ the saturated vapor pressure for water is only $23.7 \mathrm{mmHg}$. Hence a water vapor pressure of $22 \mathrm{mmHg}$ at $25^{\circ} \mathrm{C}$

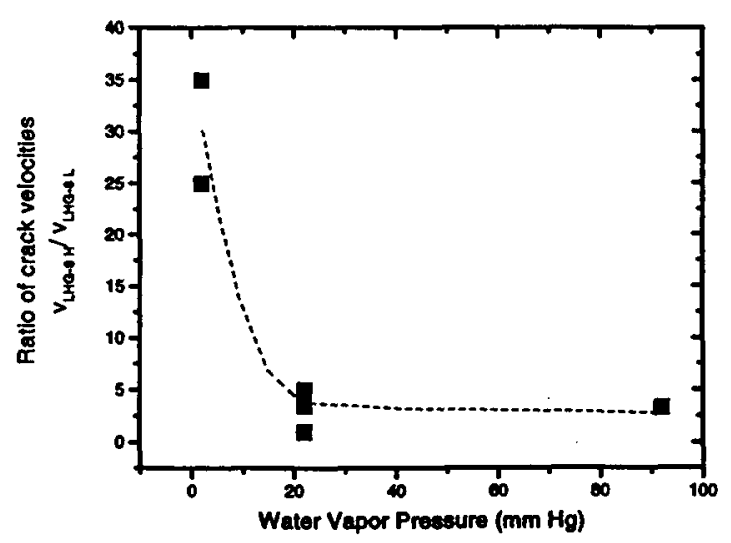

Fig. 8. Ratio of measured crack velocities in LHG-8H (128 ppmw - OH) to that in LHG-8L (773 ppmw-OH) as a function of water vapor pressure. Data are for a fixed $K_{\mathrm{l}}$. The line is drawn as a guide for the eye. 


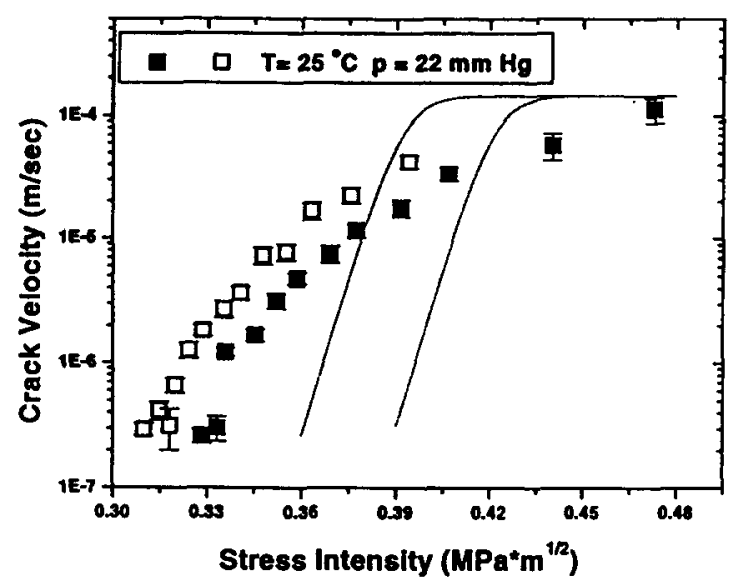

Fig. 9. Crack velocities for LHG-8L (ש) and LHG-8H ( $\square$ ) measured at $25^{\circ} \mathrm{C}$ and $22 \mathrm{~mm} \mathrm{Hg}$. The solid curves represent the predicted crack velocities based on the Wiederhorn model for region I and II crack growth (Eq. (7)).

is close to the dewpoint. Therefore liquid water may form at the crack tip due to temperature variations within the apparatus. In addition, the curved surface at crack tip can lead to capillary condensation as predicted by the well-known Kelvin equation [43]. The region of expected capillary condensation (for a crack tip radius of 1.5 $\mathrm{nm}$ ) is shown in Fig. 6. Note the condition where increased slow crack growth is observed also falls within this region. Measurements under similar conditions on another metaphosphate glass showed the same effect [14].

Apart from the increased crack growth velocities, the data at $25^{\circ} \mathrm{C}$ and $22 \mathrm{mmHg} \mathrm{H}_{2} \mathrm{O}$ also depart from the expected linear dependence of $\log v$ with $K_{\mathrm{I}}$ (Fig. 9). The curvature in these plots is similar to that seen in data on other glasses measured in liquid water and saturated water vapor environments $[31,44]$.

\section{Conclusions}

The crack velocities for both LHG-8 samples in regions I and II can be described using Wiederhorn's chemical and mass transport limited reaction rate model for crack growth. The model is fit to the data using a single set of parameters that predict crack velocities as a function of temperature, water vapor pressure and stress intensity in the absence of crack blunting and capillary water condensation at the crack front.

An increase in $\mathrm{OH}$ content of the glass results in an increase in the slow crack growth velocities in region $I$ and III. We argue that the greater velocities in regions I and III are due to a strength decrease which we attribute to a reduction in the number of $\mathrm{P}-\mathrm{O}-\mathrm{P}$ bonds at the fracture surface caused by chain terminating $\mathrm{P}-\mathrm{OH}$. A simple model relates the glass $\mathrm{OH}$ content to the activation energy for fracture. The activation energies predicted from this analysis correlate with the activation energies obtained by fitting the reaction rate model to the measured crack velocities.

At higher temperatures and water vapor pressures, crack blunting is observed. Under these conditions measured crack velocities are less than those predicted using the reaction rate expression. An increase in the crack tip radius can account for these discrepancies. We propose that the steadystate crack tip radius is determined by a balance between the rate of mass transport (causing blunting) and the rate of crack propagation (causing crack sharpening). The higher - $\mathrm{OH}$ content glass is found to be more susceptible to blunting.

\section{Acknowledgements}

The assistance of Ms Andrea Flammini and Ms Alene Clasen in the preparation of this manuscript and the contributions by the late W.A. Steele for designing and fabricating the experimental setup are deeply appreciated. This work was supported by the US Department of Energy by Lawrence Livermore National Laboratory under contract No. W-7405-ENG-48.

\section{References}

[1] B.M. VanWonterghem, J.R. Murray, J.H. Campbell, D.R. Speck, C.E. Barker, I.C. Smith, D.F. Browning, W.C. Behrendt, Appl. Opt. 36 (1997) 4932.

[2] J.T. Hunt, D.R. Speck, Opt. Eng. 28 (1989) 461. 
[3] J. Campbell, T. Suratwala, J. Non-Cryst. Solids (1999) these Proceedings.

[4] S. Wiederhorn, J. Am. Ceram. Soc. 50 (1967) 407.

[5] S. Wiederhorn, L. Bolz, J. Am. Ceram. Soc. 53 (1970) 543.

[6] S. Wiederhorn, J. Am. Ceram. Soc. 55 (1972) 81.

[7] S. Wiederhorn, E.R. Fuller, R. Thomson, Met. Sci. (August-September) (1980) 450.

[8] M. Tomozawa, W. Han, W. Lanford, J. Am. Ceram. Soc. 74 (1991) 2573

[9] M. Tomozawa, Phys. Chem. Glasses 39 (1998) 65.

[10] T. Michalske, V. Frechette, J. Am. Ceram. Soc. 63 (1980) 603.

[11] T. Michalske, B. Bunker, J. Am. Ceram. Soc. 76 (1993) 2613.

[12] W. Hillig, R. Charles, in: V. Zacklay (Ed.), High Strength Materials, Wiley, New York, 1965, p. 682.

[13] B. Lawn, Mater. Sci. Eng. 13 (1974) 277.

[14] S. Crichton, M. Tomozawa, J. Hayden, T. Suratwala, J. Campbell, J. Am. Ceram. Soc. 82 (1999) 3097.

[15] E. Gehrke, Silikattechnik 33 (1992) 238.

[16] J.R. Murray, ICF Quarterly Report, LLNL Report UCRL-LR-105821-97, 7 (1997) 95.

[17] M. Andre, M. Novaro, D. Schirmann, Chocs. Rev. Sci. Techni. Direct. Appl. Milit. 13 (1995) 73.

[18] J. Campbell, T. Suratwala, C. Thorsness, J. Hayden, A. Thorne, J. Cimino, A. Marker, K. Takeuchi, M. Smolley, G. Ficini-Dorn, these Proceedings, p. 342.

[19] V. Scholze, Glastech. Ber. 32 (1959) 381.

[20] J. Shelby, Handbook of Gas Diffusion in Solids and Melts, ASM International, Materials Park, OH, 1996, p. 217 (Chapter 10).

[21] H. Toratani, Properties of laser phosphate glasses, PhD thesis, Kyoto University, 1989.

[22] T. Michalske, W. Smith, E. Chen, Eng. Fracture Mech. 45 (1993) 637.

[23] S. Wiederhorn, in: R. Bradt, D. Hasselman, F. Lange (Eds.), Fracture Mechanics of Ceramics, Plenum, New York, vol. 2, 1996, p. 613.
[24] A. Tobolsky, H. Eyring, J. Chem. Phys. 11 (1943) 125.

[25] Y.L. Huang, N. Brown, J. Mater. Sci. 23 (1988) 3648.

[26] J. Michel, J.A. Manson, R.W. Hertzberg, Polymer 25 (1984) 1657.

[27] S.L. Kim, M. Skibo, J.A. Manson, R.W. Hertzberg, Polym. Eng. Sci. 17 (1977) 194.

[28] G. Pitman, L.M. Ward, J. Mater. Sci. 15 (1980) 635.

[29] A. Ramirez, J. Manson, R. Hertzberg, Polym. Eng. Sci. 22 (1982) 975.

[30] K.P.R. Reddy, E.H. Fontana, J.D. Helfinstine, J. Am. Ceram. Soc. 71 (1988) C310.

[31] S. Wiederhorn, in: R.C. Brandt, D.P.H. Hasselman, F.F. Lange (Eds.), Fracture Mechanics in Ceramics, Plenum, New York, 1978, p. 549.

[32] R.J. Kirkpatrick, R.K. Brow, Solid State Nucl. Magn. Reson. 5 (1995) 9.

[33] S. Martin, Eur. J. Solid State Inorg. Chem. 28 (1991) 163.

[34] J. Otaigbe, G. Beall, TRIP 4 (11) (1997) 369.

[35] S.D. Haman, in: R. Bradley (Ed.), High Pressure Physics and Chemistry, 1963 (Chapter 8).

[36] Y. Bando, S. Ito, M. Tomozawa, J. Am. Ceram. Soc. 67 (1984) C-36,37; C-254.

[37] J.S. Hayden, A.J. Marker, T. Suratwala, J.H. Campbell, these Proceedings, p. 228.

[38] R.M. Wenslow, K.T. Mueller, J. Phys. Chem. B 102 (1998) 9033.

[39] L.H. Sperling, Introduction to Physical Polymer Science, 2nd Ed., Wiley, New York, 1992.

[40] K. Sun, J. Am. Ceram. Soc. 30 (1947) 277.

[41] C. Inglis, Trans. R. Inst. Nav. Archit. 60 (1913) 219.

[42] W.D. Kingery, H.K. Bowen, D.R. Uhlmann, Introduction to Ceramics, 2nd Ed., Wiley, New York, 1976.

[43] P. Atkins, Physical Chemistry, 5th Ed., Freeman, Oxford, 1994.

[44] S. Wiederhorn, J. Am. Ceram. Soc. 56 (1973) 192.

[45] S. Wiederhorn, H. Johnson, A. Diness, A. Heuer, J. Am. Ceram. Soc. 57 (1974) 336. 


\title{
Optical loss and $\mathrm{Nd}^{3+}$ non-radiative relaxation by $\mathrm{Cu}, \mathrm{Fe}$ and several rare earth impurities in phosphate laser glasses
}

\author{
P.R. Ehrmann a,*, J.H. Campbell a, T.I. Suratwala a , J.S. Hayden ${ }^{\text {b, }}$ \\ D. Krashkevich ${ }^{b}$, K. Takeuchi ${ }^{c}$ \\ - Lawrence Lbermore Nationad Laboratory, P.O. Box 808, L500, Lbermore, CA 94550, USA \\ - Schotr Glass Technologies, Inc, 100 York Ave, Durged, PA 18612, USA \\ - Hoga Corporation USA, 3400 Edison Way, Fremont, CA 94538, USA
}

\begin{abstract}
Abetract
Extinction coefficients (at $1053 \mathrm{~nm}$ ) and $\mathrm{Nd}^{3+}$ fiuorescence quenching rates are reported for $\mathrm{Cu}, \mathrm{Fe}, \mathrm{Dy}, \mathrm{Pr}, \mathrm{Sm}$ and Ce at doping concentrations up to $1000 \mathrm{ppmw}$ in two meta-phosphate laser glasses melted under oxidizing conditions (1 atmosphere $\mathrm{O}_{2}$ ). The extinction coefficient and quenching rate for $\mathrm{Cu}$ are $2.7( \pm 0.1) \times 10^{-3} \mathrm{~cm}^{-1} / \mathrm{ppmw}$ and $10.4 \pm 0.2$ Hztppmw, respectively. The extinction coefficient and quenching rate for $\mathrm{Fe}$ are concentration dependent below 300 ppmw due to an observed change in $\mathrm{Fe}^{2+} / \mathrm{Fe}^{3+}$ distribution; an empirically derived expression is used to describe this effect. The extinction coefficient and quenching rates for $\mathrm{Dy}$, Pr and $\mathrm{Sm}$, are nearly the same: 1.6, 1.2 and $1.3( \pm 0.05) \times 10^{-3} \mathrm{~cm}^{-1} / \mathrm{ppmw}$ and $0.89,0.72$ and $0.63 \pm 0.04 \mathrm{~Hz} / \mathrm{ppmw}$, respectively, while those for Ce are less: $0.84( \pm 0.03) \times 10^{-5} \mathrm{~cm}^{-1} / \mathrm{ppmw}$ and $0.061 \pm 0.03 \mathrm{~Hz} / \mathrm{ppmw}$. The quenching results are explained using the FörsterDexter theory for dipolar energy transfer. 12000 Published by Elsevier Science B.V. All rights reserved.
\end{abstract}

\section{Introduction}

Neodymium-doped phosphate glasses are the preferrod material for use in high-energy and highpeak-power laser systems [1-3]. There are a number of reasons for this choice, but perhaps the three most important are: (1) energy can be efficiently stored and extracted from these glasses [4,5], (2) high energy storage densities ( $>250 \mathrm{~J} / \mathrm{h}$ ) can be achieved $[2,4]$ and (3) the glasses can be manufactured in moter-ecale sives with high optical homogeneity and low Pt-inciuxion concentrations [6].

\footnotetext{
"Corresponding author. Tel: +1-925 423 2949; fox: +1-925 4230792.

Emaul addrexx chrmanal ellinl.gov (P.R. Bhrmann).
}

Transition metal and rare carth ion impurities degrade the laser performance of the glass by reducing both the stored energy and optical transmission [7]. The stored energy, which rofers to the $\mathrm{Nd}^{3+}$ excited state density in the ${ }^{4} F_{3 / 2}$ upper laser level, is affocted by these impurities through increased non-radiative losses. In addition, the optical absorption of many transition metal impurities contributes to absorption 7 losses at the laser wavelength, even at contaminant concentrations in the low ppenw range. In this regard, $\mathrm{Fe}$ and $\mathrm{Cu}$ are particulariy troublesome: Fe because it is present in most materials due to the use of iron-based processing equipment and $\mathrm{Cu}$ because of its exceptionally lange optical absorption cross-ection at the $1053 \mathrm{~nm}$ laser transition. For these reasons, $F e$ and $\mathrm{Cu}$ are the main focus of this study. We also examine Dy, Pr, Sm and Ce 
contaminants because they are difficult elements to separate from Nd and therefore are common impurity ions in Nd raw materials [6].

Optical absorption by impurities decreases the net gain of a laser glass amplifier. For example, in the small-signal region, the amplifier gain, $G_{S S}$, is

$$
G_{\mathbb{S S}}=\frac{F_{\text {out }}}{F_{\text {in }}}=\exp \left(\left(g_{0}-\alpha\right) 1\right),
$$

where $F_{\text {m }}$ and $F_{\text {out }}$ are the input and output fluence $\left(\mathrm{J} / \mathrm{cm}^{2}\right)$, respectively, $l$, the laser glass length $(\mathrm{cm})$, and $\mathrm{g}_{0}$ the gain coefficient $\left(\mathrm{cm}^{-1}\right)$ [J]. Here $\alpha$ represents the sum of all optical loss terms

$\alpha=\alpha_{\text {sentlec }}+\sum_{i=1}^{n} \alpha_{T M_{4}}+\sum_{j=1}^{n} \alpha_{R E_{j},}$

where ane loss coefficient $\left(\mathrm{cm}^{-1}\right)$ due to scattering by defects and inclusions (such as bubbles and Pt particles), and $\alpha_{\mathrm{TM}}$ and $\alpha_{R E}$, represent the individual absorption coefficients due to transition metal ion, $i$, and rare earth ion, $J$, respectively. The absorption coefficient for a given ion is the product of the extinction coefficient, $\varepsilon\left(\mathrm{cm}^{-1} /\right.$ ppmw) and the impurity concentration, $c$ (ppmw). Generally, scatter losses are negligible (in the absence of laser damage) because of the highly polished surfaces and the lack of inclusions or bubbles in the laser glasses used on laser systems [8]. Therefore, absorption by impurities is the dominant loss term.

Apart from increasing the optical losses, ( $\alpha$ ), impurities can also adversely effoct laser performance by decreasing the stored enecgy through non-radiative energy losses $[4,7]$. The rate of energy transfer between $\mathrm{Nd}^{3+}$ and an impurity is generally described on the basis of a dipolo-dipole interaction using the model originally formulated by Förster [9] and later extended by Dexter [10]. In the Fordter-Dexter model, $\mathrm{Nd}^{3+}$ is the "donor" (D) and the impurity the 'acceptor' (A); the energy transfer rate is given as

$$
k_{\mathrm{DA}}=\eta R_{\mathrm{DA}}^{-\sigma} \int \frac{G_{\mathrm{D}}(v) K_{\mathrm{A}}(v) \mathrm{d} v}{\mu}
$$

where $\eta$ is a constant for a given base glass composition and $R_{D A}$ is the inter-atomic distance between the donor and acceptor. The integral describes the spectral overlap between the donor emission, $G_{D}(v)$ and acceptor absorption $K_{\Lambda}(v)$, where $v$ is in wave numbers. Thus acceptors that are the strongest absorbers at the emission wavelength tend to produce the greatest increase in the non-radiative decay rate.

There have been numerous studies of the optical absorption properties of $\mathrm{Fe}$ and other transition metal ions in phosphate glasses (see for example [11-22] and fluorophosphate glasses [20,21,2320]. However, only a few previous studies have addressed the issue of optical loss at $1053 \mathrm{~nm}$ and/ or fluorescence quenching by transition metal and rare earth ions present at impurity levels of $\$ 1000$ ppmw in Nd-doped phosphate laser glasses [7,2729]. In this work, we report for the first time both the absorption loss and the increase in $\mathrm{Nd}^{3+}$ nonradiative decay rate due to $\mathrm{Fe}$ and $\mathrm{Cu}$ over a range of doping concentrations from about 10 to 1000 ppmw in two widely used commercial meta-phosphate glasses: LHG-8 and LG-770. We also report the absorption loss and fluorescence quenching by several common rare earth impurities (Dy, $\mathrm{Pr}, \mathrm{Sm}$ and $\mathrm{Ce}$ ) doped mostly at $1000 \mathrm{ppmw}$. All melting has been carried out in an oxidizing environment $\left(\mathrm{O}_{2}\right.$ gas; $\left.1 \mathrm{~atm}\right)$ because these conditions are widely used in commercial laser glass processing $[6,30,31]$.

\section{Experimental}

\subsection{Preparation and chemical analysis of glass melts}

The two glass compositions used in this study are LHG-8 and LG-770. LHG-8 has the composition (mol\%): (55-60) $\mathrm{P}_{2} \mathrm{O}_{5}-(8-12) \mathrm{Al}_{2} \mathrm{O}_{3}-(13-$ $17) \mathrm{K}_{2} \mathrm{O}-(10-15) \mathrm{BaO}$ and $(0-2) \mathrm{Nd}_{2} \mathrm{O}_{3} ;$ similarly LO-770 is (58-62) $\mathrm{P}_{2} \mathrm{O}_{5}-(6-10) \mathrm{Al}_{2} \mathrm{O}_{3}-(20-25) \mathrm{K}_{2} \mathrm{O}$ $(5-10) \mathrm{MgO}_{2}$ and $(0-2) \mathrm{Nd}_{2} \mathrm{O}_{3}$. Both glasses are near meta-phosphates (O/P 3.0). The compositions are reported as ranges to account for variability due to doping and melting methods and to protect certain proprietary aspects of the compositions $[4,0$. Several recent studies have shown that the 
laser, optical, and physical properties of these two glasses are quite similar $( \pm 10 \%$ for most properties) suggesting that over the minor ranges in composition (and modifiers) listed above, the laser glass properties are largely unchanged $[4,6,32]$.

All glasses were prepared using procedures described elsewhere $[27,29]$ and using the same source and purity starting materials. Impurity concentrations were verified by chemical analysis as described below. Several undoped samples were prepared as references. All camples were melted in quartz crucibles with both dry $\mathrm{O}_{2}$ bubbling and dry $\mathrm{O}_{2}$ cover gas and homogenizod by stirring; prior to melting both the crucible and stirrer were cleaned with $6 \mathrm{M} \mathrm{HCl}$ to minimize contamination. The LG-770 samples were first melted at $1200^{\circ} \mathrm{C}$ and then refined for four hours at $1375^{\circ} \mathrm{C}$ to remove bubbles. The LHG-8 eamples were prepared in a similar fashion using melt temperatures of $1100^{\circ} \mathrm{C}$ and refining at $1250^{\circ} \mathrm{C}$. In the case of both LHG-8 and LG-770, the liquid was then cooled to approximately $900^{\circ} \mathrm{C}$ and cast into a mold. The samples were then annealed to reduce residual stress at a rate of about $30^{\circ} \mathrm{C} / \mathrm{h}$ starting at approximately $500^{\circ} \mathrm{C}\left(\sim 50^{\circ} \mathrm{C}\right.$ above $\left.T_{\varepsilon}\right)$ and ending near room temperature.

The use of a dry cover gas during melting was to minimize hydroxyl group contamination caused by water vapor reacting with the glass $[6,33]$. The OH concentration was measured by the intensity of the O-H vibration band near $3000 \mathrm{~cm}^{-1}[34,35]$. The measured absorption at $3000 \mathrm{~cm}^{-1}$ for the LG-770 samples was $\$ 0.6 \mathrm{~cm}^{-1}$ and for the LHG8 camples $\$ 5 \mathrm{~cm}^{-1}$.

The impurity doping concentration of each sample was verified by analyais of fully dissolved glass solutions using inductively coupled plasma (ICP) emission spectrometry (Thermo Iris Model 6943) for $\mathrm{Fe}$ and $\mathrm{Cu}$ and ICP mass spectrometry (Hewlett Packand Model 4500) for the rare earths. Sc, Be and/or Pr were used as internal standards depending on the analyte. National Institute of Standards and Technology traceable standards (SPEX Industries) were used to calibrate the instruments. The measured dopant ion concentrations in the glasses were in close agreement with the batch compositions ( $\pm 10 \%$ ).

\section{2. $N d^{3+}$ fuorescence decay}

The fluorescence decay rates were measured using $2 \times 2 \times 2 \mathrm{~mm}^{3}$ polished glass cubes. The sample was held in an anodized mount and illuminated with the broadband spectral output ( 300-1100 nm) from a flashlamp (BG\&G LS1130-4) having a $2.2 \mu s$ pulse-width. Two optical filters (Melles Griot KG-3 and BG-18) effectively blocked all but the visible pump wavelengths $(340-620 \mathrm{~nm})$. A photo-multiplier tube (Hamamatsu R5108), mounted perpendicular to the flashlamp, monitored the fluorescence signal. An optical filter on the photo-multiplier (Melles Griot RG-850) blocked the pump light and allowed transmission of the fluorescence signal. The temporal decay of the signal was recorded on an oscilloscope (Tektronix TDS 380) and fit to a single exponential function to determine the characteristic Nd N $^{3}$ fluorescence decay time. A signal generator (Tucker Blectronics, TFG 8140) is used to trigger the flashlamp and oscilloscope. The fluorescence lifetimes were corrected for non-radiative decay due to $\mathrm{OH}$ contamination using the empirical correlation developed by Campbell and Suratwala [4]. Also, a minor correction was made $(\leqslant 20 \mathrm{~Hz}$ ) for radiation trapping within the finite sample volume [36].

\subsection{Optical absorption measurements}

Optical extinction coefficients were measured using both a conventional spectrophotometer and a custom-built laser calorimeter. The calorimeter method was used to confirm the spectrophotometric measurements on glasses doped with Fe concentrations. Calorimetric measurements were performed at $1064 \mathrm{~nm}$ using a steady-state laser heating technique; details of this method are described elsewhere $[8,37$.

Transmission measurements were carried out with a spectrophotometer (Shimadzu model UV1601 PC) using two polished samples of the same glass but with different thickness (5 and $50 \mathrm{~mm}$ ) to compensate for fresnel surface losses. A series of four transmission measurements per sample were made to eliminate effects by striae or inclusions; for these measurements the samples were rotated 
about the beam axis within the spectrophotometer. The average of the four transmission measurements was used to compute the absorption coefficient $\left(\alpha, \mathrm{cm}^{-1}\right)$ using the exponential form of Beer's law [38]. The extinction coefficient $\left(\varepsilon, \mathrm{cm}^{-1} / \mathrm{ppmw}\right)$ was then computed from the absorption coefficient and the doping concentration (c, ppmw); $\varepsilon=\alpha / c$.

The optical absorption measurements at 1053 nm were corrected for absorption by $\mathrm{Nd}^{3+}$ ions that thermally populate the ${ }^{4} I_{11 / 2}$ terminal laser level using the empirical expression [4]

$\alpha_{\mathrm{Nd}}(T)=1.03 \times 10^{-20}\left[\mathrm{Nd}^{3+}\right] \exp \left(\frac{-2576}{T}\right)$

where $\alpha_{\mathrm{Ndd}}(T)$ is the loss $\left(\mathrm{cm}^{-1}\right),\left(\mathrm{Nd}^{3+}\right]$ the $\mathrm{Nd}$ dopant ion concentration (ions/ $\mathrm{cm}^{3}$ ) and $T$ the temperature $(K)$. The $\mathrm{Nd}^{3+}$ concentrations used in this study are $4.6 \times 10^{20}$ and $4.2 \times 10^{20}$ ions $/ \mathrm{cm}^{3}$ for the LG-770 and LHG-8 samples, respectively. Therefore the corresponding 1054-nm absorptions at $22^{\circ} \mathrm{C}(295 \mathrm{~K})$ due to the $\mathrm{Nd}^{3+}$ are $7.6 \times 10^{-4}$ and $7.0 \times 10^{-1} \mathrm{~cm}^{-1}$, respectively.

No attempt was made to correct for scatter losses in these optical quality glasses because the surfaces were highly polished and prepared using the same polishing procedure. Accurate measurements of scatter losses on highly polished pieces of phosphate laser glasses have been reported previously using an integrating sphere scatterometer [8]; the results show surface losses of less than $5 \times 10^{-5}$ per surface and bulk glasses losses $<10^{-5} \mathrm{~cm}^{-1}$ (detection limit).

\section{Resuilts}

\subsection{Optical measurements}

The measured optical tranemission spectra between 800 and $1100 \mathrm{~nm}$ for Nd-doped LG-770 containing various concentrations of $\mathrm{Fe}$ and $\mathrm{Cu}$ are shown in Fig. 1. The absorption bands at about 815 and $870 \mathrm{~mm}$ are due to the $\mathrm{Nd}^{3+}$ transitions from the ${ }^{4} I_{2 / 2}$ ground state to the overlying ${ }^{4} \mathrm{~F}_{3 / 2}$ and ${ }^{4} \mathrm{~F}_{5 / 2},{ }^{2} \mathrm{H}_{9 / 2}$ states, respectively. The region of interest in this study is the absorption near

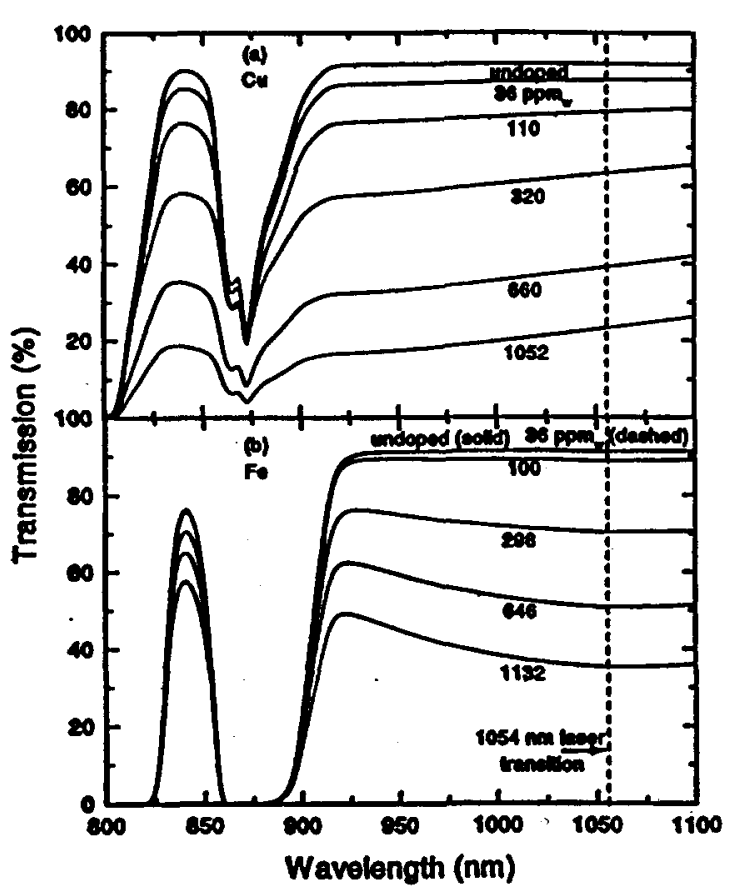

Fig. 1. Transmission spectru measured on LG-770 doped with various concentrations of (a) Cr and (b) Fe. The vertical dashed line represents the $1053 \mathrm{~nm} \mathrm{Nd^{3+ }}$ laser transition. The $\mathrm{Cu}$ and Fe spectra shown here are for nominal 0.5-cm and 5-cm-thick samples, respectively.

$1053 \mathrm{~nm}$ that corresponds to the ${ }^{4} F_{3 / 2}-{ }^{4} I_{11 / 2}$ laser transition.

Fig. 2 shows the measured transmission spectra for LG-770 doped with various Fe impurity concentrations but without $\mathrm{Nd}^{3+}$; $\mathrm{La}^{3+}$ was substituted as the rare-earth dopant. Because of the lack of interference by the $\mathrm{Nd}^{3+}$ absorption bands, these spectra show the major absorption bands due to $\mathrm{Fe}^{2+}$ and $\mathrm{Fe}^{3+}$ between about 300-3000 nm. The band assignments ahown are based on reported values for $F e$ in phosphate glasses $[14,17,39,40]$. The absorption below $400 \mathrm{~nm}$ is due to the tail of the intense absorption bands of $\mathrm{Fe}^{3+}$ charge transfer states at about 195 and $240 \mathrm{~nm}$ [40,41]. Kurkjian and Sigety [17] assign the bands at about 415, 520 and $735 \mathrm{~nm}$ (Fig. 2(b)) to the $\mathrm{Fe}^{3+}$ transitions ${ }^{6} A_{1}-{ }^{4} E^{4} A_{1},{ }^{4} T_{2}$ and ${ }^{4} T_{1}$, respectively.

The results from transmission measurements on the $\mathrm{Cu}, \mathrm{Fe}$ and rare earth-doped samples are 

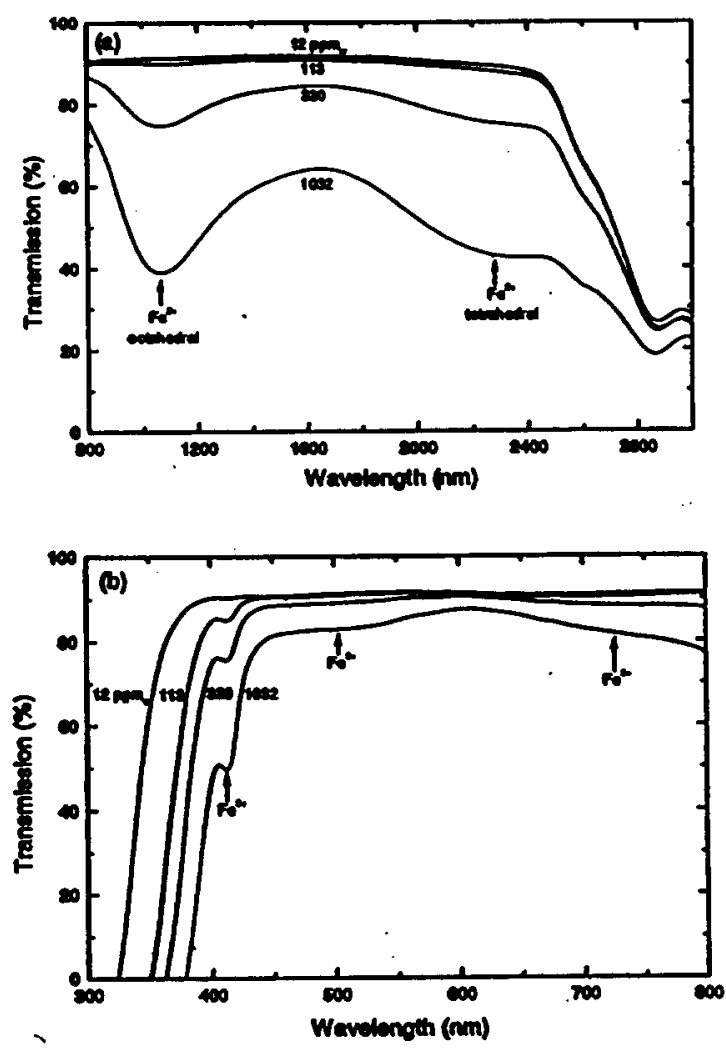

Fig 2 Transmission apectra between (a) 800-3000 nm and (b) $300-800 \mathrm{~mm}$ for S-cm-thick samples of LG-770 doped with various concentrations of Fe and using La rather than $\mathrm{Nd}$ as the rave-arth dopant. summarized in Table 1 as extinction coefficients at $1053 \mathrm{~nm}$. The extinction coefficients for the rare earths in LG-770 follow the observed trend: Dy $z \operatorname{Sm} Z \operatorname{Pr}>$ Ce. The extinction coefficients, $\varepsilon$ (cm-1/ppmw), were calculated from the measured absorption coefficients, $\alpha\left(\mathrm{cm}^{-1}\right)$, by simply dividing by the impurity concentration (ppmw). It is straightforward to convert these reported extinction coefficients to other common concentration units (e.g. ions/ $\mathrm{cm}^{3}, \mathrm{~mol} / \mathrm{h}$ ) from the known glass densities (2.83 and $2.59 \mathrm{~g} / \mathrm{cm}^{3}$ at $20^{\circ} \mathrm{C}$ for LHG-8 and LG-770, respectively).

\subsection{Non-radiative decay rates}

The increase in the $\mathrm{Nd}^{3+}$ fluorescence decay rate (i.e. quenching rate) due to the presence of the various metal ion impurities is summarized in Table 1 (H/ppmw). The quenching rate was computed from the measured fluorescence lifetimes

$k_{\mathrm{A}}=\frac{\left(\tau^{-1}-\tau_{0}^{-1}\right)}{[A]}$

where $\tau$ and $\tau_{0}$ are the $\mathrm{Nd}^{3+}$ fluorescence lifetimes for the doped and undoped samples, respectively, [A] is the impurity (acceptor) ion concentration, and $k_{\mathrm{A}}$ is the decay rate per unit impurity-ion concentration. The Nd concentration is fixed.

The quenching rate by $\mathrm{Cu}$ is nearly 10-fold greater than $\mathrm{Fe}$ at ion concentrations of more than

Trable 1

Batinction coeficients at $1053 \mathrm{am}$ and fluorescence quenching rates due to various impurity ions in LG-770 and LFG-8 melted under oxidiving conditions (1 atmoephere $\left.\mathrm{O}_{2}\right)^{2}$

\begin{tabular}{|c|c|c|c|c|}
\hline \multirow[t]{2}{*}{ Element } & \multicolumn{2}{|c|}{ Queaching rate $k_{n}$ (Hdtppm) } & \multicolumn{2}{|c|}{ Extinction coeficient \& $\left(10^{-3} \mathrm{~cm}^{-1} / \mathrm{pgmm}\right)$} \\
\hline & LFO-8 & LG-770 & LHG-8 & LO-770 \\
\hline $\begin{array}{l}\text { Cr } \\
\text { Fe }(>1000 \text { ppmw }) \\
\text { Fe }(<1000 \text { ppinw }) \\
\text { Dy } \\
\text { Pr } \\
\text { Sm. } \\
\text { Ce }\end{array}$ & $\begin{array}{l}10.2 \pm 1.5 \\
0.86 \pm 0.03 \\
\text { Bq. }(9)^{6} \\
= \\
1.1 \pm 0.06 \\
=\end{array}$ & $\begin{array}{l}10.6 \pm 1.5 \\
1.4 \pm 0.06 \\
B q .95 \\
0.09 \pm 0.04 \\
0.72 \pm 0.04 \\
0.63 \pm 0.03 \\
0.061 \pm 0.03\end{array}$ & $\begin{array}{l}2.78 \pm 0.34 \\
0.11 \pm 0.005 \\
\text { Eq. }(6)^{6} \\
- \\
- \\
- \\
-\end{array}$ & $\begin{array}{l}2.61 \pm 0.28 \\
0.18 \pm 0.008 \\
\text { Bq. }(0) \\
0.016 \pm 0.0006 \\
0.012 \pm 0.0005 \\
0.013 \pm 0.0005 \\
0.0084 \pm 0.0003\end{array}$ \\
\hline
\end{tabular}

The data ase for Nd-doping dewitices of 4.6( \pm 0.1$)$ and 4.2( \pm 0.1$) \times 10^{20}$ lons/cm for LO-770 and LHG-8, respectively.

See Bq. (9): $\beta=7.8 \mathrm{kFz} / \mathrm{cm}^{-1}$ and en per Bq. (0).

'See Eq. (O): $c_{\text {max }}=1.8( \pm 0.17) \times 10^{-4} \mathrm{~cm}^{-1} / \mathrm{ppm}$ and $1.1( \pm 0.09) \times 10^{-4} \mathrm{~cm}^{-1} / \mathrm{ppm}$ for LG-770 and LHG-8, respectively; [Fe $\mathrm{k}=170$ ppomw. 
300 ppmw (i.e. about $10 \mathrm{~Hz} / \mathrm{ppmw} \mathrm{Cu}$ vs. $1 \mathrm{~Hz}$ ppmw Fe). The Fe quenching rate is about $40 \%$ lower in LHG-8 compared to LG-770; however the $\mathrm{Cu}$ quenching rates are nearly identical in both glasses.

The effect of the rare earth impurities on the $\mathrm{Nd}^{3+}$ non-radiative decay rate in LG-770 varies from about 0.06-0.9 Hz/ppmw (Table 1) and follows the trend: Dy $\gtrsim \operatorname{Pr} \approx S m>C e$. This trend approximately parallels that observed for the absorption cross-section of these ions (Table 1). LHG-8 samples doped with $\mathrm{Pr}^{3+}$ showed about a twofold greater decay rate than LG-770: $1.1 \mathrm{~Hz}$ ' ppmw at $4.2 \times 10^{20} \mathrm{Nd}$ ion $/ \mathrm{cm}^{3}$.

\section{Discussion}

\subsection{Optical absorption by Cu at $1053 \mathrm{~nm}$}

The $\mathrm{Cu}^{2+}$ absorption at $1054 \mathrm{~nm}$ increases lincarly with $\mathrm{Cu}$-doping concentration giving an extinction coefficient of about $2.7 \times 10^{-3} \mathrm{~cm}^{-1} / \mathrm{ppmw}$ in both LHG-8 and LG-770 (sec Fig. 3). The magnitude of the $\mathrm{Cu}^{2+}$ extinction coefficient is similar to that observed in other phosphate laser glasses (Table 2). In particular, Sapak et al. [27] report a value of $2.7 \times 10^{-3} \mathrm{~cm}^{-1} / \mathrm{ppmw}$ measured for LG-750 prepared in an $\mathrm{O}_{2}$ melting atmosphere. The composition of LG-750 is reported to be nearly identical to LHG-8 [4]. Here we assume $\mathrm{Cu}$ is present only as $\mathrm{Cu}^{2+}$ based on the work of Bae and Weinberg [13] who report $100 \% \mathrm{Cu}^{2+}$ in fully equilibrated melts prepared in air using quartz crucibles and containing less than 50\% CuO. All the melts in our study were prepared using quartz crucibles and $\mathrm{O}_{2}$ and thus satisfy this criteria. Note that Sapak et al. [27] report that melts of LG-750 meta-phosphate containing $\mathrm{Cu}$ and prepared under neutral conditions $\left(\mathrm{N}_{2}\right)$ have extinction coeffcients at $1053 \mathrm{~nm}$ about $20 \%$ lower than melts prepared in $\mathrm{O}_{2}$ (Table 2). This suggests some conversion ( 20\%) of $\mathrm{Cu}^{2+}$ to $\mathrm{Cu}^{+}$under these conditions.

Extinction coefficients for $\mathrm{Cu}$ impurities at ppmw concentrations in other glass forming systems have been reported. Bhrt [26] reports a value of about $7 \times 10^{-1} \mathrm{~cm}^{-1} / \mathrm{ppmw}$ in a fluorophos-
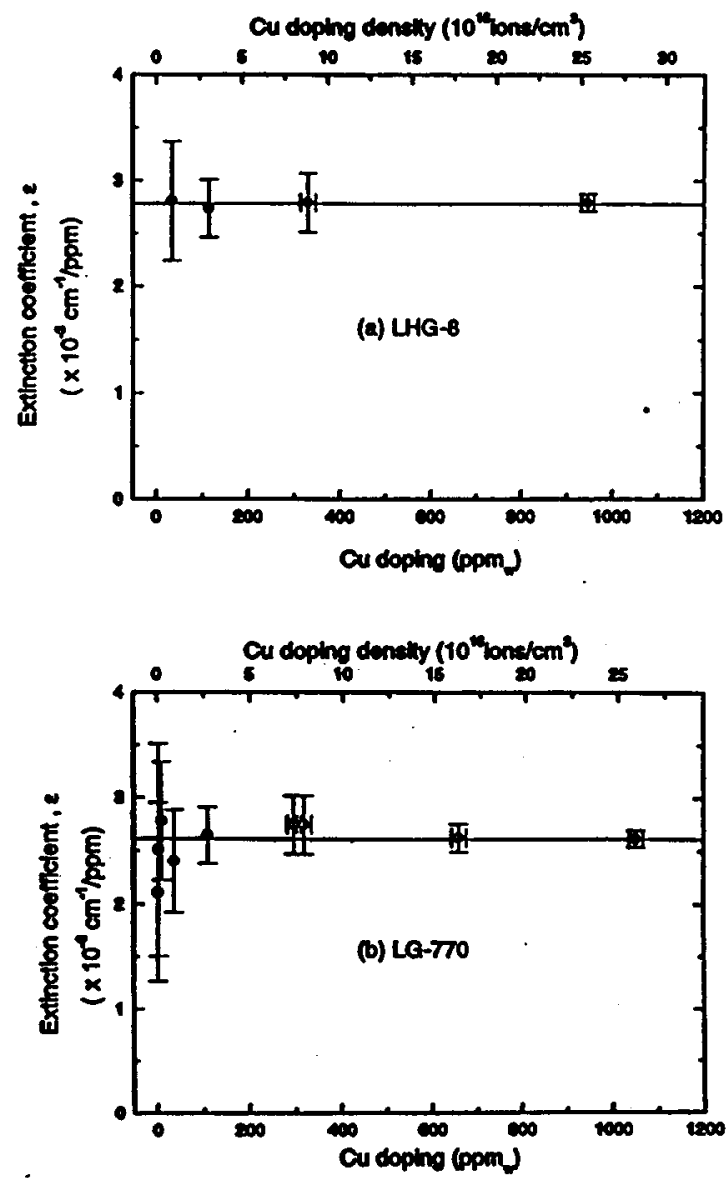

Fig. 3. $\mathrm{Cu}^{2+}$ extinction coefficient per ppmw at $1053 \mathrm{~mm}$ in LHG-8 (O) and LG-770 (O) as a function of $\mathrm{Cr}^{2+}$-doping density.

phate giass $\left(10 \mathrm{Sr}\left(\mathrm{PO}_{3}\right)_{2}-35 \mathrm{AlF}_{3}-30 \mathrm{CaF}_{2}-15 \mathrm{SrF}_{2}\right.$ $-10 \mathrm{MgF}_{2}$ ) prepared using $\mathrm{O}_{2}$ bubbling through the melt. Stokowski and Krashkevich [7] measured a value of $3.8 \times 10^{-4} \mathrm{~cm}^{-1} / \mathrm{ppmw}$ in a commercial alkali-zinc-silicate laser glass (LG-660) melted under neutral $\left(\mathrm{N}_{2}\right)$ conditions. These extinction coefficients are about 4-8 times lower, respectively, than observed in phosphate glasses.

\subsection{Optical absorption by Fe}

In contrast to $\mathrm{Cu}^{2+}$, the extinction coefficient for Fe at $1053 \mathrm{~nm}$ is concentration dependent below about 300 ppmw (Fig. 4). We propose that this concentration dependence is due to a shift in the 
Table 2

Comparison of extinction coeficients $\left(\times 10^{-3} \mathrm{~cm}^{-1} / \mathrm{ppmw}\right)$ at $1053 \mathrm{~nm}$ from this study with previous work on phosphate laser glasses (doping concentrations greater than 300 ppmw)

\begin{tabular}{|c|c|c|c|c|c|c|c|}
\hline \multirow{2}{*}{$\begin{array}{l}\text { Source } \\
\text { Glass }\end{array}$} & \multicolumn{2}{|l|}{ This study } & \multirow{2}{*}{$\begin{array}{l}\text { Toratani } \\
{[28,29]} \\
\text { GPP' }\end{array}$} & \multicolumn{2}{|c|}{$\begin{array}{l}\text { Stokowski and } \\
\text { Krashkevich [7] }\end{array}$} & \multicolumn{2}{|c|}{ Sapak et al. [27] } \\
\hline & LG-770 & LHG-8 & & UP-916 & UP-16 & LG-750' & LG-750 \\
\hline $\begin{array}{l}\text { Atmosphere } \\
\text { Impurtity }\end{array}$ & $\mathbf{O}_{2}$ & $\mathbf{O}_{2}$ & - & $\mathbf{N}_{2}$ & $\mathbf{N}_{\mathbf{2}}$ & $\mathrm{O}_{2}$ & $\mathrm{~N}_{2}$ \\
\hline $\mathrm{Cu}$ & 2.6 & 2.8 & 2.4 & 2.3 & 2.1 & 2.7 & 2.1 \\
\hline $\begin{array}{l}\mathrm{Fe}(\geqslant 1000 \\
\text { ppmw) }\end{array}$ & 0.18 & 0.11 & 2.4 & 0.7 & 0.6 & 0.13 & 0.55 \\
\hline Fe (<1000 ppmw) & Eq. $(6)^{\mathbf{e}}$ & Eq. (6) & - & - & - & - & - \\
\hline Dy & 0.016 & - & 0.011 & - & - & - & - \\
\hline PT & 0.012 & $\leqslant 0.01$ & - & - & - & - & - \\
\hline $\mathbf{S m}$ & 0.013 & - & 0.011 & - & - & - & - \\
\hline ce & 0.0084 & - & - & - & - & - & - \\
\hline
\end{tabular}

Random errors for values from this atudy are given in Table 1.

GPP: $51.5 \mathrm{P}_{2} \mathrm{O}_{5}-18.5 \mathrm{CeO}_{2}-30 \mathrm{CaO}_{2}$; UP-91 (ultraphophate): $68.2 \mathrm{P}_{2} \mathrm{O}_{5}-11.8 \mathrm{~A}_{2} \mathrm{O}_{3}-14 \mathrm{~K}_{2} \mathrm{O}-6\left(\mathrm{La}+\mathrm{Nd}_{2} \mathrm{O}_{3}\right.$; UP-16: $70 \mathrm{P}_{2} \mathrm{O}_{5}-20$ $\mathrm{K}_{2} \mathrm{O}-10\left(\mathrm{La}+\mathrm{Nd}_{2} \mathrm{O}_{3} ; \mathrm{LG}-750\left[4\right.\right.$ ) (meta-phosphate): (55-60) $\mathrm{P}_{2} \mathrm{O}_{5}-(8-12) \mathrm{Al}_{2} \mathrm{O}_{3}-(13-17) \mathrm{K}_{2} \mathrm{O}-(10-15) \mathrm{BaO}-(0-2) \mathrm{Nd}_{2} \mathrm{O}_{3}$.

'LO-770: $=0.179 \times 10^{-1} \mathrm{~cm}^{-1} / \mathrm{ppmw},[\mathrm{Fe}]_{e}=170 \mathrm{ppmw}$.

LHO-8: $\varepsilon_{-2}=0.106 \times 10^{-3} \mathrm{~cm}^{-1} / \mathrm{ppmw},[\mathrm{Fe}]_{\varepsilon}=170 \mathrm{ppmw}$.
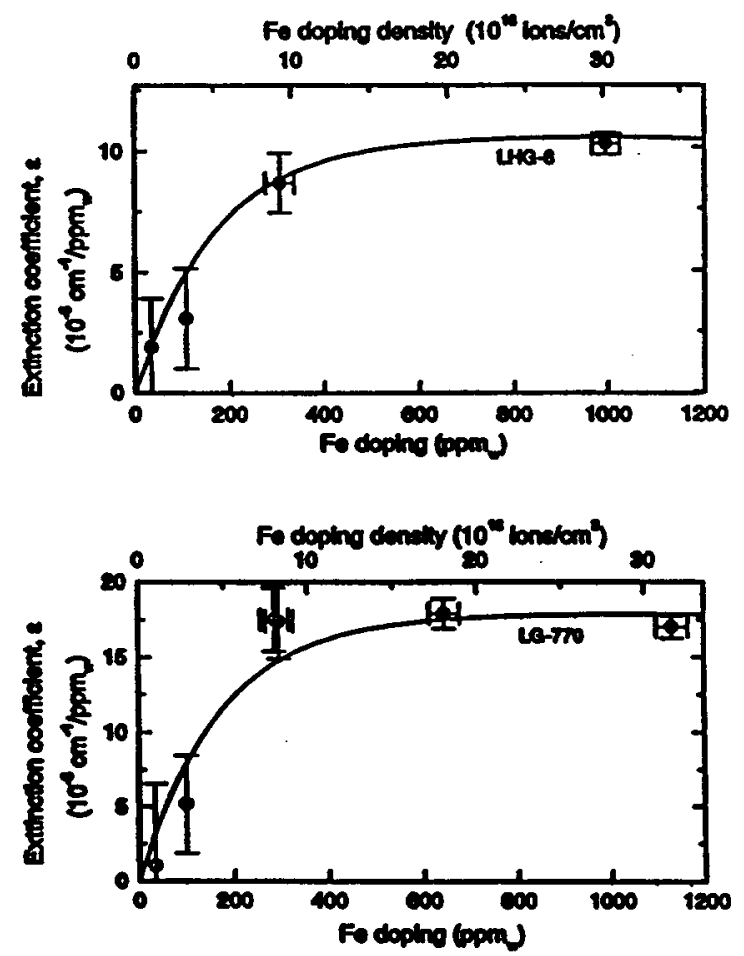

Fig. 4. Fe extinction coeficieat at $1053 \mathrm{~nm}$ in LHO-8 (O) and LO-770 $(O)$ as a function of Fe-doping dentity. The tine is calculated uxing Eq. (O). redox equilibrium between $\mathrm{Fe}^{3+}$ and $\mathrm{Fe}^{2+}$ at low doping levels. It is well known that $\mathrm{Fe}$ in glasses is distributed between $\mathrm{Fe}^{2+}$ and $\mathrm{Fe}^{3+}$ and that this distribution depends on the redox state of the glass. In a study of barium aluminophosphate glasses, Zirkelbach and Brückner [14] estimate the distribution to be about $23 \% \mathrm{Fe}^{2+} / 77 \% \mathrm{Fe}^{3+}$ and $25 \% \mathrm{Fe}^{2+} / 75 \% \mathrm{Fe}^{3+}$ for their glasses when melted in air and $\mathrm{O}_{2}$, respectively. This distribution is for a Fe doping level of 1 mol\%. They also determined the distribution of $\mathrm{Fe}^{2+}$ between octahedral and tetrahedral coordination by measuring the intensities of the characteristic bands for these two sites near 1050 and $2100 \mathrm{~nm}$, respectively.

The Fe 1053-nm extinction coefficient reported here is also dependent on the glass type, although this effect is much smaller than the doping concentration dependence. In particular, the Fe extinction coefficients differ by about a factor of two between LHG-8 and LG-770 samples for Fe concentrations of $300 \mathrm{ppmw}$ or greater. The compositions of LHG-8 and LG-770 differ mainly in the group II modifiers they contain: $\mathrm{BaO}$ and $\mathrm{MgO}$, respectively. Thus it is possible these modifiers alter the oxygen fugacity sufficiently to change the $\mathrm{Fe}^{2+} / \mathrm{Fe}^{3+}$ ratio; such effects are well-known in silicate glasses (see for example [15,42,43]. It is also possible that the slightly different melt tempera- 
tures used to prepare our glasses cause this difference. Specifically the LHG-8 and LG-770 samples were melted and refined at $1200 / 1375^{\circ} \mathrm{C}$ and $1100 /$ $1250^{\circ} \mathrm{C}$, respectively. Standard melt thermodynamics favor $\mathrm{Fe}^{2+}$ formation at higher temperatures $[20,21,43,44]$ that could account for the higher $\mathrm{Fe}^{2+}$ in the LG-770 sample.

A comparison of the Fe extinction coefficients at $1053 \mathrm{~nm}$ determined from the optical transmission measurements and via laser calorimeter is given in Fig. 5. Absolute calibration of the calorimeter is difficult but relative changes in absorption can be readily measured. Therefore in Fig. 5 we compare the relative change in sample absorption measured via the calorimeter with that determined by direct transmission measurements on both LHG-8 and LG-770 samples. Data from these two measurement techniques agree to within the error limits shown (Fig. 5).

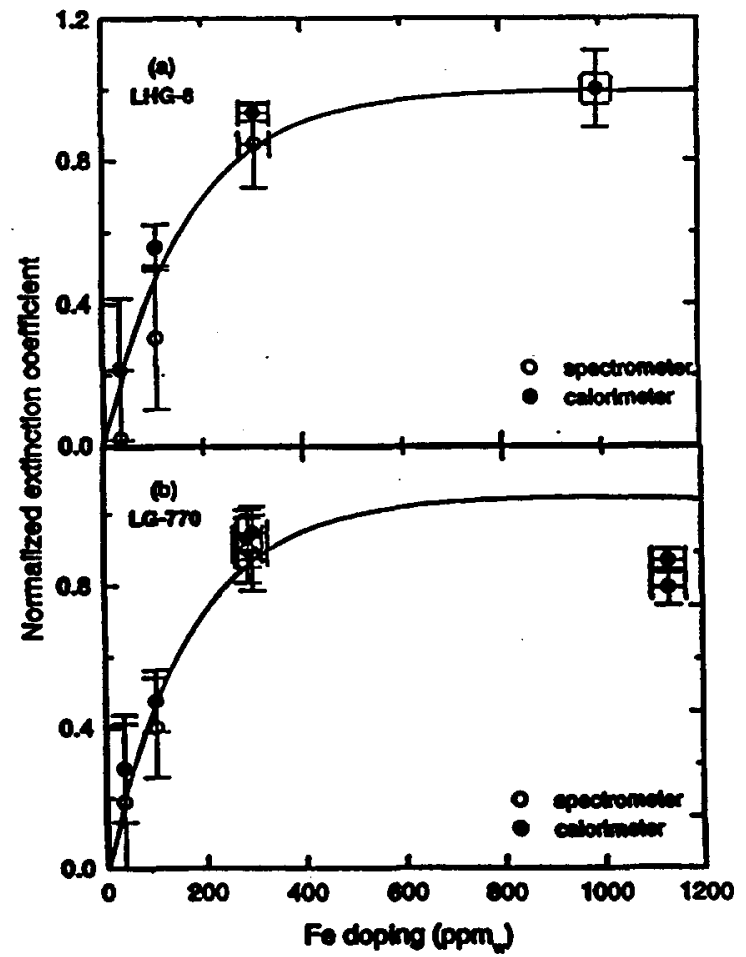

Fis. 5. Normalized extinction cofficient at $1053 \mathrm{~nm}$ as a function of varying Fodoping coscentrations as measured by epectronoopic and calorimetric methods for LHG-8 and LO-770. The solid line is Eq. (6) with en normalized to 1.
To more fully analyze our data, we chose to fit the measured Fe extinction coefficient at $1054 \mathrm{~nm}$ to a single parameter equation of the form

$\varepsilon_{\mathrm{Fe}}=\varepsilon_{\max }\left(1-\exp \left(-[\mathrm{Fe}] /[\mathrm{Fe}]_{\mathrm{c}}\right)\right)$,

where, $\varepsilon_{\mathrm{Fe}}$, is the $\mathrm{Fe}$ extinction coefficient, $\varepsilon_{\max }$, the limiting extinction coefficient at Fe concentrations of 1000 ppmw and [Fe], the Fe doping concentration (ppmw). The parameter, $[\mathrm{Fe}]_{c}$, is a characteristic doping density for the system and is the single fitting parameter. The best fit to the data for both LG-770 and LHG-8 samples gives $[\mathrm{Fe}]_{c}=170$ ppm. The measured $\varepsilon_{\operatorname{mex}}$ are $1.79 \times 10^{-4}$ and $1.06 \times 10^{-4} \mathrm{~cm}^{-1} / \mathrm{ppm}$ for LG-770 and LHG-8, respectively (see Fig. 4).

The data in Fig. 2 show there is little change with concentration in the $\mathrm{Fe}^{2+}$ distribution between sites of tetrahodral and octahodral coordination. Instead, the dominant reason for the drop in $1053 \mathrm{~nm}$ absorption appears to be due to the redistribution in $\mathrm{Fe}$ between the $2+$ and $3+$ states. The change in the ratio of $\mathrm{Fe}^{3+} / \mathrm{Fe}^{2+}$ can be measured from the change in intensity ratios for bands associated with $3+$ and $2+$ ions.

The change in the $\mathrm{Fe}^{2+} / \mathrm{Fe}^{3+}$ ratio at low dopings was verified not only by measuring the decrease in $\mathrm{Fe}^{2+}$ but also the corresponding increase in $\mathrm{Fe}^{3+}$ using the characteristic band at $415 \mathrm{~nm}$. These data are plotted in Fig. 6 as normalized $\mathrm{Fe}^{2+}$ and $\mathrm{Fe}^{3+}$ extinction coefficients, for various $\mathrm{Fe}$ doping levels. The extinction coefficients are both constant above about 300 ppmw, however below $300 \mathrm{ppmw}$ the extinction coefficient for the $415 \mathrm{~nm}$ bands $\left(\mathrm{Fe}^{3+}\right)$ increases whereas the value for the $1050 \mathrm{~nm}$ band $\left(\mathrm{Fe}^{2+}\right)$ docreases. The data in Fig. 6 are meant to illustrate the increase in $\mathrm{Fe}^{3+}$; however, the absolute magnitude of the increase should be viewred with caution because of the lack of a numerical band fitting analysis.

The observed change of the $\mathrm{Fe}^{2+} / \mathrm{Fe}^{3+}$ ratio without a corresponding change in melting conditions (i.e. the oxygen pressure over the melt) is unusual but not without precedence. Glebov et al. [45] has reported similar behavior for $\mathrm{Fe}$ in silicate glasses at low doping levels ( $\leqslant 500$ ppmw Fe doping). Glebov suggests that at high $\mathrm{Fe}$ concentrations the $\mathrm{Fe}^{2+} / \mathrm{Fe}^{3+}$ ratio is determined by the 


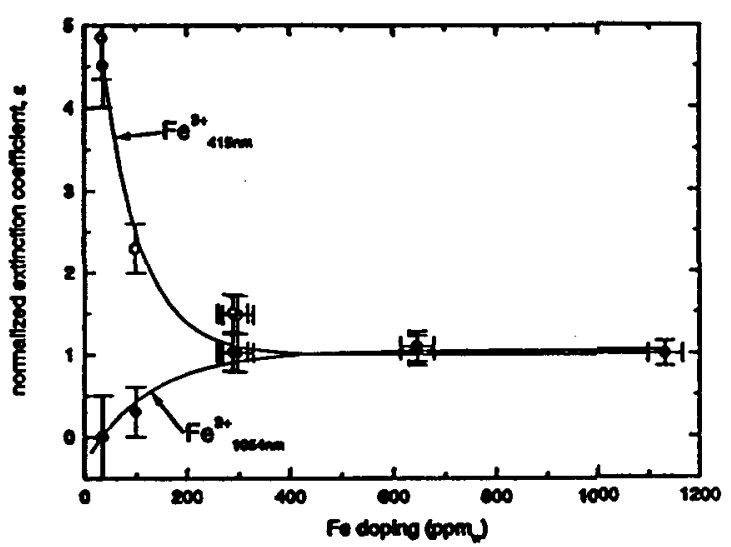

Fig. 6. Relative change in the $\mathrm{Fe}^{2+}(415 \mathrm{~nm})$ and $\mathrm{Fe}^{3+}(1053$ nm) extinction coeficients with change in Fodoping density; values are normulized to the extinction coefficients at the high concentration limit (1100 ppmw).

structural association (i.e. correlation) between the $\mathrm{Fe}^{2+}$ and $\mathrm{Fe}^{3+}$ ions because of their close proximity. However, he proposes that at low concentration the ions become spatially separated and are no longer correlated and consequently, the $\mathrm{Fe}^{2+} /$ $\mathrm{Fe}^{3+}$ ratio changes due to localized site (structural) changes. If Glebov's physical description is correct, then the characteristic Fo-Fe interatomic distance for this change corresponds to the average spatial separation at the characteristic iron concentration $\left(\mathrm{Fe}_{\mathrm{c}}\right)$ determined via Bq. (6). This separation is about $55 \AA$ for $\mathrm{Fe}_{c} \approx 170 \mathrm{ppmw}$.

In a related study, Bac and Weinberg [13] report changes in the $\mathrm{Cu}^{2+} / \mathrm{Cu}^{+}$ratio with total $\mathrm{Cu}$ concentration even though the melt environment remains unchanged. Like Glebov, they also suggest this is due to structural (site accommodation) effects.

\subsection{Optical absorption by Dy, Sm, Pr and Ce}

The extinction coefficients reported here for Dy and $\mathrm{Sm}$ in LG-770 are similar to the values reported by Toratani [28] for a germanium-gallium phosphate giass (Table 2). Similarly the value for Pr is only about 10-30\% lower than Sm and Dy, respectively. The extinction coefficient for $\mathrm{Ce}$ is about $50-100 \%$ lower than the other rare earths for these samples melted in $100 \% \mathrm{O}_{2}$. The small extinction coefficients are simply representative of the fact that only the tails of the characteristic absorption bands for these rare earths extend to $1053 \mathrm{~nm}[46]$.

\subsection{Analysis of measured quenching rates}

The measured quenching rates are analyzed using the Förster-Dexter theory for dipolar energy transfer $[7,9,10]$ that was discussed in Section 1 . The quantity $k_{\mathrm{D} \Lambda}$ given by Eq. (3) is equal to the measured quantity $k_{\mathrm{A}}[A]$ from Eq. (5) and thus

$k_{\mathrm{A}}=\frac{\eta R_{\mathrm{DA}}^{-6}}{[A]} \int \frac{K_{\mathrm{A}}(v) G_{\mathrm{D}}(v) \mathrm{d} v}{v^{A}}$.

The data in Fig. 1 show that the impurity absorption, $K_{A}(v)$, is approximately constant over the frequency region of the donor emission bands and thus, this term can be moved outside the integral

$k_{\mathrm{A}}=\frac{\eta R_{\mathrm{DA}}^{-6} \bar{K}_{\mathrm{A}}}{[\Lambda]} \int \frac{K_{\mathrm{D}}(v) \mathrm{d} v}{v^{4}}$,

where $\bar{K}_{A}$ is the mean absorption over the emission band and is proportional to $\varepsilon_{A}[A]$, the acceptor extinction coefficient at the emission band maximum. Eq. (8) can now be written in the useful form

$k_{\mathrm{A}}=\beta \varepsilon_{\mathrm{A}}$,

where $\beta$ is a constant for a fixed Nd concentration and a given glass composition

$\beta=v^{\prime}[D] \int \frac{K_{D}(v) d v}{v^{4}}$.

Note that we have replaced $\eta R_{\mathrm{DA}}^{-6}$ with $\eta^{\prime}[A][D]$, where $[D]$ is the Nd (donor) concentration. The Nd concentration used in this study, $\sim 4 \times 10^{20}$ ions/ $\mathrm{cm}^{3}$ while the impurity doping densities are $<0.3 \times 10^{20} \mathrm{ions} / \mathrm{cm}^{3}$. In words, Bq. (9) states that the measured decay rate, on a per-ion basis, should vary directly with the impurity (acceptor) extinction coefficient for samples containing a fixed $\mathrm{Nd}$ doping level. In the case of $\mathrm{Cu}^{2+}$, the extinction coefficient is nearly constant for all $\mathrm{Cu}^{2+}$ doping concentrations in both LHG-8 and LG-770 samples (Fig. 3). Similarly the Nd decay rate per unit 
$\mathrm{Cu}$ doping density (i.e. $\mathrm{Hz} / \mathrm{ppmw}$ ) is also nearly constant (Fig. 7 ) as predicted by Eq. (9).

In contrast to $\mathrm{Cu}^{2+}$, the $\mathrm{Fe}$ extinction coefficient depends on the concentration as shown in Fig. 4 and discussed in Section 4.2. Therefore, based on Bq. (9), one expects the decay rate, $k_{\mathrm{Fe}}$, to vary with the concentration in the same fashion as $\varepsilon_{\mathrm{Fe}}$; this is found to be the case (Fig. 8). The line shown in Fig. 8 is calculated by the expression

$k_{\mathrm{Fe}}=\beta \varepsilon_{\mathrm{Fe}}$,

where $\varepsilon_{\mathrm{Fe}}$ is the extinction coefficient at $1053 \mathrm{~nm}$ for Fe given by Eq. (6) and $\beta$ is $7.8 \mathrm{kHz} / \mathrm{cm}^{-1}$ as determined from the measured $k_{\mathrm{Fe}}$ and $\varepsilon_{\mathrm{Fe}}$ at $\mathrm{Fe}$ doping concentrations of 1000 ppmw.
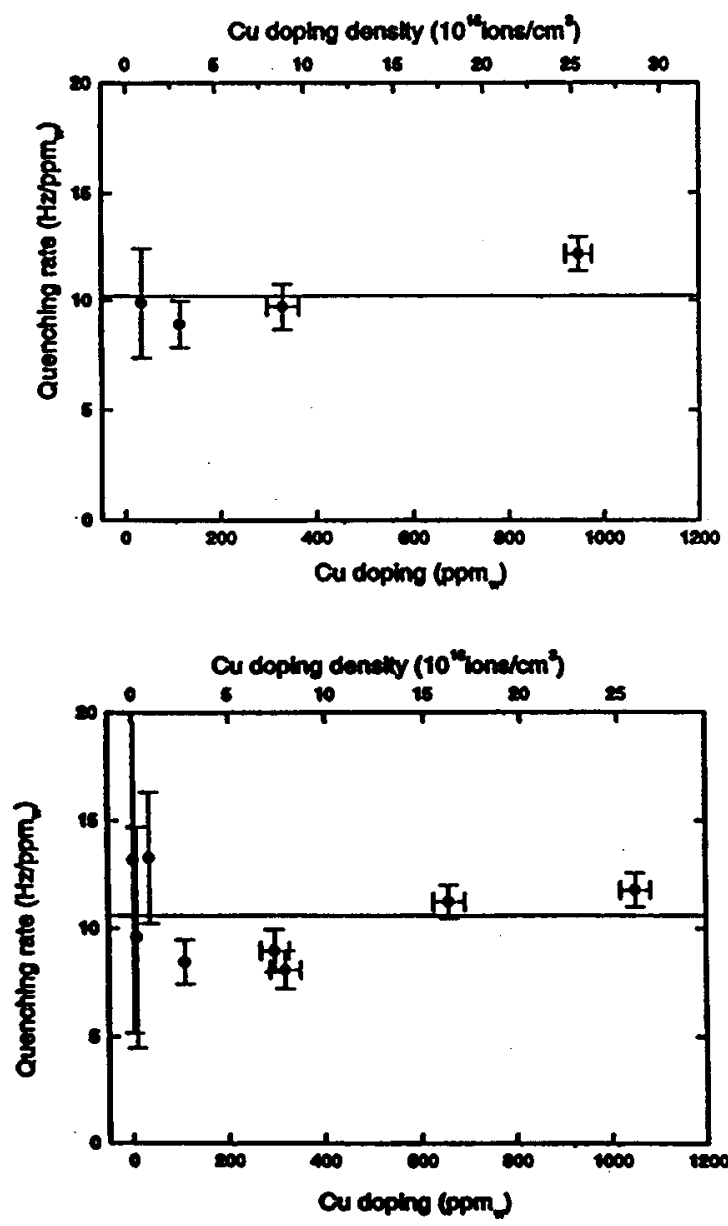

Fig. 7. Nd't fluorescenoe quesching rate as a function of $\mathrm{Cu}^{2+}$. doping concentration for both LHO-8 (O) and LG-770 (O).

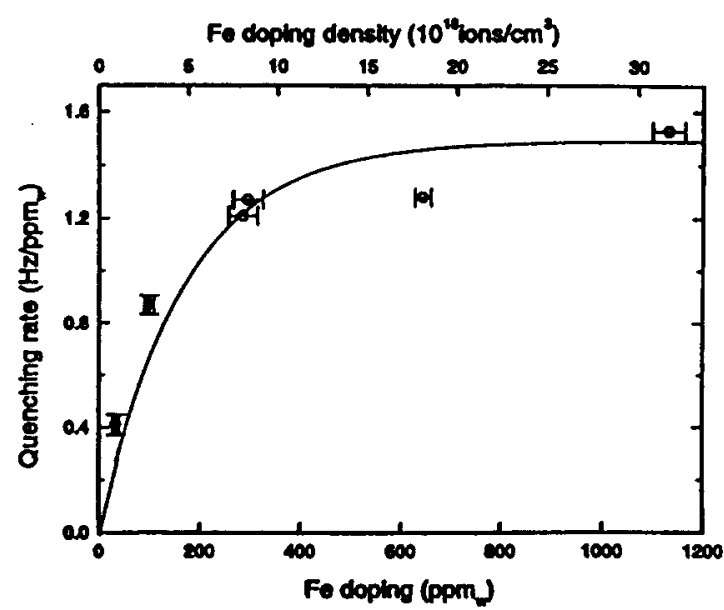

Fig. 8. $\mathrm{Nd}^{3+}$ fluorescence quenching rate for $\mathrm{Fe}$ in LG-770 as a function of Fe-doping density. The line is calculated using Eq. (11).

The quenching rate for the rare earths follows approximately the same trend as the extinction coefficients. Note however that whereas the extinction coefficients differ by more than 10-100 between the rare earths and $\mathrm{Fe}$ and $\mathrm{Cu}$, respectively, the corresponding difference in quenching rates is about an order-of-magnitude less (Table 1).

\section{Conclusions}

The Fe extinction coefficient at $1054 \mathrm{~nm}$ in two meta-phosphate laser glasses decreases by more than 10-fold from about 1.1 and $1.8 \times 10^{-4} \mathrm{~cm}^{-1} /$ ppmw to less than $1 \times 10^{-5} \mathrm{~cm}^{-1} / \mathrm{ppmw}$ with a change in $\mathrm{Fe}$ doping concentration from 1000 to $30 \mathrm{ppmw}$. In contrast, the extinction coefficient for $\mathrm{Cu}$ remains constant at about $2.7 \times 10^{-3} \mathrm{~cm}^{-1} /$ ppmw over the same doping range. The quenching rates for these two ions follow the same behavior as the change in extinction coefficients as predicted by Förster-Dexter theory for dipolar energy transfer.

The unusual behavior of $\mathrm{Fe}$ is shown to be caused by a change in the $\mathrm{Fe}^{2+} / \mathrm{Fe}^{3+}$ ratio even though the melt conditions remain constant. This change is proposed to be caused by structural effects on the redox distribution similar to that 
reported by Glebov et al. [45] in silicates at low $\mathrm{Fe}$ doping concentrations.

The extinction coefficients at $1053 \mathrm{~nm}$ of the rare earths Dy, Sm, Pr and Ce are 10-100 times less than $\mathrm{Fe}$ and $\mathrm{Cu}$ at $\mathbf{1 0 0 0}$ ppmw doping levels and follow the trend $\operatorname{Dy} Z \operatorname{Sm} \approx \operatorname{Pr}>C$ C. The quenching rates follow the same trend but are only about 2-10 times less than $\mathrm{Fe}$ and $\mathrm{Cu}$, respectively.

\section{Acknowledgements}

The authors gratefully acknowledge the helpful discussions with Dr Leonid Glebov regarding the reason for the change in $\mathrm{Fe}^{2+} / \mathrm{Fe}^{3+}$ ratio. The assistance by Ms B. Gober-Mangan, Mr J. Spaeth, and Ms T. Duewer on certain of the measurements presented in this work is appreciated. The assistance by Ms A. Clasen in the preparation of the manuscript is also deeply appreciated. Finally, the contributions by the late W.A. Steele on many aspects of the early stages of this study are deeply appreciated; he is fondly remembered and greatly missed. This work is supported by the US Department of Energy by Lawrence Livermore National Laboratory under contract W-7405BNG-48.

\section{References}

(1) J.T. Hunt, D.R. Speck, Opt. Eng. 28 (1989) 461.

[2] B.M. Van Wonterghem, J.R. Murray, J.H. Cumpbell, D.R. Speck, C.E. Barker, I.C Smith, D.F. Browning, W.C. Behreadt, Appl. Opt. 36 (1997) 4932.

[3] J. Murray, SPIE 3492 (1998) 1.

[1] J. Cumpbell, T. Suratwala, these Proceodings, p. 318.

[J] W. Koechner, Solid-State Laser Engineering, 4th Ed. Springer, New York, 1996.

[6] J. Campbell, T. Suratwala, C. Thornes, J. Hayden, A. Thome, J.M. Cimino, A. Marker, R. Takeuchi, M. Smolley, G. Ficini-Dorn, these Proceedinge, p. 342.

[7] S.E. Slokowaki, D. Kmathkevich, Matex. Res. Soc. Symp. 61 (1980) 273.

[8] J.A. Cuird, F.P. Milanovich, N.D. Nieteen, H.T. Powell, J.E Marion, A.J. Pertica, J.N. Roe, in: Proceedings of the Conference on Lasers and Electro-Optian (CLEO), 1989, p. 1.

[9] T. Förter, Ann. Phys. 2 (1948) 56.

[10] D.L. Dexter, J. Chem. Phys. 21 (1953) 836.

[11] A.M. Bishay, L. Makar, J. Am. Ceram. Soc. 52 (1969) 605.
[12] B. Kumar, J. Am. Ceram. Soc. 74 (1991) 226.

[13] B.S. Bae, M.C. Weinberg, J. Am. Ceram. Soc. 74 (1991) 3039.

[14] K. Zirkelbach, R. Brückner, Glastech. Ber. Glass Sci. Technol. 60 (1987) 312.

[15] J.A. Duffy, Phys. Chem. Glasses 40 (1999) 54.

[16] L.E. Bausa, J.G. Sole, A. Duran, J.M.F. Navarro, J. NonCryst. Solids 127 (1991) 267.

[17] C.R. Kurkjian, E.A. Sigety, Phys. Chem. Glasses 9 (1968) 73.

[18] G.K. Marasinghe, M. Karabulut, C.S. Ray, D.E. Day, M.G. Shumsky, W.B. Yelon, C.H. Booth, P.G. Allen, D.K. Shuh, J. Non-Cryst. Solids 222 (1997) 144.

[19] B. Pivac, A. Mogus-Milankovic, D.E. Day, J. Non-Cryst. Solids 226 (1998) 41.

[20] D. Ehrt, M. Leister, A. Matthai, Molten Salt Forum $5 \& 6$ (1998) 547.

[21] A. Matthai, D. Ehrt, C. Russel, Glastech. Ber. Glass Sci. Technol. 71 (1998) 187.

[22] B. Kumar, C. Chen, Phys. Chem. Glasses 33 (1992) 204.

[23] L. Cook, K.H. Mader, J. Am. Ceram. Soc. 65 (1982) 597.

[24] D. Ehrt, W. Seeber, J. Non-Cryst. Solids 129 (1991) 19.

[25] D. Ehrt, M. Curt, T. Kittel, M. Müller, W. Seeber, J. NonCryst. Solids 177 (1994) 405.

[26] D. Ehrt, J. Non-Cryst. Solids 196 (1996) 304.

[27] D. Sapak, J. Ward, J. Marion, SPIE 970 (1988) 107.

[28] H. Toratani, PhD thesis, Kyoto University, Kyoto, 1989.

[29] H. Toratani, H.E. Meissaer, T. Izumitani, S.E. Stokowski, J. Non-Cryst. Solids 95\&96 (1987) 701.

[30] J.H. Cumpbell, E.P. Walleratein, J.S. Hayden, D.L. Sapak, D.E. Warrington, A.J. Marker, Glastoch. Ber. Glass Sci. Technol. 68 (1995) 11.

[31] J.H. Cumpbell, E.P. Wallerstein, H. Toratani, H.E. Meissaer, S. Nakajima, T.S. Irumitani, Glastech. Ber. Glass Sci. Technol. 28 (1995) 59.

[32] T.I. Suratwale, R.A. Stecle, G.D. Wilke, J.H. Campbell, K. Takeuchi, these Procecdings, p. 213.

[33] J.S. Haydea, A.J. Marker, T. Suratwala, J.H. Campbell, theoe Procoudings, p. 228.

[34] H. Ebendort-Heidepriem, D. Ehrt, Glastech. Ber. Glass Sci. Technol. 68 (1995) 139.

[35] J. Shelby, ASM International, Materials Park, OH, 1996.

[36] S. Payne, M.L. Elder, J.H. Campbell, G.D. Wilke, M.J. Weber, in: AJ. Bruce, B.V. Firemuth (Bds), Solid-State Optical Materials, American Ceramic Society, Westervilie, OH 28, 1991, p. 253.

[37] A. Ramponi, J. Caird, J. Appl. Phys. 63 (1988) 5476.

[38] G.M. Barrow, Phycical Chemistry, MoOraw-Hill, New York, 1973.

[39] B. Camirn, Glartech. Ber. Glass Sci. Technol. 51 (1978) 87.

[40] U. Kolberg, in: H. Bach, N. Neuroth (Bds), The Properties of Optical Glase, ch. 8.8, Springer, Berlin, 1995, p. 351.

[41] W. Seeber, D. Ehrt, Glastech. Ber. Glass Sci. 70 (1997) 312.

[42] C. Rised, S. Geriach, The Influence of Glass Composition on the Thermodynamic of the $\mathrm{Fe}^{2+} / \mathrm{Fe}^{3+}$ Equilibrium, Fith ESG Conference, Prague (1999), A1-18-A1-27.

[43] A. Paul, J. Non-Cryst. Solids 123 (1990) 354. 
[44] A. Matthai, O. ClauBen, D. Ehrt, C. Rüssel, Glastech. Ber. Glass. Sci. Technol. 71 (1998) 29.

[45] L.B. Glebov, V.G. Dokuchaev, G.T. Petrovskii, M.N. Tolstoi, Sov. J. Glass Phys. 10 (1984) 90, English transla- tion, Lawrence Livermore Laboratory, Report UCRL UR-136672 (1999) 1-9.

[46] R.C. Powell, Physics of Solid-State Laser Materials, Springer, New York, 1998. 


\title{
Platinum Particle Detection in Phosphate Laser Glasses
}

\author{
John H. Campbell, Sheldon Schwartz \\ and \\ James F. Kimmons
}

This paper was prepared for submittal to

Schott Glass Technologies Series

Vol. 7, Section 5.5:

"Analysis of Composition and Structure of Glass and Glass Ceramics"

March 9, 1998

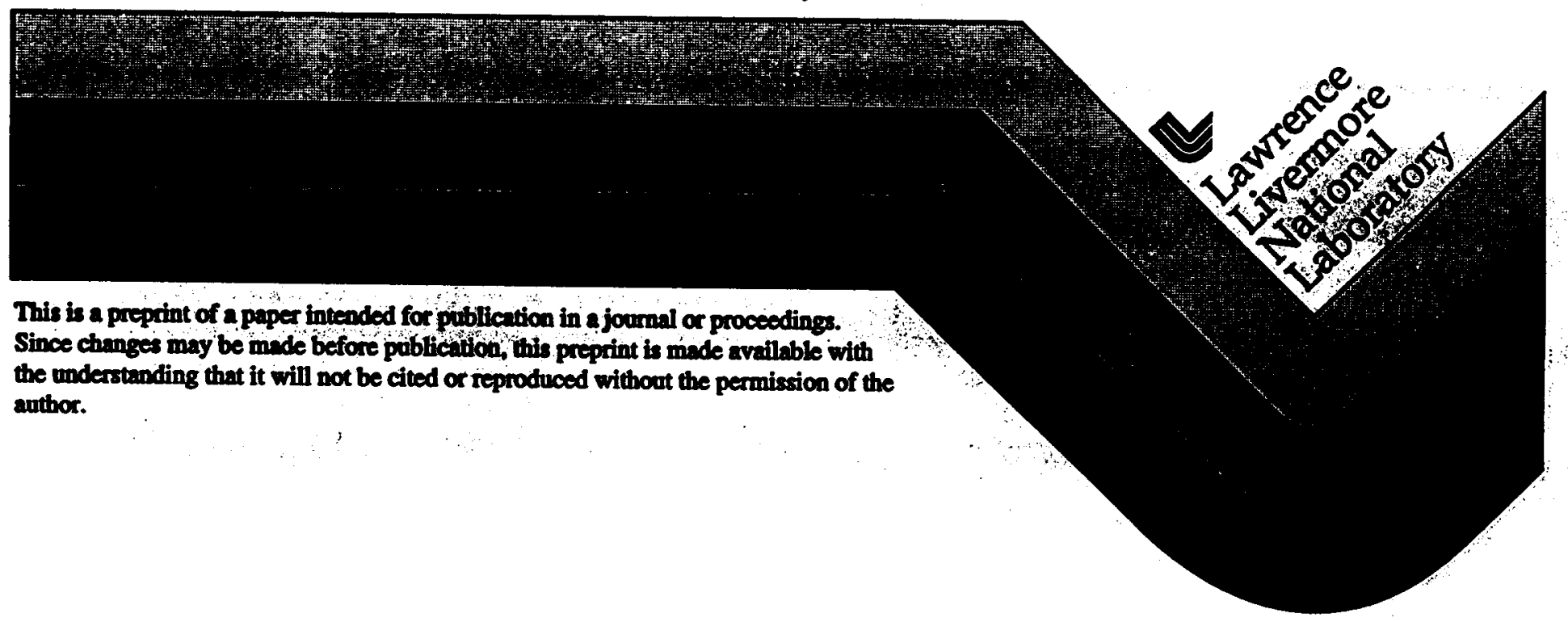




\section{DISCLAIMER}

This document was prepared as an account of work sponsored by an agency of the United States Government. Neither the United States Government nor the University of California nor any of their employees, makes any warranty, express or implied, or assumes any legal liability or responsibility for the accuracy, completeness, or usefulness of any information, apparatus, product, or process disclosed, or represents that its use would not infringe privately owned rights. Reference herein to any specific commercial product, process, or service by trade name, trademark, manufacturer, or otherwise, does not necessarily constitute or imply its endorsement, recommendation, or favoring by the United States Government or the University of California. The views and opinions of authors expressed herein do not necessarily state or reflect those of the United States Government or the University of California, and shall not be used for advertising or product endorsement purposes.
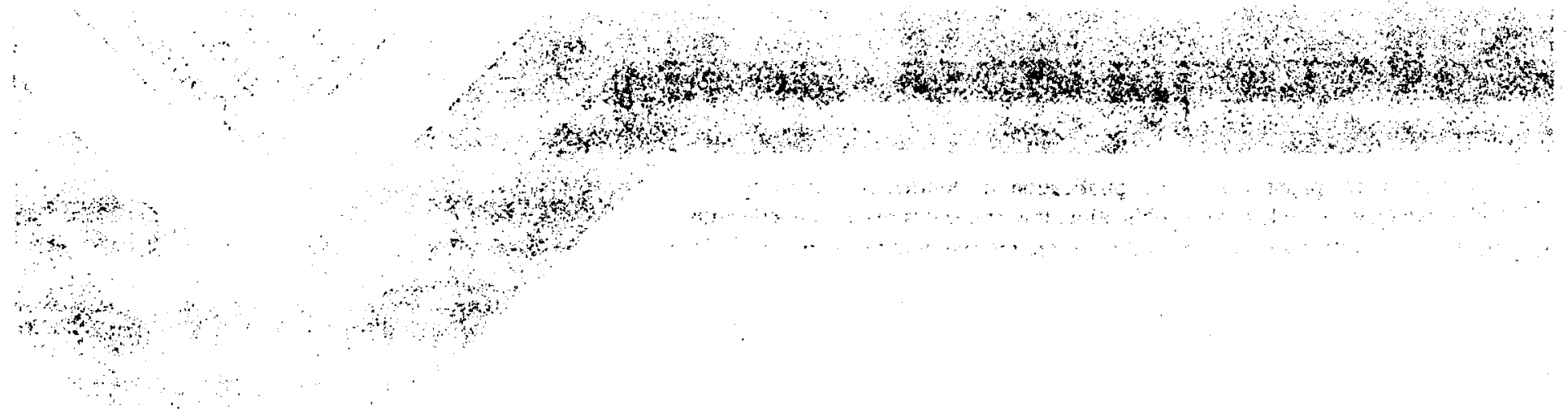


\subsection{Platinum Particle Detection in Phosphate Laser Glasses}

\subsubsection{Source of Platinum Particles}

Platinum and platinum alloys have been used successfully as container materials in the glass melting industry since the 1940's to produce very high-quality, homogeneous optical glasses. Although relatively inert, platinum still produces some level of contamination in glasses. This contamination is in the form of either microscopic platinum particles (inclusions) and/or low levels (ppb to ppm) of ionic (dissolved) platinum. In most applications, the level of contamination is sufficiently low that the optical performance of the glass is not effected. However, with the advent of high-peak-power lasers, it was discovered that platinum inclusions produced fracture sites when irradiated above a certain fluence threshold (Fig. 5.5.1) [5.5.1-3]. Since that time, significant effort has focused on trying to reduce or eliminate inclusions in both laser glasses and other laser optical components.

The two major laser glass manufacturers in the world (Schott Glass Technologies, Inc., Duryea, PA and Hoya Corporation, Fremont, CA) have each developed proprietary melting processes that largely eliminate Pt inclusions from laser glasses. The basic physics and chemistry underlying these processes were jointly investigated by LLNL and the two glass companies and the results from this work have been published elsewhere [5.5.4-7]. In brief, it has been shown that Pt inclusions can be eliminated by using oxidizing process conditions that dissolve the inclusions in the glass matrix; platinum present in the dissolved (ionic) state presents no damage threat. Phosphate glasses are the best compositional choice for making Pt-inclusion-free glass because phosphates have much greater platinum solubility than either silicate or fluorophosphate glasses. By using an oxidizing gas environment and other proprietary process conditions, the platinum inclusion concentrations in phosphate glasses can be reduced from the typical range of $10^{4}$ to $10^{6} / \mathrm{m}^{3}$ to less than $10^{2} / \mathrm{m}^{3}$. Most laser glass optics contain less than about 15 liters of glass and thus are essentially free of platinum inclusions.

An important part of the success of the Pt-inclusion-free manufacturing processes is the use of a quality control tool to detect the few remaining platinum particles in the glass. Often, the size of the inclusions are less than 5 to $20 \mu \mathrm{m}$ and therefore they are too small to be seen visually with the unaided eye. In addition, the glass parts are too large for inspection utilizing conventional microscopy. Thus LLNL has developed a series of platinum particle inspection systems that use a commercial high-peak-power laser to automatically scan the entire laser glass optic. When the laser beam irradiates a Pt-inclusion it causes localized fracture (that we call "damage") that on subsequent shots grows to a size where it is easily detected by visual examination. These systems, which are the subject of this chapter, are fully automated and compatible for use in a production environment [5.5.8]. 


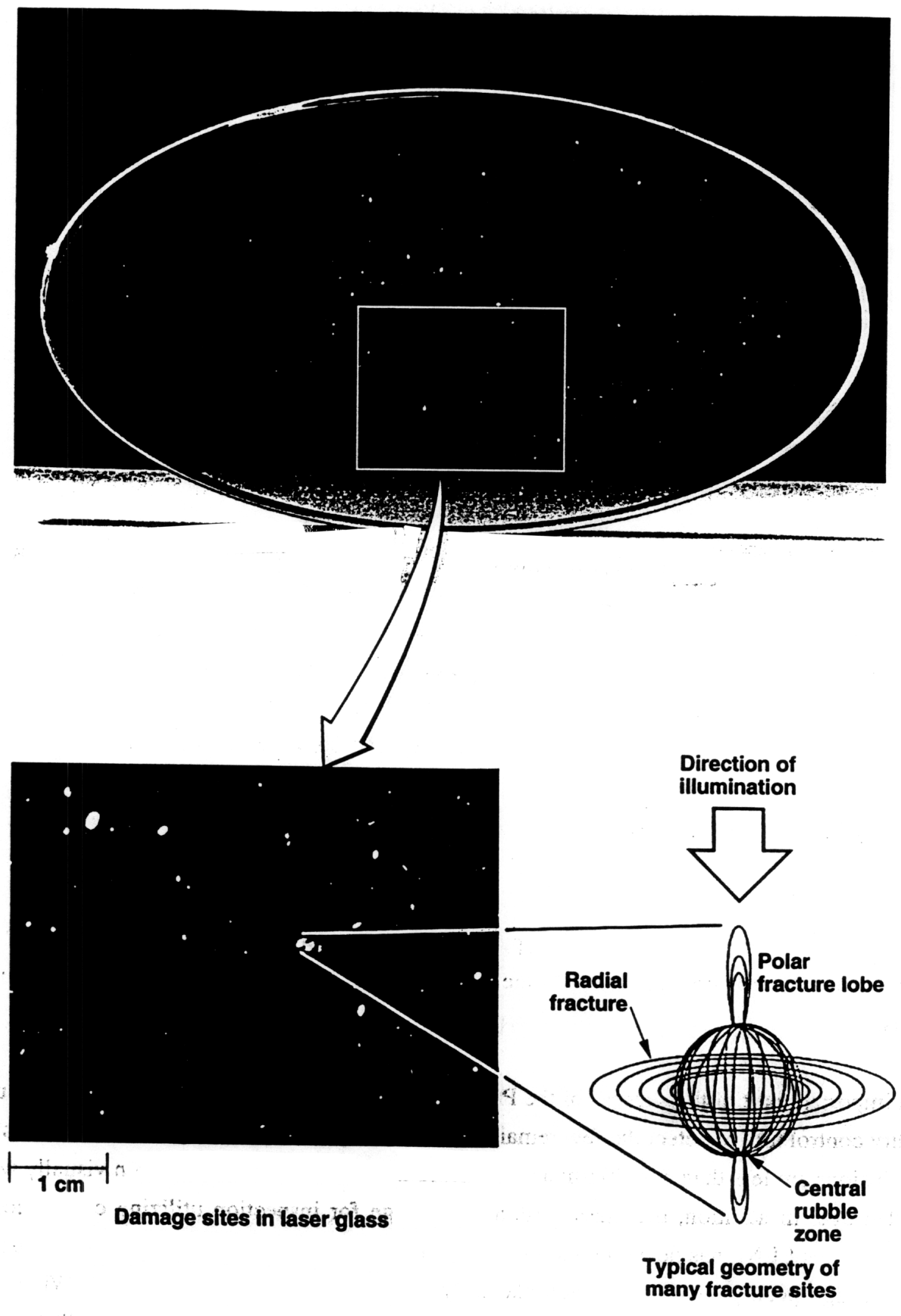

10-05-0386-1124

Figure 5.5.1 Photograph of a $315 \times 615 \mathrm{~mm}^{2}$ laser glass disk showing fracture sites from laser induced damage of $\mathrm{Pt}$ inclusions. The drawing is a schematic representation of the typical damage morphology. 
In the sections that follow, we first give a brief discussion of the damage mechanism of $\mathrm{Pt}$ inclusions subject to high fluence laser light followed by a description the Pt-particle scanning and inspection systems that are in use at the manufacturing facilities. These systems have recently been upgraded in preparation for the continuous laser glass production campaigns required to build future high-peak-power fusion laser systems; a full description is given of the upgrades.

These damage systems are designed to test an entire large laser optic under the fluence conditions it will see in application. The successful use of these systems in a production plant environment has established a trend for customers purchasing not only laser glass but also other optical components to be used in high power laser applications. For example, laser scanning systems, such as those described here, are also used for testing multi-layer dielectric coatings installed on high-peak-power lasers systems.

\subsubsection{Basis for Platinum Particle Detection: Laser Induced Damage}

Key to the detection of Pt particles in glass is the fact they damage when irradiated at a given laser fluence. This "destructive" detection technique is the basis for the inspection process we use today, thus details of the damage mechanism are briefly reviewed.

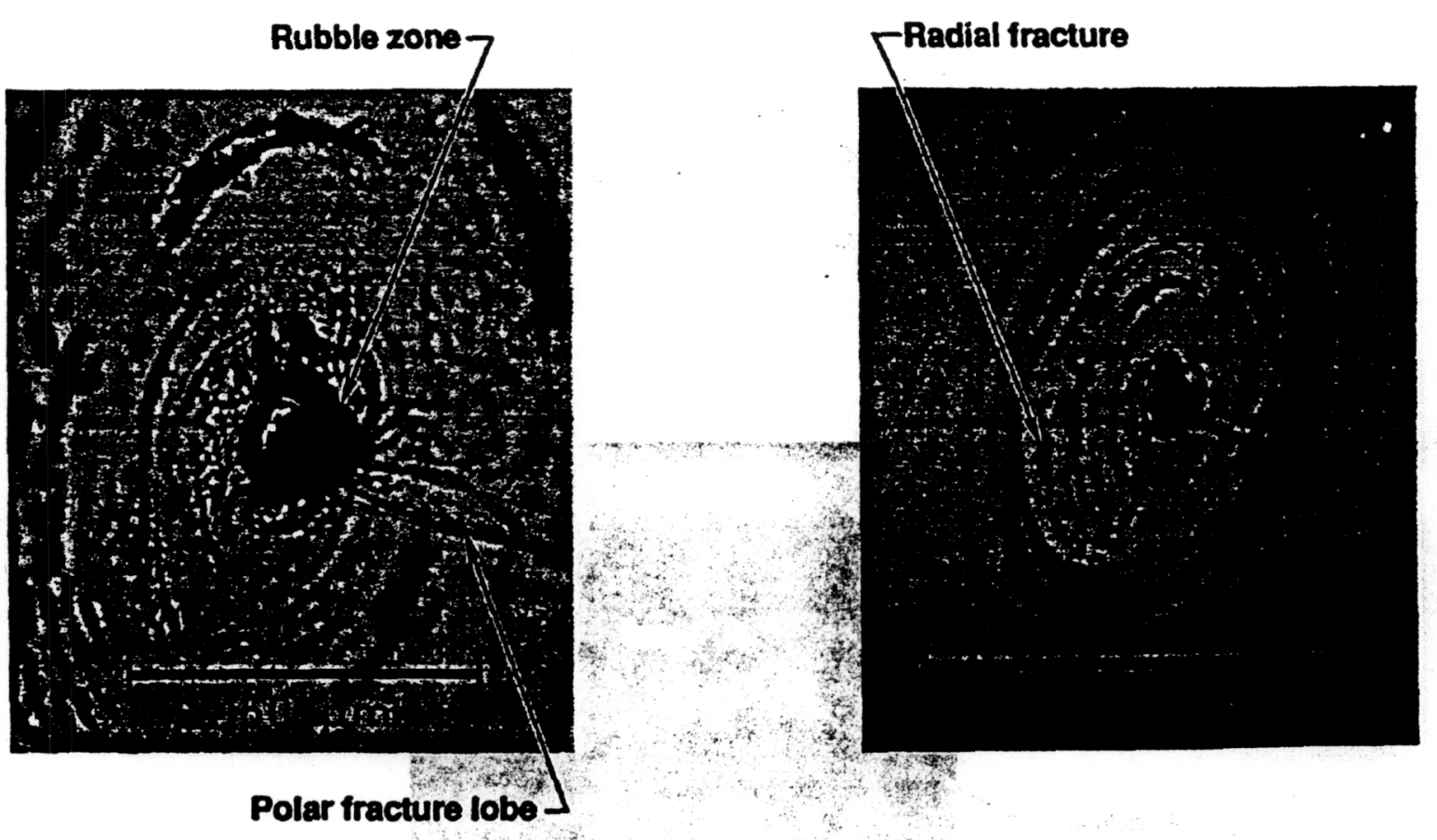

Figure 5.5.2 Optical photographs at two different magnifications of a typical damage site showing the characteristic radial fracture and polar lobes discussed in Fig. 5.5.1. The highly fractured spherical "rubble zone" surrounds the location of the original inclusion. 
Most platinum damage sites are distinguished by a series of radial fractures that form a circular pattern perpendicular to the beam direction. In addition, two minor fracture lobes are often observed extending above and below the radial fracture plane. This damage morphology is shown in the schematic drawing given in Fig. 5.5.1 and the fracture pattern is clearly visible in the photographs shown in Fig. 5.5.2. The damage occurs at laser fluences above about $2.5 \mathrm{~J} / \mathrm{cm}^{2}$ at a pulse length of $1 \mathrm{~ns}$.

To verify that the damaging inclusions are indeed platinum, glass samples have been coredrilled from a number of damage sites in the laser disks. The cores were then cleaved at the plane of the damage fracture and analyzed by energy dispersive $\mathrm{x}$-ray (EDX) using a scanning electron microscopy (SEM). Figure 5.5.3 shows typical SEM back-scattered electron (BSE) images of one such sample at two different levels of magnification showing the typical glass conchoidal fracture pattern of the laser damage site. At the center of the photograph is a high-atomic-number particle that can be clearly seen by the white image it produces in the high-magnification BSE photograph. The EDX analysis of several such particles verified that they are platinum.

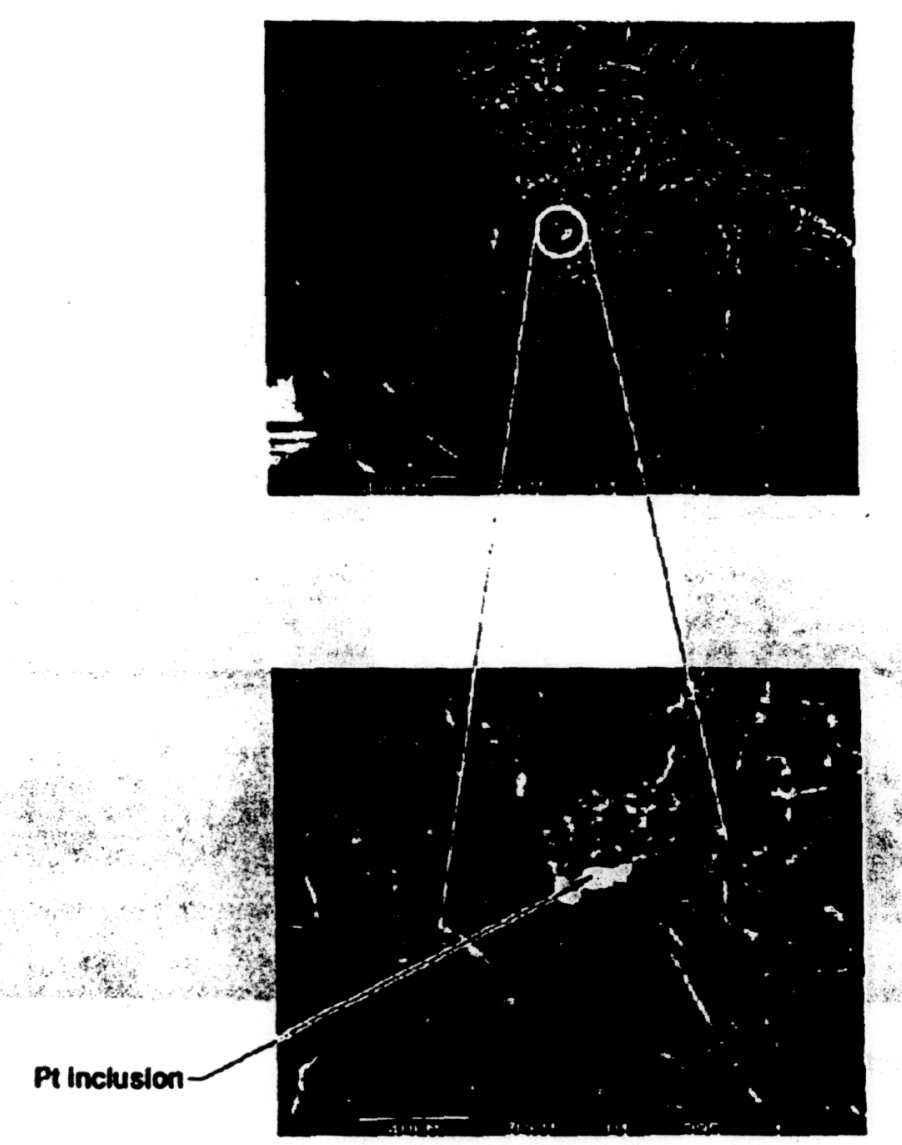

Figure 5.5.3 SEM back-scatter electron images at two different magnifications of a cleaved damage site. The remaining kernel from the original platinum inclusion is the small white particle that can be seen near the center of the lower photograph. 
Studies of laser damage caused by platinum inclusions can be broken into two categories: (a) theoretical/modeling studies[5.5.9-13] and (b) damage threshold measurements [5.5.2,14-17]. The first combined study of damage measurements and modeling was done by Gonzales and Milam [5.5.18] and Pitts [5.5.19] as part of an analysis of damage in the laser glass of the $100 \mathrm{~kJ}$ Nova laser system at the Lawrence Livermore National Laboratory (LLNL) [5.5.20].

Gonzales and Milam measured the platinum damage threshold and then repeatedly irradiated the inclusions to determine the rate of damage growth. Undamaged glass samples containing platinum inclusions were cut from phosphate glass amplifier plates. The major dimensions of the inclusions ranged from 4 to $75 \mu \mathrm{m}$. These samples were irradiated at normal incidence with $1.064-\mu \mathrm{m}$ pulses for durations of $1.3,9$, or $50 \mathrm{~ns}$.

Gonzales and Milam defined the damage threshold as the appearance of one or more fractures extending a few micrometers into the glass surrounding the inclusion. These initial fractures had shapes that were peculiar to individual inclusions. After a few irradiations at fluences above threshold, the damage usually evolved into a circular, planar fracture oriented perpendicular to the incident beam. This damage morphology is the same as that observed on operating laser systems (Figs. 5.5.1 and 2).

In most experiments, repeated irradiation of an inclusion caused damage growth to sizes larger than $250 \mu \mathrm{m}$; note that $250 \mu \mathrm{m}$ is the maximum size defect allowed in optical materials used on the LLNL laser system. This is clearly shown in Fig. 5.5.4 from Gonzales and Milam. Here the inclusion survived three irradiations at fluences up to $2.4 \mathrm{~J} / \mathrm{cm}^{2}$ and was first damaged during the
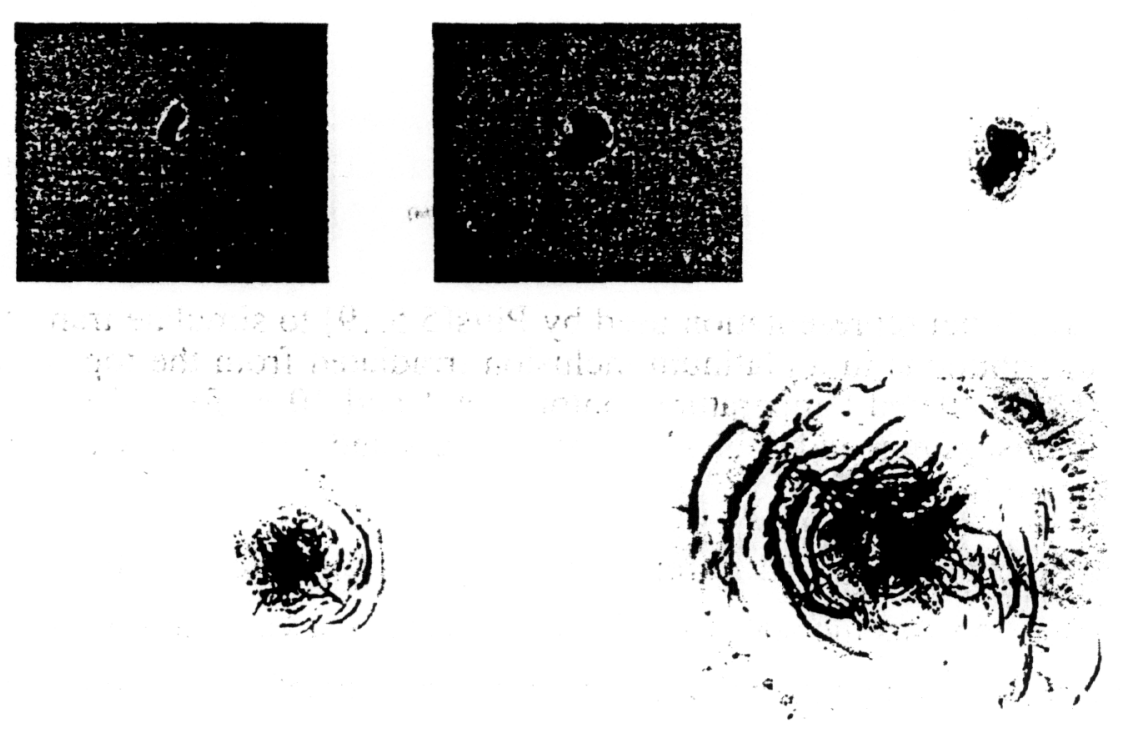

Figure 5.5.4 Photographs showing growth in damage around a 75- $\mu \mathrm{m}$ inclusion (initial size) during 12 irradiations by $1-n s, 1.064-\mu \mathrm{m}$ pulses [5.5.18]. 
fourth shot at $3.8 \mathrm{~J} / \mathrm{cm}^{2}$. Damage grew rapidly during subsequent shots at higher fluences, eventually reaching a size much larger than $250 \mu \mathrm{m}$. Note that damage ceases to grow if the fluence drops below the initial damage threshold (i.e. $2.5 \mathrm{~J} / \mathrm{cm}^{2}$ ).

Gonzales and Milam found the damage threshold to be independent of platinum inclusion size at all three test pulse durations used in their study. This observation is explained by finiteelement heat transfer calculations by Pitts who shows that at short pulse lengths the laser energy which is absorbed at the surface of the platinum inclusion has insufficient time to diffuse into the particle, thereby causing a thin skin of platinum to vaporize. Pitts postulates that this rapid ablation of material produces a shock wave that propagates through the inclusion and is transmitted to the glass. The combined stresses produced by the shock wave and the vaporized platinum causes localized glass fracture.
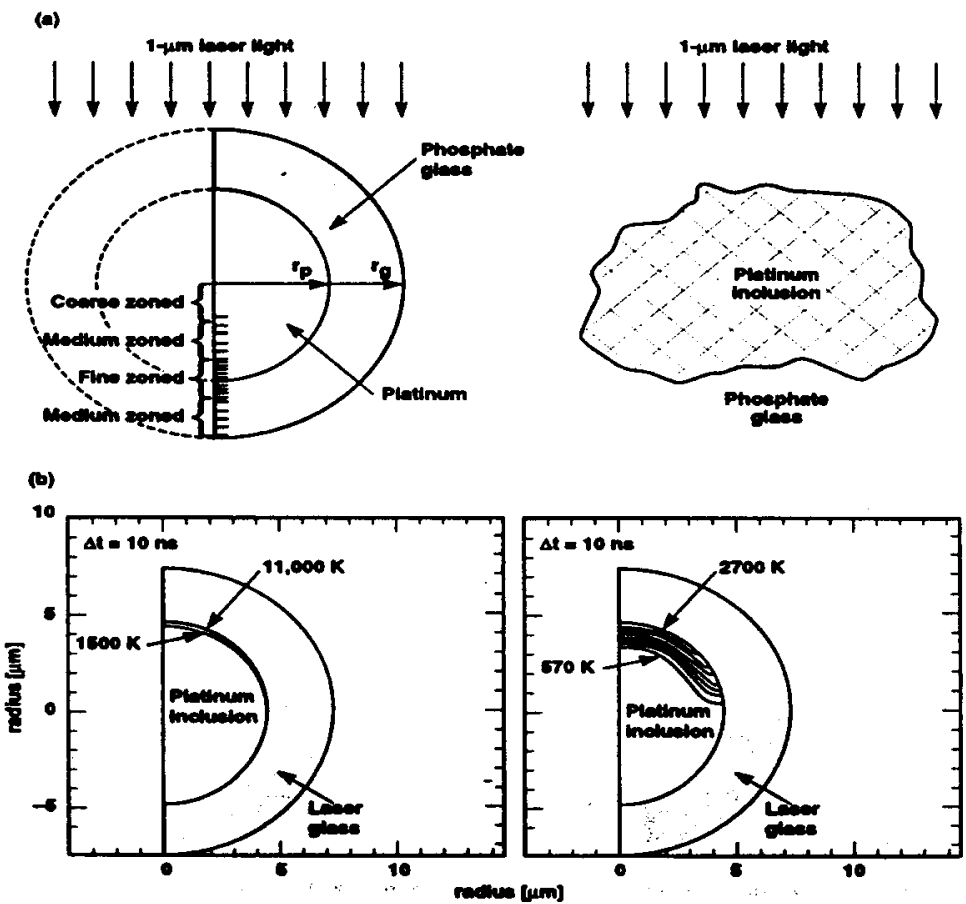

Figure 5.5.5 (a) Model representation used by Pitts[5.5.19] to simulate transient temperature distributions in a platinum inclusion irradiated from the top with a laser pulse; (b) calculated temperature contours at 1 and $10 \mathrm{~ns}$ for a $5-\mu$ m-radius platinum inclusion embedded in a phosphate glass and irradiated with a 1-ns laser pulse having a fluence of $3.7 \mathrm{~J} / \mathrm{cm}^{2}$.

The finite-element model used to represent the physical system is shown schematically in Fig. 5.5.5. The inclusion was modeled as a spherical particle; a variable finite-element mesh size was used to increase the computational accuracy in the regions of greatest change Also shown in Fig. 5.5.5 are the thermal profiles predicted for a platinum inclusion irradiated with a 1-ns pulse of $1.064-\mu \mathrm{m}$ laser light at a fluence of $3.7 \mathrm{~J} / \mathrm{cm}^{2}$. The thermal profiles shown are for two time periods: $1 \mathrm{~ns}$ (immediately at the end of the pulse) and $10 \mathrm{~ns}$ ( $9 \mathrm{~ns}$ after the end of the pulse). The profile at 
10 ns shows the cooling that occurs at the inclusion surface as a result of radiation plus thermal conduction into the platinum; there is negligible heat conduction into the surrounding glass due to its low thermal diffusivity compared to Pt. Peak temperatures at the end of the pulse are high (greater than $10,000 \mathrm{~K}$ ), suggesting significant vaporization of platinum with associated plasma formation at the inclusion surface.

Table 5.5.1 summarizes the calculated maximum platinum surface temperatures and corresponding pressures of vaporized platinum for laser shots at various fluences. The pressures are obviously sufficient to propagate fractures. It is proposed that damage will occur if the platinum surface temperature exceeds the normal boiling point of platinum (i.e. $\mathrm{T}>4100 \mathrm{~K}$ ). This is somewhat of an oversimplification because the platinum is in a constrained volume. Nevertheless, it is clear that for relatively small temperature increases above the platinum boiling point, the pressures will become exceedingly large and produce fractures. Note that apart from this assumption about the onset of damage, the model has no free parameters

Table 5.5.1 Model predictions of platinum inclusion surface temperature and pressure at various incident laser fluences [5.5.19]

\begin{tabular}{ccccc}
\hline $\begin{array}{c}\text { Incident fluence } \\
\left(\mathrm{J} / \mathrm{cm}^{2}\right)\end{array}$ & $\begin{array}{c}\text { Absorbed fluence } \\
\left(\mathrm{J} / \mathrm{cm}^{2}\right)\end{array}$ & $\begin{array}{c}\text { Pulse width } \\
(\mathrm{ns})\end{array}$ & $\begin{array}{c}\text { Maximum platinum } \\
\text { temperature } \\
(\mathrm{K})\end{array}$ & $\begin{array}{c}\text { Maximum platinum } \\
\text { vapor pressure } \\
\left(10^{11} \mathrm{~Pa}\right)\end{array}$ \\
18 & 10 & 1 & $1.3 \times 10^{5}$ & 2.8 \\
3.7 & 5 & 1 & $7.6 \times 10^{4}$ & 1.5 \\
1.8 & 1 & 1 & $1.5 \times 10^{4}$ & 0.5 \\
1.5 & 0.5 & 1 & $6.5 \times 10^{3}$ & $<<0.5$ \\
3.7 & 0.4 & 1 & $5.3 \times 10^{3}$ & $<<0.5$ \\
\hline
\end{tabular}

The high temperatures predicted by the model calculations are confirmed experimentally (at least qualitatively) by the strong plasma light emission that always accompanies Pt-inclusion damage. Also, the plasma emission supports the contention that damage is initiated by the high pressures produced by platinum vaporization rather than by simply solid state thermal expansion differences.

The results of model calculations are compared with measured $\mathrm{Pt}$ inclusion damage thresholds in Fig. 5.5.6. The agreement is generally quite good although the model predicts a $t^{0.5}$ dependence with pulse length whereas experimentally a $t^{0.3}$ dependence is observed. The model also predicts the damage threshold will be independent of particle size (for inclusions greater than $1 \mu \mathrm{m}$ ) over the 1-50 ns region; this also agrees with Gonzales and Milam's experimental results [5.5.18]. 
If inclusions are eliminated from the bulk laser glass, the damage threshold is limited only by the quality of the surface finish. The fluence limit due to surface damage is also shown in Fig 5.5.6 where the surface damage threshold is plotted versus pulse length for laser glass as well as fused silica. The surface damage threshold for finely polished glass samples follows a $t^{0.4}$ pulse length dependence. Note that by eliminating Pt inclusions the fluence limit in laser glass increases 10-fold. This clearly illustrates the critical importance of producing Pt free glasses for laser applications.

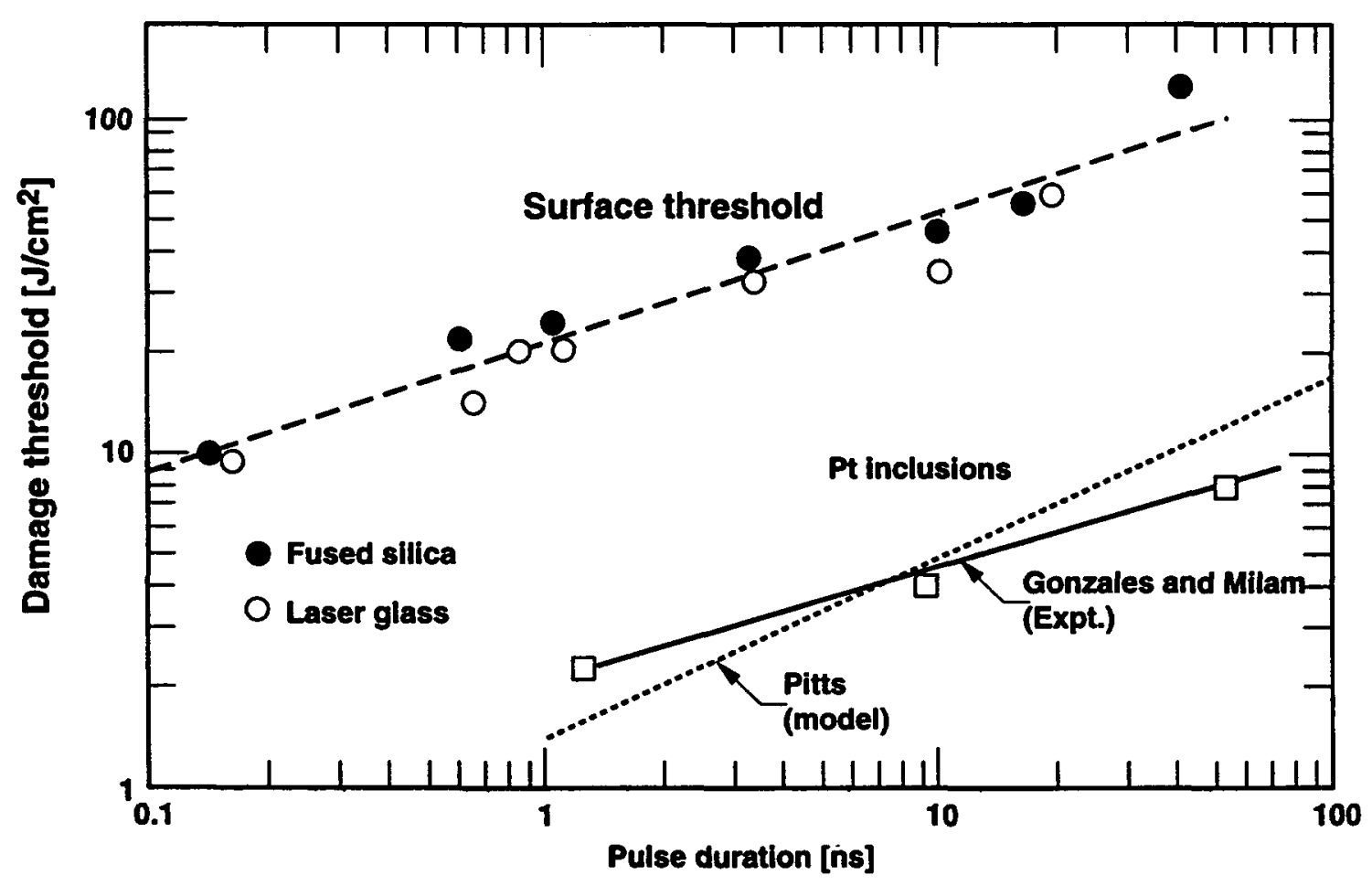

40-00-0ase-0216por

Figure 5.5.6 Platinum inclusion damage thresholds vs. pulse length measured by Gonzales and Milam and predicted by Pitts; also shown, for comparison, are measured surface damage thresholds for finely polished laser glass and fused silica.

As might be expected, the platinum damage threshold is largely independent of glass type. Campbell et al [5.5.6] have summarized the results from platinum damage threshold measurements carried out on various glass compositions [5.5.2,15-18]; these data show good agreement with the measurements by Gonzales and Milam and the model predictions by Pitts.

In summary, studies of platinum inclusion damage have lead to four key conclusions important to the design and operation of the inclusion inspection systems: (1) the damage is caused by the high stresses produced by platinum vaporization and is accompanied by visible-light emission; (2) the damage threshold is independent of particle size for inclusions larger than $1 \mu \mathrm{m}$ over the range of laser pulse widths of interest for most high-peak-power laser applications (1-50 ns); (3) the 
damage thresholds are roughly independent of glass type; and (4) the measured damage threshold for Pt inclusions in phosphate laser glass scales by the relation:

$$
D_{P_{t}}=2.5 t_{p}^{0.3}
$$

where $D_{P t}$ is the damage threshold $\left(\mathrm{J} / \mathrm{cm}^{2}\right)$ and $t_{p}$ the laser pulsewidth (ns).

Finally, we note that dielectric inclusions (e.g., refractory ceramic particles) also damage when subjected to high fluence laser irradiation. The damage thresholds at $1064 \mathrm{~nm}$ for ceramic inclusions depends on the material composition but, as a general rule, damage initiates at fluences about 2-3 times greater than Pt inclusions and appear to scale approximately as the square root of the laser pulse length. Like Pt, the damage from these inclusions grow with subsequent shots.

\subsubsection{Description of the Pt-inclusion Inspection System}

Current Pt-inclusion inspection systems use a commercial Q-switched Nd-YAG laser (Spectra Physics, Inc. Model GCR 290-30) and a custom x-y stage (Newport Instruments Inc.) to automatically scan the entire volume of glass for the presence of damage producing inclusions (Fig. 5.5.7). The laser operates at a $30 \mathrm{~Hz}$ repetition rate producing 10-ns output pulses, each having

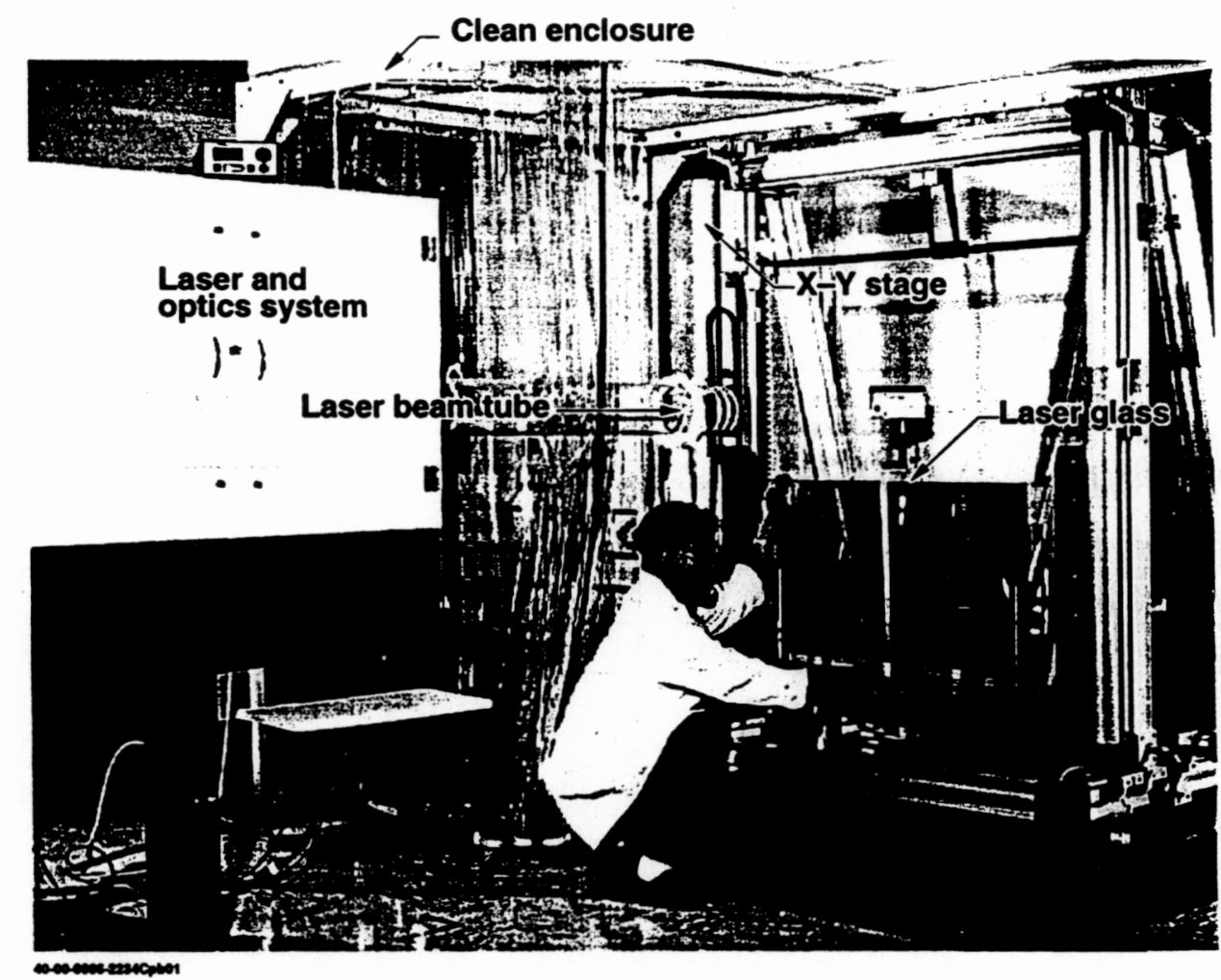

Figure 5.5.7 Photograph showing the physical layout of the LLNL platinum inclusion inspection system; note the laser glass plate mounted on the large $x-y$ stage enclosed within the curtained, class 100 cleanhood. 
a maximum energy of about $1.0 \mathrm{~J}$. The output from the laser is a collimated 13-mm-diameter beam that is fed to an energy attenuator consisting of a half-wave plate and thin-film polarizer (Fig. 5.5.8). The attenuator is used to control the beam energy delivered to the sample by simply rotating the half-wave plate. The attenuator has the advantage of allowing one to vary the beam energy without adjusting the laser operating conditions, thereby providing greater overall system stability.

(a)

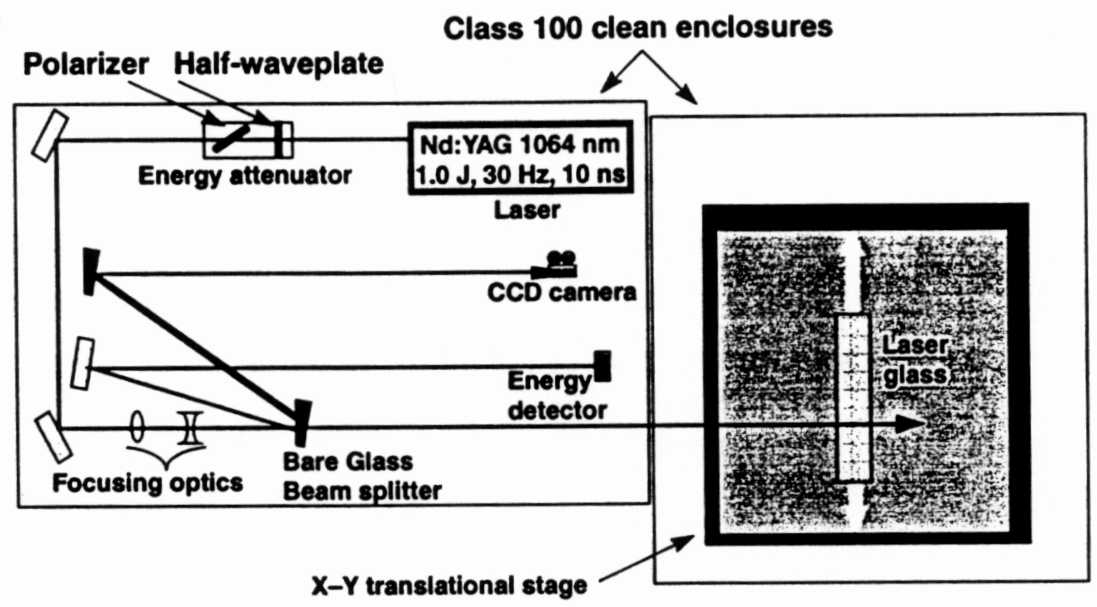

(b)

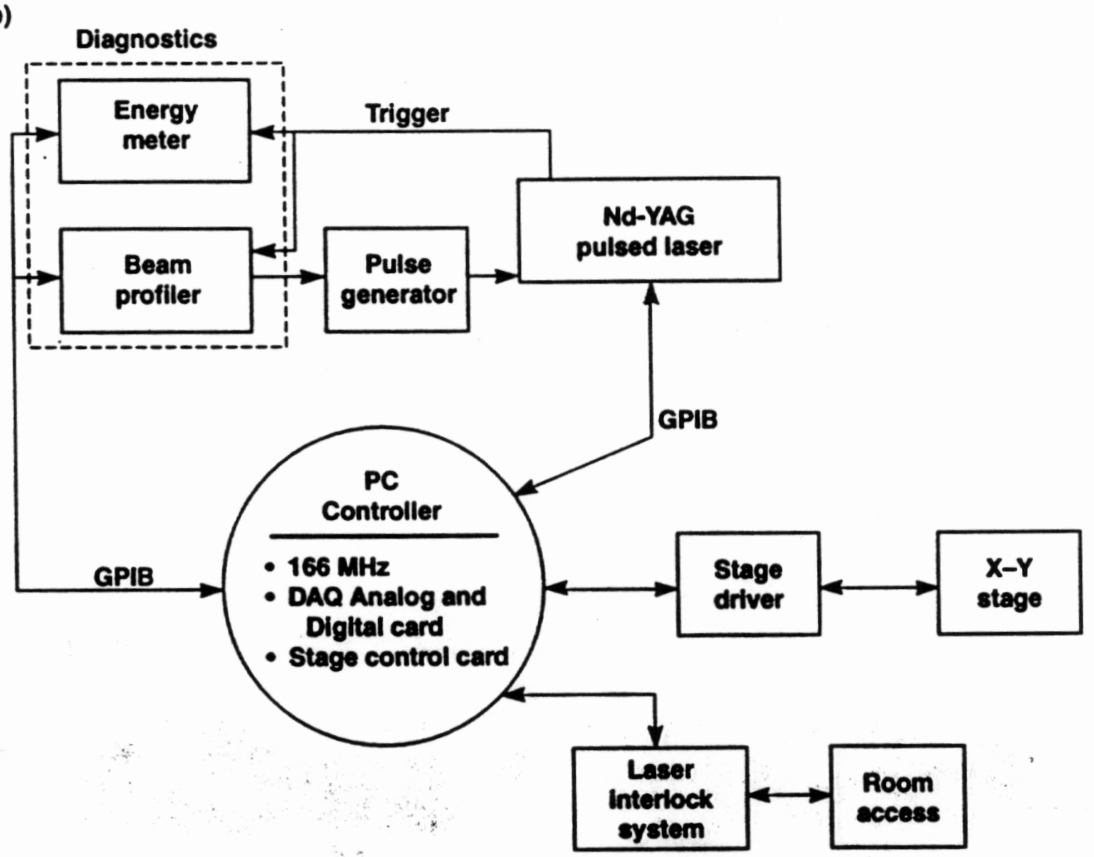

Figure 5.5.8 Schematic drawing of the (a) optical and (b) control system layouts of the platinum inclusion damage test system.

The beam is directed towards the sample using a series of dielectric-coated mirrors and focusing optics consisting of a positive-negative lens combination with an effective focal length of $16 \mathrm{~m}$. The focusing optics produce an approximately $2 \mathrm{~mm}$ diameter gaussian-shaped far-field spot at the 
sample plane. The length of the beam waist at the focal plane is much greater than the sample thickness so that the fluence remains constant throughout the sample volume. A helium-neon laser is co-aligned with the Nd-YAG laser to assist in beam path alignment and sample positioning.

A beamsplitter, located between the focusing optics and the test sample, sends a portion of the beam to a CCD camera (Cohu model 4800) and an energy meter (Molectron Joulemeter model EPM 1000) that monitor the energy and beam profile of each pulse. The CCD camera is part of a commercially available beam profile system (Coherent Instruments); a typical beam profile is shown in Fig. 5.5.9. The beam profile system is used to trigger the laser through a pulse generator (Stanford Research Systems) that operates at $30 \mathrm{~Hz}$. The laser beam characteristics are continuously monitored by the beam profiler and automatically compared to pre-set pass-fail characteristics. If the measured beam characteristics fail, the beam profiler sends an alarm to the control system. The control system then initiates a beam interrogation sequence that either corrects the scan parameters or terminates the run.
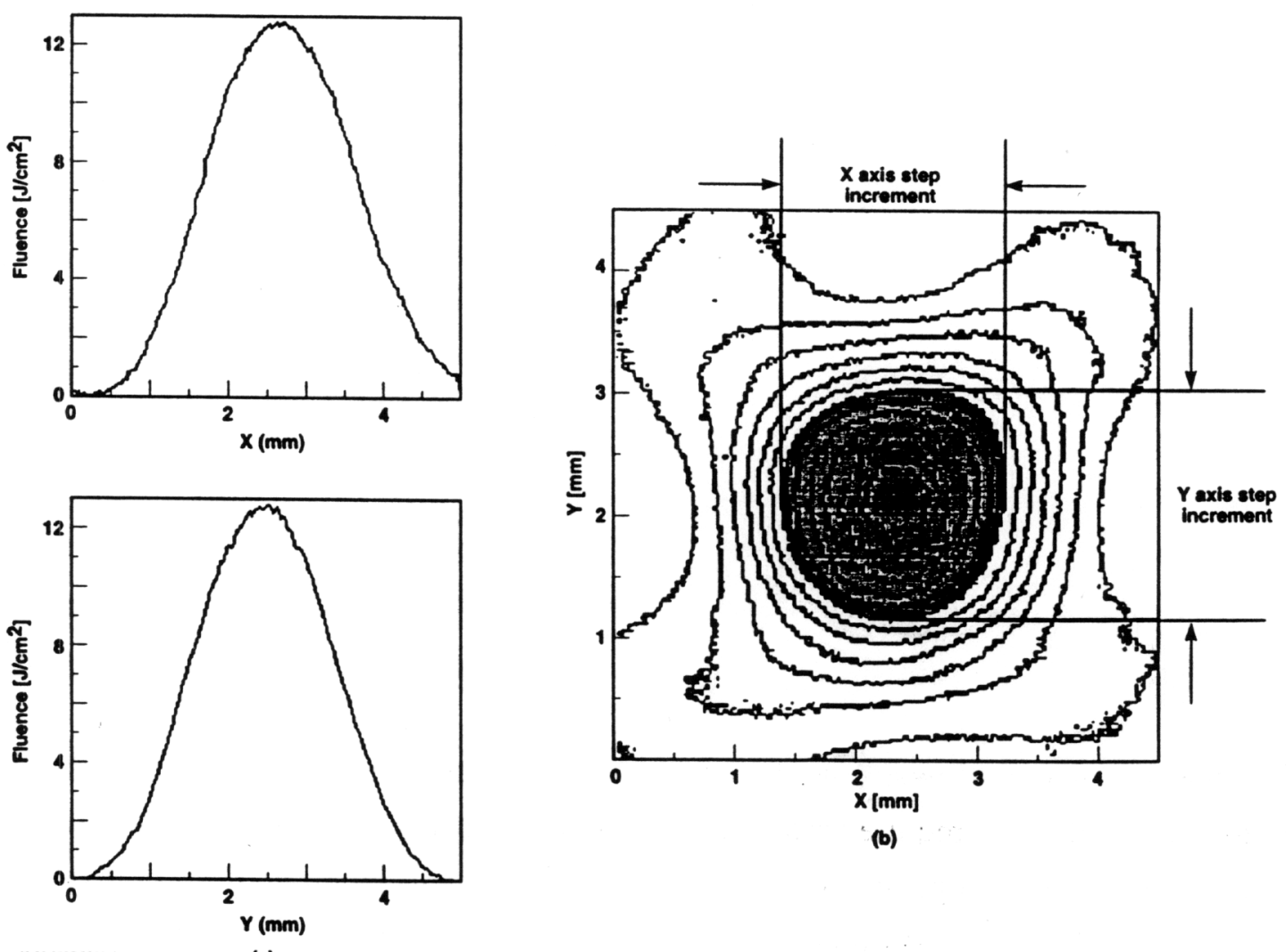

(b)

Figure 5.5.9 (a) Test beam spatial profiles through the peak intensity in both $x$ and $y$ directions; the beams are near-gaussian. (b) Contour plot showing the spatial energy distribution in the far-field spot in $1 \mathrm{~J} / \mathrm{cm}^{2}$ contour intervals. The shaded region denotes the beam size where the fluence exceeds the minimum test requirement of $7 \mathrm{~J} / \mathrm{cm}^{2}$; also shown is the single shot step increment for scans in the $\mathrm{x}$ and $\mathrm{y}$ directions. 
The $x-y$ stage (Newport, Inc. Model MD4) has a range of movement of up to $1-\mathrm{m}$ in either dimension and can scan meter-size pieces of glass weighing up to $200 \mathrm{~kg}$. The stage moves the sample continuously in front of the laser beam and the scan speed can be varied to produce either single or multiple shots through the sample. Typically, we use scan rates that give between 5 to 10 shots through the entire volume. The stage, the laser and the optical train are contained in class 100 clean enclosures to minimize possible damage to the optics and/or test sample from dust or other contamination.

The laser, stage and associated beam diagnostics are controlled by a computer (Dell-PC) and standard GPIB controller (National Instruments) (Fig. 5.5.8b). The stage motion is controlled using a plug-in card (Newport Instruments model MM2000) and motor driver. In addition, a joystick allows manual positioning. The control system continuously archives the key test parameters (beam dimensions, peak fluence, energy, beam location and scan rate) on a hard disk.

A coded safety interlock system controls room access while the system is in operation; any inadvertent or unauthorized entry trips the interlock and de-activates the laser system. The room interlock controller is interfaced to the computer through a data acquisition card (National Instruments).

\subsubsection{Inclusion Test Specification and Procedures}

The test specifications must, of course, fit the intended application of the glass. Therefore the specifications given here should be considered as guidelines. Current laser glass manufacturing specifications require the average inclusion density to be 2 or less within the clear aperture of a single laser glass plate containing approximately 15 liters of glass (i.e., $\leq 0.13 /$ iter); this average applies to a lot-size of 10 slabs. Generally, up to five inclusions are allowed in any one glass plate as long as the average for the lot stays within the 0.13 inclusion/liter specification (Table 5.5.2).

The reason for the allowable variation in inclusion density is a matter of economic and engineering practicality. To require zero inclusions in all parts, particularly for an order of several hundred to several thousand plates, may result in enormous yield losses and prohibitive costs. In addition, a few small inclusions do not necessarily render an optic unusable. In general damage due to small inclusions often stops growing after reaching some maximum size; this maximum is usually attained within 50-60 high-fluence shots. As long as this size remains below a limit acceptable for the application (e.g. about $250 \mu \mathrm{m}$ ) then the slab meets specification. Note however that the total number of inclusions in the laser glass must remain low to avoid transmission losses due to scattering. 
Table 5.5.2. Summary of typical Pt-inclusion specifications for laser glass used in fusion research lasers.

Sample damage test conditions:

Inclusion density:

Minimum distance between inclusions:

Maximum number of inclusions:

Inclusion damage size after testing:

$\begin{array}{ll}\text { Wavelength: } & 1053 \text { to } 1064 \mathrm{~nm} \\ \text { Incidence angle: } & \sim 90^{\circ} \\ \text { Fluence: } & \geq 7 \mathrm{~J} / \mathrm{cm}^{2} \\ \text { Pulsewidth: } & 8 \mathrm{~ns} \\ \text { No. of shots: } & 100 \\ <0.1 \text { to } 0.2 \text { per liter } & \\ 25 \mathrm{~mm} & \\ 0.35 \text { per liter } & \\ 1 \text { damage spot } \leq 0.50 \text { mm (largest dimension) and } \\ \text { remainder } \leq 0.25 \mathrm{~mm} \text { (largest dimension) }\end{array}$

In certain cases it may be necessary to require zero inclusions in the laser glass part, particularly small optics to be used in high-fluence applications (e.g., laser rods). In such cases the glass manufacturers can often cut the part from the raw glass blank without including any inclusions. This first requires that the location of the inclusions be identified using the laser scanning system.

Also, in some cases, statistical testing may be adequate. For example, the Laboratory for Laser Energetics (LLE) at the University of Rochester, has used statistical testing of Pt-inclusions in their laser rods (up to $370 \mathrm{~mm}$ length $\times 90 \mathrm{~mm}$ diameter) with good success.

During testing the glass is first cleaned with standard liquid glass cleaner and then either manually or mechanically loaded onto the stage. The control system starts the laser either upon operator command or at a pre-set time. The control system automatically initiates a beam characterization sequence that sets the stage velocity to match the desired test conditions (i.e. shotsper-site). The sample is then irradiated at near-normal incidence with up to 10 shots per site at a fluence level between 7 and $14 \mathrm{~J} / \mathrm{cm}^{2}$. At this fluence, any platinum inclusions in the glass will produce optically visible damage sites. This fluence corresponds to about twice the damage threshold for platinum inclusions in glass assuming a 10-ns pulse-width (see Equation 5.5.1). A test scan may take only a few moments for a small glass piece or up to 8 hours for larger pieces. Because the system is automated, it can operate unattended and archives the data as the scan proceeds; it also shuts down the laser at the end of the test.

Following the scan, the part is removed and taken to a separate visual inspection station where it is mounted on a black felt base. The room is darkened and a visual inspection is performed by illuminating the sample from the side with several intense fiber-optic, white-light sources. Visual 
inspection generally takes about one hour for an $80 \times 46 \times 4.5 \mathrm{~cm}^{3}$ glass plate. Automated damage mapping system are presently under development and offer the promise of greatly reducing the time required for post-damage inspection.

When damage sites are found they are marked and sized using optical microscopy (40x). In some cases an additional 90 -shot test is performed on each damage site [5.5.6,8]. The purpose of the 90 -shot test is to grow the damage to its maximum dimension. The 90-shot test usually takes only a few minutes. After the 90-shot test, the damage sites are re-measured for growth. If the damage site is still within specifications (e.g. Table 5.5.2) the part is accepted.

\subsubsection{Past System Operational Experience and Current Status}

Pt inspection systems, such as those described here, have been in operation at the two major laser glass manufacturers (Schott Glass Technologies and Hoya Corporation) since 1986. They have proven reliable, with less than $5 \%$ down time, and have become an integral part of the glass manufacturing process. These inspection systems have been used to qualify the laser glass that is currently in use on all the large high-peak-lasers around the world (Nova and Beamlet lasers [LLNL], Phebus [CEA, France], Omega Upgrade [LLE, Univ. of Rochester], and Gekko XII [Univ. of Osaka, Japan]).

Presently, the US Department of Energy and the French Commissariat a l'Energie Atomique (CEA) are each designing and constructing fusion ignition laser systems with output energies of nearly $2 \times 10^{6} \mathrm{~J}$ and powers of nearly $5 \times 10^{14} \mathrm{~W}$. These laser systems will each require $3000-4000$ large plates of Nd-doped phosphate glass. In preparation for this manufacturing campaign, LLNL has installed the second generation Pt-inspection systems described in this chapter at each of the laser glass companies. These new systems have been used in test melting campaigns and proven to be as reliable as the earlier systems while at the same time being much easier to operate.

Laser glass is not the only optical material required to have a high damage threshold. As a consequence, scanning systems have recently been built or are under construction for testing other optical materials such as fused silica and multi-layer dielectric coatings (e.g., high reflectivity mirrors and thin film polarizers). Such systems also may prove useful for the detection of inclusions (either metallic or dielectric) in other high-value glass articles not necessarily intended for high-peakpower laser applications. 


\section{Acknowledgment}

The authors are grateful to Dr. J.S. Hayden, Dr. E. Vozenilek, and Dr. A. Marker of Schott Glass Technologies, Inc., and Dr. H. Toratani, Mr. K. Takeuchi, and V. Alvarez of Hoya Corporation for their support in the installation and operation of this equipment. Work performed under the auspices of the U.S. Department of Energy by Lawrence Livermore National Laboratory under contract No. W-7405-Eng-48.

\section{REFERENCES}

5.5.1 C.G. Young: "Glass lasers", Proc. IEEE 57, 1267-1289 (1969)

5.5.2 Fundamentals of Damage in Laser Glass (National Materials Advisory Board, Division of Engineering, National Research Council, Report No. NMAB-271, Washington, DC, 1970)

5.5.3 E.S. Bliss: Damage in Laser Glass (Special Technical Publication No. 469, American Society for Testing and Materials, Philadelphia, PA 1970).

5.5.4 J.H. Campbell, E.P. Wallerstein, J.S. Hayden, D.L. Sapak, and A.J. Marker: "Effects of melting conditions on platinum-inclusion content in phosphate laser glasses", Glastechn. Ber. 68 (1), 11-21 (1995)

5.5.5 J.H. Campbell, E.P. Wallerstein, H. Toratani, H. Meissner, and T. Izumitani: "Effects of process gas environment on platinum-inclusion density and dissolution rate in phosphate laser glasses," Glastechn. Ber. 68 (2), 59-69 (1995)

5.5.6 J.H. Campbell, E.P. Wallerstein, J.S. Hayden, D.L. Sapak, D. Warrington, A.J. Marker, H. Toratani, H. Meissner, S. Nakajima, and T. Izumitani: Elimination of Platinum Inclusions in Phosphate Laser Glasses, (Lawrence Livermore National Laboratory Report UCRL53932, Livermore, CA, 1989)

5.5.7 J.H. Campbell: "Modeling platinum-inclusion dissolution in phosphate laser glasses", Glastechn. Ber . 68 (3),91-101 (1995)

5.5.8 C.L. Weinzapfel, G.J. Greiner, C.D. Walmer, J.K. Kimmons, E.P. Wallerstein, F.T. Marchi, J.H. Campbell, J.S. Hayden, K. Komiya and T. Kitiyama: "Large scale damage testing in a production environment," in Laser Induced Damage in Optical Materials:1987, H.E. Bennett, A. H. Guenther, D. Milam, and B.E. Newman, eds. (NIST Special Publication 756, National Institute of Standards and Technology, Washington, DC 1987) pp. 112-122

5.5.9 R.W. Hopper and D.R. Uhlmann: "Mechanism of inclusion damage in laser glasses", J. Appl. Phys. 41(10), 4023-4037 (1970)

5.5.10 R.W. Hopper and D.R. Uhlmann: "Vaporization of inclusions during laser operation", J. Appl. Phys. 41(4), 5356-5357 (1970)

5.5.11 R.W. Hopper, C. Lee, and D.R. Uhlmann: "The inclusion problem in glass," in Damage in Laser Materials: 1970, A.J. Glass and A.H. Guenther, eds. (Spec. Publ. 341, Nat. Bureau of Standards, Boulder, CO, 1970) pp. 55-66 
5.5.12 M. Sparks and C.J. Duthler: "Theory of infrared absorption and material failure in crystals containing inclusions", J. Appl. Phys. 44(7), 3038-3045 (1973)

5.5.13 Yu.K. Danileiko, A.A. Manenkov, V.S. Nechotailo, A.M. Prokhorov, and V.Ya. KhaimoMal'kov: "The role of absorbing impurities in laser-induced damage of transparent dielectrics", Sov. Phys.-JETP 36(3), 541-543 (1973)

5.5.14 N.E. Alekseev, V.P. Gapontsev, M.E. Zhabotinskii, V.B. Kravchenko, and Yu.P. Rudnitskii: Laser phosphate glasses, English translation, UCRL-Trans-11817 (Lawrence Livermore National Laboratory, Livermore, CA, 1983)

5.5.15 P.V. Avizonis and T. Farrington: "Internal self-damage of ruby and Nd-glass lasers", Appl. Phys. Lett. 7, 205-206 (1965)

5.5.16 C. Yamanaka, T. Saski, M. Hongyo, and Y. Nagao: "Investigations of damage in laser glass," in Damage in Laser Materials: 1971, A.J. Glass and A.H. Guenther, eds. (Spec. Publ. 356, Nat. Bureau of Standards, Boulder, CO, 1971)pp. 104-112

5.5.17 S. Stokowski, D. Milam and M. Weber: "Laser induced damage in fluoride glasses: a status report," in Laser Induced Damage in Optical Materials: 1978, A.J. Glass and A.H. Guenther, eds. (Spec. Publ. 541, Nat. Bureau of Standards, Boulder, CO, 1978) pp. 99-108

5.5.18 R.P. Gonzales and D. Milam: "Evolution during multiple-shot irradiation of damage surrounding isolated platinum inclusions in phosphate laser glass," in Laser Induced Damage in Optical Materials: 1978, H.E. Bennett, A. H. Guenther, D. Milam, and B.E. Newman, eds. (Spec. Publ. 746, Nat. Bureau of Standards, Boulder, CO, 1985) pp. 128-137

5.5.19 J.H. Pitts: "Modeling laser damage caused by platinum inclusions in laser glass," in Laser Induced Damage in Optical Materials: 1985, H.E. Bennett, A. H. Guenther, D. Milam, and B.E. Newman, eds. (Spec. Publ. 746, Nat. Bureau of Standards, Boulder, CO, 1985), p. 537-546

5.5.20 C.W. Hatcher: “Assessment of laser glass damage on the Nova system," in 1985 Laser Program Annual Report, UCRL-50021-85 (Lawrence Livermore National Laboratory, Livermore, CA, 1986), chap. 6, pp. 4-6

5.5.21 T. Izumitani, K. Hosaka, and C. Yamanaka: "Laser damage of Hoya laser glass, LCG-11," in Laser Induced Damage in Optical Materials: 1972, A.J. Glass and A. H. Guenther eds. (Spec. Publ. 372, Nat. Bureau of Standards, Boulder, CO, 1972) pp. 3-10 


\section{Appendix F}

\section{Press coverage, trade journal articles, newspaper articles, press releases}




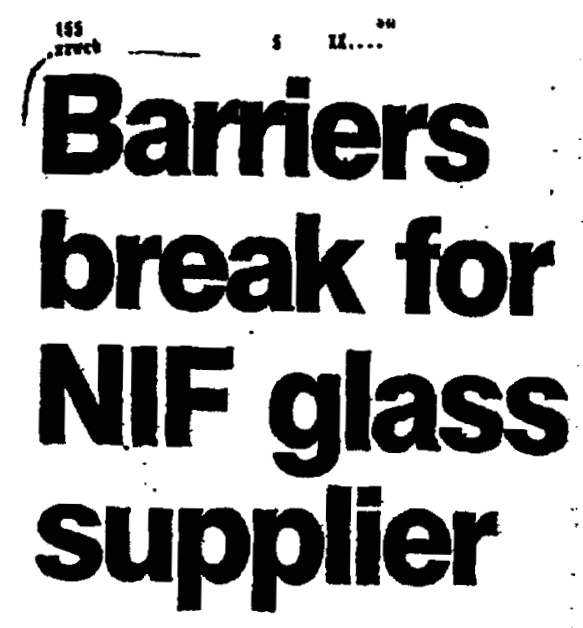

Lab's specialty glass produced 20 times faster.

Br Emorn Robertes.

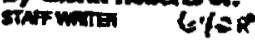

LTVARORE - A das monufacturer for the

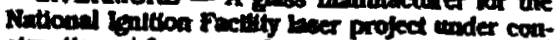

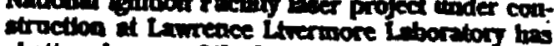

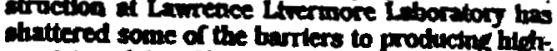
chattered some of the burrlars

The aew techingue, deriloped by sxhot otese

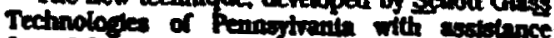

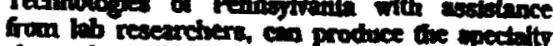

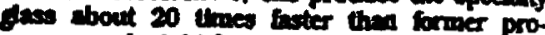

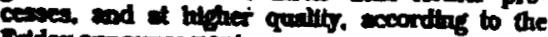
Fridey enowowicenent

Monefecturert had formerty filled to ind a way to manseprodince bser tasswere to the tidd spectications of the bollon-dollar difs project.

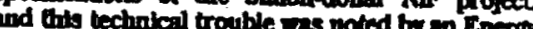
Depertuent task force that reviened the project.

Enera Secretary Bull Pichurdoon fremed the hok fores to an eloct to underibad the scope of

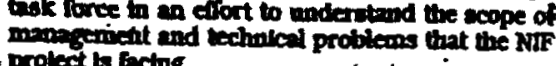
- project is Enchg

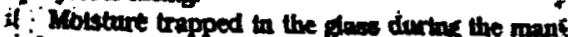

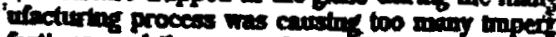

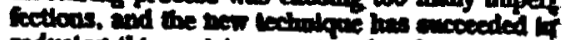
redectas this modture content by bout so per

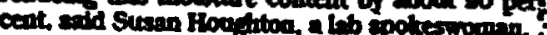
Lab and schot revearchers fornd thes conld

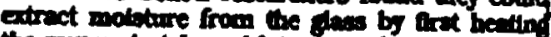

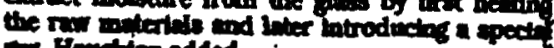
wi, forified added

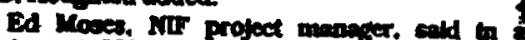

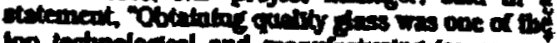

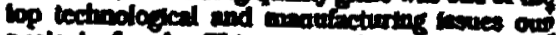

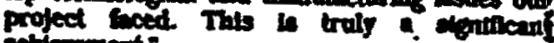
cheren-it:

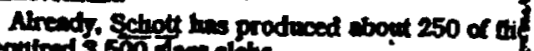
nequined 3500 dexibe slbe

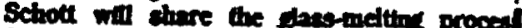

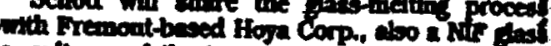
opplicr. and the ho companies are expectiod ts

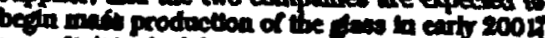

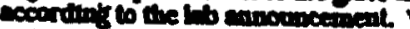

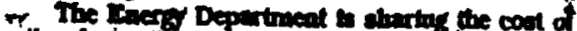

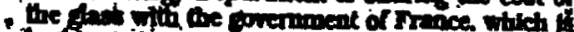

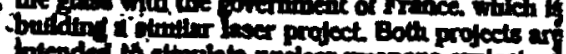

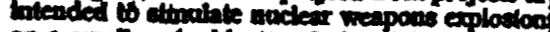

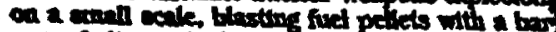
rage a cultratiolet boer enery.

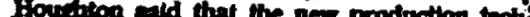

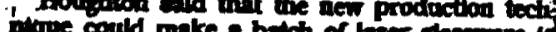

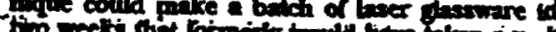

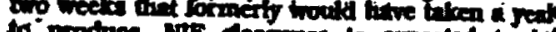

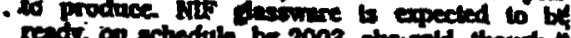
gend, on achedule by 2003 , abe eald, thond th could be didned based on the neede of the prot fears overnil bed tet nad echedole.

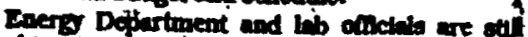

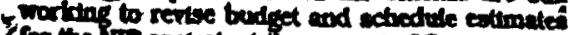
Yor the in project at the requed of Congreas.

$$
\text { Copies g j }
$$

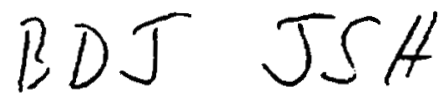

SK<smiles>C1CC2CCC1C2</smiles>

$C S$ $A C K$<smiles>c1ccccc1</smiles>
$A M$<smiles>CCC(C)C1CC1</smiles>

F.ish: D.W.5. 
APPUL 15, 2000

VOLUME 7 NOS

\section{Glass vendors meet NIF specifications}

LMERMORE, CA-Glass vendors for the Lawrence Livermore National Laboratory (UNL; Livermore, CA) National Ignition Facility (NIF) have achieved a major milestone and addressed one of the key technological questions that plagued the NIF when scheduling and cost overnuns were reported last September. OHApril 1 LNL

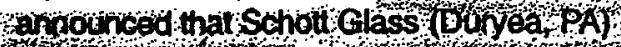

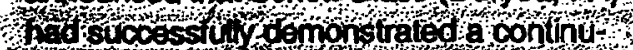
o s shel process tónable production of Eoon on al high optcal olathy neodymin doped phosphate laserglass for the NIF

Hoya Corp. (Freinotit, $\mathrm{CA}$ ), the second of two NIF laser glass vendors, is scheduied to begin a similar process next month. More than 3500 laser glass slabs will be needed for the NIF, and a similar quantity. will be needed for the Laser Megajoule to be constructed later in this decade by the French Commissariat a L'Energio Atomique (CEA; Grenoble, France). Each slab measures about $80 \times 45 \times 4 \mathrm{~cm}$ and weighs

$$
\begin{aligned}
& \text { To: JC BDJ, } \\
& \text { JSH, SK, } \\
& \text { ACK, AM } \\
& C S, R J S \\
& A T
\end{aligned}
$$

$$
\text { From: } \begin{aligned}
& j \omega J \\
& 5 / 1 / 00
\end{aligned}
$$

about $100 \mathrm{lb}$. Schott had produced 250 of the slabs by the beginning of April using the continuous-melt process, which is 20 times faster than the previous one-slab-ata-time batch melting technology.

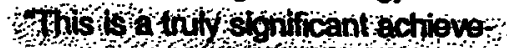

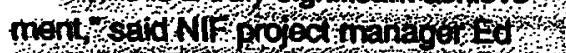

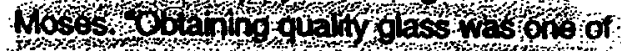

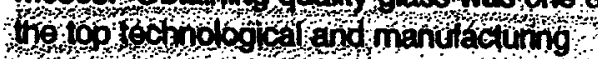
is siles our project taced.This achiovement demonstrates that NIF's remaining technical challenges are rapidty being solved." Late last summer, NIF management came under US Department of Energy scrutiny because of a reported $\$ 300$-million cost overrun and a schedule delay of at least one year. Technological concems raised by unofficial sources included target fabrication, diagnostics, and glass development and delivery. Both NIF glass vendors had demonstrated last yoar that continuous glass melt was possible, but at the time they were unable to achieve all of the project specifications.

A major concem was traces of hydroxyl group contamination in the recin:- - ! due to moisture in the atmosphere and raw materials. Initial attempts 10 remove the moisture degraded other glass properties, but cooperative research by UNL. Schott, and Hoya during the last six months has overcome those problems, according to the UNL statement. Following the current successful demonstration of the new technolo. gy by Schott, both-vendors are expected to begin production campaigns using the continuous-melt process early next year. Development costs for continuous-melt technology were shared equally by LNL and CEA.-HJ-B 


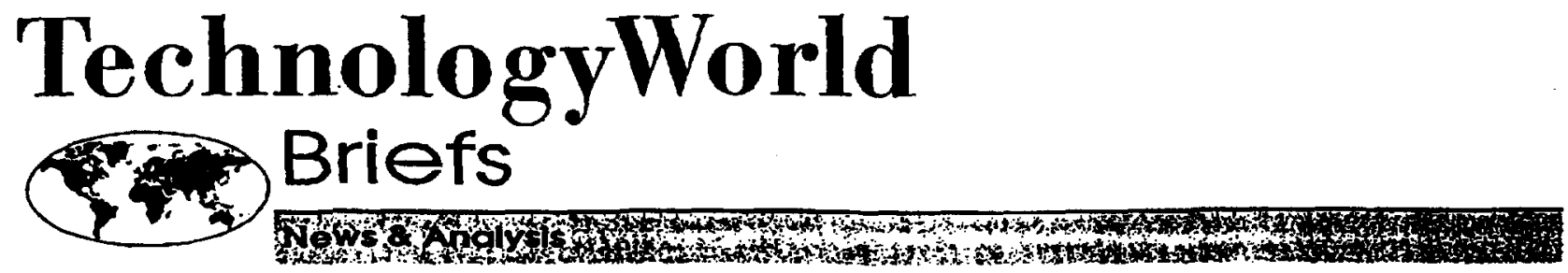

\section{SDL Tests Raman Amplifiers}

Researchers from sDL inc. of San Jose, Callf., and ATET Labs-Research of Red Bank. N.J., have reported that their field tests show that distributed Raman amplification improves the performance of 10-Gb/s wavelength division multiplex transmission. They used $40 \mathrm{~km}$ of installed older-vintage fiber to demonstrate that SDL's RL30 Raman pump modules can be incorporated into existing terrestrial networks without damaging the fiber or connectors.

The researchers estimate that, at optimum pump power levels of 650 $\mathrm{mW}$, the 17-dB average channel $Q$-value would enable transmission over up to seven $120-\mathrm{km}$ spans, rather than three without Raman amplification. Rump powers of up to 950 mW did not damage the fiber.

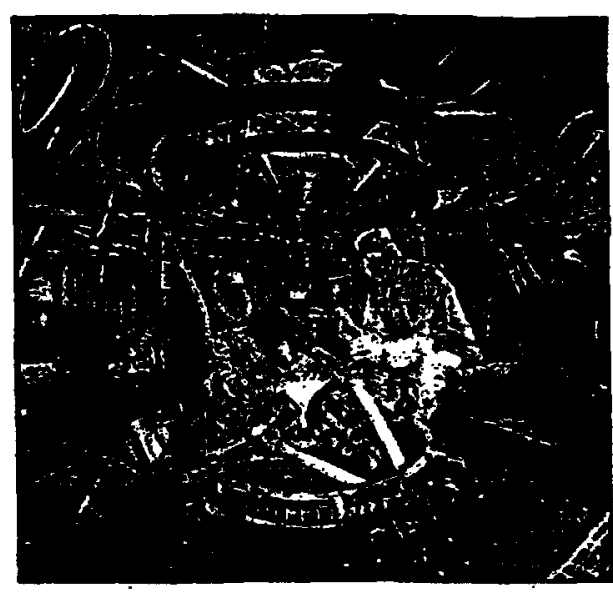

Space-Based Laser Boosis Power

An April 24 test of the megawatt-class hydrogen-fluoride chemical laser known as Alpha Increased the output of the device by approximately 25 percent and improved Its beam ct-.. . by TRW Space and Flectronics Group of Redondo Beach, Calli.. in 1989 as a test bed for the US Bailistic Missile Defense Organization's Space-Based Laser program.

Techiniclans removed Alpha's clippers (the circular, fold fixtire at their feet), which restrict the size of its lasing cavity. Brooks McKinney, manager of media relations at the company, said the next step in the technology maturation tests is to optimize the chemical flow rates of the laser to improve its "fuel mileage."

\section{Synchrotron Produces Femtosecond Pulses}

A team at Lawrence Berkeley National Laboratory's Advanced Light Source in Berkeley. Calif., reported in the March 24 issue of Sclence that it had produced 300 fs $x$-ray pulses with the facllity's 1.5-GeV synchrotron. Improved designs should produce 100-fs pulses for directly probing the atomic-scale structural dynamics of condensed matter.

The researchers injected a fentosecond pulse from a Tlisapphire laser Into a resonantly tuned wiggler magnet with a 30 -ps electron bunch. Bend magnets separated the $x$-rays from the energy modulation produced tin the electrons. .

Plans are under way to decrease the distance between the magnets, a move that is expected to yield 100-fs pulses. Replacing the bend magnets with an undulator should increase the flux to $10^{7}$ photons per second for studies yoine timn mankrar x-ray diffraction and extended $x$-ray absorption fine structure.

\section{Sehott Turns Out Glass for Ignition Facility}

Following months of cooperattve research with Foy Corp. of Fremont, Calif., Schott Giass Technologies Inc. of Duryea, Pa.. has achleved continuous production of laser glass slabs for Lawrence Livermore Na. tional Laboratory's National Ignition Facility in Livermore, Calif. The process should produce the slabs 20 thmes faster than by batch melting - good news for the ignition project. which has been plagued by administrative, budgetary and technical problems.

The National Ignition Facility

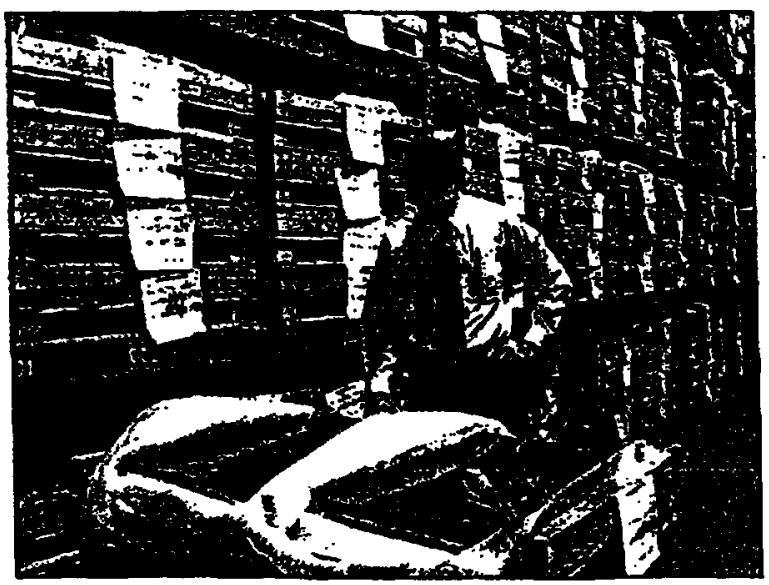

will require more than $\mathbf{3 5 0 0}$ of the neodymtum-doped phosphate glass slabs. The development costs of the production process have been shared with the Commisandiat - L'Energie Atomique of France, which also will use the glass in its Laser Megajoule project.

\section{Bell Liths Extends} 3-Tb/s Trensmission Bell Labs in Murray Hill, N.J., has announced ouccossful long-distance transmission at triple-terabit speeds. The researchers displayed transmission of 82 wavelengths at $40 \mathrm{~Gb} / \mathrm{B}$ over three $100-\mathrm{km}$ spans of parent Lucent Technologies Inc.'s TrueWave aber.

The experiment employed 40 channels in the $C$-band and 42 in the $L$ band. Both dense wavelength division multiplexing and distributed Raman amplification techniques were used to produce 3.28- $\mathrm{Tb} / \mathrm{s}$ transmission. 


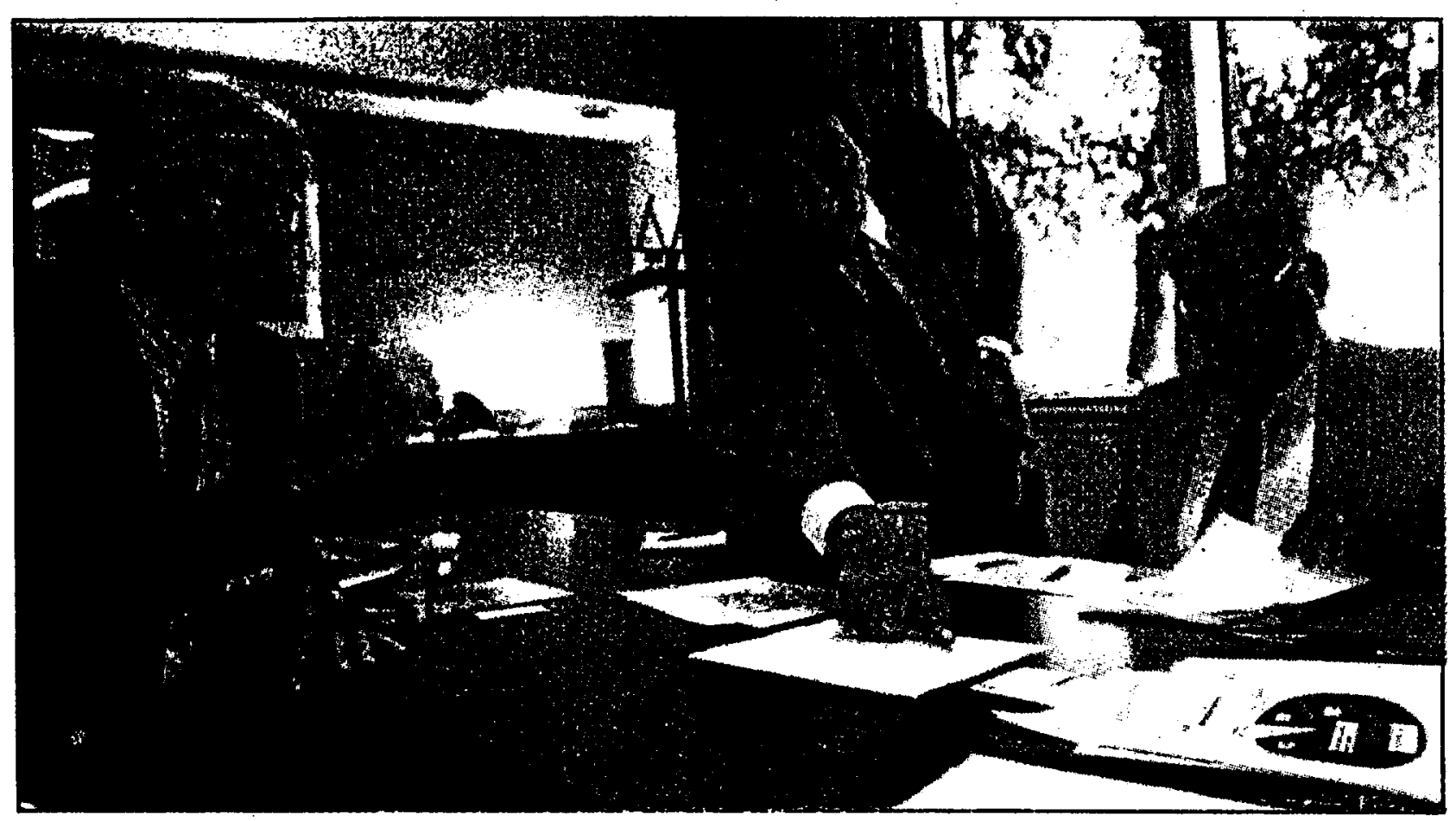

William Hogan, left, a scientist at Lawrence Livermore Bottero, center, and Fremont Mayor Bill Ball discuss a National Laboratory, Hoya Senior Vice President Gerald proposed $\$ 1.1$ billion superlaser.

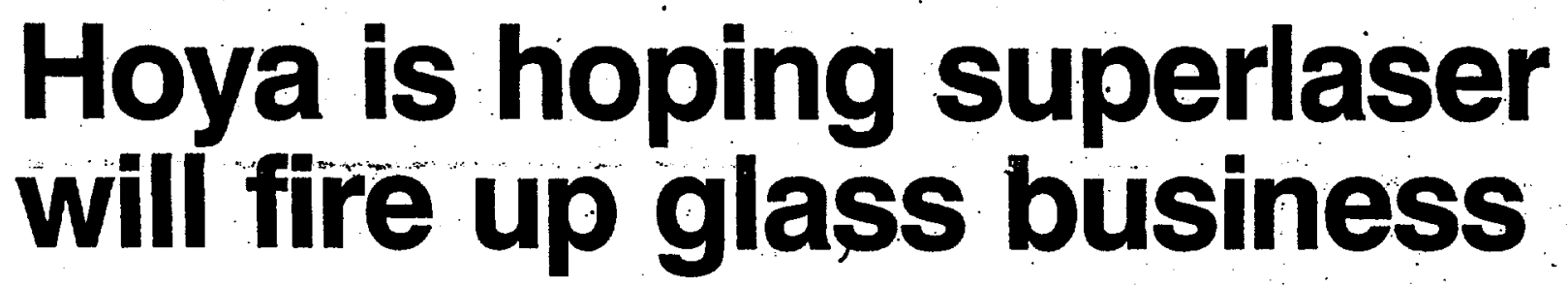

By David R. Berkowitz

STAF WRITER

FREMONT

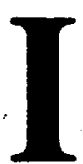

$\mathrm{N}$ a remote section of Hoya Optics Inc.'s cavernous glass factory lies a row of furnaces, cold and ignored for nearly seven years.

The last time they were stoked up for melting glass was when Lawrence Itvermore National Laboratory had hired Hoya to make filters for the world's largest laser, the Nova.

Fremont-based Hoya officials now hope the lab's latest proposal, a $\$ 1.1$ billion superlaser for conducting indoor thermonuclear tests, will give them a reason to reignite those furnaces.

U.S. Industry - California and Washingtón firms in particular - stands to gain about $\$ 770$ million dollars in contracts for building and equipping the federal National Ientition Facillty.

Department of Energy Secretary Hazel O'Leary is expected to decide by late August or early September whether to fund the NIF, which would create indoor radioactive blasts equal to about 10 pounds of dynamite.

With underground nuclear testing on its way to becoming a practice of the past in the United States, supporters argue the super-laser will be needed to keep nuclear scientists' skills sharp.

To trigger the blasts, scientists from Lawrence Ltvermore would target intense beams of heat energy at tiny pel. lets composed of hydrogen isotopes,

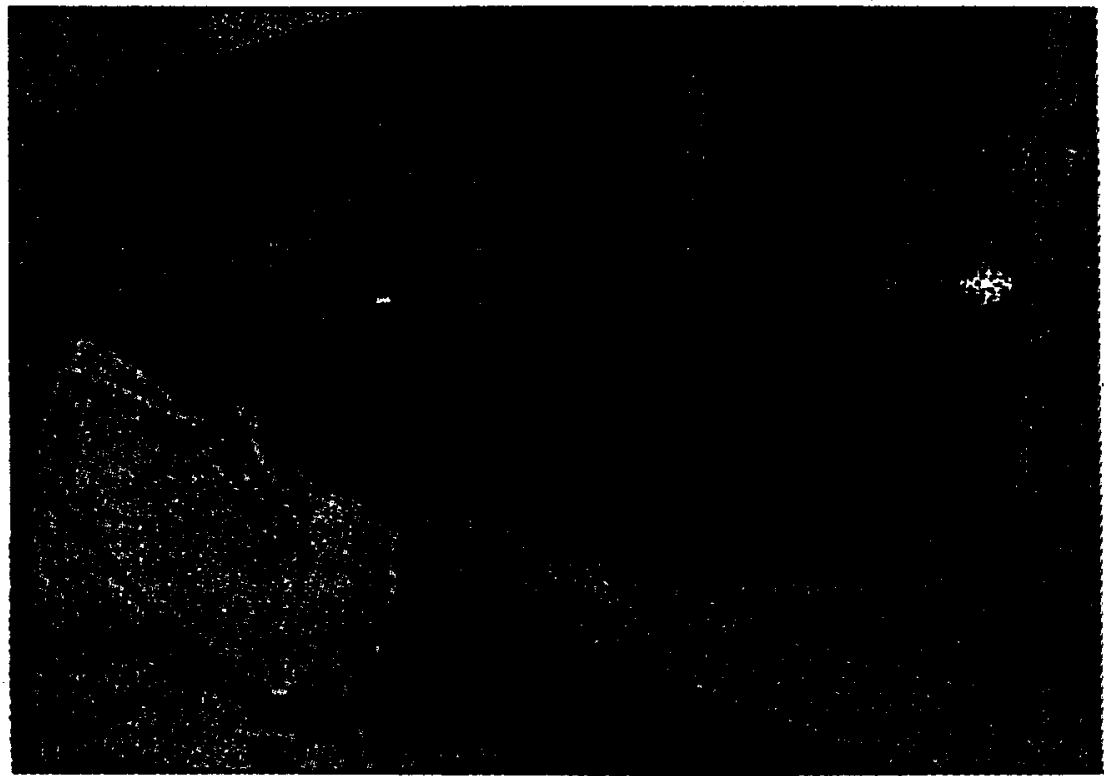

Hoya worker Vondo Alvarez checks optical glass for quality.

deuterium and tritium.

When hit, isotopes in the pellets would fuse, creating blasts of energy similar to the type given off by the sun or atom bombs.

Lab officials consider the project crucial to their survival in the post-Cold War era, and they have mounted an aggresstve public relations effort on its behalf.

A focal point of that effort is the lab's estimate that fallure to approve the super-laser will result in about 1,000 lost jobs over the next eight years.

On the other hand, approval would protect those jobs while creating another 800 private-sector manufacturing jobs 400 construction industry jobs, 230 jobs at the Ltvermore lab plu's 90 at other national laboratorles, said William Hogan, 


\section{Hoya: Company is counting on laser}

\section{Continued from C-1}

a key lab scientist involved with the project.

Hogan and other lab officials also have been working hard to pacify anti-nuclear activists who fear approval of the laser will continue the lab's involvement in weapons research. Lab officials continually stress that the laser cannot be used to design or build bombs.

But with construction of another $\$ 3$ billion to $\$ 5$ billion facility, the superlaser could be used to generate nuclear fusion energy for civilian use, Hogan added.

Nearly the size of a football arena, the NIF would be built at either Lawrence Livermore laboratory or the Nevada Test Site near Las Vegas between 1997 and 2002 . The final decision on the site isn't expected before 1996.

Regardless of its location, lab scientists would oversee the project, and they would turn to several Bay Area companies to help build it, including Hoya and Tinsley Laboratories of Richmond.

Tinsley, best known for providing lenses for the Keck Observatory in Hawaii and the Hubble Space Telescope, stands to gain about $\$ 3$ million to $\$ 5$ million in contracts, said Robert Aronno, president and chief executive officer.

"It is an important program for us because, again, this is the kind of program that contributes not only in the way of immediate business but also in improved technology on which to base futiure business opportunities," he said.
Hoya, the U.S. glass filters arm of Hoya Corp., a $\$ 1.2$ billion Japanese firm, could snare about $\$ 25$ million in contracts from the project, said Gerald Bottero, a senior vice president at the firm.

That's about half of the estimated $\$ 50$ million that would be budgeted for the type of optical glass the company makes, which would be used to carry and intensify the laser's energy.

While the impact on Tinsley's work force would be negligible, Hoya's Fremont staff could more than double from 30 to 70 people.

Initially, Hoya would recetve about $\$ 3$ million to $\$ 5$ million from the ignition facility project to develop a technique for continuously melting glass.

By continuously melting glass, the company would greatly increase output and trim the cost of manufacturing about 3,200 glass panels for the project half would be made by Hoya and half by one other firm.

If Hoya or other firms researching continuous melting can perfect the process, they would begin actual production in about two years.

If not, the project would go forward using techniques for melting glass that have been around since the late 1950s. The higher production costs would be covered from a $\$ 120$ million project contingency fund, said Hogan.

To handle the job, Bottero said Hoya would have to ship a furnace to Fremont from Japan and might also fire up the plant's long-dormant furnaces - provided enivironmental restrictions don't prohibit it.

\section{State: Troubles create investing opportunities}

\section{Continued from C-1}

Zane Mann, publisher of the California Municipal Bond Advisor, a newaletter in Palm Springs devoted to individual investors, said people will be hard-pressed to find a better deal for short-term securitles. "If you shopped around the junk
Earnings: $\mathrm{TI}$

Continued from $\mathrm{C}-1$

but APC lost money replacing the ship during routes.

"For the remainder of 1994, we exf modest seasonal improvements in cargo mis each of our international markets, but pressur continuing on international rates," Lillie said.

However, Lillie said export cargo volumes expected to be lower as APC earlier this year : replaced by Sea-Land Service Inc. in yearly 1 ding to become the preferred carrier for U.S. 1 itary cargo.

Still, the "basic company fundamentals sound," said Bob Schulz, associate director the Standard \& Poor's Ratings Group. "We st stable outlook."

\section{In other earnings reports:}

$>$ Triad Systems Corp. of Livermore repor record third-quarter revenues of $\$ 41.4$ millior 10 percent increase over the same period 1 year and the fourth consecutive quarter of rec. sales for the company.

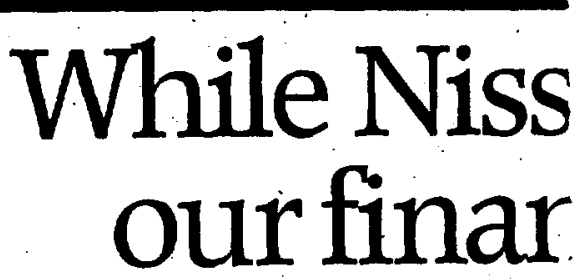

terest among investors who are skittish about the stock and bond markets and are looking for a shortterm hideout.

They say investors have been turned off by the unstable performance of the stock market in the last year and many are waiting to see what the federal onvernment 

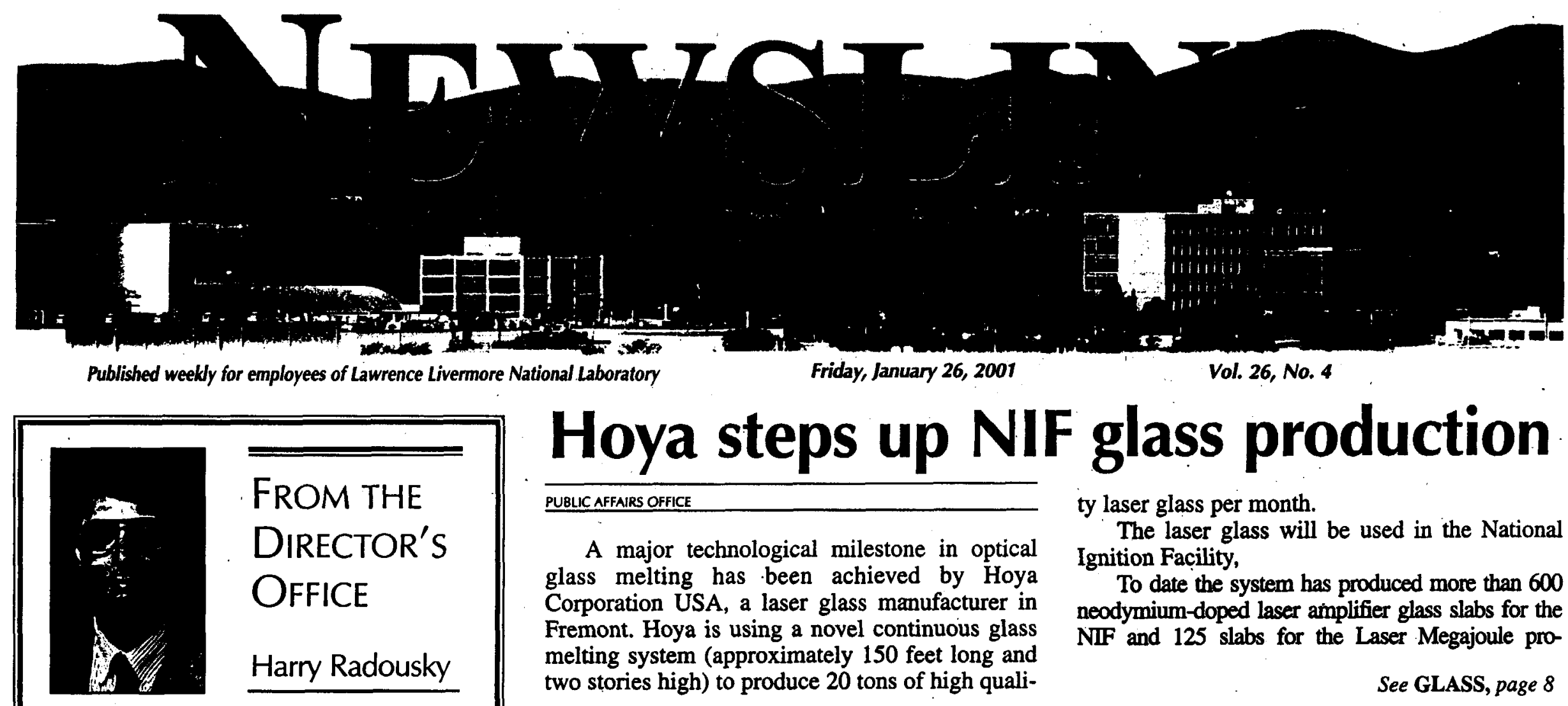

\section{Hoya steps up NIF}

PUBLIC AFFAIRS OFFICE

A major technological milestone in optical glass melting has been achieved by Hoya Corporation USA, a laser glass manufacturer in Fremont. Hoya is using a novel continuous glass melting system (approximately 150 feet long and two stories high) to produce 20 tons of high quali- ty laser glass per month.

The laser glass will be used in the National Ignition Facility,

To date the system has produced more than 600 neodymium-doped laser amplifier glass slabs for the NIF and 125 slabs for the Laser Megajoule pro- 


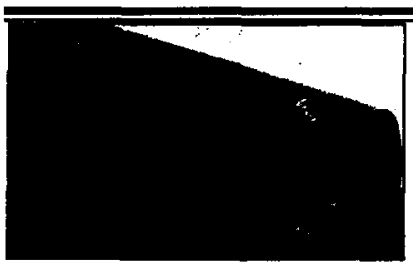

\section{THE BACK PAGE}

\section{GLASS}

Continued from page 1

ject (LMJ), a French government facility currently under construction near Bordeaux, France.

Each laser glass slab, which measures $790 \mathrm{~mm}$ by $440 \mathrm{~mm}$ and is $45 \mathrm{~mm}$ thick, is carefully fine annealed and extensively tested and inspected in Hoya Corporation's new 32,000 square-foot laser glass manufacturing facility in Fremont. The glass produced by Hoya's continuous melting system has successfully achieved all of the stringent glass specifications required for NIF and LMI. In particular, the glass contains essentially no microscopic platinum particles that could cause laserinduced damage within the glass at NIF and LMJ's high operating fluence. In addition, the "water" $(\mathrm{OH})$ content in the glass is less than $200 \mathrm{ppm}$ thus minimizing Nd fluorescence quenching. Finally, the optical homogeneity surpasses the transmitted wavefront specification by about a factor of two.

"Hoya's work in this area is outstanding," said Ed Moses, NIF project manager. "Along with the glass slabs produced by Schott Glass Technologies, roughly half of the total glass slabs needed for NIF have been nroduced. This fechnological achievement is sionifi- cant. Our goal was for Hoya to produce 500 glass slabs during their current melting campaign - they've exceeded that by 50 percent."

Hoya's current continuous glass melting campaign, which began in June, will end as planned in February. Beginning this summer, Hoya will begin to produce the remaining laser glass needed to supply their 50 percent share of the amplifier slabs required for NIF and LMI. Schott is to provide the other $\mathbf{5 0}$ percent. It is anticipated that between Hoya and Schott, approximately 1,500 slabs will be produced annually. The combined amount needed for NIF and LMJ is about 8,000 laser slabs.

"We appreciate the opportunity to work with LLNL and the French Government on these very important projects," said Gerald Bottero, president and chief executive officer of Hoya Corporation USA. "We've worked with this special glass since 1973 and we commend our employees for their dedication and commitment to perfecting this technology."

Hoya was founded.in 1941 as Japan's first specialty manufacturer of optical glass. The company is the world's leading supplier of molded aspheric lenses for cameras, VCRs and DVD players, and operates a state-ofthe-art melting facility in Akishima, Japan. In addition, Hoya offers glass magnetic disks, semiconductor photomask blanks, eyeglasses, contact lenses and a variety of other products through 46 subsidiaries in 22 countries.

Hoya is headquartered in Tokyo, Japan.

The National Ignition Facility, currently under construction, is one of the cornerstones of the DOE's Stockpile Stewardship Program. NIF will use the world's largest laser to heat fusion fuel to thermonuclear ignition.

The experiments will help scientists sustain confidence in the nuclear weapons stockpile without actual testing. NIF will also produce additional benefits in basic science and fusion energy. Further information can be found at http://www.llnl.gov/nif 


\section{DEDICATION CEREMONY}

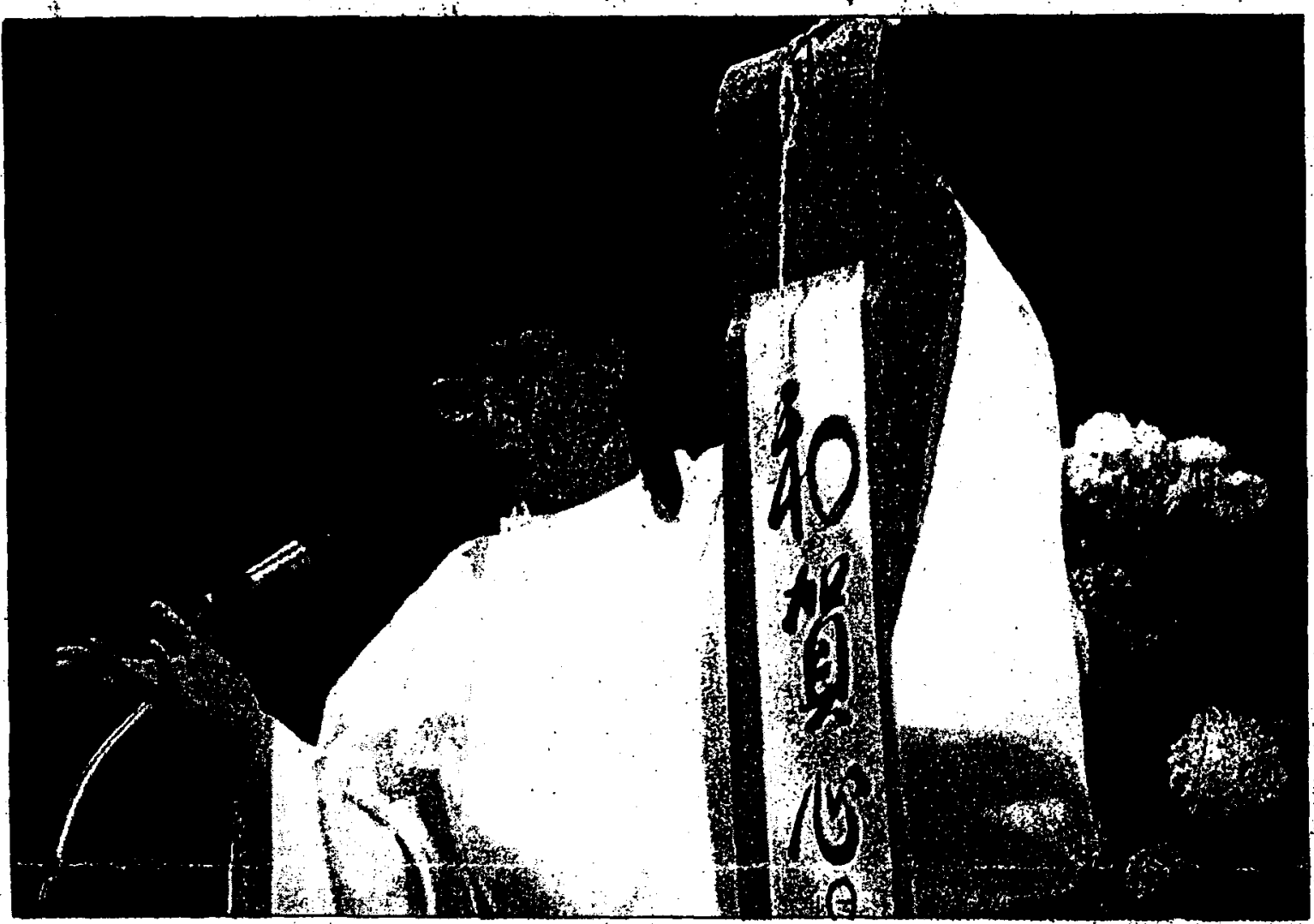

The Rev. Masato Kawahatsu, a Shinto priest, presents a scroll to the directors of the new. Hoya laser glass tacllity In Fremont on Friday.

\section{Firm open} laser glass facllity Frlday - a move nuclear scientusts hope will bring them a step closer to igniting thelr own solar furnace in the East Bay.

"What the National Ignition Facillty will do - and I am convinced of this - is make a small star here on Earth," declared: Mike Campbell, associate director of laser programs at Lawrence Livermore Laboratory. "Hoya will be a major part of making that happen."

The NIF will be the world's largest optical instrument. It is designed to focuis 192 separate lasers on a thy target area the size of a BB. By doing so, scientists hope to create the first controlled fusion reaction - just like those that occur. in the sun and in thermonuclear weapons.

At the heart of the new laser system will be about 3,000 panes of violet-hued laser glass that will be produced by the Japanese optics company at its new Fremont factory.

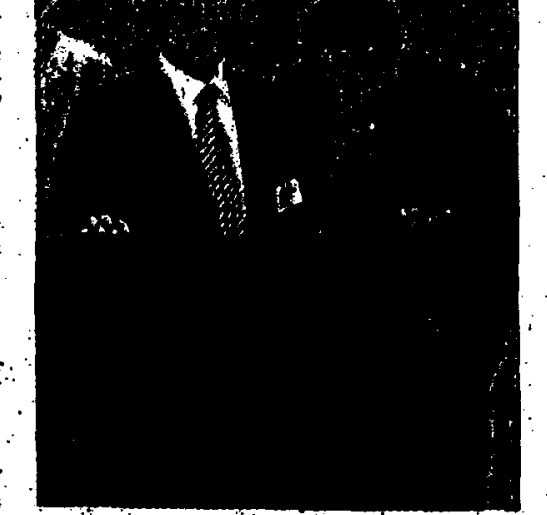

Sholchil Harad (lofit) and Gerry Bottero of Hoya examine a plece of laser glass Friday evenlng during the dedication.

Hoya opened the plant with a traditional Japanese ceremony that featured a blessing by a Shinto priest - and a prayer for peace between all natioñs.

Bullt at a cost of $\$ 12$ million, it

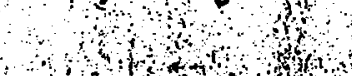

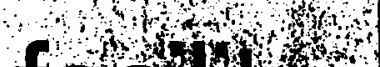

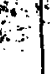
ss facinty

wall supply ultra-high-quality laser anplification glass - for the NIF project and for an even large laser project in France.

"It is the heart of the laser." sald Campbell, who is in charge of the NIF project. "It is the single most essential component."

The new laser glass faclity reptesents an expansion of an exdsting factory operated here by Hoya's opfics division. Construction started in 1997. Workers at the facllity are alteady experimenting . with - prototypes and actial work on the NIF project will - begin . next - week, pocording to Hoya spokeswoman Julie Storms. Production Manager Mark Smolley hopes to turn out as many as 10 panes a day once the plant.reaches peak capacity.

Campbell called the glasss-making process "radically different." It was developed only through close collab: oration among Hoya, Livermore Lab and the French "Commissarlat a l'Energie Atomlque:"

In addition to providing technical 
Laser: Factory to bring in 45 jobs, most for area residents

Continued from NEWS-1

collaboration, both the French and American governments are paying for the new glass factory. Under the terms of Hoya's agreement with the two governments, the plant must be dismantled when work on the laser systems is completed.

That, sald Smolley, will take 10 years. He said the deal is worth more than $\$ 50$ million to Hoya.
The plant is already paying off for Fremont: however. The factory will provide 45 jobs, largely to area residents.

While igniting the world's first controlled fusion reaction may be the Holy Grail Campbell and the other scientists at Ltvermore Lab are seeking, the NIF laser system will be used primarly to maintain the nation's nuclear weapons stockpile. It is a fact Campbell readily acknowiedges.

"Fusion is part of stewardship," he sald, referring to the "Stockplle Stewardship and Management Program" which is designed to make sure Arnerica's aging arsenal of nuclear warheads can stll explode on command: The Energy Department says NIF will play a central in that effort.

Nuclear weapons also account for the French government's interest in fusion, according to Michel Andre. Andre heads the Laser Megajoule Project, the French version of the NIF, which is being built in
Bordeaux,

The American project will be com pleted well before the French one, ani Campbell said there is little doubt h team will have the first crack achieving fusion. Andre acknowledge this, but sald he will be content to plad second in this race against America.

We will learn from them," he' said "Of course. we would have liked to hav Ignited at the same time." 


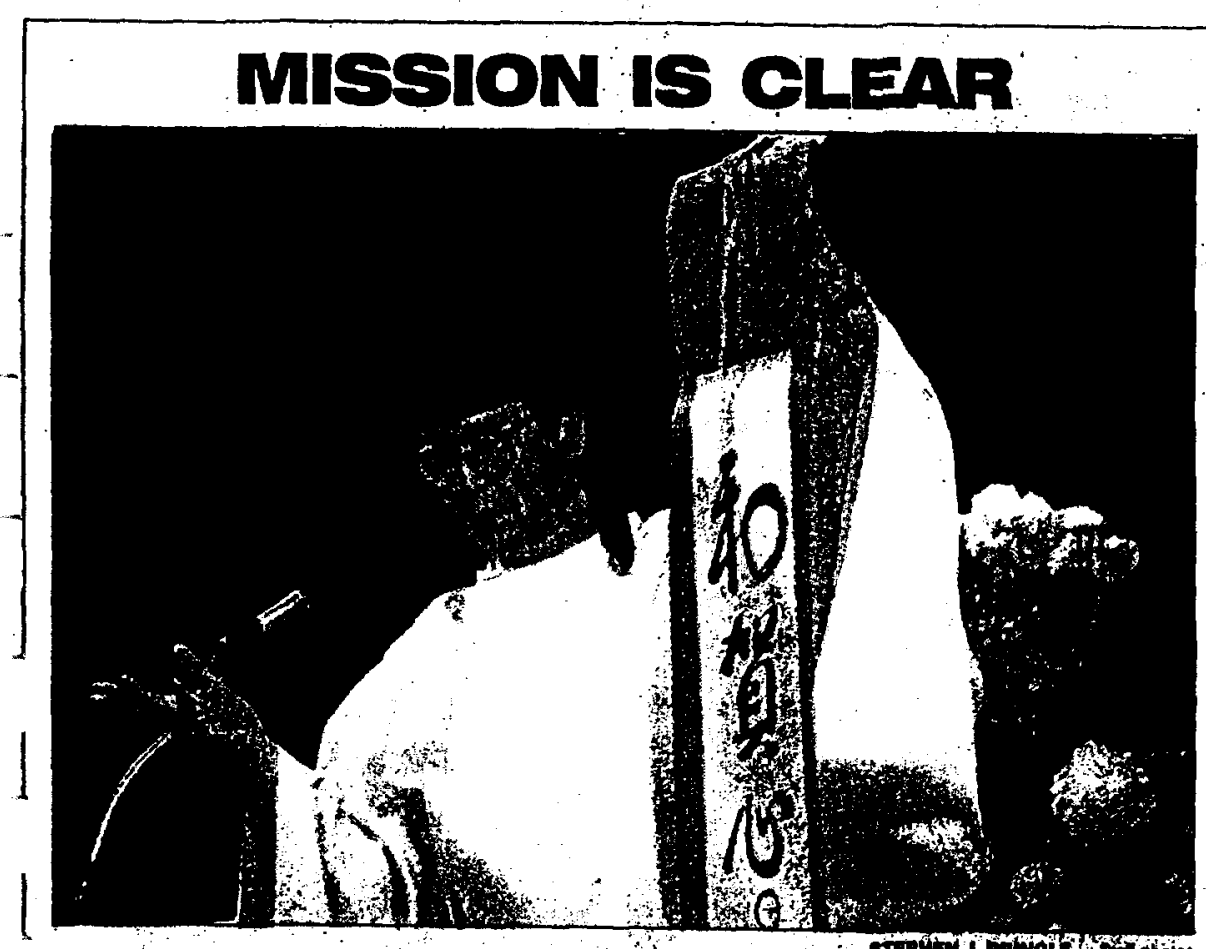

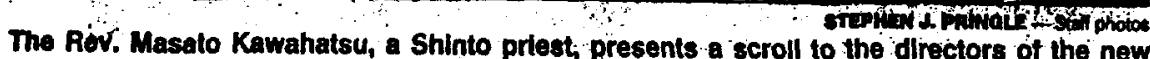
Hoya laser glass facillty in Fremont on Friday.

'Heart of lab's laser project
to take shape at Hoya site

\section{By Bryce G. Hoffman}

MSNESS WFTER

FREMONT - With a prayer to the sun. Hoya Corp. opened its new laser glass facllity Frtday - a move nuclear scientists hope will bring them a step closer to foniting their own solar furnace in the East Bay.

What the National Imition Facllity will do - and I am convinced of this - is make a small star here on Earth," declared Mike Campbell, assoclate dlrector of laser programs at.Lawrence Livermore Laboratory. - Hoja will be a major part of maktng that bappen."

Bulit at a cost of 812 million the 32,000-8quare-foot plant will supply ultra-high-quality Inser amplincation glass for the new high-powered laser system being constructed by the U.S. Department of Eneroy in Ltver. more. The factory also will provide glass for an even larger aser project in France.

"It is the heart of the laser." eald Campbell, who is in charge of the NIF project. "It is the angle most essential compovent."

Please soe Lasor, NEWS-12

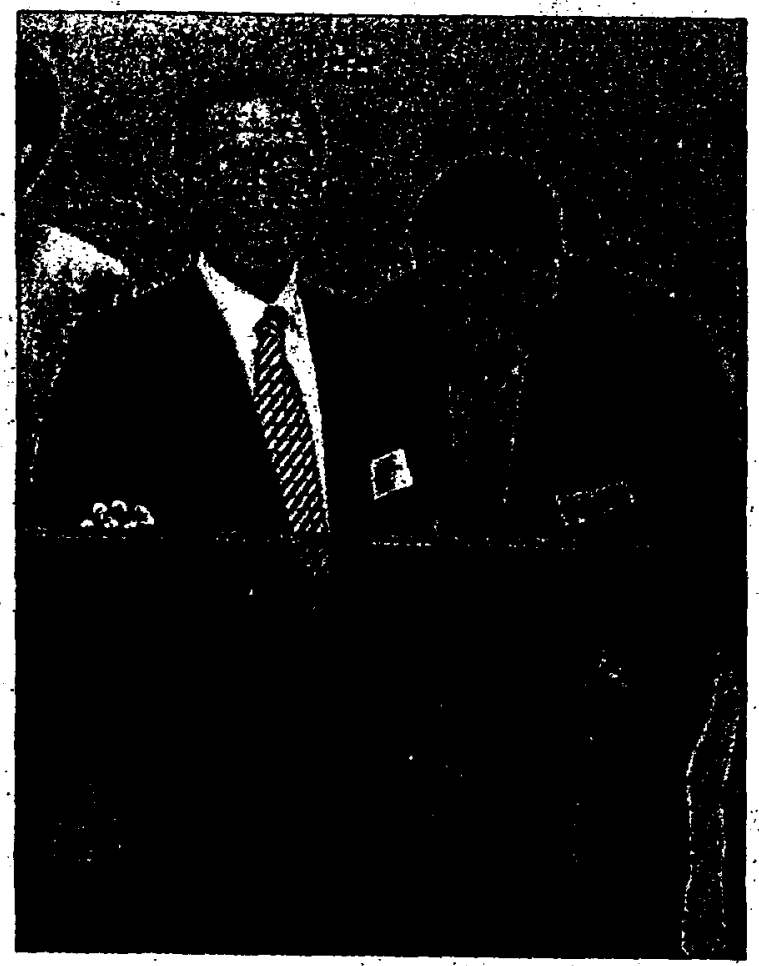

Sholchl Harad (foft) of Hoya Japan and Gerry Bottero of Hoya Corp. USA Inspect a pane of laser olase Frintav 


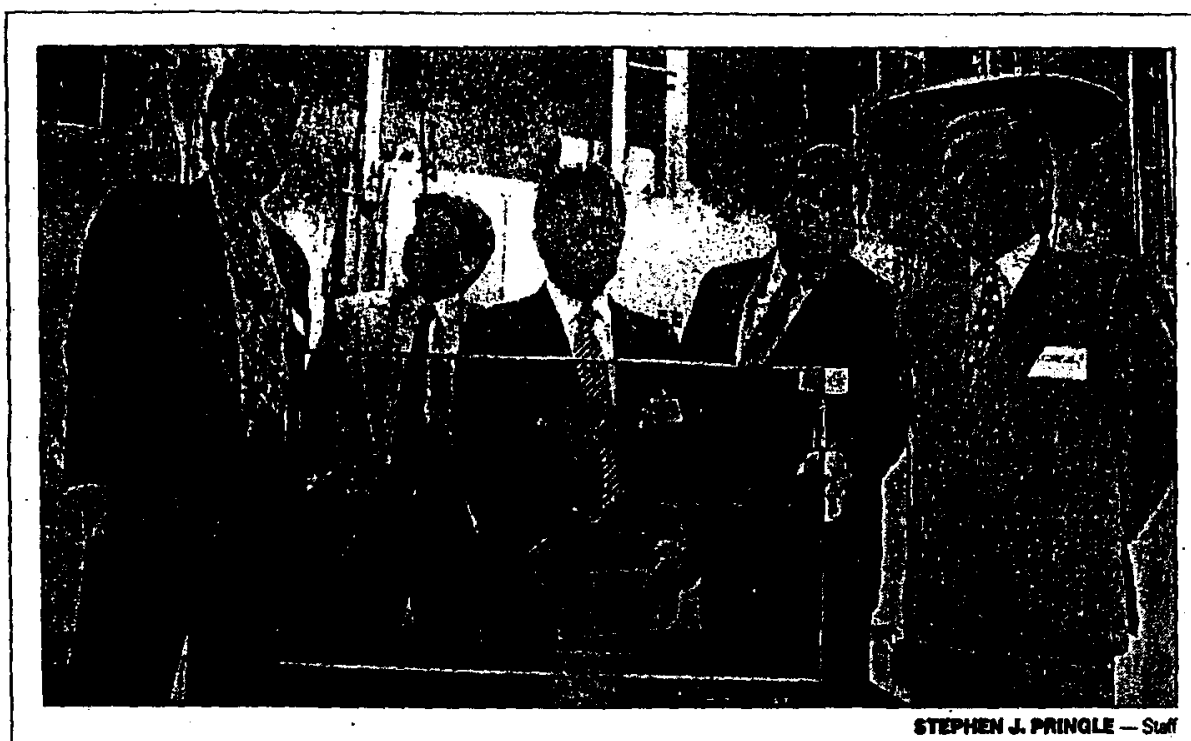

Executives examine a plece of neodymlum-doped laser ampilfication glass Friday at Hoya Laser Glass Facllity In Fremont. From left are Mike Campbell of Lawrence Livermore Lab, and Hiroshi Suzukl, Sholchl Harada, Gerry Bottero and Kunlo Takeuchl, all of Hoya.

\section{Laser: Work on NIF pieces expected to start next week}

Continued from NEWS- 1

The NIF will be the world's largest optical instrument. It is designed to focus 192 separate lasers on a tiny target area the size of a BB. By doing so, scientists hope to create the first controlled fusion reaction - just like those that occur in the sun and in thermonuclear weapons.

The new laser glass facllity represents an expansion of an existing factory operated here by Hoya's optics division. Construction started in 1997 and process testing began earller this month. Workers at the facllity are already experimenting with prototypes and actual work on the NIF project will begin hext week. according to Hoya spokeswoman Julle Storms.

The laser system will require about 3,000 glass panes. Each one welghs more than 100 pounds and is capable of amplifying laser energy by 14 percent. Production Manager Mark Smolley bopes to turn out as many as 10 panes per day once the plant reaches peak capacity.

The process - beginning with powdered chemicals and ending with finely polished panes of violet-hued laser glass - will be carried out at the Fremont faclity.

It is a process that Camp. bell called "radically different" and one that was developed only through close collabora. tion among Hoya, Livermore Lab and the French Commissarlat a I'Energe Atomique.

"Laser glass is very specialtzed. Hoya is one of the few companies in the world that can make this type of technology." Campbell explained. They have risen to the challenge:"

In addition to providing technical collaboration, the French and American governments are paying for the new glass factory. Under the terms of Hoya's agreement with the two governments, the plant must be dismantled when work on the laser systems is completed.

That, said Smolley, will take 10 years. He said the deal is worth more than $\$ 50 \mathrm{mil}$ lion to Hoya.

But, even with the gift of the bullding, Campbell satd the project carries a certain amount of Anariclal risk for the Japanese opttics' company. It must be able to meet the production demands established by Livermore Lab.

The plant is already paying off for fremont. however. The factory will provide 45 jobs. largely to area residents.

While toniting the world's irst controlled fusion reaction may be the Holy Grall that Campbell and the other scien tists at Livermore. Lab are seeklng, the NIF laser system will be used primarliy to maintain the nation's nuclear weapons stockpile. It is a fact that Campbell readily acknowledges.

"Fusion is part of stewardship," he said, referring to the "Stockplle Stewardship and Management Program," which is designed to make sure America's aping arsental of nuclear warheads can sull explode on command. The
Energy Department says NIF will play a central role in that effort.

Nuclear weapons also account for the French government's interest in fusion. according to Michel Andre. Andre heads the Laser MegaJoule Project, the French version of the NIF, which is being bullt in Bordeaux.

The French laser system is slightly larger than the NIF.

"We are a little more careful," Andre sald. "(But) the goal is the same."

The American project will be completed well before the French faclity, and Campbell sald there is little doubt his team will have the first crack at achieving fuston.

Andre acknowledged this, but sald he will be content to place second in this race agatnst America.

"We will learn from them." he sald. "Or course, we would have liked to have ignited at the same time."

Although the NIF laser system will not be completed unt1 2003, the lab would like to begin test-firing the lasers in October 2001.

Campbell hopes to conduct the first full-scale attempts at gniting a fuston reaction in 2005 or 2006

While earlier attempts to start a controlled fusion re action using smaller laser systems have falled, Andre and Campbell sald this time will be different.

Hoya opened the plant with a traditional Japanese ceremony that featured a blessing by a Shinto priest - and a prayer for peace between all nations. 


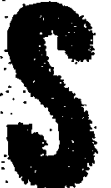

The American company, Schott

s

chott Glass Technologies is one of only two suppliers of laser glass to NIF!? and $(M)^{2}$, the world's most powerful laser systems. The size and rapid pace of construction of these projects are responsible for the development of advanced laser glass manufacturing at' SGT. This laser glass specialist has been dedicated for the past several years to developing, the facilities and the melting, forming, annealing, finishing and QAQC processes for NIF and LM] laser glass projects.

In order to produce the roughly 8,000 meter long plates of laser glass in accordance with the very tight deadlines set by NIF and LMJ, coniteessary. Each laser glass plate contains more than 15 liters of glass having an optical homogeneity of $+/-1 \times 10^{-4}$. The SCT laser glass hanufacturing facility has the capacity tö produce an estimated 1,700 plates for NIF by about 2003. and 2,300 plates for $[M \mathrm{MJ}$ by 2007 .

Production has already: begun, and some of thie glass plates needed for: the two projects : are already in the post processing stage after complettion of melting and casting. SGT is also: processing an absorberit: glass needed for edge cladding, which prevents the glass plate from selflasing and depleting the optical energy stored in thie glass.

After final inspection and packing, the plates are then shipped to ZYGO Corporation (NIF plates); Middlefield, Connecticut USA and to REOSC (LM)
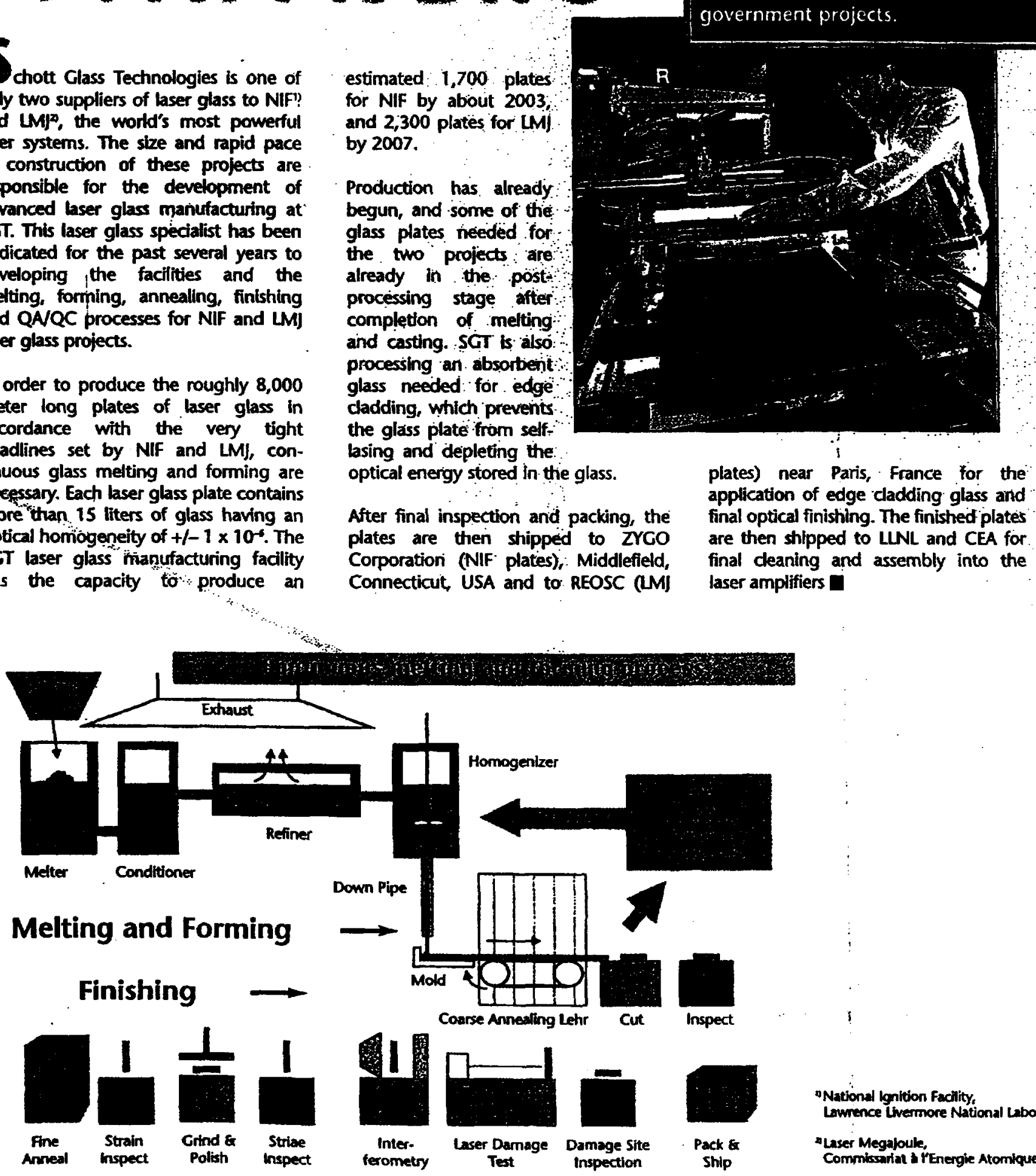

"National Ignition facility, Lawrence Livermore National Laboratory -Laser Megajoule Commissariat i PEnergie Atomique application of edge cladding glass and final optical finishing. The finished plates are then shipped to LUNL and CEA for final cleaning and assembly into the laser amplifiers 


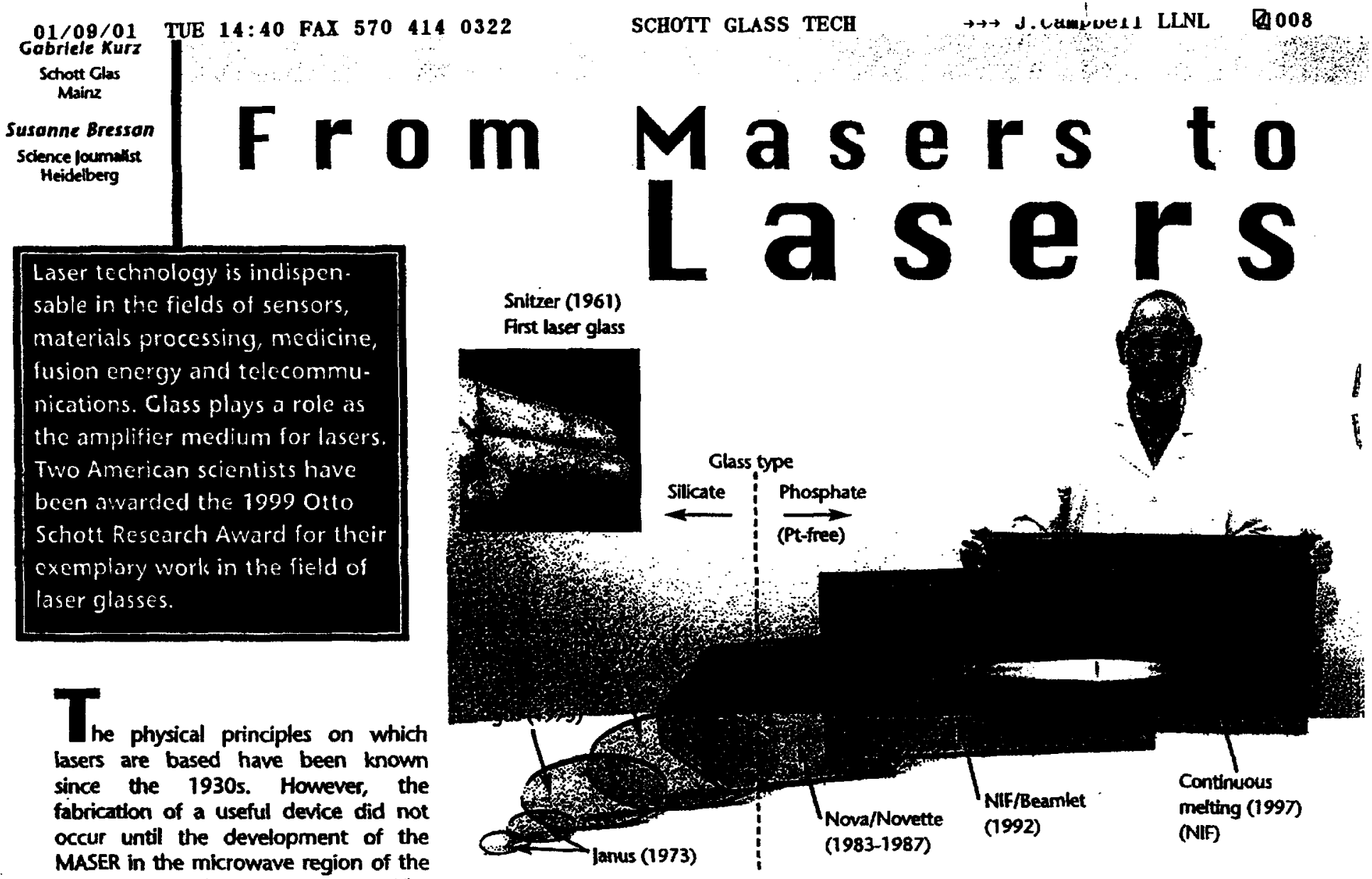
spectrum in the earty 1950s. The acronym stands for Microwave Amplification by Stimulated Emission of Radiation.

In 1958, Schawlow and Townes suggested that stimulated emission devices would be extended into the infrared and visible spectra. Maiman was the first to operate at these shorter wavelengths with the ruby laser at $0.69 \mathrm{um}$ (1960). One year later, in 1961, Javan, Bennett and Herriott built the first operational gas laser.

The same year, Elias Snitzer became the first to generate laser action in glass. He buitt the first glass laser which operated at $1.06 \mathrm{\mu m}$ and used neodymium as the lasant-ion. He literally had to do everything himself; from constructing the laser hardware, making the flashlamp source, making the laser glass, and then getting the whole system to work - an amazing feat! His first laser used a very small piece of laser glass; in fact it was just a fiber. Maybe this was the first indication of just how difficult laser glass is to manufacture.

In the "early" days of glass lasers, virtually every major optical glass manufacturer was involved in making laser glass. Most of them supplied glass just for scientists, because lasers were still mainly a curiosity rather than a commercial product. Evaluating a particular laser glass was quite difficult in those days. A researcher had to order a glass, have it manufactured to a given size and specification (or even make it himself), then install it in a laser to determine its performance. This was a laborious, time-consuming process.

In the first ter: $\cdots, \quad i^{\prime \prime}={ }^{\prime \prime}$ technology, R \& D expenditure greatly exceeded the commercial retums. A common

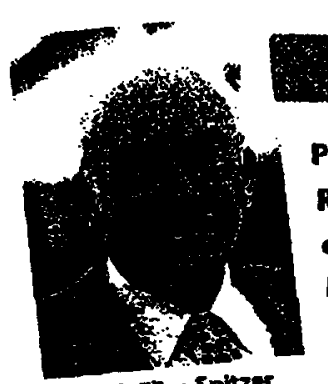

Prof. Elas Snitzer
Prof. Elias Snitzer, a scientlst at Rutgers Untversity, Piscataway, N], is one of the ploneers in the fleld of laser glass research. It was he who established the basis on which other scientists, such as Dr. John $H$. Campbell, University of Callfornia, Lawrence Utvermore Mational Laboratory,
Livermore, CA, succeeded in making major advances in the development of laser glasses for nuciear fusion research. The two scientists were awarded the 1999 Otto Schott Research Award for their exemplary work $\mathrm{a}$

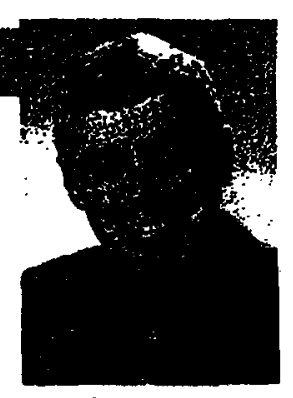

Dr. John H. Campbell 


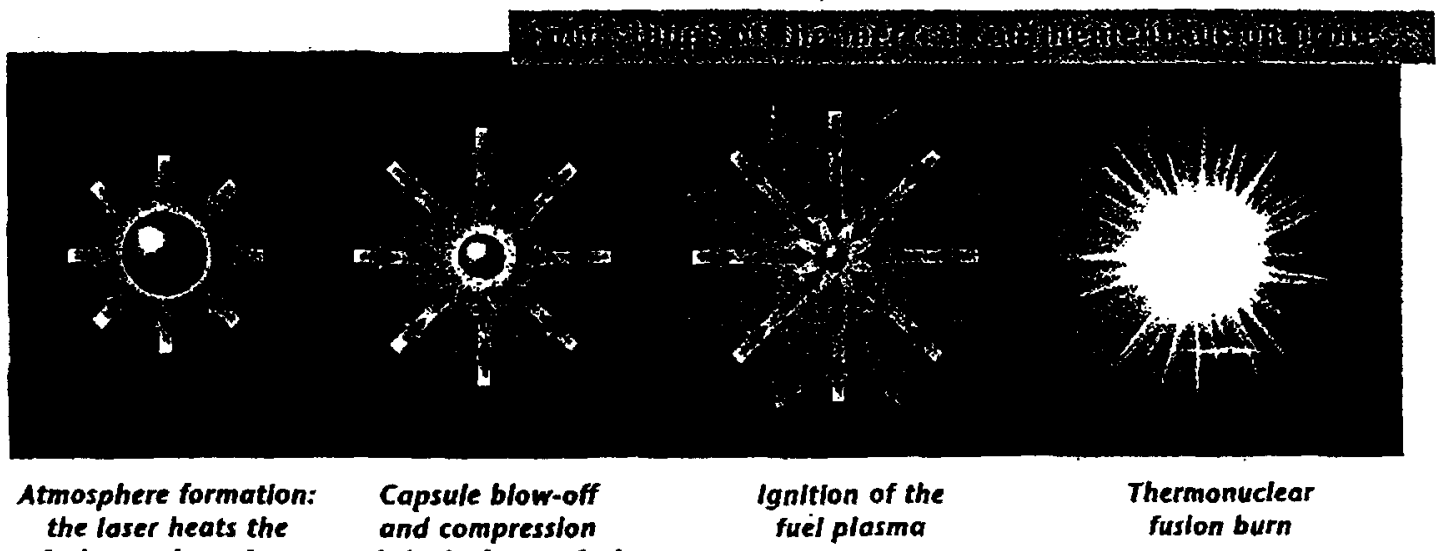

fuel-capsule surface

of the hydrogen fuel

humorous designation for MASER was Money Acquisition Scheme for Expensive Research. But there was no stopping the onward march of laser technology. There was a world-wide rush to explore the materials, power levels and configurations possible.

\section{Telecommunications by Laser Beams}

As time progressed, lasers became increasingly important as signal carriers for telecommunication, since they could transport much more information than Hert' electromagnetic waves. Elias Snitzer led ploneering research in this particular field. He conducted earty work on waveguide mode propagation in glass fibers. In another far-reaching discovery that preceded today's communication devices by 30 years, he co-developed the first fiber optic laser amplifier using neodymium glass. He was co-inventor of the erbium glass laser operating in the infrared at 1.5 microns, which has become as important for fiber optic telecommunications as the erblum-doped fiber amplifier (EDFA).

By selective use of wavelengths between the source and receiver in fiber transmission, a large number of independent communication channels can be amplified. Over 100 separate channels each with a bandwidth greater than 10 Gigahertz have been demonstrated for a communications system. In dense wavelength division multiplexing, EDFAs are projected to exceed USS 1 billion world-wide in just five years for one laser application.
In 1997 Snitzer was appointed Professor Emeritus at Rutgers and is active to this day, particularty in research areas relating to rare earth doped glasses and glass fibers.

\section{Search for Fusion Energy}

The second major application of laser glass is the search for fusion energy as a power source for future generations. Unfortunately, the conditions needed to Initiate fusion are daunting: the nudear fuel, consisting of isotopes of hydrogen, must be heated to temperatures in excess of $100,000,000^{\circ} \mathrm{C}$ and maintained at that temperature long enough for the nuclear fuel to ignite and bum. The problem of achieving fusion energy then boils down to developing a method to simultaneously heat the fuel and confine it long enough for it to react.

One of the ways this can be done is Inertial Confinement Fusion (ICF), in which the fuel is compressed using high-initensity laser beams that simultaneouisly heat as well as confine the nuclear fuel. John Nuckolls (Lawrence Livermore National Laboratory, Livermore, CA (UNL) was the first to propose the ICF concept of using lasers to drive fusion reactions. This was in 1961, the same year that Professor Snitzer demonstrated the

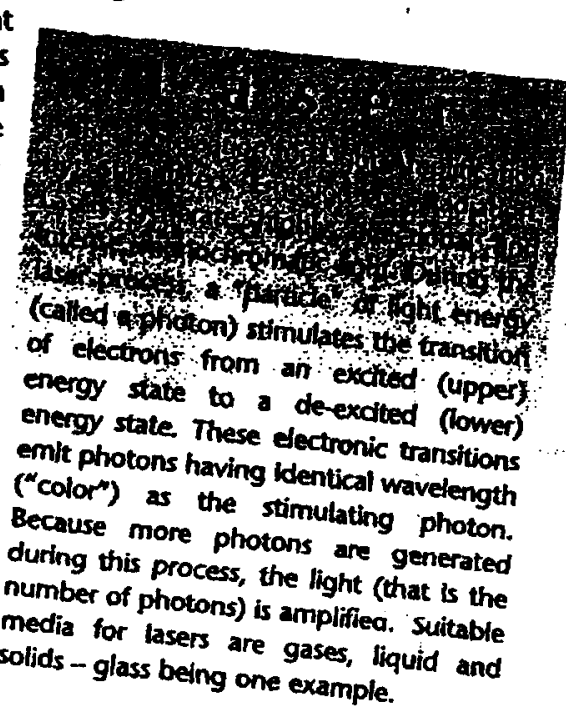

first glass laser. Early researchers at UNL used lasers powered by synthetic rubies. However, as the systems grew larger and more powerful, ruby lasers became impractical.

The use of glass lasers for ICF research became popular in the early 1970s. The researchers at LNL soon realized that if there were to be a successful fusion program it would require the partnership of laser physicists, optical glass manufacturers, and laser hardware builders. Two well-known optical glass companies became the key players in the development of laser glass for fusion energy: Schott Glass Technologies (Duryea, Pennsylvania) and Hoya Corporation (Tokyo, Japan). This partnership with the optical glass industry, that ; LUNL started nearly 25 years ago, is still intact today. 


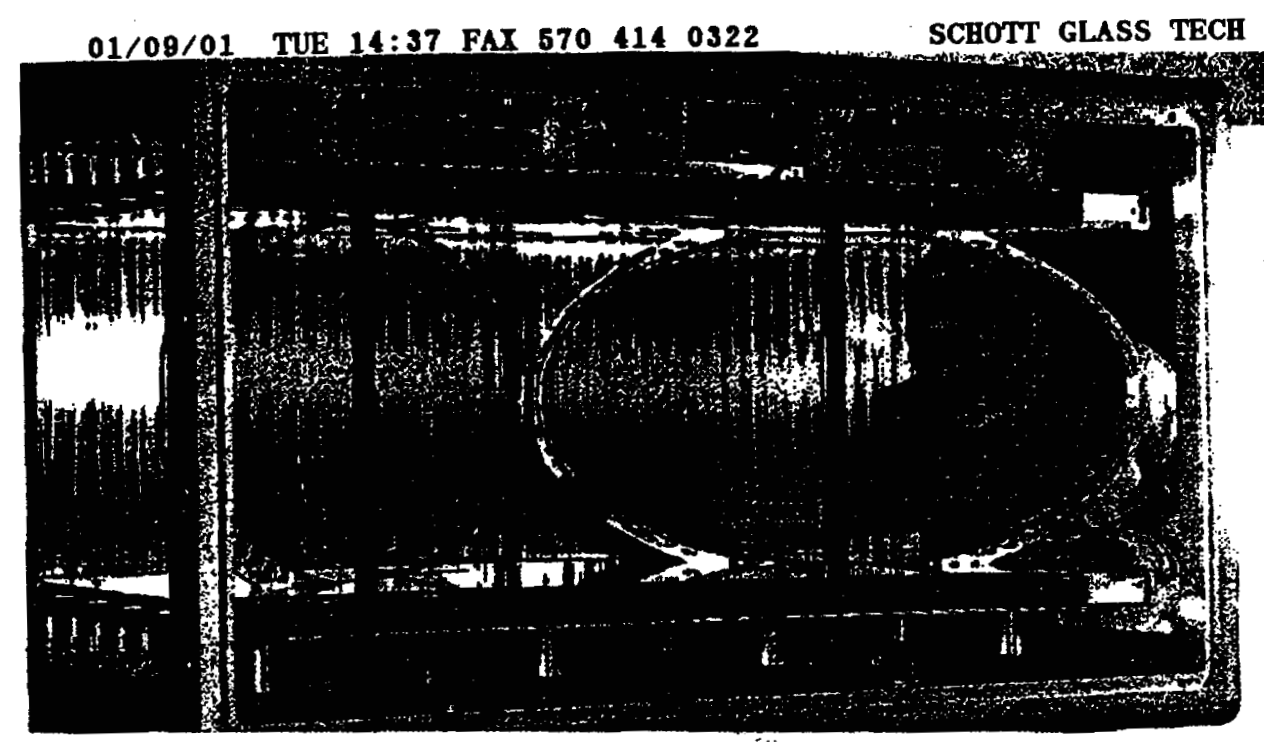

Photograph of a Nova ampllfier showing the wall of flashlamps ond stiver reflectors that surround the two laser glass disks.

The first question facing glass chemists and laser physicists relates to the type of glass best suited for laser fusion applications. Laser glass $R$ \& $D$ began to shift away from the search for a broad range of glasses and focused instead on specific glass types. By the mid-80s it was realized that phosphate glasses (as opposed to the more common silicate glasses) were the best overall glass type for use in laser fusion applications.

During that period, John Campbell joined the laser glass group at UNL His research has resulted in major improvements in the laser damage resistance of optical glasses and coatings to intense laser light in the near-UV, visible, and near- $\mathbb{R}$ spectra.

The year 1985 marked a low point in the development and production of laser glass. Platinum indusions were found in the laser glass manufactured for the Nova Laser. These inclusions, only a few microns in size (about the size of a human blood cell), exploded when Hluminated at high intensity and soon made the laser glass unusable. There were substantial fears that this problem, which at that point had been unsolved for more than 20 years, would spell the end to the laser fusion program.

Thanks to remarkable collaboration between Campbell's research team at UNL, Schott and Hoya, a process was developed that enabled platinum inclusions to be dissolved in the glass during its manufacture. They also devised an inspection technique that used a laser to scan each glass piece to verify that it did not contain platinum inclusions. Thus for the first time in the history of laser glasses, a manufacturing process was available that gave indusion-free glass.

\section{Laser glass}

The laser glass used nowadays for amplifying laser energy at a wavelength of $1.05 \mu \mathrm{m}$ is of very high optical quality, phosphate based and doped with neodymium. The glass is highty homogeneous and very high internal defects. At the very hiser, any energies generated by the laser, anys defects, such as solid inclusions would explode and fracture the glass. in such applications, electrons in the neodymium atoms are using Xenon higher energy levels using $X$ glass. flash lamps focused on the laser glass. A baser is then fired through the glass The incident photons sumulate the excited neodymium electrons to process, to lower energy states. In the process, they emit photons equal in wave length and phase to the stimulating photoin. The result is an increase input eriengy.

Requirements for laser glass:

-mist efficiently capture and store the entergy emitied by the pump sounce (e.g. flash lamps)

imust lase efficiently

- must resist being damaged by the

- must resuse beam

intense fliow "scaling-up" to very

mint powived lasers

pol an factured
This process is uead avtancinely today, and glasses malnuiacuured by this technology are in use in all the highpower fusion lasers throughout the world (France, Japan, Britain, China, Russia and the U.S.). But to date none of these lasers has been large enough to achieve ignition - even though fusion reactions have been detected.

Perhaps the best way to visualize the progress toward achieving fusion ignition is with a simple analogy. Sippose one wishes to ignite a piece of wood issing a torch. If the torch is only briefly applied to the wood, the wood will begin to chaf und generate smoke, but it will not ignite. 0 n the other hand, if the torch is held on the wood for a long time then eventually it will ignite and a flame will be produced. Similar to this analogy, the current lasers are able to produce "smoke", indicating that fusion reactions are occurring, but these lasers cannot supply enough heat to achieve ignition.

Hopes in this area are pinned on a new generation of laser systems like the National lgnition Facility (NIF) at UNL, which requires about 3500 rectangular plates of high optical quality laser glass; each glass plate is about a meter long, half a meter wide and $4 \mathrm{~cm}$ thick. Construction of the NIF, which uses 192 separate laser beamlines, began in 1997 and is scheduled for completion in 2003. The French Commissariat à l'Energie Atomique (CEA) is planning to build a similar laser called "Laser Megajoule" (LMI) near Bordeaux. The LMI is planned to have as many as 240 beamlines and require nearty $\mathbf{4 5 0 0}$ laser glass plates

\footnotetext{
- myst be able to be meter) and large intarge slizes (-1 meter)
} 
01/09/01 TUE 15:35 FAX 570 4140322 opportunity for improving out work

\section{SCHOTT GLASS TECH}

the day.

All activities for the day will take place in the Bldg. 123 auditorium beginning at 1 p:m.; all employees axe invited to attend. The day's events will also be broadcast on Lab TV
002

- DOE headquar duced by Secretary $B$

- Introduction $t$

\section{Breakthrough for manufacture of NIF glass}

\section{MBCAFARSOFCE}

\section{A major laser glass milestone has been achieved for the Laboratory's National Ignition Facility - thenks to exteusive research and development spearhead- od by the Lab and two leading hightechnology glass veodors.}

Schiott Glass Tochnologies, based in Duryea, Pem, has successfully demonstrated a process to ensure continnous production of economical, high-optical quality, neodymiumdoped, phosphate laser ghass noeded for the National Ignition Pacility. Schott is oxe of two NIF laser glass veadoes wodking on the process. The second vendon, Hoya Comp., based in Fremont, is scheduled to begin similar glass melting operations eady next month.

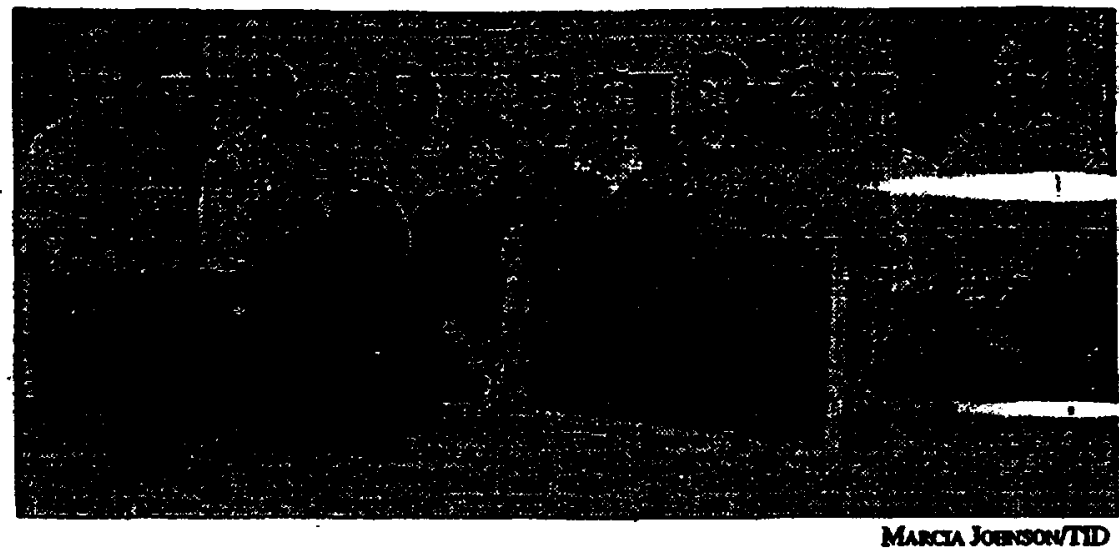

LUN's NIF Laser Glass Group shown with a polished laser glass plate (on left) and the continuously melted glass blank from which it is manufactured. Group members (from left to right): Jack Campbell, Paul Ehmann, Dennis Gavity, Sara Kassahum, Mike Riley, Andrea Flammini, Jim Kimmons, Nene Clasen, Chuck Thorsness, Tayyab Suratwala, Rusty Steele, Greg Rogowski.

To date, Schott has produced more than 250 of the roughly meter-sized glass slabs needed for NIF's demanding optical specifications. In addition, the giass has been produced at a rate 20 times faster than
Richardsol changes tc NIF maną

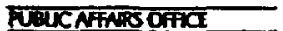

Secretary of Er announced manager oversight of the $\mathrm{N}$ Department of $\mathrm{I}$ Richundson said tha ment would address were identified du review of the projoc

The review, whi be was informed $c$ inadequate manage resuling back of 0 schodule problems . Energy Department II remain deep which these probler Richandson. 'But I : lying science of the? the NIF had were di 
Director Brice Truter said the Lab folly suppoxts Secretary Richardson and the changes that have been addressed within the NIF project, and remains commitued to working cooperatively with the secretary and DOE.

"NIF is getting back on track" said Bruce Thrter, LLNL director. "We will continue to wark cooperatively with DOE to ensure NIF's success and funding."

Richardson said NIF is an important research facility that, in conjunction with other facilities, will allow Laboratory researchers to conduct the science needed to maintain the nation's nuclear weapons without the need for underground moclear testing.

Problems were first discovered last year in the NIF construction project when it was found that the assembly and integration of the laser infrastructure had been underestimatod in both cost and schectule.

Richardson instituted changes at DOE headquarters, the DOB Oaldand Field officen the Laboratory and the University of California, which manages the Laboratory for the department. They include:

- LLNL has established a new senior position, associate director for NIP Programs, reporting direct. ly to Director Bruce Tarter. George Miller, AD for Nationsl Security, is the acting NIPAD.

- In recognition of its need to have stronger oversight of laboratory construction projects, the University of Califomia established a new standing panel of its President's Council and has substantially increased its interaction with the NIP Project Office.

\section{GLASS}

Conttrued from pägë I

could be achieved using the existing one-slab-at-atwo batch-melting technology.

- . "This is traly a significent echioverent," said Bd - Moses, NIP paject manager. "Obtrinitug quality giass was one of the top technological and manufucturing issues our project faced. This achiovement demonstrates that NIF's remaining tochnical challenges are rapidly betog solved."

More than 3,500 laser glass slabs will be needed for NIR. Each slab is about 80 centimeters long; 45 centimeters wida, four centimeteses thick and weighs approximately 100 pounds. If placed end to end, the

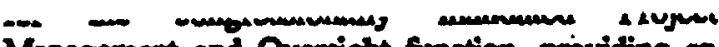
Management and Oversight function, providing an on-site contractor with project management expertise to the Depertment of Enexgy. This outside contractor will provide a resident expert in complex project management, enabling the DOB staff to more effectively analyze the industrial contractor's project performance. This contractor will be paid from the $\$ 2$ million performance fee that the University of Callfomia was required to retum to the department in recognition of the significant mission disnuption caused by the project's problems;

- The NIF. Project has been placed on the Department's Chief Operating Ofificer's Watch List, where it is subject to more stringent reporting requiroments. Key project decisions must be discussed and approved by the deputy secretary of Energy before funding can continue.

In September, when Secretary Richandson first announced the steps he was taking in reiponse to the cost and schectule problems, be asked that an internal review be conducted to determinie why these problems were not dealt with immediately.

The review, and a similar review conducted by LLNL, determined that the LUNL associate director responsible for NIF had a preliminary assessment of the project undertaken in late March 1999, which indicated major construction issues with potentially serious cost implications. No one at the Laboratory informed DOB of the depth of their concerns.

Over the next several months, LLNL, continued to assess the problema internally in an attempt to deter-

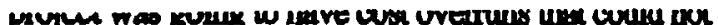
bo bandled within the total project cost. The DOE beadquarters officials responsible for the project were also too slow in clarifying this information and bring ing it to the attention of senior officials.

In Angust, the acting assistant secretary for Defense Programs and Secretary Richardson briefed on the extent of the project's problems.

The review also found that the NIF project managers at headquarters and in Oakland had been assigned additional duties that prevented them from exercising proper oversight and supervision over the project.

Since the project's problems have surfaced, several of the most senior LLNL and DOE managers involved with the project have.either left or have been reassigned internally to different positions that have significantly less or no NIF-management responsibility. In addition, corrective action has been taken with respect to other employees.

The Energy Department is considering options for addressing the NIF's cost and schedule issues. Once Secretary Richardson has determined which option be wants to pursue, the Office of the Deputy Administrator for Defense Programs, with input from LLNL, will put forward a detailed rebaselining plan which will include a budget and key project milestones. The rebaselining plan is due to Congress by June 1, although Secretary Richardson has said he hopes to have it completed in advance of that deadline.
3,500 slabs would extend nearfy two miles and in total. would weigh more then 150 tors,

The costs for the development of the continuous melting process 'has been shared equally between LLNL and the French Commissariat a L'Bnergie Atomique (CBA).The CBA plans to purchase a similar quantity of slabs for tieir Laser Megajoule that will begin construction later this decade

While initial attempts by Schott and Hoya in 1999. demonstrated that continuous melts could oceur, certain glass specifications were not achieved at that time. In particular, the glass product contained trace quantities of hydroxyl group contamination that originated from small amounts of moistwre in the surrounding air and in the intial glass rav materials. Attempts to remove the moisture-derived contamination in the glass degraded the other glass properties. But over the past six months, LLNT, Schott and Hoya have carried out cooperative research specifically aimed at moisture contamination. So 'ott's current melting campaign is the first succest il demonstration of this research and improv I technology

BOW yendors will begin production campaigns using this technology in early 2001.

NIF is one of the cornerstones of the Department of Energy's Stockpile Stewardship Program. It will use the world's largest laser to heat fusion fuel to thermo-nuclear ignition. The experiments will help scientists sustain confidence in the nuclear weapons stockpile without actual testing. NIF will also produce additional 


\subsection{Optics Technology Development}

$\mathrm{T}$ his past year, the four-year optios technology development effort was essentially completed to demonstrate the feasibility of the new technologies, equipment, and manufacturing processes to meet the National Ignition Facility (NIF) cost, performance, and schedule requirements.

In amplifier slab development, there were successful laser glass melting campaigns at Schott Glass Technologies (full size) and Hoya Corporation USA (half size) using the continuous melting technologies planned for NIF. These campaigns produced laser glass meeting most of the NIF technical specifications, including platinum inclusions, absorption at $400 \mathrm{~nm}$ and $1053 \mathrm{~nm}$, refractive index stability, bubbles, and striae. Schott and Hoya used these results to confirm most of the design details of the full-size melters to be used in 1999 for the pilot production, as well as to make minor changes in some of the process parameters.

NIF-size amplifier slabs were finished to NIF specifications at Zygo Corporation using the NIF process and NIF equipment designed and installed under the facilitization contract awarded in 1997. The pilot production contract was awarded to $Z_{y g}$ to begin hiring and training critical staff in preparation for the main pilot in FY99.

In the rapid-crystal-growth development effort, NIF-quality potassium dihydrogen phosphate (KDP) and deuterated KDP (DKDP) boules were grown with constant filtration to NIF-size. Crystals were fabricated ind tested on the Beamlet laser facility, a prototype NIF beamline at Lawrence Livermore National Laboratory (LLNL), and shown to meet the NIF optical and frequency conversion specifications. The rapidgrowth pilot was started in April 1998 based on these successful development results. The pilot production campaign produced a NIF-size tripler boule that should yield about 15 plates (remarkably about $8 \%$ (st NIF from one boule), and KDP boules to yield about 20 Pockels cell plates (about $10 \%$ of NIF).
Following work in 1997 that identified the importance of polishing compound composition and minimizing subsurface damage to achieve high damage thresholds at a wavelength of $351 \mathrm{~nm}$, we fabricated full-size, high-damage-threshold focus lenses at Eastman Kodak and Tinsley Laboratories, Inc, The damage thresholds were demonstrated by raster-scanning in the Large Area Testing facility. The pilot production contract for fused silica was awarded to Coming on schedule and budget.

All three diffractive optic components for NIF were fabricated and tested at full size: the color separation grating (CSG), the beam sampling grating (BSG), and

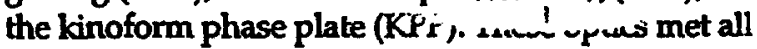
performance specifications in the absence of sol-gel coatings. The CSG and BSG both produced unacceptably high wavefront modulation following application of the sol-gel antireflection (AR) coating. This modulation was traced to nonuniformities in the coating thickness, and has led to reevaluation of the baseline design. It is now expected that an unooated BSG and subaperture CSG will be used on NIF.

NII-size polarizers were coated at the Laboratory for Laser Bnergetios (LLE) at the University of Rochester and Spectra-Physics. These polarizers were laser conditioned to meet the NIF damage threshold using an advanced single-step process. Improvements in the coating process also produced coatings that met the stress/reflectedwavefront specification for a low-humidity environment, as well as the challenging spectral requirements.

The reconfiguration of the Building $391 W$ facility at LLNL was completed to create the glass processing capability in the Optics Processing Development Laboratory. Virtually all of the full-scale cleaning and sol-gel coating equipment was also ondered for the facility. The crystal spin coater was received; initial coating experiments on glass suhctrosioe orrpeded the design specification of $\pm 5 \%$ unitormuty. 


\section{NIF-Size Laser Glass Continuous Melt}

Schott Glass Technologies was successful in melting and forming phosphate-doped LG-770 laser glass at full NIF-size in the first attempt ever to melt laser glass continuously at this size. This glass, shown in Figure 1, met many of the NIF specifications, including platinum inclusions, bubbles, and absorption losses both at $400 \mathrm{~nm}$ and $1053 \mathrm{~nm}$. The refractive-index stability of the glass was also very good, which is needed to achieve high yields with good optical wavefront quality. This run showed that most of the laser-glass melter units should not require any modification for the pilot production work in 1999. Some design issues were discovered during the course of the run, and additional experiments at Schott and LLNL were done to guide appropriate responses. The intexpretation of this work was aided by a chemical engineering process model developed this past year at LLNL to relate key glass properties to manufacturing conditions. Modifications to the melter design and process conditions based on these experiments were implemented in late 1998 in preparation for the pilot production.

\section{Laser-Glass Formation at Approximately Half NIF-Size}

Hoya completed its final subscale development campaign, successfully producing phosphate laser glass at half-NIF linear aperture size; the glass met all NIF specifications except for size. Homogeneity tests on sixty fine-annealed pieces of the Hoya glass demonstrated that the Hoya melter is capable of meeting the NIF specifications, thus indicating the potential of this continuous melting process to achieve high yields. The process model discussed above was also used to analyze the results of the Hoya run, and identified modified conditions that should further improve the glass quality. The results of this campaign were used to finalize the design of Hoya's full-size melter (designed and built as part of NIF optios facilitization). The facilitization effort was completed in 1998 in preparation for Hoya's pilot production in 1999. Figure 2 shows the first full-size, continuous-melted laser glass from Hoya's initial pilot production.

\section{KDP Rapid Growth, Including Fabrication and Beamlet Testing}

The rapid-growth technology was demonstrated early in the year by growing two KDP boules to NIF

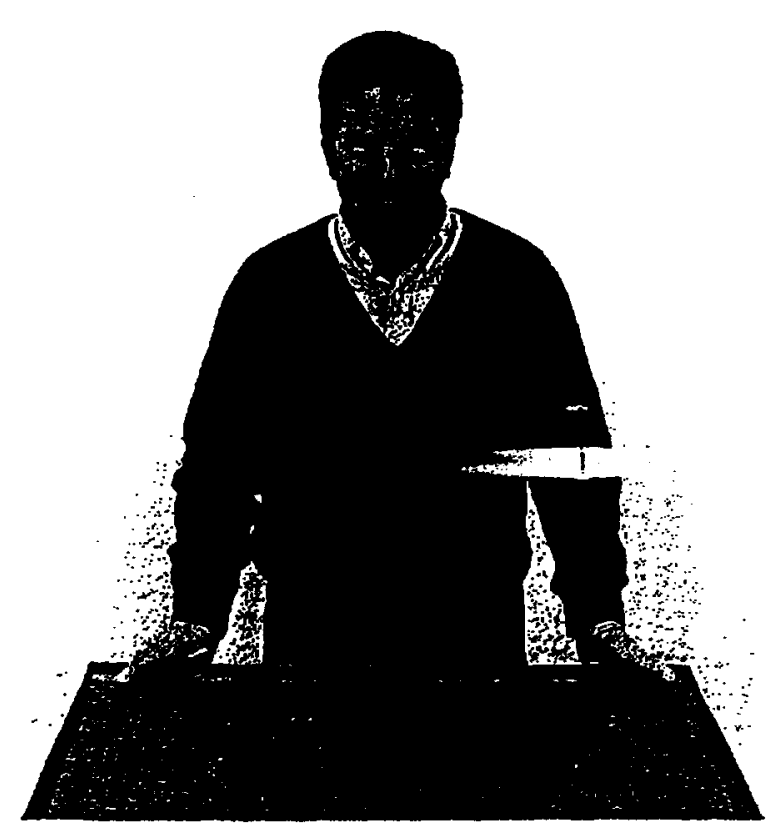

FIGURE 1. NIR-size laser glass slab from Schott's 1998 development campaign. (70-00-0198-0098pb01)

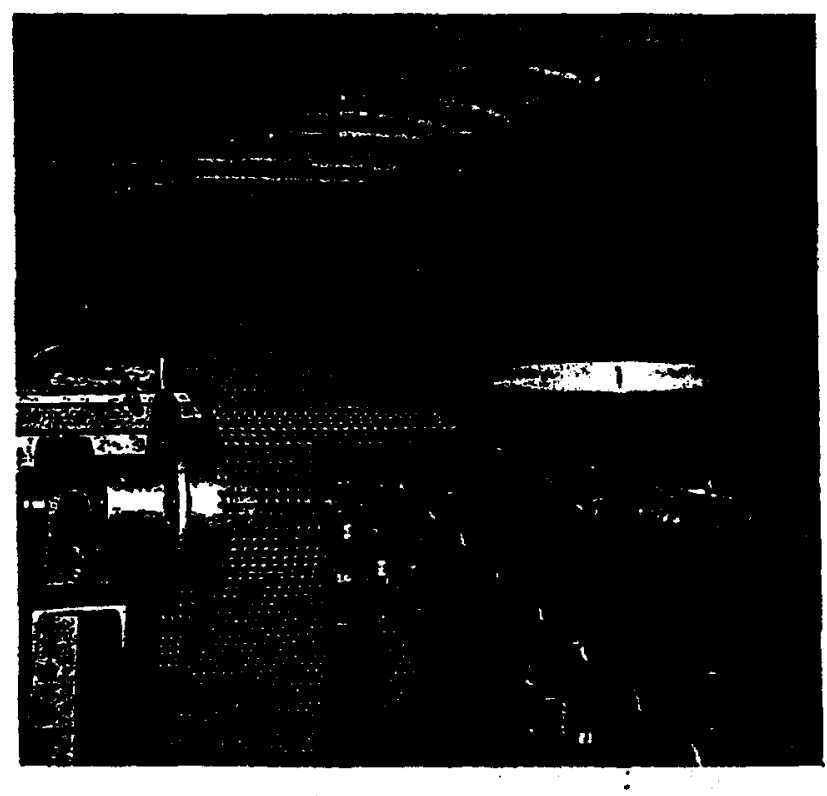

FICURE 2. The first fult-aize, continuous-melted NIF bser glass from Hoya's initial pilot production. (s000-02090474t01)

size and one DKDP boule very close to NIF size (see Figure 10 on p. 68). Pockels cell, doubler, and tripler crystals of NIF or Beamlet size were fabricated from these boules. These crystals demonstrated that the 


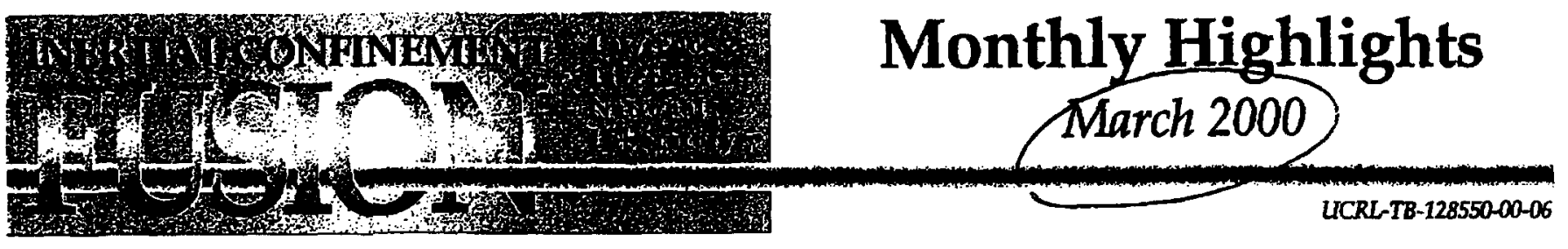

Continuous Glass iyelting Improves Laser Glass 'ields. Schott Glass Technologies (SGT), Duryea, $\mathrm{Pa}$, and Hoya Optics, Fremont, Calif., are now demonstrating continuous laser glass melting capability, which is necessary to produce slabs at the rate and yield required for the National Ignition Facility (NIF).

At SGT, production of laser glass in the Pilot II Phase II nun will begin in May. In Phase I, which has been completed, about 250 NIF-quality amplifier slabs were produced. In Phase II, the total is expected to be about 580 slabs.

At Hoya, Phase I of Pilot II production has recently begun. Start-up problems appear to be under control, and quality glass is expected by the second half of June.

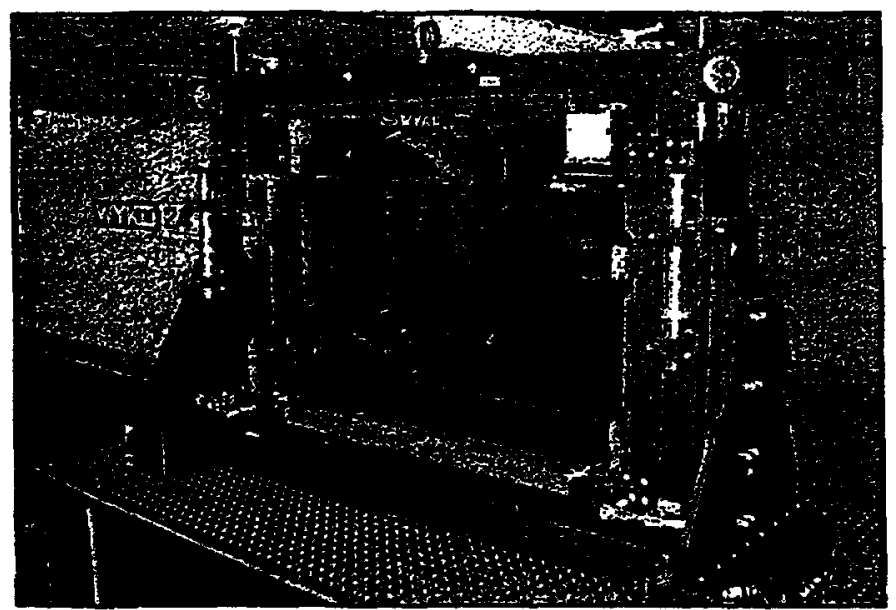

Interferometer testing of finished SGT amplifier stab.

Effects of ${ }^{3} \mathrm{He}$ in Ignition Targets. As the tritium decays in a cryogenic target, the resulting ${ }^{3} \mathrm{He}$ is likely to be concentrated in the central gas region of the capsule. Recent simulations have been done to develop a fielding strategy for NIF ignition targets. Quite high concentrations of ${ }^{3} \mathrm{He}$ in the DT gas can be developed; after four weeks, in a baseline target, there will be $0.2 \mathrm{mg} / \mathrm{cm}^{3}$ of ${ }^{3} \mathrm{He}$ in the gas, which is nominally 0.3 to $0.5 \mathrm{mg} / \mathrm{cm}^{3}$ of DT. In 1D simulations the ${ }^{3} \mathrm{He}$ has little impact on target performance, but in 2D and 3D simulations, the ${ }^{3} \mathrm{He}$ delays ignition and increases the Rayleigh-Taylor instability growth. This tightens the specifications for surface roughness significantly if the target is more than about one week old since being filled with clean DT. We conclude that the DT fuel should be less than about one week old in order to control the Rayleigh-Taylor instability growth.

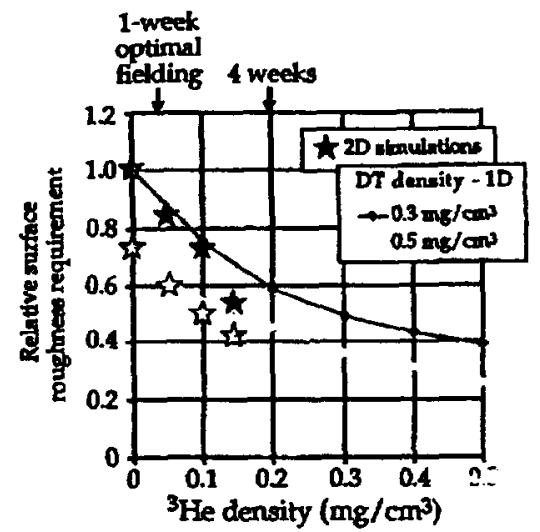

The normalized surface roughness specification for different concentrations of DT and ${ }^{3} \mathrm{He}$ in the gas core. The stars show the results of 20 cat culations, while the lines show the results prodicted by a 1D model that estimates the Rayleigh-Taylor growth during deceleration.

Cryogenic Hohlraums for MIF Targets. Indirectdrive NIP ignition targets consist of a Dr-filled shell suspended at the center of a hohlraum. Cryogenically cooling the DT fuel below its triple point forms an ice layer on the inner wall of the target shell. Spherical symmetry in the DT ice layer, required for high-yield ignition, is achieved by thermally shimming the hohlraum with two heaters on the hohlraum body. The cooling rods attach to temperature equalizers that symmetrize the hohiraum azimuthal temperature. The additional heaters on the cooling rods allow axial control of the temperature within the $\mathrm{He} / \mathrm{H}_{2}$ gas-filled hohlraum cavity. We have constructed a full-scale shimmed NIF hohlraum (Figure a) and have demonstrated the basic concepts of temperature control (Figure b).

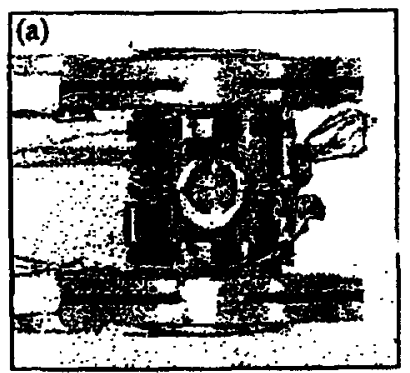

Temperature-shimmed hohlraum

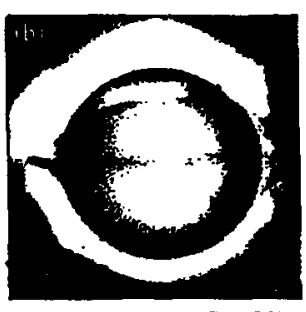

$D_{2}$-filled capsule

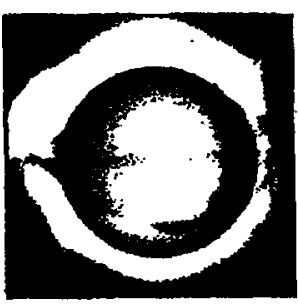

A temperature shimmed hohlraum (a) with a $D_{2}$-filled cepsule suspended at the center. Applying temperature gradient ceuss$\therefore \mathrm{D}_{2}$ los to clump on the colder side of the target: reversing the gradient causes the ice to chump on the oppostte side (b).

For comments about content of the Monthly Highlights, contact Bob Kauffman (925) 122-0419.

To get on the mailing list of the LLNL ICF Monthly Hightights, Quarterly Report, or Ammual Report send a request to carpenter130illi.gov These reports and other LUNL ICF Program information are available on our Web page at http://lasers.linLgov/lasers/inertial himl

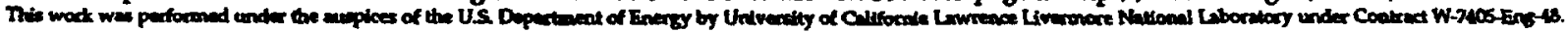




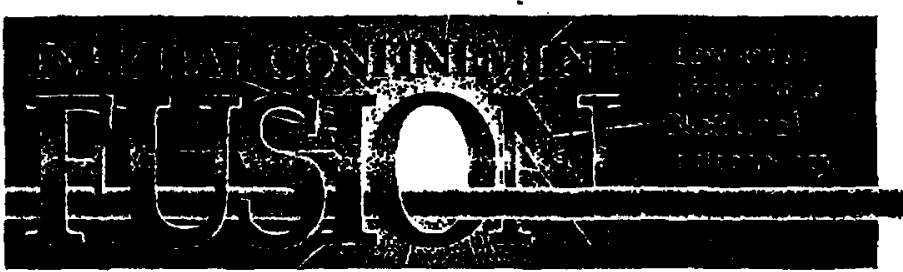

NIF Vacuum End Vessels Installed. Installation of the first beamline of the National Ignition Facility (NIF) laser has begun. Following final completion and acceptance of conventional construction work in the two laser bays, a team of industrial contractors led by M. A. Mortenson Co., one of the nation's $\mathbf{4 0}$ largest construction companies, is assembling the first beamline components of the NIF atop reinforced concrete support structures. This team won the NIF Laser assembly contract that was based on a design package jointly produced by Lawrence Livermore Lab's Engineering Department and Parsons Engineering Group Inc., Pasadena. The first stages of the NIF laser assembly involves placing and aligning all of the major optical foundations for the line replaceable units: Laser Mirror 1, cavity spatial filter, periscope, and transport spatial filter (TSF) components. In addition, contractors are installing all the

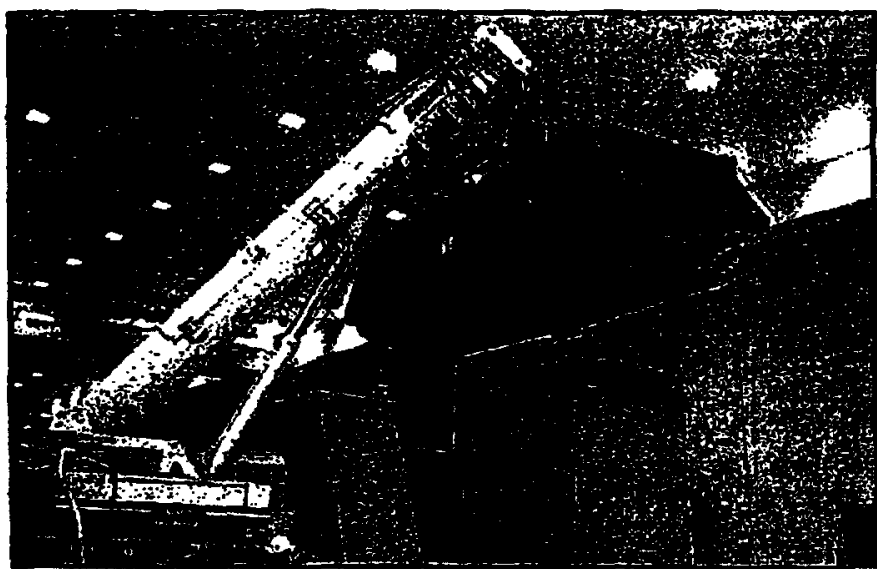

NIF vacuum and vessel being fffted onto the foundation by a mobile truck crane.

preamplifier support structures and optical foundations of the NIF injection laser system. The first components to be installed were a series of 50-ton steel support structures, the TSF vacuum end vessels (see photograph above).

\section{Designs for High-Temperature Diagnostics} Presented at Conference. The High-Temperature Diagnostics Conference held in Tucson, Ariz, in June provided an opportunity for all those involved in NIF core target diagnostics to air their concepts. The core target diagnostics, requested by many experimenters, are those that will be first used to diagnose the laser-tanget interactions. The optical, $x$-ray, and neutron diagnostic designs were well represented, allowing the NIF user community to discuss them before formal conceptual design reviews

\section{Monthly Highlights July/August 2000 \\ UCRL-TB-128550-00-10/11}

are presented, and specifications and schedules are placed under configuration control. Some designs for common packages, such as the chargecoupled device (CCD) camera unit shown at right, used in streak and framing cameras, were shown. The papers will be published in a dedicated issue of Reoiew of Scientific Instruments.

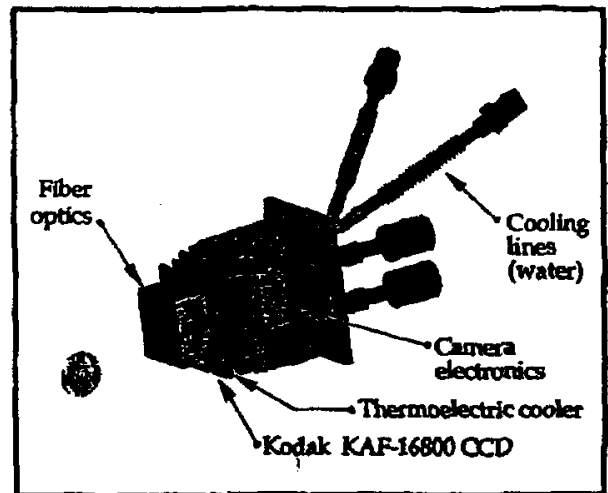

The CCD camera paclage intended for use in $x$-ray streak camera: : : "..

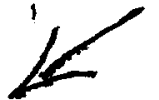

First Finished Amplifier Slabs Received. Zygo Corporation, Middlefield, Conn, completed the first amplifier slabs for the National Ignition Facility (NIF). Zygo will finish the 3,072 amplifier slabs for NIF utilizing laser and cladding glass melted at Schott Glass Technologies, Duryea, Pa., and Hoya Optics, Fremont, Calif. In order to finish an amplifier slab, cladding strips of absorbing glass are epoxied onto a shaped laser glass blank. The optic is then ground to final dimensions and polished to meet the NIF wavefront requirements. This capability is the culmination of a five-year effort starting with a program to develop a process for finishing optios to NIP specifications and progressing to a pilot program of full-aperture demonstrations and production-rate optimization.

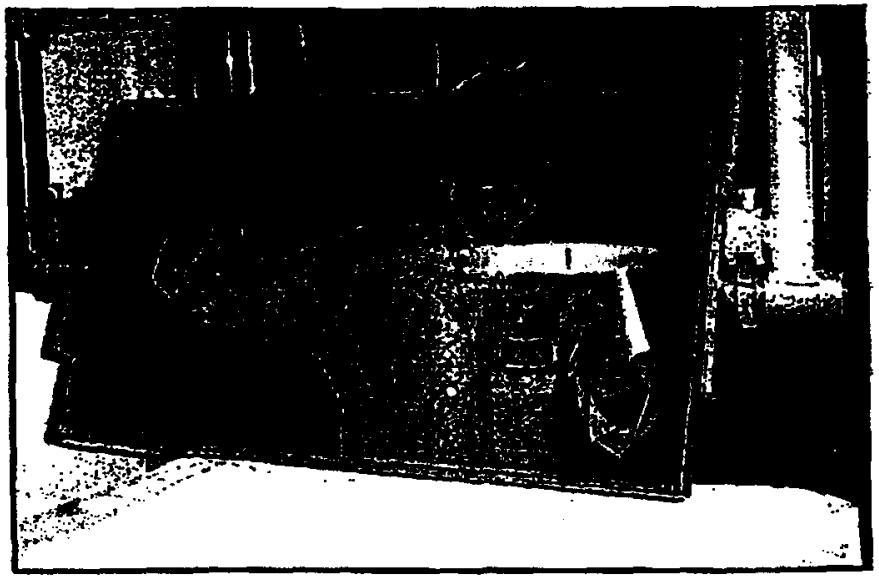

Final visual inspection of a finished amplifier stab.

For comments about content of the Monthy Highlights, contact Bob Kauffiman (925) $422-0419$.

To get on the mailing list of the LINL ICF Monthly Highlights, Quarterby Report, oc Arumal Report send a reguest to carpenter 130 llnl gov These reports and other ULNL ICP Program information are available on our Web page at http://lasers/inl.gov/lasers/inertial html

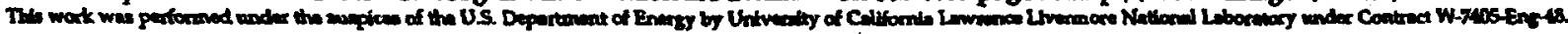




\title{
Appendix G
}

\author{
Video
}

\section{"Manufacturing Laser Glass \\ by}

Continuous Melting" 